Jacek Leociak

\title{
Text und Holocaust
}

Die Erfahrung des Ghettos in Zeugnissen und literarischen Entwürfen

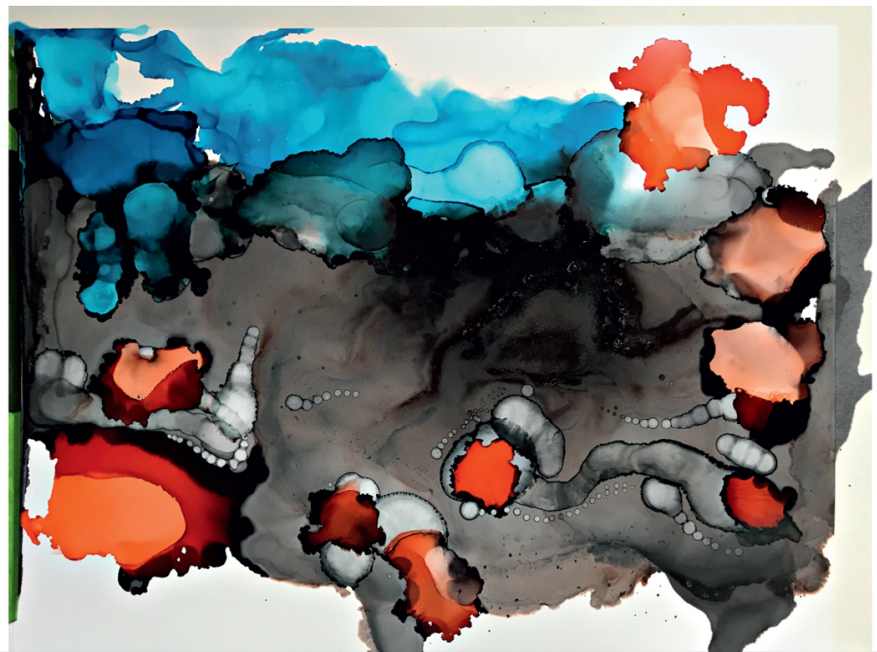


Jacek Leociak

\section{Text und Holocaust}

Der Autor analysiert Tagebücher, Erinnerungen, Memoiren, Chroniken, Berichte und Briefe, die während der Zeit des Zweiten Weltkriegs und der deutschen Besatzung im und um das Warschauer Ghetto entstanden. Er untersucht die Gattungsspezifik und den speziellen Status dieser Texte, die das in Worte zu fassen versuchen, was gemeinhin als unbeschreibbar gilt. Der Autor widerspricht der verbreiteten These von der Unausdrückbarkeit. Er betont die Notwendigkeit des Ausdrucks jener Erfahrung und die Notwendigkeit des Versuchs zu verstehen.

\section{Der Autor}

Jacek Leociak ist Professor am Institut für Literaturforschung der Polnischen Akademie der Wissenschaften in Warschau, Leiter der dortigen Forschungsgruppe für Holocaustliteratur sowie Gründungsmitglied des Zentrums für die Erforschung der Judenvernichtung beim Institut für Philosophie und Soziologie der Polnischen Akademie der Wissenschaften. 
Text und Holocaust 


\section{EASTERN EUROPEAN CULTURE, POLITICS AND SOCIETIES}

Edited by Irena Grudzińska-Gross

and Andrzej W. Tymowski

VOL. 13

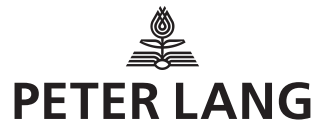


Jacek Leociak

\section{Text und Holocaust:}

Die Erfahrung des Ghettos in Zeugnissen und literarischen Entwürfen Aus dem Polnischen von Lisa Palmes 
Bibliografische Information der Deutschen Nationalbibliothek Die Deutsche Nationalbibliothek verzeichnet diese Publikation in der Deutschen Nationalbibliografie; detaillierte bibliografische Daten sind im Internet über http://dnb.d-nb.de abrufbar.

\section{H national programme FOR THE DEVELOPMENT OF HUMANITIES}

The Publication is founded by Ministry of Science and Higher Education of the Republic of Poland as a part of the National Programme for the Development of the Humanities.

This publication reflects the views only of the authors, and the Ministry cannot be held responsible for any use which may be made of the information contained therein.

Cover illustration: Magdalena H. Gross Cover Design: (๑) Olaf Gloeckler, Atelier Platen, Friedberg Gedruckt auf alterungsbeständigem, säurefreiem Papier. Druck und Bindung: CPI books GmbH, Leck

ISBN 978-3-631-67266-2 (Print)

E-ISBN 978-3-653-06855-9 (E-PDF)

E-ISBN 978-3-631-70998-6 (EPUB)

E-ISBN 978-3-631-70999-3 (MOBI)

DOI 10.3726/978-3-653-06855-9

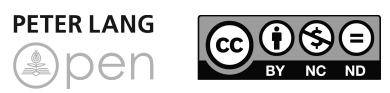

Open Access: Dieses Werk ist lizensiert unter der Creative Commons Lizenz Namensnennung - Nicht kommerziell - Keine Bearbeitungen 4.0 International (CC BY-NC-ND 4.0). Den vollständigen Lizenztext finden Sie unter: https://creativecommons.org/licenses/by-nc-nd/4.0/deed.de

(C) Jacek Leociak, 2018

Peter Lang - Berlin · Bern · Bruxelles · New York · Oxford · Warszawa $\cdot$ Wien

Diese Publikation wurde begutachtet. www.peterlang.com 


\section{Inhaltsverzeichnis}

Einleitung ……………………………………………………………... $\quad 7$

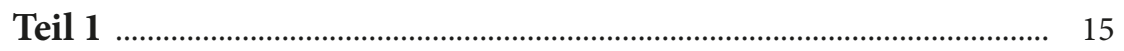

1 Die Suche nach einer Formel ............................................................. 17

2 Autoren, Ort und Zeit ………………………………………………. 39

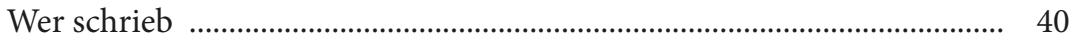

Ort und Umstände des Schreibens ............................................................. 58

3 Das Schicksal der Texte ………………………………………………….. 87

4 Gründe für das Schreiben ................................................................ 99

„Schreibe! Notiere!" ........................................................................................ 102

„Alarmieren und das Gewissen der Welt erschüttern“ ............................... 105

„Für ein zukünftiges Tribunal“ - „der Rache wegen“ .................................... 109

„Eine Spur hinterlassen“ ................................................................................. 114

In der Tradition verwurzelt ........................................................................ 120

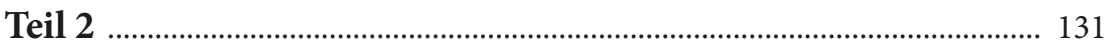

1 Zwischen persönlicher und unpersönlicher Erzählweise ........ 133

Jakub - Hirszfeld - Levin - Perechodnik .................................................... 136

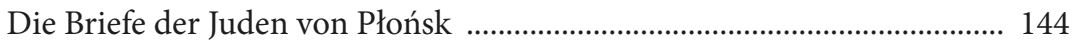

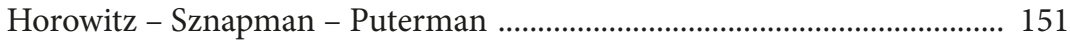

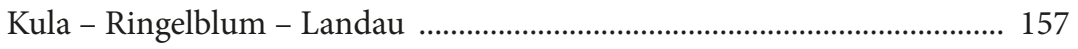




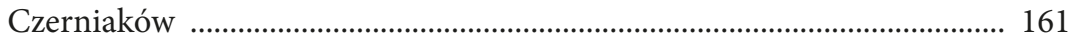

Berichte - Rapporte - Arbeiten .................................................................. 170

2 Die Darstellung des Ghettos ...................................................... 175

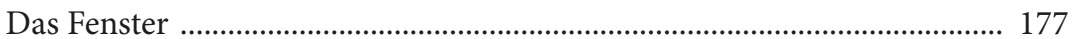

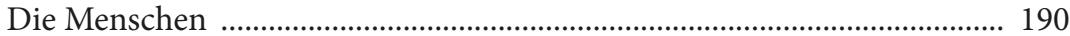

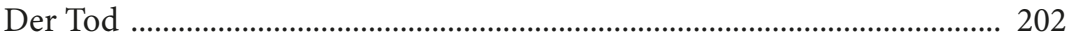

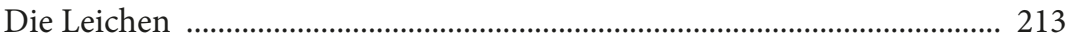

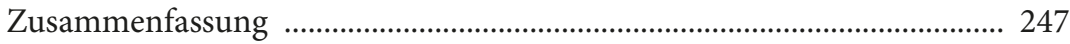

Der religiöse Diskurs ...................................................................................... 251

Das religiöse Leben während der Besatzung …….......................................... 252

Die Klagelieder Karol Rotgebers ................................................................. 265

Das Martyrologium des Rabbi Szymon Huberband .................................... 283

Die Predigten des Rabbi Klonimus Kelmisz Szapiro ..................................... 299

Zusammenfassung ………………………………………………………..... 309

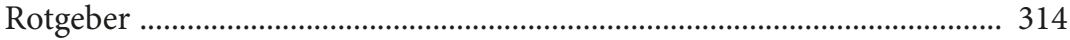

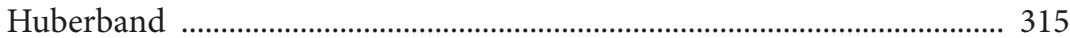

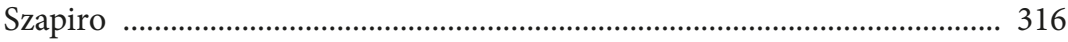

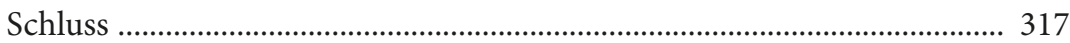

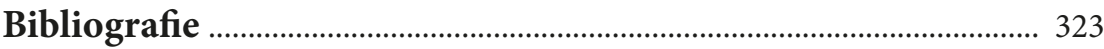

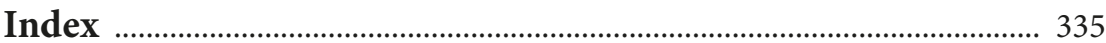




\section{Einleitung}

1

Gegen jede Erwartung, entgegen allen landläufigen Vorstellungen, ja, jeglicher Wahrscheinlichkeit zum Trotz sind aus der Zeit des Holocaust zahlreiche schriftliche Zeugnisse erhalten. Den Anstoß für die vorliegende Arbeit gab denn auch meine Verwunderung, dass eine solche Vielzahl von Texten überdauern konnte, obschon doch gemäß der Logik der „Endlösung“ keine Spur von ihnen - wie auch von ihren Autoren - hätte bleiben dürfen. Und dennoch sind sie da. Aufbewahrt unter Gefahr für Leib und Leben, zwischen Schichten von Kleidern weitergeschmuggelt, in Kästchen, Milchkannen oder leeren Karbiddosen verborgen und im Schutt vergraben, auf Dachböden oder in Kellern zwischen Mauersteinen versteckt, unter losen Bodenbrettern, in der noch heißen Asche menschlicher Gebeine ... überdauerten diese Texte. Ihre Existenz bedeutet eine Herausforderung für uns alle.

Um sich dieser Herausforderung stellen zu können, gilt es, zu den Relikten der damaligen Wirklichkeit vorzudringen, ähnlich wie man die vergrabenen Überreste längst vergangener Zivilisationen - die einzige Spur dessen, was einst gewesen ist - unter mehreren Erdschichten zutage fördert. So nah wie irgend möglich gilt es zum Text vorzudringen und die Gestalt der in ihm festgehaltenen Erfahrung zu entziffern.

Gegenstand meiner Lektüre sollen Tagebücher, Erinnerungen, Chroniken, Berichte, Notizen, Briefe sein, wobei ich ausschließlich Texte betrachte, die "damals dort" entstanden sind - dort: im (zumeist) Warschauer Ghetto oder rings um seine Mauern, also im Versteck auf der sogenannten „arischen Seite“, und damals: während des Krieges und der Besatzungszeit. Nicht in den Blick nehmen will ich belletristische Werke sowie rückblickend in der Nachkriegszeit entstandene Erinnerungsliteratur und Memoiren. Diese zeitliche Begrenzung erklärt sich vor allem durch das Postulat, einzig Schriften zu untersuchen, die während des Krieges, der Besatzung, der Vernichtung verfasst wurden. Zusätzlich war die Beschränkung der Analyse auf Texte persönlich-dokumentarischen Charakters insofern vorgegeben, als ich eine umfassendere Beschreibung derartiger Zeugnisse versuchen möchte, sind diese doch aus der Perspektive literaturwissenschaftlicher Praxis bislang nicht erschöpfend präsentiert worden. ${ }^{1}$

1 Eine Pionierstudie soziologischer Art über die Zeugnisse des Holocaust ist M.M. Borwiczs Dissertation Écrits des condamnés à mort sous l'occupation allemande (1939-1945). 
Dahingegen ist die (sowohl "damals dort" als auch post factum geschaffene) Holocaustliteratur ${ }^{2}$ bereits seit langem Gegenstand vielfältigster Forschungen und Arbeiten. Daher habe ich mich entschieden, mich hier nicht mit den literarischen Werken zu befassen.

Hinweisen möchte ich lediglich auf einige in der polnischen wissenschaftlichen Literatur sehr bedeutende Arbeiten zu diesem Thema: Michał Borwicz: Literatura w obozie [Literatur im Lager], Krakau 1946; Ders.: „Wstęp“ [Einleitung], in: Pieśń ujdzie cało ... Antologia wierszy o Żydach pod okupacją niemiecka [Das Lied entkommt heil und ganz ... Eine Anthologie von Gedichten über die Juden unter deutscher Besatzung], Warschau 1947; Helena Zaworska: „Medaliony“ Zofii Nałkowskiej [Zofia Nałkowskas „Medaillons“], Warschau 1961; Andrzej Werner: Zwyczajna Apokalypsa. Tadeusz Borowski i jego wizja świata obozów [Eine gewöhnliche Apokalypse. Tadeusz Borowski und seine Sicht auf die Welt des Lagers], Warschau 1971; Tadeusz Drewnowski: Ucieczka $z$ kamiennego świata. O Tadeuszu Borowskim [Flucht aus der steinernen Welt. Über Tadeusz Borowski], Warschau 1972; Irena Maciejewska: „Getto Warszawskie w literaturze polskiej" [Das Warschauer Ghetto in der polnischen Literatur], in: Literatura wobec wojny i okupacji [Die Literatur angesichts von Krieg und Besatzung], hrsg. von M. Głowiński und J. Sławiński, Wrocław 1976; Henryk Grynberg: „Der Holocaust in der polnischen Literatur", in: Unkünstlerische Wahrheit (Prawda nieartystyczna), poln. Originalausgabe Berlin 1984, dt. Übers. von L. Quinkenstein, Berlin 2014; Jan Błoński: „Die armen Polen blicken aufs Ghetto“ (Biedni Polacy patrzą na getto), poln. Original Krakau 1994, dt. Übers. von K. Wolff, in: Marek Klecel: Polen zwischen Ost und West. Polnische Essays des 20. Jahrhunderts. Eine Anthologie, Berlin 1995; Irena Maciejewska: „Wstęp“ [Einleitung], in: Męczeństwo i Zagłada Żydów w zapisach literatury polskiej [Martyrium und Vernichtung der Juden in den Schriften der polnischen Literatur], Warschau

Étude sociologique, Paris 1954, verteidigt durch den Autor an der Sorbonne im Jahr 1953. Über die Arbeiten, die meine eigene Forschungshaltung zu persönlichen Holocaustzeugnissen am stärksten beeinflusst haben, schreibe ich im Kapitel „Die Suche nach einer Formel“.

2 Das Wort Holocaust, das sich vom griechischen Ausdruck holókauston ableitet, hatte ursprünglich die Bedeutung eines freiwillig Gott dargebotenen Brandopfers (siehe 1 Sm 7,9). Zweifellos drückt das hebräische Wort Schoa (Vernichtung) umfassender und wahrhaftiger das Wesen dessen aus, was den Juden während des Krieges widerfuhr. In meiner Arbeit verwende ich dennoch den Begriff „Holocaust", da dieser sich durch die Verwendung im Englischen so weit verbreitet hat, dass er in den allgemeinen Sprachgebrauch einging. Dieser Praxis möchte ich mich nicht widersetzen. 
1988; Józef Wróbel: Tematy żydowskie w prozie polskiej 1939-1987 [Jüdische Themen in der polnischen Prosa 1939-1987], Krakau 1991; Natan Gross: Poeci i Szoa. Obraz Zagłady Żydów w poezji polskiej [Dichter und die Schoa. Das Bild der Judenvernichtung in der polnischen Lyrik], Sosnowiec 1993; Irena Maciejewska: „Getta doświadczenie w literaturze“ [Die Ghettoerfahrung in der Literatur], in: Słownik literatury polskiej XX wieku [Wörterbuch der polnischen Literatur des 20. Jahrhunderts], hrsg. von A. Brodzka et al., Wrocław 1993. Von den ausländischen Publikationen, die ich in Händen hielt, möchte ich vor allem auf folgende Bücher aufmerksam machen: Frieda W. Aaron: Bearing the Unbearable. Yiddish and Polish Poetry in Ghettos and Concentrations Camps, New York 1990 (eine fundierte literaturwissenschaftliche Publikation, die eine breit angelegte Präsentation polnischsprachiger Quellen in die Reflexion mit einbezieht); Lawrence L. Langer: The Holocaust and the Literary Imagination, New Haven London 1975 (eine Untersuchung über den literarischen Ausdruck von Grenzerfahrungen, bei denen das unfassbare Grauen eines unausweichlichen Todes an die Stelle des normalen Lebensbewusstseins tritt, Zeitgefühl und rationales Denken außer Kraft setzt); Alvin H. Rosenfeld: A Double Dying: Reflections on Holocaust Literature, Bloomington - Indianapolis 1988 (die Holocaustliteratur als Zeugnis einer doppelten Katastrophe - Zeugnis sowohl des Todes eines Menschen als auch des Todes menschlicher Ideen; eine Reflexion über fundamentale Fragen: Wie ist es nach dem Holocaust möglich, Literatur zu schreiben und zu lesen?, Gibt es eine Sprache, die den tiefen Riss zwischen Schrei und Schweigen überbrückt, die Täuschung und Korruption durch Wörter überwindet?); Sem Dresden: Vervolging, vernietiging, literatuur [Verfolgung, Vernichtung, Literatur], Amsterdam 1991 (eine Arbeit über das Verhältnis zwischen Literatur und Realität des Holocaust, zwischen der Wahrheit von Aufzeichnungen und der faktischen Wahrheit, zwischen der Zeit der Ereignisse und der Zeit von erinnernder oder erzählerischer Narration, darüber, wie Erleben in ein literarisches Zeugnis des Erlebten transponiert wird).

\section{2}

Als grundlegendes Quellenmaterial dienten mir die Archivbestände des Jüdischen Historischen Instituts (Żydowski Instytut Historyczny, ŻIH) in Warschau und der Jerusalemer Gedenkstätte Yad Vashem. Archivmaterial über das Warschauer Ghetto lässt sich des Weiteren in den Sammlungen des Kibbuz Lochamej haGeta’ot - Kibbuz der Ghettokämpfer - in Israel finden.

Mein Ansinnen bei dieser Arbeit war nicht die Einbeziehung sämtlichen vorhandenen Materials aus obigen umrissenen Gattungen; ein derartiges 
Unterfangen wäre in vielerlei Hinsicht schlicht unmöglich gewesen. Die Quellengrundlage, über die ich verfüge, ist, wie ich denke, dennoch hinreichend repräsentativ.

Was das Archiv des ŻIH betrifft, so ist hier der Typus von Texten, der mich im Folgenden interessieren soll, in zwei Gruppen gebündelt. Die erste Gruppe setzt sich aus „Ring I“ und „Ring 2“ zusammen: zwei nach dem Krieg wiedergefundenen Teilen eines von Emanuel Ringelblum initiierten Untergrundarchivs des Warschauer Ghettos. "Ring I“ umfasst 1.208 archivarische Einheiten aus der Zeitspanne von September 1939 bis zum 3. August 1942; „Ring II“ besteht in 484 Einheiten aus der Zeit vom 22. Juli 1942 bis Ende Februar 1943 sowie persönlichen Gütern (Briefen, Versammlungsprotokollen, Schulzeugnissen, Universitätsdiplomen, wissenschaftlichen Arbeiten, literarischen Werken usw.) der Mitglieder von Oneg Schabbat [auch: Oyneg Shabes] - der Gruppierung, die das Archiv anlegte. Tagebücher und Erinnerungen sind im Ghettoarchiv seltener vertreten. Die zweite Gruppe trägt die Bezeichnung „Tagebücher“ und enthält 272 Archiveinheiten, von denen 65 das Warschauer Ghetto betreffen. Unter jenen 65 Warschauer Tagebüchern wurden nur 8 kurz nach dem Krieg verfasst. Nicht in meine Untersuchung einfließen sollen die Materialien aus der Sammlung „Berichte“, in der Aussagen von Überlebenden aus der Nachkriegszeit deponiert sind. Von über 7.000 Positionen beziehen sich lediglich ca. 1.600 auf das Warschauer Ghetto. ${ }^{4}$

Im Jerusalemer Archiv von Yad Vashem gibt es u.a. eine „Sammlung von Zeugnissen, Erinnerungen und Tagebüchern": hand- und maschinenschriftliche Berichte von Augenzeugen des Holocaust in den Ländern Europas und aus verschiedenen Vernichtungslagern. Vom Warschauer Ghetto handeln ca. 100 Archiveinheiten, die meisten davon stammen bereits aus der Nachkriegszeit.

3 Diese beiden Teile des Archivs wurden von einer Kommission studiert und mit geringfügigen Änderungen in Warschau veröffentlicht. Ein dritter Teil, der angeblich existieren soll, wurde bisher nicht gefunden (siehe die Einleitung von Arieh Tartakower, in: Emanuel Ringelblum: Ghetto Warschau. Tagebücher aus dem Chaos, Stuttgart 1967, S. 14; Anm. d. Übers.)

4 Auf der Grundlage von: M. Grynberg: „Wstęp“ [Einleitung], in: Pamiętniki z getta warszawskiego. Fragmenty i regesty [Tagebücher aus dem Warschauer Ghetto. Auszüge und Regesten], bearb. von M. Grynberg, Warschau 1988, S. 9-10; R. Sakowska: Archiwum Ringelbluma. Getto warszawskie lipiec 1942-luty 1943 [Das Ringelblum-Archiv. Warschauer Ghetto Juli 1942-Februar 1943], bearb. von R. Sakowska, Warschau 1980, S. 19; „Diaries, Holocaust“, in: I. Gutman (Hg.): Encyclopaedia of the Holocaust, New York, London 1990. 
Lediglich 9 der 36 in polnischer Sprache verfassten Texte sind zwischen 1942 und 1944 entstanden. ${ }^{5}$

Die Archivbestände des ŻIH sowie die mir zugänglichen in Polen (einzeln bzw. im „Biuletyn Ż̇H“ [BŻIH, Bulletin des Jüdischen Historischen Instituts]) oder im Ausland publizierten Texte sind mein grundlegendes Forschungsmaterial. ${ }^{6}$ Ein beträchtliches Hindernis bei der Quellensuche stellte die Sprache dar, in der die erhaltenen Zeugnisse verfasst sind. So überwiegen im Ghettoarchiv Texte in jiddischer und hebräischer Sprache, polnischsprachige Materialien gibt es nur wenige. Auf Polnisch verfasst ist dagegen die Mehrzahl der Texte aus der Gruppe „Tagebücher" (um die 5.000 maschinengeschriebene Seiten), hier sind lediglich 8 von 65 Texten auf Jiddisch geschrieben. Ich beschränke mich in meiner Arbeit notwendigerweise auf die polnischsprachigen Textdokumente - mit einigen wesentlichen Ausnahmen: Texte in polnischer oder englischer Übersetzung.

Somit ist mein Quellenmaterial zwar begrenzt, genügt jedoch vollkommen dem grundlegenden chronologischen Kriterium: Sämtliche Texte stammen aus der Kriegs- und Besatzungszeit. Den Anfang markiert das Datum des 1. September 1939, das Ende allerdings lässt sich bereits schwieriger festlegen. Für die Warschauer, die sich rechts der Weichsel versteckten, endete der Krieg Mitte September 1944, als die Russen das rechte Weichselufer einnahmen. Zur gleichen Zeit war links des Flusses der Warschauer Aufstand im Gange, an dem manche Autoren der hier besprochenen Texte aktiv oder passiv teilnahmen. Nach der Niederschlagung des Aufstands verbargen sie sich in den Trümmern. Manche Verfasser stellten ihre Texte just in dem Moment fertig, in dem die Rote Armee und Berlings Truppen in das ruinierte Warschau links der Weichsel einmarschierten. So zum Beispiel Dawid Fogelman, der sich bis zum 17. Januar 1945 in einem Bunker versteckte, wo er seine Erinnerungen niederschrieb. Den Anblick der polnischen und sowjetischen Soldaten empfand er als einen Moment des

5 Auf der Grundlage des Katalogs des Yad-Vashem-Archivs: B. Klibanski (Hg.): Collection of Testimonies, Memoirs and Diaries (Record Group 033), Bd. 1, Jerusalem 1990.

6 Die Quellenbibliographie befindet sich am Ende dieses Buches. Die Zitierregeln sind wie folgt: Wird im Text der Autor des aufgeführten Textdokuments genannt, so gebe ich daneben die Seitenzahl an. Die vollständigen Quellenangaben findet der Leser im Anhang unter „Literatur des persönlichen Dokuments aus dem Warschauer Ghetto" unter dem Namen des Autors oder, bei Texten unbekannter Verfasser, unter der Bezeichnung der archivarischen Gruppe und der Signaturnummer. Verwende ich zwei Quellengrundlagen, gebe ich neben der Seitenzahl in Klammern die benutzte Grundlage an. 
Umbruchs - den Anfang einer neuen Zeit und eines neuen Lebens. Damit war seiner schreibenden Tätigkeit ein natürliches Ende gesetzt, und diese Zäsur des überstandenen Krieges betont er deutlich in seinem Text: „Ich höre auf, mein Tagebuch zu schreiben, denn nun fange ich - als freier Mensch - ein ganz anderes Leben an" (Pamiętniki z getta warszawskiego [Tagebücher aus dem Warschauer Ghetto], S. 310).

Andere Autoren wiederum gaben nach der Befreiung das Schreiben nicht auf, sondern vervollständigten und bearbeiteten ihre zu Kriegszeiten entstandenen Texte. Henryk Rudnicki komplettiert seine Notizen aus der Besatzungszeit, versieht sie mit einem zusammenfassenden Nachwort und lässt sie 1946 in Łódź herausgeben. Beniamin Horowitz schreibt im Juli 1944 in einem Versteck auf der „arischen Seite“ sein verschollenes Ghettotagebuch zum zweiten Mal. Ein Teil des rekonstruierten Manuskripts geht wieder verloren; der Autor ergänzt und überarbeitet die beschädigte Textversion 1945 in Lublin. Verloren geht ebenfalls Leon Najbergs im Versteck verfasster Entwurf eines Tagebuchs; dem Autor gelingt es jedoch, den Text gleich nach der Befreiung Warschaus aus dem Gedächtnis noch einmal niederzuschreiben. Derartige Texte haben ihre endgültige Gestalt erst nach dem Krieg erhalten, verwurzelt sind sie jedoch tief in der Kriegszeit.

Des Weiteren gab es Überlebende, die erst nach der Befreiung überhaupt zur Feder griffen und ihre noch frischen Erinnerungen notierten - entweder auf Anregung von Dokumentationszentren für die Kriegsverbrechen oder auch aus eigenem Antrieb, aus dem inneren Bedürfnis heraus, die Bilder des eben beendeten Krieges festzuhalten. Die Distanz ihrer Schriften zu den beschriebenen Ereignissen ist nicht groß, dennoch haben sie die Zäsur des Kriegsendes bereits überschritten. Zu dieser Art Texte zählen zum Beispiel Marek Edelmans 1945 vom Bund ${ }^{7}$ herausgegebener Bericht Getto walczy (Das Ghetto kämpft; dt. Übers. von E. und J. Czerwiakowski, Berlin 1993) oder Władysław Szpilmans Śmierć miasta [Der Tod einer Stadt] ${ }^{8}$, ein - wie wir heute sagen würden - „gesprochenes Tagebuch“, das von Jerzy Waldorf niedergeschrieben und 1946 in Warschau publiziert wurde. Jene Texte sprengen zwar formell den hier abgesteckten Zeitrahmen, sie völlig außer Acht zu lassen wäre jedoch auch nicht sinnvoll, stellen sie

7 Allgemeiner jüdischer Arbeiterbund von Litauen, Polen und Russland [jiddisch: Algemeyner Yidisher Arbeter Bund in Lite, Poyln un Rusland]; Anm. d. Übers.

8 Auf Deutsch erschien eine erweiterte Fassung mit dem Titel Das wunderbare Überleben - Warschauer Erinnerungen 1939-1945, Übers. von K. Wolff, Düsseldorf, München 1998. Auf der Grundlage von Szpilmans Tagebuch entstand der Film Der Pianist (2002); Anm. d. Übers. 
doch eine Art Zwischenstadium zwischen den „damals dort“ verfassten Texten und der Erinnerungsliteratur der Nachkriegszeit dar.

3

Meine Arbeit teilt sich in zwei Abschnitte. Der erste Teil ist als erweiterte Einleitung zu verstehen; er bereitet den Grund für den zweiten Teil, in dem Analysen und Untersuchungen folgen. In Kapitel 1 bespreche ich die Spezifik der Gattung und den besonderen Status der behandelten Texte. Des Weiteren stelle ich Überlegungen zu einer Formel für die Beschreibung von Holocaustzeugnissen an, welcher sich ein Forscher bedienen kann. Ich rekonstruiere die Lesarten, die mir bei diesen Zeugnissen am nächsten sind, und deklariere meine eigene methodologische Vorgehensweise. Kapitel 2 skizziert ein Gesamtportrait der Verfasser von Zeitzeugendokumenten aus dem Warschauer Ghetto und charakterisiert deren Entstehungszeit und -ort bzw. rekonstruiert die Art und Weise, wie Zeit und Ort von den Schreibenden wahrgenommen wurden. Kapitel 3 wiederum konzentriert sich auf die materielle Geschichte der Texte als Holocaustrelikte, darauf, wie sie versteckt, aufbewahrt, wieder aufgefunden wurden. Kapitel 4 schließlich analysiert die offen deklarierten und interpretierbaren Motive für das Schreiben und führt im Weiteren zu Fragestellungen, die für diese gesamte Arbeit entscheidend sind: auf welche Arten die Erfahrung des Holocaust ausgedrückt wird, welche Form ihre Niederschrift annimmt und auch, welche Möglichkeiten es gibt, diese Erfahrung zu lesen und zu verstehen.

Der zweite Teil setzt sich aus drei Studien zusammen. In der ersten stelle ich zwei Erzählweisen vor, die sich bei den untersuchten Zeugnissen erkennen lassen - eine persönliche und eine unpersönliche -, und zeige auf, wie sich die jeweilige Diskursart auf die Gestaltung des sprechenden „Ich“ und dessen Verhältnis zur dargestellten Welt auswirkt. In der zweiten Studie befasse ich mich mit der Stellung, die das beschreibende Element und bestimmte Formen dieses Elements (Themen wie das Bild der Figur, des Todes, der Leiche) in der narrativen Struktur des Textes einnehmen. Die dritte Studie dreht sich um den religiösen Diskurs, und dabei im Besonderen um die Spannung zwischen einerseits der Redeweise, die die Gegenwart des Sacrum erfassen möchte und einem besonderen Traditions-, Konventions-, Ritualisierungsdruck unterliegt, und andererseits der Herausforderung, zu der die Erfahrung der Ghettorealität für den Autor wird.

Häufig, und manchmal auch sehr ausführlich, zitiere ich dabei die besprochenen Quellen, sind diese doch in der Mehrzahl wenig bekannt, schwer zugänglich, manches Mal nur im Archiv erhältlich. Zwar erweitert das den Umfang 
dieser Arbeit, es lässt jedoch auch die Stimmen, die den Holocaust überdauert haben, hörbarer erklingen.

Der Warschauer Stadtteil Muranów (also das Gebiet des ehemaligen Ghettos) ist meine Heimat. Ich weiß nicht, ob ich ohne die Begegnung mit jenem einzigartigen Ort dieses Buch hätte schreiben können.

Ebenso viel verdanke ich den Menschen, mit denen ich inspirierende Gespräche führen durfte und die meinen Text besonders bei der Endredaktion einer aufmerksamen und sehr hilfreichen Lektüre unterzogen. Meine herzlichen Dankesworte für ihre wertvollen Anmerkungen und Ergänzungen möchten auch Prof. Michał Głowiński, Prof. Jan Błoński, Prof. Małgorzata Czermińska und Prof. Tomasz Szarota entgegennehmen. Ebenfalls herzlich danke ich Dr. Ruta Sakowska und Prof. Michał Czajkowski für ihre Beratung sowie meinen Freunden Dr. Stanisław Fałkowski und Dr. Andrzej Stanisław Kowalczyk für die gemeinsamen Überlegungen zu den vielfältigen Fragestellungen dieses Buches. 
Teil 1 



\section{Die Suche nach einer Formel}

Die Texte, mit denen ich mich in dieser Arbeit befassen möchte, zählen zur Literatur des persönlichen Dokuments - ein Begriff aus der humanistischen Soziologie. Ins Leben gerufen wurde die sogenannte Methode des persönlichen Dokuments von Florian Znaniecki, der die Autobiographie als wertvolles soziologisches Material entdeckte. ${ }^{9}$ Bei seiner Beschreibung dieses literarischen Phänomens betont Roman Zimand, dass sowohl Leser als auch Autoren und Forscher die Sonderstellung anerkennen, die das persönliche Dokument in der Literatur einnimmt. Innerhalb der Gattungsgemeinschaft jedoch sind die Grenzen zwischen den einzelnen Varianten fließend und leicht überschreitbar. Jene Leichtigkeit bei der Übertretung von Gattungsgrenzen, deren Ursprung Zimand in der personalisierten Narration sieht (die grammatische Dominanz des Singulars in allen Varianten), ist eines der drei Kriterien, die er vorschlägt, um die Gattungsspezifik der Literatur des persönlichen Dokuments zu erfassen. Die beiden anderen Kriterien sind der verschwimmende Gegensatz zwischen „Wahrheit“ und „Erdachtem“ (das Spiel zwischen der Referenzialität eines Textes und den kompositionellen Erzählregeln) und die große Vielfalt von Gattungen und Varianten. ${ }^{10}$

9 Siehe J. Szacki, Historia myśli socjologicznej [Geschichte des soziologischen Denkens], T. 2, Warschau 1981, S. 755; K. Kazimierska, „O metodzie dokumentów biograficznych“ [Über die Methode des biographischen Dokuments], „Kultura i Społeczeństwo“ 1990, Nr. 1. Praktische Anwendung findet diese Metode in den Arbeiten The Polish Peasant in Europe and America, 1918-1920 von F. Znaniecki und W. I. Thomas sowie Drogi awansu społecznego robotnika [Wege des Arbeiters zum sozialen Aufstieg] und Młode pokolenie chłopów [Die junge Bauerngeneration] von J. Chałasiński.

10 R. Zimand, Diarysta Stefan Ż. [Der Tagebuchschreiber Stefan Z.], Wrocław 1990, S. 15-17, 23; R. Lubas-Bartoszyńska schreibt, Gattungen wie Tagebuch, Memoiren, Notizen, Erinnerungen, Autobiographie seien „unscharfe Mengen“ in dem Sinne, dass es angesichts der Vielzahl von Texten, die hypothetisch zu einer bestimmten Menge gehörten, schwerfalle, eine gut motivierte Entscheidung über jene Zugehörigkeit zu treffen. [...] „[S] olcherart in Gattungen gefasste unscharfe Mengen erfahren wiederum eine Unschärfe zweiten Grades, [...] Texte, die sich aus per se unklar abgegrenzten Elementen zusammensetzen, wie zum Beispiel autobiographischen, memoirischen oder Tagebuch-Elementen, unterliegen den Einflüssen einer noch weniger abgegrenzten Gattung, und zwar der Essayistik (oder einer starken Literarität). Im Ergebnis 
Auffällig bei der hier untersuchten Textgruppe ist die - nicht selten erhebliche - Spannung zwischen der Einschätzung und Benennung der Texte durch ihre Autoren einerseits und der Zuordnung der Texte anhand ihrer textuellen Merkmale andererseits. Nicht die endgültige Einteilung in Gattungen und komplizierte Klassifikationen habe ich hier jedoch im Sinn; mir ist bewusst, dass eine vollkommene Präzisierung unter diesem Gesichtspunkt weder erreichbar ist noch Erkenntnisgewinn verspricht. Im Übrigen sollen genologische Forschungen auch gar nicht Gegenstand dieser Arbeit sein. Daher belasse ich es bei einer allgemeinen Einordnung des analysierten Materials und einem Vorschlag zur Typologie der Gattungsvarianten. Zuvor jedoch lohnt ein Blick auf das in den Texten verzeichnete genologische Bewusstsein ihrer Autoren.

„Pamiętnik“ [„Erinnerungen“ (eigentlich: Erinnerungsbuch oder „gesammelte Erinnerungen“, ohne wortwörtliche Entsprechung im Deutschen; Anm. d. Übers.)] ist bei Weitem die häufigste Bezeichnung und dabei zugleich auch die dehnbarste und vieldeutigste Gattungskategorie bei den persönlichen Dokumenten. An zweiter Stelle folgen „wspomnienia“ [„Erinnerungen“, „Memoiren“] und „dziennik“ [„Tagebuch“]; ebenfalls anzutreffen sind Benennungen wie „zapiski“ [„Aufzeichnungen“], „notatki“ [„Notizen“], „szkic kronikarski“ [„Entwurf einer Chronik“], „reportaż“ [„Reportage“]. Das genologische Bewusstsein der Verfasser erscheint dabei manches Mal überraschend unkonventionell. ${ }^{11}$

Stanisław Sznapman beispielsweise betitelte seinen Text Dziennik z getta [Tagebuch aus dem Ghetto]. Eine irreführende Klassifikation, weist der Text doch keine der traditionellen Merkmale eines Tagebuchs auf: Er wurde nicht Tag für Tag geschrieben und besteht auch nicht in einer Sammlung von Eintragungen, deren Anordnung sich durch irgendeine chronologische Ordnung

entstehen Texte, die in ihrer Gattungsstruktur doppelt unscharf sind“ (Style wypowiedzi pamiętnikarskiej [Äußerungsstile in Tagebuch und Erinnerungen], Krakau 1983, S. 8).

11 L. Łopatyńska hat aufgezeigt, dass historisch gesehen der Ausdruck „dziennik“ [Tagebuch] äußerst unpräzise verwendet wurde; entweder bezeichnete er täglich festgehaltene Aufzeichnungen, oder ergänzende Materialien und Dokumente zu den verzeichneten Geschehnissen, oder einen Text, der sich auf solche Aufzeichnungen stützte, oder aber Sammlungen von Briefen mit täglichen Berichten über Ereignisse. Auch wurde er synonym zum Begriff „pamiętnik“ [Erinnerungsbuch, Erinnerungen] eingesetzt („Dziennik osobisty, jego odmiany i przemiany“ [Das persönliche Tagebuch, seine Abwandlungen und sein Wandel], „Prace Polonistyczne“, S. 8, Łódź 1950, S. 259-260). Die Autoren des Ghettos verwenden den Ausdruck „pamiętnik“ oder „dziennik“ gemäß der damaligen kulturellen Norm, d.h. in unscharfer und vieldeutiger Weise. So sind beispielsweise S. Brzozowskis Pamiętnik betitelte „Erinnerungen“, eigentlich ein „dziennik“ [also ein Tagebuch im engeren Sinne]. 
auszeichnen würde. Der Autor hält keinen aktuellen Verlauf von Begebenheiten fest, er registriert weder aufeinanderfolgende Ereignisse noch Erlebnisse oder Reflexionen, die diese begleiten würden. Dziennik $z$ getta ist eine Erzählung über das Schicksal der Warschauer Juden in der Zeit von September 1939 bis Juli 1943, platziert vor dem breiteren Hintergrund des europäischen Kriegsschauplatzes und verfasst mit einer zwar geringen, aber dennoch deutlich markierten zeitlichen Distanz. Die Geschichte, die Sznapman erzählt, hat sich zu diesem Zeitpunkt bereits ereignet, wenn auch der Krieg noch im Gange ist. Der Autor ist allerdings überzeugt, dass die Vernichtung der Juden, deren Zeuge er wird, bereits unumkehrbar feststeht. Daher verbirgt er sein im Verhältnis zu den geschilderten Begebenheiten vorauseilendes Wissen nicht, sondern manifestiert es geradezu: Die Erzählung ist gespickt mit wertenden Kommentaren und Appellen an den Leser, und ein überindividueller Blickwinkel wird erkennbar (im narrativen „Wir“).

Und dennoch, auf der Suche nach einer Gattungsformel bezeichnet Sznapman seinen Text, der schließlich eher Erinnerungen als laufende Ereignisse verzeichnet, als „dziennik“. Es ist anzunehmen, dass diese Formel weniger den genologischen Status des Textes markieren soll als die Position des Autors, der ja direkter Zeuge des Geschehens gewesen ist, sowie die Authentizität und Glaubwürdigkeit des Geschilderten. Ein Tagebuch kann in der Gegenüberstellung mit Erinnerungen als glaubwürdiger gelten, und zwar, wie ich denke, aus drei ihm zugeschriebenen Prinzipien. Erstens befindet sich der Tagebuchschreiber „innerhalb“ der verzeichneten Zeitspanne und ist nicht durch den Filter der Erinnerung von dem Beschriebenen getrennt. Zweitens wird die Ordnung der Aufzeichnung nicht durch eine von vornherein feststehende kompositorische Regel bestimmt, sondern durch das stattfindende Geschehen - und damit gewissermaßen durch die Realität. Drittens schließlich scheint das Gebot der Augenzeugenschaft beim Tagebuch rigoroser zu sein als bei Erinnerungen. ${ }^{12}$

12 M. Głowiński betont, dass das private Tagebuch eine Aussageform sei, die keinen im Vorhinein festgelegten Regeln folge, und dass die Einteilung des Tagebuchs in datierte Eintragungen nicht zur Entstehung eines Ganzen führe. Das Tagebuch sei eine offene Form, was es in Opposition setze sowohl zum Tagebuchroman, in dem die chronologische Reihenfolge eine vom Autor festgelegte kompositionelle Regel sei, als auch zur Autobiographie, deren Verfasser sein Leben anhand von gewissen, im Vorhinein festgesetzten Prinzipien oder Ideen vorstelle, um eine Sicht auf das Ganze zu schaffen („Powieść a dziennik intymny“ [Roman und privates Tagebuch], in: M. Głowiński, Gry powieściowe [Romanspiele], Warschau 1973, S. 79-80). R. Zimand schreibt vom Gebot der Augenzeugenschaft als Regel für die gesamte Literatur des persönlichen 
Darüber hinaus kommen Textbezeichnungen vor, die sich direkt oder metaphorisch auf die Gattungen der Sprache im weitesten Sinne beziehen, die das Hauptgewicht auf deren axiologische Dimension und nicht auf die genologische Charakteristik legen. Sie sagen etwas über das moralische und emotionale Verhältnis des Verfassers zum Geschriebenen aus, darüber, was ein Text sein, wozu er dienen, welche Rolle er spielen sollte. Eine solche Benennung enthält weniger die Zuordnung zu einer bestimmten Gattung, als sie die Haltung des Autors markiert sowie Werte bezeichnet, die er mit seinem Text ausdrücken will. Ein „Kleines Gleichnis“ oder „familiäres Buch Hiob“ (Natan) akzentuieren, dass die niedergeschriebene persönliche Erfahrung nach Absicht des Autors eine universelle Aussage annehmen soll. Eine „Beichte“ (Calel Perechodnik) ${ }^{13}$ oder eine „Stimme meiner Seele“ (Karol Rotgeber) verweisen auf die Tiefe des intimen Bekenntnisses angesichts des nahenden Todes. Henryk Bryskers Erinnerungen, ein „Denkmal aus Worten und Papier“, das er seiner ermordeten Frau errichtete, sind eine Geste der Ehrerbietung im Gedenken an das Leiden seiner Nächsten und ein Ausdruck des Willens, deren Schicksale als Beispiel für das Los vieler anderer Menschen zu verewigen. Und schließlich gibt es eine ganze Reihe von Benennungen wie "Anklage“ (Jan Mawult), „Zeugnis eines Verbrechens“, „Anklageschrift“, „Material für den Staatsanwalt“ (Marian Berland), die das häufigste Motiv ausdrücken: das Gefühl der Pflicht, die Verbrechen zu bezeugen, und das starke Verlangen nach Gerechtigkeit oder auch nach Rache an den Verbrechern.

Die Autoren selbst widmen der Frage nach der Gattung ihrer Texte kaum je weitschweifige Erklärungen. Nicht so Janusz Korczak: Sein Pamiętnik [„Erinnerungsbuch" $]^{14}$ beginnt mit einer umfassenden autothematischen Reflexion,

Dokuments, ohne jedoch anzugeben, bei welcher Gattung wir diese Augenzeugenschaft am ehesten erwarten (Diarysta Stefan Z., S. 18-19). Ich nehme aber an, dass das Tagebuch, das wir vor allem mit der Niederschrift unmittelbarer Beobachtung assoziieren, eine sozusagen aktuelle Augenzeugenschaft mit sich bringt, anders als die Erinnerungen, in denen an früher einmal Gesehenes zurückgedacht wird. Außerdem erfolgt im Tagebuch meistens eine deutlichere Unterscheidung zwischen Eintragungen, welche auf eigener Beobachtung beruhen, und Begebenheiten, die nur gehört, d.h. aus zweiter Hand erfahren wurden.

13 Perechodniks Aufzeichnungen sind 1997 erstmals auf Deutsch erschienen: Bin ich ein Mörder? Die Beichte einer Tragödie. Bericht aus dem Ghetto, deutsche Übers. von L. Oelkers; Anm. d. Übers.

14 Auf Deutsch erschienen unter dem Titel Tagebuch aus dem Warschauer Ghetto 1942, dt. Übers. von A. Dross, Göttingen 1996; Anm. d. Übers. 
durchwoben von Metaphern, Parabeln, dramatisch ausgearbeiteten Szenen, Zitaten aus der Literatur. Der Autor stellt Überlegungen über die psychologische und existentielle Situation an, in der sich ein Verfasser von Erinnerungen, Autobiographie, Lebenslauf, Memoiren befindet (all diese Bezeichnungen erwähnt Korczak), und über den Sinn eines solchen Schreibens. Bereits im ersten Satz seines Pamiętnik wird dieser Gattungsname eingeführt, sodann erfolgt eine gewisse Distanzierung: „Düster, niederdrückend ist die Lektüre von Erinnerungen. “15 Für Korczak dokumentieren die traditionellen schriftlichen Erinnerungen das zunehmende Nachlassen von Lebensenergie; die Dynamik eines schriftlich festgehaltenen Lebenslaufs gibt die Richtung vor: von der Jugend zum Alter, von Vitalität, Ehrgeiz, Hoffnung zu Erschöpfung und Zweifel. Korczak äußert den Wunsch, dieses Modell zu ändern:

In meinen eigenen Lebenserinnerungen will ich versuchen, es anders zu machen. Vielleicht ist das ein glücklicher Gedanke, vielleicht gelingt es, vielleicht ist es gerade so richtig. (S. 20)

Der Entwurf des positiven Vorschlags ist in einem metaphorischen Bild verborgen, das auf diese Deklaration folgt: Der Tagebuchschreiber gräbt einen Brunnen, um durch die miteinander verwobenen Erinnerungsschichten zu den unterirdischen Quellen zu gelangen. Somit beschreibt der Verfasser von Erinnerungen weniger sein Leben, als er bis zur Tiefe seines Selbst vordringt. Er entdeckt, wer er wirklich ist. Mühselig ist diese Arbeit, von Hindernissen und Fallen gespickt, niemals ganz zu vollbringen. Auch kann niemand dabei helfen. „[D]as muss jeder selbst tun. Keiner kann ihm dabei helfen, und keiner kann einen da vertreten“(l.c.).

Am Ende des ersten Teils seiner Erinnerungen kehrt Korczak noch einmal zur autothematischen Reflexion zurück. Nun geht es nicht mehr um ein Vorhaben, sondern um die Durchführung:

Ich habe alles noch einmal durchgelesen. Nur mit Mühe habe ich es verstanden. Und der Leser?

Kein Wunder, dass ein Tagebuch unverständlich für den Leser bleibt. Kann man denn überhaupt fremde Erinnerungen, ein fremdes Leben verstehen?

Ich sollte ja wohl ohne Mühe erkennen, was ich schreibe.

Nun freilich, aber kann man eigene Erinnerungen verstehen? (S. 86)

Hier hat die Frage nach der Möglichkeit zu verstehen zwei Adressaten: den Leser und den Autor. Letzterer scheint hier der wichtigere zu sein. Das Festhalten von

15 Ebd., S. 18; Anm. d. Übers. 
Erinnerungen in Buchform nimmt nämlich für Korczak die Eigenschaften einer Art geistigen Übung an, wird zu einer disziplinierten, systematisch und gegen den Druck der Außenwelt vollführten Meditation. In diesem Kontext zu lesen sind Korczaks Bemerkungen über die Beziehung zwischen der Zeit, die der Schreibende durchlebt, und der erinnernden Erzählung über die Zeit. Die Zeit ist ein Element, das sich nicht beschreiben lässt. Keine Narration ist in der Lage, das tatsächliche Pulsieren der Zeit, den Lauf der Ereignisse, Gedanken, Gefühle wiederzugeben. Damit ist der Verfasser in dieser Hinsicht zur Unerfülltheit, zum unvermeidlichen Scheitern verurteilt. Dennoch muss er die Herausforderung annehmen:

Jede Stunde - das ist ein dickes Heft, das ist eine Stunde Lesen.

Nun ja.

Du musst einen ganzen Tag lang lesen, um einen meiner Tage in etwa zu verstehen.

Woche für Woche, Jahr für Jahr.

Und wir wollen in einigen Stunden, um den Preis von ein paar eigenen Stunden - ein ganzes langes Leben durchmessen.

So einfach geht das nicht. Du wirst es in einer undeutlichen Kürzung, in einer flüchtigen Skizze kennenlernen - eine Episode für tausend, für hunderttausend (S. 87).

Korczaks Überlegungen zur Niederschrift von Erinnerungen lassen sich interpretieren als Suche nach einer Formel, welche zugleich die Wahrheit über den Autor erfassen und Zeugnis über die Zeit geben könnte - einer Formel, die hilfreich dabei wäre, nicht nur das eigene Leben zu verstehen, sondern auch die Welt, in der man leben muss, und den Platz, der einem darin zukommt. Indem er über sich und für sich schreibt, richtet sich der Verfasser von Erinnerungen schließlich auch an andere. Korczaks Suche nach einer Formel ist somit auch die Suche nach einer Möglichkeit, Zeugnis zu geben.

Ich möchte nun also folgenden Vorschlag für eine Typologie der Gattungsvarianten innerhalb der hier analysierten Literatur des persönlichen Dokuments unterbreiten:

Tagebuch (dziennik) und Chronik-Tagebuch (dziennik-kronika) verbinden einer solchen Einteilung zufolge, dass keine zeitliche Distanz zu den dargestellten Ereignissen herrscht, dass es keine im Vorhinein festgelegten Kompositionsregeln gibt und dass jeweils aktuelle Begebenheiten fortlaufend geschildert werden. Dagegen unterscheidet sie, dass beim Tagebuch die private Beobachtungsperspektive exponiert wird, dass die Beschreibung subjektiviert und die Sprache individualisiert wird bis hin zu einer Verwendung von literarischen Ausdrucksformen, wohingegen das Chronik-Tagebuch eher bemüht ist, ein breiteres Spektrum zu erfassen, das über das Beobachtungsfeld 
des schreibenden Subjekts hinausgeht, sowie nach einer Objektivierung der Beschreibung, einer panoramischen Darstellung des Lebens einer bestimmten Gruppe strebt. ${ }^{16}$

Innerhalb des nun abgesteckten Gattungsbereiches finden verschiedene Varianten Platz. Die Tagebücher von Avrom Levin [Abraham Lewin] und Chaim Aron Kaplan verdienen dank der subjektivierten Schreibweise und Emotionalität voll und ganz die Bezeichnung „intimes Tagebuch“. Dagegen konzentriert sich Adam Czerniakóws Tagebuch ${ }^{17}$ auf öffentliche Angelegenheiten und zeichnet in knappen Notizen ein Bild der Gemeinschaft. In der Textkonstruktion jedoch, in der Form der Sprache trägt es deutlich den individuellen Stempel des Autors. Emanuel Ringelblums Notitsn fun varshever geto [Warschau 1952; engl. Ausgabe: Notes from the Warsaw Ghetto, bearb. und übers. von J. Sloan, New York 1958] gehen entschieden über die individuelle Perspektive der Narration hinaus und versuchen sich an einem allumfassenden, objektivierten Blick, der dennoch nicht frei ist von persönlichen Emotionen des Verfassers. Ludwik Landaus monumentale Kronika lat wojny i okupacji [Chronik der Kriegs- und Besatzungsjahre] liefert ein Panorama vieler verschiedener Perspektiven aus den Besatzungsjahren, das weit über das Ghetto und das besetzte Warschau hinausgeht und eine Fülle an detaillierten Beobachtungen und auch allgemeinen Reflexionen aufweist.

Die Erinnerungen (pamiętnik) sind vor allem durch ihre zeitliche Distanz zu den beschriebenen Geschehnissen und zu der Person, die diese durchlebt, in Opposition zum Tagebuch angesiedelt. Jene Distanz gestattet es, im Vorhinein gewisse Kompositionsregeln und narrative Strategien festzusetzen, die Position eines allwissenden Erzählers einzunehmen oder nicht, Ereignisse aus der allwissenden Position heraus zu kommentieren und zu bewerten. Die Welt in festgehaltenen Erinnerungen ist immer auf irgendeine Weise erzählt, was bedeutet, dass sie auch kognitiv geordnet, angeeignet ist. Sie lässt sich als Kette von Ereignissen erzählen, während sie im Tagebuch die Gestalt nur locker verbundener, ungeordneter und nicht hierarchisierter einzelner Kettenglieder von Ereignissen annehmen kann.

16 R. Zimand zufolge (Diarysta Stefan Z., S. 18) ist die Domäne des persönlichen Tagebuchs „die Welt des direkten Schreibens über sich selbst“, während die Domäne des Chronik-Tagebuchs „die Welt der Augenzeugenschaft“ sei.

17 Deutsche Ausgabe: Im Warschauer Getto. Das Tagebuch des Adam Czerniaków. 1939 1942, München 1986; Anm. d. Übers. 
Alle in diese Untersuchung einbezogenen Erinnerungen wurden mit einer kleinen zeitlichen Distanz zu Papier gebracht; die Autoren beschreiben Geschehnisse, die wenige Monate bis höchstens anderthalb Jahre zurückliegen. Die Zeit des Beschriebenen und die Zeit des Schreibens nähern sich dabei zunehmend einander an, bis sie am Ende des Textes zusammenfließen. So ist es zum Beispiel bei Marian Berland, der im Mai 1944 seine Aufzeichnungen beginnt, die mit der Schilderung seiner Erlebnisse während des Ghettoaufstands im April und Mai 1943 einsetzen. Calel Perechodnik beschreibt die Liquidierung des Ghettos in Otwock (17.-19. August 1942) genau zu dem Zeitpunkt, an dem sich dieses Ereignis zum ersten Mal jährt, was er im Text deutlich vermerkt. Stefan Ernest wiederum fängt seinen Erinnerungsbericht mit der Abriegelung des Warschauer Ghettos (November 1940) an und beendet ihn am 28. Mai 1943.

Die Verfasser von Erinnerungen bemühen sich überwiegend, ihr Kriegsschicksal in Gänze zu schildern, d.h. vom September 1939 oder von der Entstehung des Ghettos an bis zu dem Zeitpunkt, an dem sie ihren Stift niederlegen. Und mehr noch, häufig versuchen sie, eine Antwort zu geben auf die Frage nach dem Sinn der Kriegserfahrung, nach der Verantwortung für das Vorgefallene wie beispielsweise Henryk Makower, Ludwik Hirszfeld, Karol Rotgeber, Stefan Ernest, Stanisław Sznapman, Calel Perechodnik oder ein unbekannter Autor, Funktionär beim Ordnungsdienst im Ghetto (N.N. „Pam.“ [Erinnerungen], 129). Bei diesen Autoren schlägt die Reflexion über das eigene Leben immer wieder in eine historiosophische Reflexion um, wobei sich diese beiden - stärker oder schwächer ausgeprägten - Motive miteinander verweben.

Der Essay ist ein Versuch, eine „unscharfe Menge“ von Gattungen zusammenzufassen, in der persönliches Dokument und Literatur, Referenzialität und Fiktionalität aufeinandertreffen, in der sich Schöpferisches mit dem Vorsatz der Berichterstattung mischt. Zu dieser Gruppe möchte ich Lejb Goldin, Rokhl Oyerbakh [Rachel Auerbach], Henryk Słobodzki oder Władysław Szlengl zählen.

BRIEFE wiederum stellen eine gesonderte, im formellen Sinn leicht von den anderen Gruppen unterscheidbare Kategorie dar. Im Ringelblum-Archiv wird eine große Briefsammlung aufbewahrt. Ein Sonderfall darunter ist die Korrespondenz von Wanda Lubelska und Halina Grabowska sowie auch Henryka Łazertównas Brief an Roman Kołoniecki.

VARIA. Dieser Gruppe habe ich ausgewählte Briefe und amtliche Schriften zugeordnet (zum Beispiel die Korrespondenzen Janusz Korczaks), Berichte von Ämtern und gesellschaftlichen Institutionen bzw. Meldungen aus dem politischen konspirativen Milieu (zum Beispiel eine Mitteilung von den vereinigten Untergrundorganisationen im Ghetto), Berichterstattungen umgesiedelter 
Menschen und schriftliche Arbeiten von Kindern aus Waisenhäusern, deren Anfertigung die Mitglieder des Untergrundarchivs im Ghetto angeregt hatten, sowie monographische Abhandlungen über besondere Problematiken (zum Beispiel Choroba głodowa [Die Hungerkrankheit] unter Anleitung von Izrael Milejkowski, Stosunki polsko-żydowskie w czasie drugiej wojny światowej [Polnisch-jüdische Beziehungen in der Zeit des Zweiten Weltkrieges] von Emanuel Ringelblum). Und es bleiben noch weitere verschiedenartige Texte, zum Beispiel Artikel für die Wochenzeitung von Janusz Korczaks Kinderheim Dom Sierot [Haus der Waisen] oder der Begrüßungstext eines unbekannten Autors für eine Lesung im Ghetto.

Die hier aufgeführten Beispiele überschreiten den Gattungsrahmen des persönlichen Dokuments und befinden sich deswegen nicht mehr im Bereich meines Interesses. Dennoch erwähne ich sie hier, weil die außergewöhnlichen zeitlichen und örtlichen Umstände ihrer Entstehung sowie die besondere Situation, in der sich ihre Verfasser befanden, in manchen Fällen auch bei solchen Schriften eine eindrückliche Spur persönlicher Erfahrung hinterlassen haben. Aus diesem Grund werde ich versuchen, ebenfalls diese Art Texte, wenn auch nur sporadisch und in Ausnahmefällen, in meine Betrachtungen einfließen zu lassen.

\section{2}

Zwar sind die analysierten Texte unter verschiedensten Umständen entstanden und repräsentieren die unterschiedlichsten Gattungsvarianten, jedoch sind sie trotzdem als ein zusammenhängendes Ganzes vorstellbar, das sich mit folgenden drei gemeinsamen Parametern beschreiben lässt: mit dem Zustand der Bedrohung, dem Bewusstsein des nahen Endes und dem Gefühl eines Gefangenseins in der Zeit.

Das Schreiben war stets von einem Gefühl der Bedrohung begleitet, doch war dieses Gefühl wechselnd stark und äußerte sich in verschiedenen Formen. Alle Schreibenden unterlagen ihm, wenn auch nicht in gleichem Maße. Es ergab sich aus der individuellen Situation des Autors, die sich einschrieb in das Schicksal der Gemeinschaft. Der Zustand der Bedrohung relativierte sich auch innerhalb der Chronologie des Ghettos; die individuelle Zeit verlief innerhalb der kollektiven Zeit, und die wiederum wurde durch die aufeinanderfolgenden Zeiträume der Geschichte des Ghettos geformt. Daher kann man sich eine allgemeine Periodisierung der Bedrohung für das gesamte Ghetto vorstellen, bezeichnet durch die einzelnen Etappen einer alle Bewohner betreffenden Vernichtung, und man kann in diesem Rahmen die aufeinanderfolgenden Phasen 
des privaten Schicksals nachverfolgen. Die Bedrohung war also verschiedenartig ausgeprägt, ließ jedoch nie nach und machte nicht nur dem Autor, sondern auch seinem Text das Überleben schwer. Da ungewiss war, wie es sich mit dem weiteren Schicksal verhielt, wurde die Bedrohung schlussendlich zu einer Sicherheit der unausweichlichen Vernichtung.

Dieser Stand der Dinge verhinderte, dass der Autor vollständig Herr seiner geschilderten Wirklichkeit war, dass er sie in eine traditionelle narrative Form bringen und ihr eine klar strukturierte, erzählbare und verständliche Gestalt verleihen konnte. Zudem war er eines grundlegenden Wissens beraubt, das unter gewöhnlichen Umständen jeder Erzähler einer Geschichte besitzt - er wusste nicht, konnte gar nicht wissen, wie und wann seine Geschichte enden würde.

Bei der Niederschrift von Erinnerungen veranlasst der zeitliche Abstand - der ja nur kurz und im Grunde illusorisch ist - die Verfasser, sich an einer Systematisierung und Interpretation des Erlebten zu versuchen, es ordnen und zur Gänze erfassen zu wollen. Dabei sitzt das überstandene Grauen den Schreibenden noch in den Fingern, Angst und Schrecken dauern fort. Schließlich sind sie nach wie vor im besetzten Warschau gefangen - in den Mauern des Ghettos oder im Versteck auf „arischer Seite“. Somit registrieren die Autoren die damalige Realität zeitgleich oder mit nur geringer zeitlicher Distanz, vor allem aber in Unwissenheit über den Ausgang des Geschehens. ${ }^{18}$ Sie verewigen die Geschehnisse jener Zeit so, wie sie sich ihrem kognitiven Horizont während des Schreibens darstellten, und geben ihre Erlebnisse, Reflexionen, Wertungen relativiert durch ihren damaligen Wissensstand weiter.

Ein gemeinsames Charakteristikum für die hier analysierte Gruppe von Texten - so unterschiedlich sie auch von der Gattung her sein mögen - ist, dass sie keine deutliche Distanz zu den geschilderten Ereignissen aufweisen. Dies hat wiederum ein gewisses "Gefangensein“ zur Folge - ein Gefangensein anderer Art jedoch als die allgemeine Situation des Tagebuchschreibers, der zwangsläufig in der Realität "gefangen“ ist, im Strom der Zeit mit seiner Einteilung in das

18 Ebendieser Kategorie bedient sich K. Zaleski bei seiner gesonderten Betrachtung einer Sammlung von Tatsachenliteratur aus der Besatzungszeit. Er untersucht Texte, die geschrieben wurden ,in der Unwissenheit über das Ende, über den Ausgang des Krieges, über spätere offizielle Interpretationen, die den Jahren 1939-1945 diesen oder jenen globalen Sinn verliehen hätten“ („Fakt i sens całości. Z problemów okupacyjnej literatury faktu" [Tatsache und Sinn des Ganzen. Von den Problemen der Tatsachenliteratur aus der Besatzungszeit], in: M. Głowiński und J. Sławiński (Hgg.): Literatura wobec wojny i okupacji [Die Literatur angesichts von Krieg und Besatzung], Wrocław 1976, S. 121). 
aktuelle „Heute“ und das nahe „Gestern“ und „Morgen“. Bei den Autoren der Ghettotexte gesellt sich zu dieser gewöhnlichen Begrenztheit noch etwas Ungewöhnliches hinzu: Sie sind eingeschlossen in einer Situation, auf deren Verlauf sie keinerlei Einfluss nehmen können und der sie vollkommen ausgeliefert sind. Jene Situation, die den gesamten Horizont des textuellen Hier und Jetzt ausfüllt, erweist sich als eine nicht nur den Schreibenden, sondern die gesamte Gemeinschaft zugrunde richtende Katastrophe. Der Tagebuchschreiber aus dem Ghetto wird weniger von den Wellen der Zeit davongetragen und kann sich - ohne zu wissen, was das Morgen bringt - noch rasch das flüchtige Heute notieren, als er vielmehr in den Fluten eines grauenvollen Jetzt zu ertrinken droht. In seiner persönlichen Erfahrung wird die Jetztzeit zur Endzeit. Das Morgen hat lediglich den Wert, dass es einen Aufschub der heute noch nicht vollzogenen Exekution bedeutet, während die Zukunft zur abstrakten Leerstelle nach der Katastrophe wird, zur gesellschaftlichen Utopie oder zum religiösen Mythos. Der Schreibende ist somit in einer Grenzsituation gefangen und fasst aus dieser Situation heraus den Entschluss zu schreiben. Und während er schreibt, ändern sich die Umstände, der Grad seiner eigenen Sicherheit - das Wesentliche jedoch unterliegt keinem Wandel. Ohne sich aus den Fluten retten zu können, verzeichnet der Schreibende das fremde und zerstörerische und dabei einzig zugängliche, unausweichliche, endgültige „Heute“.

Der bedrohliche Zustand, das Gefangensein in der Grenzsituation und die Unwissenheit über deren Ausgang sind die grundlegenden Maßstäbe sowohl für die kommunikative als auch für die existentielle Situation desjenigen, der sich ans Schreiben macht. Sie formen seine kognitive Perspektive und nehmen des Weiteren Einfluss darauf, welche kommunikative Rolle er wählt, wie er seine Erfahrung artikuliert, welche Form er seinen Aufzeichnungen gibt - kurz: Sie bestimmen die Gestalt des Diskurses.

Zwischen den hic et nunc und den erst post factum geschriebenen Texten gibt es einen essenziellen Unterschied, dessen Ursprung zwar in der außertextuellen Realität liegt (die Zäsur des Kriegsendes, die radikale Veränderung von äußeren Umständen und der Lebenssituation des Verfassers), der aber dennoch die Struktur des Textes deutlich beeinflusst. Die unüberschreitbare Grenze, welche die Kriegs- von der Friedenszeit trennt, spiegelt sich in der Spannung zwischen den rekonstruierbaren Kommunikationsrollen: der Rolle des „berichtenden Augenzeugen“ (also des „damals dort“ schreibenden Autors) und der Rolle des „erinnernden Überlebenden“ (des erst nach dem Krieg schreibenden Autors). Jenen Rollen entsprechen zwei Typen von Erfahrung: auf der einen Seite die Erfahrung, umzingelt zu sein, in eine Situation des allumfassenden Horrors geraten und zur Vernichtung verurteilt zu sein, und auf der anderen Seite die 
Erfahrung, gerettet zu sein und sich „äußerlich“ in Sicherheit zu befinden, wobei aber ein verinnerlichtes Grauen zurückbleibt - die Wunde der Erinnerung.

Ein grundlegender struktureller Maßstab für textuelle Zeugnisse, die aus der Kriegszeit stammen, sind Formen, mittels derer eine radikal neue und fremde Erfahrung ausgedrückt wird (eine Rhetorik des Horrors und des Alltags), Strategien zur Aneignung der Gegenwart (die Beschreibung einer unbeschreiblichen Welt), die Projizierung einer Zukunft (explizit ausgedrückte oder rekonstruierbare Motivationen für das Schreiben, Appelle an einen zukünftigen Leser und die Modellierung einer zukünftigen Rezeptionssituation). Konstitutiv für Texte aus der Nachkriegszeit hingegen sind Methoden zur Aneignung der Vergangenheit (eine Narration der Erinnerung als Therapie des Gedenkens), Muster für die Konstruktion eines autobiographischen „Ich“ (die Art der Distanz, ein offen dargelegter Wissensstand über die Realität sowie Kriterien für deren Bewertung) sowie Konventionen, nach denen thematisches Material angeführt, organisiert und bewertet wird (von den biographischen Erlebnissen des privaten "Ich“ bis hin zur existentiellen Formel für das menschliche In-der-Welt-Sein).

\section{3}

Die Dokumentationen persönlicher Erfahrung aus dem Ghetto bilden eine wahre Flut von Texten verschiedenster Gattungen mit ganz unterschiedlicher Ausdrucksweise und Erzählperspektive, bewahren aber dennoch eine Einheit von Ort, Zeit und Geschehen - wie in einer antiken Tragödie. Die in ihnen festgeschriebene Erfahrung weist eine doppelte Dimension auf: eine individuelle und eine universale, eine private und eine allgemeine. All das macht diese Texte auf eine Weise lesbar, als seien sie ein Ganzes, ein spezieller „Makro-Roman“. Der einzelne Text ist eingebunden in ein Netz vielfältigster Verbindungen. Erstens ist ein solcher Text in gewissem Sinne verwaist, begleiteten ihn doch zur selben Zeit und im selben Raum andere, von einer ähnlichen Erfahrung berichtende und aus ähnlicher Motivation entstandene Texte, die jedoch verloren gegangen sind. Mit jenen verlorenen Texten ist der erhaltene Text somit durch Bande verknüpft, die sich nicht wiederherstellen lassen. Es lässt sich jedoch nie genau sagen, was unwiederbringlich verloren ist und was nur im Verborgenen liegt und wieder auftauchen kann (wie zum Beispiel Janusz Korczaks auf geheimnisvollen Wegen wiedergefundene und erst 1992 veröffentlichte Schriften aus dem Ghetto). Zweitens findet der einzelne Text seine Vervollständigung in anderen erhaltenen Texten. Sie erscheinen im gegenseitigen Licht und ergänzen einander; die Lücken und Unklarheiten eines Textes können durch andere behoben werden. Als Strom von Texten gelesen überwinden die einzelnen Texte ihren bruchstückhaften 
und amorphen Charakter. Drittens schließlich kann ein Text auf vielerlei Weise fragmentarisch sein - sei es, dass er nur in Teilen erhalten oder niemals vollendet worden ist, sei es, dass er durch den subjektiven Gesichtspunkt oder das begrenzte Wissen seines Autors unweigerlich zum Bruchstückhaften und zur Unvollständigkeit verurteilt ist.

Dem Forscher nun stellt sich die Aufgabe, eine Formel für die Gesamtheit zu entwerfen. Dies verlangt nach einer entsprechenden Art der Lektüre, und infolgedessen nach einer gewissen hermeneutischen Einstellung ${ }^{19}$. Geht man davon aus, dass ein Untersuchungsgegenstand sinnvoll gewählt ist, so lässt sich des Weiteren annehmen, dass man zu jenem Sinn gelangen oder es wenigstens versuchen kann. Diese Feststellung liegt nicht auf der Hand. Sie birgt vielmehr einen gewissen Forschungsoptimismus, drückt einen Glauben an die Gültigkeit und Folgerichtigkeit bestimmter Forschungsprozeduren aus, die einen Weg zum Verständnis der analysierten Texte eröffnen können. Bei Holocaustzeugnissen sind das beileibe keine offensichtlichen Annahmen.

Es stellt sich nämlich unweigerlich die Frage, ob die Erfahrung des Holocaust überhaupt vermittelbar ist, ob sie nicht die menschliche Ausdrucksfähigkeit und die menschliche Fähigkeit zu begreifen übersteigt. Lässt sich über diese Erfahrung sprechen? Und wenn ja, wie? In seiner Analyse von Stanisław Pigońs Bericht aus Sachsenhausen weist Michał Głowiński auf das schwierige Problem einer angesichts der beschriebenen Wirklichkeit inadäquaten Sprache hin: „Wie lässt es sich über Erfahrungen schreiben, die so außergewöhnlich sind in ihrer Ungeheuerlichkeit, dass sie keinerlei Vorgänger haben und die Sprache gewissermaßen unvorbereitet treffen, mit deren Mitteln Berichte über jene Erfahrungen zusammengesetzt werden sollten? [...] [W]elche Sprache ist zu wählen, damit sie wenigstens teilweise Botschaft einer Epoche der totalen Barbarei sein kann, damit sie Bericht erstatten kann über eine beispiellose Lage des Menschen [...].

19 M. Głowiński vermeidet den Begriff der „Interpretation“, da dieser - im Unterschied zur „Analyse“, wenn man sie als Darstellung der Textstrategie und der angewandten Sprechregeln betrachtet - eine hermeneutische Einstellung voraussetze. Eine verstehende Haltung gegenüber totalitären Texten einzunehmen - wie Mein Kampf oder Geschichte der KPdSU (B) - Kurzer Lehrgang [Offenbach 2012; Anm. d. Übers.] -, erscheine, so der Autor, weder möglich noch wünschenswert, die Analyse ihrer Poetik hingegen sei überaus interessant. Im Falle von Zeugnissen des Holocaust lassen sich jedoch beide Ansätze - der analytisch-beschreibende und der hermeneutische - vereinen; ich meine sogar, dass sie vereint werden sollten („Poetyka tekstów nieliterackich“ [Die Poetik nicht-literarischer Texte], in: W. Głowiński: Poetyka i okolice [Die Poetik und ihr Umfeld], Warschau 1993, S. 83-84). 
Die bisherige Sprache hat sich als ungeeignet erwiesen, über solcherart Erfahrungen zu berichten, reduzierte sie diese doch auf das Altbekannte und daher mit jenen Erfahrungen Unvergleichbare. “20

Das Problem einer entsprechenden Sprachwahl ist eine Herausforderung, der sich sowohl der Übermittler als auch der Adressat eines Zeugnisses stellen muss. Mit anderen Worten: Die Frage nach der Ausdrückbarkeit von Holocausterfahrungen betrifft beide Seiten. Sie ist die Suche nach einer Methode, mittels derer der Berichterstatter seine Erfahrungen übermitteln und der Adressat sie empfangen und begreifen kann. Die Perspektive des Adressaten - also unser aller Perspektive - umfasst auch die Situation des Forschers. Eine Formel für die Beschreibung zu finden, ist für den Forscher von entscheidender Bedeutung. Wie soll also die Vielfalt der erhaltenen Texte erfasst, wie sollen sie gelesen, welche Haltung ihnen gegenüber eingenommen werden?

Bevor ich meinen eigenen Vorschlag formuliere, weise ich auf die Arbeiten hin, die mir die wichtigste Inspirationsquelle waren. Der dort herausgearbeitete Stil der Lektüre von Holocaustzeugnissen hat den Findungsprozess meiner eigenen Lesart stark beeinflusst. Schulden dieser Art lassen sich schwerlich durch Angaben in Fußnoten begleichen.

Jerzy Jedlicki holte die vom Museum in Oświęcim [im ehem. KL Auschwitz; Anm. d. Übers.] publizierten Handschriften von Mitgliedern des Sonderkommandos in Birkenau aus der Vergessenheit. In der Skizze „Dzieje doświadczone i dzieje zaświadczone“ [Erlebte Geschichte und bezeugte Geschichte] ${ }^{21}$ stellt er u.a. Überlegungen zur - wie er es selbst leicht scherzhaft-distanziert bezeichnet - „Kommunikationssituation“ persönlicher Zeugenberichte aus der Zeit des Holocaust an. Eingang in seine Reflexionen findet die Frage sowohl nach der Motivation der Autoren und deren psychologischen, kulturellen und existenziellen Beweggründen als auch nach der Haltung der Adressaten. Er weist auf verschiedene Rezeptionsstrategien hin: von einer dem empfundenen Entsetzen geschuldeten Abwehrhaltung über die Aneignung bis hin zur Durchtrennung der Verbindungen, zu einer „Taubheit der Rezeption“. Jedlicki spricht ebenfalls die wichtige Frage nach der Wahl einer Sprache an, nach der Wahl einer Form der Überlieferung, verbirgt sich doch seiner Ansicht nach hinter dieser Wahl die prinzipielle Entscheidung für eine kognitive Perspektive und eine Sicht auf die Welt. Des Weiteren

20 M. Głowiński: „Stanisława Pigonia relacja z Sachsenhausen“ [Stanisław Pigońs Bericht aus Sachsenhausen], in: ders.: Gry powieściowe, S. 308-309.

21 Erstabdruck in: Z. Stefanowska und J. Sławiński (Hgg.): Dzieło literackie jako źródło historyczne [Das literarische Werk als historische Quelle], Warschau 1978. 
macht er (nach Andrzej Werner) auf die Existenz zweier opponierender Perspektiven bei Holocaustüberlieferungen aufmerksam. Maßstab hierbei ist die Position des sprechenden Subjekts gegenüber der Welt. Eine Außenperspektive setzt die klare Trennung in Gut und Böse, in Opfer und Henker voraus; das Böse ist der Aggressor von außen und trifft auf den solidarischen Widerstand der Verteidiger des Guten. Eine Innenperspektive offenbart gemischte Werte, eine Zwangslage und eine Machtlosigkeit angesichts der Zerstörung.

Ein jeder ist bedroht, alle sind gezeichnet. Bei den persönlichen Dokumenten aus dem Warschauer Ghetto könnte zum Beispiel die Biographie Ludwik Hirszfelds eine Exemplifikation für die Außenperspektive sein könnte, während die Innenperspektive durch Calel Perechodniks Erinnerungsbuch repräsentiert würde.

Roman Zimands Essay über Adam Czerniakóws Tagebuch ist - wie der Autor es im Untertitel bezeichnet - der „Versuch einer Lektüre“. Ich erlaube mir, eine Stelle aus der Einleitung des Buches zu zitieren, gibt sie doch genau meine eigene Haltung wieder: „Der Schreiber dieser Worte ist kein Fachmann, er ist kein Kenner der Geschichte des polnischen Judentums, kein Historiker im Allgemeinen. Sieht man jedoch Czerniakóws Tagebuch als außergewöhnliches Dokument an, dann schließlich u.a. deshalb, weil es zu Nicht-Fachleuten spricht. Und da es das tut, darf bezeugt werden, wie ein Nicht-Fachmann jenen Text versteht. ${ }^{\text {"22 }}$

Im Tagebuch des Vorsitzenden der Jüdischen Gemeinde im Warschauer Ghetto, das bis dahin lediglich als wertvolles Quellenmaterial für historische Forschungen betrachtet worden war, erkannte Zimand eine kunstvoll komponierte Aufzeichnung der Erfahrung des Holocaust. Er untersuchte daher vor allem die Methoden zur Konstruktion einer Übermittlung, die Rhetorik des Textes, und bewies damit - entgegen mancher anderer Einschätzungen -, dass eine Analyse des Diskurses um die Dokumente des Völkermordes nicht nur gerechtfertigt ist, sondern auch in erkenntnisbezogenem Sinne außerordentlichen Nutzen bringt. Darauf beruht, wie ich denke, die durch Zimand vollführte "kopernikanische Wende" in der Lesart von Holocaustzeugnissen. Diese sind für ihn weniger geschichtliche Quelle als eine Art der Manifestation des Autors. Somit konzentriert er sich auf die Analyse der Regeln, die den gelesenen Text steuern, auf die Poetik der Niederschrift, die Grundsätze ihrer Grammatik, um daraus resultierend den Autor zu verstehen.

22 R. Zimand: „W nocy od 12 do 5 rano nie spałem.“ „Dziennik“ Adama Czerniakowapróba lektury [In der Nacht habe ich von 12 bis 5 Uhr früh nicht geschlafen. Das „Tagebuch“ des Adam Czerniaków - Versuch einer Lektüre], Paris 1979, S. 7. 
Piotr Matywieckis Buch Kamień graniczny [Der Grenzstein; Warschau 1994] ist ein Versuch, zu den Wurzeln der Holocausterfahrung vorzudringen. Der Autor möchte mittels seiner Worte das Unberührbare berühren, das, was sich zwischen Existenz und Nichtexistenz erstreckt. Sein Buch sticht hervor in seiner Kompromisslosigkeit und seinem Mut, es schockiert in seiner Radikalität, verzeichnet auf einzigartige Weise das Ringen des menschlichen Bewusstseins mit dem Ghetto. Der erste Teil - „Wstyd“, „Puste magie“, „Trzy traktaty“ [Scham; Leere Magien; Drei Traktate] - stellt eine negative Hermeneutik des Ghettos dar, weist Elemente aus der Mystik und aus der apophatischen - d.h. negativen - Theologie (vom griechischen apophatikos - „verneinend“) auf. Matywiecki umflicht die Unbegreiflichkeit des Ghettos mit einem Netz von Widersprüchen und Antithesen. Der zur Zustimmung und Verneinung zugleich gezwungene Geist gerät in ein Nichts, dem er nur hilflose Metaphern und eine Rhetorik der Leere entgegensetzen kann. Das meditierende Subjekt befindet sich in einer Art Seinsspalt - zwischen dem Ghetto, zu dem es keinen Zugang hat, und der Realität nach dem Ghetto, der es sich entfremdet fühlt. Es sehnt sich zurück, kann aber nicht dort sein; es will nicht, muss aber HIER sein. Matywiecki durchläuft in seiner Meditation mehrere Grade der „Entblätterung“. Befreit von den Ausuferungen der Sprache, dem Hochmut des Denkens und den Anmaßungen des Willens, bringt er sich eine Haltung der inneren Gedämpftheit, in eine „gebetsähnliche Gedankenruhe, ein Schalom“. Jene Gedämpftheit lässt ihn offen werden für die Stimmen der Toten, und seine Leser führt sie zu Teil 2, der um vieles länger ist als Teil 1: „Zdania z getta“ [Ansichten aus dem Ghetto]. Eine Zeit des Lauschens und des Lesens kehrt ein. „Zdania z getta“ ist eine ganz eigene Anthologie von Tagebüchern, Erinnerungen, Briefen, Berichten von Überlebenden aus dem Warschauer Ghetto. Die umfänglich zitierten Textstellen sind umrahmt von einem meditativen Kommentar. Matywiecki spürt jedem Wort aus der Feder der Überlebenden nach, durchdringt in tiefer gedanklicher Versunkenheit die aus den Trümmern befreiten Texte, erforscht wie ein Blinder mit den Fingern die Struktur eines jeden Satzes. Die aus den eingestürzten Kellergewölben Muranóws geborgene Rede der Opfer begegnet der Rede eines Geretteten. In dieser Bewegung vollzieht sich das Unmögliche - die Berührung des Ghettos.

Von den ausländischen Arbeiten muss an dieser Stelle ein außerordentliches und für mich persönlich überaus inspirierendes Buch von James E. Young erwähnt werden: Writing and Rewriting the Holocaust. Narrative and the Consequences of the Interpretation (Bloomington, Indianapolis 1988). Der Autor analysiert darin verschieden geartete Zeugnisse aus der Zeit des Holocaust - vor allem persönliche Dokumente wie Tagebücher, notierte Erinnerungen, Erinnerungsberichte, und im Anschluss daran Lyrik (zum Beispiel ein Poem von 
Jizchak Katzenelson, Gedichte von Sylvia Plath), auf Video aufgezeichnete Aussagen von Überlebenden, Ikonographien - und zwar unter dem Gesichtspunkt ihrer Textualität. Er zeigt die Verschiedenartigkeit von Diskursformen, narrativen Strategien und Gattungsvarianten auf, welche die Gestalt des Überlieferten bestimmen, stellt dar, auf welche Weise Sprache, kulturelle Konventionen und Ausdrucksschemata eine vermittelnde Rolle zwischen dem Geschehenen und dessen textueller Repräsentation spielen, und erläutert das Spannungsverhältnis zwischen den Polen Berichterstattung und Kreierung.

\section{4}

Oberste methodologische Direktive ist für mich die Analyse des Diskurses, nicht die Rekonstruktion von Fakten. Unter „Diskurs“ verstehe ich hier einfach die Erzählweise einer Geschichte. Es interessiert mich demnach vor allem, wie über die herangezogenen Texte gesprochen wird, wie der Übermittlungsprozess der kommunizierten Inhalte organisiert ist. Ohne mich in die komplizierte und häufig (sowohl methodologisch als auch terminologisch) verwickelte Problematik der Untersuchung von narrativen Botschaften hineinzubegeben, die die Begriffe Diskurs und Geschichte ${ }^{23}$ markieren, berufe ich mich auf Seymor Chatmans klare und für meine Zwecke ausreichende Unterscheidung dieser Termini. Geschichte - „Historie“ - (engl. story, franz. histoire) ist die Bezeichnung des Inhalts, also dessen, wAs übermittelt wird; Diskurs hingegen bezeichnet die Ausdrucksweise jenes Inhalts, also das, wIE etwas übermittelt wird ${ }^{24}$.

Die textuellen Holocaustzeugnisse sind eine auf bestimmte Weise organisierte Überlieferung. Die Art der Überlieferung und die Regeln, nach denen sie organisiert ist, sind grundlegender Gegenstand der hier vollführten Untersuchung. Im Mittelpunkt meiner Forschungsinteressen steht in erster Linie der Text selbst, weniger jedoch das GescheHen, von dem er erzählt. Eigentlicher Gegenstand meiner Reflexionen ist demnach nicht das, was damals tatsächlich geschah, sondern die textuellen Zeugnisse aus der damaligen Zeit. Schließlich untersuche ich die Arten, in der die Texte über die damalige Wirklichkeit sprechen, und nicht

23 Siehe die neueste synthetische Arbeit zum Stand der Forschung: H. Markiewicz: Teorie powieści za granica. Od początku do schyłku XX wieku [Die Romantheorien im Ausland. Vom Anfang bis zum Ende des 20. Jahrhunderts] (Unterkapitel „Narratologia strukturalna i generatywno-transformacyjna" [Die strukturelle und die generativtransformative Narratologie]), Warschau 1995, S. 469-501.

24 Siehe S. Chatman: „Towards a Theory of Narrative“, in: „New Literary History“ Bd. 6, Nr. 2, 1975, S. 295-318. 
so sehr jene Wirklichkeit selbst. Ich analysiere die Aufzeichnung einer bestimmten, in Textform festgehaltenen Erfahrung und decke die Gestaltungsprinzipien für diese Aufzeichnung und die Ausdrucksformen für diese Erfahrung auf. Des Weiteren stelle ich Überlegungen zu den Expressionsarten, ihren Grenzen und Möglichkeiten an.

Eine so orientierte Untersuchung könnte hinsichtlich der Beschaffenheit meines Forschungsgegenstandes als unangemessen betrachtet werden. Bei Arbeiten dieser Thematik herrschen erwiesenermaßen Bedenken, was die Analyse der „Textualität" von Holocaustzeugnissen betrifft. Roman Zimand verwahrt sich in seinem Buch über Czerniakóws Tagebuch dagegen, dass „die bloße Beschäftigung mit der Problematik schriftstellerischer Spielregeln jemandem taktlos erscheinen könnte, wenn es sich um einen Text über das Leid und die Vernichtung hundert-

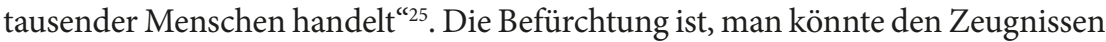
auf diese Weise nicht nur ihre ungewöhnliche Aura nehmen, sondern auch die Geschehnisse, von denen sie sprechen, in den Hintergrund rücken.

In diesem Zusammenhang schreibt James Young von zwei extremen Herangehensweisen an textuelle Zeugnisse des Holocaust ${ }^{26}$. Der erste Ansatz ignoriert

25 R. Zimand: „W nocy od 12 do 5 rano nie spałem“, op. cit., S. 14. Es scheint, als teilten die Autoren der zuletzt zu diesem Thema erschienenen Arbeiten - N. Gross (Poeci i Szoa: obraz Zagłady Żydów w poezji polskiej [Die Dichter und die Schoa: das Bild der Judenvernichtung in der polnischen Lyrik], Sosnowiec 1993) und J. Wróbel (Tematy żdowskie w prozie polskiej 1939-1987 [Jüdische Themen in der polnischen Prosa 1939-1987], Krakau 1991) - jene von R. Zimand polemisch angeführte Sichtweise. Gross bemüht sich vor allem, den „Inhalt" herauszuarbeiten, weniger Aufmerksamkeit widmet er der Materie der poetischen Sprache, den Formen der dichterischen Kommunikation, den literarischen Konventionen. Wróbel wiederum bezweifelt, ob es in manchen Fällen überhaupt sinnvoll sei, einen Text analytisch zu zerlegen und ihn literarisch zu bewerten. Über die Erinnerungsprosa sagt er, „man kann [sie] bezüglich der enthaltenen Beobachtungen und festgehaltenen Fakten geschichtlich bewerten, eine literarische Bewertung erscheint hier jedoch unangemessen“ (S. 98). In Bezug auf Ida Finks Buch Eine Spanne Zeit [dt. Übers. von K. Staemmler, I. und B. Fink; Zürich 1983; Anm. d. Übers.], das er hoch schätzt, schreibt Wróbel dennoch: „[...] es erscheint unangemessen, über diese Erzählungen zu schreiben, als handle es sich um ein literarisches Spiel“" (S. 105). Eine solche Haltung lässt sich nicht einmal in Wróbels eigenem Buch beibehalten, greift der Autor doch mehr als einmal auf analytisch-interpretative Praktiken zurück, indem er zum Beispiel über Narrationsperspektiven schreibt, über die Kreierung von Erzähler und Protagonisten, und nicht zuletzt über die Sprecharten in einer vorgestellten Welt.

26 Vgl. J.E. Young, op. cit., im Einzelnen: „Introduction“. 
jeglichen „Plan“ bezüglich des textuellen Ausdrucks, jeglichen Erzählrahmen, und betont den dokumentarischen Wert der Zeugnisse als Überlieferungen authentischer Ereignisse. Der zweite Ansatz legt den Akzent darauf, dass die Narration in Wirklichkeit nichts dokumentiere als ihre eigene konstruierende Aktivität. Im ersten Fall verwiese der Text somit unmittelbar auf die reale Welt, er verhielte sich wie eine vollkommen durchsichtige Scheibe. Im zweiten Fall verwiese er auf ein vom Erzähler konstruiertes Weltbild, das ein komplexes System von aufeinander bezogenen Zeichen bildete. Eine so verstandene Konstruktion würde die realen Ereignisse nicht repräsentieren, sondern ersetzen. Letzte Konsequenz dieses Ansatzes wäre schließlich die Feststellung, dass Ereignisse und Texte nie unabhängig voneinander existieren könnten und dass alle Bedeutungen, die bestimmten Ereignissen in deren verschiedenen textuellen Repräsentationen zugeschrieben werden, sich jeweils in Bezug auf den Text relativierten.

Ich möchte gegenüber den beiden hier aufgezeigten extremen Haltungen einen gemäßigten Standpunkt einnehmen. Die Texte, die mir für diese Arbeit als materielle Grundlage dienen, sollen nicht nur als historische Quellen betrachtet werden, auch wenn ich ihren geschichtlichen Wert wahrnehme und nutze. Als Literaturwissenschaftler interessiert mich - selbst bei Dokumenten, Meldungen, Berichten - die Sphäre der Sprache, mittels derer der Autor seine Erlebnisse sowie die Organisation von deren Niederschrift kommuniziert. Ich glaube nicht, dass man vollständig zum übermittelten Inhalt vordringen kann, wenn man die Poetik eines Textes ignoriert. Ein Text ist keine durchsichtige Scheibe, durch die man eine „objektive“ Wirklichkeit sieht. Andererseits kann ich aber auch nicht annehmen, dass der Text die einzige dem Forscher zugängliche Realität sei, dass nichts existiere außer den Zeichenstrukturen, die sich ineinander betrachten und ihre eigenen Spiegelungen bis ins Unendliche vervielfältigen. Auch wenn ein Text der Welt anderer Texte verhaftet ist, bezieht er sich doch auf die Wirklichkeit und ist mit ihr verbunden. Er ist ein Medium zwischen der Welt und dem Menschen; Welt und Mensch drücken ihm ihren bleibenden Stempel auf.

Eine Untersuchung der Poetik schriftlicher Holocaustzeugnisse tastet nicht im Mindesten deren Gewicht an, sondern bietet die Chance, den Artikulationsprozess jener Erfahrung genau zu erkunden. Die Entscheidung zur Niederschrift zog schließlich viele weitere Entscheidungen nach sich, die die Autoren der erhaltenen Texte - ob bewusst oder unbewusst - nacheinander treffen mussten. Dazu gehörte zum Beispiel die Wahl zwischen verschiedenen Regeln der Diskursgestaltung sowie die Anwendung bestimmter literarischer Kunstgriffe, stilistischer Konventionen, Arten der Schilderung. Eine Beschreibung der 
Entscheidungsmechanismen gestattet die Frage nicht nur nach den Tatsachen des Holocaust, sondern auch danach, wie man über ihn sprechen kann und warum genau diese und keine anderen sprachlichen Muster gewählt wurden.

Die Lektüre eines Forschers darf keine naive Lektüre sein. Bei der Frage, wie ein Text "gemacht" ist, fragen wir zugleich danach, INWIEFERN und wAs er für uns bedeutet. Ich kann nichts Unangemessenes daran finden, derartige Fragen an Texte über den Holocaust zu stellen, befördern sie doch eine Botschaft, die mit besonderer Sorgfalt und Wertschätzung gelesen werden sollte. Die „Textualität" von Holocaustzeugnissen zu untersuchen ist nicht pietätlos, sondern gestattet vielmehr eine eingehende Ergründung des Sinns der Niederschriften, die uns die Zeugen der Vernichtung hinterlassen haben. Die Diskursanalyse führt nämlich unweigerlich an die anthropologischen Horizonte: Wer einen Text liest, will letzten Endes zum Menschen vordringen und ihn verstehen.

Die Situation eines Forschers auf der Suche nach einer Formel zur textuellen Beschreibung von Holocaustzeugnissen beschränkt sich allerdings nicht nur auf die Entscheidung für eine Methodologie und eine bestimmte Forschungsperspektive. Es scheint, als ziehe die Direktive, derzufolge wissenschaftliche Forschungen nach der Wahrheit streben sollten, in diesem Fall schwierige moralische Entscheidungen nach sich, ein bisweilen extremes Spannungsverhältnis zwischen Beschreibung, Verstehen und Wertung. Das Entsetzen, das sich demjenigen mitteilt, der mit Zeugnissen eines Völkermordes zu tun hat, kann den Weg zu den Zeugnissen selbst verstellen. Wird dieses Entsetzen als niederdrückende emotionale Last empfunden, die in gewissem Sinne unsere Ratlosigkeit rechtfertigt, befreit es uns vom Risiko, zu verstehen, und lässt uns verschiedene Therapien zur Selbstberuhigung ersinnen. Zygmunt Bauman kritisiert in seinem Buch Dialektik der Ordnung. Die Moderne und der Holocaust eine Strömung der Holocaustforschung, die sich eher darauf zu konzentrieren scheint, Schutzmechanismen zu schaffen, als das Wesen des Phänomens zu ergründen. Die These, der Holocaust sei eine ungeheuerliche Verirrung und ein wesentlicher Bruch mit der kulturellen und zivilisatorischen Kontinuität, sei eher der Ausdruck eines frommen Wunsches von Historikern und Soziologen. Vielmehr erweise der Holocaust sich als Erscheinung der Neuzeit. Die nur unvollständig erkundete und unseren Erkenntnishorizont übersteigende dunkle Seite der modernen Zivilisation stelle nach wie vor eine reale Bedrohung dar. Wirkungsvoll etwas entgegensetzen könnten ihr weder alljährliche Gedenkveranstaltungen noch Warnungen vor einer Wiederholung der Tragödie.

Die Wahrheit über den Holocaust kollidiere mit dem Glauben an einen Konsens, der die zivilisierte Welt regiert, und an die Beständigkeit einer die menschliche Gemeinschaft einenden Werteordnung. Zeugnisse des Holocaust seien für 
den Forscher eine radikale Herausforderung, bringen sie doch die moderne Welt auf die Anklagebank. Sie provozieren zur Überschreitung der traditionell gezogenen Erkenntnishorizonte, zwingen dazu, das Risiko einzugehen und sich dem zu stellen, wovor wir uns auf verschiedene Arten zu schützen versuchen. Die erschreckendste Lehre aus dem Holocaust, schreibt Zygmunt Bauman, sei nicht die Annahme, dass so etwas auch uns selbst passieren, sondern dass auch wir selbst so etwas vollbringen könnten ${ }^{27}$.

27 Siehe Z. Bauman: Dialektik der Ordnung. Die Moderne und der Holocaust, dt. Übers. von U. Ahrens, Hamburg 1992. 



\section{Autoren, Ort und Zeit}

Das Element der persönlichen Dokumentationsliteratur ist die auf eine bestimmte Weise erlebte und festgehaltene umgebende Welt. Einzelheiten über den Autor $\mathrm{zu}$ wissen sowie die Situation und die Bedingungen der Entstehung eines Textes rekonstruieren zu können, ist hier von wesentlicher Bedeutung. Die Umstände, unter denen ein Tagebuch entsteht, bestimmen dessen Gestalt und Inhalt, beeinflussen die Ausformung unterschiedlicher Gattungsvarianten (zum Beispiel intimes Tagebuch, Reisetagebuch, Chronik aus Kriegszeiten). Die Literatur des persönlichen Dokuments ist von ihrem Wesen her in das konkrete „Hier und Jetzt“, in den Zeitpunkt des Schreibens eingebettet.

In diesem Kontext betrachtet besteht die Spezifik der Texte aus dem Warschauer Ghetto darin, dass die Umstände des Schreibens - im weitesten Sinne - nicht bloß den Inhalt eines Textes, sondern auch dessen Entstehung überhaupt bedingen. Die Umstände entscheiden hier schließlich oftmals über Sein oder Nichtsein des Autors, und an ihnen liegt es, ob ein Text überdauern kann. Die Situation des Schreibenden drückt dem Niedergeschriebenen ihren unauslöschlichen Stempel auf. Sie entscheidet auch - auf so endgültige Weise wie keine andere Situation -, ob überhaupt etwas aufgeschrieben wird, ob es überdauert und gelesen werden kann.

Der Analyse persönlicher Dokumente aus dem Warschauer Ghetto sollte daher eine Skizze zu einem Sammelportrait ihrer Autoren sowie eine Charakteristik von Zeit und Ort des Schreibens vorausgehen. Es gilt, zu überlegen, wER schrieb, und WO UND UNTER WELCHEN UMSTÄNDEN ${ }^{28}$ der Schreibende dies tat.

28 Ich möchte schon jetzt die grundlegenden Quellen erwähnen, die ich in diesem Kapitel über geschichtliche und biographische Informationen nutze. In den weiteren Fußnoten werde ich mich nur noch auf Texte von außerhalb des folgenden Kanons beziehen: R. Sakowska: Menschen im Ghetto: Die jüdische Bevölkerung im besetzten Warschau 1939-1943, dt. Übers. von R. Henning, Osnabrück 1999; Dies.: Die zweite Etappe ist der Tod. NS-Ausrottungspolitik gegen die polnischen Juden, gesehen mit den Augen der Opfer. Ein historischer Essay und ausgewählte Dokumente aus dem Ringelblum-Archiv 1941-1943, Berlin 1993; Archiwum Ringelbluma. Getto warszawskie lipiec 1942-styczeń 1943, bearb. von R. Sakowska, Warschau 1980; Pamiętniki z getta warszawskiego. Fragmenty i regesty [Tagebücher aus dem Warschauer Ghetto. Auszüge und Regesten], 2., korrigierte und erweiterte Auflage, bearb. von M. Grynberg, Warschau 1993; Im Warschauer Getto. Das Tagebuch des Adam Czerniaków 1939-1942, München 1986; E. Ringelblum: Kronika getta warszawskiego: wrzesień 1939-styczeń 1943 [Chronik des 


\section{Wer schrieb}

1

Emanuel Ringelblum war ohne Zweifel einer der bestinformierten Menschen im Ghetto. Die von ihm geleitete Gruppe Oneg Schabbat, die ein Archiv des Warschauer Ghettos anlegte, wurde zu einem Zentrum, an dem alles Wissenswerte über das Leben im geschlossenen Bezirk und anderen jüdischen Ballungsräumen in Polen zusammenflossen. In den gesammelten Notizen verbindet sich die individuelle mit einer überindividuellen Perspektive, was das Betrachtungsspektrum erheblich erweitert.

In seinen Notitsn fun varshever geto bemerkt Ringelblum ein Phänomen, das man als typische Eigenschaft jüdischer Ghettoerfahrung ansehen kann. Es geht um das Phänomen des Schreibens: die Dokumentation von Fakten, die Registrierung von Terror, Leiden und Verbrechen, die Notierung aktueller Ereignisse, Erlebnisse, Reflexionen. Das betrifft nicht nur die organisierten kollektiven Unternehmungen (das Wirken von Oneg Schabbat), sondern auch - oder vielleicht sogar vor allem - individuelle, rein private und spontane Initiativen.

Ringelblum notiert:

Der Terror nahm stetig zu, [...] er richtete sich gegen ganze Gruppen und Gesellschaftsschichten. Die Deutschen interessierte nicht, was der Jude bei sich zu Hause tat. Und deswegen eben begann der Jude zu schreiben: Alle schrieben: Journalisten, Literaten, Lehrer, gesellschaftlich engagierte Menschen, die Jugend, ja selbst Kinder. Die meisten Schreibenden führten Tagebücher, in denen sie die tragischen Geschehnisse unter dem Gesichtspunkt ihres eigenen Erlebens betrachteten. Es wurde sehr viel geschrieben, doch der größte Teil wurde, gemeinsam mit den Warschauer Juden, bei den Deportationen vernichtet. Nur das im Ghettoarchiv aufbewahrte Material blieb erhalten (S. 471).

Die Autoren der erhaltenen Texte sind größtenteils unbekannt. Viele von ihnen konnten lediglich mit dem Kryptonym N.N. und einer Signatur in den Archivsammlungen gekennzeichnet werden. In manchen Fällen überdauerte nur der Vorname des Schreibenden, wie zum Beispiel Jakub, Natan oder Stefa. Dennoch bleibt selbst mit Vor- und Nachnamen eine recht umfängliche Gruppe von Autoren anonym. Unser Wissen über sie geht meistens nicht über ihren Text selbst hinaus und lässt sich in keinster Weise verifizieren. Ringelblum, der auf die überwältigende Vielzahl an Schreibenden hinwies, nannte außerdem zahlreiche Namen von Menschen, von denen er wusste, dass sie im Ghetto Notizen

Warschauer Ghettos: September 1939-Januar 1943], hg. von A. Eisenbach, aus dem Jiddischen ins Polnische übers. von A. Rutkowski, Warschau 1983. 
angefertigt hatten, die aber zusammen mit ihnen selbst untergegangen waren. Die mit N.N. versehenen Texte repräsentieren gewissermaßen alle diejenigen, die in der damaligen Zeit geschrieben haben, dessen Stimme jedoch nie zu uns vordringen konnte. Diese Texte zeugen - in symbolischer Weise - von anderen, doppelt unbekannten Texten - Texten, die verschollen sind, von deren Existenz nie jemand etwas wusste und die niemand bezeugen kann.

\section{2}

Unter den Ghettoautoren am zahlreichsten vertreten ist die Intelligenz. Außer den von Ringelblum erwähnten Journalisten, Literaten, Lehrern und gesellschaftlich Engagierten betätigten sich Juristen, Ärzte, Pädagogen und Wissenschaftler auf diese Weise, viele von ihnen öffentliche Personen, die in jüdischen oder polnischen Kreisen bekannt waren und sich großer Autorität und hohen gesellschaftlichen Ansehens erfreuten. Sie repräsentierten unterschiedliche weltanschauliche und politische Orientierungen, hatten vor dem Krieg auf Polnisch, Hebräisch, Jiddisch geschrieben und publiziert.

Adam Czerniaków (1880-1942) gehörte zur assimilierten jüdischen Intelligenz, die Geschmack gefunden hatte an der polnischen Literatur und Kultur. Er war Chemieingenieur mit Diplomen von der Warschauer Technischen Hochschule und der Technischen Universität Dresden. In Warschau war er Stadtrat für die jüdischen Handwerksverbände, bekleidete kurze Zeit sogar den Posten eines Senators der polnischen Republik. In der Warschauer Jüdischen Gemeinde repräsentierte er die Interessen von Handwerk und Berufsschulwesen. Er publizierte viel zum Thema Wissenschaft, Kultur, Erziehung (u.a. in den Zeitschriften „Izraelita“ [Der Israelit], „Nasze życie“ [Unser Leben], „Miesięcznik żydowski“ [Jüdische Monatsschrift]), schrieb wissenschaftliche Abhandlungen und Gedichte. Am 23. September 1939 wurde er durch den Warschauer Stadtpräsidenten Stefan Starzyński zum Vorsitzenden der Jüdischen Glaubensgemeinde ernannt, am 4. Oktober setzten die Deutschen ihn an die Spitze des Judenrates. Janusz Korczak (1878 oder 1879-1942), Arzt, Pädagoge, Schriftsteller und Redakteur, Mitgründer des jüdischen Waisenhauses Dom Sierot [Haus der Waisen] und des Waisenhauses für polnische Kinder Nasz Dom [Unser Haus], gehörte zu den bekanntesten Ghettobewohnern. Ein hervorragender Pädagoge und Hebraist war ebenfalls Chaim Aron Kaplan (1880-1942 oder 1943), der Betreiber einer privaten polnisch-hebräischen Grundschule in der Warschauer DzielnaStraße 15. Er war der Autor zahlreicher Lehrbücher für Hebräisch. 1937 veröffentlichte er eine Sammlung von Artikeln, literarischen Skizzen und Feuilletons mit dem Titel Pizzurai (Meine verstreuten Werke). Professor Ludwik Hirszfeld 
(1884-1954), ein weltberühmter Wissenschaftler, Bakteriologe und Serologe, Begründer der polnischen Schule der Immunologie, war assimilierter und polonisierter Jude. Er gehörte zu einer Gruppe von Katholiken, die im Ghetto das Pfarrhaus bei der Allerheiligenkirche am Grzybowski-Platz bewohnte. Und schließlich Emanuel Ringelblum (1900-1944), der Hirszfeld und Czerniaków gegenüber weltanschaulich und politisch am entgegengesetzten Pol stand. Er war an der Universität Warschau ein Schüler Marceli Handelsmans ${ }^{29}$ gewesen, erwarb mit seiner Arbeit $Z \dot{y} d z i w$ Warszawie od czasów najdawniejszych do ostatniego wygnania w $1527 \mathrm{r}$. [Die Juden in Warschau, von frühesten Zeiten bis zur letzten Vertreibung im Jahr 1527] den Doktortitel in Philosophie. Ringelblum gehörte zu einem Kreis von Historikern, die sich in der Zwischenkriegszeit um die Kommission für die Geschichte der Juden am Jüdischen Wissenschaftlichen Institut in Wilna gruppierten, die zu einem der Zentren marxistischen Gedankenguts im damaligen Polen wurde.

Eine gesonderte Gruppe innerhalb der Schreibenden im Ghetto bildeten natürlich die Literaten ${ }^{30}$. Hinter den Mauern des geschlossenen Bezirks wohnten zahlreiche Dichter, Schriftsteller, Publizisten, die ihre Texte sowohl auf Jiddisch als auch auf Polnisch verfassten. Nahezu niemand von ihnen überlebte.

Jizchak [Yitzhak] Katzenelson (1866-1944) schrieb auf Hebräisch und Jiddisch. Dichter, Dramaturg, Übersetzer und Pädagoge, machte er sich noch vor dem Ersten Weltkrieg in der Literatur einen Namen. In der Zwischenkriegszeit gehörten zu seinen meistdiskutierten Werken die Dramen Hanawi [hebr.: Der Prophet] und Tarschisch [hebr.: Forsterit]. Im Warschauer Ghetto wirkte er im Untergrund im Bereich Bildung und Kultur. Wirklich großen Ruhm in der jüdischen Literatur brachte ihm Dos lied vunem ojsgehargetn jidischn volk ein [auf Deutsch erschienen unter dem Titel Großer Gesang vom ausgerotteten jüdischen Volk, Übers. von W. Biermann, Köln 1994; Anm. d. Übers.], das er nach seiner

29 Marceli Handelsman, geb. am 8. Juli 1882 in Warschau, verstorben am 20. März 1945 in Dora-Nordhausen, polnischer Jurist und Historiker jüdischer Abstammung, Mediävist, Historiker mit dem Forschungsgebiet neue und neueste Geschichte, Geschichtsmethodologe, einer der exzellentesten polnischen Geschichtswissenschaftler der ersten Hälfte des 20. Jh.; Anm. d. Übers.

$30 \mathrm{Zu}$ den jüdischen Schriftstellern im Warschauer Ghetto siehe (außer den bereits genannten Quellen): E. Ringelblum: „Jak zginęli pisarze żydowscy?“ [Wie kamen die jüdischen Schriftsteller um?], in: ders.: Kronika getta warszawskiego, S. 569-585; die Arbeit eines anonymen Autors: Polscy pisarze (Stosunki polsko-żydowskie) [Polnische Schriftsteller (Polnisch-jüdische Beziehungen)] (Ring I, 92); S. Liptzin: A History of Yiddish Literature, New York 1985. 
Deportation vom Ghetto in das Internierungslager Vittel auf Jiddisch verfasste. Izrael Sztern [Israel Shtern] (1894-1942) und Jechiel [Ichiel] Lerer (1910-1942 oder 1943) schrieben religiöse Lyrik. Sztern betrieb seine Dichtung auch hinter den Mauern intensiv weiter, stand jedoch den grausamen Realien im Ghetto fassungslos gegenüber. „Er verhielt sich wie ein harmloses Täubchen“, bemerkt Ringelblum, „und ging in Hungerstreik“ (S. 574). Seine Handschriften sind verschollen, doch einige verstreute Poeme und Essays, die er ab 1919 verfasst hatte, wurden 1955 publiziert. Lerer, der vor dem Krieg „der jüdische Tagore“ genannt wurde und den Schalom Asch sehr schätzte, war im Ghetto als Postbeamter tätig. Er kam in Treblinka um. Manche seiner Gedichte aus dem Ghetto sind erhalten geblieben und wurden im 1948 erschienenen Sammelband Lieder Un Poemen [Lieder und Poeme] veröffentlicht. Der talentierte Dichter und Volksliedermacher Hersz Danielewicz [Herschele Danilewitch] (1882-1941), dessen vor dem Krieg komponierte und in mehreren Sammlungen herausgegebenen Lieder in aller Munde waren, brillierte im Ghetto mit seinem schwarzen Humor. Dichter, Übersetzer und Autor von Liedern, die u.a. in den Theatern des Warschauer Ghettos aufgeführt wurden, war auch M. Korentajner (dessen Vorname sich nicht mehr ausfindig machen lässt).

Szlojme [Schlojme, Shlomo] Gilbert (1885-1942), dessen Essays und Novellen in der Zwischenkriegszeit in den Warschauer jüdischen Zeitschriften veröffentlicht wurden, und Lejb Pluskałowski (1908-1942), dem die Autorschaft an einem im Ringelblum-Archiv enthaltenen Roman namens Swastyka zugeschrieben wird, fanden bei der großen Liquidierungsaktion den Tod. Zur selben Zeit auf den Umschlagplatz ging auch Hillel Zeitlin (1872-1942) - Philosoph, Literaturkritiker, Essayist und Publizist, Mitarbeiter bei der Warschauer Tageszeitung „Haynt“, der im Ghetto Übersetzungen von Psalmen ins Jiddische anfertigte.

Viele Schriftsteller arbeiteten mit der Untergrundpresse des Ghettos zusammen. Der Dichter Josef Kirman (1896-1943) publizierte Prosatexte in konspirativen Schriften, u.a. „Mówię do ciebie, moje dziecko ... “ [Ich spreche zu dir, mein Kind ...], „Miasteczko uchodźców - Dzika i Niska“ [Stadt der Flüchtlinge - die Dzika- und die Niska-Straße]; sie wurden später, im Jahr 1955, auf Jiddisch im Sammelband Między życiem i śmiercia [Zwischen Leben und Tod] veröffentlicht. Kirman wurde im SS-Arbeitslager Poniatowa erschossen. Zahlreiche Schriftsteller waren auch Mitglieder bei Oneg Schabbat und unterstützten aktiv das Wirken des Ghettoarchivs. Zu Ringelblums engsten Mitarbeitern gehörte Avrom Levin [Abraham Lewin] (1893-1943) - Pädogoge, Lehrer am jüdischen Gymnasium in Warschau, Historiker und Schriftsteller, Autor des zwischen den Weltkriegen sehr populären Romans Kantonistn [Die Kantonisten]. Sein Ghettotagebuch wurde zusammen mit anderen Dokumenten aus dem Archiv nach dem Krieg 
ausgegraben. Der Lyriker und Prosaist Perec Opoczyński (1895-1943), der vor dem Krieg das Leben der chassidischen Juden in Polen beschrieben hatte (woher auch sein Pseudonym Perec Chasyd stammt), arbeitete im Ghetto als Briefträger. Er war eines der aktivsten Mitglieder von Oneg Schabbat, Autor von Reportagen über das Ghetto, u.a. „Listonosz żydowski“ [Der jüdische Briefträger], ein Text, der 1941 in einem Literaturwettbewerb einen Preis erhielt. Joszua Perle (1888-1944), Prosaist und Autor von Sittenromanen wie Mirla, Ruta, Złoty Paw [Der goldene Pfau] oder Zwyczajni Żydzi [Gewöhnliche Juden; 1935], für den er vor dem Krieg einen Preis des Bund [Allgemeiner jüdischer Arbeiterbund von Litauen, Polen und Russland] und den Jizchok-Leib-Perez-Preis bekommen hatte, schrieb für das Ghettoarchiv den Bericht „Zagłada Warszawy“ [Die Vernichtung Warschaus]. Im Milieu rund um Oneg Schabbat vertreten waren außerdem Lejb Goldin (1906-1942), Publizist, Literaturkritiker und Übersetzer von Werken der europäischen Literatur in die jiddische Sprache, Autor eines erschütternden Essays über den Hunger, Kronika jednej doby [Chronik eines Tages], sowie Cecylia (Luba) Słapakowa, Literaturkritikerin und Übersetzerin, die für das Archiv des Ghettos eine Monographie über eine jüdische Frau im Zweiten Weltkrieg verfasste.

Rokhl Oyerbakh schrieb sowohl polnisch als auch jiddisch. Unter den Schriftstellern, die mit Ringelblum zusammenarbeiteten, war sie die einzige Überlebende (sie starb 1976 in Israel). Vor dem Krieg arbeitete sie überwiegend für die jüdische Presse, publizierte jedoch auch in polnischsprachigen Zeitschriften. In den 1930er Jahren begann sie eine Zusammenarbeit mit der polnisch-jüdischen Tageszeitung „Chwila“ [Der Augenblick], die von 1919-1939 in Lwów [Lemberg] erschien und ein aktives und konsolidiertes literarisches Milieu um sich versammelte ${ }^{31}$. Zeitungen wie „Chwila“, der Krakauer „Nowy Dziennik“ [Neues Tageblatt], „Nasz przegląd“ [Unsere Rundschau] oder die Wochenschrift „Opinia" [Meinung] in Warschau spielten eine wesentliche Rolle bei der Formung einer polnisch-jüdischen Literatur und Kultur, die sich in der Zeit zwischen den beiden Weltkriegen dynamisch entwickelte.

31 Für „Chwila“ schrieben damals u.a. Stanisław Jerzy Lec und Artur Sandauer; Julian Stryjkowski publizierte hier seine Übersetzungen aus dem Hebräischen. Aus den Kreisen um „Chwila“ gingen drei Lemberger Dichter hervor: Daniel Ihr, Stefan Pomer und Maurycy Szymel; sie hatten einen entscheidenden Einfluss auf die Entwicklung der polnisch-jüdischen Lyrik. Siehe E. Prokop-Janiec: Międzywojenna literatura polsko-żydowska jako zjawisko kulturowe i artystyczne [Die polnisch-jüdische Literatur der Zwischenkriegszeit als kulturelles und künstlerisches Phänomen], Krakau 1992, S. 32, 158 . 
Viele Dichter und Schriftsteller innerhalb der Ghettomauern gehörten zu diesem Milieu. Władysław Szlengel (1914-1943), der größte polnischsprachige Lyriker des Warschauer Ghettos, dichtete schon vor dem Krieg Schlager und war im Ghetto wohl der produktivste Kabarettschreiber. Seine Gedichte, zusammengestellt unter dem vom Autor selbst gewählten Titel Co czytałem umarlym [deutsche Ausgabe: Was ich den Toten las. Gedichte aus dem Warschauer Getto, Übers. von U. Herbst-Rosocha, nachgedichtet von R. Erb, U. Grüning, K. Drawert, M. Erb, Leipzig/Weimar 1990; Anm. d. Übers.], brachten es bei den Bewohnern des geschlossenen Bezirks zu enormer Popularität. Henryka Łazertówna (19101942), die in der Vorkriegszeit zur Dichtergruppe Skamander ${ }^{32}$ gehört hatte, ist die Autorin des in Polen sehr bekannten Gedichts „Mały szmugler“ [Der kleine Schmuggler]. Erhalten ist auch ihr Brief aus dem Ghetto an Roman Kołoniecki (datiert auf den 6. November 1941) - eine lyrische Impression der Straßen und Menschen im geschlossenen Bezirk. Gustawa Jarecka (1908-1942), Romanschriftstellerin, Autorin mehrerer vor dem Krieg erschienener Bücher, arbeitete bei der Jüdischen Gemeinde als Beamtin in der Korrespondenzabteilung, hielt jedoch gleichzeitig engen Kontakt zum Untergrundarchiv des Ghettos. Aus ihrer Feder stammt die umfassendste Schilderung der großen Liquidierungsaktion, erhalten ist ein Textstück mit dem Titel „Ostatnim etapem przesiedlenia jest śmierć" [Die letzte Etappe der Umsiedlung ist der Tod]. Eugenia Szajn-Lewin (1909-1944), Absolventin der Universität Warschau im Fach Polonistik sowie der Hochschule für Journalismus, publizierte vor dem Krieg Reportagen u.a. in der Zeitung „Kurier Warszawski“ [Warschauer Kurier]. Sie ist die Autorin eines Romans namens Życie na nowo [Leben aufs Neue], hinterließ eine originelle, zu einer Erzählung umgearbeitete Aufzeichnung ihres Lebens im Ghetto. Andrzej Marek (Marek Arensztajn), Dramaturg und Regisseur, machte vor dem Krieg jüdisches Theater in polnischer Sprache. Im Ghetto war er literarischer und künstlerischer Leiter des Neuen Kammertheaters in Warschau (Nowolipki-Straße 52). Gedichte, Sketche und Lieder für das Ghettokabarett lieferten u.a. Andrzej Włast (Gustaw Baumritter), von 1972 bis 1932 Leiter des kleinen Revuetheaters Morskie Oko, Autor zahlreicher Schlager aus der Vorkriegszeit, sowie Jerzy Jurandot (1911-1979), einer der Gründer des Theaters Quid pro

32 Die berühmte Dichtergruppe wurde um 1916 von einigen bekannten polnischen Dichtern gegründet - u.a. Jarosław Iwaszkiewicz, Antoni Słonimski, Julian Tuwim, Kazimierz Wierzyński, Jan Lechoń - und bestand bis 1939. Die Skamandriten traten viel in Kabaretts und auf Lesungen auf; sie vertraten die Ansicht, in die Lyrik sollte mehr Alltagssprache einfließen; Anm. d. Übers. 
Quo, Autor der im Ghetto sehr beliebten Posse Miłość szuka mieszkania [Die Liebe sucht eine Wohnung], nach dem Krieg langjähriger Direktor des Warschauer Teatr Syrena.

3

Die schreibende Zunft war besonders prädestiniert dafür, schriftlich Zeugnis über ihre Erfahrungen im Ghetto zu geben. Einige Schriftsteller - wie zum Beispiel Chaim Aron Kaplan oder Barbara Temkin-Bermanowa - schrieben im Übrigen schon lange vor dem Krieg Tagebuch, gehörten sie doch zu einer Generation der Intelligenz, für die das Tagebuchschreiben eine Selbstverständlichkeit war ${ }^{33}$. Es gibt allerdings eine große Gruppe von Autoren, die ohne die Erfahrung des Ghettos möglicherweise nie zur Feder gegriffen hätten. Sie stammten aus den unterschiedlichsten Berufen - waren Juristen (zum Beispiel Marek Stok oder Stanisław Adler) und Buchhalter (zum Beispiel Chaim Hasenfus oder Jakub, der über sich schreibt: "Jestem z zawodu buchalterem" [Ich bin Buchhalter von Beruf]), Ladengehilfen (Leon Guz, Pelzlager an der Świętojerska-Straße), Zahntechniker (Karol Rotgeber), Architekten (Ingenieur und Architekt B. Goldman) und Drechsler (Dawid Fogelman, bis Kriegsausbruch in der Landmaschinenfabrik an der Leszno-Straße). Beamte und Arbeiter. Und auch Kinder.

Erinnerungen oder Tagebücher von Kindern bilden unter den erhaltenen Texten aus der Zeit des Holocaust eine gesonderte und außergewöhnliche Gruppe. Eines der meistgelesenen persönlichen Dokumente des Zweiten Weltkriegs ist Das Tagebuch der Anne Frank. Weit weniger bekannt ist Das Tagebuch des Dawid Rubinowicz, geschrieben von einem 13-jährigen Jungen aus der Gegend von Bodzentyn nahe Kielce. Solche Zeugnisse von Kindern haben einen besonderen Wert. Ein Kind sieht mehr, spürt mehr und versteht manches Mal auch mehr als ein Erwachsener. In der kindlichen Narration verbindet sich die Verwunderung über das unbegreifliche Grauen der Welt mit einer einfachen und natürlichen Ausdrucksweise. Die Sprache eines Kindes scheint der Wirklichkeit am nächsten zu kommen, sie am wenigsten zu verschleiern. Daher meint auch Henryk Grynberg, das Kind habe sich als glaubwürdigster Narrator des Holocaust erwiesen ${ }^{34}$.

33 Z. Stefanowska weist darauf hin, dass das Tagebuchschreiben eine Art Sucht der damaligen Intelligenz gewesen sei, und äußert die Vermutung, dass auch Adam Czerniaków bereits länger als seit Kriegsbeginn ein Tagebuch geführt haben könnte. Siehe „Dyskusja nad esejem o Dzienniku Adama Czerniakowa“ [Diskussion um den Essay über Adam Czerniakóws Tagebuch], in: „Biuletyn ŻIH“ 1974, Nr. 90, S. 100.

34 „Aaron Appelfeld [...] sagte kürzlich, [...] die Kinder des Holocaust könnten am besten über ihn berichten, war doch für sie der Holocaust der Anfang der Welt, es gab keinen 
Im Archiv des Jüdischen Historischen Instituts in Warschau befinden sich in der Abteilung „Erinnerungen“ die Tagebücher und Aufzeichnungen von Kindern aus dem Krakauer Ghetto (zum Beispiel die Tagebücher von Rena Knoll, Mai 1940 bis September 1941, Sign. 197, oder von Irena Glück, ebenfalls Mai 1940 bis zum August 1942, Sign. 255) und dem Ghetto Litzmannstadt (zum Beispiel die Tagebücher zweier nicht identifizierter Mädchen: eines vom Februar und März 1942, Sign. 86, das andere, von einer Verfasserin namens Estera, vom Juli und August 1944, Sign. 9). Die Jüdische Historische Kommission in Krakau veröffentlichte 1946 die Erinnerungen der 12-jährigen Janina Hescheles an ihre Zeit im Zwangsarbeiterlager Lemberg-Janowska, niedergeschrieben im Versteck in Krakau. Vor kurzem wurde Rena Wollerównas Pamiętnik uczennicy [Tagebuch einer Schülerin] herausgebracht; die Autorin kehrte aus dem Krakauer Ghetto und den Lagern Płaszów, Auschwitz und Bergen-Belsen im Juli 1945 nach Krakau zurück. Ihr Tagebuch schrieb sie in Bergen-Belsen und kurz nach ihrer Rückkehr nach Krakau ${ }^{35} .1960$ wurde in Polen das im Ghetto von Łódź verfasste Ghettotagebuch des Dawid Sierakowiak herausgegeben [auf Deutsch erschienen 1998, Übers. von R. Matwin-Buschmann; Anm. d. Übers.]. Eine Altersgenossin von Sierakowiak im Warschauer Ghetto war Mary Berg, deren Tagebuch in englischer Sprache bereits im April 1945 in New York publiziert wurde [The Diary of Mary Berg: Growing up in the Warsaw Ghetto; Anm. d. Übers.]; es war eines der ersten weithin bekannten Dokumente über die Vernichtung der europäischen Juden.

Mary Berg (Miriam Wattenberg) war die Tochter eines bekannten Lodzer Kunstantiquars. Als der Krieg ausbrach, war sie 15 Jahre alt. In der Besatzungszeit zog ihre Familie nach Warschau; im Ghetto organisierte Berg Maßnahmen zur Selbsthilfe, nahm an Grafik- und Architekturkursen der Jüdischen Gemeinde teil. Sie sang in einem Jugendtheaterkreis. Ihre Mutter war amerikanische Staatsbürgerin. Im Juli 1942 wurden die Wattenbergs zusammen mit mehreren Dutzend anderen Juden - Bürgern neutraler Länder - im Pawiak-Gefängnis ${ }^{36}$

anderen Bezugspunkt. Kinder betrachteten den Holocaust auf ganz natürliche Weise und sprachen über das, was sie sahen, ohne sich dabei auf die Vergangenheit, auf ein früheres Wissen zu beziehen. [...] Und genau das ist meine Herangehensweise an den Holocaust.“ Zitat aus: „Polsko, czego ty ode mnie chcesz. Z Henrykiem Grynbergiem rozmawia Jacek Leociak“ " [Polen, was willst du bloß von mir. Jacek Leociak im Gespräch mit Henryk Grynberg], in: „Nowe Książki“ 1994, Nr. 3, S. 2.

35 Siehe „Kalendarz Żydowski“ [Jüdischer Kalender] 1991-1992, (Warschau), S. 145-154.

36 Der Pawiak war von 1835 bis 1944 ein berüchtigtes Gefängnis für politische Häftlinge in Warschau. Ab 1940 wurde es von der Gestapo geführt. Der Gebäudekomplex 
interniert. Am 17. Januar 1943 deportierte man sie von dort aus in ein Lager im französischen Vittel; am 14. März 1944 gelangten Mary und ihre Familie nach New York. Die Kinder hingegen, deren schriftliche Zeugnisse im RingelblumArchiv überdauerten, wurden höchstwahrscheinlich über den Umschlagplatz nach Treblinka gebracht. Unter ihnen waren Beniek Frylingsztajn, Minia Mądra und Gitla Szulcman aus dem Halbinternat an der Nowolipki-Straße 25, die eine Umfrage von Oneg Schabat beantwortet hatten: „Welche Veränderungen hat der Krieg für uns gebracht?" Ebenfalls darunter waren die Jungen aus dem Waiseninternat in der Gęsia-Straße 6/8, die eine eigene kleine Zeitschrift mit dem Titel "Głos Domu Chłopców" [Stimme des Jungenheims] herausgebracht hatten J. Denda, M. Lipman, S. Hajtler, Sz. Gogol, Josef Fibich, Jankiel Hanower, Jakub Lerych, J. Rutowicz, M. Bafiks, J. Cwinkiel.

Aufmerksamkeit verdienen noch zwei weitere Autorengruppen: Beamte und Funktionäre der Jüdischen Gemeinde (besonders Polizisten) sowie Ärzte. Die Jüdische Polizei (also der Ordnungsdienst) ${ }^{37}$ und die Judenräte sind die beiden kontroversesten Institutionen der von den Nazis in Ghettos gesperrten jüdischen Gemeinschaft. Es herrscht Streit sowohl über die Organisationsstrukturen

liegt zwischen Dzielna-, Pawia- und Więżienna-Straße, daher auch der Name; Anm. d. Übers.

37 Wann diese Formation genau entstand, lässt sich schwer sagen. A. Podolska schreibt über den gesamten Prozess ihrer Einberufung (Służba Porządkowa w getcie warszawskim w latach 1940-1943 [Der Ordnungsdienst im Warschauer Ghetto 1940-1943], Warschau 1996, S. 22-28). Gedanken zu einer jüdischen Ordnungsformation kamen bereits in den ersten Besatzungsmonaten auf, und im September 1940 wurde Czerniaków zur Abteilung „Umsiedlung“ gerufen, wo man anordnete, er möge schnell eine jüdische Miliz auf die Beine stellen (laut eines im Archiv aufbewahrten Berichts von T. Wittelson, auf den sich Podolska beruft). Im Tagebuch des Gemeindevorsitzenden findet sich unter dem Datum 12. Oktober 1940 folgenden Bemerkung: „Man beauftragte mich, eine jüdische Miliz mit 1000 Personen aufzustellen" (S. 122). Am 27. Oktober 1940 verzeichnet Czerniaków: „Gestern habe ich Oberstleutnant Szeryński zum Leiter des Ordnungsdienstes bestellt“ (S. 126); am 15. November 1940 notiert er: „Man verlangt, daß morgen früh um 7 je 10 unserer Milizionäre an den Ausgängen der Straße stehen" (S. 131). Daraus geht hervor, dass die ersten Funktionäre des Ordnungsdienstes auf den Straßen erschienen, gleich nachdem das Ghetto zum geschlossenen Bezirk gemacht worden war. Doch es gibt eine Notiz in Ringelblums Kronika, die davon zeugen könnte, dass schon früher jüdische Polizisten auf den Straßen erschienen. Unter dem Datum des 20. Oktobers 1940 ist zu lesen: „Worin besteht der [Ordnungs]Dienst. Er reguliert den Straßenverkehr. Auf der Karmelicka-Straße hat er bereits für Ordnung gesorgt. Diese Leute sitzen schon in den Kommissariaten, auch wenn dort im Moment noch die polnische Polizei ihren Dienst tut. Sie geht am 31. dieses Monats" (S. 174). 
als auch über die in ihnen beschäftigten Menschen ${ }^{38}$. Der Blick auf das Ghetto in den Aufzeichnungen von Polizisten oder Beamten der Jüdischen Gemeinde erfolgt demnach aus der Perspektive derjenigen Milieus, die von den meisten anderen Autoren als Brutstätte des Bösen bezeichnet wurden.

Außer der grundlegenden Quelle - dem Tagebuch des Gemeindevorsitzenden Adam Czerniaków - haben wir hier das umfassende Tagebuch eines Beamten der Beschäftigungsabteilung der Gemeinde, Stefan Ernest: Trzeci front. $O$ wojnie wielkich Niemiec z Żydami Warszawy 1939-1943 [Die dritte Front. Vom Krieg Großdeutschlands gegen Warschaus Juden 1939-1943] sowie die 1945 redigierten Erinnerungen von Beniamin Horowitz, Leiter einer Abteilung der Versorgungsanstalt der Jüdischen Gemeinde [Zakład Zaopatrzenia Gminy]: Przesiedlenie $w$ zaświaty [Umsiedlung ins Jenseits]. Im RingelblumArchiv erhalten sind außerdem schriftliche Aufzeichnungen von (höchstwahrscheinlich) Nachum Remba, einem Beamten der Jüdischen Gemeinde, der sich im Ghettountergrund engagierte. In dem erhaltenen Dokument geht es um den September und Oktober 1939. In seinen Notitsn führt Ringelblum auch ein Textstück aus Rembas verloren gegangenem Tagebuch an. Darin beschreibt er, wie Janusz Korczak und die Kinder aus dem Haus der Waisen auf Waggons geladen wurden (Remba hatte am 6. August 1942 Dienst auf dem Umschlagplatz).

Die Rekrutierung zum Ordnungsdienst fand vor allem unter Angehörigen der assimilierten jüdischen Intelligenz statt. Als Funktionäre des Ordnungsdienstes waren oftmals Juristen tätig, die als Polizisten ebenfalls Tagebuch

38 Siehe v.a. die fundamentale Monographie von I. Trunk: Judenrat. The Jewish Councils in Eastern Europe under Nazi Occupation, New York, London 1972. Der Autor beschreibt umfassend die Strategie und Taktik der verschiedenen Judenräte und der jüdischen Polizei gegenüber der deutschen Besatzungsmacht und der von ihr durchgeführten Extermination der Ghettobewohner, er befasst sich auch mit den Prozessen, die in der Nachkriegszeit gegen die Gemeindebeamten und Polizeifunktionäre geführt wurden. Vgl. auch R. Sakowska: Ludzie z dzielnicy zamkniętej, S. 141-150; I. Gutman: Żydzi warszawscy 1939-1943. Getto - podziemie - walka [Die Warschauer Juden 1939-1943. Ghetto - Untergrund - Kampf], poln. Übers. v. Z. Pelermuter, Warschau 1993, S. 6670, 124-160. H. Arendts Buch Eichmann in Jerusalem. Ein Bericht von der Banalität des Bösen (dt. Übers. von B. Granzow, München 1964), in dem die Autorin u.a. am Beispiel der Tätigkeit der Judenräte aufzeigt, wie der von den Deutschen geplante Mechanismus des Verbrechens funktionierte, der dazu führte, dass auch Juden andere Juden den vielfältigsten Repressalien aussetzten, rief eine Welle von Polemiken hervor. Siehe beispielsweise den Briefwechsel zwischen H. Arendt und G. Scholem (auf Deutsch: M.-L. Knott und D. Heredia (Hgg.): Hannah Arendt/Gershom Scholem. Der Briefwechsel: 1939-1964, Berlin 2010). 
schrieben: Stanisław Adler, Jan Mawult (Stanisław Gombiński) oder der unbekannte Autor eines Tagebuchs, das im Jüdischen Historischen Institut (Abteilung „Erinnerungen“) unter der Signatur 129 geführt ist. Calel Perechodnik, Polizist im Ghetto von Otwock, war Ingenieur und Agronom. Man weiß nicht, wer der unbekannte Werkschutzmann war, der eine Handvoll Notizen hinterlassen hat. Auch weiß man nicht, wer Ber Warm - Funktionär des Ordnungsdienstes, der in der Befehlsstelle und der Werterfassungsstelle arbeitete und der ein Tagebuch mit dem Titel Niska i Prosta, czyli ostatnie dni żywota Żydów w Warszawie [Niska- und Prosta-Straße, oder Die letzten Lebenstage der Juden in Warschau] verfasste - vor dem Krieg war. Als Funktionär beim Ordnungsdienst tätig war auch Mojżesz Passenstein, Verfasser einer Arbeit über den Schmuggel.

Von den Zeugnissen der Ärzte aus der damaligen Zeit bis heute überdauert hat Henryk Makowers Pamiętnik z getta warszawskiego. Październik 1940-styczeń 1943 [Tagebuch aus dem Warschauer Ghetto. Oktober 1940-Januar 1943]. Makower war Chefarzt der Infektionsabteilung im Berson-Bauman-Kinderspital, ein Mitarbeiter Ludwik Hirszfelds, Arzt beim Ordnungsdienst (Leibarzt von Polizeikommandant Józef Szeryński). Erhalten blieb auch das Tagebuch des Kinderarztes Jan Przedborski, Leiter des Kinderheims an der Wolność-Straße 14; es trägt den Titel Likwidacja getta warszawskiego [Die Liquidierung des Warschauer Ghettos]. Henryk Słobodzki, der im Krankenhaus an der StawkiStraße beschäftigt war, hinterließ eine Mischung aus Essay und Erzählung, Dni na krawędzi [Tage am Rande].

Die Ärzte - die Spezialisten für die Rettung von Menschenleben - wurden im Ghetto zu fachmännischen Beobachtern des Sterbens und hilflosen Handlangern des Todes. Ein ergreifendes Zeugnis jener neuen Rolle ist die einzigartige wissenschaftliche Gemeinschaftsarbeit einer Gruppe von Warschauer Ärzten: Choroba głodowa [Die Hungerkrankheit] ${ }^{39}$, mit einem Vorwort von Dr. med. Izrael Milejkowski, Leiter der Abteilung für Öffentliche Gesundheit der Jüdischen Gemeinde und Initiator dieses wissenschaftlichen Projekts.

39 Choroba głodowa. Badania kliniczne nad głodem wykonane w getcie warszawskim w roku 1942 [Die Hungerkrankheit. Klinische Untersuchung über den Hunger, vorgenommen im Warschauer Ghetto im Jahr 1942], Warschau 1946. Autoren der einzelnen Arbeiten waren: Dr. med. und phil. Józef Stein, Dr. med. Julian Fliederbaum, Dr. med. Anna Braude-Hellerowa, Dr. med. Emil Apfelbaum-Kowalski, Dr. med. Michał Szejnman, Dr. med. Szymon Fajgenblat. 
Ein Blick auf die Schicksale der Schreibenden bestätigt, dass das Überdauern im Ghetto für die Texte ungleich leichter war als für ihre Autoren. Nur wenige Autoren überlebten. Das Schicksal vieler von ihnen ist unbekannt, was in diesem Fall mit fast völliger Sicherheit Tod und nicht Rettung bedeutet. Von anderen wissen wir, wann und unter welchen Umständen sie gestorben sind.

Wir kennen die Umstände des Selbstmordes von Adam Czerniaków, dem Vorsitzenden der Jüdischen Gemeinde, der sich am 23. Juli 1942, am zweiten Tag der Deportationen, in seinem Arbeitszimmer vergiftete. Wir wissen, dass Emanuel Ringelblum, dem es Ende 1943 gelungen war, mit Frau und Sohn aus dem Ghetto zu entkommen und sich in einem Unterschlupf in der Grójecka-Straße 84 zu verbergen, am Vortag des Warschauer Ghettoaufstands hinter die Mauern zurückkehrte. Dort wurde er gefasst und ins Zwangsarbeiterlager Trawniki gebracht. Freunde organisierten seine Flucht und schmuggelten ihn nach Warschau zurück, wo er in der Radzymińska-Straße 2 und später wieder in der Grójecka-Straße 84 wohnte. Am 7. März 1944 wurde sein Versteck enttarnt, weil jemand ihn denunziert hatte. Zusammen mit Ringelblum wurde eine große Gruppe Männer, Frauen und Kinder festgenommen, außerdem die Familie Marczak, die Eigentümer des Unterschlupfs, und Mieczysław Wolski, der den Versteckten half. Sie alle wurden zum PawiakGefängnis gebracht und am 10. März in den Ruinen des Ghettos erschossen. ${ }^{40}$

„Der Strom der Umsiedlungen reißt alles mit sich ...", schreibt Ringelblum (Bd. 1, S. 146) über die große Liquidierungsaktion vom 22. Juli bis 21. September 1942. In diesem reißenden Strom gingen zusammen mit den Autoren ihre Tagebücher, Aufzeichnungen, Notizen unter. Von manchen der 300.000 Juden, die damals nach Treblinka deportiert oder gleich an Ort und Stelle umgebracht ${ }^{41}$

40 Den 10. März 1944 als Tag der Erschießung Ringelblums wird zwei Mal bei W. Bartoszewski angegeben: in 1859 dni Warszawy 1895 Tage Warschaus], Krakau 1974, S. 523, und in Warszawski pierścień śmierci 1939-1944 [Warschauer Todesring 1939-1944], [ohne Ortsangabe] 1967. Ebendort wird auch, basierend auf konspirativen Meldungen aus dem Pawiak, die wahrscheinliche Anzahl der zusammen mit Ringelblum verhafteten Personen genannt: 24 Frauen und 16 Männer.

41 Die genaue Anzahl der Menschen, die bei der Liquidierungsaktion umkamen, ist schwer zu schätzen. Zumeist werden zwei Zahlen angegeben: um die 275.000 oder um die 310.000. Erstere Angabe findet sich im sog. Raport listopadowy [Novemberapport] mit dem Titel Likwidacja żydowskiej Warszawy [Die Liquidierung des jüdischen Warschau], datiert auf den 15 . November 1942, den die Untergrundorganisationen des Ghettos für die polnische Exilregierung in London und für die Alliierten Regierungen erstellte. Letztere Zahl nennt General J. Stroop in seinem Bericht über die 
wurden, blieben die Texte erhalten. Aus einem Bericht wissen wir über die letzten Lebensstunden Janusz Korczaks, der am 6. August 1942 mit Stefania Wilczyńska ihre gemeinsamen Schützlinge aus dem Haus der Waisen zu den Waggons auf dem Umschlagplatz führte. Damals kamen höchstwahrscheinlich auch die Kinder aus dem Waiseninternat an der Gęsia-Straße 6/8 um, die ihre Zeitschrift "Głos Domu Chłopców" hinterließen, und die Schüler des Halbinternats an der Nowolipki-Straße 25, deren Antworten auf den Fragebogen von Oneg Schabbat im Ringelblum-Archiv enthalten sind.

Sehr selten jedoch gelingt es, auch nur annähernde Todesdaten auszumachen. Die Opfer der Umsiedlung starben massenweise und namenlos. Alles deutet darauf hin, dass bei der Liquidierungsaktion auch Lejb Goldin den Tod fand. Der letzte Hinweis auf seine Existenz stammt vom 3. August 1942: ein Vermerk auf einer Liste von Menschen, die sich im Untergrund oder gesellschaftlich betätigten und die dem Jüdischen Städtischen Fürsorgekomitee zugeschrieben waren; sie erhielten an jenem Tag eine Zuteilung von einem halben Kilogramm Brot pro Person. Auf einer im Ringelblum-Archiv unter Nummer 13 aufbewahrten Liste ist Goldins Name verzeichnet. Leizor Czarnobroda ${ }^{42}$, der zwei mit Bleistift geschriebene Hefte mit Einträgen vom 28. August bis zum 2. September 1942 hinterließ, wurde festgenommen, zum Umschlagplatz gebracht und dort in einen Waggon verfrachtet, konnte aber auf der Fahrt entkommen und kehrte nach Warschau zurück. Mit Igor Newerlys Hilfe versteckte er sich in Bielany und später in Kazimierz nad Wisłą, wo er unter unbekannten Umständen zu Tode kam.

Um den Tod Izrael Szterns rankt sich sogar eine Legende, derzufolge der Schriftsteller, vom Hunger völlig entkräftet, mehrere Tage lang auf den Pflastersteinen eines verfallenen Hinterhofs gelegen haben soll, bis er schließlich sein Leben aushauchte. Der exzellente jüdische Dichter Halpern Leivick, der in Belarus geboren wurde und ab 1913 in den Vereinigten Staaten lebte, schrieb 1943 ein Gedicht, in dem er diese Legende gewissermaßen sakralisiert. Das Gedicht trägt

Niederschlagung des Ghettoaufstands. Es ist schwer zu sagen, welche der Wahrheit näher kommt.

42 Leizor Czarnobroda war Redaktionssekretär bei der Zeitung „Mały Przegląd“ [Kleine Rundschau], die von J. Korczak 1926 ins Leben gerufen worden war und ab 1930 von I. Newerly redigiert wurde. Es war eine für junge Leser gedachte Beilage zur Zeitung „Nasz Przegląd“ [Unsere Rundschau], der wichtigsten jüdischen Tageszeitung in polnischer Sprache unter der Leitung von Jakub Appenszlak, Natan Szwalbe, Saul Wagman und Daniel Rozencwajg. Die Zeitung versammelte die Elite der Publizisten, Journalisten und zionistischen Intellektuellen um sich. 
den Titel „Mój brat Izrael Sitem“ [Mein Bruder Izrael Sitem] und stammt aus der Sammlung Nie byłam $w$ Treblince [Ich war nicht in Treblinka; 1945]. Leivick vergleicht das stille, unterwürfige Opfer seiner selbst, das Sztern auf den Pflastersteinen des Ghettos darbrachte, mit der Opferung Isaaks. Tatsache ist jedoch, dass Sztern nicht an Hunger gestorben ist. „Als die Liquidierungsaktion der Warschauer Juden beginnt“, schreibt Ringelblum, „versteckt Izrael Sztern sich in Hoffmanns »Shop«. Längere Zeit kann er sich so über Wasser halten. Bei einer der zahlreichen Selektionen wird er gefasst, dann geht es über den Umschlagplatz nach Treblinka." (Bd. 1, S. 575). Was von Hillel Zeitlins Tod überliefert ist, unterstreicht seine religiöse Haltung. Ringelblum gibt an, Zeitlin habe „auf dem Wagen stehend, der ihn und andere zum Umschlagplatz brachte, den Tallit angelegt und laut das "Widduj" [Sündenbekenntnis vor dem Tod] gebetet" (Bd. 1, S. 574). Joszua Perle wiederum stellt jene Szene so dar: „Es war ein erstaunlicher Anblick - der Wagen voller Frauen und Kinder, alle unterwegs in den sicheren Tod, und mitten unter ihnen der hochgewachsene, würdige alte Mann mit langem, schneeweißem Bart, eingehüllt in seinen Tallit." ${ }^{\text {43 }}$

Ein zweiter breit angelegter Schlag gegen die dezimierte Ghettobevölkerung war die Januaraktion (18.-22. Januar 1943), bei der die Deutschen zum ersten Mal auf bewaffneten Widerstand stießen. Dabei kam u.a. Avrom Levin um - der letzte Eintrag in seinem Tagebuch findet sich unter dem Datum des 15. August 1943 - sowie auch Dr. Izrael Milejkowski, der seine Einleitung zu Choroba głodowa auf Oktober 1942 datierte. Bei der Januaraktion fand auch Gustawa Jarecka den Tod; sie erreichte Treblinka nicht mehr lebend. Stanisław Adler führt in seinen Erinnerungen den Bericht eines Menschen an, der aus dem Zug entkommen konnte. Unter den auf- und übereinanderliegenden Leichen, die den Boden des Waggons bedeckten, erkannte jener Mensch die sterbende Gustawa Jarecka. Vor seinen Augen tat sie ihren letzten Atemzug (siehe S. 327). Chaim Aron Kaplans Tagebuch bricht am 4. August 1942 ab. Es gibt jedoch Grund zur Annahme, dass Kaplan im Dezember 1942 oder Januar 1943 umgekommen ist, höchstwahrscheinlich in Treblinka ${ }^{44}$.

Beim Aufstand im Warschauer Ghetto starb Władysław Szlengel. Nicht einmal sein Geburtsdatum und sein genauer Todestag lassen sich heute zweifelsfrei

43 Zitat nach den Anmerkungen des Herausgebers zu: A. Lewin: A Cup of Tears. A Diary of the Warsaw Ghetto, hg. von A. Polonsky, London 1990, S. 277-278. Zeitlin konnte damals vom Umschlagplatz geholt und in ein Krankenhaus gebracht werden. Wenig später jedoch teilte er das Los anderer nach Treblinka deportierter Kranker.

44 Siehe das Vorwort zu Ch. A. Kaplan: Buch der Agonie: das Warschauer Tagebuch des Chaim A. Kaplan, hg. von Abraham I. Katsh, Frankfurt/Main 1967, S. 16. 
feststellen. Man weiß, dass er sich im Bunker von Szymon Kac an der Świętojerska-Straße 36 aufhielt ${ }^{45}$. In Leon Najbergs Erinnerungen ist allerdings eine Bemerkung über Szlengel in einem äußerst wichtigen zeitlichen Kontext vermerkt. Najberg versteckte sich den ganzen Aufstand hindurch und auch später noch, bis zum September 1943, in verschiedenen Bunkern innerhalb des Ghettos. Der Eintrag in seinem Tagebuch bestätigt, dass der Dichter sich im Bunker an der Świętojerska 36 aufhielt, bis dieser entdeckt und zerstört wurde, d.h. bis zum Samstag, dem 8. Mai 1943:

Nur drei Tage ließ es sich in Szymek Kac' Unterschlupf überdauern - heute [8. März 1943 - J.L.] ist dieser Unterschlupf „aufgeflogen“ und „abgewickelt“ worden. [...] Gestern Abend schrieb der Dichter Władysław Szlengel noch seine Gedichte, in denen er den Heldenmut der jüdischen Kämpfer lobte und das Schicksal der Juden betrauerte. [...] Gestern wusste Szlengel noch nicht, dass er zum letzten Mal die Geschichte der heldenhaften Kämpfer und die Geschichte der Verstecke beschrieb. Vielleicht wird sein Manuskript niemals gefunden (S. 73-75).

Najberg und eine Handvoll weiterer gruzowcy [in etwa: „Trümmerkämpfer“, Menschen, die nach der Liquidierung des Ghettos weiter in dessen Ruinen kämpften; Anm. d. Übers.] konnten dem Hinterhalt entgehen. Die restlichen kamen zu Tode. Man darf annehmen, dass der stets sehr exakte und den Realien verpflichtete Tagebuchautor sich nicht irrt und Władysław Szlengel zum letzten Mal am 8. Mai 1943 gesehen wurde, als „um 5 am Nachmittag ein Zug von Märtyrern sich auf seinen letzten Weg machte" (S. 75).

Die Autorin einiger im Bunker niedergeschriebener Notizen über die Aufständischenkämpfe (N.N. „Erinnerungen“, Sign. 39) wurde wahrscheinlich über den Umschlagplatz nach Majdanek deportiert, wo sich ihre Spur verliert. Ein anderer anonymer Autor eines während des Aufstands verfassten Tagebuchs (N.N. „Erinnerungen“, Sign. 228) wurde ebenfalls zum Umschlagplatz gebracht. Sein weiteres Schicksal ist unbekannt. Im April oder Mai 1943 wird Jizchak Katzenelson ins Konzentrationslager im französischen Vittel deportiert. Dort schreibt er seinen monumentalen Großen Gesang vom ausgerotteten jüdischen

45 Die Herausgeberin von Szlengels Gedichten aus der Ghettozeit, I. Maciejewska, gibt nach B. Marek: Umgekumene szrajber fun die getos un lagern [Umgekommene Schreiber aus Ghettos und Lagern, Warschau 1954] an, dass der Dichter „im April 1943 im Warschauer Ghetto, im Bunker von Szymon Kac, in der Świętojerska-Straße 36“ starb („Nachwort“, in: W. Szlengel: Was ich den Toten las: Texte und Gedichte aus dem Warschauer Ghetto, S. 105). Ich denke, dass Leon Najbergs Zeugnis, das ich hier anführe, die Grundlage für eine Präzisierung des Todesdatums des Dichters liefert. 
Volk, dort führt er Tagebuch. Nach seiner Deportation nach Auschwitz wird er am 3. Mai 1944 ermordet.

Viele Menschen fanden den Tod auch erst auf der arischen Seite von Warschau, nachdem sie aus dem Ghetto entkommen waren. So starb im November 1943 Nachum Remba. Joszua Perle verließ sein Versteck bei polnischen Freunden seines Sohnes und ging den Deutschen im Hotel Polski an der Długa-Straße in die Falle ${ }^{46}$. Statt nach Südamerika brachte man ihn nach Bergen-Belsen und von dort aus nach Auschwitz, wo er im Mai 1944 ermordet wurde. Stanisław Sznapman, dessen Tagebuch dem Jüdischen Historischen Institut nach dem Krieg von Helena Boguszewska und Jerzy Kornacki übergeben wurde, gelangte erst im Juli 1943 auf die arische Seite und kam dort unter unbekannten Umständen um. Der Ingenieur Goldman, Verfasser eines Berichts aus dem brennenden Ghetto, den er im Auftrag des auf arischer Seite tätigen Jüdischen Nationalen Komitees schrieb, starb zwischen Februar und August 1944. Im Warschauer Aufstand wurde der „,buchalter“ Jakub, der sich im Stadtteil Praga verbarg, getötet. Sein umfassendes Tagebuch bewahrte die Frau auf, die ihn versteckte. Im August $1944 \mathrm{kam}$ in den Trümmern des bombardierten Warschau Eugenia Szajn-Lewin um. Nach dem Fall des Warschauer Aufstands führten Plünderer ein paar Deutsche zu dem Versteck, in dem sich der damals bereits typhuskranke Calel Perechodnik aufhielt. Er hatte keine Kraft, hinauszugehen wie seine Gefährten, die draußen erschossen wurden, sondern starb in den Flammen des in Brand gesteckten Bunkers. Besonders dramatisch spitzte sich das Schicksal derjenigen zu, die den Krieg nur kurz überlebten. Noemi Szac-Wajnkranc, deren Erinnerungsband Przeminęto z ogniem [Vom Feuer verschlungen] im Jahr 1947 erschien, arbeitet bis Kriegsende auf einem Landgut in der Nähe von Łódź als Dienstmagd. Ein jüdischer Offizier der Roten Armee kümmert sich um sie und

46 Der Fall Hotel Polski ist bis heute nicht ganz geklärt. Es wird angenommen, dass die Deutschen nach der Niederschlagung des Ghettoaufstandes Juden anlocken wollten, die sich noch auf arischer Seite versteckten, und daher verkündeten, es gebe die Möglichkeit einer legalen Ausreise nach Südamerika. Grundlage dafür sollten Dokumente sein, die den Ghettobewohnern von ausländischen Verwandten geschickt würden. Die meisten Adressaten wurden jedoch damals bereits ermordet, somit wurden die Papiere zum Handelsgegenstand. Das Hotel Polski, wo die Ausreisewilligen versammelt wurden, erwies sich als Falle. Dennoch stellt der israelische Historiker N. Eck fest („Yad Vashem Studies“, Vol. 1, 1957), dass die Nazis anfangs tatsächlich Juden gegen in Südamerika internierte Deutsche austauschen wollten. Wer sich zu Anfang der Aktion im Hotel Polski meldete, wurde ins Interniertenlager nach Vittel deportiert und entkam der Vernichtung. Die weiteren Transporte gingen dann nach Auschwitz. 
rät ihr, aus Sicherheitsgründen nach Łódź zu gehen, das am 19. Januar 1945 durch die sowjetische Armee befreit worden war. Diese Entscheidung erweist sich als folgenschwer. Als Noemi durch eine der verlassenen Straßen geht, wird sie von einer Gruppe Deutscher erschossen, die sich noch in einem der Häuser versteckt ${ }^{47}$. Henryk Bryskier, Verfasser eines Tagebuchs mit dem Titel $\dot{Z} y d z i$ pod swastyka, czyli getto warszawskie [Juden unterm Hakenkreuz oder Das Warschauer Ghetto], wird während des Ghettoaufstands nach Majdanek deportiert, flieht von dort und versteckt sich in Warschau am rechten Weichselufer. Dort erlebt er 1944 den Einmarsch der sowjetischen Truppen. Kurze Zeit arbeitet er im Lubliner Komitee [Polski Komitet Wyzwolenia Narodowego PKWN - Polnisches Komitee der nationalen Befreiung], nach seiner Rückkehr nach Warschau wird er Direktor der Abteilung Chemie am Industrie- und Handelsministerium. Im Oktober 1945 stirbt er an Angina Pectoris. Stanisław Adler, Jurist bei der jüdischen Polizei im Ghetto, der sich in Anin versteckt, wird im Herbst 1944 von den sowjetischen Truppen befreit, als sie die Deutschen vom rechten Weichselufer verdrängen. Adler geht nach Lublin, wo er als Jurist Mitglied der Beratergruppe der Lubliner Übergangsregierung wird. Zudem bekommt er eine Stelle in Wissenschaft und Lehre an der Juristischen Fakultät der Universität Warschau angeboten. Am 11. Juli 1946 - wenige Tage nach dem Pogrom von Kielce ${ }^{48}$ - begeht Adler, der in immer tiefere Depressionen versinkt und sich weder entscheiden kann, in Polen zu bleiben, noch, nach Palästina zu emigrieren, Selbstmord ${ }^{49}$.

Viele der Überlebenden verließen Polen früher oder später. Nach Israel gingen u.a. Rokhl Oyerbakh ${ }^{50}$, Symcha Rotem-Ratajzen, Marian Berland. Adolf

47 Vorwort von E. Kaganowski zu: N. Szac-Wajnkranc: Przeminęło z ogniem. Pamiętnik [Vom Feuer verschlungen. Erinnerungen]; Warschau 1947, S. 5.

48 Beim Pogrom von Kielce am 4. Juli 1946 wurden in einer Serie von Überfällen um die 40 jüdischen Einwohner von anderen Einwohnern, Mitgliedern der Polnischen Volksarmee, des Korps der Inneren Sicherheit und Funktionären der Bürgermiliz ermordet und zahlreiche weitere verletzt. Grund war die angebliche Entführung eines christlichen Jungen für einen Ritualmord. In der Folge verließen viele Juden Polen und das Stereotyp des antisemitischen Polen verbreitete sich weiter; Anm. d. Übers.

49 L. „Lola“ Zeldowicz: „Personal Notes on Stanisław Adler“, in: In the Warsaw Ghetto 1940-1943. An Account of a Witness. The Memoirs of Stanisław Adler, aus dem Polnischen ins Englische übers. von S. (Chmielewska) Philip, Jerusalem 1982, S. XIV-XVIL.

50 Vor ihrer Ausreise aus Polen schrieb Rokhl Oyerbakh für jüdische Zeitungen, die in polnischer Sprache erschienen: „Mosty“, „Opinia“, „Nasze słowo“, „Przełom“. Sie veröffentlichte auch ihre Erinnerungen Oif di fetder fun Treblinke [Auf den Feldern von Treblinka], Warschau 1947. In Israel erschienen auch ihre Memoiren Warszewer cawoes [Warschauer Testamente], Tel Aviv 1974. Sie publizierte dort auf Polnisch und auf 
Berman, Mitglied des Landesnationalrats [Krajowa Rada Narodowa, KRN], ab 1947 Vorsitzender des Zentralkomitees der Juden in Polen, verließ das Land gemeinsam mit seiner Frau im Jahr 1950. Bekannt ist, dass Marek Stok nach Brasilien emigrierte, nicht bekannt dagegen, auf welche Weise sein Tagebuch über das erste Halbjahr 1944 ins Archiv des Jüdischen Historischen Instituts gelangte. Samuel Kahan (mit arischem Namen Mieczysław Lewandowski) stellt sein in der Besatzungszeit verfasstes Tagebuch im März 1945 fertig. Der letzte Eintrag vermerkt, dass der Autor nach Brasilien zu seinen Söhnen zu fahren plant.

Andere Überlebende wiederum blieben für immer in Polen. Marek Edelman war einer von ihnen. 1945 wurde mit der Hilfe des Bund sein Bericht Das Ghetto kämpft in Warschau herausgegeben, in der polnischen Ausgabe versehen mit einem Vorwort von Zofia Nałkowska, der bekannten Schriftstellerin und Verfechterin eines unabhängigen Polens, die ihre Erinnerungen an den Zweiten Weltkrieg und den Holocaust im Roman Medaillons [dt. Übers. von H. Bereska, Berlin 1956, Frankfurt/Main 1968] verarbeitete. Henryk Makowers Pamiętnik z getta warszawskiego erschien erst 44 Jahre, nachdem er es geschrieben hatte, im Druck; da war der Autor bereits seit 20 Jahren tot. Makower, Professor an der Wrocławer Medizinischen Akademie, verstarb 1964 in Polen. Ludwik Hirszfelds Geschichte eines Lebens, die seine während des Krieges aufgezeichneten Erinnerungen enthält, wurde mehrmals neu aufgelegt. Ihr Autor, ein ausgezeichneter Gelehrter von internationalem Rang, beteiligte sich direkt nach dem Krieg an der Gründung der Marie-Curie-Skłodowska-Universität in Lublin. 1945 ließ er sich in Wrocław nieder, übernahm eine Professur an der dortigen Medizinischen Akademie. Ebenfalls in Wrocław verstarb 1954 Józef Gitler-Barski, Autor eines Berichts über die Liquidierung des Ghettos von Mitte 1943 sowie eines Bands über seine Erinnerungen an das Ghetto; er wurde nach Bergen-Belsen deportiert, überlebte aber und kehrte im April 1945 nach Polen zurück. Er arbeitete im Staatsapparat der Volksrepublik Polen, war Generaldirektor des Joint ${ }^{51}$ in Polen, hatte eine leitende Position am Jüdischen Historischen Institut in Warschau inne.

Jiddisch, arbeitete für die polnischsprachige Presse („Nowiny-Kurier“ [NeuigkeitenKurier]) und für die wichtigste literarische Quartalsschrift in Jiddisch, „Di Goldene Kejt“ [Die Goldene Kette], die von Avrom Sutzkever gegründet worden war und seit 1949 in Israel erschien. Zu Oyerbakhs Zusammenarbeit mit der polnischsprachigen Presse in Israel nach dem Krieg siehe R. Löw: „Ostatki polskie. Rzecz o izraelskiej prasie w języku polskim [T.1], in: „Zeszyty literackie“ 1994, Nr. 48, S. 153.

51 American Jewish Joint Distribution Committee: seit 1914 bestehende Hilfsorganisation US-amerikanischer Juden, vorwiegend in Europa tätig, ursprünglich gegründet, um jüdischen Opfern des Ersten Weltkriegs Hilfe zu leisten; Anm. d. Übers. 


\section{Ort und Umstände des Schreibens}

1

Am 24. August 1940 wurden in der "Gazeta Żydowska"52 [Jüdischen Zeitung] die genauen Informationen zu den festgelegten Ghettogrenzen bekannt gegeben. Vier Tage später publiziert dieselbe Zeitung bereits Ergänzungen und Korrekturen dazu. Am 14. Oktober erscheint im „Nowy Kurier Warszawski“ [Neuer Warschauer Kurier - ein von den Deutschen herausgegebenes polnischsprachiges Propagandablatt], der offizielle Text der Verordnung Gouverneur Fischers zur Eröffnung eines deutschen Bezirks in Warschau sowie eines Ghettos für die jüdische Bevölkerung. Am nächsten Tag veröffentlicht der „Nowy Kurier Warszawski“ einen Stadtplan von Warschau mit eingezeichneten Ghettogrenzen. Bis der jüdische Bezirk geschlossen wird, d.h. bis zum 15. November 1940, werden seine Grenzen noch mehrmals anders gezogen. Am 14. November 1940 publiziert die Propagandazeitung einen neuen, detaillierten Plan des Ghettos, seiner Eingänge und Straßenbahnlinien. Doch auch dieser Plan sollte in Kürze nicht mehr aktuell sein.

Indessen notiert Adam Czerniaków bereits am 10. April 1940: „An über zehn Stellen hat die Gemeinde mit dem Bau von Mauern begonnen“ (S. 60). Der Bau der Mauern, dessen Kosten die Juden selbst tragen müssen, wird von da an zur Hauptbeschäftigung für die Maurertrupps des Ghettos. Am 22. November 1940 bemerkt Mary Berg: „Die roten Backsteinmauern, die die Straßen des Ghettos schließen, sind sehr gewachsen.“ Am 15. Februar 1941 schreibt sie ihre nächsten Beobachtungen nieder: „Nun wachsen die Mauern höher und höher [...]. Oben sind sie von einer dicken Schicht Ton bedeckt, vermischt mit Glasscherben, damit Menschen, die zu flüchten versuchen, sich die Hände zerschneiden." (S. 42, 52). Es gab auch Abgrenzungen aus Stacheldraht und Holzzäune. Tafeln bei den Eingängen informierten über eine im Ghetto wütende Seuche. Die deutsche Propaganda erklärte die Abriegelung des Ghettos mit der Notwendigkeit, eine Barrikade zu Hygienezwecken zu errichten, um Warschau vor der Seuche zu

52 Das einzige öffentliche, vom Besatzer genehmigte polnischsprachige jüdische Periodikum im Generalgouvernement. Die "Gazeta Żydowska“ erschien in Krakau vom 23. Juli 1940 bis zum Juli 1942 zwei Mal (dienstags und freitags), eine Zeitlang auch drei Mal pro Woche. Gewidmet war sie überwiegend den Angelegenheiten des Warschauer Ghettos. Der Redaktionssitz der „Gazeta Żydowska“ in Warschau befand sich in der Elektoralna-Straße 4/1. Siehe M. Fuks: „Życie w gettach GG na tle ,Gazety Żydowskiej‘ (1940-1942)“ [Das Leben in den Ghettos des Generalgouvernements in der Darstellung der „Gazeta Żydowska“], in: „Biuletyn ŻIH“ 1971, Nr. 3. 
schützen. Auf den Straßen der Stadt hingen „[r]iesige Plakate mit einem Juden aus dem Stürmer und der Aufschrift: Juden - Läuse - Fleckfieber. Eine riesige Laus kriecht in den Bart eines Juden“, notiert Ringelblum (S. 243). Czerniaków schreibt am 4. April 1940, nach einem Besuch im Blank-Palast, wo sich das Büro des Warschauer Stadthauptmanns Ludwig Leist befand, eine mitgehörte These auf und setzt sie in Anführungsstriche: „Die Mauern sind dazu da, die Juden vor Ausschreitungen zu schützen“ (S. 58). Das Gespräch fand wenige Tage nach heftigen antijüdischen Exzessen statt. Die Mauern sollten somit auch ein Beweis für die Großzügigkeit der Deutschen sein, die die Juden vorgeblich so vor der Bedrohung durch die Polen schützten ${ }^{53}$.

53 Der Leiter der Umsiedlung, Waldemar Schön, erklärt die Einrichtung des Ghettos v.a. mit einer hygienischen Notwendigkeit - dem Schutz des deutschen Heers und des deutschen Volkes „,or dem Juden, dem immunen Überträger von epidemischen Erregern“ - sowie mit einer politisch-moralischen und einer wirtschaftlichen Notwendigkeit. Siehe „Z referatu Schöna, kierownika wydziału przesiedleń w Urzędzie gubernatora dystryktu warszawskiego, o gecie warszawskim, 20 stycznia 1941 r." [Aus dem Referat Waldemar Schöns, Leiter der Abteilung Umsiedlungen im Amt des Gouverneurs des Distrikts Warschau, über das Warschauer Ghetto, 20. Januar 1941], in: Eksterminacja Żydów na ziemiach polskich w okresie okupacji hitlerowskiej. Zbiór dokumentów [Die Ausrottung der Juden in polnischen Gebieten während der Besatzung durch die Nazis. Eine Sammlung von Dokumenten], bearb. von T. Berenstein, A. Eisenbach, A. Rutkowski, Warschau 1957, S. 106. L. Landau wiederum stellt nach antisemitischen Exzessen auf Warschaus Straßen im Frühjahr 1940 einen charakteristischen Tonfall deutscher Propaganda fest: „Zweck dieser Aktion ist es [...], Dokumente zu erhalten, die die Deutschen auf polnischem Gebiet in den Augen des Auslands rechtfertigen sollen - ach, was sage ich, die sie auf das Podest der Ordnungshüter, der Rächer der Unterdrückten erheben sollen. Dazu dienen Photographien und Filme; dazu dienen soll auch, dass die Juden sich an die Deutschen wenden, um Schutz vor Angriffen der christlichen polnischen Bevölkerung zu erhalten. [...] Die Absichten der Deutschen sind klar. [...] [E]in Unglück ist nur, dass diese Absichten sich auf dem Boden, den die Endecja [Nationaldemokratie, eine polnische nationalistische und antisemitische Bewegung; Anm. d. Übers.] ihnen jahrelang bereitet hat, so leicht realisieren lassen“ (Bd. 1, S. 370-371). Über die Pogrome in Warschau im Frühjahr 1940 schreibt T. Szarota: „Zajścia antyżydowskie i pogromy w okupowanej Europie“ [Antijüdische Vorfälle und Pogrome im besetzten Europa], in: D. Grynberg und P. Szapiro (Hgg.): Holocaust z perspektywy pótwiecza. Pięćdziesiąta rocznica powstania w getcie warszawskim. Materiały z konferencji zorganizowanej przez Żydowski Instytut Historyczny $w$ dniach 29-30 marca 1993 [Der Holocaust aus der Perspektive eines halben Jahrhunderts. Der fünfzigste Jahrestag des Aufstands im Warschauer Ghetto. Materialien von einer Konferenz des Jüdischen Historischen Instituts, 29.-30. März 1993], Warschau [ohne Erscheinungsdatum]. 
Die Grenzen des Ghettos wurden zu Grenzen zwischen Leben und Tod. Bewacht wurden sie von der deutschen Gendarmerie in ihren grünen Uniformen mit braunen Aufschlägen, von der polnischen dunkelblauen Polizei und vom jüdischen Ordnungsdienst mit seinen gelben Mützenbändern. Die Mauern verliefen entlang der Häuserlinien, teilten benachbarte Grundstücke, schnitten Gehsteige von Straßen ab, versperrten Straßen in der Mitte, zerschlugen die bisherige, gewohnte Topographie der Stadt und schufen eine neue, fremde und feindliche Raumordnung. Der Raum wurde jetzt anders erlebt als zuvor beklemmend und traumatisch. Der Anblick der Mauern, die auf der Rymarska-Straße hochgezogen worden waren, ruft bei Ringelblum das alptraumhafte Gefühl hervor, lebendig begraben worden zu sein: „Man will uns lebendig einmauern" (S. 186), vermerkt er am 1. November 1940, zwei Wochen vor der Abriegelung des Ghettos. Wanda Lubelska, die kurz vor dem Krieg ihre Matura im A.-Piłsudzka-Gymnasium (heute S.-Sempołowska-Lyzeum) im Stadtteil Żoliborz abgelegt hatte, vertraut ihrer Schulfreundin in einem Brief, der auf den 22. Dezember 1940 datiert und demnach bereits aus dem geschlossenen Ghetto verschickt wurde, an, sie fühle sich auf beklemmende Weise gefangen:

Du ahnst ja nicht, wie schrecklich gern ich hier von hier fort würde, nach Żoliborz [...] Das Schlimmste sind die Szenen auf der Straße, du hast ja keine Ahnung, welche Wirkung das auf mich hat. [...] Überall Mauern, Polizei, Wachen, eine furchtbare Gefangenschaft, all das zusammen und dieses Gefühl, man säße in einem Gefängnis, hat so eine schreckliche psychische Wirkung (S. 154).

Nach fast zwei Jahren des Lebens im geschlossenen Bezirk schreibt Chaim Kaplan von einer doppelten Mauer:

Wir sind hinter Doppelmauern eingesperrt: hinter einer Mauer aus Ziegeln für den Körper und einer Mauer aus Schweigen für den Geist. Was auch geschieht oder getan wird, ist von einem Mantel des absoluten Schweigens umhüllt (Buch der Agonie, S. 356).

Was sich auf der einen und auf der anderen Seite der Mauer befand, nahm neue Dimensionen an. Die Welt jenseits der Mauern war gleich hier, zum Greifen nahe. Doch im drastischen Kontrast zur physischen Nähe der beiden Welten stand der Abgrund zwischen ihnen. Die paar Schritte von der einen zur anderen Seite zurückzulegen war unter Androhung von Todesstrafe verboten ${ }^{54}$.

54 Am 15. Oktober 1941 erschien die „Dritte Verordnung über Aufenthaltsbeschränkungen im Generalgouvernement“von Generalgouverneur Hans Frank; einen Auszug daraus lohnt es wegen der eigentümlichen Stilistik anzuführen: „(1) Juden, die den ihnen zugewiesenen Wohnbezirk unbefugt verlassen, werden mit dem Tode bestraft. Die gleiche Strafe trifft Personen, die solchen Juden wissentlich Unterschlupf gewähren. 
Das Raumempfinden musste somit einer gewissen Umwertung unterzogen werden. In Aufzeichnungen von damals ist der Kontrast zwischen Ghetto und arischer Seite häufig als ein endgültiger, unüberwindbarer, geradezu ontologischer Graben dargestellt. Etwas Bekanntes wird verändert bis zur Unkenntlichkeit. Es dominiert ein bizarrer Eindruck von Fremdheit. Chaim Kaplan hält am 4. November 1940 fest:

Das Aussehen Warschaus hat sich derartig verändert, daß niemand, der die Stadt kannte, sie jetzt noch erkennen würde. [...] Aber das Aussehen des jüdischen Warschau hat sich besonders verändert. [...] [S]eit der jüdische »Wohnbezirk" errichtet wurde, ist das jüdische Warschau eine Stadt für sich geworden, die sich charakteristisch vom arischen Warschau unterscheidet. Jeder, der vom jüdischen Bezirk in den arischen geht, gewinnt den Eindruck, daß er eine neue Stadt betritt, die völlig anders aussieht, ihren eigenen Lebensstil hat und nicht mit ihrem jüdischen Nachbarn gemein hat. (S. 260)

Das Passieren der Wachposten an den Ghettoeingängen und der Übertritt auf die andere Seite der Mauer wurden empfunden wie der Wechsel in eine andere Dimension, in eine andere Wirklichkeit. Leon Guz konnte 1941 nach Mińsk Mazowiecki gelangen. Über seine Eindrücke nach der Durchfahrt durch das Ghettotor schreibt er:

Ich betrachte die Straßen auf der ,anderen Seite“ und fühle mich, als wäre ich zum ersten Mal in Warschau. Ich war in einer anderen Welt angelangt. Dabei war das ein mir sehr gut bekannter Teil der Stadt (S. 54).

Bereits im Juli 1941 wird Wanda Lubelska bewusst, dass Warschau in zwei getrennte und einander fremde Welten zerfallen ist, die von der Mauer getrennt werden. Zwei Welten, in denen Menschen, die einander noch vor kurzem nahe waren, nun andere Sprachen zu sprechen scheinen. Sie dankt ihrer Freundin von der anderen Seite für ihren Brief und schreibt zur Antwort:

Geliebte Zeta. Jedes Deiner Worte ist mir, die heute so von Schmerz erfüllt ist, wunderwirkender Balsam für meine Seele. Manchmal scheint es mir, als sprecht „Ihr“ dort in einer Art anderer Sprache, anderen Worten als wir hier (S. 158).

Die alten Kategorien und Parameter von Raum haben sich als ungeeignet erwiesen. Begrifflichkeiten wie „fern - nah“, „dort - hier“ mussten neu definiert

(2) Anstifter und Gehilfen werden wie der Täter, die versuchte Tat wird wie die vollendete bestraft." Bereits am 17. November 1941 kündigt der Kommissar des Ghettos, Heinz Auerswald, in einer speziellen Bekanntmachung die Erschießung von 8 Juden „wegen unerlaubten Verlassens des jüdischen Wohnbezirks in Warschau“ an. Siehe Eksterminacja Żydów na ziemiach polskich, op. cit., S. 122-123. 
werden. Sie hatten einen neuen Sinn angenommen. Hier zwei Zeugnisse jener dramatischen Umwertung der räumlichen Kategorien. Eines stammt aus den Aufzeichnungen Franz Blättlers, eines Fahrers der Schweizer Ärztemission, der sich 1942 in Warschau aufhielt. Blättler ist ein Außenstehender, sowohl im Verhältnis zum Besatzer als auch zum besetzten Land. Als Bürger der neutralen Schweiz hat er sich als Freiwilliger für eine Mission des Roten Kreuzes gemeldet. Er distanziert sich von den Deutschen in allem, was er tut, schreibt voller Sympathie und Mitgefühl über die Polen. Mit Mut, scharfem Blick und Wissensdurst beobachtet er das Leben im besetzten Warschau. Er betritt auch das Ghetto und gelangt zum jüdischen Friedhof. So beschreibt er die Fahrt über die OkopowaStraße zum Friedhofstor:

Ich fahre weiter der Ghettomauer entlang. Nun taucht auch zu meiner Linken eine langgestreckte Ziegelmauer auf, das muss der Judenfriedhof sein. Die Straße ist eingekeilt zwischen den beiden Stätten des Grauens. Für mich „Arier“ bedeutet sie noch körperliche Freiheit, für die Juden zu meiner Rechten und Linken ist sie so nahe und doch nicht erreichbar. ${ }^{55}$

Das zweite Zeugnis ist die Innenansicht eines Menschen, der die Realien des Ghettos bestens kennt, da er darin lebt. Władysław Szlengel zeigt in seinem Gedicht „Gespräch mit einem Kind“ in künstlerischer Kürze auf, was der Begriff „weit“ im Ghetto bedeutete:

Neunzehnhundertzweiundvierzig das Jahr.

Werkstatt-Block. Mutter und Kind sieht man da ...

Mutter, sag mir, fragt der Kleine,

was bedeutet: WEIT ...

Weit bedeutet hinter den Bergen, hinter den Flüssen und Wäldern ...

Wie soll man dem Kind erklären, was das Wort bedeutet: WEIT ... wenn es nicht weiß, was ein Berg ist, und auch nichts von Flüssen weiß ...

55 Franz Blättler: Warschau 1942: Tatsachenbericht eines Motorfahrers der zweiten schweizerischen Aerztemission 1942 in Polen, Zürich 1945, S. 27. Blättler zeichnete in Warschau Notizen auf und machte Photos. Als er Polen verließ, schmuggelte er seine Filmrollen und Notizen in den Absätzen seiner Schuhe mit. 


\author{
Weit, mein liebes Kind \\ (eine Träne hängt an ihren Wimpern), \\ weit, das ist von hier, wo wir sind, \\ bis zum Block von Toebbens ${ }^{56} .^{57}$
}

2

Was das Aussehen des Bezirks betraf, so wurden verschiedenste Eigentümlichkeiten eingeführt, die nicht nur die bisherige Gestalt des Stadtteils deformierten, sondern auch einen neuen Maßstab erzwangen, eine neue Zeichen- und Werteordnung - eine neue Art, den Raum wahrzunehmen und sich in ihm zu bewegen. Den Bewohnern des Ghettos blieb nichts übrig, als sich schnell an die manchmal schockierenden Veränderungen und beschwerlichen Verunstaltungen zu gewöhnen.

Eine davon waren zweifellos die hölzernen, über die Straßen verlegten Fußgängerbrücken. Diese Art baulicher Lösung wandten die Deutschen zunächst im Ghetto von Łódź und später dann auch in Warschau an. Im Warschauer Ghetto gab es vier solcher Holzbrücken: Ein Fußgängersteg führte von der jüdischen Seite der Żelazna-Straße zu einem Gebäude auf arischer Seite, in dem sich das Arbeitsamt [im Orig. deutsch] der Gemeinde befand (Leszno-Straße 86); die Mitte 1941 errichten Brücken in der Przebieg-Straße (ein kleines Sträßchen zwischen Muranowski-Platz und Bonifraterska-Straße) und in der Mławska-Straße (am nordöstlichen Rand des Ghettos) sowie die größte und bekannteste Überführung über der Chłodna-Straße, die das große mit dem kleinen Ghetto verband. Adam Czerniaków verzeichnet in seinem Tagebuch die einzelnen Phasen ihres Baus. Erbaut wurde sie bei klirrendem Frost: „18.I.1942. Frost. Die Brücke in der Żelazna-Str. ist beinahe fertiggestellt“. Zum Gebrauch freigegeben wurde die Brücke am 26. Januar 1942: „Morgens um 8:30 hielt mich Probst auf der Straße an, bei der Holzbrücke Ecke Chłodna-Żelazna-Str. (jetzt Eisgrubenstrasse und Eisenstrasse), und befahl, die Brücke für die Öffentlichkeit freizugeben. Ich bat darum, keinen Zoll für die Öffentlichkeit einzuführen (Auerswald plant Gebühren).“ (S. 219-221). Sie blieb bis zur Liquidierung des kleinen Ghettos in Betrieb, d.h. bis Mitte August 1942. Im traditionellen Raumerleben symbolisiert die Brücke positive Werte, erlaubt sie es doch, Schluchten oder das ungezähmten Element Wasser zu überqueren, erweitert die Bewegungsmöglichkeiten, schafft

\title{
56 S. 5
}

57 W. Szlengel: „Gespräch mit einem Kind“, dt. Übers. von R. Erb, in: ders.: Was ich den Toten las, op. cit., S. 54. 
mehr Komfort - und ist somit ein Zeichen für die Überwindung von Widrigkeiten. Sie verbindet zwei Ufer, zwei Ränder und schafft einen gemeinsamen Raum - einen Raum der Begegnung. Eine Brücke fügt in unserer Vorstellung mehrere Teile zu einem Ganzen zusammen und hilft, Trennendes zu überwinden.

Für die Bewohner des Warschauer Ghettos verlor die Brücke jene Bedeutung. Stattdessen war sie ein spektakulärer Beweis dafür, dass diese Menschen sich in einem absurden räumlichen Arrangement befanden. Die Brücken erinnerten sie an die demütigende Situation des Eingesperrtseins. Sie machten ihnen bewusst, dass jegliche Verbindungen zwischen dem Ghetto und der restlichen Welt durchtrennt werden sollten. Im Ghetto war die Brücke somit - gegenteilig zu ihrer sonstigen Bedeutung - ein Zeichen für Trennung und Freiheitsberaubung. Henryk Makower nennt sie „eine urbanistische Wunde im Antlitz Warschaus“:

Wie viele Male bin ich über die Brücke gegangen - 2 Stockwerke hinauf und 2 hinunter, durch eine hastende, immer dicht gedrängte Menge - [...] ich hörte nicht auf, mich zu wundern, dass so etwas möglich ist, dass ich mich daran gewöhnen konnte (S. 175).

Von der Brücke an der Chłodna-Straße sah man den Turm der Hl. Karl-Borromäus-Kirche, umgeben von Baumkronen, und unten den normalen, arischen Straßenverkehr. Die Nähe und zugleich Unerreichbarkeit der gewöhnlichen Welt wurden als Trauma empfunden. So erzählt der jüdische Dichter Josef Kirman seinem Sohn von der Brücke:

Nur mit mir, mit mir allein wolltest du auf die hölzerne Brücke steigen. Fragen über Fragen stelltest Du mir: Wie viele Stockwerke hatte die Brücke? Wie weit war es von der Brücke bis in den Himmel? Durfte man von der Brücke nach unten schauen? [...] Als du mich fragtest, ob ich nicht fürchte, dass die Brücke einstürzen könnte, griff ich danach wie nach einem rettenden Strohhalm. Ja, mein Kind, komm schnell weiter. Sie kann einstürzen, sie sollte es sogar ... [...] So oft ich die Brücke erklimme oder hinabsteige, so oft bitte ich Gott darum, diese hölzerne Brücke möge in ihre Einzelteile zerfallen. ${ }^{58}$

Die Menschen gehen vom engen, überfüllten, mit Mauern umgebenen Ghetto hinauf auf die Brücke, um den Anblick eines weiten, offenen Raumes in sich aufzunehmen. Von der Brücke über der Przebieg-Straße „erstreckt sich [...] der Blick über die Weichsel und Żoliborz. [...] [Ü]ber jene freie Welt" (Ringelblum, Bd. 1, S. 293). Die Brücke an der Chłodna-Straße nennt Jan Mawult ironisch „Seufzerbrücke“:

58 Text aus Archiwum Ringelbluma, op. cit. 
Tausende hängende Köpfe heben sich, begrüßen das Panorama von Chłodna- und Wolska-Straße, die Hallen und den Sächsischen Garten, die Wolkenkratzer am Napoleon-Platz, den Cedergren-Turm an der Zielna-Straße [Sitz der polnischen Tochter der schwedischen Telefongesellschaft Cedergren; Anm. d. Übers.], die Kreuze auf den Kirchtürmen und weit entfernt das Band der Weichsel. Seufzend sinken die Köpfer wieder, die Ghettobrücke - Ponte dei Sospiri (Seufzerbrücke) („Biuletyn ŻIH“ 62, S. 108). Vom Dach eines Altbaus, der an der Chłodna-Straße in der Nähe der Brücke steht, schaut Mary Berg „auf die Stadt hinter Mauern“ herab und träumt „von der weiten Welt, fernen Ländern, von der Freiheit“ (S. 159).

Eine andere alltäglich gewordene Absonderlichkeit waren das Gedränge und der Lärm auf den Straßen, die jede normale Fortbewegung unmöglich machten ${ }^{59}$. Das Motiv des Gedränges taucht in vielen Texten auf; das veränderte Aussehen der Straße war bestürzend und verlangte danach, notiert zu werden.

Auf den jüdischen Straßen - ein entsetzlicher Betrieb. Nicht nur der Gehsteig ist voller Menschen, sondern auch die ganze Fahrbahn. Dort hindurchzukommen ist sehr schwer,

schreibt Ringelblum (Bd. 1, S. 186), und bei Marek Stok lesen wir:

Tausende Elendsgestalten, Bettler hausen auf der Straße. [...] Sie sind überall. In Hinterhöfen, auf Gehsteigen, vor Mauern und auf der Fahrbahn hockend, sie klagen, schreien, bitten um ein Almosen (Pamiętnik z getta [Tagebuch aus dem Ghetto], S. 40).

Die verstopften Straßen werden zu einem Teil der Alltagserfahrung, an den verstümmelten Raum aber kann sich niemand gewöhnen. Die Straße - so schreibt Stanisław Różycki - „frisst“ Junge und Alte, Männer und Frauen, deklassiert und degradiert alle und jeden:

Ich sehe mich auf der Straße um. Ein ungeheurer Betrieb, ein Gebrodel, Gedränge, Gejammer und Gegreine, Gezanke ... Durch die Nadelöhre der einstigen Straßen, durch die schmalen Schläuche, die die beiden großen Teile des Ghettos miteinander verbinden, wälzen sich Tausende Menschen, ergießen sich Wellen von Passanten. Die Gehsteige reichen nicht aus, man muss die Fahrbahn mitnutzen, auf der ebenfalls sehr starker Verkehr herrscht. [...] Dreckig, dunkel, beengend, kalt, fremd (Bd. 2, S. 135).

59 B. Engelking widmet sich bei ihrer Schilderung des Alltagslebens im Warschauer Ghetto ausführlich dem Phänomen des ständigen Gedränges (Zagłada i pamięć. Doświadczenie Holocaustu i jego konsekwencje opisane na podstawie relacji autobiograficznych [Vernichtung und Gedächtnis. Die Erfahrung des Holocaust und seine Konsequenzen, dargestellt auf der Grundlage von biographischen Berichten], Warschau 1994, S. 85-87). Die Situation der pathologischen Einengung, die eine Dekomposition des gesellschaftlichen Raums und eine Zerschlagung der Privatsphäre bedeutet, nennt sie nach E.T. Hall (Die Sprache des Raumes; Düsseldorf 1976) - einen „Verhaltenspfuhl“. 
Aufgrund der enormen Überbevölkerung des Ghettos war die Regelung des Fußgängerverkehrs auf den Straßen eine der wichtigsten Aufgaben des Ordnungsdienstes. Das erwähnt Stanisław Adler; er widmet diesem Thema ein eigenes Unterkapitel in seinem Tagebuch. Besonders neuralgische Punkte in dieser Hinsicht waren die Karmelicka-Straße sowie die Kreuzung Chłodna-/ŻelaznaStraße.

Die schmale Karmelicka-Straße stellte bis zum Herbst 1941 die einzige Verbindung zwischen dem nördlichen und südlichen Teil des großen Ghettos dar. So beschreibt sie Makower:

Menschenmassen wälzen sich über den Gehsteig, drängen sich zwischen Rikschen, Straßenbahnen und Wagen auf der Fahrbahn. Es gibt kaum ein Durchkommen, besonders in Zeiten stärkeren Verkehrs wie am Nachmittag oder vor der Polizeistunde (S. 171),

und so Ringelblum in den Notitsn:

Das Zumauern des Straßenabschnitts Przejazd-Nowolipie hat die Situation auf der Karmelicka-Straße unerträglich gemacht. Es ist furchtbar eng dort, ein riesiger Betrieb (S. 141).

Auf der Karmelicka unbeschreibliches Gedränge. Über Gehsteige und auch Fahrbahn [wälzt sich] eine dichte Menschenflut; die Durchfahrt ist unerhört schwierig und zeitraubend (S. 196).

Die Karmelicka macht einen schrecklichen Eindruck. Es ist so dunkel dort, dass einer über den andern fällt (S. 242).

Genannt wurde sie „die Straße von Gibraltar“ oder „Todesschlucht“ (Ringelblum, Bd. 1, S. 217, 175). Auf ihrer gesamten Länge, besonders auf dem Abschnitt zwischen Nowolipie- und Leszno-Straße, wurden die Passanten notorisch geprügelt und malträtiert. Täglich fuhr ein SS-Lastwagen durch die Karmelicka bis zum Pawiak-Gefängnis. „Ein Gestapo-Mann auf dem hinteren Teil des Lastwagens lehnt sich in der engen Karmelicka-Straße hinaus und schlägt mit einer langen Peitsche mit einem Stück Blei am Ende der Schnur auf die Passanten ein“ (Ringelblum, Bd. 1, S. 377). Die Durchfahrten des deutschen „Geisterautos" schildert Henryk Bryskier und erläutert dabei zugleich das komplizierte Verkehrssystem auf der Karmelicka-Straße:

Auf der geraden Seite der Leszno-Straße gab es auf dem Abschnitt zwischen Przejazd und Żelazna-Straße drei Seitenstraßen, von denen die erste und die dritte durch die Mauer versperrt waren, offen war nur noch die Karmelicka-Straße [...]. Der ganze Fahrund Fußgängerverkehr wurde in diese eine Straße geleitet, wodurch sich ein grässliches Gedränge bildete. Das Vorwärtskommen der ganzen Menschenflut musste zwangsläufig sehr langsam vonstatten gehen; obwohl der Verkehr so geregelt war, dass man auf der geraden Straßenseite von der Leszno- zur Dzielna-Straße gelangte und auf der 
ungeraden in die Gegenrichtung, von der Dzielna- zur Leszno-Straße. Die Straßenmitte war für gewöhnlich von Rikschen und Wagen vollkommen blockiert (BŻIH 67, S. 121).

Die Kreuzung von Chłodna- und Żelazna-Straße, die das kleine mit dem großen Ghetto verband, war stets von massenweise Passanten belagert. Es bildeten sich Staus und Warteschlangen, Möglichkeit, die Fahrbahn zu überqueren, musste man lange warten. Juden, die durch diesen Engpass von einem Teil des Ghettos in den anderen gelangen wollten, waren Schikanen und Schlägen ausgesetzt. Der Durchgang wurde auch „die Dardanellen“ (Ringelblum, Bd. 1, S. 217) oder „bei Skylla und Charybdis“ (Adler, S. 115) genannt. Das Verkehrssystem war hier besonders kompliziert. Durch die Chłodna-Straße, und nach der neuen Grenzziehung im Herbst 1941 auch durch einen Teil der Żelazna-Straße, floss der arische Verkehr. Mal war die eine, mal die andere Straße durch bewegliche eiserne Tore versperrt, die Menschen und Fahrzeuge anhielten oder passieren ließen. In einer poetischen Aufzeichnung von der anderen Seite der Mauer, aus der Feder Miron Białoszewskis, verwandelt sich die ganze eigentümliche Maschinerie in ein biblisches Tor, das das auserwählte Volk - das auf den Durchzug wartet - vom Rest der Welt trennt.

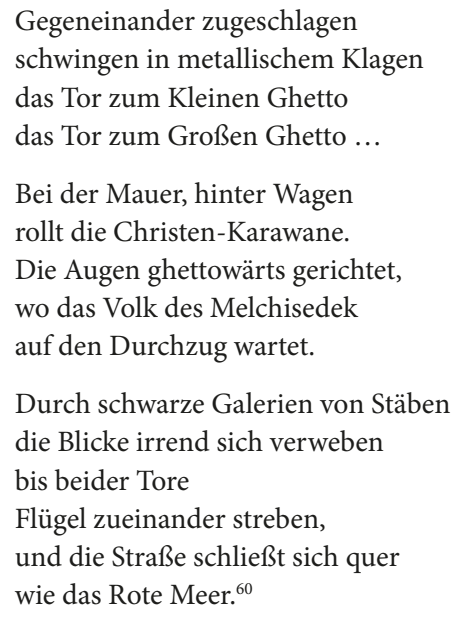

Die Topographie des geschlossenen Bezirks widersprach jeglichem gesunden Menschenverstand. Die Grenzen trennten das Ghetto nicht nur vom übrigen

60 Erstabdruck in: „Akademik“, Warschau 1946, Nr. 14/19. Zitat nach: Męczeństwo i Zagłada Żydów w zapisach literatury polskiej. Antologia [Märtyrertum und Vernichtung der Juden in Aufzeichnungen der polnischen Literatur. Anthologie], bearb. von I. Maciejewska, Warschau 1988, S. 140; dt. Übers. hier von mir, Anm. d. Übers. 
Warschau, sondern waren zudem eine weitere perfide Schikane, eingerichtet zur Plage der jüdischen Bevölkerung. In einem „irren Zickzack“ - wie Stanisław Adler schreibt (S. 34) - verliefen sie mitten durch die Stadt. „Die Straßenausgänge sind verschlossen“, berichtet Wanda Lubelska ihrer Freundin aus dem Stadtteil Żoliborz in einem Brief, „häufig muss man, wenn man nur ein paar Häuser weiter will, einen Umweg außen herum über mehrere Straßen nehmen“ (S. 154). Die durch den Grenzverlauf erzwungenen Verkehrswege innerhalb des Ghettos nahmen manches Mal absurde Form an.

Die Mauern - notiert Chaim Kaplan in seinem Tagebuch - versperrten die bis dahin betriebsamsten Straßen. So wurde zum Beispiel an der Ecke Nowolipki- und NalewkiStraße eine Mauer errichtet; ein Bewohner der Nalewki-Straße 2 musste nun, um zum Haus Nowolipki-Straße 5 zu gelangen (früher eine Sache von wenigen Schritten), über verschlungene Wege etwa eine halbe Stunde laufen, und zwar über die Nowolipki-, Zamenhof-, Gęsia- bis zur Nalewki-Straße. Genauso verhält es sich bei der Rymarska-, der Leszno- und mehreren weiteren Straßen (BŻIH 50, S. 111-112).

Ein weiteres Beispiel topographischer Verirrung, die den Ablauf des täglichen Lebens der Ghettobewohner störte, gibt Ringelblum:

Am 22. Dezember [1941] wurde es den Juden plötzlich verboten, die Sienna-Straße direct zu verlassen. Es gab nur einen Weg - über die angrenzende Śliska-Straße. Diesen Weg zu nehmen war aber nicht überall möglich, es war vonnöten, einige Häuserwände einzureißen, um auf die Śliska-Straße zu gelangen. Manch einer musste somit durch Maueröffnungen, Keller usw. kriechen (Bd. 1, S. 347).

Das bisher bestehende Stadtbild wurde zerschlagen, die Menschen wurden aus ihrem bekannten, sicheren, eigenen Umfeld hinausgedrängt. Das Ghetto wurde zur Domäne der Entfremdung. Stanisław Różycki schildert seine Verlorenheit im fremden Raum des Ghettos wie folgt:

Ich trete auf die Straße hinaus. Zunächst starre ich alles und alle mit den Augen eines Reisenden aus fernen Landen bei der Besichtigung exotisch und exzentrisch wirkender Stadtteile an. Was ist mit mir geschehen? Ich kenne doch jede Straße hier, fast jedes Haus, jeden zweiten Menschen, und dennoch erkenne ich Straßen und Menschen nicht. Ich weiß nicht, auf welcher Straße ich mich befinde, ich kann den Weg zu meinem Haus nicht finden (Bd. 2, S. 134).

Unentwegt neu errichtete, ausgebaute, versetzte und reparierte Mauern riegelten den beständig kleiner werdenden und die Bewohner beengenden Ghettoraum ab. „[Mauern] wachsen unvermittelt an den verschiedensten Stellen empor, verschließen Straßen“, notiert Marek Stok (Pamiętniki z getta [Tagebücher aus dem Ghetto], S. 27). Mary Berg sagt das Gleiche: „Rote Backsteine türmen sich 
höher und höher auf [....] Von allen Seiten mauert und schließt man uns ein“ (S. 133). Einen Monat vor Beginn der Deportationen ist die Mauer fast fertiggestellt. Chaim Kaplan beschreibt unter dem Datum des 22. Juni 1942 die letzte Etappe der Einmauerung. Damals wird bereits der letzte Abschnitt der zusammenhängenden Mauerlinie errichtet, entlang der Muranowska-Straße, zwischen Bonifraterska- und Pokorna-Straße; wenn jenes Mauerstück gebaut ist, wird die Mauer den jüdischen Bezirk vollständig umschließen. In Kaplans Aufzeichnungen lässt sich eine symbolische Dimension ausmachen. Die Arbeiten enden, als der Mauerring sich endgültig um das Ghetto zusammenzieht wie die Schlinge um den Hals des Verurteilten.

An den Grenzen, die nach dem Plan ihrer Errichter das Ghetto dauerhaft und endgültig vom Rest der Stadt abschneiden sollten, wurden fast ununterbrochen Veränderungen und Korrekturen vorgenommen. Auch das war eine Tortur, der man die Bewohner unterzog - die daher von der ständigen Angst begleitet wurden, dass gerade ihr Haus, ihre Straße oder auch Straßenseite vom Ghetto ausgeschlossen werden würden. Durch die Grenzänderungen wurden Umzüge erzwungen, die für stetige Unruhe sorgten und Menschen samt ihrer Habe von Ort zu Ort ziehen ließen. Bereits am 24. Oktober 1940, also vor der Abriegelung des Ghettos, schrieb Kaplan: „Die Qualen, die mit der Einrichtung des Ghettos einhergehen, sind vielleicht schlimmer als das Ghetto selbst. Stündlich werden bezüglich des einen oder anderen Gebietes Änderungen vorgenommen" (Buch der Agonie, S. 252).

Im August 1942 wird das kleine Ghetto liquidiert und die Menschen nach Treblinka deportiert oder ans nördliche Ende der Leszno-Straße im großen Ghetto verlegt. Im September, nach der großen Liquidierungsaktion, blieb innerhalb drastisch verengter Grenzen das sogenannte Restghetto übrig, und in ihm ein paar vereinzelte „Shops“ - von Holzzäunen umgrenzte kleine Arbeitslager. Zwischen den Shops erstreckte sich ein verwilderter, wie ausgestorbener Raum, den man nicht betreten durfte. Die ehemals überfüllten Straßen waren jetzt menschenleer. Offene Fensterhöhlen von Wohnungen, in Hinterhöfen und auf Gehsteigen verstreute Habseligkeiten von Deportierten, Federn aus zerrissenem Bettzeug. Leere. Ein Verbot, sich während der Arbeitszeiten auf den Straßen aufzuhalten, wurde erlassen. Auf Passanten wurde ohne Vorwarnung geschossen. Durch das Restghetto bewegten sich nur organisierte Arbeiterkolonnen, Funktionäre des Ordnungsdienstes und Wagen zum Abtransport von Leichen. Doch selbst zu jener Zeit waren die Grenzen, innerhalb derer die Lebenden versammelt worden waren, nicht stabil. Eine Aufzeichnung von Stanisław Sznapman handelt vom Ende des Jahres 1942: 
Um das Gelände des Shops zu verkleinern, bauen sie eine neue Mauer, gleichzeitig reißen sie die alte ab. Und so geht es immer weiter. Mauerbau, Mauerabriss, Umzüge, Deportationen. Das ist das 20. Jahrhundert (Pamiętniki z getta, S. 142).

Um ein Minimum an notwendigen Verkehrswegen aufrechtzuerhalten, begannen die Ghettobewohner, versteckte Durchgänge zwischen Kellern und Dachböden benachbarter Häuser anzulegen. Das bildete die Grundlage für das Netz von unter- und oberirdischen Geheimwegen, die später während des Ghettoaufstands genutzt wurden. Die Bausubstanz des Ghettos erinnerte mit ihren unzähligen Durchschlupfen, Gängen, Verkehrspfaden auf den unterschiedlichsten Ebenen - von Dächern bis zu Kanälen - an einen Schwamm. Der gleiche Prozess weitete sich während des Warschauer Aufstands 1944 auf das ganze Stadtgebiet aus.

Endgültig vernichtet wurden die Straßen und Häuser im Feuer des Aufstands. Der Raum des Ghettos verlor damals jegliche Merkmale einer wie auch immer gearteten - selbst der irrsten - Ordnung. Er verwandelte sich in ein Chaos aus Schutt und rauchenden Trümmern, unter denen noch lange Zeit in Bunkern verborgenes Leben schwelte.

Der Schutt stellte für die Deutschen jedoch nach wie vor einen großen Wert dar. Man beschloss also, die Brandstätte bis zum Letzten zu nutzen, sie erst danach dem Erdboden gleichzumachen und an der Stelle einen weitläufigen Park anzulegen. Die Topographie des Ghettos wurde somit einer weiteren Metamorphose unterzogen, und der Prozess der räumlichen Zerstörung trat in eine neue Phase ein. Im Sommer 1943 wurde auf den Ruinen ein Konzentrationslager gegründet; dieser Plan wurde von General Stroop in seinem Bericht über die Erstickung des Aufstands erstmals zur Sprache gebracht und von Himmler für gut befunden. Die Häftlinge sollten - wie Stroop schrieb - „die Millionen von Backsteinen, den Eisenschrott und andere Materialien aus[...]bauen, [...] sammeln und der Verwertung zu[...]führen ${ }^{\text {“61 }}$. Das Gelände des Lagers nahm ein Gebiet ein, das sich entlang fast der gesamten Gęsia-Straße erstreckte, d.h. von Zamenhof- bis Okopowa-Straße. Es reichte vom Gefängnis in der ehemaligen Kaserne der Kronartillerie an der Kreuzung Gęsia-/Zamenhof-Straße (der sog. Gęsiówka) bis zur Mauer des Friedhofs an der Okopowa-Straße. Das Lager wurde zu einem Unterlager von Majdanek; es war (neben Majdanek und

61 Zitat aus: J. Stroop: „Es gibt keinen jüdischen Wohnbezirk in Warschau mehr“, Warschau, 16. Mai 1943, in: Die Verfolgung und Ermordung der europäischen Juden durch das nationalsozialistische Deutschland 1933-1945, Bd. 9. Polen: Generalgouvernement August 1941-1945, bearb. von K.-P. Friedrich, München 2014, S. 656; Anm. d. Übers. 
Plaszów bei Krakau) eines der insgesamt drei Konzentrationslager im Gebiet des Generalgouvernements.

Am 5. August 1944 wurde das Lager auf den Ghettoruinen von Aufständischen des Bataillons „Zośka“ eingenommen. Sie befreiten rund 350 Gefangene - ausländische Juden. Auch Michael Zylberberg befand sich darunter. So beschreibt er seine Wanderschaft durch die befreiten Ruinen des Ghettos im aufständischen Warschau:

Wir betraten das Ghetto über den Krasiński-Platz und gingen weiter durch holprige Gassen, bis wir die Zamenhof-Straße erreichten. Die geradezu fühlbare Stille, der grauenvolle Anblick der Ruinen versetzten sogar meinen Begleiter in Angst und Schrecken. Wir sahen keine lebende Seele. [...] Ich suchte nach der Miła-, der Muranowska-, der Nalewki-Straße - alles ein einziger Trümmerhaufen. Die Miła-Straße war im schlimmsten Zustand. Kein Durchkommen. Inmitten der Ruinen ragte das ausgebrannte Skelett des Gebäudes auf, in dem zuletzt der Judenrat seinen Sitz gehabt hatte - ZamenhofStraße 31. Wir gingen einfach durch das zerstörte Haustor hinein. Das Gebäude, vor dem Krieg ein Militärgefängnis, besaß ein ganzes System von Hinterhöfen. Wir betraten jeden einzelnen von ihnen. Im dritten entdeckten wir etwas, das vom jüdischen Aufstand übriggeblieben sein musste: einen Haufen Knochen und Asche an einer Seite des Hofes. Man konnte sich leicht denken, was sich hier zugetragen hatte (S. 168-169).

Januar 1945 befand Zylberberg sich wieder auf dem Gelände des Ghettos - eine gigantische Grabstätte aus Gesteinstrümmern, die ihm ausgestorbener vorkam als ein Friedhof. Die Substanz der Stadt war endgültig vernichtet worden und zerfiel zu Staub, ohne eine erkennbare Spur ihrer alten Existenz zu hinterlassen.

Ich beschloss, meinen Ausflug in den Stadtteil Praga zu verschieben und stattdessen für mich allein zu den Ruinen des ehemaligen Ghettos zu pilgern. Es war still wie in einem Grab. Das ganze Gelände war von einer dicken Schicht Schnee bedeckt. Sein Weiß, das doch eigentlich ein Symbol der Reinheit sein sollte, erfüllte mich mit Grauen. Unter diesem Weiß wogte ein Meer von unschuldig vergossenem jüdischem Blut. Ich irrte ziellos durch die Ruinen, stieß auf kein einziges Anzeichen dessen, was hier früher existiert hatte. Es war unheimlich und erschreckend. Unversehens fand ich mich an der Stelle wieder, wo einst der Friedhof an der Gęsia-Straße gewesen war. Ein Gefühl der Erleichterung ergriff mich. [...] Es schien mir, als seien alle hier beerdigten Menschen, alle, die im Ghetto gewesen waren, zum Leben zurückgekehrt. Auch ich kam wieder zu mir, fühlte mich fast beschwingt, es ging mir hier um einiges besser als zwischen den schweigenden Ruinen. Die Friedhofsmauer war niedergerissen worden wie die Grenze zwischen zwei Welten - zwischen Leben und Tod (S. 211-212).

Die Häuser und Straßen, in denen sich die Menschen des geschlossenen Bezirks bewegten, existieren nicht mehr. Wie unvergleichlich leichter fällt es aber, sich in Gedanken das Bild eines niedergerissenen Altbaus auszumalen, als sich vorzustellen, wie die Menschen von damals jenen abgeschnittenen und für sich 
stehenden Raum empfunden haben mussten. $\mathrm{Zu}$ verstehen, dass es eine eigene Semantik des Ghettoraumes gab, ist die Bedingung für eine sinnvolle Antwort auf die Frage: Wo schrieben die Autoren der überlieferten Zeugnisse ihre Texte?

3

Tagebuch über ihr Leben innerhalb der Ghettomauern führten Czerniaków, Kaplan, Levin, in Teilen auch Mary Berg; Ringelblum schrieb seine Notitsn, Korczak seinen Pamiętnik [Tagebuch aus dem Warschauer Ghetto]. Adam Czerniaków, der Vorsitzende der Jüdischen Gemeinde, schrieb in der Nächten in seiner Wohnung in der Elektoralna-Straße 11 und später, vom 13. Dezember 1941 an, in der Chłodna-Straße 20. Er versuchte, sich möglichst nie von seinen Notizen zu trennen, trug kleine Hefte in schwarzen Wachstuchumschlägen bei sich, in die er laufend mit hastiger und schwer entzifferbarer Schrift die aktuellen Geschehnisse eintrug. Das fünfte dieser Notizhefte, mit Aufzeichnungen vom 14. Dezember 1940 bis zum 22. April 1941, ist verloren gegangen; es wurde dem Autor wahrscheinlich bei seiner Verhaftung im April 1941 von der Gestapo abgenommen. Avrom Levin wohnte in der Mylna-Straße 2, die an dieser Stelle mit der Przejazd-Straße zusammenlief. Entlang der Przejazd-Straße verlief die Grenze. Schaute Levin beim Schreiben aus dem Fenster, sah er die Mauer - und in der Mauer ein Loch, durch das Schmuggler Säcke schoben. Dieses Loch wurde in schöner Regelmäßigkeit zugemauert und ebenso regelmäßig mit großem Fleiß wieder in die Mauer gehauen. Emanuel Ringelblum hörte draußen vor dem Fenster seiner Wohnung in der Leszno-Straße 18 vor Hunger schreiende Kinder. In Henryka Lazertównas Wohnung drang durch die Fenster der unablässige Tumult des Ghettos. „Die Straße. Auch jetzt, wo ich an Dich schreibe, ist sie mit mir hier im Raum", gab sie ihre Eindrücke in einem Brief an Roman Kołoniecki weiter, skizzierte eine ganze Galerie singender, klagender, vor Hunger stöhnender Bettler. Auffallend an diesem Bild ist die nahezu aggressive Gegenwart der lärmenden, schreienden Straße im Zimmer der Schreibenden, das Gefühl der Einkesselung und zugleich Durchdringung.

Das Zuhause war ein fester Punkt im Ghettoraum, mit dem die Situation des Schreibens verknüpft wurde. Obwohl die Realität alles bisher Erlebte überstieg, schienen die Bedingungen, unter denen es festgehalten wurde, doch - sozusagen - traditionell, geradezu klassisch: Der Tagebuchschreiber kommt nach einem Tag voller Eindrücke von der Straße in seine Wohnung und schreibt auf, was er gesehen und gehört hat.

Hunderte Juden geprügelt und verletzt, Dutzende ermordet - das ist die Ernte nur eines Tages. Ich habe es mit eigenen Augen gesehen, ich komme eben von dort zurück und 
kann mich kaum beruhigen! In so einem Seelenzustand fällt es schwer, zur Ruhe zu kommen, die Feder zur Hand zu nehmen,

notiert Chaim Kaplan am 2.5.1940 (BŻIH 50, S. 107). Haus und Straße sind die beiden grundlegenden Gemeinschaftsbereiche des Ghettos. Die Straße ist ein öffentlicher Raum, in dem sich das Leben des Bezirks konzentriert, ein Ort des Waren- und Informationsaustauschs, eine Arena der aktuellen Ereignisse. Das Haus ist ein privater Raum, der bis zu einer bestimmten Zeit noch die Illusion eines geschützten Bereichs und eine Art imitierte Privatsphäre bieten kann ${ }^{62}$. Seit Beginn der Besatzung wurden die Juden selbst in ihren Häusern von den Deutschen verfolgt und ungestraft ausgeraubt. Zudem mussten sie, aufgrund der Überbevölkerung im Ghetto, die beschwerliche Anwesenheit von Untermietern ertragen. Daher waren sie selbst in ihren Wohnungen selten wirklich „bei sich zu Hause“.

Das Schreiben fand demzufolge in einer beständig schrumpfenden und fortwährend gestörten Privatsphäre statt. Auch lässt sich die häusliche Situation der Schreibenden kaum als stabil bezeichnen. Ständig drohte der Umzug. Bei einem Wohnungswechsel veränderte sich die nächste Umgebung. Ein anderes Haus, andere Zimmer, ein anderer Blick aus dem Fenster. Andere Möbel, meistens von fremden Menschen. Unter diesen Bedingungen fiel es schwer, die Distanz eines Beobachters, der von einem festen Punkt aus den Strom der Ereignisse an sich vorbeiziehen lässt, herzustellen und aufrechtzuerhalten. Die Realität vor dem Fenster gestattete keine passive Beobachtung, sie drang auch in die intimsten Bereiche ein, während die Aufenthaltsorte der Schreibenden in immer rascherer Folge wechselten und zunehmend flüchtig und zufällig wurden.

Korczak schrieb sein Tagebuch noch an nur einem Ort: im Dom Sierot, dem Haus der Waisen, das sich damals im Gebäude der Gesellschaft der Handelsarbeiter in der Sienna-Straße 16, Ecke Śliska-Straße 9 befand - was wohlgemerkt bereits die dritte Adresse war. Vom Altbau in der Krochmalna-Straße 92, der 1912 eigens für das Haus der Waisen errichtet worden war, mussten die

62 Ausführlich über Straße und Zuhause im Ghetto schreibt Różycki. Im RingelblumArchiv sind lediglich seine Reportagen vom Februar und März 1942 erhalten: Obrazki uliczne $z$ getta [Straßenbilder aus dem Ghetto] (Ring I, 428). Der Autor weist auf die große Bedeutung des gemeinschaftlichen Aspekts des häuslichen Lebens im Ghetto hin (Hauskomitees, Feiern, Nachbarschaftshilfe). Unter den polnischsprachigen Dokumenten im Ringelblum-Archiv befinden sich außerdem die Thesen eines unbekannten Autors zu einer Monographie über die Straße im Ghetto (Ring I, 135) und eine 23-seitige Studie über das jüdische Straßenleben im Ghetto, ebenfalls von einem unbekannten Autor (Ring I, 154). 
Heimbewohner im November 1940 in den Stadtteil hinter die Mauer umziehen, in das Gebäude der Roesler-Handelsschule an der Chłodna-Straße 33. Im Oktober 1941 folgte dann der Umzug von der Chłodna- in die Śliska-Straße. Und im August 1942 von der Śliska-Straße nach Treblinka.

Korczak schrieb überwiegend nachts: „In dieser nächtlichen Stille (es ist zehn Uhr) will ich den heutigen Tag überdenken, einen - wie ich schon sagte arbeitsreichen Tag" (S. 53) - hinter einem Paravent, der seinen Schlafbereich vom Schlafsaal der Kinder trennte, umgeben von den Seufzern der Schlafenden und dem Geräusch hallender Schüsse auf den Straßen:

Zehn Uhr. Schüsse: zwei, mehrere, zwei, einer, mehrere. Vielleicht ist ausgerechnet mein Fenster schlecht verdunkelt.

Aber ich unterbreche meine Notizen nicht.

Im Gegenteil: lebendiger (ein einzelner Schuß) werden die Gedanken. (S. 107)

Er war bei sich im Zimmer, hatte einen schreibbereiten, mit Tinte gefüllten Federhalter, Papier und eine Karbidlampe, die hin und wieder erlosch und das Schreiben unmöglich machte: „Moszek hat wieder zu wenig Karbid nachgefüllt. Die Lampe verlischt. Ich muss unterbrechen. (S. 34).“ Auch hatte er etwas Spiritus, mit dem er sich stärken konnte: „Fünf Gläschen Spiritus, halb und halb mit heißem Wasser, bringen mich in Stimmung" (S. 52).

Mit jener Szenerie des nächtlichen Schreibens schuf Korczak sich, selbst wenige Tage vor dem Gang zum Umschlagplatz, ein Asyl der Ruhe und Sicherheit:

So still ist es hier und so sicher. Ja, sogar sicher - denn ich glaube nicht, daß Besuch von draußen kommt. Gewiß, es könnte so ein Besuch kommen, wie zum Beispiel eine Feuersbrunst, ein Luftangriff, ein über meinem Kopf herabstürzender Verputz. Aber schon allein der Ausdruck „Gefühl der Sicherheit“ beweist, daß ich mich subjektiv wie der Bewohner eines weit abgelegenen Hinterlandes fühle. Wer die „Front“ nicht kennt, kann das nicht verstehen.

Ich fühle mich wohl und will lange schreiben, bis zum letzten Tropfen Tinte in meinem Federhalter (S. 54).

Die Deportation zerschlug endgültig jeden Anschein von Stabilität, riss alle aus ihrer bisherigen Umgebungen. Levin fand sich in der Gęsia-Straße 30 wieder, im Shop der OBW (Ostdeutsche Bautischlerei-Werkstätte, Produktion von Möbeln und Truhen). Die Arbeiter des Shops waren in Wohnblocks an der Miła-Straße untergebracht. Im Gebiet zwischen Gęsia- und Miła-Straße führte Levin weiterhin Tagebuch. Ringelblum war formal in Hallmanns Tischler-Shop an der Nowolipki-Straße 68 eingetragen. Dort führte er seine Dokumentationsarbeit über das Ghetto weiter, hielt seine Notitsn fest. Und dort wurde auch das Ghettoarchiv 
vergraben. Leizor [Leizer, Lejzor] Czarnobroda, der wie alle bei der Großaktion verfolgt wurde, beschreibt seine Situation in seinem Tagebuch so:

Ich schreibe in der Fabrik, versteckt in einer Ecke, an dem einzigen Ort, wo wir noch bleiben dürfen. [...] Ich weiß nicht, ob ich überleben werde. Höchstwahrscheinlich erklingt hier schon eine Stimme aus dem Grab. Ein Pogrom ist im Gange. [...] Ich schreibe nur unter Schwierigkeiten (Archiwum Ringelbluma, S. 112-113).

Der Aufstand trieb diejenigen, die noch im Ghetto geblieben waren, unter die Erde: in Keller, Bunker, in Höhlen, die sie sich in den Trümmern gruben. Menschen versteckten sich zusammengepfercht zwischen den aufgeheizten Kellerwänden brennender Häuser. Über sich hörten sie Schüsse hallen und die Schritte der die Trümmer durchsuchenden Deutschen.

Im Archiv des Jüdischen Historischen Instituts befindet sich unter der Signatur 39 in der Gruppe „Pamiętniki“ [Erinnerungen] ein ungewöhnliches Dokument: die Photokopie von 15 herausgerissenen Schulheftseiten, bedeckt mit winzig kleiner Schrift. Die grammatischen Formen verraten, dass die Niederschrift von einer Frau stammen muss [im Polnischen lässt sich an den Verben in der Vergangenheit und an den Adjektiven die Geschlechtszugehörigkeit des/ der Schreibenden erkennen; Anm. d. Übers.]. Darüber hinaus ist nichts bekannt. Jene paar Seiten sind Teil eines weitaus größeren Ganzen, weisen sie doch die Seitenzahlen 319-334 auf. Eine Anmerkung auf Seite 322 lautet: „Im Versteck. 23/IV [1943]“. Der Text muss somit während des Aufstands in irgendeinem Bunker entstanden sein. Unter dem Datum „27/IV“ deckt die Verfasserin die Umstände ihres Schreibens auf:

Mein Schreiben ist nun ungeordnet, da ich nur schreibe, wenn ich Licht habe - ich lebe schließlich jetzt überwiegend in der Dunkelheit des Kellers -, und wenn ich meine herumwirbelnden Gedanken einigermaßen fassen kann (S. 8).

Die Aufzeichnungen wurden laufend geführt, bis zur letzten Minute, bis der Bunker entdeckt wurde. Dann reißt das Tagebuch mitten im Satz ab, mitten in einer panischen Notiz, die das Entsetzen über die Entdeckung des Verstecks und die Geräusche der eindringenden Deutschen beschreibt. Der Rest der Seite ist leer. Das Heft gelangte vom brennenden Ghetto nach Majdanek, wo seine Reste gefunden wurden.

Etwas mehr wissen wir über eine Autorin namens Stefa („Pamiętniki“, Sign. 180), die sich während der Aufständischenkämpfe in einem Bunker an der Wołyńska-Straße 6 und in den Trümmern ringsum versteckt hielt. In ihrem Manuskript finden sich zwei Daten: der 6. Mai 1943 und der 13. Mai 1943. Die Aufzeichnungen brechen Ende Mai 1943 ab; Stefas weiteres Schicksal ist nicht bekannt. Wo der Text genau entstand, lässt sich nicht endgültig festlegen. 
Vielleicht zum Teil im Bunker und zum Teil auf der arischen Seite Warschaus, falls es der Verfasserin gelungen sein sollte, dem Ghetto zu entkommen? Ihre Aufzeichnungen enthalten Korrekturen in einer anderen Tinte und wahrscheinlich auch anderen Handschrift. Es bleibt die Frage: Wer hat sie korrigiert und unter welchen Umständen? Konnte Stefa den Mauern lebend entkommen, oder haben nur ihre Notizen überlebt? Vielleicht war die Szenerie, in der sie schrieb, der überfüllte Bunker an der Wołyńska-Straße, vielleicht war es auch das Versteck in den Trümmern unter dem Wellblech eines eingestürzten Daches, wo sie lange Stunden verbrachte. Ferner wissen wir nicht, ob der unbekannte Autor, der seinen Text wie folgt betitelte: „W nocy na dzień $18 . \mathrm{V}$ śmiertelna cisza ulicy“ [In der Nacht zum 18.5. Todesstille auf den Straßen] („Pamiętniki“, Sign. 228) und sich dabei im Datum irrte - es handelte sich nämlich um den April, nicht Mai seine Aufzeichnungen wirklich im Versteck in der Zamenhof-Straße 35 anfertigte, wo er sich während der 23 Tage des Aufstands verbarg. Wir wissen nur, dass er gefasst und auf den Umschlagplatz gebracht wurde. Der Text reißt mitten in der Beschreibung der sich dort ereignenden makabren Szenen ab. Hier verliert sich auch die Spur des Autors. Was bleibt, sind nur die beschriebenen Blätter Papier.

An der materiellen Substanz des Ghettos, und auch an dessen Bewohnern, vollzog sich eine langsame Degradierung, die bis zur völligen Vernichtung ging. Menschen und ihre Orte wurden ausgelöscht. Die Zerstörung des Raumes verlief etappenweise, analog zu den Etappen der Vernichtung der Bevölkerung, die ihn bewohnte. Zunächst erfolgte eine Verdichtung, dann die Zerschlagung der bisherigen Strukturen, darauf die schrittweise Zerbröselung, Ausdünnung. Indem man die alte Ordnung in ein Chaos verkehrte, wurde alles, was bis dahin beständig war, hinweggefegt von einem Element der Unbeständigkeit - bis schließlich der Moment der völligen Vernichtung gekommen war ${ }^{63}$.

Die jenem Prozess übergeordnete Typologie der Situation und der Umstände des Schreibens im Ghetto enthüllt eine charakteristische Entwicklungsrichtung: vom Schreibtisch in der eigenen Wohnung über ein improvisiertes Eckchen in einem fremden, überfüllten, zu irgendeinem Shop gehörenden Zimmer

63 Das Ausmaß der Zerstörung des Ghettoraumes lässt sich am vollständigsten erfassen, wenn man eine Luftaufnahme, die am 24. September 1939 von der Luftwaffe gemacht wurde (zur Einsicht in den Sammlungen des Hauptstadtarchivs in Warschau), mit einem Photo vergleicht, das die sowjetischen Luftkräfte im Juni 1945 anfertigten (zur Einsicht in den Sammlungen des Jüdischen Historischen Instituts). Beide photographischen Landkarten wurden nebeneinander in der Zeitschrift „Polska-Izrael“, 1993, Nr. 2 veröffentlicht. 
bis hin zu zufälligen Schlupfwinkeln oder sorgsam vorbereiteten Bunkern. Die Richtung ist deutlich erkennbar - ein Weg nach unten, unter die Erde. Das Leben mit seiner Domäne des offenen Raums führt auf den Tod zu, auf das, was in der Erde vergraben liegt. Somit befindet sich das Schreiben in direkter Nachbarschaft zum Tod. Diese Nähe ist sowohl im übertragenen Sinn zu verstehen, schwebt doch der Schreibende in ständiger Todesgefahr, als auch im wörtlichen Sinne als unmittelbare Nachbarschaft. Dr. Izrael Milejkowski weist den Friedhof als den Ort aus, an dem seine wissenschaftliche Abhandlung über die Hungerkrankheit entstand. Die Umstände des Schreibens nehmen in diesem Moment eine symbolische Dimension an:

Eine charakteristische Besonderheit darf nicht außer Acht gelassen werden: Die Anordnung und Beschreibung des Forschungsmaterials geht in einem der Friedhofsgebäude vor sich - was symbolisch für den Hintergrund und die Bedingungen stehen mag, unter denen wir leben und arbeiten (S. 99).

4

Im Versteck auf der arischen Seite schrieb, wer den Mauern glücklich entkommen war. Die Grenze sollte, außer in wenigen streng reglementierten Ausnahmesituationen, für die Ghettobewohner unübertretbar sein. Dennoch wurde sie immer wieder überschritten. Die Berührung der beiden Räume - des arischen und des Ghettoraumes - schuf eine eigene Zone, die weder zu der einen noch zu der anderen Seite gehörte. Das waren Knotenpunkte, Übergangsorte - im wörtlichsten wie auch zutiefst metaphysischen Sinn des Wortes „Übergang“.

Sämtliche Flüchtlinge und Deportierte, die im geschlossenen Bezirk eintrafen, mussten die „Schwelle zum Ghetto “ überschreiten - das heißt, eine Quarantäne in der Leszno-Straße 109 durchlaufen, in unmittelbarer Nähe zur Mauer. „Die Quarantänestation Leszno 109 stellt die Schwelle zum Ghetto dar. Alles, was ins jüdische Warschau hinein- oder hinausgeht, durchläuft diese Institution“, lesen wir im anonymen Bericht eines Mitarbeiters der Station (Ring I, 143, S. 2). Das Gebäude Leszno-Straße 109 wurde zum Tor, durch das die Juden, noch voller Glauben und Hoffnung, in eine unbekannte Welt eintraten. Sein Eintreffen in der Quarantänestation beschreibt ein unbekannter Autor, der von Jeziorna bei Warschau hergebracht worden war:

Allein der Anblick des modernen Gebäudes, das vor uns aus dem nächtlichen Dunkel auftaucht, weckt in uns die Hoffnung, dass uns dort, hinter dieser Tür, ein guter Empfang erwarten möge, wenigstens ein warmes Wort zur Begrüßung (Ring I, 22, S. 1).

Die Mauer trennte Welten und wurde damit sozusagen zu einer eigenen Welt; die Durchlässe im Mauerwerk und die an ihnen hängenden menschlichen 
Schicksale bilden eine eigene Geschichte. Durch jene Spalten der Existenz ging der Schmuggel vonstatten. Mojżesz Passenstein - der Autor einer im Versteck auf arischer Seite verfassten Abhandlung über den Schmuggel im Warschauer Ghetto - beschreibt die Gestalt jener Löcher genau:

Geschmuggelt wird durch Öffnungen, die direkt am Boden in die Mauer geschlagen und oftmals noch durch Aushöhlung des Bodens vertieft werden. [...] Öffnungen mit einem Durchmesser von einem halben Meter, die häufig mit lose aufeinandergeschichteten Ziegelsteinen und Erde getarnt wurden, waren bei den Schmugglern besonders beliebt. [...] Die Hauptöffnungen - hinsichtlich der Intensität des Warenverkehrs befanden sich bei der Zegarmistrzowska- [...], der Przejazd- (Mostowski-Palast) und der Leszno-Straße (Post, Finanzministerium) (S. 47).

Die Mauer selbst war trotz allem (vor allem während des Aufstands und in der Zeit danach) nur selten die Übergangsstelle zur arischen Seite. Über die Mauer bei der Bonifraterska-Straße entkamen Leon Najberg, der später in Żoliborz seine Erinnerungen aufschrieb, und seine Gefährten.

Der offizielle Weg, das ummauerte Gebiet zu verlassen, führte an den Wachposten bei den Eingängen vorbei. Schmuggelnde Kinder stahlen sich dort hinaus auf die andere Seite, wenn der Gendarm nicht hinsah oder ihnen eine besondere Gnade erwies. An diesen Stellen ging der große Schmuggel vonstatten; unter Mithilfe von bestochenen Gendarmen und Polizisten verkehrten Transportfahrzeuge und Lastwagen. Bei den Ghettoeingängen fand auch „Menschenschmuggel“" statt.

Polen wollten ins Ghetto eingelassen werden - schreibt Passenstein -, um dort industrielle Artikel zu kaufen und sie auf die arische Seite zu exportieren. Juden wiederum wollten das Ghetto verlassen, um für immer oder auch für kurze Zeit auf die arische Seite zu gelangen; im letzteren Fall, um ihre Waren zu verkaufen oder Produkte fürs Ghetto einzukaufen. Der Menschenverkehr fand nach Einbruch der Dunkelheit statt, wenn semitische Gesichtszüge den Deutschen nicht so ins Auge sprangen und Juden keine Erpressung durch „szmalcownicy“ [„,Schmalzowniks“; Menschen, die Juden Geld dafür abpressten, sie nicht an die Deutschen zu verraten; Anm. d. Übers.] zu befürchten hatten, die hinter den Ausgängen auf „koty“ [„Katzen“, also Juden $\left.{ }^{64}\right]$ lauerten. [...] An manchen Ghettoausgängen, besonders bei der Okopowa- und bei der Leszno-Straße, umfasste dieser Verkehr [bis zur Großaktion] mehrere Hundert Personen täglich (S. 59).

64 Die Bezeichnung „Katzen“ für Juden bezieht sich auf eine antisemitische Redensart aus der Besatzungszeit, derzufolge jeder Jude vor dem Krieg „alles im Überfluss hatte“ [poln. „miat i mial“ [,hatte und hatte"]], was ähnlich klingt wie „miau miau“; Information nach A. Bikonts Biographie von Irena Sendlerowa: Sendlerowa. W ukryciu; Warschau 2017, S. 48; Anm. d. Übers. 
Zusammen mit der täglichen Kolonne "placówkarze“ - Arbeiter, deren Arbeitsstellen außerhalb des Ghettos lagen - verließ das Ghetto, wer in der Lage war, sich auf arischer Seite zu verstecken. So gelangten viele hinaus, besonders zwischen den Liquidierungsaktionen im Juli [1942] und im Januar [1943]. Ende Januar 1943 versuchte Henryk Makower gemeinsam mit seiner Frau und anderen Flüchtenden mit einem Lastwagen an einem bestochenen Wachposten an der Dzika-Straße, gleich beim Umschlagplatz, vorbeizukommen. Die Eskapade misslang jedoch, und die Makowers entgingen nur durch ein Wunder dem Tod. Der zweite Versuch am nächsten Tag glückte dann; das Ehepaar gelangte in einem Lastwagen versteckt an dem Wachposten vorbei und suchte einen Unterschlupf in Miłosna bei Warschau auf.

Einen außergewöhnlichen Grenzpunkt stellte das Gerichtsgebäude der Sądy Grodzkie [„Städtisches Gericht“; Anm. d. Übers.] zwischen Leszno- und Ogrodowa-Straße dar. Es hatte zwei Eingänge: einen auf Ghettoseite an der Leszno 53/55, den anderen auf arischer Seite an der Ogrodowa 12/14 durch den arischen Korridor der Biała-Straße, welche die arische Seite der Chłodna-Straße mit dem Gerichtsgebäude verband. Die komplizierte Topographie des Ghettos sorgte dafür, dass jenes Gebäude zu einer Art exterritorialem Gebiet wurde. Dort konnten sich - natürlich illegal - Menschen von beiden Seiten der Mauer treffen. Durch das Gerichtsgebäude erfolgte der Übergang vom Ghetto auf die arische Seite, und umgekehrt - von der arischen Seite ins Ghetto ${ }^{65}$.

Schreibt man über Orte des Übergangs, darf man den Umschlagplatz nicht vergessen. Das Tor des „Umschlag“ [ugs. Abkürzung für Umschlagplatz; Anm. d. Übers.] führte zu den Waggons nach Treblinka. Das war die Endstation. Vom Umschlagplatz in Stawki zu entkommen glückte nicht vielen: Manche Menschen

65 So schildert Helena Rufeisen-Schüpper, die im Frühjahr 1941 auf Schleichwegen von Krakau nach Warschau gelangte, in ihren Erinnerungen den Moment, in dem sie durch das Gerichtsgebäude das Ghetto betrat: „Man musste mit der Vorgabe, etwas zu erledigen zu haben, in den dritten Stock hinauf- und von da aus über eine Seitentreppe wieder ins Erdgeschoss hinuntergehen. Dort befand sich eine Garderobe, an der ein Pförtner aufpasste. Ich drückte ihm eine Fünf-Złoty-Note in die Hand, legte meine Armbinde an und war wieder eine Jüdin. [...] Die Eingangspforte zum Gericht auf der Ghettoseite wurde von einem polnischen Polizisten bewacht. Er hielt mich an und fragte: ,Sie sind nicht zufällig Polin?' Ich entgegnete: ,Mal ja, mal nein - je nach Lage.' Und so fand ich mich auf der mir unbekannten Leszno-Straße wieder.“ - H. Rufeisen-Schüpper: Pożegnanie Miłej 18. Wspomnienia łączniczki Żydowskiej Organizacji Bojowej [Abschied von der Miła-Straße 18. Erinnerungen einer Meldegängerin der Jüdischen Kampforganisation [die in der Miła-Straße 18 ihren Sitz hatte; Anm. d. Übers.]], Krakau 1996, S. 25. 
wurden freigekauft, in Sanitäterkleidung oder auf Leichenwagen herausgeschmuggelt, andere stiegen in die Waggons und sprangen später ab. Im April 1943 sprang Marian Berland aus einem fahrenden Zug, nachdem er während des Ghettoaufstands aus einem Bunker gezerrt worden und auf dem Umschlagplatz für den Transport nach Majdanek abgefertigt worden war. Berland kehrte nach Warschau zurück und notierte in einem Versteck auf der arischen Seite seine Erinnerungen. Auch die aus Treblinka geflohenen Menschen strebten nach Warschau. Die Geschichte eines solchen Flüchtlings hält Samuel Puterman in seinem Tagebuch fest (S. 254-258), und Avrom Levin notiert unter dem Datum „21. September, Tag des Gerichts (1942)“:

In unseren Shop kam ein Jude zurück, den man drei Wochen zuvor mitgenommen hatte, er hatte 9 oder 11 Tage lang in Treblinka als Totengräber gearbeitet, war von dort in einem Waggon geflüchtet, mit dem die Kleidung der Ermordeten abtransportiert wurde. Er erzählt grauenvolle, erschütternde Geschichten (BŻIH 22, S. 104).

Die Berichte der Flüchtlinge aus Treblinka wurden im Ringelblum-Archiv deponiert ${ }^{66}$.

Um auf die arische Seite zu gelangen, musste man manche Grenzen überwinden - Grenzen aus Ziegelsteinen und Stacheldraht und Grenzen aus Angst und Hass. Zusätzlich gab es schwer zu meisternde Barrieren: die nötigen Geldmittel, ein Netz von Bekanntschaften auf der anderen Seite, „das richtige Aussehen“... Nicht für alle Ghettobewohner bot die Seite außerhalb der Mauer eine Chance für Flucht und Rettung. Viele schlossen von vornherein die Möglichkeit eines Wechsels auf die andere Seite aus, sahen sie dort doch keinerlei

66 Bericht von D. Nowodworski (in jiddischer Sprache) (Ring I, 296); Bericht von J. Rabinowicz (Ring II, 298) veröffentlicht in: Archiwum Ringelbluma, S. 122-123. Im 2. Teil des Ringelblum-Archivs befinden sich auch zwei andere, anonyme Berichte von Geflohenen aus Treblinka. Autor des ersten ist ein Warschauer (Ring II, 295), Autor des zweiten ein von Częstochowa nach Treblinka deportierter Jude (Ring I, 297). Beide Texte wurden im „Bulletin des Jüdischen Historischen Instituts“ 1961, Nr. 40, S. 78-88 veröffentlicht. Bekannt sind auch Berichte aus Treblinka von A. Krzepicki, S. Rajzman, J. Rajgrodzki. Am meisten Aufsehen erregte das noch 1944 von der Jüdischen Koordinationskommission mit Hilfe der Polnischen Heimatarmee AK herausgegebene Tagebuch von J. Wiernik: Ein Jahr in Treblinka, dt. Ausgabe übers. aus dem Englischen von Philip Bauer, Wien 2014. Ein anderer Treblinka-Flüchtling, S. Willenberg, gab seine Erinnerungen 1986 in Tel Aviv heraus (auf Hebräisch). Polnische Ausgabe: Bunt w Treblince [Aufstand in Treblinka], Warschau 1991; deutsche Ausgabe: Treblinka: Lager, Revolte, Flucht, Warschauer Aufstand, übers. von S. Hänschen, Münster 2009. 
Überlebenschancen für sich. Und von denjenigen, die sich für eine Flucht entschieden, kehrten doch viele ins Ghetto zurück - ohne Geld, ohne Habe und jeglicher Illusionen beraubt, dass hinter der Mauer die Rettung für sie liege. Die arische Seite war eine andere Welt, gewebt aus Träumen, Ängsten und Hoffnungen. Schnell stellte sich heraus, dass jene Welt, die so ganz anders war als die Ghettowelt, ebenfalls Grausamkeit und Gefahren barg. Verbissen um sein Leben kämpfen musste man hüben wie drüben.

Adressen von Verstecken auf arischer Seite gab es verschiedene, von vielen werden wir nie erfahren. Zahlreiche Autoren der erhaltenen Texte fanden Schlupfwinkel im Stadtteil Praga jenseits der Weichsel. Henryk Bryskier kam nach seiner Flucht aus Majdanek nach Warschau zurück und verbarg sich zunächst in der Wohnung des Ehepaars Kanigórski an der Chełmska-Straße. Im Mai 1944 musste er, da er erpresst wurde, nach Praga übersiedeln. Auf dem Dachboden eines bis heute erhaltenen Altbaus in der Targowa-Straße 64 versteckte sich Leon Guz. Marek Stok fand Unterschlupf bei Herrn und Frau Koper in der Ratuszowa-Straße 6/3. So beschreibt er die Umstände, unter denen sein Text entstand: „Geschrieben wurde er im Frühsommer 44 in einer kleinen 2-Zimmerwohnung in Praga, in der 12 Personen aus der jüdischen Intelligenz gemeldet waren“ („Pamiętniki“, Sign. 228, S. 32). Die Adressen Jakub oder Karol Rotgebers in Praga können wir uns nur denken. „Aus dem Fenster meines Wohnsitzes jenseits der Weichsel sieht man den Feuerschein des brennenden Ghettos", schrieb Rotgeber (S. 39). In einem Haus im Stadtteil Saska Kępa, ebenfalls mit Blick auf das in Flammen stehende Ghetto, versteckte sich Stanisław Adler; später zog er auf den Dachboden einer Villa in Anin. Adolf und Barbara Berman wohnten im Stadtteil Żoliborz bei Irena Kurowska. In Żoliborz versteckte sich auch Leon Najman, und Marian Berland in einem Zimmer in der Sienna-Straße. Calel Perechodnik lebte bei Frau Hela, in einem Raum neben ihrem Laden, dessen Tür direkt auf die Pańska-Straße führte. Man weiß nicht, in welchem Teil Warschaus sich der Dachboden befand, auf dem ein unbekannter Autor diese Worte notierte:

Ich wohne zur Zeit auf dem Dachboden eines Hauses. Mein Tisch ist der Boden eines umgedrehten Kübels, mein Stuhl ein kleines Schränkchen. Ich schreibe hastig, mit dem Gedanken, dass diese Blätter sich irgendwann in einem befreiten Warschau wiederfinden werden (Pamiętniki z getta, S. 199).

Stefan Ernest beendete sein Tagebuch mit einem Vermerk zu Ort und Zeit: „Deutscher Bezirk. Kellerloch, Mai 1943“. Früher beschreibt er nicht nur die Bedingungen, in denen er verharren musste, sondern auch die charakteristische Schreibsituation: 
Ich sitze [...] im Souterrain, fast gänzlich isoliert von der Außenwelt. Mein Manuskript schreibe ich mit dem Bleistift, habe ich mich doch gerade gestern auf der Straße mit meinem Füllfederhalter von einem Spitzel freigekauft, der meine jüdische Herkunft erraten hatte - ganz simpel und blödsinnig an der Ecke Wilcza- und Poznańska-Straße („Pamiętniki“, Sign. 195, S. 6).

Der Autor, dem sein Füller in einem brenzligen Moment das Leben gerettet hat, schreibt nun mit einem Bleistift die Fortsetzung seines Überlebenskampfes weiter. Der Text endet mit der Beschreibung seines Verstecks - des Ortes, an dem sich die letzte Spur von ihm verliert:

Ich verstecke mich in einem Kellerloch, ohne frische Luft, ohne genügende und regelmäßige Ernährung, ohne ausreichende Kanalisationsanlagen, ohne den Hinblick auf irgendwelche Veränderungen in diesem Zustand des Dahinvegetierens, in dem jede überlebte Stunde mit Gold aufgewogen werden muss („Pamiętniki“, Sign. 195, „Posłowie“ [Nachwort]).

Das Schicksal eines Juden auf arischer Seite hing von einer ganzen Kette engagierter Menschen ab, die für sein Versteck und für seine Unterstützung sorgten. Der Alltag in der Besatzungszeit war ein Zustand stetiger Bedrohung für Retter und Schützlinge. Gefahr lauerte überall, vor allem jedoch ging sie von den nächsten Mitmenschen aus - von Nachbarn, Hausmeistern, Passanten auf der Straße, Verkäufern in Geschäften. Gefährlich waren die alltäglichsten Verrichtungen - das Hinaufsteigen der Treppe zur Wohnung, die Fahrt in der Straßenbahn, der Einkauf (es gab die Regel, dass man möglichst nie zu viele Nahrungsmittel an einund demselben Ort kaufen sollte). Die Deutschen standen im Grunde außerhalb der Gefahrenzone; sie waren die fremden und rücksichtslosen Vollstrecker eines grausamen Schicksals. Mit dem Schicksal gespielt wurde hauptsächlich unter den unmittelbaren Mitmenschen. Am häufigsten musste man sich vor Nachbarn verstecken, am häufigsten musste man vor Seinesgleichen Ausflüchte machen, Spuren verwischen, Irrfährten legen.

In manche Texte sickert, zusammen mit manchmal winzig kleinen situativen Realien, die Atmosphäre ihres Schreibens ein:

Klopft jemand, lasse ich das Schreiben sofort sein, damit man das Kratzen der Feder nicht hört [...]. Schon ist es dunkel, und ich kann nicht weiterschreiben, denn Licht darf ich keines machen (Jakub, S. 164, 135).

[...] [I]n diesem Moment, während ich schreibe, höre ich deutlich ein Geschoss detonieren (Rotgeber, S. 55).

Beim Schreiben dieses Tagebuchs bin ich mir nicht sicher, ob ich irgendwann meinen Bekannten werde zeigen können, denn auf der einen Seite besteht jederzeit die Gefahr, dass hier ein Schrapnell eindringt und mein ganzes Versteck zerstört, und auf der anderen Seite könnten die Deutschen mich erwischen (Fogelman, S. 107). 
Unerträglich war auch die Situation des Eingesperrtseins. Wer sich versteckte und sich trotzdem frei in der Stadt bewegen, sogar arbeiten konnte, galt als Glückspilz. Das Eingeschlossensein und die erzwungene Untätigkeit waren für viele ein direkter Impuls zum Schreiben.

Jakub versteckte sich von Mai 1943 bis August 1944 in Praga, in einem feuchtmuffigen Kämmerchen im Hinterhaus seiner engen Bekannten Julia Rogowińska. In seinem Tagebuch klagt er wiederholt über die Qual der freiwilligen Gefangenschaft, des Bewegungsmangels, der Monotonie und Einsamkeit. Das Warten und die Langeweile setzen ihm beinahe körperlich zu, „Zwicken ihn in die Fersen“.

Was soll ich tun, Verzweiflung packt mich [...]. Wie ich die beneide, die schon im Grab liegen [...]. Man muss mich verstehen, ich lechze nach der offenen Straße und nach Luft (S. 130).

Um die Zeit herumzubringen, beginnt er zu schreiben:

[...] ich schreibe ein wenig, damit die Zeit schneller zum Teufel geht, und unter anderem habe ich ein Gedicht gemacht (S. 120).

Ich schreibe diese Gedichte aus Langeweile, habe ich doch nichts anderes zu tun (S. 124).

Ich muss etwas schreiben, wenn ich anderes zu tun hätte, [würde] ich dieses widerwärtige Schreiben gewiss bleiben lassen [...]. Schreiben tue ich nur aus Langeweile (S. 335).

Je mehr Seiten er aber zu Papier dringt, desto deutlicher entsteht in ihm ein Bewusstsein für die tiefere Bedeutung dessen, was er tut. Er erkennt nach und nach den Wert seines persönlichen Zeugenberichts.

Seine Langeweile erwähnt mehrmals auch Dawid Fogelman, der sich nach dem gescheiterten Warschauer Aufstand in einem Bunker in der SzczęśliwaStraße 5 versteckt:

Da ich hier den ganzen Tag in der Grotte sitze, bin ich jetzt aus Langeweile dazu gezwungen, meine Erlebnisse aufzuschreiben; vielleicht sind sie ja irgendwann zu etwas nütze (S. 107).

Wieder ist Langeweile eingekehrt. Ich fange an, Tagebuch zu schreiben, obwohl ich nur eine Grundschulbildung besitze und die Handwerksschule abgeschlossen habe (S. 137).

Für den Entflohenen, der irgendwo auf der arischen Seite an einem Ort festsitzt, bekommt das Zeitempfinden einen neuen, anderen Wert als im Ghetto. Es ist ein Zuviel an Zeit, beschwerlich wie eine untragbare Last. Der Mensch wird zum Gefangenen seiner unausgefüllten Zeit. Er ist zur zwangsläufigen Untätigkeit verurteilt; ohne Wissen um den genauen Tag und die genaue Uhrzeit wird er zum passiven Zeugen der verstreichenden Minuten. Das Einzige, was er tun kann, ist warten. Diese Haltung weckt seine Hoffnung und verstärkt zugleich die 
Angst und Einsamkeit. Die Zeit erweist sich für die aus dem Lebensrhythmus des Ghettos herausgerissenen Geflüchteten als neue Herausforderung. Manch einer empfindet das als weitere Folter, anderen gelingt es, eine Chance darin zu sehen.

Eine der Methoden, mit dem Übermaß an Zeit umzugehen, ist das Schreiben. Manche Schreibenden - wie Fogelman oder Jakub - betrachten es anfangs als einfache Flucht vor der Langeweile und nehmen erst später seinen eigenständigen Wert wahr. Für andere - wie Marian Berland, Leon Najberg, Karol Rotgeber, Stefan Ernest, Ludwik Hirszfeld, Henryk Makower - stellt das Schreiben von Anfang an eine der wichtigsten Tätigkeiten dar, die der Existenz im Versteck irgendeinen Sinn verleihen. Die meisten von ihnen entdecken den Impuls, Aufzeichnungen anzufertigen, in sich selbst. Anders ist es bei Berland. Zum Schreiben regen ihn seine Beschützer an: Jan Wesołowski und Basia Bermanowa. Die einzelnen Hefte seines Tagebuchs gab der Verfasser sukzessive an das Untergrundarchiv weiter, das er „Komitee“ nannte. Die Anregung verinnerlichte er allerdings sogleich; das Schreiben wurde ihm zum tiefsten seelischen Bedürfnis:

Ereignisse, Erinnerungen und Bilder fließen in einem Strom zu Papier, und schon nach wenigen Tagen ist das erste Heft gefüllt und bereit zur Übergabe an Frau Basia. Das Schreiben gibt mir Befriedigung, es scheint mir, dass auch ich zu etwas nütze bin. [...] Ohne Frau Basias glücklichen Einfall, Tagebuch zu schreiben - ich würde in diesen Tagen unweigerlich verrückt werden (S. 411-412).

Leon Najberg gelang es im September 1943 als einem der Letzten nach dem Aufstand, das Gebiet des Ghettos zu verlassen. Versteckt im Haus von Teofilia und Aleksander Szczypiorski in der Chełmżyńska-Straße 88 [heute Płatnicza-Straße] in Żoliborz, begann er, seine Erinnerungen aufzuschreiben, schlussendlich wurden es 800 Heftseiten. Er schrieb wie in Trance:

Als ich mich ans Schreiben machte - begannen meine Erinnerungen wie ein Springbrunnen hervorzusprudeln und drängten aus der Feder aufs Papier. Der Strom der Erinnerungen war so reißend, breit und stark, dass ich nicht imstande war, alles zu notieren, was mein Gedächtnis mir eingab. [...] Das Schreiben absorbierte mich gänzlich. Es beherrschte mich in einem Maße, dass ich nicht rechtzeitig zu den Mahlzeiten kam (S. 5-6).

Die Umstände, unter denen Berlands und Najbergs Texte entstanden, sind das deutlichste Beispiel für eine therapeutische Funktion des Schreibens. Beide Autoren sind sich dessen bestens bewusst. Sie bekannten offen, dass ihnen das Schreiben half, mit der Last des soeben Durchlebten zurechtzukommen.

Wer es geschafft hatte, dem Ghetto zu entkommen und einen Unterschlupf auf der anderen Mauerseite zu finden, nahm eine Distanz zu den zurückliegenden Erlebnissen ein. Diese Menschen waren sich von da an stets bewusst, dass die 
Vernichtung ihres Volkes im Gange war; das Gefühl einer nur relativen persönlichen Sicherheit verließ sie nie mehr. Als sei das Urteil, dem sie vorübergehend entgangen waren, lediglich vertagt worden. Jener illusorische und zerbrechliche Zustand der Ruhe setzte in manchen Menschen Energien frei und regte zum Nachdenken, zur Reflexion an. Es war ein Zustand, der das Schreiben förderte und das wiederum erwies sich als eine Möglichkeit, das Leben im Versteck zu meistern. Leon Najberg notiert: „Es begannen Tage himmlischer Ruhe, die jedoch nicht von langer Währ sein sollte“ (S. 5). Leon Guz lässt seine Beschreibung des Zimmers in der Targowa-Straße mit folgender Bemerkung enden: „Es ist still und friedlich. Nur die Atemzüge der Schlafenden sind zu hören. [...] Nun kann ich, unter relativ ruhigen Bedingungen, diese Notizen machen" (S. 11-12). Marian Berland, der im Schreiben eine Möglichkeit fand, der grausamen Wirklichkeit zu entfliehen, war sich jedoch bewusst, dass dieses Asyl illusorisch und nicht von langer Dauer war:

Ich sitze auf dem Fußboden und beschreibe Blätter, die Welt hat aufgehört zu existieren. Ringsum tobt der Sturm der Geschichte. Das Stückchen Boden und mein Heft sind für mich eine kleine Insel, die jeden Moment von den wütenden Wogen fortgerissen warden kann (S. 411).

\section{5}

Eine der Eigenschaften jener Erfahrung, die den Autoren der geretteten Texte zuteil wurde, war die radikale und präzedenzlose Verwandlung der sie umgebenden Welt in ihren grundlegendsten Dimensionen - in Zeit und Raum. Die Wirklichkeit, in deren Rahmen sie sich bewegten, war zunehmend weniger erkennbar. Sie stellte ein unbekanntes Antlitz zur Schau - ein seltsames, erschreckendes, vor allem aber fremdes Antlitz. Die vertraute Topographie der eigenen Stadt verwandelte sich in ein absurdes, von Mauern durchkreuztes Labyrinth von Straßen und später von leeren, jeglichen Lebens entbehrenden Flächen, schlussendlich in eine formlose Masse von Trümmern. Der Druck jener Situation im Angesicht des Todes veränderte auch das Empfinden von Zeit. Die Zeit verläuft im Ghetto in ihren eigenen Schlaufen und Variationen, die eine unweigerlich auf den Abgrund zukreiselnde Spirale bilden. In so wortwörtlichem Sinne wie nie zuvor durchdringen sich die Erfahrung der Zeit und die Erfahrung des Todes ${ }^{67}$.

67 Siehe zu diesem Thema auch die hervorragende Studie von B. Engelking: „Czas przestat dla mnie istnieć ...": analiza doświadczenia czasu w sytuacji ostatecznej [„Die Zeit hörte für mich auf zu existieren ...“: Eine Analyse der Zeitwahrnehmung im Angesicht des Todes], Warschau 1996, die vor allem auf einer Analyse persönlicher Dokumente aus 
Was dauerhaft erschien, zerfällt zu Staub. Was bekannt und vertraut schien, erweist sich als bizarr und fremd. Was gewöhnlich und alltäglich war, ist jetzt ein grauenvoller Alptraum. Das Leben scheint schlimmer als der Tod. In den Texten, die das Schicksal uns heutigen Lesern in die Hände gespielt hat, wird der Prozess der Erfahrung und kognitiven Beherrschung jener plötzlich enthüllten Fremdheit und Andersartigkeit erkennbar. Sie sind der Versuch einer Beschreibung jener Erfahrung - entstanden sie doch im Moment der Veränderung von Raum und Zeit, als die Wirklichkeit vor den Augen der Autoren, die sie zu beschreiben suchten, zu Staub zerfiel.

dem Warschauer Ghetto basiert. „In einer abyssischen Situation (vom griechischen Wort abyssos, das „Abgrund“ bedeutet) erweist sich, dass der bis dahin als horizontal wahrgenommene Zeitstrom plötzlich in einen direkt in den Abgrund führenden Spalt stürzt. [...] Die Zeit des Ghettos ist eine abyssische Zeit, ein Leben in Spalten der Zeit", schreibt die Autorin und zeigt damit auf, dass die einzelnen Etappen der Geschichte des geschlossenen Bezirks die Chronologie jener Zeitspalten enthüllen, die aufeinanderfolgenden Schlaufen der Zeit: die Zeit des Ghettoalltags; die Zeit der großen Liquidierungsaktion; die Zeit nach jener Aktion; die Zeit des Ghettoaufstands; die Zeit im Versteck, also die Zeit der Juden auf arischer Seite (S. 12). 


\section{Das Schicksal der Texte}

Die Reflexion über die Geschichte der noch erhaltenen Holocausttexte scheint universelle Eigenschaften des jüdischen Schicksals zu bestätigen, wurden die Juden doch stets von der Überzeugung begleitet, dass ein Text, der wahre Worte enthält, kostbarer sei als das Leben. Daraus ergab sich die Notwendigkeit, einen solchen Text um jeden Preis vor Vernichtung zu bewahren.

Die Wertschätzung für Bücher, für das geschriebene Wort wurde unter den Juden zu etwas allgemein Verbreitetem, Alltäglichem. Die tiefen Quellen einer solchen Haltung liegen in der Ehre, welche dem Schriftstück der Tora entgegengebracht wird. Wenn Juden vor Pogromen flohen, wenn sie ins Exil gingen, trugen sie oftmals lediglich eine Schriftrolle mit der Tora bei sich, eingedenk der Worte ihrer Weisen: „Alle heiligen Schriften muss man vor dem Feuer retten“ [Vers der Mischna (Traktat Schabbat); Anm. d. Übers.].

Brände, in denen Bücher vernichtet wurden, ereigneten sich auf dem Weg der Juden überaus häufig. Ryszard Löw fasst die Situation in seiner Skizze $O$ (żydowskiej) miłości do (hebrajskich) ksiag [Von der (jüdischen) Liebe zu den (hebräischen) Büchern] wie folgt zusammen: „Die Bücher im Besitz der Juden fielen in einem Maße, das anderen Völkern unbekannt ist, Zerstörung und Verlust anheim. In Zeiten von Vertreibung und Flucht gingen Bücher verloren, als sie unter den ersten konfiszierten Gegenständen waren und von ihren Besitzern unter Einsatz deren Lebens beschützt wurden; Bücher gingen unrechtmäßig in den Besitz anderer über. [...] Jüdische Bücher wurden vom 12. Jahrhundert an bei periodisch wiederkehrenden Pogromen und Ausschreitungen vernichtet, sie wurden auf den Scheiterhaufen der kirchlichen Inquisition verbrannt. Auch von ihren Besitzern selbst wurden sie manchmal zerstört, die sie eher der Erde übergeben wollten als sie einer aufgepeitschten, die jüdischen Viertel verwüstenden Menge in die Hände fallen zu lassen. "“68

Die Zeugen des Holocaust mussten somit den ewigen Kampf um ihre Bücher wiederaufnehmen. Es genügte nicht, Zeugenberichte bloß niederzuschreiben, die beschriebenen Seiten mussten auch geschützt werden. Jeder gerettete Text besitzt seine individuellen Kennzeichen und seine eigene Geschichte. Die besonderen Begleitumstände, unter denen die Texte geschrieben, verwahrt und

68 R. Löw: Pod znakiem starych foliantów [Im Zeichen alter Folianten], Krakau 1993, S. 37-38; dort finden sich auch andere Gedanken über die Einstellung der Juden zu Büchern, von dort stammt das Zitat der Weisen. 
versteckt wurden und die sich teils aus den Bedingungen in Ghetto, Bunker oder Versteck und teils durch Zufall ergaben, stellen bei jedem einzelnen von ihnen eine unvergleichliche Aura her. Die Wirklichkeit, in der sie entstanden sind, beeinflusst sowohl ihre äußerliche als auch innerliche Gestalt - die materielle Substanz eines Textes und seine sprachlichen Regeln. Dieses tief eingeprägte Mal der Zeit lässt sich als gemeinsames Kennzeichen vieler Zeugnisse erkennen, wenn es auch bei jedem Text auf bestimmte Weise einzigartig ist.

Der Leser wird bei der Lektüre derartiger Texte gewissermaßen in doppeltem Sinne in medias res eingeführt. Erstens verfolgt er die wieder heraufbeschworenen Ereignisse von „damals dort“. Zweitens befasst er sich mit einem Erlebensmoment der dargestellten Welt, der in höchst aktuellem Zustand - also ebenfalls damals dort - festgehalten worden ist. Jene Texte bescheinigen nämlich nicht nur die geschilderten Ereignisse, Gefühle und Gedanken, sie werden vielmehr in ihrer substanziellen Existenz - zum Zeugnis. Damit sind sie nicht bloß eine Kombination sprachlicher Zeichen, die sich auf eine außersprachliche Wirklichkeit beziehen, sondern stellen selbst eine besondere Art der Wirklichkeit dar. Kostbar werden sie nicht nur durch das, was sie erzählen, sondern auch dadurch, dass sie überhaupt existieren. Das geschriebene Wort nimmt das Gewicht der Sache selbst an. Es kündet nicht nur von Fakten, sondern ist selbst Faktum. Wie die materiellen Gegenstände, die die Katastrophe überdauert haben, bekommen diese Texte einen Wert bereits dadurch, dass sie existieren, dass sie in der Gestalt überdauert haben, welche ihnen jene Menschen gaben, jene Zeit. So erlangen sie einen Doppelbezug: Erstens verweisen sie auf ihren Autor und die von ihm erlebte Welt, zweitens verweisen sie auf sich selbst als auf einen Gegenstand, der selbst eine Spur, ein Krümchen des Vergangenen ist. Damit sind sie nicht nur ein „sprachlicher Ausdruck des Gewesenen“, sondern auch ein „Sein an sich“, ein Stück jener Existenz ${ }^{69}$.

Die dem Forscher heute zugänglichen Texte konnten dank einer geheimnisvollen Schicksalsfügung, dank einer Laune des Zufalls oder auch dank der

69 Vgl. K. Bartoszyńskis Bemerkungen über die Quellfunktion eines Textes: „Ein Text wird in diesem Fall nicht nur und nicht in erster Linie als Kommuniqué betrachtet, sondern als ein Faktum, das mit Namen wie ,Zeichen ',Spur' ,Produkt ' bezeichnet ist. [...] [E]in Text wird hier als Gegenstand behandelt, aus dem bestimmte Informationen herauszuholen sind, ohne ausschließlich - oder ohne überhaupt - von seinen kommunikativen Eigenschaften (insofern er Kommuniqué ist) und seinen gegenständlichen Bezügen (Referenzialität) Gebrauch zu machen.“- K. Bartoszyński: „Aspekty i relacje tekstów“ [Textuelle Aspekte und Beziehungen], in: Z. Stefanowska und J. Sławiński (Hgg.), op. cit., S. 59. 
Entschlossenheit, des Mutes und der Opferbereitschaft vieler Menschen überdauern. Meistens sind wir heute nicht mehr in der Lage zu sagen, warum und wie ihre Rettung tatsächlich vor sich ging. Entscheidend ist die Tatsache, dass die Texte überdauert haben. Mit diesem Bewusstsein gehen wir an die Lektüre und blättern durch die vergilbten Seiten eines karierten Heftes oder einige lose, mit Kopierstift beschriebene Zettel, die Spuren von Rost oder Schimmel tragen. Hinter jedem dieser Flecken, hinter jedem Riss und jeder Verschmutzung steht eine eigene Geschichte, ein eigenes Drama.

1

Geschrieben wurde auf allem, was zu bekommen war und worauf sich eine Spur von Buchstaben hielt. Abram [Abraham] Kajzer, ein Weber aus dem Ghetto Litzmannstadt in Łódź, schrieb auf Fetzen von dickem grauem Papier und alten Zementsäcken.

Jeden Tag zog ich mich auf die Latrinen des Lagers zurück - bekennt der Autor des Tagebuchs - und notierte rasch meine neuesten Erlebnisse. Die Notizen versteckte ich an irgendeiner Stelle, und wenn die Nachricht kam, dass ich in ein anderes Lager verlegt werden sollte, holte ich sie alle hervor und nagelte sie unter das Latrinenbrett. ${ }^{70}$

Der Autor überlebte. Nach dem Krieg fuhr er mit dem Fahrrad die meisten Lager $\mathrm{ab}$, in denen er interniert gewesen war, und holte die versteckten Zettel hervor. Der Rabbiner Ephraim Oshry überlebte das Ghetto Kauen [in Kaunas; Anm. d. Übers.]. Die Juden wandten sich häufig mit Fragen an ihn; er schrieb diese Fragen und seine Antworten auf Papierfetzen, die er heimlich von Zementsäcken abriss und anschließend in Büchsen verbarg, welche den Krieg überdauerten $^{71}$. Gustawa Dränger, Aktivistin der Jüdischen Kampforganisation ŻOB in Krakau, schrieb im Gefängnis während der Ermittlungen auf Streifen von Toilettenpapier und verschiedenen anderen Papierfetzen ${ }^{72}$. Zwischen Abfällen in den

70 Dieses Bekenntnis führt der Herausgeber eines Tagebuchs von A. Ostoja an, Vorwort zu: A. Kajzer: Za drutami śmierć [Hinter Stacheldraht der Tod], Łódź 1962, S. 6. Das Tagebuch ist auf Jiddisch verfasst.

71 Siehe N. Solomon: „Czy Szoah wymaga radykalnie nowej teologii“ [Verlangt die Schoa nach einer radikal neuen Theologie], in: W. Chrostowski (Hg.): Żydzi i chrześcianie $w$ dialogu [Juden und Christen im Dialog], Warschau 1992, S. 135. Die Responsen von Rabbi E. Oshry wurden in englischer Sprache herausgegeben: Responsa from the Holocaust, New York 1983, Judaica Press IX.

72 Siehe M. M. Borwicz: „Wstęp“ [Einleitung], in: ders. (Hg.): Pieśń ujdzie cało ... Antologia wierszy o Żydach pod okupacja niemiecka [Das Lied entkommt heil und ganz... Anthologie von Gedichten über die Juden unter deutscher Besatzung], Warschau, 
Ruinen des Ghettos von Łódź wurde ein hebräisches Buch gefunden, und darin auf einer unbedruckten Seite eine handschriftliche Notiz über die „Aktion“, die gerade im Gange war. Die Notiz bricht mitten im Satz $\mathrm{bb}^{73}$.

Im Ghettoarchiv befinden sich Drucke, maschinengeschriebene Dokumente und handgeschriebene Manuskripte. Die einzelnen Handschriften liegen gewöhnlich in Form von mehreren verschieden großen Blättern aus Schul- oder Notizheften vor, manchmal sind es auch nur abgerissene Papierstücke mit ausgefransten Rändern. Zum Beispiel ist auf 32 losen Blättern aus einem karierten Heft mit Kopier- und Bleistift der Bericht eines unbekannten Autors über die erste Liquidierungsaktion (22. Juli - 21. September 1942) (Ring II, 196) festgehalten. In zwei Heften mit verblichenen violetten Umschlägen hielt ein unbekannter Werkschutzmann [im Orig. deutsch] aus dem Shop der OBW mit schwarzer Tinte auf einem ungewöhnlichen, länglich karierten Papier seine Erlebnisse während des sog. Kocioł na Miłej ${ }^{74}$ fest (6.12.-September 1942) (Ring II, 203).

Einige Dokumente sind auf unterschiedlichen Typen von Makulatur verfasst, auf der Rückseite von Firmendokumenten oder auf herausgerissenen Seiten aus Buchhaltungsheften, mit sichtbaren Linien und Aufdrucken. Emanuel Ringelblum schrieb einen Teil seiner Notitsn auf die Rückseiten von Etiketten, zum Beispiel von Weinflaschen der Marke „Wermut-Santoza“, oder auf alte Papiere aus der Arztpraxis.

Im zweiten Teil des Ghettoarchivs ist die Notiz eines unbekannten Verfassers enthalten; sie steht auf einer Armbinde aus weißem Karton, wie sie die Mitarbeiter des „Czyste“-Spitals beim Dienst auf dem Umschlagplatz trugen. Auf der Innenseite sieht man einen roten Davidstern, einen schwarzen Aufdruck „Seuchen-Krankenhaus »Czyste " und einen runden roten Stempel des Spitals. Die Notiz mit blauem Bleistift befindet sich auf der anderen Seite:

9. September 1942, 6 Uhr - Frau und Schwestern.

10. September 1942 - Eltern. ${ }^{75}$

Łódź, Krakau 1947, S. 33. Der Text erschien 1946, herausgegeben von der Jüdischen Geschichtskommission der Woiwodschaft in Krakau, in einer Bearbeitung von J. Wulf als Pamiętnik Justyny [Justynas Tagebuch]. Die Ausgabe enthält ein Faksimile des handschriftlichen Textes.

73 Siehe M. M. Borwicz: „Wstęp“, in: ders. (Hg.): Pieśń ujdzie cało, op. cit., S. 33.

74 Der „Kessel in der Miła-Straße“: In der Endphase der Deportationen wurden Tausende Ghettobewohner in der Miła-Straße zusammengetrieben, und es fand eine Selektion derjenigen statt, die deportiert werden sollten; Anm. d. Übers.

75 Archiwum Ringelbluma, S. 120. Reproduktion der Armbinde im „Biuletyn ŻIH“ 1969, Nr. 71-72. 
Karol Rotgebers Tagebuch setzt sich aus 15 Heften zusammen. Die dem Autor offenstehenden Möglichkeiten der Niederschrift erzwangen eine solche Unterteilung des Textes. Jedes Heft beginnt mit einer längeren oder kürzeren, Rotgebers 13-jährigem Sohn gewidmeten Apostrophe sowie einer religiösen Anrufung; jedes stellt einen eigenen Teil oder ein eigenes Kapitel dar. Die Unterteilung ist jedoch nicht inhaltlicher, sondern rein formeller Art: Es war einfach nicht mehr Platz im Heft. Begann er ein neues Heft, versah der Autor den Text wieder mit den Anfangssignalen.

Adam Czerniaków schrieb in schwarz eingebundene Notizhefte mit einem Format von 9,8×16,5 cm. Insgesamt waren es neun. Eines ging im April 1941 bei der Verhaftung des Autors durch die Gestapo verloren. Acht Hefte sind noch erhalten, sie umfassen insgesamt 1.056 Blätter. Dawid Sierakowiaks Tagebuch gelangte in Gestalt zweier eng beschriebener Schulhefte zu uns, die gleich nach dem Krieg durch Zufall in Łódź entdeckt wurden. ${ }^{76}$ Marian Berlands und Leon Najbergs Erinnerungen füllten zahlreiche Notizhefte. Jedes Mal, wenn Berland ein Heft beendet hatte, übergab er es seinen Beschützern, die das gesamte Manuskript aufbewahrten; Najberg wiederum brachte jedes vollgeschriebene Heft selbst in Sicherheit.

Ringelblums Handschriften sind extrem schwer zu entziffern. Verfasst in eiligen, undeutlichen kleinen Buchstaben, häufig auf zufällig gefundenen Papierfetzen oder am Rand von anderen Drucken und Notizen, von Feuchtigkeit angegriffen stellen sie für den Herausgeber eine echte Herausforderung dar ${ }^{77}$. Czerniakóws Handschrift ist ebenfalls sehr unleserlich, und in seinem Text wimmelt es von Streichungen, Korrekturen und unklaren Abkürzungen.

So sehen die Schriften der Opfer aus. Die Schriften der Henker sind anders. Jürgen Stroops Bericht über die Niederschlagung des Warschauer Ghettoaufstands besteht aus drei Teilen: einer allgemeinen Einleitung, Tagesberichten und einem ikonographischen Teil mit einer photographischen Dokumention

76 Erst als ich dieses Buch bereits geschrieben hatte, stieß ich auf die vollständige Ausgabe von Sierakowiaks Tagebuch. Sie war um drei weitere Hefte ergänzt worden, welche ein Lodzer Journalist namens Konrad Turowski 1967 und 1968 gefunden hatte. Der gesamte bis dato aufgefundene Text wurde von Konrad Turowskis Sohn Kamil ins Englische übersetzt und im Herbst 1996 durch die Oxford University Press veröffentlicht.

77 Ich danke Frau Dr. Ruta Sakowska für die Informationen zu Ringelblums Handschriften. Józef Kermisz entzifferte, übersetzte (ins Hebräische), bearbeitete und veröffentlichte die Stimmen Ringelblums an den Rändern anderer Texte in Jerusalem (Information von R. Sakowska). 
der „Großaktion“. Das maschinengeschriebene Schriftstück ist durchschnittlich, weicht in nichts vom bürokratischen Muster eines pedantisch angefertigten Dokuments ab. Graphisch ungewöhnlich ist Stroops Rapport einzig dank der sorgsamen Bindung und Ausschmückung. Der Titel Es gibt keinen jüdischen Wohnbezirk in Warschau mehr! ist in einer stilisierten gebrochenen Schrift gehalten. Die dem Bericht beigefügten Photographien sind gewissenhaft geordnet, eingerahmt und mit Bildunterschriften versehen. Jedes Bild besitzt eine eigene, ebenfalls in gebrochener Schrift gehaltene Unterschrift. Der dicke, kunstvoll in Ziegenleder gebundene Band ruhte, bis die 7. US-Armee das Gebiet einnahm, friedlich auf einem Bücherregal in General Stroops bayerischer Villa. Er wurde dem Beweismaterial für den Nürnberger Prozess gegen die Hauptkriegsverbrecher und für Stroops Warschauer Prozess beigefügt. ${ }^{78}$

\section{2}

Viele Autoren vergruben ihre Texte in dem Glauben, auf diese Weise deren Überdauern zu sichern. Ludwik Landaus Manuskript Kronika lat wojny i okupacji umfasst die Zeit von September 1939 bis Dezember 1942; er steckte es in Metalldosen und vergrub diese auf dem Gelände der Freien Polnischen Universität an der Opaczewska-Straße. Die Fortsetzung seiner Kronika, die er bis zum Februar 1944 anlegte, versteckte Landau zusammen mit einigen abgetippten Anfangsstellen unter der Kohle im Keller eines Hauses in Włochy, wo er damals wohnte. Die Papiere unter der Kohle hielten sich, der Chronikteil jedoch, den er bei der Opaczewska-Straße vergraben hatte, konnte später nicht mehr aufgefunden werden ${ }^{79}$. Landaus monumentales Werk wurde 1962 in drei Bänden herausgegeben. Henryk Bryskiers Tagebuch überdauerte in einer Karbiddose, die er im Keller eines Hauses in Praga verbarg, in dem er und seine Tochter auf die Befreiung warteten. 1947 übergab Bryskiers Tochter das Tagebuch ihres Vaters an das Archiv des Jüdischen Historischen Instituts. Eugenia Szajn-Lewin brachte ihr im Ghetto entstandenes Manuskript in einer Wohnung in der Puławska-Straße unter, wo sie sich nach ihrer Flucht auf die arische Seite versteckte; es lag in einem geheimen Fach unter dem Fußboden. Die Verfasserin kam im August 1944 beim Warschauer Aufstand um. Ihre Schwester kehrte im Januar 1945 in das noch stehende Haus in der Puławska-Straße zurück und holte die zusammengerollten

78 Siehe B. Mark: „Introduction“, in: The Report of Jürgen Stroop Concerning the Uprising in the Ghetto of Warsaw and the Liquidation of the Jewish Residential area, Warschau 1958.

79 Siehe B. Mark: „Introduction“, in: The Report of Jürgen Stroop Concerning the Uprising in the Ghetto of Warsaw and the Liquidation of the Jewish Residential area, Warschau 1958. 
Blätter. Jahre später übergab sie das Original des Manuskripts, nachdem sie eine Abschrift angefertigt hatte, an die in Frankreich lebende Tochter der Verfasserin. Dort ging das Schriftstück verloren, jedoch wurde der Text auf Grundlage der Abschrift im Jahr 1989 veröffentlicht. Jizchak Katzenelson versteckte sein Manuskript mit dem Großen Gesang vom ausgerotteten jüdischen Volk in drei Flaschen und vergrub diese unter einem Baum im Lager von Vittel. Nach Frankreichs Befreiung wurden die Flaschen ausgegraben, und das darin befindliche Poem erschien bereits 1945 im Druck. Gleichfalls sofort in den Vereinigten Staaten abgedruckt, erschienen in zahlreichen Anthologien wurde es zu einem Klassiker der jiddischen Holocaustliteratur ${ }^{80}$.

Stanisław Adler verzeichnete von Beginn des Krieges an Notizen, verlor sie und machte neue. Sein Schreiben vergleicht er mit Penelopes Webarbeit: „[M]eine Schriften glichen, wie sich zeigte, Penelopes Totentuch; kaum hatte ich ein Stück fertiggestellt, zwang mich das Schicksal, mein Manuskript zu vernichten“ (S. 3).

Die Aufzeichnungen aus den ersten Kriegsmonaten warf ein Grenzwächter in den Ofen, als der Autor von der sowjetischen Besatzungszone nach Warschau überwechselte. Den rekonstruierten Text verlor Adler beim Übergang ins Ghetto 1941 ein weiteres Mal. Bei der Deportation fertigte er rasche Notizen an, die er bei seiner Flucht aus dem Ghetto im Februar 1943 „den Wölfen zum Fraß vorwerfen“ musste. Seine mittlerweile vierte Tagebuchversion vergrub Adler unter dem Fußboden einer Villa in Anin. Das Manuskript, das auf diese Weise überdauerte, übergibt der Verfasser im Mai 1946 auf dem Warschauer Bahnhof an seine Freundin Ludmiła Zeldowicz, „Lola“, als er selbst nach Palästina ausreist. Adlers auf Polnisch verfasstes Tagebuch erschien 1982 in Jerusalem in englischer Übersetzung ${ }^{81}$.

Der letzte, auf den 4. August 1942 datierte, Eintrag in Chaim Aron Kaplans Tagebuch - „In den Abendstunden“ -, der sprichwörtlich letzte Satz des Textes, lautet: „Wenn mein Leben endet - was wird aus meinem Tagebuch werden?" (Buch der Agonie, S. 404). Während die drohende Deportation näherrückte, wuchs auch Kaplans Angst um sein Tagebuch - die größer war als die Angst um sein Leben. Der Text überdauerte. Seine hebräische handschriftliche Fassung ist sauber, ohne Streichungen und Korrekturen. Festgehalten in zahlreichen kleinen Notizheften wurde das Tagebuch zur Gänze durch die Mauer geschmuggelt, noch vor der großen Liquidierungsaktion. Der Autor gab das Manuskript

80 Siehe S. Liptzin: A History of Yiddish Literature, S. 428.

81 In the Warsaw Ghetto, 1940-1943. An Account of a Witness. The Memoirs of Stanisław Adler, Yad Vashem 1982; Anm. d. Übers. 
seinem Freund Rubinstein mit, der als "placówkarz“ jeden Tag zur Arbeit auf der arischen Seite ging - und dabei ein Notizheft nach dem anderen unter seiner Kleidung hinausschmuggelte. Entgegengenommen wurden die Hefte von einem Polen, der mit dem Ghettountergrund in Verbindung stand, Władysław Wojcek. Nach dem Krieg half Wojcek, der beim Bau der Wohnsiedlung Muranów mitarbeitete, bei der Entdeckung des zweiten Teils des Ringelblum-Archivs. 1952 händigte er dem damaligen Direktor des Jüdischen Historischen Instituts, Prof. Bernard Mark, einen Teil der von ihm aufbewahrten Notizhefte Kaplans aus die Aufzeichnungen aus den Jahren 1940 und 1941. Warum er die restlichen Hefte weiterhin in einer leeren Petroleumdose auf dem Grundstück des Bauernhofs seines Vaters beließ, ist nicht bekannt. 1962 emigrierte Wojcek mit Frau und Tochter in die USA. Mit einem Empfehlungsschreiben von Prof. Mark wandte er sich an Abraham Katsh von der New York University, bat um Unterstützung bei der Arbeitssuche. Das Gespräch wurde mit einer Transaktion beschlossen: Für die New York Library of Judaica and Hebraica kaufte Katsh dem frischgebackenen Immigranten ein gutes Dutzend von Kaplans Notizheften ab - die Jahrgänge 1935-1936, 1939, einen Teil von 1940 und einen Teil von 1942. Wojcek erklärte, er habe die Handschriften nicht mehr zum Jüdischen Historischen Institut in Warschau bringen können, da es ihm erst kurz vor seinem Abflug in die Staaten gelungen sei, sie aus der vergrabenen Petroleumdose zu befreien. Diese Erklärung klingt, gelinde gesagt, seltsam. Man darf annehmen, dass Wojcek in seinem neuen Leben als Immigrant irgendein As im Ärmel haben wollte. Bei den Textteilen in Warschau und New York handelte es sich noch immer nicht um das gesamte Dokument. Es fehlten die Aufzeichnungen vom 4. April 1941 bis zum 2. Mai 1942. Abraham Katsh, der englische Übersetzer und Herausgeber von Kaplans Tagebuch, äußerte 1966 die Hoffnung, dass die fehlenden Textteile früher oder später wieder ans Tageslicht gelangen würden. Und tatsächlich, schon sieben Jahre später kann Katsh eine zweite, vervollständigte Ausgabe des Tagebuchs herausgeben, ergänzt um das letzte fehlende Kettenglied - die Aufzeichnungen aus 13 Monaten (4. April 1941-2. Mai 1942). Er hatte sie von Israel Gutman vom Mordechaj-Anielewicz-Gedenkinstitut in Israel bekommen ${ }^{82}$.

Das Manuskript von Janusz Korczaks Erinnerungen gelangte zunächst in die Hände Igor Newerlys, anschließend Maria Falskas, schlussendlich wurde es im Gebäude des Kinderheims Nasz Dom in Bielany eingemauert, das 1928 eigens

82 Siehe das Vorwort in: Buch der Agonie, op. cit., S. 9-18; „Introduction“, in: The Warsaw Diary of Chaim A. Kaplan, korrigierte Ausgabe, New York 1973, S. 9, 15. 
für das von Falska geleitete Heim errichtet worden war $^{83}$. Unter bislang nicht geklärten Umständen konnte der Teil von Korczaks Schriften, der aus dessen letzten Lebensmonaten stammte, überdauern und wurde erst 1988 von einer geheimnisvollen Person, die sich Anonymität auserbat, der Korczak-Gesellschaft in Israel überreicht. Die Materialien wurden 1992 von der Korczak-Werkstatt des Warschauer Instituts für Bildungsforschung veröffentlicht. Wie die Papiere überdauerten und welchen Weg sie zurückgelegt haben, ist unbekannt. Vielleicht waren sie in dem geheimnisvollen Koffer, in dem das Archiv des Waisenhauses Dom Sierot verpackt worden sein soll. Einer Version des Geschehens zufolge soll der langjährige Erzieher Michał Wróblewski die zurückgelassenen Dokumente in den Koffer gelegt haben, als er am 6. August in das leere Waisenhaus zurückkehrte. Dieser Koffer wurde dann an unterschiedlichen Orten versteckt, bis sich seine Spur verlor. Eine andere Version gibt Dr. Anna Margolisowa an. Im Dom Sierot, das nach der Deportation sämtlicher Bewohner leer stand, soll sie einem Jungen begegnet sein, der nach seiner nächtlichen Arbeitsschicht außerhalb des Ghettos niemanden mehr im Haus antraf und nun Korczaks Unterlagen in einen Koffer packte, um ihn auf die arische Seite hinüberzubringen. Weder Koffer noch Unterlagen wurden später je wieder gesehen, bis sie schließlich nach 46 Jahren wieder auftauchten. „Wir wissen nicht“, gibt Aleksander Lewin, der wissenschaftliche Redakteur der Ausgabe, allerdings zu bedenken, „ob das tatsächlich derselbe Koffer und dieselben Materialien sind“" ${ }^{84}$

Das Schicksal des Tagebuchs des Adam Czerniaków ist ebenfalls äußerst geheimnis-, wenn nicht gar skandalumwittert. Jahrelang galt es als unwiederbringlich verloren. Erst 1964 wurde das Manuskript von der staatlichen Gedenkstätte Yad Vashem in Jerusalem jemandem in Kanada abgekauft, für einen sehr hohen Preis. Marian Fuks, der Herausgeber des Tagebuchs in Polen, rekonstruiert den möglichen Weg des Schriftstückes wie folgt: Czerniakóws Witwe entkam dem Ghetto und versteckte sich, solange der Krieg dauerte, bei Freunden auf arischer Seite. „1947 oder später“, schreibt Fuks, „meldete sich Dr. Felicja Czerniaków beim Jüdischen Historischen Institut in Warschau mit dem Angebot [...]. Wie die Materialien nach Kanada gelangten, weiß man nicht. ${ }^{\text {“85 }}$

83 Siehe die Fußnoten der Herausgeber zu: J. Korczak: Pisma wybrane [Ausgewählte Schriften], Bd. 4, hg. von A. Lewin, Warschau 1986, S. 431-432.

84 A. Lewin: „Ostatnie świadectwa“ [Die letzten Zeugnisse], in: Janusz Korczak w getcie. Nowe źródła [Janusz Korczak im Ghetto. Neue Quellen], Warschau 1992, S. 6-8.

85 Siehe die Einleitung von M. Fuks zur polnischen Originalfassung des Tagebuch des Adam Czerniaków, op. cit., S. 14-15. 
Ein eigenes Kapitel ist die Geschichte der Sammlungen des Untergrundarchivs des Warschauer Ghettos. Sie wurden fast von Kriegsbeginn an zusammengestellt (Ringelblum legt seine Notitsn ab dem September 1939 an) - in systematischer und organisierter Weise von 1940 an, seit der Gründung des auf Ringelblums Betreiben hin gegründeten Untergrundarchivs und Dokumentationszentrums Oneg Schabbat. Ringelblum wusste, dass viele Zeugnisse nicht gerettet werden konnten, dass viele Texte unwiederbringlich verloren gingen:

Bücher, Bilder, Manuskripte wurden in die Hinterhöfe geworfen und dann zusammen mit den Abfällen entsorgt oder auch mitten auf dem Hof verbrannt - beschreibt er die Landschaft des Ghettos während der großen Liquidierungsaktion. - So wurden die Manuskripte von Sz. Gilbert zerstört, der während des Krieges ohne Unterlass schrieb, und zwar stets über die aktuellen Themen. Dasselbe geschah mit Izrael Szterns Werken aus der Kriegszeit [...] [und] mit den Tagebüchern anderer Personen. Samuel Hirszhorns Tagebuch kam irgendwo abhanden. Das Tagebuch eines jungen begabten Wirtschaftswissenschaftlers, Menachem Linder, wurde bei der Deportation in einem Moment der Verzweiflung von dessen Ehefrau verbrannt. [...] Es war bekannt, dass in Warschau zahlreiche Menschen Tagebuch führten. Doch es zeigt sich, dass nur sehr wenige von der breiten Allgemeinheit wahrgenommen werden. Der Strom der Umsiedlungen reißt alles mit sich, zerstört alles, von nichts bleibt eine Spur. Umsonst schickte man Menschen in die Wohnungen der Deportierten, wo sie nach hinterlassenen Manuskripten suchen sollten. Sie fanden nichts, war doch alles auf den Müll geworfen, alles zerstört und verbrannt worden (Bd. 1, S. 461).

Angesichts eines solchen Ausmaßes der Zerstörung wurden die Dokumente, die glücklich ins Ghettoarchiv gelangten, sorgsamst gehütet. Es galt, sie so abzusichern, dass sie den Krieg überdauern würden.

Am 3. August 1942, als auf den Straßen des Ghettos Blockaden von Häusern stattfanden und vom Umschlagplatz zwei Mal täglich Transporte abgingen, wurde der erste Teil des Archivs im Keller eines Hauses in der Nowolipki-Straße 68 auf dem Grundstück des Shops von Hallmann versteckt. Die vor Feuchtigkeit geschützten Papiere wurden in zehn Metallkisten mit einem Maß von $50 \times 30 \times$ $15 \mathrm{~cm}$ untergebracht und vergraben. Der zweite Teil der Materialien, verstaut in zwei Milchkannen, wurde Ende Februar 1943 an derselben Stelle verborgen. Den dritten Teil des Archivs brachte Marek Edelman am Vortag des Ghettoaufstands in ein Versteck auf dem Gelände des Bürstenshops an der ŚwiętojerskaStraße 34.

Nach fast genau vier Jahren - am 18. September 1946 - konnten aus den Trümmern die Metallkisten mit dem ersten Teil des Archivs geborgen werden. Am 1. Dezember 1950 fand man an derselben Stelle im Schutt die beiden Milchkannen mit dem zweiten Teil. Der dritte Teil wurde - bis auf ein paar angesengte, 
zwischen den Gesteinsbrocken des Hauses Świętojerska 34 liegende Blätter aus dem Tagebuch von Szmuel [Schmuel] Winter, Mitglied der Jüdischen Gemeinde und zugleich Untergrundaktivist, Betreuer von Oneg Schabbat - nie wiedergefunden.

Michał Borwicz, der dabei war, als das Ghettoarchiv gefunden wurde, beschreibt diesen Augenblick wie folgt:

[I]n den Kellerbereich auf dem Gelände an der Nowolipki-Straße, wo früher das Wohnhaus mit der Nummer 68 gestanden hatte, kämpften wir uns durch eine Art Schacht, den wir anlegten, indem wir die aufgehäuften Ziegelsteine beiseite schaufelten. Unter der Erde waren nur zwei Kammern zugänglich, deren Deckengebälk irgendwie durchgehalten hatte; der Rest war vollkommen verschüttet. An welcher Stelle war wohl das Archiv vergraben? Der anwesende Koll. Wasser war auch dabeigewesen, als die Kisten versteckt wurden. Damals jedoch hatte man einen anderen Weg hinein genommen; das erschwerte uns nun die Orientierung. Nach dem „Abbolzen“ des Gebälks begann das Graben: Wir wussten, dass das gesuchte Archiv sich ungefähr einen Meter unter der Bodenfläche befinden konnte. Die Schaufeln tragen einen Dezimeter Erde nach dem anderen ab. [...] Da - die Schaufel trifft auf „etwas Hartes“. Kurz darauf kommt die erste Metallkiste zum Vorschein. Danach folgen in Schichten weitere Kisten aufeinander: acht. In der anderen Kammer - zwei weitere. ${ }^{86}$

Das Ghettoarchiv war somit gefunden, doch das bedeutete noch lange nicht, dass es auch gerettet war. Die Materialien, die unter extrem schwierigen Bedingungen versteckt worden waren, hatten nicht ausreichend gesichert werden können. Die Kisten zuzulöten, hatte man damals nicht mehr geschafft. Wasser war hineingelaufen. Das Papier war aufgequollen und mit Schimmel überzogen, von Photos hatte sich die Emulsion abgelöst, die miserable „Kriegs“-Tinte war zerlaufen. In dieser feuchten, zusammengepappten Papiermasse war eine Botschaft verzeichnet, die es zu entziffern galt.

Die Texte aus dem Ringelblum-Archiv, geschrieben im Angesicht des Holocaust, zusammengetragen und sicher verwahrt unter Lebensgefahr, bestanden im brennenden Ghetto die Feuerprobe und unter dem Ghetto die Wasserprobe, um ihren Weg in der Konservatorenwerkstatt zu beschließen. Zum wiederholten Male vor der Vernichtung bewahrt, begannen sie zu sprechen:

Am 3. August 1942 um zehn Minuten nach halb zwei beende ich mein Schreiben. Ich möchte leben. Nicht nur, weil ich mein eigenes Leben retten will - sondern weil Welt und Menschen unbedingt gewarnt werden müssen! ${ }^{87}$

86 M. M. Borwicz: „Wstęp“, in: ders.: Pieśń ujdzie cało, op. cit., S. 42-43.

87 Zitat nach R. Sakowska: „Wstęp“, in: Archiwum Ringelbluma, op. cit., S. 17 (Übers. aus dem Jiddischen). 
- das ist ein Auszug aus einem Testament, das in einer der Kisten gefunden wurde. Geschrieben hat es der 18-jährige Nachum Grywacz im letzten Augenblick, bevor das Geheimfach zugemauert wurde. Dawid Graber, der ebenfalls bei der Vergrabung des Archivs zugegen war, notierte zweieinhalb Stunden später in seinem Testament:

Die Nachbarstraße ist schon umstellt. Wir spüren alle, es liegt Gefahr in der Luft. Wir stellen uns auf das Schlimmste ein. Beeilen uns. Gleich fangen wir mit den letzten Gruben an [für die Kisten] ... Hoffentlich schaffen wir es noch, sie zu vergraben ... ${ }^{88}$ Was wir nicht in die Welt hinausschreien durften, haben wir in der Erde vergraben. [...] Auf dass der Schatz in gute Hände gelange, auf dass er bessere Zeiten erlebe, auf dass er die Welt alarmiere, die im 20. Jahrhundert auf Abwege geraten ist. ${ }^{89}$

Ich möchte den Moment erleben, wenn die von uns versteckten Schätze ausgegraben werden und die Welt die ganze Wahrheit erfährt. ${ }^{90}$

Heute wissen wir, dass es ihnen gelang. Wir wissen ebenfalls, dass weder Grywacz noch Graber noch ihr ehemaliger Lehrer Izrael Lichtensztajn, der die gesamte Aktion leitete, überlebt haben.

88 Zitat nach M. M. Borwicz: „Wstęp“, in: ders.: Pieśń ujdzie cało, op. cit., S. 45 (Übers. aus dem Jiddischen).

89 Zitat nach A. Eisenbach: „Wstęp“ [Einleitung], in: E. Ringelblum: Kronika getta warszawskiego, op. cit., S. 18 (Übers. aus dem Jiddischen).

90 Zitat nach R. Sakowska: „Wstęp“, in: Archiwum Ringelbluma, op. cit., S. 17 (Übers. aus dem Jiddischen). 


\section{Gründe für das Schreiben}

Das Papier, auf dem die Chroniken des Holocaust festgehalten waren, wurde auf die Erde geworfen wie ein Samenkorn für eine künftige Ernte. So sah es der jüdische Dichter Abraham Sutzkever im Wilnaer Ghetto im März 1943. Sein Gedicht „Kerndlekh vayts“ [Weizenkörner] ist ein Kommentar zu einer Aktion, an der Sutzkever sich beteiligte und bei der Bücher und Manuskripte aus dem Jüdischen Wissenschaftlichen Institut in Wilna und der dortigen M.-StraszunBibliothek versteckt wurden:

Grab ich und pflanz Manuskripte, und geht mir der Mut verlorn, dann denk ich an Ägypten die Geschichte vom Weizenkorn.

Und ich erzähle den Sternen:

Einst baute ein Pharao seine Pyramide am Nil und fand nach seinem Tode da sein ewiges Domizil.

Man hat auch einen goldnen

Sarg hineingestellt voll Weizen - zum Gedenken an unsere Erdenwelt.

Neuntausend Jahre lang haben

Wüstensonnen gebrannt, wo man, erst vor kurzem, die Weizenkörner fand.

Nun hat man nach all den Zeiten die Körner ausgestreut, und mit sonnigen Ähren blühen sie erneut.

Auch in unseren Wäldern geht das Licht seinen Lauf, und zu guter Stunde

blüht Vergrabenes wieder auf.

Wie es uraltem Weizen wieder zu blühen gelang, 
also nähren die Wörter, also gehören die Wörter dem Volk bei seinem ewigen Gang. ${ }^{11}$

Die aktuellen Umstände von Ort und Zeit - bedenken wir, dass das Werk auf den März 1943 datiert ist - werden durch Gleichnis, Allegorie, Metapher verhüllt. Sutzkevers Gedicht spricht von der Hoffnung, in einem sich erneuernden Rhythmus der Kultur zu überdauern. Das Samenkorn widersetzt sich dem zerstörerischen Wirken der Zeit, birgt es doch in sich eine Energie, welche die organische Welt lebendig macht. In der Welt der Kultur ist jene Energie die Kraft des geschriebenen - im Text verewigten - Wortes, die darin verborgen liegt wie in einem Samenkorn. Ein flüchtiger Moment lässt sich dauerhaft machen dank des Wortes, das ihn formuliert. Die Spur des Moments hat die Chance, zu überdauern, wenn sie schriftlich festgehalten wird. Der Text ist eine Anlage für die Zukunft. Er kann lange im Verborgenen liegen wie ein Korn in der Erde, bis die Zeit der Ernte kommt, wenn er - gelesen - wieder auflebt und erblüht.

Erstaunlich klingen die „Weizenkörner“ aus dem Wilnaer Ghetto, wenn man Ossip Mandelstams Strophen im Gedächtnis hat. 20 Jahre vor Sutzkever - im Jahr 1923 - schrieb er in seinem Gedicht „Der Hufeisenfinder“:

Was ich jetzt sage, sage nicht ich,

Es ist ausgegraben aus der Erde, Körnern gleich von versteinertem Weizen. ${ }^{92}$

Ein „Korn von versteinertem Weizen“ führt uns ein in das Ewige Jetzt der Kultur. Die großen Tempel der Menschheit waren für Mandelstam Lager für Samenkörner. „Das Korn“, schreibt Ryszard Przybylski in einem Essay über Mandelstams Dichtung, „ist grundlegende Nahrung für die jüdisch-christliche Zivilisation. [...] Als potenzielle Möglichkeit, als formgebende Kraft lebt in ihm die Zeit der zukünftigen blühenden Ähren. Mit einem Wort, das Korn ist ein Symbol für die Existenz, da es hier und jetzt existiert und in sich die Existenz anderer Körner nach deren Tod oder vor deren Leben birgt. ${ }^{\text {“93 }}$

Die Tätigkeit der Wortkunst wird eingegliedert in die uralte Ordnung von Saat und Ernte. Die Niederschrift überdauert, leben jedoch heißt, zu schaffen oder Texte zu lesen. Wieder erteile ich Przybylski das Wort: „Für Mandelstam ist

91 A. Sutzkever: „Weizenkörner“, in: ders.: Gesänge vom Meer des Todes, dt. Übers. von H. Witt, Zürich 2009, S. $73 f$.

92 Übers. v. R. Dutli, Zitat aus: O. Mandelstam: Bahnhofskonzert. Das Ossip-MandelstamLesebuch. Frankfurt/Main 2015, S. 139.

93 R. Przybylski: Wdzięczny gość Boga. Esej o poezji Mandelsztama [Gottes dankbarer Gast. Ein Essay über Mandelstams Dichtung], Paris 1980, S. 95. 
der Inhalt der Zeit vor allem das Lesen von Texten. Natürlich frisst die Zeit den Menschen auf, doch ist sie machtlos gegenüber der geistigen zwischenmenschlichen Kommunikation. Im tatsächlichen Austausch von Texten ist ein Sieg über die Zeit angelegt. Jeder Mensch existiert für seine Nächsten nur als mehr oder weniger beständiger Text. [...] Du musst sterben, existierst aber weiter, solange Menschen deinen Text lesen. ${ }^{\text {"94 }}$

Der Text wird zur lebenspendenden Nahrung. Zu einem solchen Verständnis führt die der Symbolik des Korns komplementär gegenüberstehende, in der Bibel tief verwurzelte Symbolik des Wortes als Brot. Das Wort lässt sich - ebenso wie das Brot - mit anderen Menschen teilen. Das Teilen des Wortes kennt keine zeitliche oder räumliche Beschränkung. Es schafft eine Gemeinschaft, einen ursprünglichen Raum des Menschen, verstanden gemäß der klassischen aristotelischen Definition als sprechendes, einen Logos besitzendes Wesen.

Das Lesen hält somit nicht nur den Autor der gelesenen Worte am Leben, es nährt auch den Leser, erlaubt ihm, an einer lebendigen Gemeinschaft von Schreibenden und Lesenden teilzuhaben. Es scheint, als hätte Niccolò Machiavelli ebendies im Sinn gehabt, als er am 10. Dezember 1513 an Francesco Vettori schrieb:

Wenn der Abend kommt, kehre ich nach Hause zurück und gehe in mein Schreibzimmer, und auf der Schwelle werfe ich das schmutzige Alltagsgewand ab und lege königliche Hoftracht an und betrete so passend bekleidet die Hallen der Männer des Altertums, die mich liebevoll aufnehmen, und wo ich mich von der Speise nähre, die mir allein angemessen und für die ich geboren bin..$^{95}$

Die Metaphorik, die den Akt des Schreibens als die Aussaat von Samenkörnern im Gedanken an eine spätere Ernte darstellt, enthüllt eine universale Ordnung der Kultur. In diese Ordnung fügt sich die Situation ein, in der im Antlitz des Holocaust schriftliche Zeugnisse verfasst werden. Das Gleichnis vom Weizenkorn, das nach Tausenden von Jahren aus einer ägyptischen Pyramide geholt wird, markiert den Horizont der Hoffnung all jener, die schrieben, ihre Texte anschließend versteckten und daran glaubten, sie als geistige Nahrung für die Zukunft zu verwahren. Die Symbolik des Vergrabens und der Aussaat von Manuskripten aus Sutzkevers Gedicht weist daher die Denkrichtung in der Titelfrage „Warum wurde geschrieben?“ Die Reflexion über diese Frage wird erstens die direkt ausgedrückten Motivationen für das Schreiben und zweitens die Traditionen und Werte hinter der Entscheidung zum Schreiben umfassen.

94 Ebd., S. 121.

95 Zitat aus: Machiavelli. Der Fürst, dt. Übers. von F. von Oppeln-Bronikowski. Frankfurt/ Main 1990. 


\section{„Schreibe! Notiere!“}

Eine lakonische Formel der höchsten moralischen Pflicht, von denen sich die Verfasser der Holocaustzeugnisse leiten ließen, und zugleich die knappste aller möglichen Arten, die Motivation ihres Schreibens zu erfassen, sprach Simon Dubnow aus. Der 81-jährige jüdische Historiker, der bei der Liquidierung des Rigaer Ghettos am 30. November 1941 ermordet wurde, soll einer Legende zufolge auf seinem Weg in den Tod, malträtiert und geschunden, seinen Landsleute zugerufen haben: „Schreibt alles auf und haltet es fest! ... Ihr Menschen, merkt es euch! Ihr Menschen, erzählt davon, beschreibt es! ... ${ }^{\text {“96 }}$ Das Schreiben ist vor allem ein mächtiger innerer Imperativ, der manchmal mit einer religiös gearteten Verpflichtung in Verbindung gebracht wird:

Ein schwerer Stein erdrückt die schwache Brust, und das Herz schlägt nur mehr schwach seinen Takt. Schwerfällig schiebt sich der Füller übers Papier und schwerfällig nur noch arbeitet das Gehirn. Aber schreiben muss ich. Ich muss wenigstens vor Gott den Strom unseres Leidens ausgießen (Rotgeber, S. 195).

Es ist eine innere Stimme, der man sich nicht entziehen kann und deren Befehl der Autor folgen muss. Stanisław Adler:

Wie Feuer verzehrt mich das überwältigende Bedürfnis, so schnell wie möglich alles aufzuschreiben, was uns in diesen Kriegsjahren geschehen ist. [...] Entsetzen packt mich bei dem Gedanken, dass die Gefahren, die uns von allen Seiten drohen, mich daran hindern könnten, dieses Manuskript fertigzustellen (S. 3).

Mary Berg:

Was kann sich schon Gutes aus dem Schreiben ergeben? Wen interessiert mein Tagebuch? Ich habe schon mehrmals daran gedacht, es zu verbrennen, aber eine innere Stimme verbat es mir.

Dieselbe Stimme befiehlt mir jetzt, all die Ungeheuerlichkeiten zu schildern, von denen ich im Laufe der letzten paar Tage gehört habe (S. 243).

Marian Berland:

Schon jetzt, schon heute muss man anfangen, aufzuschreiben, was wir gesehen haben, welcher Ereignisse wir Zeugen geworden sind, wie man uns mordet und quält, wie man uns körperlich und seelisch zu brechen versucht. Schreiben, solange Zeit ist, schreiben, so lange die Erinnerung es erlaubt (S. 411).

Chaim Kaplan, Eintrag vom 10. März 1940:

96 Auf Jiddisch: Yidn, shraybt un farshraybt!, siehe Enzyklopädie jüdischer Geschichte und Kultur, Bd. 6, Te-Z, S. 549. 
Selbst an den gefährlichsten Kriegs- und Besatzungstagen, als feindliche Flieger uns unter einem Bombenhagel begruben, setzte ich mein Tagebuchschreiben nicht aus. Ich verspürte ein inneres Bedürfnis, das Geschehen auf Papier zu verewigen. Unablässig drohte mir der Tod, dennoch widmete ich mich auch damals der ganzen gottgefälligen Mühe. Es war, als steckten übermenschliche Kräfte in mir (BŻIH 45-46, S. 207).

Die Situation der Schreibenden gleicht, will man sie psychologisch interpretieren, einem Zustand der Besessenheit. In kulturellen Kategorien betrachtet jedoch lässt sie den Gedanken an ein beseeltes Schreiben aufkommen, das sich im Rahmen einer auf besondere Weise begriffenen Prophetie ansiedelt. Auf besondere Weise - beruht diese Prophetie doch hier nicht auf Prophezeiung, auf der Vorhersage zukünftiger Ereignisse, der Übermittlung einer göttlichen Botschaft, der Funktion als Medium für die göttliche Stimme. Sie verwirklicht sich vielmehr in einem kategorischen und keinen Widerstand duldenden Gebot, zu schreiben und zu bezeugen. Der Schreibende handelt in dem Gefühl, eine Mission zu erfüllen - im Namen derer zu sprechen, die nicht mehr sprechen können. Er hat eine Wahrheit zu überbringen, die die Welt erfahren muss. Der Imperativ des Schreibens ist so stark und so unleugbar, dass seine Quelle nicht nur die selbstständige Entscheidung des Schreibenden sein kann. Indem der Autor auf diese seine innere Stimme reagiert, stellt er sich in einen Dienst und erfüllt eine Aufgabe, die weit über seinen Privatbereich hinausgeht. Die Frage des eigenen Überlebens tritt in den Hintergrund angesichts der Rolle, die zu spielen ihm gegeben ist.

Der Kampf um meine persönliche Rettung wird hoffnungslos [...] - Doch das ist unwichtig. Denn meinen Bericht kann ich zu Ende führen, und ich vertraue darauf, dass er zur rechten Zeit ans Tageslicht gelangt (Ernest, „Pamiętniki“, Sign. 195, „Posłowie“ [Nachwort]).

Ein Prophet handelt, obwohl ihm Gefahr droht, aller Verzweiflung und Entmutigung zum Trotz. Und er überwindet seine eigene, menschliche Willensschwäche. Aus den Ghettozeugnissen lässt sich eine ähnliche Entschlossenheit herauslesen. Der Autor befindet sich in einer unfreiwilligen Situation. Nicht er selbst trifft die Wahl, sondern er wird ausgewählt, auserwählt. Ein Entrinnen ist nicht möglich, er muss die Mission antreten.

Eine so verstandene Haltung drückt sich am vollständigsten in Chaim Kaplans Tagebuch aus. Der auf Hebräisch geschriebene Text knüpft allein durch die Sprachwahl an die biblische Urquelle an. Es scheint auch, als nehme der Autor manchmal die eigene Situation als vorherbestimmt durch eine Art biblischer Prophetie wahr. Davon zeugen nicht nur direkte Formulierungen, sondern auch die Sprache der Symbole, welche Kaplan verwendet: 
Ich bin einer der Glücklichen, deren Feder selbst in dieser Wahnsinnsstunde nicht rastet. Jeder, der solche Berichte aufzeichnet, gefährdet sein Leben, aber das schreckt mich nicht ab. Ich ahne in meinem Innern die Größe dieser Stunde und meine Verantwortung ihr gegenüber, und ich bin mir bewußt, daß ich eine nationale Pflicht erfülle, eine historische Verpflichtung, der ich mich nicht nach meinem Belieben entziehen darf. [...] [I]ch bin sicher, daß mich die Vorsehung sandte, um diese Mission zu erfüllen (Buch der Agonie, S. 124).

Der Tagebuchschreiber ist demnach entsandt worden, um eine Mission zu erfüllen. Auch angesichts der allgegenwärtigen Bedrohung rastet seine Feder nicht und klingt seine Stimme weithin. In all dem Unglück bricht sein Rufen nicht ab, wie in Jeremias Klageliedern über die Zerstörung Jerusalems. An einer Stelle wählt Kaplan seine Worte ganz deutlich im Tonfall jenes Propheten:

Ein seltsamer [...] Gedanke will mir seit Kriegsausbruch nicht mehr aus dem Sinn. [...] Dieser Gedanke brennt in mir und ruft: „Schreibe! Notiere!“ (BŻIH 50, S. 107).97

Das Gebot, Zeugnis zu geben über den Holocaust, entflammte die Schreibenden gleich einem inneren, die Eingeweide verzehrenden Feuer. Jizchak Katzenelson oder Chaim Kaplan übernehmen vollkommen bewusst die biblische prophetische Formel, in die ein Spannungsfeld zwischen Verzweiflung und Hoffnung, Zorn und Ergebenheit, Aufbäumen und Vertrauen eingeschrieben ist. Beide waren vor dem Krieg Bibellehrer in der Schule, beide waren außerdem zionistische Intellektuelle, und die Bibel war für sie vor allem kultureller Code, Sprache universeller Werte. Daher erscheinen bei ihnen die Figuren von Propheten, von Vertreibung, die Figur Hiobs als Methoden einer Artikulation von historischen, ethischen und metaphysischen Dimensionen der Ghettoerfahrung ${ }^{98}$. Und auch

97 Die Metapher eines inneren Feuers, die den Imperativ des Schreibens zum Ausdruck bringen soll, lässt an eine Textstelle aus dem 20. Kapitel des Buches Jeremia denken. Jeremia, der die Zerstörung Jerusalems voraussagt, will wegen der Sinnlosigkeit seines Mahnens - man lacht ihn lediglich aus, verachtet, quält ihn und hört vor allem nicht auf seine Worte - die göttliche Mission aufgeben und verstummen: „Sagte ich aber: Ich will nicht mehr an ihn denken und nicht mehr in seinem Namen sprechen!, so brannte in meinem Herzen ein Feuer, eingeschlossen in meinen Gebeinen. Ich mühte mich, es auszuhalten, vermochte es aber nicht“ (Jeremia 20,9). Ein Prophet ist Gottes Sklave und kann seiner Berufung nicht entrinnen. Jonas versuchte es, Jeremia dachte daran, doch beide waren nicht imstande, das Feuer des göttlichen Wortes in sich zu löschen und den eindringlichen Befehl, es zu verkünden, beiseitezuschieben.

98 D.G. Roskies schreibt, es gebe kein Werk mit einer größeren Fülle von kulturellen Anspielungen als Katzenelsons Großer Gesang vom ausgerotteten jüdischen Volk, in dem sowohl altertümliche als auch heutige Stimmen der Vernichtung erklingen - von den Klageliedern und den Propheten bis hin zu Chaim Nachman Bialik (1873-1934), 
als Formen der Beschreibung ihrer eigenen existenziellen Situation. Katzenelson wendet sich in seinem Großen Gesang vom ausgerotteten jüdischen Volk an seinen bei der Liquidierungsaktion deportierten Sohn Ben-Zion: „Mein Benni, Frühgeniechen, du verstehst es mühelos/Des letzten Jidden letztes Klagelied $[\ldots]^{\text {“99 }}$. Kaplan wiederum verleiht mit dem Bezug auf die biblische Symbolik eines seine Gedanken verzehrenden Feuers seiner prophetischen Versklavung Ausdruck, die sich im Gebot „Schreibe! Notiere!“ bündelt.

\section{„Alarmieren und das Gewissen der Welt erschüttern“}

Die Gefangenen des Sonderkommandos in Birkenau versteckten ihre Manuskripte in Einmachgläsern, deutschen Feldflaschen aus Aluminium, Feldgeschirr und vergruben diese in menschlicher Asche. Die Gruben mit der Asche aus den Krematorien schienen ihnen der sicherste Ort zu sein. So wurde die Geschichte des ausgerotteten Volkes in dessen eigener Asche verborgen. Salmen Gradowski schreibt Folgendes über sein Tagebuch:

Ich habe es begraben in einer Aschengrube als sicherstem Platz, an dem man sicher graben wird, um Spuren von den Millionen Umgekommener zu suchen. [...]

Dieses Büchlein sowie noch andere haben in den Gruben gelegen.

Es hat Blut an sich gezogen von zeitweise nicht ganz verbrannten Knochen oder Stücken Fleisch. ${ }^{100}$

Auf einer durchfeuchteten Papierrolle, die zusammen mit einem Stapel anderer Papiere geborgen werden konnte, hatte Salmen Lewenthal den von ihm vergrabenen Schriftstücken einen Kommentar beigefügt. Trotz der Beschädigungen lässt sich die einfach formulierte Botschaft entziffern:

Alles weitere überlasse ich den Historikern und Wissenschaftlern.

Wir unsererseits verbergen alles, was interessant, brauchbar ist, Wort, Schrift [...] Nachrichten, die ganz sicher interessieren und nützlich sein werden für einen zukünftigen Historiker.

dem hebräischen Dichterpropheten der Neuzeit (Against the Apocalypse. Responses to Catastrophe in Modern Jewish Culture, Cambridge, Mass. 1984, S. 223).

99 J. Katzenelson: Großer Gesang vom ausgerotteten jüdischen Volk, op. cit., Zweiter Gesang, S. 58-59 [im jiddischen Original: „her, Benzik'l mein junginker, mein go'en, $d u$ varstehst/an' ejche-lied a letzts vun letztn, letztn jid“].

100 Zitat aus: S. Gradowski: Die Zertrennung - Aufzeichnungen eines Mitglieds des Sonderkommandos, hg. von A. Kalisky, aus dem Jiddischen von A. Seiffert, Berlin, erscheint 2018. 
[...] gibt das den zukünftigen Wissenschaftlern, Historikern, und mehr noch den Psychologen ein klares Bild und [wirft] ein Licht auf die Geschichte dieser Ereignisse und Leiden $[\ldots]^{101}$

Am Ende seines Tagebuchs, das er beim Krematorium III in Birkenau in der Erde vergrub, schreibt der Autor: „[...] erachte ich es deshalb als meine Pflicht, es so zu verbergen, dass es lange Zeit übersteht. Auch deshalb, damit [...] Mühe nicht umsonst war. Und mehr [noch] deshalb, damit die Welt in der Zukunft [... ${ }^{\text {“102 }}$.

In den Schriften kehrt daher die inständige Bitte wieder:

Suchet gut, und ihr werdet vieles finden. [...] Sucht das noch verborgene, umfangreiche Material, das dir, du große Welt, noch viel Nutzen bringen wird [...]. Sucht dort in den Gruben. [...] Suchet weiter! Ihr werdet noch mehr finden,

sowie die Hoffnung, dass „es jemandem gelingt, unsere Dokumente zu finden, das, was innerhalb der Mauern des schwarzen Gebäudes aufgeschrieben werden konnte. “103

Die aus den Todesgruben geborgenen Aufzeichnungen ${ }^{104}$ der in Katyń ermordeten polnischen Offiziere enthalten keine Reflexionen über die Motivation zum Schreiben. Es kommen keine Appelle oder Aufrufe an die Leser vor, keine Kommentare zum Inhalt der Aufzeichnungen und zur Rolle, die sie in der Zukunft spielen sollten. Auch ist nichts darüber vermerkt, dass es gefährlich gewesen sei, Tagebuch zu führen, oder dass die Tagebücher versteckt gehalten werden müssten. Die Autoren hatten keine besonderen Gründe, ihr Schreiben als etwas zu betrachten, das über private, zur eigenen Erinnerung notierte Einträge in Kalendern oder Terminplanern hinausging. Wenn auch alles schwankend und unbekannt war, so gingen doch weder ihr persönliches Schicksal noch die sie umgebende Realität in besonderem Maße über eine vorhersehbare Erfahrung hinaus. Sie verzeichnen somit aufeinanderfolgende Ereignisse, die Routen der Durchmärsche und Etappen von Konvois, die Topographie des Lagers, das

101 Siehe Inmitten des grauenvollen Verbrechens. Handschriften von Mitgliedern des Sonderkommandos, Verlag des Staatlichen Auschwitz-Birkenau Museums, Oświęcim 1996, S. $192-197$.

102 Ebd., S. 196.

103 Ebd., S. 193-197. Salmen Lewenthals Manuskript wurde nach einer konservatorischen Behandlung gelesen, vom Jiddischen ins Polnische übersetzt und zum ersten Mal im Buch „Szukajcie w popiołach“. Papiery znalezione w Oświęcimiu [„Sucht in der Asche“. In Auschwitz gefundene Papiere], Łódź 1965, veröffentlicht.

104 Ich beziehe mich auf 20 gefundene Texte, die im Band Pamiętniki znalezione w Katyniu [Tagebücher aus Katyń], Vorwort von J. Zawodny, 2., erweiterte Auflage, Paris, Warschau 1990 veröffentlicht wurden. 
Alltagsleben der Kriegsgefangenen, verschiedene Gerüchte, Familienerinnerungen, persönliche Geheimnisse. Wenn die Verfasser den Leser direkt ansprechen, dann vor allem in Äußerungen, die sich an die abwesende Ehefrau oder die Kinder richten. Eine solche Aufzeichnung hat den Charakter eines Privatgesprächs mit den nächsten Mitmenschen, denen der Verfasser seine Sehnsüchte, seine Liebe, seine Sorgen mitteilt.

Die Notizen der Offiziere lassen zwar eine Angst vor dem Unbekannten spüren, aber nicht die Vorahnung dessen, als was dieses Unbekannte sich erweisen könnte, wenn sie auch in einigen Fällen fast bis zum Zeitpunkt der Hinrichtung verzeichnet werden. Das volle Wissen um das, was ihnen bevorstand, war den Verfassern erst im letzten Moment gegeben - am Rand der Todesgruben -, sodass sie es nicht mehr schriftlich festhalten konnten.

Die Schriften aus der Asche von Birkenau und aus den Gräbern von Katyń unterscheidet vor allem der Wissensstand ihrer Autoren. Die polnischen Offiziere gingen als Soldaten einer regulären Armee in die Gefangenschaft; sie sollten eigentlich durch von der internationalen Gemeinschaft anerkannte Grundregeln des Umgangs mit Kriegsgefangenen geschützt werden. Lange Zeit hatten sie auch keinen Grund, an einer solchen Lage der Dinge zu zweifeln. Die Juden aus dem Sonderkommando von Birkenau befanden sich in einer prinzipiell anders gearteten und vollkommen neuen Situation; sie waren sich der Außergewöhnlichkeit der von ihren übermittelten Erfahrungen zur Gänze bewusst. Inhalt ihrer Aufzeichnungen, zu deren Suche sie so eindringlich aufriefen, ist all das, dessen Zeuge sie wurden und das weit über die bis dahin geltenden Grenzen des begreifbaren Schicksals des Einzelnen und der Gemeinschaft hinausging. Die Beziehungen zwischen dem Privaten und dem Öffentlichen unterlagen nämlich einem Wandel. Das individuelle Schicksal wurde dem kollektiven Schicksal gleichgemacht, das „Ich“ in ein „Wir“verwandelt. Der Holocaust betrifft schließlich nicht das Individuum, sondern die Gemeinschaft. Er verändert außerdem die gesamte Welt, die nie mehr sein wird wie zuvor. Was die Autoren so unbedingt zu vermitteln suchen, ist auch in dem Sinne eine Grenzerfahrung, dass es sich als endgültige Ausrottung, definitives Ende präsentiert.

Aus der Tiefe jener Erfahrung - im wortwörtlichen Sinne: aus dem Versteck unter menschlicher Asche - ertönt eine Stimme an die Welt. Das Wissen um den Holocaust muss mit anderen geteilt werden. Die Wahrheit des Holocaust ist eine untragbare Last, doch muss sie um jeden Preis verbreitet werden; sie ist schließlich der einzige Schatz, den die Opfer den zukünftigen Generationen hinterlassen können.

Dawid Graber, der beim Verstecken des Ringelblum-Archivs half, war überzeugt, einen „Schatz“ zu vergraben. Er schrieb: „[A]uf dass [dieser Schatz] die 
Welt alarmiere, die sich im 20. Jahrhundert verloren hat. [...] [Auf dass] die Welt

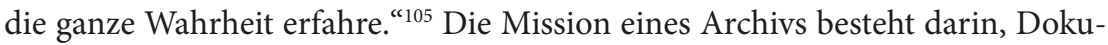
mente zu sammeln, zu verwahren und weiterzugeben - Zeitdokumente. Damit die Welt es erführe. Im Juni 1942 notiert Ringelblum auf die Nachricht hin, dass die BBC Sendungen ausstrahlt, die auf Aussagen von Archivmitarbeitern über die Judenvernichtung in Polen basieren, mit unverhohlenem Stolz und voller Freude:

Die Gruppe „Oneg Schabbat" hat auf diese Weise eine historische Mission erfüllt, hat sie doch die Welt über unser Schicksal alarmiert und vielleicht Hunderttausenden polnischer Juden vor der Vernichtung bewahrt. Letzteres wird, das liegt klar auf der Hand, die nächste Zukunft zeigen. Ich weiß nicht, wer aus dieser Gruppe überleben wird [...]. Eines ist aber uns allen klar: Unsere Mühe und Anstrengung, unsere Aufopferung und unser Leben in ständiger Angst waren nicht vergebens. [...] Wir haben unsere Pflicht erfüllt (Bd. 1, S. 369).

„Die Welt alarmieren“ heißt, Fakten offenlegen, dafür sorgen, dass die Menschen sie erfahren. Henryk Makower notiert: „[M]an muss das alles beschreiben, für sich selbst, vor allem aber für andere, damit die Menschen wissen, was 19401943 in Warschau geschah" (S. 149). Das Bedürfnis, dieses Wissen weiterzugeben, ist stärker als die Sorge um das eigene Schicksal. Stefan Ernest lässt sein Tagebuch mit einem refrainartig wiederkehrenden Aufruf enden:

Ich vertraue darauf, dass [mein Bericht] zur rechten Zeit ans Tageslicht gelangt ... Und dann werden die Menschen wissen, wie es war ... [...] Sollen die es erfahren, die weniger gesehen und weniger gehört haben vom genaueren Verlauf der Realität. Sollen die Menschen in anderen Ländern es erfahren [...] und die Menschen, die das Glück hatten, keine Juden zu sein [...]. Sollen sie wissen, was sich damals ereignete [...]. Sollen sie wissen, dass jedes einzelne Wort hier von Blut befleckt ist ... („Pamiętniki“' Sign. 195, „Posłowie“ [Nachwort]).

„Das Gewissen der Welt erschüttern“ bedeutet, anzunehmen, dass das enthüllte Faktenwissen bei den Adressaten nicht nur moralische Erschütterung, sondern auch einen moralischen Wandel auslöst. Der Verfasser eines Textes, der solche Folgen zeitigen soll, glaubt, dass die Wiederherstellung der erschütterten Ordnung möglich ist. Indem er das Grauen der durchlebten Katastrophe vermittelt, drückt er die Hoffnung aus, das Geschriebene möge nicht nur dokumentarischer Bericht sein, sondern auch Lehre und Warnung. So sieht den Zweck seines Schreibens Karol Rotgeber:

105 Zitat nach R. Sakowska: „Wstęp“, in: Archiwum Ringelbuma, op. cit., S. 17. 
Ich suche nach einer Methode, an das menschliche Gewissen zu rühren, einen Weg dafür zu finden. [Ich glaube daran, dass mein Tagebuch] wenigstens teilweise diese unsere schreckliche Zeit mit ihren Morden, ihren Brände und ihrem Blut [beleuchtet] [...], [dass] in dem Chaos [...] die Konturen dieses wahrhaft unerhörten Verbrechens sichtbar werden, das in seiner Niedertracht und unfassbaren Widerwärtigkeit selbst die abgestumpftesten Herzen anrührt und seine Täter mit ewiger Schande bedeckt (S. 43; „Wstęp“ [Einleitung]).

Avrom Levin verzeichnet am Abend des 30. Mai 1942:

Die Details dieser Ereignisse sind so ungeheuerlich, dass sie sich unter keinen Umständen in Tagebucheinträge pressen lassen. All das muss genau und in allen Einzelheiten geschildert werden. Ich hoffe und glaube, dass dies geschehen und das Gewissen der Welt erschüttern wird, und dass es dazu beiträgt, das Ungeheuer, das alle Völker Europas drangsaliert, ein für alle Mal zu zähmen und unschädlich zu machen (BŻIH 19-20, S. 196-197).

Ludwik Hirszfeld erklärt in erhabenem Stil die Entscheidung, seine Erinnerungen an die Besatzungszeit niederzuschreiben:

[I]ch beschloss, zur Stimme derer zu werden, die gelitten haben, auf dass diese Stimme jene erreiche, die noch zu fühlen imstande sind. Aus meinem Schmerz, so beschloss ich, wollte ich eine Waffe schmieden, um an das Gewissen zu rühren [...] (S. 322).

So musste ich aus meinem Leben eine Geschichte formen, damit ihr wisst: Es waren Millionen Menschen, die dort ermordet wurden. [...]

Besitzen die Toten keine Stimme? Dieses Buch habe ich geschrieben, um ihnen eine Stimme zu geben. Damit die Welt ihr Klagen, ihr Seufzen hört. Und so lange soll sie es hören, wie der unermessliche Schmerz der Gemarterten dauern wird, so lange, wie die Glut meiner Worte sich erhält.

Es darf nicht sein, dass Wehrlose ermordet werden.

Ich will, dass es bis ins zehnte Glied noch erklingt, sich in die Gewissen der Menschen brennt, dass es eingegraben wird in ihre Seelen für alle Zeit (S. 344).

\section{„Für ein zukünftiges Tribunal“ - „der Rache wegen“}

Der israelische Geheimdienst entführte im Mai 1960 Adolf Eichmann aus Argentinien und brachte ihn nach Israel. Dort stand er vom 11. April bis 15. Dezember 1961 vor Gericht, bis der Oberste Gerichtshof sein Todesurteil verkündete, das am 1. Juni 1962 vollstreckt wurde. Eichmann wurde gehängt, anschließend verbrannte man seinen Leichnam und verstreute die Asche auf hoher See. Kurz vor der Exekution bat der Verurteilte um eine Flasche Rotwein. Auf den Stufen zum Galgen hielt er seine letzte Rede, ein Konglomerat von verzweifelten Phrasen, in dem dieser Mörder von Millionen Juden, der im Lichte der Anklage wie 
ein blutrünstiges Ungeheuer wirkte, endgültig - wie Hannah Arendt schreibt die „furchtbare Banalität des Bösen“"106 enthüllte.

Der Eichmann-Prozess war der erste große Prozess, dessen einziger Gegenstand die Massenvernichtung der Juden war. Daher maß David Ben Gurion, der israelische Ministerpräsident und „Bauherr des Staates Israel“, ihm auch besondere Bedeutung bei. Der Prozess sollte seiner Meinung nach der gesamten Welt eine große Lektion werden. Ben Gurion schrieb unter anderem: „Wir wollen vor den Nationen der Welt zeigen, wie Millionen Menschen, weil sie Juden waren, und eine Million Babys, weil sie jüdische Babys waren, von den Nazis ermordet wurden. [...] Wir wollen, daß die Nationen der Welt [all dies] erfahren ... und daß sie sich schämen. ${ }^{107}$

Die Rhetorik der Autoren von Holocaustberichten, die Ausdruck findet in Formulierungen wie „alarmieren und das Gewissen der Welt erschüttern“ oder Motiven wie dem des „zukünftigen Tribunals, das die Schuldigen zur Verantwortung zieht" (Ringelblum, Bd. 1, S. 480) läuft mit der Rhetorik jener zusammen, denen es nach dem Krieg gegeben war, die Täter des Holocaust zu richten. Zum Schlüsselbegriff wird der Begriff des „Zeugnis“, verstanden sowohl im rechtlichen als auch moralischen Sinne. Genau so, stellt sich Marian Berland vor, könnte sein Tagebuch genutzt werden:

Es ist nicht auszuschließen, dass ein Tagebuch der Juden, der Augenzeugen des Verbrechens, in der Zukunft ein unschätzbar wertvolles historisches Dokument sein wird, ein Zeugnis des Verbrechens, eine Anklageschrift [...]. Es handelt sich hierbei schließlich um Material für den Staatsanwalt, der [...] die Verbrecher anklagen wird (S. 414).

Ähnlich begreift Jan Mawult den Sinn seines Schreibens: „,[D]iese Erinnerungen [...] sind eine Anklage an die einzigen, die wahren Schuldigen“ („Pamiętniki“, Sign. 38, S. 2). Für Robert G. Storey wiederum, einen der amerikanischen Kläger im Nürnberger Prozess gegen die Hauptkriegsverbrecher, ist es eine der wichtigsten Aufgaben des Internationalen Militärgerichtshofs, „eine geschlossene Dokumentation des Hitlerregimes vorzulegen, die der Prüfung durch die Geschichte standhält" ${ }^{\text {"108 }}$.

Jenes „zukünftige Tribunal“, für das das Ringelblum-Archiv seine Dokumentation zusammenstellte, sollte über präzedenzlose Verbrechen richten, die alles übertrafen, was die Geschichte bis dahin kannte. So bewerteten die Opfer

106 Siehe H. Arendt: Eichmann in Jerusalem. Ein Bericht von der Banalität des Bösen, München 1964, S. 300.

107 Ebd., S. 33-34.

108 Ebd., siehe „Epilog“. 
selbst diese Verbrechen, und an diesem ihrem Charakter maßen sie auch die Bedeutung ihres Zeugnisses. Die Nachkriegsjustiz stand also vor einer nie da gewesenen Herausforderung. Sie musste eine Definition für eine neue Art von Verbrechen erstellen, ein ganzes Knäuel von rechtlichen, moralischen und politischen Fragestellungen entwirren. Der Wille zur Verurteilung von Kriegsverbrechern - auch denjenigen, die für den Holocaust verantwortlich waren -, den die Alliierten noch während des Krieges bekundet hatten, führte letztendlich zur Ernennung des Internationalen Militärgerichtshofs und zum Nürnberger Hauptkriegsverbrecherprozess, der vom 18. Oktober 1945 bis zum 1. Oktober 1946 dauerte. In Artikel 6 des Statuts des Internationalen Militärgerichtshofs, auf dessen Grundlage die Schuldigen in Nürnberg verurteilt wurden, waren drei Verbrechenskategorien angeführt und definiert: Verbrechen gegen den Frieden, Kriegsverbrechen und Verbrechen gegen die Menschlichkeit. Das Verbrechen des Völkermords fand seine definitive rechtliche Regelung in einer 1948 von der UNO verabschiedeten speziellen Konvention. ${ }^{109}$

Jedoch lässt sich das Wesen des Verbrechens Völkermord nicht in den Rahmen der bis dahin geltenden gerichtlichen Tradition und juridisch begriffenen Rechtsprechung fassen. Es entsteht ein Ungleichgewicht zwischen der Dimension des Verbrechens einerseits und Gerichtsverfahren und Urteil andererseits. Die Einhaltung der grundlegenden Prinzipien für Gerichtsverfahren, wie zum Beispiel Neutralität oder die Regelung, im Zweifel zugunsten des Angeklagten zu urteilen, scheinen in diesem Fall dem intuitiven Gerechtigkeitsempfinden und dem Bedürfnis nach Wiedergutmachung entgegenzustehen. Achse jenes schwerwiegenden Konflikts ist die Notwendigkeit, die von einer zivilisierten menschlichen Gesellschaft erarbeiteten fundamentalen rechtlichen Werte auf Taten anzuwenden, die nicht einmal mehr eine Verletzung dieser Werte bedeuten,

109 Bereits am 13. Januar 1942 gaben die Alliierten die sog. Declaration of St James's Palace heraus. Auf Grundlage des Londoner Statuts [der Nürnberger Charta], das nach Ende der Kriegshandlungen am 8. August 1945 geschlossen wurde, richtete man den Internationalen Militärgerichtshof ein. Siehe die Einträge „Trials of War Criminals“ und "Crimes against Humanity", in: Encyclopaedia of the Holocaust. Die Vereinten Nationen hielten in Art. 1 der Konvention u.a. fest, dass „ein Völkermord, ob in Friedens- oder in Kriegszeiten verübt, ein Verbrechen im Sinne des internationalen Rechts" sei, und definierten in Art. 2 den Völkermord als Handlungen, die vollzogen werden „,in der Absicht, bestimmte Volksgruppen, ethnische oder religiöse Gruppen vollständig oder in Teilen zu vernichten", worauf diese Gruppen einzeln aufgezählt werden. Siehe Lord Russell of Liverpool: The Trial of Adolf Eichmann, London 1962. 
sondern weit außerhalb der traditionell begriffenen Grenzen von Verbrechen und Strafe liegen.

Die Tragödie, jenen neuen Verbrechenstypus und neuen Typus des Bösen nicht angemessen verurteilen zu können, stellt Hannah Arendt in ihrem Buch Eichmann in Jerusalem auf eindringliche - und dennoch für viele jüdische Milieus nicht annehmbare - Weise dar. Sie beschreibt das Spannungsverhältnis zwischen dem grundlegenden Zweck einer jeden Gerichtsverhandlung: „Recht zu sprechen und der Gerechtigkeit Genüge zu tun" und der Strategie der Kläger, die das Konzept „Höherer Zwecke“ verfolgten: der Welt ein erschütterndes Zeugnis dieses Verbrechens und des unermesslichen Leids seiner Opfer zu geben. Arendt schreibt: „Unmißverständlich war die Zurückweisung der Anklage in den Worten, daß Leiden so unerhörten Ausmaßes »jenseits des menschlichen Verstehens« liegen, daß sie eine Sache »für große Schriftsteller und Dichter« sind und nicht in einen Gerichtssaal gehören, während die Taten und Motive, die diese Leiden hervorgebracht haben, weder jenseits des Verstehens noch außerhalb der Gerichtsbarkeit liegen." Alle anderen, noch so erhabenen Ziele, führt die Autorin aus, könnten „hiervon nur ablenken; sie werden zudem unweigerlich das eigentliche Rechtsverfahren, das heißt die erhobene Anklage, die Urteilsfindung und die Festsetzung des Strafmaßes, in einem zweifelhaften Licht erscheinen lassen. "110

In den noch erhaltenen Holocausttexten zeichnen sich deutlich zwei Argumentationslinien für die Motivation des Schreibens ab. Eine beruft sich auf den Gerechtigkeitsbegriff, die andere auf Rache; eine benutzt Schlüsselwörter wie „Tribunal“, „Staatsanwalt“, „Anklageschrift“, „Schuldige“, „Rechenschaft“, die andere Begriffe wie „rächen“ und „Vergeltung“ in allen erdenklichen Varianten.

Wer sich für die Rache entscheidet, glaubt nicht, dass es möglich ist, Gerechtigkeit walten zu lassen. Das Verbrechen, das Böse übersteigen jegliches Maß und lassen sich daher auch nicht mit normalen Maßstäben messen.

Vor dem Hintergrund des brennenden Warschauer Ghettos - schreibt Calel Perechodnik - habe ich mit eigenen Augen den Untergang des polnischen Judentums gesehen. [...] Ich habe dann gedacht, daß in diesem Fall niemand übrigbleiben wird, um das Los meiner Frau zu beweinen und ihr ein ehrendes Andenken zu bewahren; daß niemand mehr Nachkommenden ihr Leiden wird berichten können; daß vielleicht niemand Rache fordern wird für ihr unschuldiges Leben, für den Tod von Millionen Juden.

Damals - genau am siebten Mai [1943] - beschloß ich, meine Geschichte aufzuschreiben. Vielleicht bleibt sie erhalten und wird in Zukunft den Juden übermittelt, als getreues Abbild dieser tragischen Zeiten. Vielleicht wird sie die demokratischen Staaten

110 Hannah Arendt: Eichmann in Jerusalem, op. cit., S. 301, 255, 302. 
dazu bewegen, alle Deutschen schonungslos auszurotten und den unschuldigen Tod von Millionen jüdischer Kinder und Frauen zu rächen. (S. 225)

Perechodnik nennt sein Tagebuch ein „Testament der Rache“. Leizor Czarnobroda wiederum schildert den Zustand einer besonderen Art der Besessenheit, wenn ein Mensch, dem bereits alles genommen wurde, der Erfahrungen machen musste, die über jedes menschliche Maß hinausgehen, nur noch vom Gedanken an Rache erfüllt ist:

Denn es ist uns nichts geblieben bis auf den Rachedurst. Unser Denken, unser Schlaf, unsere Nahrung, unser einziges Sehnen und Streben - Rache (Archiwum Ringelbluma, S. 112).

Beherrscht von diesem einzigen Gedanken ist ein bei Eugenia Szajn-Lewin erwähnter Flüchtling aus Treblinka: „[...] [I]ch werde mich rächen, rächen werde ich mich. Diese Worte spricht er deutlich aus, berauscht sich an ihnen. Seine Hände verschränken sich, als erwürgten sie jemanden“" (S. 45). Die Geschichte des Geflüchteten wird zur Schilderung einer imaginierten Exekution. Deutsche werden in Gaskammern getötet, exakt mit dem Ritual, das sie selbst entworfen haben und peinlich genau anwenden.

Besondere Beachtung verdient das Motiv der Rache in Aufzeichnungen eines Mannes namens Wojdysławski, die dieser zwischen Herbst 1939 und Januar 1942 anfertigte und die eine charakteristische Entwicklung belegen. Erklärt sich der Autor anfangs noch dem mediterranen kulturellen Wertesystem verbunden, so zeigt er sich am Ende als deformierter, von Hass und Rachedurst besessener Mensch. Im ersten Herbst der Besatzungszeit widmet er dem Gedenken an seine geliebte Rachela, die bei einem Bombenangriff auf Łomża getötet worden ist, eine glühende ideelle Deklaration:

Kämpfen werde ich in Deinem Namen, im Namen unserer Kultur und im Namen der Liebe. Kämpfen werde ich um diese Kultur und Menschlichkeit mit Worten und Taten, kämpfen werde ich gegen Barbarei, gegen Verbrechen, gegen die Mörder, gegen den Faschismus (S. 16).

In drastischem Kontrast zu dieser Deklaration steht der letzte erhaltene Eintrag mit dem Datum des 8. Januar 1942:

Homo sum, nihil humani a me alienum puto. - Eine Lüge. Menschliche Gefühle sind mir fremd. Fremd ist mir Liebe, fremd Erbarmen. [...] In aller Ruhe erschießen, eigenhändig abstechen würde ich Tausende Menschen, junge Menschen, Söhne, Ehemänner, Brüder und Väter, die für Führer und Faterland [sic!] kämpfen. Nach der Arbeit würde ich à la recherche du temps perdu zu ihrer Abschlachtung und auf ein Glas Wein gehen (S. 29-30). 
Henryk Rudnicki stellt seinem Bericht mit dem Titel Szósty września 1942 [Der sechste September 1942] über die Endphase der großen Liquidierungsaktion dieses Motto voran:

Gott! Wenn Du nicht nur erfundene Legende bist - RÄCHE sie

und lässt ihn wie folgt enden:

DAS MUSS GERÄCHT WERDEN!

Kein Recht zu leben hat, wer Unschuldige tötet.

Kein Recht zu leben hat, wessen Recht der Tod ist (S. 49, 54).

Hier tut sich eine Kluft zwischen der Sehnsucht nach Gerechtigkeit und dem Durst nach Rache auf. Der Ruf nach Gerechtigkeit gründet auf der Überzeugung, dass die fundamentale Ordnung der Welt trotz allem noch nicht unwiederbringlich zerstört ist. Er ist eine Stimme, die den Glauben an eine unantastbare Rechte- und Werteordnung ausdrückt; ein Akt, der den Willen ausdrückt, Teil einer sich nach diesen Gesetzen richtenden Gemeinschaft zu sein. Der Ruf nach Rache ist ein Schrei der Verzweiflung und des Schmerzes, die keine Linderung finden können. Er ist ein Zeichen von Einsamkeit und Verlassenheit. Vor allem aber ist er Zeugnis einer Leere, die sich nie wieder füllen lassen wird, einer unumkehrbaren Zerstörung, die der Holocaust hinterlässt.

\section{„Eine Spur hinterlassen“}

Charakteristisch für die verschiedenen Formen der Literatur des persönlichen Dokuments ist, dass die Autoren die Motivation ihres Schreibens offenlegen, und zwar häufig in Form von mehr oder weniger stark konventionalisierten autothematischen Kommentaren. Bevorzugter Ort dafür sind vor allem der Textanfang oder auch der Beginn einer neuen chronologisch-kompositorischen Texteinheit, zum Beispiel der Anfang eines neuen Tagebuchbandes, eines neuen Jahres oder auch ein aktualisierender Eintrag nach einer längeren Schreibpause. Manche Tagebuch- und Memoirenverfasser kommen viele Male auf diese Fragen zurück, wiederholen ihre eigenen Argumente oder führen die Meinungen anderer an. Die erklärten Gründe für das Schreiben können innerhalb eines Textes auf verschiedene Art formuliert werden, was vor allem von der verstrichenen Zeit oder von veränderten Lebensumständen abhängt. Nicht immer kommentieren die Autoren ihre Vorgehensweise direkt; ihre Motivation und die Bedeutung des Tagebuchschreibens für sie lassen sich der Art des 
Schreibens und den vorrangigen Themen entnehmen - oder auch dem, was verschwiegen wird ${ }^{111}$.

Überlegungen zu den explizit formulierten oder auch nur erschließbaren Gründen für das Tagebuchschreiben sind schon so lange und so häufig Gegenstand der Forschung, dass sie - wie manche meinen - „zur klassischen Gruppe der literaturkritischen Banalitäten gehören “112. Ohne weiter erörtern zu wollen, ob und warum sich in der Gegenstandsliteratur gerade bei dieser Fragestellung eine Trivialisierung vollzogen haben soll, möchte ich betonen, dass sie von wesentlicher Bedeutung für die hier vorgenommenen Analysen ist - enthüllt sie doch ein wiederholt auftretendes Bündel von Motiven, das in Texten verschiedenster Gattung anzutreffen ist und die Haltung der Autoren beschreibt. Die Motive lassen sich auf bestimmte Formeln zurückführen, wobei sie Hinweis geben auf die Art Tradition, in die sich die Autoren jeweils einschreiben.

Das Modell dieser Tradition bilden - einfach gesagt - zwei Hauptgruppen von Motiven. Eine betrifft die Persönlichkeit des Schreibenden, der danach strebt, sich selbst zu verstehen, und durch das Schreiben sein Leben zu ordnen und zu beurteilen sucht. Die zweite äußerst sich im Bestreben, Erfahrungen zu verewigen und vorübergehende Ereignisse vor dem zerstörerischen Wirken der Zeit zu bewahren. Im ersten Fall liegt der Schwerpunkt auf dem schreibenden „Ich“, im zweiten dagegen auf allem, was dem Autor im Leben begegnet, was ihn umgibt und den Strom von Eindrücken, Erlebnissen, Gedanken in Gang setzt. Für manche ist das Schreiben vor allem eine Reise ins eigene Ich, eine Art, sich selbst kennenzulernen und zu vervollkommnen, ein Instrument zur Beobachtung des eigenen Lebens, der eigenen geistigen Entwicklung. Für andere erweist es sich als das Wichtigste, den ungreifbaren Moment, die flüchtige Materie der Fakten und den unfassbaren Reichtum der das Leben ausfüllenden Kleinigkeiten zu erfassen ${ }^{113}$.

111 Zur Frage nach der Motivation des Schreibens am Beispiel der englischen Diaristik siehe R.A. Fothergill: Private Chronicles. A Study of English Diaries, London 1974, Kapitel „Motive and Manner“.

112 A. Cieński: Pamiętniki i autobiografie światowe [Weltberühmte Tagebücher und Autobiographien], Wrocław 1992, S. 51.

113 Die Unterteilung der Motive für das Schreiben in zwei grundlegende Arten deckt sich mit dem in der Gegenstandsliteratur vertretenen Vorschlag zur Unterscheidung zweier unterschiedlicher autobiographischer Typen. Die Autobiographie als Aufnahme des Innenlebens, die sich v.a. auf das schreibende „Ich“ und die Privatsphäre konzentriert, wird dem Tagebuch als Verzeichnung des Außenlebens gegenübergestellt, das sich v.a. auf Ereignisse und die öffentliche Sphäre konzentriert. Siehe R. Lubas-Bartoszyńska: Między autobiografia a literatura [Zwischen Autobiographie und Literatur], 
In den hier analysierten Texten finden sich beide klassischen Motivationstypen. Es scheint daher, als müsse die bis hierhin erörterte Frage „Warum wurde geschrieben?" auf eine Weise beantwortet werden, die die Zeugnisse des Holocaust mit der langen Tradition der Literatur des persönlichen Dokuments verknüpft und erst vor diesem Hintergrund ihre charakteristischen Eigenschaften hervortreten lässt. Als das Wichtigste gelten muss hier das Bestreben, laufende Ereignisse festzuhalten, sowie die Hoffnung, dass damit zugleich die Existenz des sie verzeichnenden Autors festgehalten werde. Eine so definierte Motivation für das Schreiben umfasst verschiedene Typen von Argumenten und Arten deren Ausdrucks, die sich zu einer Reihe fügen: Schreiben - Gedächtnis Bewahrung. Jene Motivation ließe sich, angelehnt an einen der Texte, in eine allgemeine Formel fassen: „eine Spur hinterlassen“. Allerdings trifft im Fall der Narratoren des Holocaust die universale Sehnsucht, die verrinnende Zeit festzuhalten und irgendeine Spur von sich für die Nachkommen zu hinterlassen, auf eine bis dahin so nicht gekannte Erfahrung der Vernichtung. Während er die Geschehnisse um sich herum verzeichnet, lebt der Verfasser von Tagebuch oder Memoiren im Bewusstsein einer doppelten moralischen Verpflichtung, die er erfüllen muss - nämlich erstens die Verpflichtung den Opfern gegenüber, und zweitens die Verpflichtung gegenüber den Folgegenerationen.

Als er im Juni 1946 seine Ghettoerinnerungen, die er während des Krieges im Versteck notiert hatte, um eine kurze Einleitung ergänzt, formuliert Henryk Rudnicki deutlich jene Verpflichtung den Opfern gegenüber:

Sollen meine Erinnerungen dafür sorgen, dass diese Ereignisse, wie sie die Geschichte noch nicht kannte, den Menschen im Gedächtnis bleiben; Ereignisse in einem Land, wo nahezu jede Erdscholle getränkt ist mit dem Blut Unschuldiger.

Damit die Qualen von Millionen nicht vergebens gewesen sind - sollten wir sie ewig in Erinnerung behalten (S. 10).

Bereits im November 1943 schreibt Rudnicki von ebendieser Pflicht zur Erinnerung. Charakteristisch ist hier der Perspektivwechsel vom Schicksal der Gemeinschaft hin zu individuellen Schicksalen:

Warschau 1993; A. Cieński: Pamiętniki i autobiografie światowe, op. cit., S. 16-17. Zwei Motivationstypen des Schreibens - einen, der als Streben nach Selbstkontrolle über das eigene geistige Leben und nach Selbstvervollkommnung, und einen anderen, bei dem Erinnerungen gesammelt und die Spuren dessen, was sich ereignet, festgehalten werden - nennt R.A. Fothergill, wobei er betont, dass die heute für Tagebücher vollkommen natürlich erscheinende Motivation, Erinnerungen zusammenzutragen, erst Ende des 18. Jh. populär wurde und im 19. Jh. zur überwiegenden Motivation zu werden begann (Private Chronicles, op. cit., S. 66-77). 
Ich weiß, dass von den Opfern keine Spur geblieben ist. Ich weiß, wo ihre Gebeine verstreut sind. Ich weiß, Du meine Frau, dass von Dir nicht ein Zeichen geblieben ist [...]. Ich schwöre Dir, wenn ich weiterleben sollte - dann bleibt die ERINNERUng an Dich (S. 40).

Die Bedeutung einer moralischen Verpflichtung hat die Metapher des Textes als Denkmal aus Worten, das der Schreibende seinen Nächsten errichtet, um die Erinnerung an ihren Namen und ihr Leiden zu erhalten. Ludwik Hirszfeld sieht den Sinn der Aufzeichnung seiner Erinnerungen eben darin:

So sei dieses Buch also zugleich ein Denkmal für jene, die allzu früh gegangen sind. Ein Denkmal unter anderem auch für mein eigenes Kind. Ein Denkmal für meine Mitarbeiter, denen ich versuchte, ein Vater zu sein (S. 322).

Henryk Bryskier beginnt sein Tagebuch mit folgender Widmung:

Unsere liebe Ehefrau und Mutter, bestialisch ermordet in Warschau im Mai 1943, ich kann Dir keinen granitenen Gedenkstein aufstellen, da jede Spur von der Ruhestätte Deiner Gebeine fehlt, nimm daher von mir und unserer Tochter dieses bescheidene Denkmal aus Worten und Papier entgegen (Pamiętniki z getta, S. 332).

Calel Perechodnik äußert sich in einer Apostrophe an seine Frau auf diese Weise über seine Tagebücher:

Ich habe Dir zu Ehren geschrieben, um Dich unsterblich zu machen, um Dir ein ewiges Denkmal zu setzen (S. 285).

Für „den zukünftigen Historiker“, für „zukünftige Generationen“ nahm die Gruppe Oneg Schabbat die Mühen der Dokumentation auf sich.

Alle haben genau verstanden - schreibt Ringelblum über seine Mitarbeiter - worin die Gewichtigkeit unserer Arbeit besteht. Sie haben verstanden, wie wichtig es ist, dass von der Tragödie der polnischen Juden eine Spur für zukünftige Generationen bleibt (Bd. 1, S. 476).

Ein Eintrag in Avrom Levins Tagebuch zeigt klar, dass der Antrieb für die Gruppe ein moralisches Pflichtempfinden gegenüber der Zukunft war. Die Aufzeichnung all diesen Leids sollte für die Nachkommen eine Pflicht zur Erinnerung sein:

Wir versammeln uns jeden Schabbat, eine Gruppe von Akteuren aus der jüdischen Gemeinschaft, um über unsere Tagebücher und Schriften zu diskutieren. Wir wollen, dass unsere Leiden, jene „Geburtsschmerzen des Messias“, eine Spur im Gedächtnis kommender Generationen und im Gedächtnis der ganzen Welt hinterlassen. Wir treffen uns jeden Schabbat und sprechen über unsere diesbezüglichen Pflichten ( $A$ Cup of Tears, S. 120). 
Das Gedächtnis ist das Schlüsselwort in jener Strategie der Verpflichtung, aus der die Autoren ihre Motivation zum Schreiben schöpfen. Die beschriebenen Blätter widersetzen sich in Massen dem Tod und überwinden das zerstörerische Wirken der Zeit. Obwohl zart und dünn, geben sie dem flüchtigen Moment eine dauerhafte Gestalt. Sie sind wie ein Denkmal aus Worten; wie in Granit ist eine unsterbliche Botschaft in sie eingemeißelt. Sie sind wie ein Sanktuarium, das die Namen der Opfer auf ewig bewahrt. Die Tätigkeit des Schreibens selbst nimmt die Form einer Liturgie des Gedächtnisses an.

Eine liturgische Form der Zelebrierung des Gedächtnisses weist Rokhl Oyerbakhs im November 1943 auf arischer Seite verfasster Essay Izkor, 1943 [Yizkor] auf. Izkor - hebräisch: „Du wirst dich erinnern“ - ist das erste Wort eines Gebets, das vier Mal im Jahr zum seligen Gedenken der Toten aus dem engsten Familienkreis gesprochen wird: am letzten Tag von Pessach, beim Schawuot-Fest (Pfingsten), an Schemini Azeret (Feiertag zum Ende des Laubhüttenfestes) und an Jom Kippur (dem Versöhnungstag). Beim Beten zählt man die Namen der Verstorbenen auf, derer man gedenkt. Rokhl Oyerbakh macht aus dieser Gebetsaufzählung die Konstruktionsachse ihres Textes.

Es beginnt mit dem Bild eines Hochwassers, eine große Metapher für die Massendeportation der Warschauer Juden, von denen nur ein „stummer Schrei“ und "Stille" bleibe. Dann folgt eine das Gedenken beschwörende Zeremonie, angelehnt an die Phrasen von Psalm 137 (Super flumina Babylonis):

Wenn ich die vergäße, die ich sah, so soll ich selbst vergessen sein und mein Name verflucht, so wie jene Verräter, die es nicht würdig sind, Deinen [vernichtetes Volk - J.L.] Schmerz zu teilen (S. 460).

Ein Echo desselben Psalms schwingt im Bekenntnis eines unbekannten Autors mit, eines Juristen aus Włocławek und höheren Funktionärs des Ordnungsdienstes im Ghetto:

Immer und überall werden wir jedes Tages, jedes Augenblicks und jedes Gesichts gedenken. Wir gedenken. Die Erinnerung an jene Tage und jene Jahre lebt eindrücklich in uns fort; so wird es immer sein, bis zu unserem letzten Atemzug. [...] Wir gedenken, wir vergessen nicht, wenn wir vergäßen - so soll verdorren unsere Rechte, soll unsere Zunge uns am Gaumen kleben. Wir gedenken und werden gedenken. Die Erinnerung an jene Jahre wird nie verwischen, wird zu jedem vordringen, überallhin („Pamiętniki“, Sign. 129, S. 252) $)^{114}$.

114 In deutscher Übersetzung: „Wenn ich dich je vergesse, Jerusalem, dann soll mir die rechte Hand verdorren. Die Zunge soll mir am Gaumen kleben, wenn ich an dich nicht mehr denke“ oder auch: „Wenn ich dich je vergesse, Jerusalem, dann soll meine rechte 
Das eigentliche Izkor-Gebet besteht in einer Kette von Aufzählungen. Ihre einzelnen Glieder, die verbunden sind durch anaphorische „und“, beginnen mit Apostrophen an die einzelnen Gruppen oder Stände des jüdischen Volkes. Die angerufenen Gestalten erscheinen wie auf Bildausschnitte gebannt, regungslos und in einem synthetischen Abbild festgehalten, samt der Attribute ihres täglichen Lebens, ihrer Arbeit, ihres Aussehens, ihrer Gewohnheiten. In ihrem ganzen, sinnlich konkreten Detailreichtum. Auf diesem kollektiven Portrait des Volkes ziehen vor unseren Augen kleine Kinder vorbei, Jungen und Mädchen, Heranwachsende, fromme Juden, Rabbiner und Lehrer, Handwerker, Arbeiter, Rikschafahrer und Lastenträger, Kaufleute und Philanthropen, Väter, Mütter, Großväter und Großmütter, Gelehrte, Künstler, Musiker, Maler, Professoren und Schneider, Uhrmachermeister und Ärzte, arme Leute aus engen dunklen Gassen, Kleingauner, Schmuggler und Straßenhändler, Bettler und hungernde Umsiedler. Wir sehen „die Schleifen im Haar der Mädchen“ oder „zarte blonde Mädchen, bei denen sich hebräisches Temperament mit slawischer Fröhlichkeit mischt"; wir sehen eine 13-jährige Bettlerin abends auf der Leszno-Straße um ein Stückchen Brot flehen und die Verkäufer angefaulter Äpfel an Winterabenden frieren.

Der Figurenreigen scheint kein Ende zu nehmen. Die Autorin versucht, die Flut der Aufzählungen aufzuhalten - „Genug, genug ... Ich muss aufhören zu schreiben. Nein. Nein. Das kann ich nicht“ -, wechselt aber nur ihre eigene Perspektive von der öffentlichen zur privaten, beginnt Namen aus ihrem eigenen Familienkreis aufzuzählen. Doch nach einer Weile stellt sich heraus, dass eine solche Trennung keinen Sinn hat, dass beide Perspektiven sich vermischen. Die Vernichteten lassen sich nicht mehr in Fremde und Nahestehende aufteilen „Sie alle gehören zu mir, sind meine Verwandten. Sie alle, die ermordet worden sind“" (S. 463).

Rokhl Oyerbakh lässt ihren Essay mit einem Appell zum Gebet und einer Verpflichtung an sich selbst enden - sie wird unablässig das Gedächtnisritual vollziehen, die Namen des ermordeten Volkes aufzählen.

Hand mich vergessen. Die Zunge soll mir am Gaumen kleben, wenn ich deiner nicht mehr gedenke“ (Psalm 137,5-6). In der polnischen romantischen Literatur beziehen sich viele Autoren auf diesen berühmten Psalm. So sagt eine der Figuren, Sobolewski, im 3. Teil von Adam Mickiewiczs Nationalepos Dziady [Die Ahnenfeier], an einer Stelle, in der es um eine Deportation nach Sibirien geht: „Wenn ich sie vergesse, dann vergiss Du, mein Gott im Himmel, mich“ [dt. Übers. hier von mir; Anm. d. Übers.]. 
Jeden Tag rufe ich einen anderen von denen an, die gegangen sind. Und wenn ich ans Ende der Liste komme, ein weiteres Glied in der Kette meines derzeitigen Lebens in der Stadt [auf der arischen Seite] hinzufüge, fange ich wieder alles von vorne an, und immer im Schmerz. Jeden von ihnen zu erwähnen, verletzt mich persönlich. [...] Und ich muss seufzen, ich muss weinen. Nicht vier Mal im Jahr. Ich spüre, ich muss den Izkor vier Mal am Tag sprechen. [...] Am Ende des Gebets, in das jeder die Namen seiner Familienmitglieder einfügt, steht eine Textstelle, die für diejenigen gesprochen wird, die niemanden haben, der ihrer gedenkt, und die zu unterschiedlichen Zeiten eines gewaltsamen Todes starben, nur weil sie Juden waren. Solche Menschen sind heute die Mehrheit (S. 464).

Das Wort wird der Vernichtung entgegengesetzt. In ihm ruht die Hoffnung auf Rettung. Gustawa Jarecka spricht im Prolog zu ihrem in Teilen erhaltenen Bericht „Ostatnim etapem przesiedlenia jest śmierć“ von einem „Bedürfnis, zu schreiben“, von einer "Aufzeichnung von Schuldbeweisen“ und von der steinernen Schwere, den „Abgrund menschlicher Grausamkeit“ zu erkennen. Das alles gebe dem Ausharren „auf dem Schlachtfeld“ Sinn und Hoffnung. Das Schreiben sei nämlich ein Akt des Widerstands gegen den Holocaust, erweise sich auch als einzige Möglichkeit der Rettung vor der Nicht-Existenz:

Diese Aufzeichnungen entstehen aus dem instinktiven Bedürfnis heraus, eine Spur zu hinterlassen, aus einer Verzweiflung heraus, die manchmal schreien möchte, und aus dem Wunsch nach einer Verteidigung des eigenen Lebens, das noch immer in tödlicher Ungewissheit schwebt. [...] Vor uns und hinter uns ist der Tod, man könnte sagen, der derzeitige Zustand des Wartens spielt sich nach einem bereits gefällten Urteil ab. Nur noch ein Zufall kann es abwenden. In diesen Momenten der Erwartung, die die ewige Hoffnung des Instinkts in sich tragen, wollen wir eine Spur von uns verewigen (BŻIH 62, S. 137).

\section{In der Tradition verwurzelt}

Die von den Autoren genannten Motivationen zum Schreiben wurzeln sowohl in der jüdischen Tradition als auch in der klassischen, im mediterranen Kulturkreis erarbeiteten Formel des Humanismus. Ihre tiefe Begründung finden sie ebenfalls in den Werten, auf denen der kommunikative Akt gegründet ist - die Verständigung mit einem anderen Menschen mittels dem Medium Sprache.

Tora und Talmud übermitteln das Gebot, Missetaten zu bezeugen. Im 3. Buch Mose steht, derjenige begehe eine schwere Sünde, der „eine laute Verfluchung gehört [hat], Zeuge [ist], da er es gesehen oder darum gewusst hat, aber er zeigt es nicht an $[\ldots]^{\text {“ }}$ (3. Mose 5,1). Im Kontext jener Tradition ist nicht nur derjenige Zeuge, der mit eigenen Augen gesehen hat, was vor sich ging, sondern 
auch derjenige, der "nur“ davon weiß. Somit macht nicht so sehr die Augenzeugenschaft jemandem zum Zeugen wie das Wissen um die Missetat allein. Dieses Wissen ist eine Verpflichtung. Der Zeugenstatus impliziert nämlich die Verpflichtung, Zeugnis zu geben - andere über das Vorgefallene zu informieren. Und diese Verpflichtung hat die Dimension sowohl einer moralischen als auch einer religiösen Pflicht. Das Zeugnis eines Menschen wird von der Bibel in den Kategorien eines gerichtlichen Verfahrens oder eines Rechtsstreits begriffen. „Bezeugen heißt die Tatsächlichkeit einer Sache beglaubigen“, indem man dieser Beglaubigung den Charakter verleiht, der von den Rechtsvorschriften verlangt wird, und sich deren Regeln unterwirft ${ }^{115}$. Ein Zeugnis ist daher in der jüdischen Tradition eng verknüpft mit dem juristischen Prozess der Beweislegung, um zur Wahrheit zu gelangen und Gerechtigkeit zu erzielen.

Die semantische Analyse des Verbs „bezeugen“, das eines der Verben für Sprechakte ist, zeigt deutlich, dass die Tätigkeit des Sprechens sich hier auf die Enthüllung der Wahrheit und deren Übermittlung an andere fokussiert. Das verbale Verhalten einer Person bedeutet dann, ein Zeugnis zu geben, wenn die Person das, was sie sagt, ausspricht, um die Wahrheit zu sagen, weil sie davon ausgeht, dass andere Menschen diese Wahrheit nicht kennen, sie aber kennen sollten. Die Situation der Zeugenschaft beinhaltet sowohl eine direkte Verbindung zum Gesagten („Ich habe es mit eigenen Augen gesehen“) als auch einen bestimmten Geisteszustand, ein Wissen („Ich kenne die Wahrheit“) ${ }^{116}$.

Diese biblisch-talmudische Tradition des Zeugnisgebens - im Kontext einer Reflexion über das Wesen des Bezeugens als Sprechakt - enthüllt eines der Fundamente, auf denen die Autoren der Holocausttexte ihre Entscheidung zum Schreiben fußen lassen konnten. Im Lichte jener Tradition nimmt der Tagebuch- oder Memoirenschreiber seine Rolle so wahr, dass er sich dem Gebot,

115 Zum Beispiel, dass man niemanden verurteilen darf, ohne dass man sich Zeugenaussagen angehört hat (Num 5,13); es müsse mindestens zwei Zeugen geben (Num 35,30); in Fällen, in denen die Todesstrafe droht, übernehmen die Zeugen Verantwortung für das Urteil und nehmen teil an seiner Ausführung (Deuteronomium 17,7); die Zehn Gebote verbieten die Falschaussage überaus streng (Deuteronomium 5,20) und sie wird allgemein von Weisen und Lehrern gebrandmarkt, weil Lüge und Falschbezeugung Gott mit Abscheu erfüllten (Buch der Sprichwörter 6,16-19). Siehe den Eintrag „Zeugnis“ in: X. Léon-Dufour (Hg.): Wörterbuch zur biblischen Botschaft, Freiburg, Basel, Wien 1964, S. 798.

116 An dieser Stelle habe ich mich von A. Wierzbickas semantischen Analysen inspirieren lassen, „Testify“, in: English Speech Act Verbs. A Semantic Dictionary, Sydney 1987, S. $130-131$. 
ein Zeugnis zu erbringen, unterordnet. Tagebücher, Erinnerungen, Berichte und andere schriftliche Botschaften über den Holocaust erweisen sich als Ergebnis einer Haltung, die sich den Quellen des Judaismus entnehmen lässt. Die Formel des Zeugnisses allein besitzt, auf die erhaltenen Texte angewandt, einen biblischen Sinn. Das ist nicht nur eine Feststellung entstandener Tatsachen, sondern die Übermittlung der Wahrheit über sie an diejenigen, welche diese Wahrheit nicht kennen. Zeugnis zu geben bedeutet somit einen eigenen Akt des Lehrens, die Sanktionierung eines göttlichen Gebots. Der Mechanismus jener Pädagogik des Zeugnisses ist folgender: Teilnehmer gewesen zu sein an einem Ereignis, das geschehen ist, und zu wissen, was es bedeutet, um danach - wenn man anderen von dem Ereignis berichtet - den darin enthaltenen Sinn zu enthüllen ${ }^{117}$.

Die Entscheidung der Autoren, über die Zeit des Holocaust zu schreiben, lässt sich demnach im Sinne der biblischen Formel des Zeugnisgebens interpretieren. Und mehr noch, die Erfahrung selbst enthüllt ihren archetypischen Charakter, sie lässt sich ebenfalls auf die biblischen Urbilder zurückführen. Die Bibel und die rabbinische Literatur liefern ein Modell der Situation und der Sprache ihrer Schilderung. Die traditionellen Arten, von Unglück und Leid zu sprechen, vom Triumph des Bösen, sind ebendort verzeichnet. Ein Text, der im Angesicht des Holocaust entsteht, der den Holocaust bezeugt, hat somit unweigerlich jenes biblische Muster hinter sich. Ob der Autor sich nun bewusst auf dieses Muster bezieht (wie Karol Rotgeber oder Chaim Aron Kaplan) oder ob er sich auf eine chronikartige Aufzeichnung der laufenden Ereignisse konzentriert (so wie Ringelblum oder Czerniaków) - die Schilderung der Realität des Holocaust scheint das Urbild zu erneuern: das biblische Paradigma der Massenvertreibung, des Verderbens und der Niederlage des jüdischen Volkes oder des individuellen Unglücks des leidenden Juden. Ein archetypischer Sänger der Vernichtung ist Jeremia, der in seinen Klageliedern - oder Lamentationes, wie sie in der Vulgata genannt werden - das vernichtete Jerusalem, den zerstörten Tempel, die Niederlage, Unfreiheit und Schande beweint. Die Bibel überliefert allen späteren Zeugen des unglückseligen Schicksals dieses Volkes eine bereits ausgestaltete "Rhetorik des Märtyrertums" und „Liturgie der Zerstörung", um sich der Wortwahl David Roskies' zu bedienen, dessen Buch aufzeigt, wie die jüdische Kultur mit der Erfahrung von Katastrophe und Zerstörung zu ringen hat ${ }^{118}$.

117 Die Rolle der biblisch-talmudischen Tradition bei der Interpretation der Einstellung jener Autoren, die schriftliche Zeugnisse des Holocaust verfassten, bemerkt J.E. Young in: Narrative and the Consequences of Interpretation, Bloomington, Indianapolis 1988, S. $18-22$.

118 D.G. Roskies: Against the Apocalypse, op. cit. 
Die Verzeichnung allen Unglücks, das die Juden traf, und die Weitergabe jener Aufzeichnungen an die Nachfahren, damit die Erinnerung an die Qualen des Volkes bei den zukünftigen Generationen lebendig bleiben würde, hat eine lange Tradition. Die Zeiten der Kreuzzüge, der Vertreibung aus Spanien oder auch des Kosakenaufstands unter Bohdan Chmelnyzkyj brachten zahlreiche Chronisten hervor, die über Pogrome und Verfolgungen schrieben.

In der Chronik Ephraim ben Jakob de Bonnas kann man über die Verfolgungen in der Zeit des zweiten Kreuzzugs (1147) lesen. Der Chronist beschreibt zum Beispiel, wie eine Horde Kreuzritter nach dem Leben des Rabbiners Jacob ben Meir [Rabbenu Tam] trachtet: „Sie führten ihn zu einer Wiese, begannen scharf mit ihm über seine Religion zu diskutieren und wollten ihn umbringen. Auch fügten sie ihm fünf Kopfwunden zu.“ Der Rabbiner wurde von einem „hohen Herrn“ gerettet, der „ihn aus der Hand der Übeltäter befreite“. Gemäß der biblischen Zeugnisformel kommentiert der Chronist die verzeichneten Fakten und gibt deren tiefen religiösen Inhalt wieder: „Gott erbarmte sich mit dem Schriftgelehrten und schenkte ihm das Leben. "119

Abraham Zacutos Chronik verzeichnet die Leiden der aus Spanien und Portugal vertriebenen Juden. Seine Schilderung der „täglich neuen Nöte“ entfernt sich ab einer bestimmten Stelle vom geschichtlichen Bericht, offenbart ihren religiösen Sinn und formuliert eine Botschaft der Hoffnung: „In ganz Spanien gibt es nicht einen Juden mehr. Möge der Herr unsere Vertriebenen zurückführen und rasch, noch zu unseren Tagen, den Tempel wiedererrichten. Amen! Möge dies Dein Wille sein!"120

Der von Bohdan Chmelnyzkyj 1648 geführte Aufstand war ein kaum an Grausamkeit zu überbietendes Gemetzel, das in der bisherigen Geschichte präzedenzlos zu sein schien. In den Aufzeichnungen der damaligen Ereignisse lässt sich eine ähnliche Sprache des Grauens wie in den Zeugnissen des Holocaust finden. Nathan Hannover war Augenzeuge des Pogroms und „spürte das blutige Hajdamakenschwert am eigenen Leibe ${ }^{\text {"121 }}$, wie Majer Balaban schreibt. Hier ein Auszug aus Hannovers Chronik Jawen Mezula [Yeṿen metsulah]:

119 Ephraim de Bonnas Chronik zitiere ich nach: M. Balaban: Historia i literatura żydowska, ze szczególnym uwzględnieniem historii Żydów w Polsce [Die jüdische Geschichte und Literatur, unter besonderer Berücksichtigung der Geschichte der Juden in Polen], Bd. 2, Lwów, Warschau, Krakau 1925, S. 182.

120 Ebd., S. 241.

121 Ebd., Bd. 3, S. 261. 
Viele Gemeinden jenseits des Dniepr die in der Nähe des Schlachtfeldes waren [...] wurden unter ausgesuchten bittern Todesarten, den göttlichen Namen heiligend, umgebracht. [...] Einigen schnitt man Hände und Füße ab und warf sie dann auf die Heerstraße, daß man mit Wagen über sie herfuhr und Rosse sie zertraten. [...] Kinder schlachtete man aus dem Schoße ihrer Mütter; andere zerriß man wie Fische in Stücke. [...] [A]ndere spießte man, briet sie am Feuer und brachte sie den Müttern, die davon essen mußten. ${ }^{122}$

Ein Text hält eine aufgezeichnete Botschaft fest und sorgt dafür, dass diese im Bewusstsein der Generationen erhalten bleibt, indem er eine geistige Verbundenheit zwischen den aufeinanderfolgenden Generationen herstellt und deren Erfahrungen zusammenbringt. Die Geschichte ist schließlich die Lehrerin des Lebens, wie Cicero schrieb - auf jenen Topos aus dem Altertum scheinen die Zeugen des Holocaust sich zu berufen, wenn sie ihren Glauben an die auf Papier notierte Botschaft manifestieren.

Die mediterrane humanistische Tradition behandelt einen Text wie die Vergegenwärtigung dessen Inhalts, unabhängig von Raum und Zeit seiner Entstehung. Der biologischen Vergänglichkeit wird die Dauerhaftigkeit des Textes gegenübergestellt, der physischen Entfernung die geistige Nähe von Verfasser und Leser. ${ }^{123}$

Geistige Gemeinschaft mithilfe eines Textes entwächst der Tiefe des Gedächtnisses. Die klassischen Gedächtnismetaphern stellen das Gedächtnis als Aufzeichnung dar - als wächserne Tafel, die den Abdruck des Griffels bewahrt (Platon, Cicero), oder als Raum, als Gefäß (Cicero); Lager, Haus (Platon, Cicero); Landschaft, Feld (hl. Augustinus). ${ }^{124}$ Die Tätigkeit des Niederschreibens ist deshalb schon von Grund auf damit verbunden, das Flüchtige festzuhalten, den Nachkommenden eine Spur unserer Existenz zu übermitteln.

David Lowenthal sagt, die Meinung, Gedächtnis schaffe Identität, sei verhältnismäßig neu. Das Gedächtnis habe immer beim Kampf gegen den Horror des

122 N. Hannover: Jawen Mezula. Schilderung des polnisch-kosakischen Krieges und der Leiden der Juden in Polen während der Jahre 1648-1653. Bericht eines Zeitgenossen, nach einer von J. Lelewel durchgesehenen französischen Uebersetzung, Hannover 1863, S. 13.

123 Siehe J. Domański: Tekst jako uobecnienie. Szkic z dziejów myśli o piśmie i książce [Text als Vergegenwärtigung. Skizze aus der Geistesgeschichte über Schrift und Buch], Warschau 1992.

124 Siehe den Eintrag „Memory in Ancient and Medieval Thought“, in: New Catholic Encyclopedia. Washington 1967. 
Vergessens geholfen, doch „das Bewusstsein, dass das Gedächtnis der Schlüssel zur Selbstentwicklung ist, dass es das ganze Leben hindurch die Identität aufrechterhält und stärkt, war eine Entdeckung des späten 18. Jahrhunderts, und das einzige, was diesem Bewusstsein vorausging, waren die biblischen Geschichten. ${ }^{125}$ Damit ist es wieder einmal die Bibel, in der sich die Fundamente dafür finden lassen, das Gedächtnis als Bewahrung und auch als Form von nationaler Identität zu verstehen.

Das Gedächtnis sei eines der Fundamente des Judaismus, schreibt Rabbi Byron L. Sherwin ${ }^{126}$, da sich der Glaube der Juden nicht auf theologische Dogmen stütze, sondern auf die Erinnerung an Ereignisse. Zur Arena der Geschehnisse, die sich im Bündnis mit Gott ereignen, wird die Geschichte. Der mittelalterliche Dichter und Philosoph Jehuda ha-Levi betont, dass die Zehn Gebote nicht mit der Feststellung eines Dogmas beginnen, sondern mit der Erinnerung: „Ich bin der Herr, dein Gott, der dich aus dem Land Ägypten geführt hat, aus dem Sklavenhaus" [Ex 20,2]. Ein Jude bestärkt seinen Glauben durch die stetige Erinnerung an Ereignisse, an denen seine Vorfahren beteiligt waren. Im 5. Buch Mose [Deut 4,9] findet sich eine bezeichnete Mahnung: „Jedoch, nimm dich in Acht, achte gut auf dich! Vergiss nicht die Ereignisse, die du mit eigenen Augen gesehen, und die Worte, die du gehört hast! Lass sie dein ganzes Leben lang nicht aus dem Sinn! Präge sie deinen Kindern und Kindeskindern ein!“

\section{4}

Der Impuls, zu schreiben, um etwas festzuhalten, zu interpretieren und den Sinn durchlebter Erfahrungen weiterzugeben, gründet in einer auf die Antike zurückgehenden Tradition. Obwohl viele Autoren sich ihrer katastrophalen Lage bewusst waren, wurde das Schreiben zu einem Akt des Widerstands gegen den Holocaust, einem Akt des Glaubens an eine bessere zukünftige Welt, einem Akt der Hoffnung, dass die nachfolgenden Generationen erfahren und begreifen würden, was der Holocaust war, ihn verurteilen und Wiedergutmachung üben würden. Von Bedeutung ist daher nicht nur, was die Zeugen schrieben, sondern auch, dass sie sich überhaupt zum Schreiben entschieden.

Ob nun der Adressat direkt in den Deklarationen des Autors erwähnt wird oder nicht - dass das Schreiben in Angriff genommen wurde, bestätigt

125 D. Lowenthal: Pamięć i zapomnienie [Gedächtnis und Vergessen], poln. Übers. von I. Grudzińska-Gross und M. Tański, in: „Res Publica“ 1991, Nr. 3, S. 12.

126 Siehe B. L. Sherwin: Sparks Amidst the Ashes: The Spiritual Legacy of Polish Jewry, New York, Oxford 1997. 
gewissermaßen die Notwendigkeit seiner Existenz. In der Lage jener Autoren wurde der ansonsten offensichtliche Gedanke an einen Leser ihrer Aufzeichnungen zur gewagten Hypothese. Aber schließlich hätte das Schreiben ohne die Annahme, dass jemand den Text würde lesen können, jeden Sinn verloren. Die Verfasser der untersuchten Texte schrieben demnach gegen die Absurdität an und lieferten damit einen Beweis für ihren Glauben an die Unzerstörbarkeit einer Welt, in der die Menschen zueinander sprechen und einander verstehen können - eine heroische Haltung, zerfiel doch die Welt gerade vor den Augen der Schreibenden und begrub sie selbst unter Trümmern. Es war eine Haltung, bei der Verzweiflung und Hoffnung aufeinanderprallten.

In Paul Celans „Todesfuge“ heißt es:

Schwarze Milch der Frühe wir trinken sie abends

wir trinken sie mittags und morgens wir trinken sie nachts wir trinken und trinken ${ }^{127}$

Celans „schwarze Milch der Frühe“ ist wohl eine der treffendsten Metaphern für das Unausdrückbare des Holocaust. Die außergewöhnliche Spannung in Celans Gedicht entsteht infolge der unweigerlichen Kollision von Hoffnung und Verzweiflung. Das Weiß des Schweigens erhellt für einen Moment das Schwarz einer Erfahrung, die nicht immer in Worte gekleidet werden kann. Der Mensch prallt gegen die Wände der Sprache, ähnlich wie in einem Gefängnis. Die Wörter sind tot, sie können die Erinnerung nicht beleben.

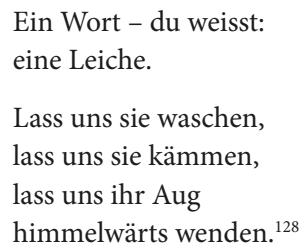

Wie weit haben wir uns entfernt vom Wort als Samenkorn aus Sutzkevers Gedicht - ein Samenkorn, das, vergraben in den Boden des Wilnaer Ghettos, die Kraft unbezwingbaren, sich stets erneuernden Lebens in sich birgt. Sutzkever legt das Wort in die Erde für eine spätere Ernte. Celan steht bereits nur noch nackten Leichnamen gegenüber und vollzieht eine Begräbniszeremonie für das Wort. Bedeutet diese poetische Selbstvernichtung auch die endgültige

127 P. Celan: „Todesfuge“, 1944/1945, Erstabdruck in: Der Sand aus den Urnen, Wien 1948. 128 Aus Paul Celans Gedicht „Nächtlich geschürzt“, in: Von Schwelle zu Schwelle. Gedichte, Stuttgart 1955. 
„Exekution des Gedächtnisses“ - um sich eines Gedichttitels von Jerzy Ficowski zu bedienen? Celan selbst scheint dem zu widersprechen, indem er in seiner Dankesrede für den Literaturpreis der Freien Hansestadt Bremen 1958 sagt:

Das Gedicht kann, da es eine Erscheinungsform der Sprache und damit seinem Wesen nach dialogisch ist, eine Flaschenpost sein, aufgegeben in dem - gewiß nicht immer hoffnungsstarken - Glauben, sie könnte irgendwo und irgendwann an Land gespült werden, an Herzland vielleicht. Gedichte sind auch in dieser Weise unterwegs: sie halten auf etwas zu. Worauf? Auf etwas Offenstehendes, Besetzbares, auf ein ansprechbares Du vielleicht, auf eine ansprechbare Wirklichkeit. ${ }^{129}$

Was der Dichter über das Gedicht sagt, lässt sich auch auf die aus Trümmern geborgenen Tagebücher, Erinnerungen und Berichte der Holocaustzeugen sagen. Die beschriebenen Blätter sind von Schmerz durchdrungen (ebenfalls eine Metapher von Celan), und somit ist es der Text selbst, der leidet. Doch das Schriftstück verlangt danach, gelesen zu werden. Indem das Lesen den Text sprechen lässt, greift es das Erbe der Erinnerung auf und belebt es. Nur auf diese Weise kann das Schreiben die Erinnerung an das Sein bewahren - und somit auch das Sein an sich.

Eine optimistische Version dieser Überzeugung äußert der Friedensnobelpreisträger René Cassin im Vorwort zu Michel Borwiczs Buch Écrits des condamnés à mort sous l'occupation allemande (1939-1945) [Schriften der Todgeweihten unter deutscher Besatzung (1939-1945)], indem er schreibt, „die überlieferten Schriften der Ermordeten wandern durch die Tiefen der Geschichte. Und solange die Erinnerung an sie erhalten bleibt, solange wird das Leiden jener Menschen nicht vergebens gewesen sein. ${ }^{\text {"130 }}$ Somit rettet das Gedächtnis (der Leser) die Niederschriften, und die Niederschriften wiederum retten das Gedächtnis (an Opfer und Zeugen).

\section{5}

Dennoch erinnert dieses Projekt - ein mittels Texten geführter Dialog der Generationen - an eine fragile Brücke über einen Abgrund. Der Weg ist schwankend, wacklig, er birgt zahlreiche Gefahren; versuchte man auf die andere Seite zu gelangen, ist das Risiko enorm. Viele meinen sogar, diesen Weg zurückzulegen,

129 Paul Celan: Gesammelte Werke, hg. von B. Allemann und S. Reichert, Frankfurt/Main 1986, Bd. 3, S. 185-186.

130 Zitat nach: R. Löw: „Czytając Borwicza“ [Beim Lesen von Borwicz], in: „Zeszyty Historyczne“, [Paris] 1991, Nr. 98, S. 218. 
sei gänzlich unmöglich. Umreißen wir daher kurz die Gefahren, die auf einen solchen Dialog lauern.

Erstens ist es nicht leicht, an diesen Dialog überhaupt anzuknüpfen, da doch sogar die Texte, die überdauert haben, den Leser nur schwer erreichen. Geradezu symbolisch ist hier die Geschichte von der Entdeckung der Manuskripte, die die Juden des Auschwitzer Sonderkommandos in der Asche versteckt hatten. Mit der Suche nach jenen Manuskripten konnte nicht direkt nach Kriegsende begonnen werden, befand sich doch an der Stelle des Lagers in Birkenau nun ein sowjetisches Lager für deutsche Kriegsgefangene. Als dann das Museum Auschwitz-Birkenau eingerichtet wurde, mussten die Nachforschungen unterbrochen werden, da sie unter den „Goldsuchern“, die in Oświęcim und Umgebung in Scharen nach zurückgelassenen Schätzen von ehemaligen Lagerhäftlingen fahndeten, für helle Aufregung sorgten. Schlussendlich konnten die Manuskripte erst 1961 geborgen und gesichert werden, obwohl der Ort ihres Verstecks dank überlebender Augenzeugen von Anfang an bekannt gewesen war. Als man sie nach 17 Jahren endlich fand, weckten sie - wie Jerzy Jedlicki bemerkte ${ }^{131}$ - kein besonderes Interesse. Das letzte, in einer Thermoskanne verborgene, Manuskript wurde zufällig im Spätherbst 1980 entdeckt, als Schüler von einer nahe gelegenen Schule an der Stelle Bäume pflanzten, wo das Krematorium von Birkenau gewesen war. ${ }^{132}$

Zweitens ist der Dialog in - wie es scheint - unüberwindliche Widersprüche verstrickt, die sich aus der fundamentalen Frage ergeben, ob es überhaupt möglich ist, die Erfahrung des Holocaust zu vermitteln. Autor und Leser sitzen in einer kommunikativen Falle. Der Imperativ, der Welt die Wahrheit über den Holocaust mitzuteilen, stößt auf einen Widerstand, der aus der Überzeugung erwächst, dass jene Wahrheit unvermittelbar sei („Diese wesentliche, echte Wahrheit lässt sich selbst mit gewichtigster Feder nicht darstellen“, schreibt Stefan Ernest [„Pamiętniki“, Sign. 195, „Posłowie“]); die Welt sei nicht imstande, sie zu begreifen. Die abgegriffene Formel zur Charakterisierung der Rhetorik eines Textes - „Das lässt sich nicht mit Worten ausdrücken“ - trifft auf ein Paradox, das die Haltung des Autors charakterisiert. Dieses Paradox lässt sich so darstellen: „Du musst verstehen und kannst zugleich nicht verstehen.“

Drittens schließlich haben wir es mit einer fehlenden Übereinstimmung der Rollen in diesem Dialog zu tun (oder eher: mit der Unmöglichkeit, eine solche

131 J. Jedlicki: „Dzieje doświadczone i dzieje zaświadczone“ [Erlebte Geschichte und bezeugte Geschichte], in: Z. Stefanowska und J. Sławiński (Hg.): Dzieło literackie jako źródło historyczne [Das literarische Werk als geschichtliche Quelle], Warschau 1978.

132 Siehe M. Gilbert: The Holocaust. The Jewish Tragedy, Fontana/Collins 1990, S. 820. 
Übereinstimmung zu erreichen). Die Zeugen sind der Tradition verhaftet, sie glauben an den Wert des schriftlichen Zeugnisses. Wird die Botschaft ihres Textes entziffert, soll sie ihrer Meinung nach nicht nur Mahnung und nützliche Lehre für die Folgegenerationen sein, sondern außerdem den Sinn des Daseins von Opfern und Zeugen bewahren. Die Adressaten der Zeugnisse aber deklarieren eher das Schweigen, indem sie die große Krise der Wortkunst nach Auschwitz proklamieren, da schließlich die alte Sprache die Erfahrung des Holocaust mit ihren Mitteln nicht in Worte kleiden könne.

Die radikale Fremdheit einer Erfahrung bedeutet eine Herausforderung für die bisherigen Ausdrucksformen und -arten, sprachlichen Muster und Kommunikationsstandards. Die in einen Text eingeschriebenen und rekonstruierbaren Versuche, jene Fremdheit vertrauter zu machen, schaffen ein Spannungsfeld von häufig außergewöhnlicher Intensität und Dramaturgie. Es sind dies Spannungen zwischen Welt und Sprache, Ding und Wort. Zwischen der Wahrheit der Aufzeichnung und der Wahrheit der Fakten, dem erlebten Grauen und dem literarischen Zeugnis über das Grauen. Zwischen konventionellen Ausdrucksformen, tradierten Verständnisarten und einer in kein gängiges Schema passenden Wirklichkeit ${ }^{133}$.

Michał Borwicz publizierte im Jahr 1954 seine an der Sorbonne verteidigte Doktorarbeit - Écrits des condamnés à mort, eine umfassende soziologisch-literarische Studie, die ein breites Panorama der verschiedensten schriftlichen, während des Krieges in Ghettos, Lagern, Verstecken entstandenen Holocaustzeugnisse präsentiert. Borwicz zeigt in dieser Arbeit ein bestimmtes Paradox auf. Die Neuartigkeit der geschilderten Erfahrung habe sich als so radikal erwiesen, dass sie sich unmöglich mittels der alten Sprache ausdrücken lasse - eine andere Sprache jedoch habe nicht zur Verfügung gestanden. Der Versuch, die bisherigen sprachlichen Mittel zu bereichern, führte zu keinem grundlegenden Wandel der Form; die Autoren hätten das bereits lang vertraute Repertoire an Ausdrucksweisen genutzt, sodass die Sprache jener Texte manches Mal geradezu ostentativ konventionell sei, voll von literarischen und stilistischen Klischees. Es gebe unter den beachtenswerten Werken kein einziges, meint Borwicz, bei dem der Autor versucht hätte, in der Artikulation des Grauens der Holocausterfahrung über die bekannten Sprechweisen hinauszugehen und die bisherige Sprache zu durchbrechen. Das betreffe sowohl das Werk professioneller als auch Amateurschriftsteller. ${ }^{134}$

133 Vgl. zum Beispiel die Textstelle „Meditationen zur Metaphysik“ von T.W. Adorno, „Nach Auschwitz“, in: Negative Dialektik, Frankfurt/Main 1966.

134 Siehe M.M. Borwicz: Écrits des condamnés à mort, op. cit., S. 259-266. 
Czesław Miłosz schrieb zu Borwiczs Arbeit: „Die, die reden, wissen nicht. Und selbst wenn sie wissen, stoßen sie auf ein Hindernis in Form der Sprache selber, die zur Erstarrung in der einen oder anderen Art von Klassik tendiert, das heißt, sich am liebsten der konventionellen Ausdrücke bedient, obwohl diese die Wirklichkeit nicht tangieren, die stets unerwartet ist." Und weiter, über die Zeugnisse des Holocaust: „Man würde meinen, daß diese Werke mit allen bisherigen Konventionen brechen müßten, bedenkt man die Ungewöhnlichkeit des geplanten Genozids sowie den großen emotionalen Druck der Menschen, denen man die Hoffnung geraubt hatte. Und doch verhält es sich anders. Die Sprache, in der sie sich Ausdruck verschafften, verwendete Klischees, die der Vorkriegslektüre entliehen waren, war also von Grund auf eine Kulturerscheinung. " 135

Wenn jedoch der Holocaust sich tatsächlich nur innerhalb eigener Kategorien und mithilfe eines eigenen Idiolektes beschreiben und erfassen lässt, dann ergibt sich daraus eine grundlegende Dualität von Erfahrungen und Sprachen der Zeugen und der Adressaten ihrer Zeugnisse. Konsequenz daraus ist die Unmöglichkeit, die eine Sprache in die andere zu übersetzen - und somit auch die Unmöglichkeit, zu verstehen. Damit wird die in den Zeugnistexten enthaltene Botschaft für nach dem Holocaust lebende Menschen - also die potenziellen Adressaten - unmöglich. Auf diese Weise trifft das Paradox in der Haltung der Zeugen selbst („Du musst verstehen und kannst zugleich nicht verstehen“) auf eine paradoxe Haltung bei den Adressaten („Verstehen können wir diese Dinge nur mittels einer unverständlichen Sprache“).

Auf diese Weise sind wir nun zum Kern der Überlegungen vorgedrungen zu den Fragen nach Arten des Ausdrucks von Holocausterfahrung, nach der Gestalt, die die Niederschrift jener Erfahrung annimmt, und nach der Möglichkeit, diese zu entziffern und zu verstehen.

135 Cz. Miłosz: Das Zeugnis der Poesie, dt. Übers. von P. Lachmann, München 1984, S. $80-81$. 
Teil 2 



\section{Zwischen persönlicher und unpersönlicher Erzählweise}

Die Erörterungen aus dem ersten Teil der Arbeit endeten mit der fundamentalen Fragestellung, ob und wie die Vermittlung von Holocausterfahrung möglich sei und welche Arten des Ausdrucks sich für sie eignen, wo die Grenzen des Ausdrückbaren liegen. Fast jedes hier analysierte persönliche Dokument enthält - gleichsam als unerlässliches rhetorisches Ornament - eine irgendwie in Worte gefasste Figur des Unausdrückbaren. „Was ist schon die Sprache der Worte im Angesicht dieses Grauens ...", fragt Leon Najberg (S. 119); Rokhl Oyerbakh bekennt: „[I]ch schaffe es nicht, ich kann dieser Wirklichkeit nicht Ausdruck verleihen ..." (Ring I, 654, S. 11); Avrom Levin notierte sich, als ihm die Unermesslichkeit des Holocaust bewusst geworden war, am 29. Dezember 1942: „An Juden vernichtete Hitler 5-6 Millionen. Es gibt keine Worte in unserer Sprache, die das unendliche Ausmaß des Unglücks ausdrücken könnten, das uns ereilt hat" (BŻIH 25, S. 124). Für Giordano Bruno aus Czesław Miłoszs Gedicht "Campo di Fiori“ - das 1943, allerdings auf der anderen Seite der Mauer, verfasst wurde - gab es ebenfalls „In der menschlichen Sprache/Kein einziges Wort [...],/Um der Menschheit Lebwohl zu sagen -/Der Menschheit, die übrig bleibt. “136

Die Unfähigkeit der Sprache, zu der sich die Autoren auf vielerlei Arten bekennen, bestätigt offenbar die These von der Hilflosigkeit der Versuche, die Holocausterfahrung zu begreifen. Diese Erfahrung lässt sich in keinster Weise ausdrücken, weil sie sich in keinster Weise begreifen lässt.

Im zweiten Teil meiner Arbeit möchte ich diese Überzeugung jedoch einer Revision unterziehen. Nicht, weil ich den tiefen Riss zwischen menschlichem Wort und unmenschlicher Wirklichkeit infrage stellen möchte, sondern um zu zeigen, dass nichts uns von der Notwendigkeit befreit, das Verstehen zu riskieren. Ohne mich in philosophischen Spekulationen über den Sinn des Holocaust zu ergehen oder in Strategien seiner kognitiven Aneignung zu verlieren, beschränke ich mich - gemäß meines Vorhabens - auf die Beobachtung der Ausdrucksebene.

Entzieht sich der Holocaust tatsächlich jeglicher Ausdrucksmöglichkeit, da er „sich nicht mit Worten ausdrücken lässt“? Dürfen wir den Versuch aufgeben,

136 Dt. Übers. von D. Daume, in: DAS und andere Gedichte, München 2004; Anm. d. Übers. 
zu dieser - schließlich in zahlreichen Schriften festgehaltenen - Erfahrung vorzudringen? In der Literatur des persönlichen Dokuments, die im Warschauer Ghetto entstanden sind, versuchen die Autoren auf verschiedene Weise, die Hilflosigkeit der Sprache zu überwinden, und bemühen sich, so über den Holocaust zu sprechen, dass sie zum Kern vordringen.

In Kapitel 1 habe ich zwei Typen von Erzählung vorgestellt - die persönliche und die unpersönliche. In Kapitel 2 befasse ich mich mit dem Ort, den das Element der Schilderung und eine ganz bestimmte seiner Ausprägungen in der narrativen Struktur einnehmen (Themen wie das Bild von Figuren, von Tod und Leichnam). Kapitel 3 wiederum handelt vom religiösen Diskurs (dabei interessiert mich vor allem das Spannungsverhältnis zwischen einerseits einer Sprechweise, die darauf abzielt, die Anwesenheit des Sacrum zu erfassen, und die einem besonderen Druck von Traditionen, Konventionen, Ritualisierung unterworfen ist, und andererseits der Herausforderung, zu der die Erfahrung der Ghettorealität für den Autor wird).

Ähnlich wie die Erzähler in Romanen lassen sich auch die Erzähler des Ghettos grob in zwei Kategorien einteilen. In eine Kategorie gehören die Erzähler, die als Sprecher ihr „Ich“ im Text aufscheinen lassen und in der ersten Person schreiben. In die zweite hingegen gehören diejenigen, die sich durch die Wahl der dritten Person hinter der erzählten Welt verbergen ${ }^{137}$. Ein personalisierter Diskurs scheint am charakteristischsten für die Literatur des persönlichen Dokuments zu sein - ist er doch Ausdruck einer autobiographischen Haltung, eine Manifestation der Person des Autors und dessen eigener Weltsicht. Eine Erzählweise in der ersten Person ist die natürliche Form, Tagebuch zu führen. Dennoch lassen sich bei den untersuchten Texten bedeutende und recht zahlreiche Beispiele für eine grundlegend andere Aussagegestaltung finden. Ein nicht-personalisierter Diskurs kommt sowohl in den Gattungen vor, die für das persönliche Dokument klassisch sind - wie Tagebuch oder Erinnerungen -, als auch in Grenzformen wie zum Beispiel Berichten. Manches Mal erweisen sich übrigens die traditionell personalisierten Gattungen unpersönlicher als Texte, die in der ursprünglichen Absicht fast einen Gebrauchscharakter haben.

Strategien, in der ersten Person zu erzählen, gibt es verschiedene; das Gleiche gilt für die Arten und für den Grad, in dem die eigene Privatheit enthüllt wird.

137 In der Theorie der Narrationsformen wird generell zwischen zwei Arten von Erzählern unterschieden; in W.C. Booth' klassischer Auffassung sind das der „dramatisierte" und der „nicht-dramatisierte“ Erzähler. 
Bei den Ghettodokumenten - die unter besonderem Zeitdruck, an einem besonderen Ort, in einer besonderen Situation entstanden sind - nimmt die Frage der Enthüllung, der Ausdruck der eigenen Persönlichkeit, die Manifestierung des eigenen „Ich“ eine zusätzliche Dramatik an. Der Schreibende ringt nicht nur mit den Konventionen der persönlichen Aussage, sondern auch mit einer endgültigen existenziellen Herausforderung. Das wachsende Bewusstsein einer - vollkommenen und unumkehrbaren - Vernichtung wirft ein neues Licht auf die Rolle des Tagebuch- oder Memoirenverfassers als eines Menschen, der von sich spricht, der seine Erlebnisse, Beobachtungen, Urteile festhält.

Die Vorstellungen darüber, was und wie man über sich oder auch von sich schreiben kann, werden einer Revision unterzogen. Umformuliert werden die bisherigen Regeln für ein solches Schreiben sowie die Motivationen, die der Anfertigung einer Niederschrift zugrunde liegen. Unter den neuen Umständen muss nämlich der Begriff der Privatheit oder auch Intimität selbst einem radikalen Wandel unterzogen werden, weswegen sich bei der Kommunikation auch deren Bereich, Methode und Zweck ändern.

Der Mensch wird zum anonymen Teil einer Masse, die einem gemeinsamen Schicksal unterworfen ist. Niemand ist mehr bei sich zu Hause, alle sind Vertriebene - sie werden aus größeren Städten und kleineren Orten hinter Mauern getrieben, aus Wohnungen auf die Straße, in Verstecke und Bunker, auf den Umschlagplatz. Der Einzelne ist zum Leben, zum Leiden, zum Sterben in Bedrängnis und Enge gezwungen - oder er muss in einem Versteck dahinvegetieren, jeden Moment in Erwartung des Todes. Hier ist kein Platz für den Luxus der Privatheit, die Intimsphäre wird zerstört. Diese Erfahrung ruft im Bewusstsein des Schreibenden einen Selbstverteidigungsreflex hervor, der sich im heroischen Akt des Schreibens äußert. Diesen Akt anzugehen, bedeutet eine Manifestierung der persönlichen Eigenheiten, der individuellen Existenz. Ich schreibe, also bin ich - trotz der Verurteilung zur Vernichtung. Mein individuelles Schicksal nimmt universale Züge an, ist es doch eine Spiegelung des gemeinschaftlichen Schicksals. Ich bin nicht mehr nur Privatperson, spreche nicht nur von mir, über mich. Daher ist auch in diesem Sinne kein Platz mehr für den Luxus der Privatheit.

Deswegen bedeutet auch das erzählende "Ich“ der Ghettoautoren mehr als nur die Realisierung einer bestimmten Diskursart. Jener personalisierte Diskurs ist in ein kompliziertes Netz eingewoben - ein Netz von Verpflichtungen der Wirklichkeit gegenüber, der Geschichte, dem zukünftigen Leser, dem sprechenden Subjekt. Wie die Rolle des Erzählers in der ersten Person zu realisieren ist, entscheidet nicht die schriftstellerische Konvention allein, sondern auch das Schicksal, das dem Schreibenden zuteil wird. 


\section{Jakub - Hirszfeld - Levin - Perechodnik}

Eindeutiges Beispiel für eine schreibende Tätigkeit, die einem völlig unvorbereiteten Menschen als Gebot des Schicksals auferlegt wurde, ist das Tagebuch des Jakub. Dieser Text überdauerte ohne Titel und ohne Autorennamen bis in unsere Zeiten, wobei zu bezweifeln gilt, dass der Autor ihm überhaupt einen Titel gegeben hat. Wäre der Krieg nicht gewesen, hätte er wahrscheinlich nie zur Feder gegriffen. Er war ein einfacher Mensch und vermutlich weit davon entfernt, in disziplinierter schriftlicher Form persönliche Reflexionen abzugeben. Bei Kriegsausbruch war er 30 Jahre alt und lebte mit Eltern und Geschwistern im Warschauer Stadtteil Praga. „Ich bin Buchhalter von Beruf“ (S. 59), stellt er sich vor, schreibt aber an anderer Stelle: „[V]or dem Krieg habe ich in Fabriken gearbeitet, meine Stellung war Expeditor oder Lagerist" (S. 161). Sich selbst nennt er einen "ganz gewöhnlichen Menschen der Arbeit“. Doch dieser gewöhnliche Arbeiter schreibt, während er sich von Mai 1943 bis August 1944 in einer Wohnung in Praga versteckt, ein umfassendes, 537 Seiten dickes Tagebuchmanuskript.

Von anderen persönlichen Dokumenten unterscheidet sich Jakubs Tagebuch durch seine Spontaneität des Ausdrucks, seine offen vorgebrachte Emotionalität, seine Authentizität bei der Schilderung von Erlebnissen und Beobachtungen. Die Form dieser Niederschrift spiegelt eine ausgeprägte Individualität ihres Autors. Jakub ist fraglos der Herr seines Textes, er beherrscht ihn auf seine eigene - könnte man sagen - naive und unreflektierte Weise. Er arbeitet ohne ein Bewusstsein für Schreibtechniken, Regeln und Konventionen, hat manchmal Probleme mit der korrekten Formulierung von Sätzen. Seine Sprache ist sehr einfach, zeitweise sogar fehlerhaft, und voller Kolloquialismen, Dialektismen und milieutypischer Ausdrücke. Bei der Lektüre dieses Textes begleitet den Leser unweigerlich das Gefühl einer besonderen Nähe zum Autor, der geradezu physisch greifbar zu sein scheint.

Was sich um ihn herum und mit ihm ereignet, ist hier stets Hauptthema der Narration. Jakubs eigenes Erleben ist stets der Mittelpunkt, selbst dann, wenn er weitschweifig über die Situation an der Front schreibt. Nachrichten bezieht er aus der täglichen Lektüre deutscher Zeitungen, füllt die Seiten seines Tagebuchs mit eingehenden Auseinandersetzungen mit der Nazi-Propaganda. Jakubs politische und militärische Analysen werden durch seine originelle Persönlichkeit und spezielle Denkweise gefiltert und sagen mehr über ihn selbst aus als über das tatsächliche Kriegsgeschehen. Es wäre im Übrigen interessant, einen Vergleich zwischen zwei Stilen anzustellen, in denen die Besatzungspresse gelesen wurde - Jakubs plebejischem und emotionalem Stil und dem 
intellektuellen und gelehrten Stil Ludwik Landaus in seiner Kronika lat wojny i okupacji.

Jakub ist authentisch. Er kennt keine Zurückhaltung, wenn er über sich selbst schreibt. Er ist aufrichtig, wenn er sich verbittert über seinen Bruder äußert, der ihn hintergeht und ausnutzt, wenn er stolz über seine Erfolge beim Handel mit deutschen Soldaten in einer Kaserne in Praga berichtet, wenn er über das Unrecht klagt, das ihm geschieht, seine Sorgen und Nöte beichtet und entsetzt die schwindenden Chancen auf Rettung beobachtet. Stellenweise verwandelt sich sein Tagebuch in einen großen inneren Monolog - den Gedankenstrom eines leidenden, seiner Freiheit beraubten Menschen, der vor Sehnsucht nach dieser fast den Verstand verliert.

Der Autor hat keine Probleme mit der „Form“ oder mit der Inadäquatheit von Wörtern gegenüber dem Inhalt. Es scheint, als sei er einer der wenigen, die sich nicht des Topos „Das lässt sich nicht mit Worten ausdrücken“ bedienen. Spontan erfindet er neue Ausdrucksmöglichkeiten, erweitert die Formel seiner Aussagen. Eine solche Rolle spielen auch seine eigenen, jeweils situativ entstandenen Gedichte, die er in die Tagebuchnarration einflicht und die persönliche Erlebnisse (zum Beispiel den Tod der Mutter im Ghetto, die Angst vor den „Schmalzowniks") sowie die allgemeine Kriegssituation kommentieren. Der Wechsel von ungebundener zu gebundener Rede ist weniger ein Zeichen für Erhabenheit oder Pathos als eine noch radikalere Enthüllung der eigenen Person. Jakub bedient sich der Versform, weil es die einzige ihm bekannte Form zutiefst persönlicher, intimer Rede ist. Deshalb sind die naiven, unbeholfen gereimten Verse trotz ihrer geradezu spektakulären Gestelztheit eine grundehrliche Manifestation seines „Ich“. Und mehr noch - sie spiegeln den Prozess wider, in dessen Verlauf in Jakub als Privatperson das Gefühl einer gesellschaftlichen Verpflichtung entsteht. Das Schreiben über sich selbst wird für den Autor zum inneren Gebot, zur Verpflichtung, anderen Menschen das selbst Durchlebte weiterzugeben. Die Gedichtform - eine fest in der Tradition verwurzelte Art der Vermittlung persönlichster Empfindungen - scheint für die Realisierung dieses Bedürfnisses am besten geeignet zu sein. So eben geht Jakub vor - ein gewöhnlicher Mensch, einer von vielen. Indem er sein von Versen durchzogenes Tagebuch verfasst, macht er seine Privatheit öffentlich, macht sie zu einer zukunftsgerichteten Botschaft.

Am entgegengesetzten Pol des personalisierten Diskurses siedelt sich Ludwik Hirszfelds Geschichte eines Lebens an. Im Juni 1943, als Hirszfeld, der sich in Stara Miłosna bei Warschau versteckte, zu schreiben begann, war er bereits eine öffentliche Person, ein Wissenschaftler von internationalem Rang. Seine Ehefrau gab ihm den Gedanken ein, „aufzuschreiben, was wir erlebt hatten und was Polen in dieser Zeit hatte erleiden müssen“, doch er entschloss sich, 
"den Rahmen auszuweiten und Erinnerungen aus meinem ganzen Leben festzuhalten“" (S. 345). Eine solch breit gefasste Autobiographie lässt sich unter den Dokumenten aus der damaligen Zeit kein zweites Mal finden, mit Ausnahme vielleicht von Janusz Korczaks Tagebuch, das jedoch eher von Absichten als von tatsächlich durchgeführten Vorhaben handelt. Wenn bei Korczak überhaupt Informationen über das Schicksal des Verfassers in der Zeit vor Kriegsausbruch enthalten sind, dann in Form von wenige Sätze langen Einschüben oder - wie bei Karol Rotgebers Erinnerungen - als Zusammenfassung auf ein paar Seiten. Hirszfeld dagegen zeichnet freimütig sein Selbstportrait. Er beginnt ganz am Anfang - bei seinen Studentenjahren, der Revolution von 1905, seiner Arbeit in Heidelberg, in Zürich, auf dem Balkan, präsentiert ein Panorama des Ersten Weltkriegs und schildert seine wissenschaftliche Tätigkeit in den Zwischenkriegsjahren, beschreibt die Geschichte seiner eigenen intellektuellen Formung vor dem Hintergrund der ersten Jahrzehnte des 20. Jahrhunderts. Im Vorwort erklärt er:

Die Geschichte eines menschlichen Leidens möchte ich darstellen und von den Geschicken eines Gelehrten erzählen, der daran glaubte, dass die Wissenschaft den Menschen zum Besseren zu bekehren vermag. Ich möchte erzählen, wie sehr er sich mit dieser Annahme irrte und wie das Schicksal ihm zuletzt das größte Leiden vor Augen führte den Tod ganzer Völker. [...]

Doch bin ich weder Historiker noch Literat, ich kann eine Epoche nicht Punkt für Punkt abhandeln, nicht Datum für Datum wiedergeben. Deshalb versuche ich - wie groß meine Widerstände auch sein mögen -, die Geschichte einer Epoche mit der Geschichte meines Lebens zu verbinden (S. 7).

Hirszfeld ging voller Eifer und Leidenschaft ans Schreiben heran, jedoch auch äußerst methodisch, er kannte sich mit dem Handwerk des Schreibens aus, mit der Erarbeitung und Redaktion von Texten. Das Geschriebene las er Freunden und Familie vor; sie waren seine ersten Kritiker und Rezensenten. Der Text entstand somit im stetigen Dialog mit seinen Adressaten; der Autor nimmt deren Erwartungen vorweg, sieht Reaktionen voraus, ist sich der Verpflichtung bewusst, die auf ihm lastet. Das Schreiben erachtet er nämlich von Beginn an als moralische Pflicht und gibt dies auch offen als seine Motivation zu erkennen. Mit einem Wort, hier ist das gesamte Vorgehen des Autors durchdacht, die Intentionen sind ihm bewusst und deren Realisierung - trotz mancher konventioneller Einwände - professionell („[I]ch [bin] weder Historiker noch Literat“, ebd.).

Manchmal stand ich um vier, fünf Uhr morgens auf, schrieb ein paar Seiten, legte mich wieder hin, diktierte später meiner Frau etwas, die es auf der Schreibmaschine tippte, legte mir während des Mittagessens die nächsten Kapitel zurecht - und so arbeitete ich wie im Rausch. Das gesamte Buch entstand im Laufe von nur zwei Monaten [...]. Dass 
mein Leid einen Sinn haben sollte, dass ich die Pflicht und die Aufgabe hätte, Bericht zu erstatten von den Leiden der Völker in dem „Lebensraum“, den die Deutschen als ihr Eigentum betrachteten - dieser Gedanke hielt mich aufrecht [...]. [D] as Schreiben war ein Kampf gegen den Feind (S. 346).

Hirszfeld hätte sicher auch ohne die Erfahrung des Krieges seine Autobiographie verfasst. Darauf lief die Logik seines schöpferischen Lebens hinaus, sein Bewusstsein, er habe zum Wohle der Allgemeinheit Anstrengungen auf sich zu nehmen, und auch seine analytische, kritische, reflektierte Geisteshaltung. Früher oder später äußert ein Mensch in Hirszfelds Position öffentlich seine Überlegungen, beurteilt den eigenen Lebensweg, zieht Bilanz über das Erreichte, formuliert Urteile über Welt und Menschen. Von da an ist er nicht mehr nur Privatperson, und das verleiht seiner persönlichen Aussage zusätzlich Berechtigung, Nachdruck und Gewicht. Der Verfasser der Geschichte eines Lebens spricht ununterbrochen über und von sich selbst, exponiert dabei aber zugleich seine Errungenschaften, seine Stellung und gewisse sich daraus ergebende öffentliche Verpflichtungen als eine besondere Bevollmächtigung, das Wort zu ergreifen. Wenn er auch in der ersten Person spricht, weiß er doch, dass er sich ebenfalls im Namen anderer äußert.

Angesichts der präzedenzlosen Kriegserfahrung bekommen sowohl das Gefühl, in öffentlicher Mission zu handeln, als auch die Wahrnehmung der Privatsphäre eine andere Dimension. In Hirszfelds Fall könnte man sogar davon sprechen, dass die tiefe innere Verpflichtung, vor der Gemeinschaft Zeugnis abzulegen über den Holocaust, und die Schilderung des eigenen und des familiären Schicksals stark miteinander kollidieren. Hirszfelds Drama ist ein Drama, das in jenen Zeiten alle Polen jüdischer Abstammung durchlitten, die vollends assimiliert und darüber hinaus sogar getauft waren. Die Nürnberger Gesetze ordneten Hirszfeld in eine ihm vollkommen fremde Gemeinschaft ein. Zunächst versuchte er, das besetzte Polen zu verlassen, und legte sich die ideelle Motivation dafür zurecht: „Sollte ich die Gelegenheit bekommen, ins Ausland auszureisen, würde ich sie nutzen. Denn dort könnte ich auf breiterer Ebene für mein Volk kämpfen“" (S. 212). Später bemühte er sich mithilfe des Grafen Ronikier und des von diesem geleiteten Hauptfürsorgerats [poln. Główna Rada Opiekuńcza] um einen legalisierten Aufenthalt auf der arischen Seite, um auf keinen Fall ins Ghetto zu müssen. Dieser Schritt jedoch sollte sich als folgenschwer erweisen. Die Deutschen nutzten ein von Ronikier zur Verfügung gestelltes Verzeichnis von Neophyten jüdischer Herkunft als Proskriptionsliste und zwangen die dort aufgeführten Personen im Frühjahr 1941 zum Umzug hinter die Mauer. ${ }^{138}$

138 Darüber schreibt E. Ringelblum in seiner Kronika getta warszawskiego, S. 236. 
Hirszfeld wird demnach erst mehrere Monate nach dessen Abriegelung ins Ghetto verlegt. Anfangs verspürt er - außer Mitgefühl - keinerlei Verbundenheit mit der Gemeinschaft, deren Schicksal er nun teilen soll.

Ich kannte keine Juden und wusste nicht, wie man zu ihren Herzen vordrang. [...]

Als Fremder für jenes Volk. Von der Menge als Christ zurückgewiesen. Ich hatte nur mein großes, grenzenloses Mitgefühl. [...]

Schon nach wenigen Tagen schickten unsere Freunde falsche Papiere und bestanden darauf, dass wir aus dem Ghetto flohen. Zudem setzte ich meine Bemühungen um Emigration fort. [...] (ebd.)

Zusammen mit seiner Familie das Ghetto zu verlassen soll ihm erst gelingen, als die große Liquidierungsaktion schon im Gange ist. Indessen ernennt Czerniaków ihn zum Vorsitzenden des Gesundheitsrates, und der Professor leitet den Kampf gegen die Fleckfieberepidemie im geschlossenen Bezirk. Er wohnt im Pfarrhaus der Allerheiligenkirche am Grzybowski-Platz, nimmt am katholischen religiösen Leben teil, und mit der Bezeichnung „mein Volk“ bedenkt er lieber Polen als Juden. Beispielsweise notiert er mit Stolz Hilfsleistungen von der anderen Seite: „[...] wie mir das Herz aufging, als ich hörte, dass mein Volk, dem die Welt so häufig Antisemitismus vorwirft, gütig war" (S. 257). Der Aufenthalt im Ghetto wird für Hirszfeld zu einer Zeit des Lernens und Umdenkens. Das über Jahre entwickelte Bild seiner eigenen Identität kollidiert brutal mit der Realität der „Endlösung“. Der Autor legt somit die Armbinde mit dem Davidstern an, tritt in eine neue Erfahrung ein - „erst im Bezirk lernte ich die jüdische Seele näher kennen“" (S. 271) - doch über Juden schreibt er nach wie vor nicht „wir“, sondern „sie“.

Die persönlichen Dokumente aus dem Ghetto enthüllen dem Leser die Dimension innerer Empfindungen, die anscheinend keinen Platz innerhalb der durch kulturelle Konventionen regulierten Normen des Sprechens über sich selbst finden. Es geht dabei natürlich nicht um drastische Details aus jemandes Privatleben oder um Sittenskandale, sondern um die radikale und kompromisslose Selbstanalyse der Autoren, um ihren Mut, bis zum Grund ihrer vor Schmerz, Angst und Rachedurst schier wahnsinnigen Seele vorzudringen. Unter den zahlreichen Zeugnissen dieser Art möchte ich zwei Texte mit besonders starker Aussage hervorheben: die Tagebücher von Avrom Levin und von Calel Perechodnik.

Avrom Levin schafft eine vielfältige Ansicht des geschlossenen Bezirks; vor allem verarbeitet er eigene Erlebnisse und Beobachtungen, zusätzlich jedoch auch Informationen aus anderen ihm verfügbaren Quellen (bei Levin als OnegSchabbat-Mitglied flossen gewissermaßen alle Informationsfäden zusammen). Sein Ghettobild setzt sich aus Realien zusammen, die sich aus der soliden 
faktographischen Schicht seiner Schilderung speisen. Die rasch hingeworfenen, oftmals auf einen Satz oder wenige Satzfragmente reduzierten Notizen - besonders charakteristisch bei der eiligen Berichterstattung über die große Liquidierungsaktion - lassen eine Welt des Grauens erkennen. Die Dokumentation jener alptraumhaften Wirklichkeit bekommt eine zusätzliche Dimension dank der eigentümlichen Aura eines tatsächlich geträumten Alptraums - eine Projektion der gequälten Psyche des Autors, die sich durch sein gesamtes Schreiben zieht. Darin genau manifestiert sich das Außergewöhnliche an Levins Zeugnis. Bei ihm ist das Ghetto eine im düsteren Spiegel der Seele gespiegelte Welt. Dieser dunkle Lichtstrahl durchdringt das gesamte Tagebuch, ist immer anwesend, mal an der Oberfläche der Sätze, dann wieder knapp darunter. Manchmal sichtbar, manchmal verborgen, bildet er eine Art Luftmaschenschnur, mit der der Tagebuchschreiber die Notizen der aufeinanderfolgenden Tage verflicht.

Wörter wie „Angst“, „Furcht“, „Grauen“ erscheinen sehr häufig auf den Seiten des Tagebuchs, kehren hartnäckig zurück, wie ein Echo. Manchmal stellen sie gar eine deutliche lexikalische Dominante dar und verdichten die Sprachschicht des Textes durch anaphorische Verbindungen, refrainartige Wiederholungen. Auf diese Weise wird die Narration quasi von innen gesättigt, nach einem existentialistischen Erzählton gestimmt. Und jener Ton ist - um den Titel eines bekannten Werkes von Søren Kierkegaard anzuführen - „Furcht und Zittern“.

Die Angst ist ein Attribut der Wirklichkeit, von Raum und Zeit:

Ein Tag der Sorge und Unruhe. [...] In den jüdischen Straßen liegt Angst in der Luft (BŻIH 21, S. 125).

Schwärze und Angst - das ist unser Heute und Morgen (S. 137).

Der Alptraum der Realität verdichtet sich unentwegt und verwandelt das Leben in eine Hölle (BŻIH 22, S. 94).

Die Angst ergreift alles und alle, niemand kann ihr entfliehen:

Eine unentwegte Angst treibt uns um [...]. Und zerfrisst uns gleich einer Motte („Biuletyn $\dot{Z} I H^{\prime \prime}$ 25, S. 124).

Unsere Herzen und Hirne erdrückt eine große Angst (S. 126).

Diese Angst ist Ausdruck einer allgemeinen Erfahrung. Alle empfinden sie, daher sagt Levin im Namen der Gemeinschaft:

Er erdrückt und bedrängt uns schwarze Angst - schreibt er unter dem Datum des 16. Mai 1942. - Immer näher kommt uns allen der Abgrund, der Schlund einer apokalyptischen Bestie, auf deren Stirn folgende Worte geschrieben stehen: Tod, Verwüstung, Vernichtung und Schmerzen der Agonie, ewige Ungewissheit; die ständige Angst ist das scheußlichste aller unserer ohnehin schwer erträglichen und quälenden Gefühle, Wahrnehmungen und Leiden. Falls wir das Ende dieses furchtbaren Krieges erleben, 
[...] werden wir feststellen, dass das ständige Verharren in einer Atmosphäre der Angst und Furcht um das nackte Überleben das Schlimmste war, [...] das unentwegte Lavieren zwischen Leben und Tod, der Zustand, in dem unser Herz jederzeit vor Angst und Furcht zu zerbrechen drohte (BŻIH 19-20, S. 176).

Auch wenn die Formeln eines kollektiven Bekenntnisses der Angst in diesem Textauszug zahlenmäßig die persönlichen Bekenntnisse überwiegen, ist es doch in erster Linie Avrom Levin, der sich hier fürchtet. Seine „Furcht“ und sein „Zittern" notiert er im Tagebuch:

Mittwoch, 29. Juli [1942]. Achter Tag der „Aktion“. [...] In manchen Momenten bin ich etwas weniger beunruhigt über mein Schicksal, manchmal werde ich nahezu gleichgültig, bis mich plötzlich wieder eine solche Angst vor dem Tod ergreift, dass ich mich dem Wahnsinn nahe fühle (BŻIH 21, S. 130).

Donnerstag, 3. September [1942]. [...] Heute war ein unglückseliger Tag. [...] Uria und ich haben nur durch ein Wunder überlebt. Gott, was war das für eine Angst, was für ein Gefühl des nahen Todes! (BŻIH 22, S. 98).

Die Tag für Tag verzeichnete Litanei der Angst wird durch einen anderen Themenstrang ergänzt: eine ebenfalls nach Art einer Litanei konstruierte verzweifelte Anklage, sich wiederholende Bekenntnisse des Schmerzes und persönlichen Leids: „Meine Seele kann keinen Trost mehr finden. [...] [I]ch verspüre tiefen Schmerz, der für ewig andauern wird“ (BŻIH 22, S. 86), schrieb Levin nach dem Verlust seiner Frau, die bei einer Blockade des Shops in der GęsiaStraße 30 auf den Umschlagplatz verschleppt worden war. Der Autor wirft sich vor, nicht genügend Mut aufgebracht zu haben, um seiner Frau zu folgen, wie es andere Männer getan hatten, nicht genügend Liebe empfunden zu haben, um gemeinsam mit ihr in den Tod zu gehen. Das Maß an innerer Zerrissenheit, das er damals fühlte, steht bereits außerhalb des Wortes, lässt sich nicht bekennen oder beschreiben. Dennoch versucht Levin nicht, der Schilderung seines Traumas auszuweichen. Er will auch die besonders intime und beschämende Erfahrung des Versagens, der Demütigung, der Erniedrigung in seinem Tagebuch festhalten und weitergeben.

Calel Perechodnik geht noch weiter in seiner radikalen Selbstanalyse, macht sich selbst zum Objekt einer grausamen Vivisektion. Bereits am Anfang, im Vorwort, klassifiziert der Autor in bezeichnender Weise sein Tagebuch: „Im Grunde genommen ist es die Beichte meines Lebens, eine aufrichtige und ehrliche Beichte. [...] Ich bitte daher, diese Memoiren als letzte Beichte zu betrachten“" (S. 17). Alles, was danach kommt, ist eine Ergänzung dieser Aussage. Wir haben es demnach mit einem Text zu tun, dem der Autor vollkommen bewusst die Form eines Bekenntnisses besonderer Art gegeben hat. Die in den Text 
eingeschriebene Situation des Bekenntnisses ist um das Wort „beichten“ herum angeordnet. Stellen wir daher nun Überlegungen zur Bedeutung des Sprechaktes an, den dieses Verb impliziert ${ }^{139}$.

Ein Beichtender verspürt den inneren Drang, eine schlimme Tat, die er selbst vollführt hat, zu gestehen. Dieses Schlimme ist zugleich eine tiefe Wahrheit, die er nicht länger verbergen muss. Das Bedürfnis, die Wahrheit zu bekennen, ist stärker als der Wunsch, die schlimme Tat zu verheimlichen. Jener innere Drang kann religiöser, moralischer oder rein psychologischer Natur sein; ein innerer Impuls zwingt den Menschen, die ganze Wahrheit über sich zu sagen, selbst wenn sie auch eine dunkle Seite beinhaltet. In Perechodniks Fall ist die Beichte nicht religiös motiviert; er stellt fest: „[W]enn ich an Gott, an Himmel, an Hölle, an Belohnung oder Strafe nach dem Tode glaubte, würde ich überhaupt nicht schreiben“" (S. 17).

Perechodniks Beichte ist ergreifend in ihrer Konsequenz. Die Schilderung seines persönlichen Leids vermeidet jeden klagenden oder gar bis zur Selbstanklage und Selbstverurteilung gehenden Tonfall. Der Autor will tatsächlich die ganze Wahrheit über sich und die Welt offenbaren - eine Wahrheit, wie er sie bei der Liquidierung des Ghettos von Otwock zu Gesicht bekommen hat, als er in seiner Funktion als jüdischer Polizist seine eigene Frau und Tochter in einen Waggon nach Treblinka setzen musste. Jene Wahrheit nahm er mit in sein Versteck auf der arischen Seite Warschaus, und mit ihr zusammen verbrannte er nach der Niederschlagung des Warschauer Aufstands in einem Bunker. Er war Zeuge und aufmerksamer Beobachter des Holocaust. Er war dessen Opfer und zugleich Henker, eingespannt in die Vernichtungsmaschinerie. In seinem Tagebuch beichtet er diese entsetzliche Erfahrung.

In der Nacht vor der Hinrichtung bewachten wir, jüdische Polizisten, unsere jüdischen Mitbrüder. Wir wußten, daß sie am nächsten Tag erschossen werden, die Verurteilten wußten es auch. [...] Alle wollten fliehen. Gewiß war das aus psychologischer Sicht eine völlig verständliche Erscheinung, wir aber hatten eine andere, eine eigene Sicht. Was sollten wir denn tun, wir, die Opfer der eigenen Niedertracht? Sollten wir die Fluchtversuche gestatten? Sie waren von vornherein zum Scheitern verurteilt, und für uns bedeuteten sie das Todesurteil. [...] Die schlimmste Stunde nahte, wenn ich ich zusammen mit den Kollegen dem Rettungswillen der anderen Juden entgegenwirken mußte. Schlimmer konnte es nicht mehr werden, ich fühlte, wie mein Herz in Stücke gerissen wurde. (S. 113, 116-117)

139 Ich stütze mich hier auf die semantische Paraphrase und den Kommentar zum Eintrag „Confess" in: A. Wierzbicka: English Speech Act Verbs. A Semantic Dictionary, Sydney 1987, S. 317-319. 
Der Gegenstand dieser Beichte in Tagebuchform ist moralisch zweideutig wobei der Autor nicht beabsichtigt, dies zu beschönigen oder zu vertuschen. Darin liegt die Stärke von Perechodniks Zeugnis. Es beschreibt die psychischen Qualen, die Leid und Schuldgefühle zugleich verursachen, ein Gefühl des Unrechts, gemischt mit Scham, Hilflosigkeit und Apathie. Perechodnik zeigt offen den Schmerz, den er erleidet und den er anderen zufügt, er registriert das entsetzliche Bewusstsein, selbst ein Beteiligter an dem Verbrechen zu sein. Dabei erwartet er weder Vergebung noch Verständnis, sondern appelliert eher an das Rachebedürfnis: „Um eines bitte ich nur: Führt mein Testament der Rache gewissenhaft aus" (S. 304).

Der Autor verschont weder sich selbst noch irgendjemanden um ihn herum. Er konstatiert einen Verfall der bis dahin geltenden Welt der Werte: einen Niedergang der Religion, einen Bankrott der moralischen Normen, einen Zerfall der Familien- und gesellschaftlichen Bande; er spricht zu seinen Adressaten gewissermaßen „,von der Höhe der Ruinen seiner selbst“ - um sich einer Phrase Cyprian Kamil Norwids zu bedienen - und zeichnet ein Bild der Verheerung.

Perechodnik beschloss, sich selbst zu beschreiben, zu verstehen, was mit ihm, mit seinem Volk, mit der Welt geschehen war. Die Erfahrung zu erforschen, welche das Schicksal ihm bereitet hatte. Er besaß den Mut, diese erkenntnisreiche Reise bis zum Ende zurückzulegen, nicht auf halbem Wege anzuhalten, sich nicht mit Halbwahrheiten zufriedenzugeben. Das versetzte ihn in eine Situation, die mit der letzten Beichte vergleichbar ist - eine Situation der absoluten Ehrlichkeit, wenn der Mensch im Angesicht des Todes erkennen muss, wer er wirklich ist -, und er hielt dieser Situation stand. In seiner Beichte gelangt er an seine Grenzen und muss schließlich feststellen: „[...] [I]ch kann nicht mehr schreiben. Ich fühle mich zu sehr schuldig“"(S. 289).

\section{Die Briefe der Juden von Płońsk}

Eine eigene Textvariante mit einem stark personalisierten, auf den Ausdruck von Privatheit und Intimität zugeschnittenen Diskurs ist der Brief. Ich abstrahiere hier von der Gattungstradition der Epistolographie, denn ich glaube, dass sie in den Briefen, die ich betrachten möchte, keine große Rolle spielt - handelt es sich dabei doch um Fetzen von Papier, die auf dem Weg zum Vernichtungslager aus Waggons ins Leere geworfen wurden. Im November und Dezember 1942 wurde das Ghetto in Płońsk aufgelöst und die dort versammelten Juden nach Auschwitz deportiert. Aus den fahrenden Waggons warfen sie Briefe an Verwandte und Bekannte im Warschauer Ghetto. Man weiß nicht, auf welchem Wege diese Briefe zu Ringelblum gelangten, der Abschriften von ihnen anfertigte und sie 
dem Warschauer Ghettoarchiv hinzufügte ${ }^{140}$. An ihrem Beispiel kann man beobachten, wie angesichts des Todes, in articulo mortis, Privatheit in bruchstückhafter Briefform ausgedrückt wird.

Ein Brief ist eine besondere Zusammenstellung von Wörtern. Intimen Wörtern, sind sie doch für diese eine, einzige Person gedacht, an die man schreibt. Es sind fliegende Wörter, da dieses eigentümliche, intime Gespräch zwischen Verfasser und Empfänger auf ein Blatt Papier geschrieben und - im wahrsten Sinne des Wortes - von einem Ort zum anderen getragen wird. Und es sind verfliegende Wörter, sind sie doch der Flüchtigkeit des Augenblicks, in dem sie geschrieben werden, verhaftet. Sie beziehen sich auf eine Situation und auf Umstände, die oft nur dem Verfasser und dem Empfänger bekannt sind. Daher sind sie nur in diesem Kontext verständlich - und auch nur in ihm wesentlich.

Die Wörter in einem Brief sind fliegend auch in dem Sinne, dass mittels der Flugmetapher Hoffnung ausgedrückt werden kann. Ein Brief fußt nämlich auf dem Fundament der Hoffnung. Wer weiß, dass sein Brief den Empfänger nicht erreichen wird, schreibt ihn erst gar nicht. Die kommunikative Hoffnung ist somit notwendige Bedingung dafür, dass ein leeres Blatt mit Schrift bedeckt wird. Und obwohl mancher Brief niemals von seinem Adressaten gelesen werden konnte, wäre doch ohne eine diesbezügliche Hoffnung kein Brief jemals verfasst worden.

Wenn jemand im Dezember 1942, in einem Viehwaggon auf dem Weg nach Auschwitz, an einen Empfänger im Warschauer Ghetto schreibt und den Brief einfach in den freien Raum wirft - dann ist das so, als glaubte er, durch ein vergittertes Fenster den Sternenhimmel erreichen zu können.

Ende 1942 erinnerte das Ghetto kaum noch an den sogenannten Jüdischen Wohnbezirk [eine Bezeichnung der Besatzer; Anm. d. Übers.] von vor dem 22. Juli selbigen Jahres, in dem die große Liquidierungsaktion begann. Wer geblieben war, wohnte nicht mehr in seinem Haus. Zum Schluss waren alle, die eine "Lebensnummer" ${ }^{141}$ besaßen, in den Shops, in denen sie ihre Arbeit verrichteten, und in zugeteilten Blocks eingepfercht. „Wilde“ oder „Illegale“ versteckten sich. Aufgrund dessen konnte zwangsläufig niemand mehr eine eigene Adresse vorweisen.

140 Ich zitiere nach R. Sakowska: Archiwum Ringelbluma, op. cit.

141 Eine gestempelte Karte, die bestätigte, dass jemand aufgrund seiner Arbeit im Ghetto unabkömmlich war und deshalb von der Deportation verschont bleiben sollte; Anm. d. Übers. 
Miła-, Niska-, Muranowska-, Nalewki-Straße waren die am dichtesten bevölkerten Straßen des Restghettos. Alle Briefe, die vom Transport der Płońsker Juden erhalten geblieben sind, tragen solche Adressen: Nalewki 47/19, Niska 6, Miła 46, Muranowska 40/35. Die physische Existenz des Adressaten war in jener Zeit eine illusorische Annahme. Illusorisch war auch die Möglichkeit der tatsächlichen Zustellung des Briefs an jenen illusorischen Adressaten.

$\mathrm{Ab}$ dem 15. Januar 1941 unterstand die Tätigkeit der Post im Ghetto der Jüdischen Gemeinde. Zu Anfang der großen Liquidierungsaktion führten die Deutschen eine sogenannte Postsperre [im Orig. deutsch] ein - ein Verbot von Postverbindungen mit der Welt außerhalb des Ghettos. Nach einer Woche änderten sie die Verordnung und gestatteten den Postverkehr in eine Richtung. Im Ghetto eintreffende Briefe durften ausgetragen werden. Doch aus dem Ghetto nach draußen durfte man keine Post senden. Während der Deportationen trugen rund 400 jüdische Briefträger ununterbrochen Briefe aus. Auf der Straße trugen sie Kappen mit orangenem Band, die sie davor schützen sollten, aufgegriffen zu werden. Auf diese Weise entging jeder Zehnte dem Umschlagplatz.

Was steht in den Briefen der Juden von Płońsk? Was wollten die Menschen, die sich auf direktem Weg nach Auschwitz befanden, ihren Verwandten mitteilen? Wie schreibt man in einer solchen Situation einen Brief?

Am 16. Dezember 1942 warf eine Frau namens Laja auf dem Bahnhof Warschau-Praga einen Brief an jemanden namens L. Przygoda, wohnhaft MiłaStraße 46, aus einem Waggon. Dieses Haus stand noch, wenn es auch fünf Monate später zusammen mit der gesamten Miła-Straße in Schutt und Asche gelegt werden sollte. Aber das konnte Laja nicht wissen. Schließlich wusste sie nicht einmal, was am nächsten Tag oder in der nächsten Stunde mit ihr selbst geschehen würde. Sie schrieb:

Ich bin an der Haltestelle Praga, schreibe nur schnell ein paar Worte an Euch. Wir fahren wer-weiß-wohin. Bleib gesund!

$$
\text { Laja (S. 197) }
$$

Ein anderer Brief trägt die Überschrift „Płońsk 16/XII - 42“. Der Verfasser ist unbekannt. Aus dem Inhalt des Briefes geht hervor, dass er gleich nach dem Verladen geschrieben wurde, als der Zug sich eben in Bewegung setzte.

Es ist Morgen. Unsere ganze Familie ist im Waggon. Wir machen uns auf unseren letzten Weg. Płońsk ist gesäubert. Bitte gehen Sie zu Familie Baum, Niska-Straße 6, und richten Sie Grüße aus (S. 196).

Laja wusste nicht, wohin sie fuhr. Wusste es der, der schrieb: „Wir machen uns auf unseren letzten Weg“? 
Der einzige der Płońsker Briefe, der nicht aus einem Waggon geworfen wurde, ist Dinas und Salas Brief an ihre Schwester Rózia im Warschauer Ghetto, datiert auf den 14. Dezember 1942. Wie er ins Ghetto gelangte, konnte nicht festgestellt werden. Er handelt u.a. von einer „letzten Seite“.

Uns scheint, das ist jetzt unsere letzte Seite. Mittwoch um 5 Uhr morgens geht es für uns alle los. Vor uns liegt schon unser bescheidenes Gepäck, und auf dem Bahnhof warten bereits die Waggons. Es ist uns schrecklich weh ums Herz, wenn wir daran denken, dass wir nur noch eine Nacht zu Hause schlafen und danach auf Irrfahrt in die weite Welt gehen. Wer weiß, wohin uns das Schicksal verschlägt, es ist überhaupt schwer, sich unser Leben vorzustellen, was uns erwartet und was wohl werden wird (S. 193).

War diese „letzte Seite“ nicht vielleicht eine Metapher für das Leben, das unweigerlich seinem Ende zuging: nur noch eine letzte Briefseite, die beschrieben werden musste, es war spät, am nächsten Morgen die Abreise ... „auf die Irrfahrt“?

Der Abschied von der Schwester ist ein Aufruf, das eigene Schicksal stoisch zu akzeptieren, aber dennoch nicht die Hoffnung aufzugeben. Auch die entsetzlichste Wirklichkeit kann den irrationalen Glauben an das Überleben nicht ersticken. Zwar lässt sich nicht vorhersehen, was die Verurteilten erwartet, absolut unvorstellbar jedoch scheint nur eins zu sein - die Vernichtung. Der letzte Brief an die Schwester im Ghetto wird daher zu einer Botschaft der Hoffnung, allem Anschein und allen Anzeichen zum Trotz.

Leb also wohl, du Liebste. Ich weiß, dass Du Dich schwer mit dem Gedanken wirst abfinden können, dass Du uns schon verloren hast, aber was können wir tun. So will es das Schicksal, und so muss es sein. Lebe wohl, ich drücke Dich fest an mein Herz. Hoffentlich sehen wir uns noch wieder. [...] Wo immer wir auch sein werden, unsere Gedanken sind immer bei Dir, unsere Liebste. [...] Bleib gesund, unsere Einzige! Wir glauben fest daran, dass wir weiterleben und dass wir uns noch wiedersehen! (S. 192).

Ähnlich zu denken scheint Gitla, die während eines Zwischenhalts in Częstochowa einen Brief an die Adresse Muranowska-Straße 40, Wohnung 35, aus dem Waggon wirft. Auf dem adressierten Zettel steht: „Wir sind schon den zweiten Tag unterwegs.“ Und auf der Rückseite, zusammen mit dem Datum „17/XII/ 42 “, folgender Text:

Meine Lieben! Wir sind gerade auf der Durchfahrt durch Częstochowa, also schreibe ich Euch ein paar Worte. Durch Warschau sind wir auch gefahren, es geht zur Arbeit. Seid zuversichtlich! Eine neue Adresse kann ich Euch nicht geben, ich habe sie noch nicht. Lebt wohl, ich küsse Euch, Eure

Gitla (S. 198)

Man kann sich fragen, wie viel Gitla von dem glaubte, was sie schrieb. War ihre Hoffnung bloß noch eine Figur der epistolischen Rhetorik, eine Aufmunterung 
für die Verwandten? Oder diente sie der Selbsttherapie? War sie ein Zeichen für Naivität oder sogar eine beschönigende Lüge, wie sie ein Arzt gegenüber dem todkranken Patienten ausspricht?

Noch schwerer erraten lassen sich die Intentionen eines Mannes namens Dawid, der einen Zettel mit dem Datum „Legionowo, 15. Dezember 1942“ an „Warschau, Nalewki-Straße 47/19“ adressierte und neben die Adresse schrieb: „Bitte freundlicherweise in den Briefkasten einwerfen“. Und ergänzte: „Nachzahlung 18 Groszy“. Hier der Inhalt:

Heute sind wir von Płońsk aufgebrochen, unsere ganze Familie und alle Juden. Gib acht, denn wir fahren zur Hochzeitsfeier.

Auf Wiedersehen

Dawid (S. 194)

Dawid bedient sich einer höflichen Formulierung, die beim Versand eines Briefes zur Anwendung kommt, bei dessen Zustellung, außer der Arbeit von Post und Briefträger, noch die Hilfe einer anderen Person benötigt wird. Penibel notiert er auch, dass der Adressat beim Empfang würde nachzahlen müssen, um die fehlende Briefmarke auszugleichen. Jenen so genau und fachmännisch adressierten Brief wirft er dann aus dem Waggon, der ihn nach Auschwitz bringen wird, ins Leere.

Dawids Text ist der beunruhigendste von allen Płońsker Briefen. Neben all den anderen Mitteilungen an die Empfänger über das Reiseziel - „[Wir gehen] auf Irrfahrt in die weite Welt“, „Wir machen uns auf unseren letzten Weg“, „Wir fahren wer-weiß-wohin“, „[E]s geht zur Arbeit“ - scheint Dawids Angabe vollkommen absurd: „[W]ir fahren zur Hochzeitsfeier“. Was kann das bedeuten? Höhnische Ironie? Einen makabren Scherz? Eine verschlüsselte Warnung? Wenn er sich schon zu schreiben entschied, wenn er sich irgendwie einen Zettel und Bleistift organisierte und im überfüllten Waggon ein paar Worte zu Papier brachte, wenn er diesen Brief nach draußen zu werfen wagte - warum schrieb er dann gerade das?

Man weiß ungefähr, was später mit Dawid geschah. Die Tötungstechnologie, die gegen ihn angewandt wurde, ist bekannt. Wir können uns alle Etappen des Prozesses vorstellen, dem sein Körper unterzogen wurde. Nur eines wissen wir nicht - und werden es auch nie erfahren: Warum er damals, im Waggon nach Auschwitz, schrieb: „Gib acht, denn wir fahren zur Hochzeitsfeier."

Das an Dawids Brief so beunruhigend wirkende Geheimnis verweist zugleich auf ein typisches Phänomen des individuellen, privaten Zeugnisses. Es ist der unschätzbare Wert eines solchen Bruchstücks vom Schicksal eines Menschen, das unverhofft in unsere Hände gerät. Die Kraft eines solchen Zeugnisses 
offenbart sich eben in jenem Unübersetzbaren, Unerklärlichen, das nicht nicht erraten lässt. Das sich nicht standardisieren oder verallgemeinern lässt, das sich der Statistik entzieht. Es ist fest und undurchdringlich, wie ein Stein. Dawids Brief bleibt ein Geheimnis für uns. Die Unruhe, die er in uns sät, enthüllt einen Spalt, durch den ein Stückchen Wahrheit über den Holocaust hervorschimmert.

Die Texte, in denen sich ein solches oder anderes Abweichen vom personalisierten Diskurs beobachten lässt, sind insgesamt inhomogener als jene, in denen eine Erzählstrategie in der ersten Person dominiert. Die verschiedenartigen Erscheinungsbilder des entpersonalisierten Diskurses haben eine gemeinsame Grundlage: die direkt oder implizit geäußerte Überzeugung ihrer Autoren, sich in einer absoluten Ausnahmesituation zu befinden, die ihnen - gewöhnlichen Privatleuten - eine außergewöhnliche Mission auferlegt. Im Vordergrund dürfe daher nicht das Schicksal des Schreibenden stehen, sondern das Schicksal der Gemeinschaft - ist es doch nicht das Wichtigste, was ,ich“ erlebe, was mich persönlich betrifft, sondern was mit uns allen, was ringsum geschieht.

Diese überindividuelle Perspektive kommt auch beim personalisierten Diskurs vor. Der Ich-Erzähler kann sie andeuten, schließlich ist er fähig zur Verallgemeinerung, zu panoramischen Aufnahmen und zu kollektiven Szenen, zu Versuchen, über die persönliche Erfahrung hinauszugehen und das große Ganze zu betrachten. Und so schildern Ludwik Hirszfeld und Calel Perechodnik jeder auf seine Weise - allgemeine Szenen der Bevölkerung in den Kriegswirren, Reflexionen über den Sinn der Geschichte, die Erfahrung des Holocaust. Avrom Levin verleiht nicht nur seinen eigenen Ängsten und Schmerzen Ausdruck, sondern schreibt auch über das Trauma der Mitmenschen, in seiner Stimme schwingen Furcht und Zittern der ganzen Gemeinschaft mit.

Für viele Autoren erweist sich die erzählerische Ich-Perspektive jedoch als nicht ausreichend. Sie wollen die individuelle - und somit eingegrenzte - Perspektive verlassen, wollen sich aus der direkten Verstrickung in die geschilderte Realität befreien und mit einer gewissen Distanz auf sie blicken, interessieren sie doch vor allem die historischen, gesellschaftlichen, wirtschaftlichen Prozesse, die Tätigkeit öffentlicher Institutionen in einer Zeit von Terror und Besatzung, die Umformung von Normen und Werten im Leben einer zur Ausrottung bestimmten Gemeinschaft, die Mechanismen von Selbstverteidigung und kollektivem Widerstand. Der Umsetzung dieser Ziele scheint am besten mit dem Modell einer Erzählweise in der dritten Person gedient zu sein. Der Autor stellt sich in den Dienst eines gestaltlosen Narrators, zieht sich selbst in den Schatten zurück. Die gesuchte Distanz ist bereits in die Konstruktion des erzählerischen Akts eingeschrieben. Der Erzählende bleibt verdeckt, die erzählte Welt wird exponiert. 
Die unpersönliche Darstellung der Welt setzt eine andere kognitive Haltung voraus als die Darstellung durch ein konkretes, in jener Welt platziertes Subjekt. Ihr fehlt der bestimmte, an die Person gebundene Gesichtspunkt, dem der IchErzähler nicht entkommen kann. Ein so angesiedeltes Subjekt wird zum durchsichtigen Medium, verstellt also nicht mit seiner Gestalt den Blick auf die Welt, sondern ordnet sie sich nur unter. Es ist so etwas wie ein „allwissender Erzähler“. Wird die Welt von einem solchen Narrator dargestellt, gewinnt sie den Wert der Objektivität. Kommentare und Wertungen werden ebenfalls als objektive Wahrheiten und nicht als subjektive Urteile übermittelt. Eine solche Platzierung des sprechenden Subjekts verleiht ihm somit eine spezielle Autorität. Diese gründet auf der Überzeugung, hinter einem erzählenden Subjekt, das sich einer solchen narrativen Konvention bedient, stehe ein verpflichtendes System von Ansichten, Bewertungskriterien und Verständnisnormen, kurz gesagt: jenes Subjekt drücke eine objektive Wahrheit aus ${ }^{142}$.

Indem der entpersonalisierte Erzähler den Fluss der Bilder registriert, die verschiedensten, ineinander verflochtenen Fragestellungen kühl und sachlich analysiert, Daten und Zahlen nennt, Schlussfolgerungen und Bewertungen formuliert, nimmt er die Gestalt eines über der Welt stehenden Beobachters an. Er überschreitet den beschränkten Horizont des Individuums, um mehr zu sehen und mehr zu wissen. Seine Stimme wird zur Stimme der Gemeinschaft, die aus der Tiefe der Jetztzeit in Richtung Zukunft spricht. Eine solche Haltung birgt die optimistische Überzeugung, dass die Fundamente der Zivilisation, die geschichtliche Kontinuität, die Bande zwischen den Generationen, wenn auch ernstlich bedroht, so doch noch nicht vollends zerrissen seien. Wer sich im Namen von Menschen, die zur Vernichtung verurteilt sind, mahnend an die dereinst kommenden Bürger einer freien Welt wendet, setzt voraus, dass eine solche Kommunikation überhaupt noch möglich sein wird. Der entpersonalisierte Erzähler richtet seine Botschaft an eine ebenso entpersonalisierte Menschheit,

142 Zur Frage der Autorität eines allwissenden Erzählers im realistischen Roman und der Wahrheit im Roman siehe M. Głowiński: „Powieść i autorytety“ [Roman und Autoritäten], in: ders: Porządek, chaos, znaczenie. Szkice o powieści współczesnej [Ordnung, Chaos, Bedeutung. Skizzen zum zeitgenössischen Roman], Warschau 1968; „Powieść i prawda" [Roman und Wahrheit], in: ders.: Gry powieściowe. Szkice z teorii i historii form narracyjnych [Romanspiele. Skizzen aus Theorie und Geschichte narrativer Formen] , Warschau 1979. Der „allwissende Erzähler“ in der Literatur des persönlichen Dokuments aus dem Warschauer Ghetto hat jedoch einen - entscheidenden Makel: In Wirklichkeit weiß er nicht, wie das alles enden und wie sein eigenes Los sein wird. 
an unpersönlich begriffene zukünftige Generationen und besonders Fachleute und Spezialisten - Historiker, Richter, Moralphilosophen. Vor allem sie sind es, für die er sein Analysematerial sammelt und Beweise zusammenstellt, glaubt er doch an die Beständigkeit von Institutionen und zivilisatorischen Errungenschaften wie Recht, Gerechtigkeit, Gerichte.

Der persönliche Erzähler appelliert an reale Personen, nimmt Einfluss auf Emotionen, weil er Emotionen offenbart. Die treibende Kraft bei seinem Schreiben ist der Glaube an das Fortbestehen des einzelnen Menschen, was nicht immer gleichbedeutend ist mit einem Sieg der Menschlichkeit und einem Triumph der Gerechtigkeit. Der Appell an den zukünftigen Leser, der zu einem späteren Zeitpunkt die persönlichen Zeugnisse des Autors in den Trümmern finden soll gleich einer aus dem Meer gefischten Flaschenpost -, klingt daher manchmal wie ein Schrei ins Leere. Ein Schrei, der zur Rache aufrufen, der beunruhigen und keine Ruhe mehr lassen soll. Der Adressat eines so begriffenen Schreibens ist ein Vertreter einer Welt nach der Sintflut, wobei den Autor mehr als einmal Zweifel befallen, ob dieser Adressat auch in der Lage sein wird, das Zeugnis anzunehmen, zu erfassen, zu glauben, was er da liest.

Die beiden oben entworfenen Figuren des sprechenden Subjekts und der ihm gegenüberstehenden Adressaten lassen sich nicht exakt und symmetrisch den zwei besprochenen Diskurstypen zuordnen. Sie können in erster oder in zweiter Ordnung auftreten, indem sie zum Beispiel einer objektivierten Narration in der dritten Person eine pessimistische Färbung geben, während sie einen persönlichen Erzähler mit dem Glauben an eine fortbestehende Ordnung der Welt und an den Sieg der zwischenmenschlichen Solidarität versehen. Auf diese Weise tritt eine stetige Spannung zwischen dem personalisierten und dem entpersonalisierten Diskurs zutage.

\section{Horowitz - Sznapman - Puterman}

Das fast 250 Seiten zählende Manuskript Przesiedlenie w zaświaty [Umsiedlung ins Jenseits] ist mit den Initialen „B.H.“ unterzeichnet, die wahrscheinlich Beniamin Horowitz zuzuordnen $\operatorname{sind}^{143}$. Er war der Leiter einer Abteilung

143 Auf diese - hypothetische - Weise löst ein Informationsblatt einer Archiveinheit aus der Gruppe „Pamiętniki“, Sign. 121, im Archiv des Jüdischen Historischen Instituts die Frage der Initialen. Michał Grynberg belässt sie in Auflage 1 der von ihm bearbeiteten Anthologie als nicht entziffert, in Auflage 2 gibt er unter Berufung auf Informationen von Antoni Marianowicz an, B.H. sei Beniamin Horowitz, siehe Pamiętniki z getta warszawskiego, op. cit., S. 371. 
der Versorgungsanstalt der Jüdischen Gemeinde und betätigte sich auch bei der Jüdischen Sozialen Selbsthilfe [poln.: Żydowska Samopomoc Społeczna; jiddisch: Yidishe Sotsyale Aleynhilf]. Er stellt eine fundierte Orientierung im gesellschaftlichen, administrativen und wirtschaftlichen Leben des Ghettos unter Beweis, kennt sich auch bei rechtlichen Problematiken und Fragen zu Wirtschaft und Handel sehr gut aus, wovon zum Beispiel eine interessante Analyse der Tätigkeit von Steuereintreibern und Zwangsverwaltern oder die Darstellung eines komplexen Systems zur Abschöpfung illegaler Gewinne zeugen. Kurz gesagt, der Autor ist vom Fach. Er hat Zugang zu zahlreichen Informationsquellen, er hat Einblick in die Arbeitsweise vieler Institutionen, kennt alle wichtigen Offiziellen des Ghettos. Dieses Wissen, diese Professionalität verleihen ihm Überlegenheit gegenüber dem durchschnittlichen Ghettobewohner. Der Autor nutzt seine privilegierte Stellung und bemüht sich, in einem Panoramablick die gesamte Besatzungszeit, soweit sie seiner Erfahrung zugänglich ist, zu erfassen. Er will nicht allein Fakten wiedergeben, sondern sich an einer Problematisierung der angeschnittenen Fragen versuchen.

Horowitz ordnet seinen Text als „Reportage“ ein und deklariert den folgenden kompositionellen Gedanken:

Die vorliegende Reportage soll die dem Autor zugänglichen Materialien sowie seine persönlichen Erfahrungen und Beobachtungen in den Jahren 1939-1944 offenlegen. Aus technischen Gründen teilt sich der Inhalt in drei Abschnitte: (a) die Beziehung der Deutschen zu den Juden; (b) die wechselseitige Beziehung zwischen Polen und Juden; c) das innere Erleben der jüdischen Gesellschaft. [...] Diese drei Aspekte des Geschehens anzusprechen und dabei zugleich strikt die chronologische Ordnung einzuhalten, schien wenig zielführend, hätte diese Vorgehensweise doch die Bedeutung jeder einzelnen Fragestellung verdunkelt. Bei der einzelnen Besprechung jeder dieser Fragen ist es jedoch nicht immer gelungen, Rückgriffe und kleine Wiederholungen zu vermeiden („Pamiętniki“, Sign. 121, S. 8).

Wir haben hier also einen Text mit durchdachter Konstruktion, dessen Autor sich seiner eigenen schreibenden Handlungen in hohem Maße bewusst ist. Indem er seiner „Reportage“ eine chronologisch-inhaltliche Ordnung verleiht, wählt Horowitz die für diese Art von Narration angemessenste Methode. Das sprechende Subjekt verschwindet aus dem Blickfeld. Die Narration ist objektiviert, besitzt häufig einen trockenen, amtlichen Stil bar jeglicher Emotionen. Im Tagebuch hingegen dominiert die gemeinschaftliche, historische Zeit (die Schilderung der Geschichte der Warschauer Juden unter der Besatzung) und nicht die private Zeit der persönlichen Erlebnisse. Auch kommen wenig direkte persönliche Reflexionen vor. 
Hierbei sollte auch das Schicksal des Textes und der Einfluss beachtet werden, den es auf die Entwicklung seiner Gestalt gehabt haben muss. Die erste Version von Horowitz” „Reportage“, an der er im Untergrund laufend weiterschrieb, ging verloren. Der Autor schrieb den ganzen Text im Juli 1944 aus dem Gedächtnis noch einmal auf, immer noch im Versteck. Auch diese Version ist nur in Teilen erhalten, sodass Horowitz den verbleibenden Textteil zum wiederholten Male aus dem Gedächtnis niederschrieb und um Neuigkeiten ergänzte, die er erst nach der Befreiung erfuhr. Im Jahr 1946 korrigierte er seinen Text (im Manuskript sind Streichungen, Kürzungen, stilistische Korrekturen zu sehen) und versah ihn, sicherlich in Vorbereitung auf eine Veröffentlichung, mit Anmerkungen unter dem Namen „Władysław Pawlak“. Auf der Titelseite des Manuskripts steht nämlich: „Verlagsgenossenschaft »Wiedza« 1947“. Der Text wurde mit einer kurzen Einleitung versehen, datiert auf „Juni 1946“, und auch mit einem Zensurstempel zur Genehmigung von Satz und Druck. Im Text selbst finden sich zahlreiche Spuren des Zensurstifts. Przesiedlenie $w$ zaświaty wurde dennoch nie veröffentlicht.

Die Version, die bis in heutige Zeiten erhalten geblieben ist, stellt somit eine Art Palimpsest dar. Sie trägt nicht nur die Spuren von mehreren Schreibperioden, sondern auch von redaktionellen Arbeiten und sogar Eingriffen durch die Zensur. Diese Phasen der Umgestaltung, Vervollständigung, Redaktion schwächen zusätzlich die Spontaneität der von vornherein kühl angelegten, emotionslosen und der geschilderten Welt distanziert gegenüberstehenden Aufzeichnung.

Über Stanisław Sznapman, dessen gerettetes Tagebuch Helena Boguszewska und Jerzy Kornacki nach dem Krieg dem Archiv des Jüdischen Historischen Instituts übergaben, ist praktisch nichts bekannt. Der Text erklärt ebenfalls nichts, zieht sich sein Autor doch programmatisch in den Schatten zurück, schreibt nichts über sich selbst. Das Einzige, was wir wissen, ist, dass er sich bis Juli 1943 im Ghetto aufhielt und anschließend auf die arische Seite hinübergelangte, wo er unter ungeklärten Umständen den Tod fand. Der Titel, den Sznapman seinem Text gab - Dziennik z getta [Tagebuch aus dem Ghetto] - suggeriert fälschlicherweise, es handle sich um laufende Aufzeichnungen. Tatsächlich jedoch beginnt der Verfasser erst in seinem Versteck auf arischer Seite zu schreiben, wobei er die zeitliche Distanz zu den beschriebenen Ereignissen deutlich macht. Er fertigt keine täglichen Notizen an, sondern schildert seine Erinnerungen und stellt Erörterungen an, nimmt dabei sehr klar eine überindividuelle Perspektive ein. Die Privatheit des Autors ist äußerst reduziert und der öffentlichen Sphäre, der öffentlichen Zeit untergeordnet. Mit seinem Blick möchte der Autor das Ganze erfassen und der Narration einen objektivierten, verallgemeinernden Ton geben, der Reflexionen mit der Registrierung von Fakten verbindet. 
Sznapmans Tagebuch ist der Gemeinschaft gewidmet, nicht der Person des Autors, der das Schicksal der Gemeinschaft teilt und beschreibt. Der Erzähler bemüht sich, neutraler Beobachter zu sein, der die Ereignisse, deren Zeuge er wird, schildert und kommentiert. Daher rühren sicherlich die vielen unpersönlichen narrativen Formeln ${ }^{144}$. Außer ihnen findet noch das kollektive „Wir" Anwendung - ein anderer Ausweg aus der persönlichen Narration. Eine Erzählperspektive der ersten Person Plural bedeutet die Manifestation einer Schicksalsgemeinschaft. Auch stellt sie für den Verfasser eine indirekte Ausdrucksmöglichkeit für starke Emotionen dar, die er ansonsten konsequent verbirgt, deren Offenbarung er sich nicht gestattet: „Hoffnung hält Einzug in unsere Herzen. Vielleicht werden wir doch noch ein Wunder erleben. Wir möchten so sehr überleben und die Niederlage der Bestie mit ansehen" (Pamiętniki z getta, S. 141).

Charakteristisch für Sznapmans Tagebuch ist die zutiefst pessimistische Reflexion über die menschliche Natur und Geschichte, die der Verfasser in die Narration einarbeitet. So bringe die Situation des Holocaust im Menschen Egoismus hervor, beraube ihn jeglicher höherer Gefühle und degradiere ihn. Die Geschichte hingegen gewähre weder Opfern noch Henkern Gerechtigkeit, stattdessen werde die Wahrheit über den Holocaust zum Gegenstand der Manipulation, wohingegen sich die Verbrecher der Gerechtigkeit entziehen und reingewaschen würden. Schließlich würden sich die Mörder für das geraubte Geld irgendwo in den warmen Ländern Südamerikas ein sicheres Asyl kaufen. Diese bitteren Worte voll beißendem Sarkasmus schrieb ein Mensch, der nicht mehr miterleben durfte, wie sich seine düstere Prophezeiung nach Kriegsende tatsächlich erfüllte.

Samuel Puterman, Funktionär beim Ordnungsdienst im Ghetto, wendet in seinem Tagebuch Methoden an, die eigentlich charakteristisch für Romane des klassischen Realismus sind. Er konstruiert einen allwissenden Erzähler in der dritten Person, dessen Geschichte über das Ghetto sich in vielen verschiedenen Akten abspielt. Die durchdacht angelegten Szenen mit plastisch gezeichneten Figuren und Dialogen besitzen eine eigene innere Dramaturgie. Ihre Form verrät, dass dem Autor die literarische Praxis geläufig sein muss; er ist sich der Funktion einer sparsamen Erzählweise, knapper und klarer Dialoge bewusst,

144 Zum Beispiel: „Die Bevölkerung atmete auf. Man begann, auf die Straße hinauszugehen und die Verheerung zu betrachten“ (Pamiętniki z getta, S. 23); „Die Menschen wurden auf Wagen platziert und zum sogenannten »Umschlagplatz« abtransportiert. Dort lud man sie in Güterwaggons“(S. 95). 
kann bei einem einzelnen Detail verweilen, an entsprechenden Stellen verstummen, Dinge unausgesprochen belassen oder aber expressiv hinausrufen. Wie es sich für einen allwissenden Erzähler gehört, gibt er den Gedankenfluss seiner Figuren wieder.

Puterman verfügt über ein weit verzweigtes Wissen über die Realität und die verschiedenen Gestalten des Ghettos. Er besitzt Scharfblick und eine besondere Fähigkeit, klare Portraits zu zeichnen, achtet auf eine genaue zeitliche und räumliche Einordnung der geschilderten Begebenheiten, auf die getreue Wiedergabe der Topographie. Somit entsteht ein literarisch ausgefeiltes Bild des geschlossenen Bezirks, das an vielen Stellen an eine erzählerische Reportage erinnert. Der Reporter bleibt weit hinter der dargestellten Realität verborgen.

Ich möchte mich nun näher mit einer Szene befassen, die einen der Kulminationspunkte jener literarischen Reportage darstellt. Darin betreten am 22. Juli 1942 drei Männer das Büro des Gemeindevorsitzenden Adam Czerniaków: SS-Sturmbannführer Höfle - Befehlshaber des soeben von Lublin in Warschau eingetroffenen Vernichtungskommandos, SS-Obersturmführer Karl Brandt - Referent für Judenangelegenheiten bei der Warschauer Gestapo, und Oberscharführer Mende. Sie geben den Deportationsbefehl an den Vorsitzenden weiter und legen ihm eine entsprechende Bekanntmachung zur Unterzeichnung vor. Wir Leser werden nun also Zeugen einer Szene, von der niemand, außer den vier Beteiligten, etwas wissen konnte. Der Autor nennt den Ort des Geschehens, schildert das Verhalten der Beteiligten, macht auf charakteristische Details aufmerksam, schafft eine Atmosphäre.

Eine Moment lang herrschte ungetrübte Stille, die Julisonne schien durch die bunten Glasfenster ${ }^{145}$ und warf regenbogenfarbene Flecken an die Wand des Arbeitszimmers. [...] Brandt wippte rhythmisch mit seinem glänzenden Schuh und schlug mit der weiBen Papierrolle den Takt dazu. Der Vorsitzende saß unbewegt da. Sein Gehirn hinter der hohen Stirn arbeitete auf Hochtouren (Pamiętniki z getta, S. 93).

145 Das Detail mit den Buntglasfenstern verrät eine ausgezeichnete Kenntnis der Realien. Czerniaków hatte tatsächlich für sein Büro Buntglasfenster mit biblischen Szenen bestellt, die ein Künstler namens Śliwiak Anfang Februar 1942 anfertigte. Czerniaków war sehr zufrieden mit dieser Arbeit: „Sie sind sehr schön gelungen“, schrieb er am 4. Februar 1942 (S. 223) - und am 12. Februar lautet der Eintrag: „Ein schöner Tag. Die Sonne reflektiert wunderbar durch die Glasfenster in meinem Arbeitszimmer" (S. 225-226). Es ist wenig wahrscheinlich, dass Puterman jene Einträge Czerniakóws kannte, dennoch ähneln beide Textstellen über die Fenster einander auf mysteriöse Weise. 
Wir verfolgen die Gedankengänge des Vorsitzenden mit, die im Kontrast zu dem trockenen Befehlston stehen, den die Gestapomänner ihm gegenüber anschlagen. Czerniaków schweigt noch immer, wird jedoch bald antworten müssen. Unerbittlich rückt der Moment der Entscheidung näher. An dieser Stelle wechselt der Erzähler in die erlebte Rede:

Czerniaków griff nach Papier und Feder. Etwas in ihm schrie, lass es, um Himmels willen, tu es nicht. Das verflixte Herz, wie es schlägt. Ich muss jetzt etwas sagen. Er seufzte tief, holte Atem und schaffte es, seine Stimme, wie ihm schien, sehr ruhig klingen zu lassen (S. 94).

Die dramatische Szene endet mit einer lakonisch vorgebrachten Information über Czerniakóws Selbstmord, einschließlich einem charakteristischen bewertenden Kommentar des Erzählers.

Das Gesicht des Vorsitzenden war bleich, doch zeichnete sich ein Lächeln auf ihm ab. Das befreiende Lächeln des Todes. Der Vorsitzende hatte sich mit einer winzigen Dosis Zyankalipulver vergiftet. Das mitfühlende Herz Adam Czerniakóws, Ingenieur und Vorsitzender der größten jüdischen Gemeinde Europas, hatte zu schlagen aufgehört (S. 94).

Dieses Beispiel beweist die literarische Gewandtheit des Verfassers (man bedenke den raffinierten Kunstgriff der erlebten Rede!) sowie das Spektrum des künstlerischen Effekts, den er bewusst anstrebt - und sei es auf Kosten der „harten Fakten". Czerniaków vergiftete sich in seinem Büro nämlich nicht am ersten Tag der Deportationen (und von jenem Tag, dem 22. Juli 1942, als die Gestapo den Vorsitzenden offiziell über den Beginn der Deportationsaktion in Kenntnis setzte, handelt die analysierte Szene), sondern einen Tag später. Puterman denkt jedoch in dramaturgischen Kategorien, sieht sich in gewissem Sinne als Regisseur der geschilderten Wirklichkeit.

Erst im hinteren Teil des Tagebuchs, bereits mit der Perspektive des Kriegsendes, erscheint das narrative „Ich“. Jener Ich-Erzähler ist ohne Zweifel Puterman selbst, der erst jetzt sein Gesicht zeigt. Er hatte sich auf arischer Seite versteckt. Nach dem Warschauer Aufstand nach Sachsenhausen und Oranienburg deportiert, kehrt er gleich nach der Befreiung nach Warschau zurück. Er ist endlich frei, doch die Freiheit kommt zu spät. In den Trümmern erwartet ihn niemand mehr. Mit der ganzen Kraft des persönlichen Bekenntnisses verleiht Puterman seinem privaten Schmerz Ausdruck. Er legt die Maske des unpersönlichen narrativen Mediums ab, spricht nur noch von sich selbst und über sich selbst:

Es ist niemand da! Und so viele Menschen ringsum. Ich bin zurück, ich habe überlebt [...], doch es gibt niemanden, der sich darüber freut. Ich ging mit klopfendem Herzen, in dem das Blut heiß wallte. [...] Ich war in die Freiheit zurückgekehrt, doch du wartetest nicht vor dem Haus auf mich, nahmst nicht bei meinem Anblick freudig die Hände 
vom Gesicht. Keine grünen Augen leuchteten auf vor Glück. Zur Begrüßung schlug mir nur der noch nicht verwehte Brand[geruch], starrten mir die leeren Augenhöhlen des zerstörten Hauses entgegen (S. 239).

\section{Kula - Ringelblum - Landau}

Im Vorwort zu Ludwik Landaus Kronika lat wojny i okupacji [Chronik der Kriegs- und Besatzungsjahre] äußert sich Witold Kula bewundernd über den unpersönlichen Tonfall, den der Autor dieses monumentalen Werkes anschlägt. Die verschiedenen Niederschriften aus den Besatzungsjahren wiesen nahezu ausschließlich den Charakter eines Tagebuchs auf, nicht jedoch einer Chronik, stellt Kula fest und meint damit wohl, dass im Tagebuch das persönliche Element offenbart werde, das in einer Chronik verborgen bleibe. In Quellen mit dem Charakter eines Tagebuchs oder persönlicher Erinnerungen sei das ,individuelle menschliche Erleben das Hauptmotiv“, wenn auch zusätzlich, wie der Verfasser des Vorworts bemerkt, „ein weiter gefasster Gedanke“ durchscheine: „ein wahres Zeugnis zu geben“. In dieser Hinsicht ist Landaus Kronika eine Ausnahme. Ihre erschütternde Aussage "leitet sich wohl davon her, dass jegliche persönlichen Akzente fehlen, dass alles ausgelassen wird, was nicht allgemeine Bedeutung besitzt". 146

Als er im Dezember 1960 jenes Vorwort verfasste, war Witold Kula bereits ein bekannter und anerkannter Historiker. Dass er Landau als Autor einer perfekt ausgearbeiteten Textquelle für historische Forschungen sei Lob ausspricht, hat somit eine besondere Aussage - es drückt die Überzeugungen eines erfahrenen Wissenschaftlers aus. Es sollte sich jedoch herausstellen, dass Kula selbst der Autor eines Textes namens Dziennik czasu okupacji [Tagebuch der Besatzungszeit] ist, das erst vor nicht allzu langer Zeit bei seinen posthumen Papieren gefunden wurde ${ }^{147}$. Jenes Tagebuch weicht stark von der Form ab, die Kula 20 Jahre später so sehr schätzt. Es besteht in mehreren Dutzend Seiten persönlicher Beobachtungen und Eindrücke, die der angehende Wissenschaftler in unregelmäßigen Abständen im besetzten Warschau notierte, und wirkt wie ein Entwurf für einen autobiographischen Roman. Auch die enthaltenen Notizen zu geplanten wissenschaftlichen Arbeiten, Berichte über Lektüren, vorläufig formulierten Thesen und Konzeptionen, Merklisten mit anstehenden Forschungsaufgaben verdecken nicht den zutiefst introspektiven Charakter dieser Aufzeichnungen.

146 W. Kula, Vorwort in: L. Landau: Kronika lat wojny i okupacji, op.cit, S. V.

147 W. Kula: Dziennik czasu okupacji [Tagebuch der Besatzungszeit], hrsg. von N. Assorodobraj-Kula und M. Kula, Warschau 1994. 
Es sind alles andere als unpersönliche Notizen. Der Autor enthüllt sein persönliches Drama, ringt mit sich selbst, und das ist der Hauptgegenstand jenes Tagebuchs. Erst durch diesen Filter bekommt der Leser die Realien der Besatzungszeit zu sehen.

Am anstrengendsten und ermüdendsten an der Besatzung ist für mich - vertraut Kula seinem Tagebuch am 23. Juli 1942 an - der ständige psychische Kraftakt, zu dem ich mich immer wieder aufschwingen muss, so wie ich immer wieder atmen muss, und der sich auf zwei Ziele richtet: keine Angst zu haben und nicht an die ganzen Gräuel ringsum $\mathrm{zu}$ denken. ${ }^{148}$

Der Versuch, sich von dem Druck der brutalen Wirklichkeit abzugrenzen, gelingt jedoch nicht. Unter dem Datum des 24. Juli notiert Kula:

„Ich durchlebe den krassesten Gegensatz dessen, was ich oben geschrieben habe. Ich kann nicht arbeiten, denken, lesen, nicht einmal schlafen - ich kann meine Gedanken nicht von all den Gräueln losreißen, die geschehen. [...] (Ich mache jetzt eine Pause. Ich kann nicht schreiben, ich gehe Schuhe zubinden). ${ }^{\text {" } 149}$

Das ist der letzte Tageseintrag. Somit gibt der Verfasser das Tagebuchschreiben zwei Tage nach Beginn der Deportationen aus dem Ghetto auf. An dieser Stelle muss daran erinnert werden, dass tatsächlich nur wenig gefehlt hätte, und Witold Kula hätte sein Tagebuch auf der anderen Seite der Ghettomauer geschrieben. Seine erste Ehefrau, die 1943 verstorbene Nina z Jabłońskich Kulina, war jüdischer Abstammung. Bereits im November 1939 stand der Autor vor einem Dilemma: „Man befiehlt mir, eine Entscheidung zu treffen zwischen dem Ghetto oder der Flucht in den Osten. ${ }^{\text {"150 }}$ Schlussendlich siegte die Ansicht, einfach auf der arischen Seite Warschaus zu bleiben. Im Kontext jener Entscheidung nimmt der Satz, mit dem der Tagebuchtext abreißt, einen tieferen Sinn an: „Sich zu einem klaren, schlüssigen Lebenskonzept durchzuringen - schon das ist nicht leicht. Dies zu tun, ohne mit dem Tod in Berührung zu kommen, ist wohl gänzlich unmöglich. " 151 Dieser Satz bestätigt endgültig auch die individuelle, persönliche Dimension der Aufzeichnungen Witold Kulas, auf den Landaus

148 Ebd., S. 46.

149 Ebd., S. 48. Kula arbeitete als Lagerist in „einer der eigentümlichsten Institutionen des besetzten Warschau: in der Schuhfabrik des Instituts für soziale Angelegenheiten [poln.: Instytut Spraw Społecznych]. Das ISS beschäftigte 100 Warschauer Schuster, und auf der Lohnliste standen über 50 exzellente Wissenschaftler und Künstler“ (ebd., S. 57, Fußnote der Herausgeber).

150 Ebd., S. 12.

151 Ebd., S. 48. 
Kronika viele Jahre später gerade aus dem Grund, „dass jegliche persönlichen Akzente fehlen", solch erschütternden Eindruck machte.

Landau legt seine Kronika systematisch an, verzeichnet laufend und akribisch Daten und Fakten. Dazu fasst er eigene Beobachtungen sowie ihm zugängliche (offizielle und konspirative) Pressematerialien und andere Quellen, an die er gelangen kann, zusammen. Die Informationen, die ihn erreichen, unterzieht er zunächst einer vorläufigen Bearbeitung. Gute Dienste leisten ihm dabei zweifellos seine vor dem Krieg erworbene wissenschaftliche Praxis und das feine Gespür des Forschers, der sich mit gesellschaftlichen und ökonomischen Prozessen befasst. Er behandelt zahlreiche Bereiche: das besetzte Warschau (samt dem Ghetto), das Generalgouvernement, die dem Deutschen Reich einverleibten und die sowjetisch besetzten Gebiete, die weltweiten Kriegsschauplätze. Diese breite Perspektive objektiviert die Narration, die dem Zweck einer Dokumentation der Ereignisse sowie deren Verifizierung und Interpretation dient.

$\mathrm{Zu}$ bedenken ist jedoch, dass auch Landaus großes Werk mit einer zutiefst persönlichen Perspektive, einem ganz deutlich als privat gekennzeichneten Blick ihren Ausgang nimmt.

Für ein Tagebuch der Kriegszeit ist es eigentlich etwas zu spät [...] - so lautet der erste Satz der Kronika, die mit dem Datum 30.9.1939-17.10.1939 beginnt. - Zwar denke ich, dass die Zeit, die noch vor uns liegt, eine Aufzeichnung lohnt, momentan jedoch möchte ich die Eindrücke erfassen, die mir von einem Monat Krieg geblieben sind (S. 3).

Dann folgt eine ausführliche Analyse der Belagerung Warschaus - eine Kombination aus dem Tagebuch eines Zivilisten, der das Kriegsgeschehen beobachtet und die momentane Stimmungslage verzeichnet, und der sachverständigen Darstellung der politischen und militärischen Lage. Auf diese Weise tritt das Spannungsverhältnis zwischen dem persönlichen und dem unpersönlichen Diskurstypus zutage. In den weiteren Partien seiner Kronika entscheidet sich der Autor ganz dezidiert für letzteren Typus ${ }^{152}$.

Emanuel Ringelblums Kronika getta warszawskiego [Chronik des Warschauer Ghettos] ist bereits nicht mehr in einem so kühlen und objektiven Ton gehalten, auch wenn ihr Verfasser sich über die individuelle Erkenntnisperspektive erhebt. Seine Interessen umfassen weit mehr als den Bereich der direkten Erfahrung - er möchte das Schicksal der Juden im gesamten polnischen Gebiet

152 Landaus Werk erwähne ich hier nur in Kürze und unterziehe es keiner tieferen Analyse. Schließlich ist es keine Chronik des Warschauer Ghettos oder des besetzten Warschau, auch wenn die Stadt ohne Zweifel die Hauptrolle bei den Aufzeichnungen spielt. Landaus Intention ist jedoch die Erfassung des weltweiten Kriegsschauplatzes. 
erfassen. Ringelblum trennt seine eigenen Beobachtungen von aufgeschnappten Informationen, selbst gesammelte Daten von Daten aus zweiter Hand. Die einzelnen Textsegmente versieht er häufig mit einem eigenen modalen Rahmen, der den Status der enthaltenen Inhalte und deren Quellen umreißt. Mal weist er auf eine gewisse Distanz zu den genannten Informationen hin und unterstreicht seine Rolle des Vermittlers, des Sammlers: „Ich habe gehört, dass“, „man sagte mir“, „es heißt, dass“, „man erzählt sich“, „Folgendes wird gesagt“. Dann wieder beschränkt er sich auf die unpersönliche Präsentation, setzt dem Eintrag eine Art Qualifikation voraus: „Szene“ oder „Bild“. Nach einem Doppelpunkt folgt die Darstellung des so angekündigten Ereignisses. Wieder ein anderes Mal gibt er deutlich seine Augenzeugenschaft an: „Mit eigenen Augen habe ich dieses Bild gesehen“ (S. 307) oder „Ich habe folgende Szene gesehen“ (S. 250).

Erstaunlich ist die Detailliertheit der Narration, die schier unerhörte Menge an rasch aufeinanderfolgenden kleinen Einzelheiten, Szenen, Bildern, die manches Mal den Rahmen eines Chronikeintrags sprengen. Im Laufe der Zeit schreibt Ringelblum immer eiliger, wie im Fieber. Die Anforderungen der konspirativen Arbeit sind der Grund, aus dem die Kronika nur in Teilen vorliegt. Nacheinander treffen die Textteile im Ghettoarchiv ein und werden sogleich versteckt. Daher sind die Eintragungen notwendigerweise fragmentarisch, ungeordnet, häufig nicht redaktionell bearbeitet. Auffällig ist auch die stilistische Uneinheitlichkeit - umgangssprachliche und für das Ghetto charakteristische Ausdrucksweisen mischen sich mit der Sprache geschichtlicher Analysen. Der Autor notiert Redensarten, Scherze, Ausdrücke von Ghettofolklore. Stellenweise wendet er eigene Verschlüsselungen, eine „äsopische Sprache“ voller Gleichnisse an. So entwickelt er beispielsweise ein ganzes System von Kryptonymen für die Deutschen. Am häufigsten treten die Bezeichnungen „Galeje“ (für die Gestapo) und „tamci“ [„die da“; die Deutschen allgemein] auf, weiterhin gibt es die „władcy“ [Herrscher], „żółci“ [„die Gelben“; die Gestapo). Hitler nennt er „Horowitz" oder „Czapnik“ [Mützenmacher, Hutmacher] - die Bedeutung des Namens „Hitler“ auf Jiddisch ${ }^{153}$. Spezifisch ist die - durch die Umstände der Konspiration erzwungene - quasi-briefliche Form der Kroniki. Besonders am Anfang leitet Ringelblum manche Textpartien mit Anreden ein: „Meine Lieben!“, „Geliebter Vater!“, „Lieber Großvater!“, „Mein lieber Freund!“, „Werter Freund!“ Das sorgt für eine Erosion der objektivierten, entpersonalisierten Chronikform.

Es scheint, als regiere hier die Regel eines kontrollierten Chaos, was Spannung in den Text bringt - gestattet doch der Zustand der ständigen Bedrohung

153 Siehe die Fußnote des Herausgebers der Kroniki, S. 160. 
keine gemäßigte Objektivität. Er erlaubt kein normales Schreiben, keine Textredaktion mit der angezeigten Ruhe. Der Chronist ist nicht imstande, eine kühle Distanz zu wahren; er ringt mit der brutal hereinbrechenden Wirklichkeit und müht sich, sie zu zähmen, irgendeiner Kontrolle zu unterwerfen, sie zu beherrschen und festzuhalten, indem er sie aufzeichnet. Ringelblums persönliches Engagement, seine Leidenschaft, die auf den Seiten der Kronika spürbar werden, sind ein charakteristischer Zug seines Werkes.

\section{Czerniaków}

Adam Czerniakóws Tagebuch fand seinen aufmerksamen Leser in Roman Zimand, der den Tagebuchtext weniger als historische Quelle denn als eine Art und Weise der Manifestation des Autors betrachtet. Folgt man diesem Ansatz, gelangt man ins Zentrum der hier erörterten Frage nach dem Spannungsverhältnis zwischen persönlicher und unpersönlicher Erzählweise. Der erste Satz, den der Tagebuchschreiber am 6. September 1939 zu Papier bringt - „In der Nacht habe ich von 12 bis 5 Uhr früh nicht geschlafen" - trägt den Charakter eines persönlichen Geständnisses und führt den Leser in die Sphäre der Privatheit ein. So könnten die Aufzeichnungen eines romantischen jungen Mannes oder auch eines schwerkranken alten Menschen beginnen, meint Zimand und bemerkt, dass „diese Worte, wenn man sie dem weiteren Inhalt des Tagebuchs gegenüberstellt, zu Reflexionen sowohl über das Schicksal als auch über die Poetik der täglichen Niederschrift anregen ${ }^{\text {“154}}$. Hinzuzufügen wäre, dass jener - wie ein Auszug aus einem journal intime klingende - Anfangssatz im Kontext der Gesamtheit einen Kontrapunkt zu den trockenen, unpersönlichen Notizen eines Beamten über sein Amt darstellen - wobei dieser Beamte der Vorsitzende des Judenrates im größten Ghetto des besetzten Europa war.

Worin besteht das Phänomen jenes entpersonalisierten und dabei zugleich zutiefst persönlichen Tagebuchs des Adam Czerniaków? Den Versuch einer Antwort auf diese Frage finden wir in Zimands Publikation; daher möchte ich mich hier auf ein paar besondere Ergänzungen beschränken.

Czerniaków legt Notizen von der Art eines Tagebuchs pro memoria an und betrachtet sie als Material, das ihm später - nach einem für die Alliierten siegreichen Krieg - als Grundlage für eine eventuelle Verteidigung seiner öffentlichen Tätigkeit dienen könnte. Zimands These von einem solchen Tagebuch als Mittel zur Selbstverteidigung erklärt sowohl die Knappheit oder geradezu Unlesbarkeit

154 R. Zimand: „W nocy od 12 do 5 rano nie spałem“, op. cit., S. 68. 
mancher Einträge wie auch die Überzahl von Informationen und Materialien, die mit Czerniakóws Funktion als Gemeindevorsitzender ${ }^{155}$ zusammenhingen, darunter eine detaillierte Dokumentation der Kontakte mit den deutschen Behörden. Schreibt er also über sich selbst, so schreibt Czerniaków zwangsläufig über die öffentliche und nicht über die Privatperson.

Und trotzdem hat die Beschreibung der amtlichen Funktionen individuelle Merkmale, trägt einen persönlichen Stempel des Autors. Das offenbart sich in der Konstruktion des Textes - angefangen bei der manchmal extremen Lakonik und Zurückhaltung im Ausdruck von Urteilen und Emotionen, bis hin zu Zweideutigkeiten und dem Spiel mit Zitaten, subtiler Ironie. Hier zum Beispiel ein selbstironischer Kommentar über die charitative Tätigkeit der Gemeinde:

Ich schreibe hin und wieder Gedichte. Dazu braucht man eine angeregte Phantasie. Niemals ist diese Phantasie so weit gegangen, die Suppen, die wir an die Bevölkerung verteilen, Mittagessen zu nennen (S. 179).

Ein anderes Beispiel ist das Spiel mit Zitaten (über die Zitatenregel, die die Grammatik eines Tagebuchtextes bestimmt, kann man ausführlich bei Zimand lesen). Ein Zitat aus Stefan Żeromskis Roman In Schutt und Asche [Originaltitel: Popioty; PL 1902, D 1904] benutzt Czerniaków eindeutig, um indirekt seine eigene Situation zu charakterisieren ${ }^{156}$. Erörterungen über die Figur Winston Churchills, die er einem Buch Roman Landaus über Paderewski entnahm (New York 1934, Warschau 1935), dienen ihm zur versteckten Aussage über die aktuellsten politischen Themen. Vier Tage nach der Besetzung der Stadt Paris durch die Deutschen, knapp einen Monat nach Churchills Amtsantritt als Premierminister, überträgt Czerniaków in sein Tagebuch einen umfänglichen

155 A. Czerniaków verwendet nicht das Wort „Judenrat“ als Bezeichnung einer vom Besatzer geschaffenen Institution, sondern „Gemeinde“, womit er die Kontinuität seines Amtes unterstreicht, zu dem er am 23. September 1939 durch die souveräne Regierung der Rzeczpospolita, vertreten durch den Warschauer Stadtpräsidenten Stefan Starzyński, berufen worden war. Wenige Tage nach der Besetzung Warschaus ernannten die Deutschen Czerniaków zum Oberhaupt des Judenrates. „Man brachte mich zur Szuch-Allee, und dort teilte man mir mit, daß ich 24 Personen für den Gemeinderat aussuchen und an dessen Spitze treten soll', schreibt er am 4. Oktober 1939 (S. 6).

156 „In Żeromskis, In Schutt und Asche' lese ich: ,Habe denn nicht auch ich unter meinem Befehl Häscher, Schergen und Mörder, und gleichwohl schone und schätze ich sie, denn sie verstehen es am besten [...]. Gerade sie werden am besten aus einer mißlichen Lage herausführen, im Falle einer Umzingelung. “" (S. 215). 
Ausschnitt aus jenem in der Vorkriegszeit erschienenen Werk, wodurch das Zitat eine überraschende Aktualität gewinnt. ${ }^{157}$

Der Gemeindevorsitzende zeigt sich selten als Privatperson. Die hierzu notierten Einträge betreffen häufig seinen Schlafrhythmus und seine Lektüren. "Ich lege mich um 9 Uhr abends schlafen und lese. Um 2 Uhr nachts wache ich auf. Und so bis 5-6 Uhr morgens, wenn ich aufstehe. Schuhe" (S. 17). Was bedeutet das Wort „Schuhe“, das hier als Satzäquivalent fungiert? Vielleicht geht es dabei um ähnliche Kleidungsprobleme wie die, von denen Czerniaków an anderer Stelle selbstironisch schreibt: „Morgens bemerkte ich das Fehlen eines Hosenknopfs. Selbst der bedeutendste Mann kann dadurch lächerlich werden“ (S. 35).

Wenn jedoch der Autor des Tagebuchs geradeheraus über sich selbst spricht, widmet er die meiste Aufmerksamkeit eindeutig seiner Gesundheit: Leberund Herzinsuffizienz, Probleme mit Hexenschuss, Zähnen, erfrorenen Zehen, Luftröhrengrippe, Verkühlung. Vor allem jedoch schreibt er von hartnäckigen Kopfschmerzen. Von 29 Bemerkungen über Krankheiten handeln allein elf von der Migräne. Die erste ist vom 22. Januar 1940: „Mit Kopfschmerzen ins Bett“ (S. 35), die letzte vom 19. Juli 1942, vier Tage vor seinem Selbstmord: „Heute habe ich 2 Kopfschmerzpulver, 1 Cybalgin und Baldriantropfen eingenommen. Trotzdem will mir der Kopf zerspringen. Ich gebe mir Mühe, daß ein Lächeln nie mein Gesicht verläßt" (S. 282). Auf den Spuren der Privatheit in Czerniakóws Tagebuch möchte ich einen Moment bei der Geschichte mit dem Hut verweilen - so nenne ich die persönlichen Erfahrungen des Gemeindevorsitzenden mit der Grüßpflicht gegenüber allen Deutschen, die den Juden auferlegt worden war. Die Geschichte mit dem Hut spielt sich in drei Zeitabschnitten ab: Juni 1940, Mai 1941 und September 1941, und wird in fünf Akten erzählt. Der Autor spielt darin die Rolle desjenigen, der den Hut nicht ziehen, keine Ehrerbietung zeigen will und damit passiven Widerstand leistet. Ein Wachmann vor

157 In dem Eintrag vom 18. Juni 1940 ist u.a. zu lesen: „Welchen englischen Politiker halten Sie für den beeindruckendsten?" „Nun, Winston Churchill natürlich. [...]“ „[I]ch wage zu behaupten, dass sich in der internationalen Politik vieles bessern würde, wenn er an der Spitze des Foreign Office stünde" (S. 82). Genau an jenem Tag - wovon Czerniaków, als er den Eintrag machte, nichts wissen konnte - lud die englische Regierung den Präsidenten der Rzeczpospolita Polska nach England ein. Einen Tag später traf General Sikorski sich mit Winston Churchill, der „die unbeugsame Haltung Polens im Bündnis gegen Hitler“ betonte und versicherte, dass „seine Regierung Krieg führen werde bis zum endgültigen Sieg“. Siehe A. Albert (eigentl. W. Roszkowski): Najnowsza historia Polski [Die jüngste Geschichte Polens], Bd. 1, London 1994, S. 450-451. 
dem Palais Brühl weist Czerniaków zurecht: „Der Wachposten wies mich [...] darauf hin, daß ich ,frühzeitig' [im Original deutsch] den Hut zu ziehen hätte" (S. 85), so lautet der Eintrag vom 25. Juni 1940 - erster Akt. Die drei folgenden Akte erhöhen die Spannung. Es ändert sich die Szenerie - zunächst ist der Ort der Sitz des Generalgouverneurs des Distrikts Warschau (bei den Einträgen vom 8. Mai 1941: „Im Hof des [Palais] Brühl rief man mir aus dem Auto zu ,Nimm den Hut ab’. Ich habe ihn nicht abgenommen“ (S. 145) sowie vom 12. Mai 1941: „Auf dem Hof des Palais ,Brühl ${ }^{\circ}$ hat man mir wieder befohlen, den Hut abzunehmen“ (S. 147), danach die Treppe vor dem Sitz der Gemeinde (beim Eintrag vom 15. Mai 1941): „Heute hat man auf der Treppe in der Gemeinde versucht, mir den Hut vom Kopf zu stoßen“ (S. 148). Der Druck erhöht sich - von Ermahnungen bis hin zu körperlicher Aggression. Czerniaków ordnet sich dem Befehl nicht unter, auch wenn er das nur am 8. Mai direkt notiert. Der fünfte und letzte Akt findet am 2. September 1941 vor dem Palais Brühl statt: „Nach dem Hinausgehen ließ uns die Wache kehrtmachen, weil wir uns nicht verbeugt hätten“ (S. 183).

Der Privatkrieg gegen die Grüßpflicht gegenüber den Deutschen hatte seine Helden und forderte seine Opfer. „Heute, am 29. September [1940] habe ich einen Fausthieb ins Gesicht bekommen, weil ich [vor dem Deutschen] nicht meinen Hut gezogen hatte", schreibt Ringelblum in seiner Kronika (S. 158). Mehrmals kommt er auf diese Sache zurück, führt Beispiele des Widerstands gegen das verpflichtende Hutziehen an. Czerniakóws Fall ist jedoch einzigartig; es scheint, als sei die oben angeführte rekonstruierte Geschichte ein Beispiel dafür, wie in seinem Tagebuch das Persönliche mit dem Öffentlichen und Offiziellen untrennbar verflochten ist. Das Verhalten des Gemeindevorsitzenden nimmt aufgrund seiner Funktion schließlich stets öffentlichen Charakter an, selbst wenn es zutiefst privaten Motiven entspringt. Das musste Czerniaków bedenken, wenn er auf der Straße den Hut nicht zog und auch, wenn er gerade diese Geste - neben vielen anderen Amtshandlungen - in seinem Tagebuch notierte.

Es gibt allerdings einen Eintrag, der dieses heroisch anmutende Bild Czerniakóws ins Wanken bringt - einen Eintrag, den ich sogar beschämend nennen würde. Roman Zimand hingegen hält eine Notiz vom 25. Juli 1941 für „den beschämendsten Eintrag im ganzen Tagebuch"; darin ist beschrieben, wie ein jüdischer Polizist Bettler vor den Fenstern von Czerniakóws Büro vertreibt, indem er milde Gaben an sie austeilt. Den Kommentar zu der Szene - „Das würde kein Polizist anderer Nationalität tun“" (S. 174) - sieht der Forscher nicht nur als Ausdruck der Naivität des Verfassers. Er entdeckt darin auch einen Schatten von Chauvinismus, obwohl Chauvinismus, wie er betont, Czerniaków 
eigentlich vollkommen fremd gewesen $\mathrm{sei}^{158}$. Ohne diese Interpretation infrage stellen zu wollen, muss ich bemerken, dass jene Textstelle mir im Vergleich mit der folgenden Notiz vom 29. Mai 1942 vollkommen harmlos erscheint:

Ich pflege mit Brandt durch die Straßen zu gehen und die Hausmeister zurechtzuweisen bzw. zu belohnen. Bei einer derart gering entwickelten Zivilisationsstufe kann das Getto nicht sauber sein. Die Menschen benehmen sich leider wie Schweine. Jahrhunderte der Nachlässigkeit rächen sich. Und gefördert wird das durch das grenzenlose Leid und Elend (S. 260). ${ }^{159}$

Nach fast drei Jahren Besatzung und 18 Monate nach Abriegelung des geschlossenen Bezirks die Feststellung zu treffen, der Schmutz im Ghetto sei eine Folge „der gering entwickelten Zivilisationsstufe“, ist eine entsetzliche Verkennung der Umstände. Czerniaków kannte die Bandbreite der Repressionen, absichtlich herbeigeführten Qualen, Gewalttätigkeiten nur zu gut. Niemand wusste besser als er, dass die Organisation einer regelmäßigen Müllabfuhr aus dem Ghetto fortwährend auf die verschiedensten Hindernisse stieß. Aus diesem Grund häuften sich auf Straßen und Hinterhöfen Berge von Unrat.

Im Winter und Frühjahr 1942 versuchte Czerniaków - so geht es aus seinen Aufzeichnungen hervor - diese Angelegenheit in Ordnung zu bringen.

Die Häuser sind entsetzlich verunreinigt. Ich habe energisch angeordnet, den Müll zu beseitigen. 2 Maulhelden, Usman und Pożaryk, habe ich dem Liegenschaftsamt zugeteilt, Abteilung Müll. (S. 230)

Die deutschen Behörden befehlen dem Vorsitzenden, vermehrt auf die Hygieneverhältnisse im Ghetto zu achten. Kontrollen werden durchgeführt. „Vor Mittag besichtigte ich mit Auerswald verschiedene Häuser und überprüfte das Maß der Veruneinigung" (S. 235), notiert er am 16. März. Einen Monat darauf findet bei

158 op. cit., S. 46.

159 R. Zimand führt in seinem Buch diese Textstelle auf, ordnet sie jedoch der Sorge des Vorsitzenden „um den allgemeinen Stand der Zivilisation“ zu und kommentiert all das nicht weiter. Beim Zitieren kürzt er die Stelle wie folgt: „Ich pflege [...] durch die Straßen zu gehen und die Hausmeister zurechtzuweisen [...]“ (ebd., Czerniaków S. 260). Dieser Schritt ist mir unbegreiflich. Die ausgelassenen Textteile umfassen nur neun Buchstaben! Gründe des Platzsparens kommen hier somit nicht infrage, umso mehr, als zwei der ausgelassenen Wörter - „mit Brandt“ - von entscheidender Bedeutung für die gesamte Textstelle sind. Es scheint, als sei Zimand besonders daran gelegen gewesen, dass Czerniaków durch die verschmutzten Straßen des Ghettos ging und allzu nachlässige Hausmeister schalt. Jedoch war Czerniaków dabei eben nicht allein, und genau deswegen erlaube ich mir, ebendiesen Eintrag als den beschämendsten im ganzen Tagebuch zu bezeichnen. 
Dr. Wilhelm Hagen, dem vom Besatzer ernannten Warschauer Oberarzt in den Jahren 1941-1943, eine Konferenz zum Thema Müllabfuhr statt, an der auch Czerniaków teilnimmt. Die Notiz von jenem Tag handelt von Unstimmigkeiten zwischen arischen und jüdischen Abfuhrunternehmen sowie von endlos sich hinziehenden finanziellen Verwicklungen.

Im Wissen um all diese Dinge schreibt Czerniaków völlig ungeniert, mit dem unverhohlenen Ärger des Beamten, der sich mit einem strafbaren Regelverstoß konfrontiert sieht, über die Ghettobewohner, sie benähmen sich wie Schweine. Die Erwähnung des "grenzenlosen Leids und Elends“ kann die Schärfe und Ungerechtigkeit jenes Urteils kaum mildern. Das Fass zum Überlaufen bringt ein Sachverhalt, der bei der Interpretation des Eintrags vom 29. Mai eine Schlüsselrolle spielt. Czerniaków nimmt die Inspektion, wie angegeben, gemeinsam mit Karl Brandt vor, SS-Obersturmführer und Leiter des Judenreferates der Warschauer Gestapo. Mir ist bewusst, dass der Gemeindevorsitzende von Amts wegen gezwungen war, Schulter an Schulter mit Brandt durch die Straßen des Ghettos zu gehen und die Sauberkeitskontrolle durchzuführen - ebenso wie er am 15. März 1940 gezwungen war, Brandts Vertreter, SS-Oberscharführer Mende, zu assistieren, als der den pünktlichen Antritt von Juden zur Zwangsarbeit überprüfte. Bei der Bestrafung der „Verspäteten“ zerbrach Mende damals seine Reitpeitsche, die er anschließend auf Kosten der Gemeinde reparieren lie $\beta^{160}$. Dem Tagebuchschreiber gelingt es, in die beiläufige Notiz zu diesem Ereignis einen bitteren Sarkasmus einfließen zu lassen, das Drama der unfreiwilligen Mittäterschaft, und eine Distanz zwischen seiner eigenen Person als schreibendes Subjekt und als Gegenstand des Schreibens herzustellen. All das fehlt hingegen bei der Schilderung der gemeinsam mit Brandt absolvierten Inspektion; hier gewinnt der von den Nazis eingesetzte Beamte des Judenrates Überhand über den Ingenieur Adam Czerniaków, den Vorsitzenden der Jüdischen Gemeinde von Warschau.

160 Czerniakóws Eintrag hierzu: „Morgens um 5 zur Twarda-Str. (Inspektion der ausrückenden Arbeiter). M[ende] erschien in Begleitung. Die Arbeiter begannen sich um 6:30 zu sammeln. Die Verspäteten bestrafte man sofort an Ort und Stelle. Die Reitpeitsche zur Reparatur“ (S. 52). Ringelblum, der dem Vorsitzenden gegenüber kritisch eingestellt war, unterstreicht Czerniakóws aktive Haltung bei dem Ereignis: „Die Geschichte mit dem Vorsitzenden der Juden und der Reitpeitsche stellte sich so dar: als [die Peitsche] beim Auspeitschen der Juden, die zur spät zur Arbeit erschienen waren, zerbrach, ordnete er an, sie zur Reparatur zum Sattler und um neun Uhr [wieder] ins Büro zu bringen“" (Bd. 1, S. 120). 
Im Kontext der Überlegungen zum „beschämendsten Eintrag“ im Tagebuch des Adam Czerniaków wäre die Frage angebracht: Was gibt es denn nicht in jenem Tagebuch? Nicht mit dem Inhalt oder Stil bestimmter Einträge sollte man sich befassen, sondern damit, ob etwas umgangen oder ausgelassen wurde. Gleich nach den blutigen Ereignissen der Nacht vom 17. auf den 18. April 1942, als im Ghetto 52 oder 53 Menschen ermordet wurden, intervenierte Czerniaków bei Auerswald und Brandt. Unter dem Datum des 18. April 1942 notiert er:

[Brandt erklärte] auf meine Frage [...], ich könne die Bevölkerung, die ihre Beschäftigung wiederaufnehmen solle, beruhigen. Wer sich nur damit beschäftige, dem werde nichts geschehen. Ich wies den Ordnungsdienst an, mit Hilfe der Hauskomitees die Bevölkerung zu beruhigen (S. 244).

Diese Notiz ergänzt Tomasz Szarota durch eine Bekanntmachung des jüdischen Ordnungsdienstes vom 19. April 1942. Der Text ist in einer der Meldungen erhalten geblieben, die an das Departement für Innere Angelegenheiten der polnischen Regierungsdelegatur gelangten. Man kann ihn als eine Art Fortsetzung des zitierten Tagebucheintrags von Czerniaków sehen, als den Teil, den der Gemeindevorsitzende schon nicht mehr notierte:

Im Auftrag des Vorsitzenden Czerniaków wird der Bevölkerung des Jüdischen Bezirks in Warschau bekanntgegeben, dass die Aktion in der Nacht vom 17. auf den 18. April 1942 sporadischen Charakter gehabt habe, mit dem Ziel, die Menschen zu bestrafen, die nicht mit ihren eigenen Angelegenheiten befasst waren. Es wird der Bevölkerung empfohlen, sich ruhig mit ihren gewöhnlichen Dingen zu beschäftigen, dann werde diese Aktion sich nicht wiederholen. ${ }^{161}$

In seinem Kommentar zu Czerniakóws Reaktion auf jene „Bartholomäusnacht“ des 17./18. April im Ghetto nennt Tomasz Szarota diese Reaktion Czerniakóws größten Fehler. ${ }^{162}$

161 Zitat aus: T. Szarota: „Getto warszawskie u progu zagłady“ [Das Warschauer Ghetto an der Schwelle zur Vernichtung], in: „Kronika Warszawy“ 1993, Nr. 2, S. 12. Ich danke Prof. Szarota, dass er mich auf die Sammlung von Meldungen aus dem Warschauer Ghetto an die Vertretung (Archiwum Akt Nowych, Abt. IV, Gruppe polnische Regierungsdelegatur, Akte 202/11 - 27 und 28) sowie auf die Korrelation zwischen Czerniakóws Eintrag und dem Inhalt der Bekanntmachung aufmerksam gemacht hat.

162 „Ich persönlich meine, dass der Vorsitzende der Gemeinde in ebenjenem Moment den größten Fehler seinen Lebens beging, indem er sich der Illusion hingab, im Gegenzug für die damals verlorenen mehreren Dutzend Menschen andere vor der Vernichtung retten zu können, wenn er nur loyal die Anordnungen der deutschen Behörden befolgte. [...] Und so forderte er sie zu Arbeit, Demut und der Aufgabe jeglicher Gedanken an Widerstand und Protest auf" (ebd.). 
Widmen wir nun unsere Aufmerksamkeit dem Wetter. Vor dem Hintergrund all der auf beiden Seiten der Mauer systematisch geschriebenen Tagebücher oder Chroniken fällt auf, dass Czerniaków häufig über das Wetter schreibt, vor allem über die Temperatur. Die erste derartige Notiz stammt vom 30. Dezember 1939: „Schrecklicher Frost, -15““ (S. 29), die nächste vom 10. Januar 1940: „Seit einigen Tagen schrecklicher Frost (morgens $-24-25^{\circ}$ ), und Kohle gibt es nicht" (S. 32). Ende Januar notiert der Verfasser wieder die Temperatur, im Februar zwei weitere Male, im März sieben Mal, im April dann beinahe täglich. Ab dann beginnt fast jeder Tageseintrag - wie ein meteorologischer Bericht - mit der aktuellen Temperaturangabe. Czerniaków geht selten über diese trockene Information hinaus, schreibt zum Beispiel: „Was für eine Gluthitze wird das heute?“ (S. 83), „Nachts Regen“ (S. 86), „Bewölkt, heiß, schwül“ (S. 91). Die lakonischen Temperaturangaben hören mit dem 8. November 1940 auf, um erst am 2. Januar 1942 wieder einzusetzen („Heute der erste Tag mit strengem Frost, $-15-20^{\circ}$ “, S. 214) und ab Ende jenes Monats an ihren alten Platz zurückzukehren. Im April und Mai nimmt die Häufigkeit der meteorologischen Einträge deutlich ab, bis sie ab dem 28. Mai 1942, an dem der Verfasser $+18^{\circ}$ registriert, ganz verschwinden.

Welche Logik steht hinter jenen Einträgen, wozu dienen sie, warum tauchen sie in Schüben auf? Am Anfang wurde Czerniaków zweifellos von der allgemeinen Atmosphäre dazu verleitet, meteorologische Aufzeichnungen zu machen. Der erste Besatzungswinter war nämlich besonders hart und frostig, was in Kombination mit den Zerstörungen durch den Krieg und dem chronischen Mangel an Brennmaterial das Leben sehr erschwerte. Über das Wetter schrieben zu der Zeit vermutlich alle. In Ludwik Landaus Kronika ist unter dem Datum des 8. Januar 1940 zu lesen: „[G]erade dieses Jahr haben wir einen besonders har-

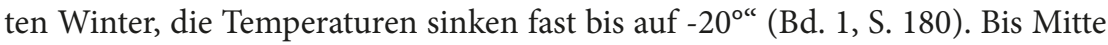
März selbigen Jahres flicht der Chronist 14 Mal kürzere oder längere Notizen über das Wetter ein, in den darauffolgenden Monaten dann nur noch sporadisch. Den strengen Frost erwähnt zu der Zeit mehrmals auch Chaim Kaplan, häufig tut dies ebenfalls Zofia Nałkowska in ihren Dzienniki [Tagebüchern]. Eine Ausnahme ist Emanuel Ringelblum, der im ersten Besatzungswinter meteorologische Beobachtungen beiseite ließ. Die erste Bemerkung über das Wetter („Der Frost zeigte seine Wirkung“, S. 334) taucht in der Kronika getta warszawskiego erst am 14. November 1941 auf.

An Czerniakóws Aufzeichnungen aus der damaligen Zeit ist demnach oberflächlich betrachtet nichts Originelles - jedoch nur oberflächlich betrachtet. Außer dem Gemeindevorsitzenden führte wohl niemand sonst so systematisch und über einen so langen Zeitraum hinweg Aufzeichnungen über das Wetter. 
In keiner der meteorologischen Aufzeichnungen, die ich in den persönlichen Dokumenten aus dem besetzten Warschau finden konnte, stehen die Wetterinformationen einfach für sich; immer erfüllen sie irgendeine Funktion. Landau dienen sie zur Illustration der Brennmaterialkrise, der Knappheit an Kohle und Torf, des sprunghaften Preisanstiegs auf dem Markt oder aber der Konsequenzen, die sich in der Praxis aus dem strengen Frost und dem Schneefall ergaben (geplatzte Wasserleitungen, die Schwierigkeiten, in der Stadt von einem Ort zum anderen zu gelangen). Im Winter 1942 werden die Bemerkungen über das Wetter für den Chronisten zum Aufhänger, um über die militärische Situation an der Ostfront zu sprechen. Bei Kaplan gesellen sich zu den Klagen über den Mangel an Heizmaterial neue Motive - der beißende Frost wird zum sichtbaren Zeichen eines auf den Juden lastenden Fluches, er ist ein weiterer Ausdruck der Torturen, denen sie ausgesetzt sind, ein weiteres Glied in der Kette von Unglückseligkeiten. Nałkowska hingegen nutzt die Beobachtungen über den Frost u.a. für die Konstruktion einer Metapher über die Versklavung durch die Besatzung ${ }^{163}$. Bei Czerniaków hingegen scheinen die meteorologischen Notizen Routine zu sein, ein rein formaler Vorgang ohne tiefere Motivation - ausgenommen sind die ersten beiden Aufzeichnungen vom 10. und 29. Januar, in denen es heißt, „Kohle gibt es nicht" und „in der Gemeinde sitzt man in kalten, ungeheizten Räumen“. Der Verfasser scheint aus einer Art Gewohnheit heraus täglich die Lufttemperatur anzugeben, ohne weitere Kommentare oder Erklärungen. Aufgrund dieser Daten lässt sich eine Isotherme zahlreicher Besatzungsmonate erstellen. Nach wie vor jedoch bleibt die Frage, zu welchem Zweck der Verfasser des Tagebuchs seine Temperaturaufzeichnungen anstellt.

Es fällt schwer, hier eine eindeutige Erklärung zu finden. Wie vieles in Czerniakóws Tagebuch bleibt auch diese Sache letztendlich geheimnisvoll. Ich denke, der Schlüssel könnte hier in Czerniakóws Persönlichkeit und auch in der Strategie seines Schreibens liegen. Die Angaben in Grad Celsius, die Beschränkung auf sachliche Zahlen ist ein extremer Ausdruck seines Strebens nach Objektivität - bleiben doch jegliche wertenden oder emotional geprägten Äußerungen bezüglich des Wetters konsequent ausgeklammert, so als vertraue Czerniaków den Angaben einer Quecksilbersäule mehr als dem eigenen Urteil. Es wirkt, als

163 Unter dem Datum des 20. Januar 1940 ist zu lesen: „Ein anhaltender Frost wie seit Jahren nicht mehr hält alles mit eisigem Griff umklammert. Kälte zu Hause, Kälte im Geschäft, alle Wege durch die Stadt finden in diesem seltsamen Medium statt, in einer Welt der Arktis oder der Eiszeit. “ Z. Nalkowska: Dzienniki V. 1939-1944 [Tagebücher V. 1939-1944]. bearb. von H. Kirchner, Warschau 1996, S. 180. 
habe er ein rein physikalisch bemessenes Quäntchen nackter Wirklichkeit auf die Seiten seines Tagebuchs übertragen und dort festhalten wollen. Auf ähnliche Weise werden z.B. in der Geologie Felssplitter zusammengetragen, um auf ihrer Grundlage die Struktur der Erdoberfläche nachzubilden. Ist die Temperaturkarte, jenes bis zum Äußersten objektivierte Abbild eines winzigen Bruchteils der damaligen Realität, möglicherweise ein Versuch, der Nachwelt einen Aspekt der Ghettoerfahrung mitzuteilen, den Czerniaków auf andere Weise nicht übermitteln konnte?

\section{Berichte - Rapporte - Arbeiten}

Zum Schluss nun möchte ich das Spannungsverhältnis zwischen dem personalisierten und dem entpersonalisierten Diskurs in Texten untersuchen, die an der Grenze des persönlichen Dokuments angesiedelt sind oder darüber hinausgehen. Ich denke dabei an Rapporte, Berichte, Arbeiten zu sozialen, wirtschaftlichen, demographischen Fragen, Feldstudien, Entwürfe von wissenschaftlichen Arbeiten. Manches Mal repräsentieren solcherart Texte eine zweifache Einordnung: Sie sollen objektives faktographisches Material darstellen, werden dabei jedoch zugleich zum persönlichen Zeugnis des Autors oder der Autoren. Einerseits versuchen sie, eine wissenschaftlich-dokumentative Funktion zu erfüllen und, wie es die Gattungspoetik besagt, dieses Ziel auf disziplinierte und methodische Weise zu erreichen, indem sie sich an vorab formulierte Problematiken und Fragebögen halten, die den Erkenntniswert des gesammelten und bearbeiteten Materials, dessen Vielseitigkeit und Vergleichbarkeit mit anderen Daten garantieren sollen. Andererseits wiederum verleihen die Autoren, die unter dem überwältigenden Ansturm der geschilderten Realität stehen und - nolens volens - ihre Emotionen und Wertungen nicht vom übermittelten Inhalt trennen können, diesen unfreiwillig oder bewusst Ausdruck. In einem Text, der eigentlich kein subjektives „Ich“ des Erzählers manifest werden lassen sollte, kommt dennoch das persönliche „Ich“ des Autors zum Vorschein.

Die überwältigende Mehrheit von Dokumenten dieses Typus entstand rund um die Gruppe Oneg Schabbat - eine geplante Entwicklung. Emanuel Ringelblum, der in seiner Kronika die Arbeitsweise und den Interessensbereich der Gruppe beschreibt, nennt dort auch deren Prinzipien und methodologischen Direktiven, wobei er die angestrebte „Objektivität“ betont, den Wunsch, „ein möglichst genaues und vielseitiges Bild der Ereignisse zu erhalten“ sowie das Ideal, dass „möglichst viele Menschen dieselbe Begebenheit schildern, [...] damit die historische Wahrheit, der tatsächliche Ablauf der Ereignisse herausgeschält wird“ (S. 479). Informationen für die weitere Bearbeitung wurden mithilfe 
von Fragebögen, Interviews, Gesprächen zusammengetragen, wobei der wahre Zweck dieser Befragungen vor den Gesprächspartnern verborgen gehalten wurde, handelte es sich doch um Untergrundarbeit. Interessant ist, dass Ringelblum, der doch solchen Wert auf Objektivität legte, den Ausdruck persönlicher Empfindungen nicht nur gestattete, sondern sogar dazu anregte.

Wir waren immer bemüht, dass der Bericht über jedes Ereignis die Zeichen des Unmittelbaren, des echten Erlebens trug. Deswegen sind die Materialien von „Oneg Schabbat“ auch so von Subjektivität durchtränkt (S. 483).

Die Verschiedenheit der Dokumente all jener Menschen, die sich zu jener Zeit an den Tätigkeiten des Ghettoarchivs beteiligten, ist enorm. Professionelle Abhandlungen wurden in Auftrag gegeben, Dokumentationen angeregt, die Mitarbeiter bekamen bestimmte Forschungsbereiche zugeteilt, man trug Informationen und Quellenmaterial zusammen und unterzog es einer ersten Bearbeitung. Das Ergebnis waren Arbeiten und Berichte auf der Grundlage von Gesprächen mit den Flüchtlingen, die im Ghetto eintrafen. Monographien wurden nach einem eigens hergestellten Konspekt verfasst, die Irrfahrten von Flüchtlingen geschildert, Arbeiten zum Überfall Deutschlands auf Polen 1939 geschrieben, Materialien über Lager und Gefängnisse zusammengetragen. Die Berichte von Rückkehrern aus Arbeitslagern - und später von Geflüchteten aus Konzentrationslagern - wurden festgehalten. Kinder wurden befragt, Textwettbewerbe organisiert, die Tätigkeit von Hauskomitees, Volksküchen, Gesundheitsdiensten dargestellt. Die Autoren waren manches Mal auch Schriftsteller, die die unpersönliche Form des Berichts mit einer erzählerisch gestalteten Form der Reportage kombinierten und ihren Texten durch die Einflechtung persönlicher Erlebnisse Merkmale eines individuellen Stils verliehen.

Des Weiteren wurden Berichte erstellt über die Arbeit verschiedener Institutionen und Zentren für soziale Hilfsleistungen. In einem dieser Berichte verfasst von einer Betreuerin im Kinderhort eines Heims für Umsiedler an der Sliska-Straße 28, Estera Karasiówna - prallen zwei Perspektiven aufeinander: die amtliche und die individuelle. Die Dynamik des persönlichen Bekenntnisses bricht die bürokratisch-trockene Form des Berichts über die dienstliche Tätigkeit auf. Karasiówna bemüht sich, die Poetik des amtlichen Gebrauchstextes zu wahren, und arbeitet deswegen sachliche Schilderungen von Aussehen, Möblierung, Tagesordnung des Hortes ein, beschreibt den Charakter der betreuten Kinder und gibt am Textende unter dem Stichwort „Was kann wie verbessert werden?" ihre Schlussfolgerungen und Desiderate bekannt. Dennoch ist nahezu jeder Satz von Emotionen durchtränkt, hinter jedem Satz steht das Erleben der Autorin. Ihr Bericht ist keine emotionslose Inventarisierung, sondern die 
Schilderung eigener Erfahrung. Geformt wird diese Erfahrung durch triviale Details aus dem alltäglichen Elend des Ghettos, durch die konkrete Welt, die Welt der Dinge: ein Eimer mit Grütze, Spucknäpfe statt Tellern, zerbrochene Scheiben, Öfen und Ofenrohre, Brot mit Marmelade, krätzebefallene Hände, die beim Waschen schmerzen. Estera Karasiównas konsequent in der ersten Person Singular verfasster Bericht verwandelt sich in die öffentliche Beichte ${ }^{164}$ eines verzweifelt hilflosen Menschen, der jedoch unermüdlich darum kämpft, , an die hundert Kinder, Menschen einer lichteren Zukunft, aus dem Sumpf zu ziehen“ (S. 105).

Durch die gemeinsamen Bemühungen der Gruppe Oneg Schabbat entstanden Rapporte, die später auf konspirativem Wege der restlichen Welt übermittelt wurden. Zu den hochrangigen Texten zählt der Bericht der vereinigten Untergrundorganisationen des Ghettos an die polnische Exilregierung in London und die alliierten Regierungen vom 15. November 1942 mit dem Titel The Liquidation of Jewish Warsaw. Von Jan Karski in den Westen gebracht, spielte jener Bericht eine internationale Rolle und wurde für die polnische Exilregierung zur grundlegenden Wissensquelle über die Judenvernichtung in polnischen Gebieten. Verfasst worden war er von führenden Köpfen der Oneg-Schabbat-Gruppe: Ringelblum, Gutkowski, Wasser. Fachmännisch verfertigt und mit zahlreichen Diagrammen, Tabellen, statistischen Darstellungen und Anhängen versehen, stellt dieser Bericht den ersten Versuch einer monographischen Erfassung des damals noch andauernden Vernichtungsprozesses dar - seines Verlaufs, seiner Mechanismen, seiner Folgen.

Bei all seinen unschätzbaren inhaltlichen Werten verbindet jener Rapport auf geschickte Weise eine berichtende Narration mit einer beinahe episch angelegten Geschichte der Tragödie eines Volkes. Zahlenkolonnen, eine Quellendokumentation, Aufzählungen von Namen, Institutionen, Städten und Dörfern - all das ist hier in einen Diskurs eingebunden, der sich häufig poetischer Bilder und Metaphern bedient, der auch Emotionalität und Pathos nicht scheut. Eine Statistik der Deportationsopfer, unterteilt nach Geschlecht und Altersgruppen, mit einer pedantischen Unterscheidung nach Todesarten - natürlicher Tod, Selbstmord, Erschießung - steht direkt neben expressiven, schmerz- und zornerfüllten

164 Charakteristischerweise verwendet Ringelblum für derartige Texte die Bezeichnung „Beichte“. Er bemerkt, dass ein dem Ghettoarchiv übergebener Bericht über die Arbeit der Sanitärabteilung „aus der Feder eines Mitglieds der Desinfektionskolonne den Charakter einer Beichte" habe (Bd. 1, S. 488). 
Darstellungen von zum Umschlagplatz verschleppten Opfern oder grauenvollen Szenen aus Treblinka.

Die ersten Sätze des Berichts exponieren auf ganz eigene Weise jenes Drama, leiten das Epos von den polnischen Juden ein:

Im Leuchten des unvergleichlichen polnischen Herbstes glänzt und flirrt eine Schicht von Schnee. Dieser Schnee ist der nichts anderes als die Federn und der Flaum aus jüdischem Bettzeug, das 500000 „nach Osten“ evakuierte Juden mit ihrem sämtlichen Hab und Gut - von Schränken, Truhen und Koffern voller Wäsche und Kleidung bis hin zu Schüsseln, Töpfen, Tellern und anderen Haushaltsdingen - zurücklassen mussten. Die herrenlosen Dinge [...] liegen in wilder Unordnung [...], sie sind bedeckt von jenem Schnee aus der Zeit des vielfachen deutschen Mordes an den Warschauer Juden von den herausquillenden Eingeweiden jüdischen Bettzeugs. [...] Verstohlen huscht ein wandelndes Gerippe eine Häuserwand entlang, blutbespritzt sind die Pfastersteine, Rauch und beißender Brandgeruch erhebt sich von glimmenden und erlöschenden Feuern in den Straßen - all das gibt dieser Todesstadt, in der vor dem schrecklichen 22. Juli innerhalb zehn Kilometern Ghettomauer fast 370000 Juden vor sich hinveregtierten, das passende Kolorit. ${ }^{165}$

Die Konstruktion jenes Textabschnitts mit seinem Gegensatz aus allgemeiner Perspektive und Detailaufnahme, mit der eingeflochtenen Figur der Enumeratio, mit einem wirkungsvoll dosierten Überraschungseffekt deutet auf bestimmte Regeln hin, die den Diskurs des Rapports lenken. Eine dieser Regeln ist unzweifelhaft das Prinzip der Gegenüberstellung von Metapher und konkreter Beschreibung, plastischem Bild und Zahl. Eine andere Regel ist die Kombination zweiter Perspektiven: der kollektiven und der individuellen, der objektivierten und der subjektivierten, persönlichen Perspektive.

Die schmucklose Poetik des objektiven und fachkundigen Gebrauchstextes mit berichtend-informativem Charakter hält dem Ansturm der zu schildernden Realität nicht stand. Die protokollarische, vom Prinzip her entpersonalisierte Aussageweise prallt auf den Drang, Emotionen, Urteilen, Wertungen Ausdruck $\mathrm{zu}$ verleihen und auch einen individuellen Blick, eine eigene Subjektivität zu manifestieren. Um es mit Ringelblums Worten zu sagen: Der Text ist „durchtränkt von Subjektivität“. In die intime Sphäre dringt die Geschichte ein, die Privatheit wird öffentlich gemacht, und die persönliche Erfahrung gewinnt unter solchen Bedingungen einen universalen Wert. Daher mischen sich hier auch der persönliche und der unpersönliche Diskursverlauf. Ein Dokumentationstext, ja selbst die einfachste Verzeichnung von Fakten wurde schließlich im Ghetto zu einem heroischen persönlichen Akt.

165 R. Sakowska: Archiwum Ringelbluma, op. cit., S. 275. 



\section{Die Darstellung des Ghettos}

Zwei einander ergänzende Fragen begleiten die Erörterungen in diesem Kapitel. Eine Frage betrifft die Ausdrucksmittel und -möglichkeiten der Autoren, die andere betrifft die Haltungen des Forschers zu den untersuchten Texten. Also: Wie ist das Ghetto zu beschreiben und welche interpretative Fährte ist einzuschlagen, damit die Aufzeichnungen dieser Erfahrung begreiflich gemacht werden können?

Hier möchte ich mich zunächst mit dem Motiv des Fensters und der Situation des Hinausschauens befassen. Philippe Hamon, der vor allem die Romane Émile Zolas erforscht, kommt zu dem Ergebnis, dass jenes Fenstermotiv eines von vielen verbreiteten Signalen sei, die einer solchen Beschreibung einen Untergrund bieten. Der realistische Diskurs unterliege verschiedenen Beschränkungen aufmerksam, auf die Hamon das Augenmerk lenkt, indem er die Einleitungssituation zu dieser Beschreibung als „leere Thematik“ bezeichnet. Fülle man die leere Thematik durch Beschreibung auf, führe das zu einer paradoxen Situation, beziehe sich doch dann der Text zunehmend weniger auf die außertextuelle Realität als auf sich selbst. Daher müsse die Beschreibung notwendigerweise in einen bestimmten Motivationsrahmen eingebaut werden, wodurch sich wiederum das Netz innertextueller Verbindungen verdichte.

Das Fenstermotiv als narrativer Kunstgriff zur Einführung einer Beschreibung konstituiere eine auf den beschriebenen Gegenstand gerichtete BLICKsITUATION. Damit sei die Beschreibung abhängig vom Blick des Beschreibenden, sie sei von diesem Blick motiviert. Das Fenster werde somit zum Zeichen für diese Art von Beschreibung, der Blick wiederum zum speziellen Vehikel der Beschreibung, das diese im Diskurs ansiedle und untermauere ${ }^{166}$. Das Fenstermotiv, das deutlich die Augenzeugenschaft akzentuiert, kann als spezielles Emblem jenes Literaturbereichs gelten - der Literatur des persönlichen Dokuments -, wie wir nach Roman Zimand Texte nennen, die "die Welt der Augenzeugenschaft"167 betreffen.

Für den Forscher eröffnet die Formel des Durchs-Fenster-Schauens einen der möglichen Wege, auf denen er zur in einen Text eingeschriebenen Holocausterfahrung vordringen kann. Diese Formel enthüllt die Organisationsweise des

166 Nach der polnischen Übersetzung von Ph. Hamon: „Qu’est-ce qu'une description?“, in: „Poétique“ 12 (1972), S. 465-485.

167 R. Zimand: Diarysta Stefan Z., op. cit., S. 17-18. 
Textes in der Materie Sprache und deckt den Ausdruckstypus auf. Damit gibt sie zugleich dem Interpretationsprozess eine gewisse Richtung vor, umreißt den Rahmen des Textverständnisses.

Die Blicksituation, die sich auf den beschriebenen Gegenstand richtet, bestimmt nicht nur die Erzählweise, sondern charakterisiert auch die kognitive Haltung des Autors der Welt gegenüber. Auch gibt sie Hinweise auf seine individuelle Art der Realitätswahrnehmung und auf die Form, in der diese verzeichnet und übermittelt wird. Entscheidend scheinen hierbei zwei Momente: die Betonung der Augenzeugenschaft beim persönlichen Zeugnis auf der einen Seite und der Konkretheit des gewissermaßen empirisch - mittels direkter Beobachtung erlangten Bildes auf der anderen Seite.

Eine nach diesen Grundsätzen konstruierte Botschaft besitzt höchste Glaubwürdigkeit. Eines der Prinzipien des Allgemeinwissens, das Autor und potenzieller Leser teilen, ist schließlich die Überzeugung, ein Sinneszeugnis könne nicht täuschen, in letzter Instanz seien unsere Sinne die Garanten für die Wahrheit unserer Erkenntnis. Der „ungläubige Thomas“ muss erst berühren, bevor er glauben kann. Die Formel der Augenzeugenschaft ließe sich wie folgt paraphrasieren: Was ich beschreibe, existiert wirklich; es ist etwas Reales, das man sehen, berühren, messen kann, das eine ganz bestimmte Gestalt besitzt - seine eigene Form; was ich beschreibe, ist die Wahrheit, denn ich habe es mit eigenen Augen gesehen. Schließlich täuschen Blick, Berührung und Gehör nicht - um es mit Czesław Miłosz’ Worten aus seinem Gedicht „Nadzieja“ [Hoffnung] zu sagen.

Der Blick durchs Fenster lässt sich demnach als metaphorische Umschreibung einer bestimmten interpretativen Haltung bezeichnen. Sie lenkt den Interpreten auf die GegenständLichkeit der Welt, gibt ihm vor, die durch den Text evozierte Schicht des Aussehens der Dinge zu beachten, misst dem Konkreten eine besondere Bedeutung bei. Dieser Fährte folgend, möchte ich zunächst beim Motiv des Fensters verweilen. Als Nächstes sollen ausgewählte Beschreibungssequenzen erörtert werden. Hinsichtlich ihres Gehalts (Inhalts) lassen diese sich in drei Themenstränge einteilen ${ }^{168}$. Zum Anfang möchte ich die Darstellung von

168 Die Themen der analysierten Beschreibungen behandle ich - jedenfalls bis zu einem gewissen Grade - so, wie es die sog. thematische Kritik [franz.: critique thématique; Anm. d. Übers.] tut: als Element der Erfahrung und des Erlebens, das in Gestalt eines Bildes im Text verzeichnet ist und das zugleich die Kategorie darstellt, mittels derer der Autor die Welt erfasst und durch die seine Persönlichkeit am vollständigsten zutage tritt. Siehe M. Głowiński: „Wprowadzenie (do przekładów francuskiej kytyki tematycznej)“ [Einführung (in die Übersetzungen der französischen thematischen Kritik)], in: „Pamiętnik Literacki“ 1971, Heft 2, S. 177. 
Personen betrachten, anschließend die Todesszenen, zum Schluss die Leichname.

\section{Das Fenster}

1

In den eilig notierten Berichten aus dem Warschauer Ghetto erscheint das Fenstermotiv auf drei Ebenen, nach denen der Diskurs organisiert ist - erstens als Element eines, sozusagen, „modalen Rahmens“ der Narration, zweitens als Element der Welt des vorgestellten Textes, seiner gegenständlichen Ausstattung, und drittens als Zeichen eines gewissen Typus von kognitiver und existenzieller Erfahrung. Die Frage lautet somit: Was sieht ein Mensch, der, eingesperrt hinter Mauern, sein Zeugnis niederschreibt?

Die weiter oben erwähnten, an einem rein literarischen Material getätigten Beobachtungen Philippe Hamons lassen sich nicht automatisch auf die Analyse persönlicher Dokumente übertragen. Vielmehr besitzen sie einen inspirierenden Wert, sie geben eine gewisse Denkrichtung vor.

So problematisch die Grenzziehung zwischen den beiden Diskurstypen auch sein mag - der Unterschied zwischen ihnen sorgt dafür, dass der Status jener „leeren Thematik“ im realistischen Roman ein anderer ist als der Status ihrer Entsprechung im Tagebuch oder in Erinnerungen. Die Rolle des Tagebuch- oder Memoirenautors ist eine andere als die Rolle des Romanautors (auch dann, wenn der Roman die Form des persönlichen Dokuments nachempfinden sollte) - sie ist stets an einen konkreten Ort und eine konkrete Zeit gebunden, durch Biographie und Geschichte determiniert und vor allem darauf angelegt, den Wert ihrer Authentizität zu exponieren. Sie ist nicht nur eine Funktion der Lebenssituation des Verfassers, eine der vielen Rollen, die dieser in seinem Leben annimmt, sondern wird zum Gegenstand eines schriftstellerischen Spiels. In die Rolle des Verfassers eingeschrieben ist eine Veränderung der kommunikativen Konvention: Der Verfasser verbirgt sich nicht mehr hinter dem narrativen Medium und der erzählten Welt. Er nimmt die Maske ab und offenbart sein wahres Gesicht oder vielmehr ein Gesicht, das sowohl der Schreibende als auch der Leser als maskenlos anzuerkennen gewillt ist.

Mit anderen Worten: Begebenheiten zu erzählen oder Situationen zu beschreiben ist für den Tagebuch- oder Memoirenautor eine vollkommen reale Tätigkeit, die keine zusätzliche Untermauerung innerhalb des Diskurses benötigt. Die hinreichende und zugleich endgültige Motivation liefert ihr die Formel des Autobiographischen: Ich schreibe über mich und über die Welt, über 
tatsächlich Erlebtes und Gesehenes. Man könnte also sagen, im persönlichen Dokument habe das, was Hamon eine „leere Thematik“ nennt, seine natürliche Referenz. Der Schreiber eines Tagebuchs sieht „wirklich“ etwas durchs Fenster, und dieses Etwas wird dann zum Gegenstand seiner Beschreibung. Im realistischen Roman muss eine solche Situation entsprechend arrangiert werden - im Tagebuch hingegen kann die Konventionalität des Fenstermotivs leicht den vereinbarten Rahmen verlassen und zu etwas Realem werden. Das Fenster ist dann nicht nur narrativer Kunstgriff, sondern mehr: ein Element der beschriebenen Wirklichkeit selbst. Ein echtes Fenster, durch das der Verfasser des Tagebuchs auf die Welt blickt.

\section{2}

Das Fenster deutet auf die besondere örtliche Situation des Schreibenden im Ghetto hin. Der Schreibende befindet sich an einem Ort, wo zwei Sphären, zwei symbolische Räume aufeinandertreffen: Haus und Straße. Das Haus als privater Raum steht dem öffentlichen Raum der Straße gegenüber; es wird zum Bezugspunkt dessen, was sich draußen abspielt. Durchs Fenster ist die zu beschreibende Welt zu sehen. Im Fenstermotiv ist somit die Haltung des Augenzeugen zusammengefasst: Ich sehe und beschreibe.

Wenn er an den Abenden in seiner Wohnung an der Leszno-Straße 18 saß, hörte Emanuel Ringelblum in der ihn umgebenden Stille immer wieder hungernde Kinder schreien. In seiner Kronika getta warszawskiego notiert er: „Heute, am 14. November (1941), habe ich abends so einen kleinen Fratz von drei oder vier Jahren weinen hören“ (S. 334) ${ }^{169}$. Nachts ist die Straße im Ghetto ein unzugänglicher Raum - nach der Polizeistunde darf sich dort niemand mehr aufhalten. Ringelblum ist somit gefangen in seinem Haus, hilflos, getrennt vom Weinen und Klagen, das direkt neben ihm ertönt. Mit einem Almosen kann er sich einen Moment der Ruhe erkaufen: „[S]chließlich wirfst du ihnen ein Stück Brot hin, andernfalls hast du keine Ruhe in deiner Wohnung" (S. 301) - doch das ist nur eine Ersatzhandlung. In Wirklichkeit raubt die Welt vor dem Fenster dem Menschen für immer die Gewissensruhe:

169 Adam Czerniaków, über den Ringelblum sich mit großer Abneigung, ja beinahe Verachtung äußert, setzte eine ähnliche Notiz in sein Tagebuch: „9. VI. 41 - Nach Mittag Arbeit zu Hause - unterbrochen von den Klagerufen der Bettler unter meinem Fenster: ,Brot, Brot! Ich habe Hunger! Hunger! “" (S. 159). 
Obwohl ich dieses Weinen jeden Abend höre, kann ich bis spät in der Nacht nicht diese paar Groszy, die ich ihnen allabendlich gebe, können mein Gewissen nicht beruhigen (S. 347).

Seine Beobachtungen aus dem Fenster seiner Wohnung in der Mylna-Straße 2, direkt an der Mauer zwischen Ghetto und Przejazd-Straße, sind die Quelle für einige der Aufzeichnungen in Avrom Levins Tagebuch. Durch ein Loch in der Mauer - das immer wieder hineingeschlagen und immer wieder zugemauert wurde - ging unablässig der Schmuggel vonstatten. Levin kommt in seinen Notizen wiederholt auf jenes Loch zurück, auf die Schmuggler und Polizisten, die es belauern, und auf die mit ihm zusammenhängenden menschlichen Tragödien.

Gestern um 9 Uhr abends ist unten vor meinem Fenster ein jüdischer Junge im Alter von 13-14 Jahren erschossen worden. Den Mord beging ein dunkelblauer Polizist [ein Mitglied der von den deutschen Besatzern aufgestellten polnischen Polizei im Generalgouvernement; Anm. d. Übers.]. Er schoss durch das Loch in der Mauer und traf den Jungen genau ins Herz (BŻIH 19-20, S. 192).

Durch ihr Fenster im Pawiak (genauer gesagt, im „Serbia“ genannten Frauentrakt des Gefängnisses) beobachtet Mary Berg die große Liquidierungsaktion, die am 22. Juli 1942 beginnt. Ihre Mutter besaß die amerikanische Staatsbürgerschaft. Die ganze Familie war zusammen mit einer Gruppe von anderen ausländischen Bürgern kurz vor Beginn der Aktion interniert worden und wurde bis Januar 1943 im Gefängnisgebäude festgehalten. In ihrem Tagebuch verzeichnet Mary nur das, was sie durch ihr Fenster zur Dzielna-Straße sehen kann oder was sie bei den ebenfalls durch dieses Fenster geführten Unterhaltungen mit nahestehenden Menschen erfährt. Daher beginnen ihre Bilder des Ghettos aus der Zeit der Deportationen häufig mit Formulierungen wie: „[A] us unserem Fenster sehe ich ...." So ist es auch bei der Beschreibung einer Szene, die - wie sich herausstellt - halb Bericht und halb Imagination ist. Ohne Zweifel jedoch sah die Autorin all das mit eigenen Augen, spielte sich die ganze Sache doch buchstäblich auf der anderen Straßenseite ab.

Vor wenigen Tagen standen wir alle am Fenster und sahen zu, wie die Deutschen das Gebäude umringten. Reihen von Kindern traten Hand in Hand aus dem Tor. [...] Jedes Kind trug ein kleines Bündel im Arm. Alle hatten weiße Kittelchen an. So gingen sie ruhig in Zweierreihen, lächelten sogar. [...] Am Ende des ganzen Zuges marschierte Dr. Korczak [...]. Er hatte hohe Schuhe mit hineingesteckten Hosenaufschlägen an, eine Jacke aus Alpakawolle und eine dunkelblaue Kappe auf dem Kopf, ging forschen Schrittes neben einem Arzt aus dem Kinderheim, der einen weißen Kittel trug. Der traurige Menschenzug verschwand hinter der Ecke Dzielna- und Smocza-Straße. Sie gingen in Richtung Gęsia-Straße, zum Friedhof (S. 186-187). 
Mary Berg irrt sich, wenn sie glaubt, Zeugin der Auflösung von Janusz Korczaks Haus der Waisen zu sein. In der Dzielna-Straße 39, in der ehemaligen StanisławKostka-Anstalt - gegenüber dem Fenster, von dem aus die Autorin die geschilderte Szene beobachtet -, befand sich das Główny Dom Schronienia [Großes Haus der Zuflucht], das bereits in der Besatzungszeit durch die Zusammenlegung mehrerer Fürsorgestellen entstanden war. Die Lebensbedingungen darin waren grauenvoll, Korczak nannte das Haus nur eine „Kindermordanstalt“. Anfang 1942 arbeitete er dort sogar einen Monat lang als angestellter Erzieher, um die Situation zu verbessern. Korczaks eigenes Waisenhaus Dom Sierot befand sich jedoch damals an der Sienna-Straße 16, Ecke Śliska-Straße 9, und von dort wurden der Alte Doktor und seine Kinder am 6. August 1942 auf den Umschlagplatz geführt - nicht auf den Friedhof an der Okopowa-Straße. Es liegen einige Berichte von Augenzeugen vor, die Janusz Korczaks letzten Weg beobachtet haben ${ }^{170}$. Keiner von ihnen beschreibt Korczaks Kleidung so detailliert wie Mary Berg. Übereinstimmend betonen sie allerdings, dass Korczak an jenem Tag nicht hinter, sondern an der Spitze des Kinderzuges gegangen sei. Auch kann er nicht jener Mann gewesen sein, der in hohen Schuhen mit forschen Schritten marschierte, denn „Korczak schleppte sich voran, setzte mühsam Fuß vor Fuß, er wirkte wie geschrumpft, murmelte von Zeit zu Zeit etwas in sich hinein“, wie es bei Rudnicki ${ }^{171}$ heißt. Erst auf dem Umschlagplatz, als die Kinder in den Zug verfrachtet wurden, ging Korczak hinter ihnen und verschwand als Letzter im Schlund des Waggons.

Mary Bergs Verwechslung ist - paradoxerweise - ein Beweis für ihre tatsächliche Augenzeugenschaft. Nahezu vollständig abgeschnitten von jeglichen Informationen über die Ereignisse im Ghetto, wusste sie nur so viel, wie es ihr aus dem Fenster im Pawiak zu erspähen gelang. Sie war Zeugin der Liquidierung des Hauses der Zuflucht; dass die Kinder, die dort unten gingen, nicht Janusz

170 Allen voran N. Remby, Gemeindesekretär, der während der Liquidierungsaktion regelmäßig auf dem Umschlagplatz unterwegs war und versuchte, Menschen von dort wegzubringen. Seinen Bericht führt Ringelblum in seiner Kronika an (S. 606-607). Die Erinnerungen von A. Berman: „O losie dzieci żydowskich w Zakładów Opiekuńczych w Getcie Warszawskim “ [Über das Schicksal der jüdischen Kinder in den Fürsorgeanstalten im Warschauer Ghetto], in: „Biuletyn ŻIH“ Nr. 28 (1958); Ida Merżan: „Ostatnia droga Janusza Korczaka“ [Der letzte Weg des Janusz Korczak], in: „Folks-Sztyme“ 1986, Nr. 6; M. Rudnickis Erinnerungen, notiert von R. Scharf: „Ostatnia droga Janusza Korczaka“ [Der letzte Weg des Janusz Korczak], in: „Tygodnik Powszechny“ 1988, Nr. 45.

171 Op. cit., S. 1. 
Korczaks Schützlinge waren, wusste sie nicht. Der Menschenzug entzog sich ihren Blicken, als er von der Dzielna- nach Norden in die Smocza-Straße einbog. Von da an konnte sie aufgrund der Lage des Frauentraktes Serbia nichts mehr sehen. Dass der Weg der Kinder durch die Gęsia- zur Okopowa-Straße führte und dass anschließend alle auf dem Friedhof erschossen wurden, hatte Berg nur aufgeschnappt, weswegen sie diese Information mit einem Zusatz versieht: „Es hieß, dass ..." Korczak selbst war bereits im Ghetto eine legendäre Gestalt. Als Mary Berg aus dem Fenster ihrer Zelle blickte, sah sie eine Verkörperung jener Legende, weil sie ebendies sehen wollte.

\section{3}

Der Verfasser eines Tagebuchs spricht - so wie auch der Autor eines Romans auf eine bestimmte, unter vielen möglichen Sprechweisen ausgewählte Weise zu seinen Lesern, er entscheidet sich für eine spezielle Kommunikationsstrategie. Die ihn umgebende Wirklichkeit und sich selbst sieht er unweigerlich aus einer bestimmten Perspektive. Daher könnte das Fenster, das hier zweifellos fester mit der Realität verbunden ist als im realistischen Roman, zugleich ein vereinbartes Zeichen für die vom Verfasser eingenommene Weltsicht sein. Es könnte als eine Art symbolisches Kürzel gelten, das den Typus der perzeptiven Sensibilität des Autors sowie die in der Niederschrift enthaltene Art der kognitiven und existenziellen Erfahrung bezeichnet.

Die beiden grundlegenden Typen dieser Erfahrung ließen sich in die Metaphern „Fenster mit Blick auf die arische Seite“ sowie „Fenster mit Ghettoblick“ fassen.

Das Fenster ist ein künstliches Gebilde, das arbiträr den Raum teilt und dessen natürliches Kontinuum stört. Zugleich jedoch zwingt es ihm eine gewisse Ordnung auf, markiert eine räumliche Semantik. Beim ersten Erfahrungstypus richtet sich der Blick nach außen, auf die andere Seite. Das „Fenster mit Blick auf die arische Seite“ ist ein Zeichen für eine unüberschreitbare Grenze. Es öffnet sich zu einem Gebiet hin, das unzugänglich ist, obgleich es in unmittelbarer Nähe - die sprichwörtliche Armeslänge entfernt - liegt. Zwischen dem Ort, an dem der Betrachter sich befindet, und dem Ort, der vor dem Fenster zu sehen ist, gibt es keinerlei Verbindung, ihn zu erreichen ist unmöglich. Zwischen beiden Orten liegt ein Abgrund. Auf dessen anderer Seite sieht man - durch den begrenzten Ausschnitt des Fensters - eine andere Welt ${ }^{172}$.

172 Auf das Motiv des Fensters mit Blick auf die arische Seite weist M.M. Borwicz hin: Écrits des condamnés à mort: „Im Ghetto, das von der arischen Seite getrennt 
Unser zweites Weihnachten im Krieg - notiert sich Mary Berg an Heiligabend 1940. Aus meinem Fenster zur ,arischen“ Seite sehe ich lichterbehängte Weihnachtsbäume (S. 46).

[20. Mai 1941:] Auf der anderen Seite des Stacheldrahtes herrscht Frühling. Aus meinem Fenster sehe ich junge Mädchen mit Veilchensträußen in den Händen die „arische“ Straßenseite entlangspazieren. Ich rieche sogar den süßen Duft der schwellenden Knospen an den Bäumen. Im Ghetto aber fehlt jede Spur von Frühling (S. 64).

Den frühlingshaften Anblick und den vom Sächsischen Garten herüberwehenden Fliederduft beschreibt Władysław Szpilman. Nach seinen Auftritten im Café Sztuka an der Leszno-Straße pflegte er gemeinsam mit dem Maler Roman Kramsztyk einen von dessen Freunden in der Elektoralna-Straße zu besuchen. Die kleine Wohnung befand sich im obersten Stockwerk eines Altbaus und besaß einen Balkon.

Bevor die Dunkelheit hereinbrach, traten wir noch auf den Balkon hinaus, um Luft zu schöpfen, die hier oben reiner war als in den staubigen und stickigen Straßenfluchten. Die Polizeistunde näherte sich; die Menschen hatten sich in ihren Häusern

war, bildeten die direkt an der Grenze stehenden Häuser die Mauer. Diese Häuser hatten Fenster, die auf die Straßen der freien Stadt hinausgingen. Infolgedessen waren ihre Bewohner zwangsläufig Zeugen für den Abgrund, der in einem wenige Meter breiten Streifen zwei unwahrscheinlich verschiedene Welten voneinander trennte. Wie sich zeigt, wird das auf die andere Seite der Mauer hinausgehende Fenster zum literarischen Rahmen für Reflexionen, Vergleiche, Visionen etc.“ (S. 234). Borwicz nennt zwei literarische Beispiele, in denen dieses Motiv zum Einsatz kommt: ein Gedicht Władysław Szlengels mit dem Titel „Das Fenster nach jener Seite“ [in: Was ich den Toten las, S. 27; Anm. d. Übers.] und ein Gedicht der 17-jährigen Adela Fruchtman aus dem Ghetto von Łódź [Litzmannstadt]: „Przez okno w getcie“ [Durch das Fenster im Ghetto]. Ebenfalls bemerkenswert ist in diesem Kontext eine Stelle in den Erinnerungen von Adina Blady-Szwajger, die sie gut 40 Jahre nach dem Krieg verfasste und in denen wir die Umkehrung eines der uns hier interessierenden Motive vorfinden: Den Blick von der arischen Seite ins Ghetto. Das Fenster, aus dem man sowohl die eine als auch die andere Seite sieht, markiert gleichbleibend den Abgrund, die Abgeschnittenheit. Die Autorin der Erinnerungen steht an einem Fenster des Spitals an der Żelazna-Straße, durch die die Ghettogrenze verlief. Sie blickt auf die andere, die arische Seite hinüber. Über die Żelazna-Straße strömen Menschenmassen auf den Umschlagplatz. „In einem Haus an der Żelazna, drüber auf der anderen Seite, trat eine Frau in geblümtem Morgenmantel auf den Balkon hinaus und goss die Blumen in den Kästen. Sie muss den Menschenstrom wohl gesehen haben, goss aber weiterhin seelenruhig ihre Blumen. Und auf dieser Seite hier gingen und gingen sie, es nahm kein Ende." (A. Blady-Szwajger: I więcej nic nie pamiętam [Und weiter erinnere ich mich an nichts], Warschau 1994, S. 40). 
eingeschlossen, die tief am Himmel stehende Frühlingssonne überzog mit rosa Schimmer die Zinkdächer, Schwärme weißer Tauben zogen am blauen Himmel ihre Bahn, und aus dem nahen Ogród Saski (Sächsischen Garten) strömte über die Mauern hinweg bis hier zu uns ins Viertel der Verdammten der Duft von Flieder (S. 70).

Das Fenster zur arischen Seite lenkt den Blick über Mauern und Grenzen und weckt dadurch im Hinausschauenden das bittere Bewusstsein, vom Raum ausgeschlossen zu sein - ein Bewusstsein, das umso schwerer zu ertragen ist, als doch der Ort, von dem er für immer vertrieben worden ist, schließlich noch immer existiert, noch immer da ist, und zwar gleich nebenan. Die Verwunderung darüber, dass alles auf jener Seite so normal ist, aber dennoch unerreichbar für einen selbst, so nah und alltäglich, einzig man selbst ist nicht mehr dort - es ist die Verwunderung eines Menschen, der gewissermaßen schon aus dem Grab auf die Welt der Lebenden blickt. Für die Ghettobewohner - die quasi schon zu Lebzeiten tot sind - scheint das Fenster ein Zeichen für ebendieses Erleben zu sein.

Von den Fenstern auf der anderen Mauerseite aus sind so viele hohe Häuser zu sehen, die keine Wohnhäuser sind - notiert Stanisław Sznapman. - Wie viele Kammern es dort gibt. Wie viele Verstecke sich dort befänden. Wie gut man sich dort unbemerkt aufhalten könnte bis zum Sommer, und danach irgendwo weit in die Wälder gehen. So groß ist die Welt, einzig für uns gibt es keinen Platz in ihr (Pamiętniki z getta, S. 206).

Der Blick aus dem Fenster weckt Sehnsüchte, bietet einen Ersatz für die Freiheit. Doch bereitet all das nur noch mehr Schmerz, wird doch das offene Fenster zu einer paradoxen Figur der Gefangenschaft. Am 18. Mai 1942 konstatiert Avrom Levin: „[H]eute ein richtiger Frühlingstag“, fügt jedoch sogleich hinzu:

Ich sitze am offenen Fenster und verspüre keinerlei Kühle. Dennoch kann man sich nicht an der Natur, an Gottes wundervoller Welt erfreuen. Wir irren in einem Gefängnis herum, wie es die Menschheit noch nicht gesehen hat (BŻIH 19-20, S. 179).

Das „Fenster mit Ghettoblick“ steht nicht mehr an der Grenze zweier Welten. Es ist kein Tor zwischen dieser und jener Seite, wurden beide doch auf endgültige Weise voneinander getrennt. Die andere Seite ist einzig und allein von der Grenze aus zu sehen. Das Leben des geschlossenen Bezirks konzentrierte sich jedoch nicht nur an seinen Grenzen, wenn auch die für den Schmuggel und für die Menschen so entscheidenden Durchgangsstellen eine Kulmination jenes geschlossenen Raumes darstellten. Dennoch erwächst die Erfahrung des Ghettos vor allem daraus, was sich innerhalb seiner Mauern ereignete. Daher führt der Blick aus dem Fenster im Ghetto zur Mitte, zum Zentrum der Welt, in der sich der Hinausschauende befindet. Er sieht eine zwischen Mauern eingesperrte, 
dicht abgeriegelte, für sich stehende und vom ganzen Rest getrennte Welt. So, als blicke man aus dem Fenster eines Seitenflügels in einen von allen Seiten durch Häuserwände umrahmten Hinterhof.

Betrachter und Gegenstand der Betrachtung sind in denselben Raum versetzt. Nichts lenkt den Blick über den Ort hinaus, an dem der Betrachter sich befindet, nichts befreit seinen Blick, nichts nährt seine Sehnsucht nach einem unerreichbaren Horizont. Das Fenster zur arischen Seite täuscht vielleicht Freiheit vor, trotzdem kann der Hinausschauende durch dieses Fenster nicht entkommen. Erst recht kein Entkommen ist möglich durch ein Fenster mit Ghettoblick. Ein metaphorisches Bild für die Gefangenschaft in einem Raum liefert ein von Ringelblum geschildertes Ereignis vom September 1941. Es ereignet sich an der Ecke Leszno- und Żelazna-Straße, vor dem Gebäude des Arbeitsamtes.

Aus einem Warschauer Vorort brachte man mit Pinkerts Wagen einige übel zugerichtete, misshandelte, blutende Lagerinsassen her. [...] Aus dem Fenster des Collegium schauten ein paar Kandidaten, die in dasselbe Lager gebracht werden sollten. Als sie sahen, in welchem Zustand [ihre Vorgänger] zurückkamen, protestierten sie und riefen: „Eher bringen wir uns um, als dorthin zu fahren!“, und begannen, einer nach dem anderen aus dem Fenster zu springen (Bd. 1, S. 321-322).

Das ist eine verzweifelte Flucht nach Nirgendwo. Das Fenster führt mitten in die Welt, der man entfliehen möchte. Aus dem Ghetto flüchten kann man nur ins Ghetto.

Ein Fenster im abgeriegelten Bezirk hat mindestens eine zweifache Symbolik. Auf der einen Seite drückt es das Verlangen aus, den Abgrund zu überwinden, die Hoffnung auf eine Begegnung mit der Welt, mit Menschen. Es ist ein Zeichen für die Sehnsucht nach dem offenen Raum, nach Freiheit. Auf der anderen Seite hingegen macht es jenen Abgrund, jene Abgeschnittenheit und Ablehnung schmerzlich erfahrbar.

Die Doppelsymbolik des Fensters wird besonders im letzten Eintrag von Janusz Korczaks Tagebuch vom 4. August 1942, zwei Tage vor dem Marsch auf den Umschlagplatz. Beim Blumengießen beobachtet Korczak einen deutschen Wachmann, ihre Blicke treffen sich.

Breitbeinig steht er da und schaut. [...] Meine Glatze am Fenster - ein gutes Ziel. [...]

Was würde er tun, wenn ich ihm zunickte? Freundlich winken? (S. 117, 119).

In dieser Textstelle bedeutet das Fenster eine Öffnung zur Welt und zum Menschen und zugleich eine Trennung von der Welt, eine Gefahr. Man kann den anderen nicht kennenlernen, ihm entgegengehen, ohne sich zu zeigen, sichtbar zu werden. Doch genau das birgt eine tödliche Gefahr. Das Fenster im Ghetto weckt in demjenigen, der hinausschaut, Sehnsucht nach einem Raum ohne 
Grenzen, während es zugleich das sichere Versteck zunichtemacht. Es gibt den Kopf zum Schuss frei. Das Fenster ist ein Spalt, durch den der Horror sichtbar wird; grauenhafte Szenarien erstreckten sich im Ghetto, so weit das Auge reichte. Es gab jedoch einen Ort, an dem man nicht aus dem Fenster sehen durfte: Rund um das Pawiak-Gefängnis, zwischen Dzielna- und Pawia-Straße - also in einem Gebiet mit dichtest bevölkerten Straßen -, galt das Verbot, aus den Fenstern der Wohnungen auf das Gefängnisgelände zu schauen.

Auf beiden Seiten des Pawiak mussten die Fenster mit dickem schwarzem Papier oder schwarzem Sperrholz verdeckt werden. Die Fenster müssen Tag und Nacht geschlossen sein. Für jeden Spalt, für jedes Loch droht Todesstrafe - notiert Ringelblum (Bd. 1, S. 377).

Das Fenster im Ghetto teilte den Raum in einen eigenen und einen nicht angeeigneten, fremden Raum ein. Aus der eigenen Wohnung oder aus einem Versteck blickte man - in einem Gefühl relativer Sicherheit - auf die fremde, bedrohliche Straße. Diese Trennung war jedoch nur eine scheinbare, sowohl im räumlichen Sinne - schließlich ereignete sich all das in derselben abgegrenzten und geschlossenen Welt - als auch im existenziellen Sinne. Blickte man aus dem Fenster auf den Horror des Ghettos, sah man schließlich sein eigenes Schicksal, sah man sich selbst.

Rokhl Oyerbakh erzählt von einer Nacht in einem Haus, in dem ein Mann von Gestapo-Männern aus seiner Wohnung gezerrt und auf offener Straße erschossen wird. Die vor Angst wie gelähmten Hausbewohner warten wie erstarrt bis zum Morgen.

Erst um fünf Uhr morgens konnte der Leichnam von der Straße geborgen werden. Wir sahen, wie man ihn durch den Hausflur trug, dann sahen wir durch die immer höher liegenden Fenster zum Treppenhaus einen kleinen Menschenzug sich nach oben bewegen (Ring I, 641, S. 30).

Die Hausbewohner sehen durch die Fensterscheiben das wohlbekannte Treppenhaus und den ermordeten Nachbarn, der in seine Wohnung hinaufgetragen wird. Sie wissen, dass jeder von ihnen an seiner Stelle hätte sein können - ist das Morden doch von keiner Logik, von keinem noch so grausamen Gesetz geleitet. Daher ist es fast so, als sähen sie, wie ihr eigener Leichnam die Treppe hinaufgetragen wird.

Der Alptraum ereignet sich gleich nebenan, greift auf den Beobachter über, ergreift ihn vollends. Marian Berland schaut vom Balkon seiner Wohnung im vierten Stock eines Altbaus an der Muranowska-Straße 38, unter dem ein Versteck eingerichtet war, auf das Ghetto im Aufstand. 
Wir gehen in ein Zimmer unserer Wohnung. Dieses Zimmer besitzt einen Balkon mit Blick auf die Muranowska-Straße. [...] Der Balkon [...] ist der Haupt- Beobachtungspunkt. [...] Dem Fenster darf man sich nicht nähern. Die da unten warten nur darauf. Der Balkon ist rundherum mit Sperrholz abgeschirmt (S. 18).

Über den Aufstand wird aus zwei Perspektiven berichtet: vom Versteck im Keller aus, der unter Trümmern begraben ist, und vom Balkon im vierten Stock. Der Autor wechselt zwischen unten und oben, steigt immer wieder aus dem Keller in seine Wohnung hinauf, kehrt an seinen Beobachtungspunkt zurück. Was Berland durch ein kleines Opernglas beobachtet, geschieht in nächster Nähe, direkt vor seinen Augen. Er hört die Deutschen reden, das Geräusch ihrer eisenbeschlagenen Stiefel, er riecht den Brandgeruch, sieht deutlich die Gesichter von Opfern und Henkern. Direkt an ihm vorbei führt der furchtbare Weg der Deportierten auf den Umschlagplatz, während er - das Opernglas am Auge - alles vom Balkon aus beobachtet wie von einer Galerie eines Dantischen Theaters. Eines Theaters, das nicht zwischen Zuschauern und Schauspielern, zwischen Bühne und Zuschauertribüne unterscheidet.

Ich leihe mir ein Opernglas und gehe ans Fenster zurück, wo sich Folgendes meinen Augen darbietet: ungefähr tausend Juden, zu einem Block zusammengetrieben, unvorstellbar zusammengepfercht, sodass einer den anderen zu Brei zerquetscht. [...] Der Block dieser Unglücklichen wird von ungefähr zweihundert Ukrainern umringt, die wie von Sinnen mit Knuten, Knüppeln und Gewehrläufen auf die Nächststehenden einprügeln, in Gesichter, auf Köpfe, Rücken, wohin sie eben treffen. Den Schindern zu Füßen häufen sich niedergeprügelte Opfer in ihren Blutlachen. [...] Mit eingeschlagenen Schädeln, mit gebrochenen Knochen schleppen sich die Halbtoten zu den Waggons. [...] Ich habe starke Nerven und bin nicht so leicht aus der Fassung zu bringen. Zahllose schreckliche Dinge hatte ich während dieses Krieges schon gesehen, doch diesen Anblick konnte ich nicht ertragen, ich wollte nicht länger hinsehen, gab das Opernglas an den Nächstbesten weiter und machte umso schneller, dass ich davonkam. [...] Ich will mir überhaupt nicht bewusst machen, dass ich und meine Nächsten uns jederzeit in derselben Lage befinden könnten wie diese Menschen dort, auf dem Umschlag[platz] ${ }^{173}$ (S. 21-22).

Das Opernglas in Marian Berlands Hand nimmt unerwartet den Rang eines symbolischen Requisits an - scheint doch gerade die Situation eines irrsinnigen "Theaters ohne Theater" das Außergewöhnliche jener Erfahrung, die den Beobachtern durch das Fenster im Ghetto zuteil wird, am besten bewusst zu machen. Um jene eigentümliche Theatralisierung des Blicks noch besser erfassen zu

173 Im Original: na Umschlagu, poln. ugs.; Anm. d. Übers. 
können, möchte ich hier etwas länger bei Chaim Aron Kaplans Aufzeichnungen verweilen.

Unter dem Datum des 21. Juli 1942, also genau am Vortrag der großen Liquidierungsaktion, schreibt Kaplan über die Ermordung eines Dr. Sztejnkolk. Kaplan wird zum Augenzeugen der Szene, die sich direkt vor seinem Haus auf der Straße abspielt; er beobachtet alles aus dem Fenster seiner Wohnung in der NowolipkiStraße. Bei der Schilderung verleiht er dem Ereignis eine innere Dramaturgie der Eintrag umfasst folgende Phasen des Geschehens: (1) Dr. Sztejnkolk kommt auf dem Bürgersteig die Karmelicka-Straße herunter; (2) er wird von den vier Mördern belästigt und (3) von einem der vier getreten; (4) der Doktor dreht sich um und fragt: „Warum trittst du mich, was habe ich dir angetan? "“174; (5) die Mörder befehlen dem Doktor, ihnen in eine Toreinfahrt zu folgen (wodurch Kaplan ihn aus den Augen verliert), wo sie ihn (6) ermorden (was Kaplan nicht sieht, er hört lediglich die Schüsse); (7) der Leichnam des Doktors bleibt in den Einfahrt liegen (nicht sichtbar für Kaplan) und die Mörder gehen ihres Weges, wobei sie sich, wie Kaplan bemerkt, mit der Hand den Mund wischen.

Der Verfasser des Tagebuchs schaut auf die Straße wie der Zuschauer eines Theaterstücks. Vor ihm spielt sich ein Drama ab: Exposition, Komplikation, Peripetie (das kann hier die Situation sein, die entsteht, als Dr. Sztejnkolk seine Frage an die Mörder richtet), Höhepunkt - jene für das Auge unsichtbare, außerhalb der Bühne stattfindende Mordszene -, und schließlich die Auflösung der Situation. Doch das Fenster im Ghetto ist keine Theaterloge, von der aus der Zuschauer in Sicherheit selbst die tragischsten Ereignisse mitverfolgen kann. In diesem Theater gibt es weder Schauspieler noch Zuschauer. Und es gibt keinen Ausgang. Alle finden sich im selben Spiel wieder - und dieses Spiel endet nicht mit dem Fall eines Vorhangs, sondern mit dem Moment, in dem die Grenze zwischen Leben und Tod überschritten wird.

Ich möchte des Weiteren einen Eintrag Kaplans erörtern, datiert auf den 28. Juli 1942. Der Tagebuchautor beobachtet die Blockade eines nahe gelegenen Hauses:

Durch das Fenster meiner Wohnung in der Nähe der » Treibjagden« erblicke ich jene, die in die Fallen gingen, und war so aufgewühlt, daß ich fast wahnsinnig wurde. Dem Festgenommenen wird der Faden seines Lebens in einem einzigen Augenblick zerschnitten, und das Werk eines ganzen Lebens, in das er seine Kräfte steckte, wird herrenloses Gut.

174 Hier klingen die Worte Christi nach der Ohrfeige durch den Diener des Hohepriesters wieder: „Wenn es nicht recht war, was ich gesagt habe, dann weise es nach; wenn es aber recht war, warum schlägst du mich?“"(Joh 18,23). 
Vor meinen Augen nehmen sie eine alte Frau fest, die an einem Stock geht. Ihre Schritte sind gemessen, und sie geht mit großer Anstrengung. Sie kann sich nicht aufrichten. Ihr Gesicht trägt die Zeichen der Vornehmheit und einer jetzt verblichenen Familie von Rang. Auch sie wurde von einem frevelhaften jüdischen Schurken festgenommen. Er braucht Mandanten, und selbst diese alte Dame zählt noch, »sozusagen«, ohne Kleider oder Wäsche, sogar ohne Essen. Sie wird »nach Osten« verschickt. Sie wird glücklich sein, wenn sie nicht mehr lange lebt (Buch der Agonie, S. 390).

In diesem kurzen Textauszug betont der Autor zweimal mit Nachdruck seine Augenzeugenschaft. Er sieht, wie auf der Straße die große Menschenhatz stattfindet, fokussiert von der ganzen Aktion jedoch nur ein bestimmtes Detail. Er konzentriert seinen Blick auf eine konkrete Person - eine alte Frau mit einer Sammelbüchse in der Hand. Dieser eingeschränkte Blick stellt Beobachter und Beobachtete direkt nebeneinander, beinahe von Angesicht zu Angesicht, im gemeinsamen Raum desselben Dramas. Derjenige, der die Szene heute von seinem Fenster aus beobachtet, kann schon morgen selbst auf der Straße stehen. Aus dem Beobachter kann jederzeit ein Beobachteter werden.

Kaplan, der die Szene beobachtet, ist erschüttert. Was ist geschehen, dass der bereits an die grauenvollen Szenen des Ghettolebens gewöhnte Autor gerade beim Anblick dieses konkreten Geschehens fast dem Wahnsinn verfällt? Oder, anders gesagt - was sah Chaim Kaplan am 28. Juli 1942 vom Fenster seiner Wohnung aus?

Es scheint, dass jene zufällig beobachtete Szene ihm einen tiefen Einblick darein gewährt, was sich im Hier und Jetzt vor seinen Augen ereignet. So als sähe er plötzlich alles in einem klareren Licht, fast wie im Glanz einer Epiphanie. Die alte Frau, deren edle Gesichtszüge ein Portrait der gesamten Menschheit in sich zu bergen scheinen, wird von einem Häscher ergriffen, einem Funktionär des Ordnungsdienstes - eine „jüdische Kanaille“. Für die Polizisten galt eine Zeit lang eine tägliche Mindestanzahl von Opfern, die sie persönlich auf den Umschlagplatz zu bringen hatten, um sich selbst vor dem Gefängnis zu retten. Die alte Frau ist einfach ein weiterer „Kopf“, der dem Häscher noch zu seiner Tagesnorm fehlt. Jene einzelne Deportationsepisode bekommt in Kaplans Augen universalen Rang. Sie enthüllt einen Teil der Wahrheit über den Holocaust. Über seine entsetzliche Absurdität. Über die Zufälligkeit des unwiderruflichen Urteils und die Willkür des endgültigen Untergangs, wenn mit einer einzigen Geste alles entschieden ist. Sie enthüllt, dass alle ohne Ausnahme verurteilt sind. Dass den Opfern alles genommen wird, selbst der Name, dass sie in eine abstrakte Zahl, ein statistisches Element verwandelt werden. Dass sich die Grenze zwischen Henker und Opfer verwischt. Sie enthüllt die Trivialität von Gewalt. Die Banalität des Bösen. 
Fassen wir nun die bisherigen Reflexionen zusammen: Marian Berlands Opernglas legt eine Theatermetaphorik nahe, mittels derer sich das Phänomen des Fensters zum Ghetto erfassen lässt. Der Fensterrahmen begrenzt wie die Bühnenkonstruktion im Theater einen bestimmten Raum, auf den sich der Blick des Zuschauers konzentriert. Die Umrahmung des Raumes ist ein bedeutsamer semiotischer Akt. Sie gibt dem, was sich auf - sozusagen - anarchische, ungeordnete Weise vor den Augen des Betrachters erstreckt, eine bestimmte Gestalt. Dem amorphen Raum vor dessen „bloßem“ Auge gibt das Fenster eine Form. Was der Zuschauer durch das Fenster sieht, wird zum Bild und damit zu etwas innerlich Organisiertem, das - ohne sein Zutun - eine eigene Struktur besitzt. Immer ist da etwas in der Bildmitte, etwas ist am Bildrand und etwas geht über den Rahmen hinaus, befindet sich außerhalb des Blickfelds. Das Fenster verleiht sozusagen der Wirklichkeit, auf die hinaus es sich öffnet, eine vorläufige Ordnung. Den Betrachter, der die Wirklichkeit durch das Fenster sieht, erreicht diese bereits in einen Rahmen gefasst - als Bild.

Das Fenster trennt und setzt den Betrachter in eine gewisse Entfernung zum Betrachteten, es organisiert den Blick - ähnlich wie der Platz auf der Zuschauertribüne, von dem aus wir ein Schauspiel betrachten. Beim Blick aus dem Fenster wählen nicht wir das Bild, das wir sehen. Eher noch werden wir selbst erwählt, um im Fensterrahmen dieses und kein anderes Bild zu sehen. Der Blick aus dem Fenster ist nicht unschuldig - er ist eine Ikone der Wirklichkeit, die sich unserer Interpretation unterwirft.

Somit ist das Fenster erstens ein Zeichen für die Augenzeugenschaft - dafür, dass jemand ein Geschehen mit eigenen Augen sieht. Zweitens ist das Fenster ein Spalt, durch den die Wirklichkeit sich dem Betrachter als Bild offenbart, das verstanden zu werden verlangt. Aus einem Fenster im geschlossenen Bezirk sieht der Betrachter ein Grauen, das er nicht ertragen kann, bis er schließlich die Augen abwenden muss. Manchmal jedoch schimmert durch jenen Spalt eine schrecklich-schöne Existenz. Dann gibt das Fenster im Ghetto den Blick frei auf ein Mysterium tremendum. Ein heiliges Grauen nimmt den Blick gefangen und lässt den Betrachter die Augen nicht abwenden. So beobachtet beispielsweise Marian Berland von seinem Balkon eine gigantische Feuersbrunst im Ghetto:

An allen Rändern stehen einzelne Häuser in Flammen. Ein wahrhaft furchterregender und ergreifender Anblick. [...]

Bis an mein Lebensende werde ich nicht vergessen, was ich damals erblickte. So weit das Auge reichte - ein einziges riesiges Flammenmeer. Es schien, als sei das Ende der Welt gekommen. Nun brennen nicht mehr einzelne Häuser, sondern ganze Straßenzüge, 
ganze Viertel. Wohin ich auch schaue, überall dasselbe. Nur unsere Straßenseite brennt nicht. Ich meine in der Arche Noah zu sitzen, rings um mich her eine Flut von Feuer. Ich liege da, schaue und kann meinen Blick nicht abwenden. [...] Eine Nacht des Grauens und des Jüngsten Gerichts (S. 32, 38).

Der Blick durchs Fenster untermauert noch, dass der Betrachter gefangen ist in einem geschlossenen Raum, verurteilt zu einem in diesem Raum vorherbestimmten Schicksal. Schlussendlich bringt er den Betrachter an den Rand des Wahnsinns (wie Kaplan) oder zwingt ihn, seine Augen abzuwenden, zuzukneifen (wie Berland). Somit führt der Blick aus dem Fenster auf das Ghetto in gewissem Sinne zu einem Nicht-Sehen, zur Blindheit. Ein Fenster mit Blick einzig auf das Ghetto ist blind in dem Sinne, dass es nur zu einer Seite hin offen ist - nach innen. Dennoch kann man durch ein solches Fenster manches Mal mehr sehen, als man zu erfassen imstande ist. Im Glanz der Epiphanie offenbart sich dem Betrachter möglicherweise eine Wahrheit über die Wirklichkeit, über sein eigenes Schicksal.

\section{Die Menschen}

1

Die Menschen im Ghetto sind, von oben betrachtet, eine wimmelnde Menge, die sich auf Straßen und in Hinterhöfen drängt. Solche Darstellungen finden sich in Schilderungen des täglichen Lebens, der allgemeinen Betriebsamkeit, des Zustands auf den Straßen und des Verhaltens der Passanten. Ist der Verfasser von Tagebuch oder Memoiren im Ghetto unterwegs, so befindet er sich stets im dichtesten Gedränge, auch die Wohnungen sind übervölkert, die Anlaufstellen für Flüchtlinge belegt bis zum Letzten. Die allgegenwärtige Menschenmenge wird mal zum eigenen Thema, mal nur zum Hintergrund der Aufzeichnungen. Ebenfalls erwähnt werden die Menschenmassen in Berichten über die große Liquidierungsaktion oder den Aufstand: in einer Blockformation auf dem Weg zum Umschlagplatz durch ausgestorbene Straßen oder auf dem Straßenpflaster sitzend in Erwartung der Selektion, oder aber bei der Verladung in Waggons. In sämtlichen Fällen bleibt die Menge gesichtslos und anonym, es sei denn, der Blick des Betrachters hält an einer konkreten Person inne, umreißt deren Aussehen und hebt sie aus der Menge hervor - manchmal nur durch einen einzigen Satz oder gar ein einziges Epitheton.

Die Betrachtung der Figuren möchte ich bei den Portraitskizzen von Personen aus bestimmten Gesellschafts-, Berufs- oder auch informellen Gruppen beginnen. Das können Beamte der Gemeinde sein (wie bei Stefan Ernest), 
SS-Männer aus der Befehlsstelle [im Orig. deutsch] (wie bei Ber Warm oder N.N. „Pamiętniki“, Sign. 129, Archiv des ŻIH), Menschen, die sich zusammen im Bunker verstecken (wie bei Leon Najberg) oder einfach die Freundeskreise der Autoren (wie in Chaim Aron Kaplans Tagebuch). Ein solches Gemeinschaftsportrait setzt sich aus den Darstellungen der einzelnen Gestalten zusammen; eine auf diese Weise konstruierte Sequenz weist eine Kettenstruktur auf: Die Kettenglieder enthalten die Portraits der einzelnen Personen. Tritt eine solche Beschreibungssequenz auf, unterbricht sie den Erzählfluss und gibt dem Autor so die Möglichkeit, die Figuren, um die sich seine Geschichte dreht, näher vorzustellen. Solche Serien von Portraitskizzen werden zu selbstständigen Einheiten, deren Länge vor allem von der Art des Diskurses abhängt. Steht eher die erzählte Handlung im Vordergrund, so sind die Gruppenportraits - wenn sie überhaupt vorkommen - kurz, oberflächlich und fragmentarisch. Dagegen sind sie in einem überwiegend beschreibenden Diskurs ausführlich gestaltet. So ist es vor allem in den Tagebüchern von Stefan Ernest, Stanisław Adler oder dem unbekannten Autor, dessen Text das ŻIH-Archiv bei den „Pamiętniki“ unter Signatur 129 aufbewahrt.

In Umfang und Systematik der Ausführungen unterscheiden sie sich von den erwähnten Aufzeichnungen Emanuel Ringelblums Sylwetki [Silhouetten], die seine Herausgeber als integralen Bestandteil in die Kronika getta warszawskiego eingliederten. Die Sylwetki bestehen aus bisweilen sehr langen, nach Art von Einträgen in biographischen Wörterbüchern oder Enzyklopädien verfassten Skizzen, aber auch aus kurzen, manchmal sogar nur einsätzigen persönlichen Notizen. Die geschilderten Personen sind nach Berufen geordnet. Am ausführlichsten charakterisiert Ringelblum politische und gesellschaftliche Aktivisten und Wissenschaftler; separat stellt er Schriftsteller und Journalisten, Schauspieler, Musiker, Pädagogen, bildende Künstler und Rechtsanwälte dar. Die Skizzen und Notizen fügen sich zu einem eigenen umfänglichen Buch zusammen, das die Verluste für die Gesellschaft im Warschauer Ghetto und die jüdische Kultur im Allgemeinen dokumentiert.

Den Text regiert das Prinzip des enzyklopädischen Biogramms: Er enthält ein Maximum an Informationen über Leben, Tätigkeit und Werk der betreffenden Person, zusätzlich dazu Urteile und allgemeinere Reflexionen. Vor allem charakterliche und geistige Eigenschaften werden exponiert, die Früchte der Arbeit eines ganzen Lebens präsentiert sowie das innere Bild der Person, ihre politische, wissenschaftliche oder künstlerische Aktivität umrissen.

Bei Ringelblum trifft die Konvention des objektivierten Biogramms auf die Schilderung von privaten Beobachtungen und Erinnerungen, Anekdoten und auf eigene Kommentare. Schließlich kannte der Autor nahezu alle Figuren seiner 
Portraits persönlich oder war ihnen zumindest schon einmal begegnet. Daher sind diese Skizzen gewissermaßen in natura entstanden. Umso mehr verwundert bei einer solch umfangreichen Darstellung verschiedenster Figuren die nahezu vollständige Auslassung äußerlicher Merkmale - als bleibe im Rahmen der gewählten Konvention kein Platz für die Beschreibung von Äußerlichkeiten. Auch wenn man von den Personen ansonsten außerordentlich viel erfährt, wird ihre Physiognomie nicht konkretisiert. Das Bild des portraitierten Menschen ist somit unvollständig. Er hat kein Gesicht - es fehlt das wichtigste äußerliche Zeichen menschlicher Individualität, das den Einzelnen von der Menge abhebt und ihn als einzigartiges Individuum identifiziert. An dieser Stelle ist zu bedenken, dass die Überzeugung vom Gesicht als Spiegel der Seele und des Charakters und vom Zusammenhang zwischen der Form der fleischlichen Hülle eines Menschen und dessen inneren Eigenschaften zu den uralten Traditionen der europäischen Kultur gehört ${ }^{175}$.

Bei über hundert in den Sylwetki charakterisierten Figuren lässt sich in lediglich fünf Fällen von einer Beschreibung physiognomischer Elemente sprechen. Zwei Mal treten sie in fragmentarischer Form auf. Der Autor beschränkt sich darauf, gewisse auf das Aussehen bezogene Stereotypen zu signalisieren, die eine rein unterstützende Rolle spielen und den Hintergrund der Situation bilden, in der die Figur sich befindet. Wenn z.B. Ringelblum schreibt, „Genosse Sagans hochgewachsene, bärtige Gestalt dominierte den Saal“, und sein „lautes, gesundes Lachen" erwähnt (S. 537), geht es ihm weniger um die Schilderung spezifischer Merkmale des individuellen Aussehens als darum, ein für die betreffende Figur typisches Verhalten zu unterstreichen. In einem anderen Beispiel erzwingt die übergeordnete Information - der Sachverhalt, dass ein bekannter jüdischer Ethnograph namens Szmul Lehman im Ghetto hungern musste - gewissermaßen eine, wenn auch dürftige, Bemerkung über dessen Aussehen: „Von geringer Körpergröße, dünn“ (S. 568). Drei weitere physiognomische Erwähnungen verselbstständigen sich sozusagen. Sie sind, anders als die vorigen, nicht mehr leichthin mitten in den Text eingeflochten, sondern treten an besonders wichtiger Stelle auf: an dessen Anfang. Die Portraitskizze beginnt mit einigen kurzen Bemerkungen zum Aussehen. Über Roza Symchowicz erfährt man, dass

175 Darüber schreibt J. Bachórz in seiner hervorragenden Skizze „Karta z dziejów zdrowego rozsądku, czyli o fizjonomice w literaturze" [Geschichtliche Karte des gesunden Menschenverstands oder Über die Physiognomik in der Literatur], in: „Teksty“ Nr. 2/1976, in der er die physiognomischen Interessen von der Antike bis zum 19. Jh. und ihren Einfluss auf die Beschreibung literarischer Figuren darstellt. 
sie "groß, schlank, mit einem lieben und freundlichen Gesicht, einem silbrig gesprenkelten Haupt, ungefähr 50 Jahre alt" gewesen sei (S. 607). Über Dr. Szymon Lubelski ist zu lesen: „Groß, gutaussehend, mit langem schwarzen Haar und loderndem Blick“ (S. 610).

Am weitesten ausgebaut und im Kontext der Gesamtheit wohl am bedeutendsten ist die Beschreibung Mordechaj Anielewiczs. Ringelblum eröffnet seine breit angelegte biographische Erzählung über den Kommandanten der ŻOB [Jüdische Kampforganisation; poln. Żydowska Organizacja Bojowa; jiddisch: Jidische Kamf Organisatie] folgendermaßen:

Jenen jungen Menschen, 25 Jahre alt, von mittlerer Größe, mit einem schmalen, bleichen, spitzen Gesicht, langen Haaren, sympathischen Äußeren, lernte ich am Anfang des Krieges kennen. Er kam wie für den Sport gekleidet zu mir [...]. Wer hätte ahnen können, dass dieser stille, bescheidene und sympathische junge Bursche zu einem Mann heranwachsen würde, der drei Jahre später der bedeutendste Mann im Ghetto sein sollte, dessen Namen die einen voller Hochachtung aussprachen und die anderen voller Angst (S. 495).

Das ist im Grunde die einzige Stelle in den gesamten Sylwetki, an der der Autor die Rolle der physiognomischen Beschreibung anerkennt und sie bewusst bei der Konstruktion des Bildes von seiner Figur einsetzt. Dieses und kein anderes Aussehen Anielewiczs, seine Kleidung transportieren nicht nur wichtige Informationen über ihn als Person, sondern erweisen sich auch als wesentliches Element für die im Text angewandte kommunikative Strategie. Das Aussehen von Anielewiczs Gesicht ist vor allem ein Zeichen für seine Jugend und seine körperliche Zartheit, die so stark mit seinem enormen Heldenmut kontrastieren, mit der heroischen Größe, zu der er bald heranwachsen sollte. Ringelblum deckt dieses Paradox gleich am Anfang auf und macht es zum Schlüssel, mit dessen Hilfe die Figur sich begreifen lässt. Die einleitende Frage - Wie kommt es, dass ein derart unscheinbarer Junge eine solche Größe in sich birgt? - wird zum Schwungrad für die gesamte biographische Erzählung. In diese Richtung gehen die Reflexionen des Autors, der eine bezeichnende Wahrheit entdeckt, die die Zeit des Ghettos, die Zeit der Vernichtung zutage fördert - waren doch die Menschen, die sich in jener Zeit zu ungeahnten Höhen aufschwangen, zumeist gewöhnliche, kleine, unerfahrene junge Leute. So wie Anielewicz - Helden ohne erhabene äußerliche Züge.

Bezeichnend ist, dass Marek Edelman - der Vertreter und annähernde Altersgenosse des ŻOB-Kommandanten - in seinem 1945 publizierten Bericht Das Ghetto kämpft kein einziges Mal Anielewiczs Äußeres erwähnt, ebenso wenig wie das Aussehen anderer Mitstreiter. Auch in seinem berühmten 
Gespräch mit Hanna Krall viele Jahre später, in dem er ein weniger heldenhaftes Bild von Anielewicz zeichnet (indem er eine befremdliche Geschichte darüber erzählt, wie Anielewicz - Sohn einer Händlerin - die Kiemen von feilgebotenen Fischen mit roter Farbe anmalt), nennt er keinerlei physiognomische Einzelheiten. Vielleicht war das Äußere des ŻOB-Kommandanten für Edelman so offensichtlich, vom Informationswert her neutral oder auch schlicht so unwichtig, dass es nicht der Erwähnung lohnte. Woran Edelman keinen Gedanken verschwendete, erstaunte hingegen Ringelblum, der eine Generation älter war als die beiden. Daher hat Anielewicz von allen bei Ringelblum beschriebenen Figuren die konkretesten Gesichtszüge. Wenn man also die Sylwetki ein Album mit Portraits von Holocaustopfern nennen wollte, so besäße einzig in Anielewiczs Fall die Bezeichnung „Portrait“ - wenigstens ein Stück weit - ihre ursprüngliche Bedeutung.

In anderen Sammlungen von Portraitskizzen ist die Dichte an physiognomischen Beschreibungen unterschiedlich, meist jedoch eher gering, oder sie sind gar nicht vorhanden. Am detailreichsten werden Aussehen, Kleidung, materielle Attribute und die Art, sich zu bewegen, noch in den Portraits von SS-Männern aus der sog. Befehlsstelle geschildert - einem in der Żelazna-Straße 103 in einem Altbau untergebrachten Spezialstab der Formation Einsatz Reinhardt [auch: Aktion Reinhardt; Anm. d. Übers.], die von Lublin nach Warschau abgestellt worden war, um die Liquidierungsaktion im Ghetto zu leiten. Gezeichnet werden diese Portraits von Ber Warm, einem jüdischen Polizisten, der dort Dienst tat, und von einem Juristen aus Włocławek, ebenfalls Funktionär beim Ordnungsdienst (N.N. „Pamiętniki“, Sign. 129, ŻIH-Archiv). Bei Warm ist die Physiognomik der Deutschen eines der Elemente seiner detailreichen Schilderung der Funktionsweise jener Maschinerie namens Befehlsstelle und hat - sozusagen - illustrativen Charakter. Bei N.N. 129 wiederum sind die Gesichtszüge der Figuren oftmals karikativ überspitzt dargestellt und werden zum Bestandteil einer wertenden metaphorisierten Beschreibung. Die ausführlichen Portraitierungen lassen literarisches Talent, eine gute Beobachtungsgabe, Humor und Erfindungsreichtum erkennen. Geballte Epitheta verleihen den Zeichnungen Dichte und lassen ausgewählte Eigenschaften stärker hervortreten. Diese Methode verrät die Intention des Verfassers, mittels der Physiognomie ins Innere der Figuren vorzudringen und sie seinem Urteil zu unterziehen.

Oberscharführer Mende [...] ähnelte einem Arbeitsgaul, einem flämischen Zugwallach. [...] [E]r war groß, hellhaarig, kräftig gebaut, hatte ein quadratisches, grobes, fülliges Gesicht, eine aufwärts gerichtete Nase und hellblaue, wässrige, tiefliegende kleine Äuglein („Pamiętniki“, Sign. 129, S. 122). 
Außer seinen vollständig gezeichneten Portraits präsentiert N.N. 129 auch einige Miniaturen. In ihnen wird die physiognomische Beschreibung wiederum auf ein absolutes Minimum reduziert, inspiriert lediglich lapidare, scharfe und bösartige Portraitaufnahmen, z.B.: „,[Oberscharführer Klostermeyer [tatsächlich wohl „Klaustermeyer“; Anm. d. Übers]] - überaus abstoßend, vom Aussehen her eine Kreuzung aus Friseur und Schlächter“, „[Unterscharführer Becker] hübsch und knackig, vom Typ Eintänzer" (S. 122). Eine einzelne Phrase oder ein treffendes Epitheton geben - den eigenen Worten des Autors zufolge - „die Unterschiede in Aussehen und Temperament bei den einzelnen Akteuren der Truppe Sonderkommando [im Orig. deutsch]“ wieder (S. 123).

Leon Najberg, der 18 Personen beschreibt, die sich gemeinsam mit ihm während des Ghettoaufstands im Bunker verbergen, bemerkt nahezu gar nichts über deren individuelles Aussehen. Zur Einleitung seiner Darstellung der gesamten Gruppe notiert er stattdessen folgenden Satz, der sich auf alle bezieht:

Die Männer sind schrecklich gealtert und sehen mit ihren ungestutzten Bärten, den unrasierten Gesichtern aus wie Urmenschen (S. 99).

Anschließend wird nur bei diesem Sammelportrait noch das Gesicht eines Mannes hervorgehoben und gesondert beschrieben.

Festinger - $[\ldots]$ heiteres, gutmütiges Gesicht und typisch jüdische, traurige Augen. Er hat dunkle Haut und schwarze Haare, ist von mittlerem Wuchs und vom Alter her um die 28 (S. 102).

Stefan Ernest lässt physiognomische Beschreibungen gänzlich aus. In seinem Tagebuch platziert er ein eigenes Kapitel mit dem Titel „Sylwetki czołowych osobistości getta" [Portraits der führenden Persönlichkeiten im Ghetto]; er nennt es "Erwägungen persönlicher Natur" und versieht es mit einer Einleitung, in der es u.a. heißt:

Es muss an die Personen erinnert werden, die sich - leider, wenn auch nicht durch eigenes Verschulden, vergebens - bemühten, jenes von so vielen Stürmen hin- und hergeworfene Schiff in ruhigere Gewässer zu geleiten („Pamiętniki“, Sign. 195, S. 117).

Die darauffolgenden Skizzen - die (wie die Stilistik der Einleitung bereits ahnen lässt) ausführlich und literarisch ausgefeilt sind - legen die Betonung auf die Interpretation von Einstellungen und Verhalten der Figuren, nicht jedoch auf deren Aussehen. Kompetent legt Ernest die formal-rechtliche Situation der höheren Gemeindebeamten dar, ihre Verstrickung in die Realien des Ghettos; auch bemüht er sich, ein moralisches Profil eines jeden von ihnen zu zeichnen. Dabei belässt er es nicht bei der Dokumentation von Ereignissen, Tätigkeiten, Entscheidungen, bei Informationen über Amtsmodus und Charakter der 
übernommenen Aufgaben. Die Darstellung der einzelnen Figuren soll vor allem dazu dienen, deren Haltung und Handlungsmotivation zu verstehen sowie sie letzten Endes auch zu rechtfertigen. Der Autor scheut auch hagiographische Tonlagen nicht, wie zum Beispiel in einer dem Rechtsanwalt Bernard Zundelewicz, Leiter der Arbeitsabteilung der Gemeinde, gewidmeten Skizze. In einer solchen Konvention finden realistische Beschreibungen von Äußerlichkeiten keinen Platz mehr.

[Zundelewicz] [...] war eine der schönsten Gestalten des Warschauer Ghettos. [...] [E]r war das Herz des Gemeinderates [...]. Er war eine aufrechte, reine, edle Gestalt, die im Dunkel, das sich über uns gesenkt hatte, hell erstrahlte (S. 124-125).

\section{2}

Schreiben mehrere Autoren über dieselben Menschen, ergänzen ihre textuellen Portraits einander. Das bei der Lektüre entstehende Bild entfaltet sich gewissermaßen im Durchschnitt verschiedener Blicke, ist aus verschiedenen Schichten zusammengesetzt. Die wichtigste offizielle Persönlichkeit im Ghetto - die daher auch häufig in Aufzeichnungen vorkam - war zweifellos der Gemeindevorsitzende Adam Czerniaków. Auf der Seite der Schinder wird wohl am häufigsten die Figur Karl Brandts erwähnt - SS-Obersturmführer der Abteilung IV B der Warschauer Gestapo, zuständig für Judenangelegenheiten. Czerniaków traf sich viele Male dienstlich mit Brandt. Versuchen wir, ihre synthetischen Portraits zu rekonstruieren.

Der Vorsitzende ist die Hauptfigur zahlreicher Aufzeichnungen, die manchmal den Umfang und die Tiefe essayistischer Skizzen erreichen. Die Autoren versuchen seine Haltung und seine Tätigkeit gerecht wiederzugeben und zu beurteilen, den Schlüssel zum Verständnis seines Leben und Todes zu finden. Mich wird jedoch im Zusammenhang mit der Figur Czerniaków nicht der moralische, politische oder historiosophische Diskurs beschäftigen, sondern der Ausdruck der physiognomischen Beschreibungen. Was verzeichneten die Tagebuch- und Memoirenautoren des Ghettos über das Aussehen ihres Vorsitzenden?

Eine Beschreibung, die in ihrer Genauigkeit verblüfft, in ihrem Streben, die Details von Czerniakóws Gesicht präzise wiederzugeben und auch die winzigsten Elemente seiner Physiognomie fein herauszuarbeiten, stammt aus der Feder von Jan Mawult (Stanisław Gombiński). Ich zitiere die Stelle vollständig, enthält sie doch eine der wenigen dichten und konsequent physiognomischen Darstellungen, in denen gerade das Äußere der beschriebenen Figur die Grundlage für Urteile über deren Charakter bietet. 
Hinter dem Schreibtisch saß ein Mann Mitte Fünfzig, beleibt, mit glattrasiertem fleischigem Gesicht, hängenden Wangen und einer leicht hängenden Unterlippe, kahl, mit der starken Brille eines Kurzsichtigen auf seiner platten, an den Nasenflügeln leicht aufgeworfenen Nase. Auf den ersten Blick, nach den ersten äußerlichen Eindrücken hätte man gedacht - ein Banker, Industrieller, Politiker, Chirurg, aber welcher Beruf auch immer, womit auch immer er befasst war: Er war ein bodenständiger Mensch, der das Leben liebte und in all seinen Ausprägungen verstand, der sicherlich mit Kennermiene den Duft einer guten Zigarre, den Geschmack exzellenter Speisen und das Bouquet trockener Weine zu beurteilen wusste. Ein Mann, der zu urteilen gewohnt war, der das Leben genoss und seine guten Seiten, seine Sinnesfreuden zu schätzen wusste - doch nicht in ihrer simpelsten Form: Trotz der schweren und sinnlichen Konturen ließen manche seiner Gesichtszüge - die Kinnlinie, der kritische Zug, der sich in den Falten um seinen Mund andeutete - eine gewisse Finesse, einen erlesenen Geschmack erkennen. Richtet er im Aufstehen seine hochgewachsene Gestalt auf - so sieht man einen starken, auf gute Jahre zurückblickenden Mann, geht er - bemerkt man seinen sicheren, raschen Schritt, spricht er - vernimmt man knappe und klare Sätze (Pamiętniki z getta, S. 52)

Die Aufmerksamkeit aller Portraitisten fesselte vor allem Czerniakóws Gesicht und seine Beleibtheit. Keiner jedoch ließ sich zu einer derart genauen Schilderung verleiten wie Mawult, einer Schilderung, die die naturgetreue Abbildung anstrebt, dabei aber frei ist von wertenden Elementen oder emotional gefärbten Bezeichnungen. Bei Stefan Ernest hat Czerniakóws Aussehen wenig konkrete Eigenschaften, sondern unterliegt einer erhöhenden Stilisierung:

Vor den Augen steht mir die mächtige, erhabene Gestalt des Vorsitzenden, jenes stets von Schmerz und Leid wie versteinerte Gesicht [...], todernst, ehrwürdig und feierlich, schwarz gekleidet, [...] er lächelte NIE (Pamiętniki z getta, S. 51).

Makower schreibt, Czerniaków sei „beleibt, apoplektisch und schwer“ (S. 200) gewesen; Hirszfeld erwähnt seinen „stark vorspringenden Kiefer, der ihn Mussolini ähneln ließ`“ (S. 253); Adler stellt einen deutlich abwertenden Vergleich an: „groß, beleibt, kahlköpfig, über sechzig Jahre alt, das Gesicht einer müden Bulldogge" (S. 69).

Was den Gestapomann Brandt betrifft, so ist von den beiden ausführlichsten Charakteristiken - Ber Warm und N.N. 129 - die erstere milder und neutraler. Der Autor wahrt eine kühle Distanz zu seinem Modell, er will einfach dessen Aussehen, dienstliche Tätigkeit, typisches Verhalten wiedergeben. Warm ist aufmerksamer Beobachter und bemüht sich, auf möglichst vollständige Weise Zeugnis zu geben, das eher die Gestalt eines objektivierten Berichts denn eines persönlichen Bekenntnisses annimmt - daher die Konzentration auf Fakten und konkrete Ereignisse, auf das äußere Erscheinungsbild von Orten, Menschen, Gegenständen. Aus diesem Grund scheint hier die einzige, noch dazu 
verhältnismäßig milde, wertende Äußerung bei der Beschreibung Brandts „äußerst unsympathisches Gesicht“ (Pamiętniki z getta, S. 75) - davon zu zeugen, dass dem Autor mehr an der getreuen Erfassung der körperlichen Eigenschaften lag als an einer Bewertung. Er nimmt zum Beispiel ein bestimmtes anatomisches Detail wahr und belässt es bei dessen Notierung: „die Falten unter seinen Augen bilden so etwas wie Kissen“ (l.c.). Dieselbe Eigenschaft bemerkt auch N.N. 129, verwendet sie aber, um wertende Vergleiche zu konstruieren:

Ein Mann [...] mit fleischigem, vollem Gesicht, stark gezeichneten, herabhängenden Augenbrauen, die große, vorstehende, dunkelbraune Augen halb verdecken, unter denen sich Augenringe abzeichnen wie bei einem Alkoholsüchtigen oder Nierenkranken (Pamiętniki z getta, Sign. 129, S. 121).

Andere, bereits sehr kurze Schilderungen gehen mehr in Richtung Karikatur und heben Hässlichkeit, Bedrohlichkeit, Grausamkeit des Beschriebenen hervor. Leon Najberg zeigt Brandt auf dem Umschlagplatz als ungerührten, routiniert und methodisch vorgehenden Schinder:

Er war ein kleiner, untersetzter Mann mit stumpfem, teigigem Gesicht, eine Peitsche in der Hand. [...] [M] it geübtem Auge trennte er Ehemann von Ehefrau, Mutter von Kind, den alten Vater vom Sohn (S. 27).

Aus Henryk Makowers Feder fließt eine deformierende und degradierende Darstellung des SS-Manns. Neutrale Formulierungen werden hier durch negativ wertende Ausdrücke ersetzt. Geschildert ist die Selektion der Gemeindemitarbeiter während des sog. Kessels auf der Mila-Straße:

Den ganzen Tag hindurch stellten sich auf beiden Hinterhöfen der Gemeinde Reihen von glücklichen Auserwählten auf, ihre roten Lebensnummern an der Brust. [...] SSMann Brandt [...] kontrollierte die Anzahl der Menschen. [...] Die aufgeblasene, ordinäre Fresse Brandts, der mit seinen kleinen Äuglein die Vorübergehenden durchbohrte (S. 202).

3

Die meisten Portraitskizzen kommen ausgezeichnet ohne physiognomische Angaben aus. Die Figuren des öffentlichen Lebens im Ghetto verkörperten ein wesentliches Fragment des Schicksals, von dem die Schreibenden Zeugnis geben wollten. Ihre Beschreibung diente vor allem der Äußerung von Urteilen über ihre Haltung, Verhaltensweisen, Charaktere, ihren Einfluss auf die Ghettorealität, viel seltener aber der Darstellung ihres Äußeren. Personen, die - wie die Gemeindebeamten - wichtige administrative Funktionen innehatten oder - wie die deutschen Aufseher - im wahrsten Sinne des Wortes über Leben und Tod 
herrschten, waren allgemein bekannt, man sah sie auf den Straßen, erkannte sie von Weitem. Im Bewusstsein der Beobachter löste das Aussehen sich häufig von der Gestalt selbst und wurde zum Aushängeschild deren Amtes, zum Zeichen der Funktion, die sie im abgeriegelten Bezirk ausübte. Durch ihre Tätigkeit weckten diese Persönlichkeiten Wertschätzung, Respekt, aber auch Ekel und Verachtung, Hass und Angst. In ihrer Beschreibung schlug sich das häufig in bestimmten Schemata des äußeren Erscheinungsbildes nieder, unterlag doch das Bild öffentlicher Personen allzu leicht einer Stereotypisierung - die sie höher stellte oder verabscheuungswürdig machte.

Als Beispiel für ein physiognomisches Stereotyp des grausamen Unmenschen kann ein im ganzen Ghetto für seine Brutalität bekannter Gendarm dienen, der Frankenstein genannt wurde und beim Tor an der Kreuzung Leszno- und Żelazna-Straße seinen Dienst tat. Zahlreiche Autoren vermerken seine blutrünstigen Vergnügungen; so schoss er z.B. auf Kinder oder quälte Passanten auf sadistische Weise. Sein dem Horrorfilm entlehnter Spitzname sollte einen abstoßenden Körper in grauenerregende Korrelation zu einer abstoßenden Seele setzen. So nimmt auch Ringelblum ihn wahr:

Er hatte diesen Spitznamen wegen seiner Ähnlichkeit zum affengesichtigen Frankenstein aus dem Film bekommen. Ein Bluthund, der täglich mehrere Schmuggler tötet. Schon zum Frühstück vergießt er das Blut von Juden (Bd. 1, S. 385).

Indessen entdeckt Rokhl Oyerbakh eine gewisse Unstimmigkeit an diesem Bild: Das tatsächliche Aussehen des Gendarmen lege den ihm zugeschriebenen Namen ganz und gar nicht nahe.

Vom Äußeren und von seiner Gestalt erinnert dieser Typ in nichts an das Filmungeheuer [...]. Er soll ein eher unscheinbares Männlein sein, nicht groß, mit schlankem Rücken, schmalem Gesicht und langer Nase, allein seine Augen sind etwas seltsam, klein, ihr Blick irrt unruhig herum (Ring I, 641, S. 24).

Um der Realität näherzukommen, die sich nicht in den Rahmen gängiger kognitiver Schemata pressen lässt, widerlegt die Autorin das Stereotyp. Sie zerschlägt die landläufige Annahme, derzufolge die äußere Hülle eines Menschen und sein Inneres einander grundsätzlich entsprechen müssten, eine Annahme, die - das muss man hinzusetzen - die Grundlage für physiognomische Konzepte bildet. Aber schließlich gibt es Situationen, in denen die klassische Physiognomik nicht greift. Die innerhalb jener Tradition entwickelten Konventionen und Darstellungsmuster lassen sich auf die Realien im Ghetto nicht anwenden. Rokhl Oyerbakhs Portrait des Gendarmen Frankenstein ist der Vorbote einer neuen Ästhetik, die sich unter dem Druck einer radikal neuen Erfahrung herausbildet. Es ist der Versuch, einen neuen Typus des Grauens und ein neues Gesicht 
des Bösen zu verzeichnen, dessen Träger sich als vollkommen durchschnittliche und triviale Gestalten erweisen. Daher ist nicht das ,affengesichtige“ Ungeheuer wahrhaft furchterregend, sondern jenes „unscheinbare Männlein“ mit dem unruhigen Blick.

Oyerbakhs Portraitierte sind überwiegend gewöhnliche, alltägliche Menschen: Bettler, an denen sie vorbeikommt, Straßenhändler, vor allem aber die Besucher der Volksküche in der Leszno-Straße 40, wo sie arbeitete. Vor ihren Augen zogen Massen von Menschen vorbei. An die Stelle jener, die hungers gestorben waren, traten stets neue Kunden. Der tägliche Kontakt mit den Ärmsten des Ghettos, mit Menschen verschiedenster Berufe und Talente, die durch Elend und Hunger nach ganz unten abgestiegen waren, macht es ihr möglich, soziologische Beobachtungen anzustellen. Diese Beobachtungen nutzt sie in ihrem Material für das Untergrundarchiv, mit dem sie intensiv zusammenarbeitete. Ringelblum (Bd. 1, S. 489-490) erwähnt Oyerbakhs Arbeit über die Volksküche, in der sie die verschiedensten Menschentypen abbildet. Sie beschreibt das Schicksal der Allerärmsten, die sich nur von Suppe ernähren, verzeichnet verzweifelt deren Weg in einen unvermeidlichen Tod und ihre eigene Hilflosigkeit.

In jener auf den ersten Blick ununterscheidbaren Menschenmenge, in der alle vom Stigma desselben Schicksals gezeichnet sind, nimmt Rokhl Oyerbakh den individuellen Menschen wahr, holt ihn aus der Anonymität. In jedem Einzelnen vermag sie etwas zu finden, was nur ihm eigen ist. Jeden Einzelnen kennt und versteht sie gut, in jeden kann sie sich einfühlen. Ihre Portraitierten sind individualisiert und konkret, so als habe sie sie photographisch festgehalten.

Die Originalität jener Portraits beruht jedoch keinesfalls nur auf einer passiven photographischen Registrierung. Ihre Außergewöhnlichkeit rührt von einer bestimmten literarischen Konstruktion her, einer bestimmten Form der Beschreibung, die Oyerbakh anwendet. Man könnte sagen, erst Rokhl Oyerbakh habe gänzlich bewusst das Portrait der Person gezeichnet, einen bestimmten Stil gewählt und der Zeichnung die intendierte Gestalt gegeben. Ihr Blick besitzt seine eigene Temperatur und Intensität. Er ist aktiv, er registriert und verarbeitet das Gesehene zur selben Zeit. Die so entstehenden Portraits sind Abbildung und zugleich Interpretation der Ghettorealität.

Die von der Autorin angegebenen stilistischen Quellen sind die filmische und die theatrale Sichtweise. Die Welt wird gewissermaßen in einer Art Filmausschnitt wahrgenommen, dessen Rahmen dem Blick eine Ordnung verleihen und ihn organisieren. Sie halten die Bewegung an und bannen die räumliche Tiefe auf die Fläche eines Bildausschnitts. Eine filmische Aufzeichnung setzt sich aus einer ungeheuren Zahl unbewegter Bilder zusammen, die eine Illusion der Bewegtheit entstehen lassen. Auf der anderen Seite weist die Vielzahl an Ausdrücken 
der Realität einen eigenen inneren Rhythmus auf. Orte und Menschen, ihre Gesten, Kleidung, Art der Bewegung, Worte, Töne - all das scheint zusammengenommen eine theatralische Komposition zu bilden. Rokhl Oyerbakh fasst ihre Art der Darstellung des Ghettos in zwei metaphorische Formeln: die eines "Initiativtheaters" und die eines „selbstaufzeichnenden Tonfilms“. Die Realität des Ghettos wird durch eine strukturgebende Form gefiltert. Jedoch besitzt die von Oyerbakh beschriebene Welt auch ihre eigene Form, ihre eigene Gestalt und ihren eigenen Ausdruck. Die Autorin entdeckt eine in der Welt des Ghettos bereits bestehende Dynamik der Expression und versucht, sie in ihrer Aufzeichnung wiederzugeben, zu rekonstruieren oder auch nachzuempfinden.

Ich meine wieder diese äußerst eigentümliche Expressivität der Phänomene, die im Leben der geschlossenen Stadt auftreten. Eine Deformation der Wirklichkeit zu einem bestimmten Zweck, eine Verschleierung näherer Umstände, das gehäufte Auftreten mancher Effekte und die Ausschaltung anderer - all das vollzieht sich wie von selbst (Ring I, 641. S. 7).

Es gibt noch eine weitere Tradition, die mit dem Namen Francisco de Goya zusammenhängt - und vielleicht ist diese Tradition der Schlüssel, mit dessen Hilfe die Spezifik von Rokhl Oyerbakhs Menschenportraits und Genrebildern des Ghettos verstanden und ihre besondere Art der Einfühlung erfasst werden kann. Es geht mir hier um die Radierungen des genialen spanischen Malers: den Zyklus Los Caprichos [Die Kaprizen] mit seiner erstaunlich gewagten Strichführung und die makabren Desastres de la guerra [Schrecken des Krieges].

Es bräuchte einen neuen Goya, der mit seinem Bleistift die Beschaffenheit der vom Hunger aufgedunsenen Gesichter plastisch herausarbeiten könnte, die Erhebungen beidseits der Nase und die starren Seen der Augen, die Färbung der Haut, alle die individuellen und die typischen Veränderungen (Ring I, 654, S. 7).

Um Oyerbakhs schriftstellerische Methode zu illustrieren, möchte ich nun zwei Portraits von Gästen der Volksküche an der Leszno-Straße präsentieren. Da ist einmal die Frau unbestimmten Alters, die im Lagerraum der Küche herumwerkelt und von allen nur „die Damówna“ [offenbar ihr Familienname; Anm. d. Übers.] genannt wird. Ihr Portrait gibt mit erbarmungsloser Genauigkeit den unumkehrbaren Prozess eines körperlichen Verfalls wieder: „[S]ie strotzt vor Dreck und Flöhen, dünstet einen üblen Geruch aus“ (Ring I, 654, S. 2). Mehr als über ihre Gesichtszüge erfahren wir über ihre Kleidung, denn diese verdeutlicht am besten den Zustand ihrer Person. Die Kleidung wird zum Ersatzbild - fast möchte man sagen: metonymischen Bild - der ganzen Person. Die Darstellung der Damówna offenbart eine ureigene Ästhetik der Hässlichkeit. Ihre Armut erweist sich als farbenfroh, verblüffend in ihrer Formenvielfalt; die Buntheit der 
zerlumpten Kleidung ist mit scharfem Strich nachgezeichnet, alle Einzelheiten festgehalten. Die Damówna wirkt wie ein tragischer Clown.

Sie trug somit seit vielen Wochen ein schwarzes, am unteren Rand zu ungleichen Schwänzen ausgefranstes abendkleidähnliches Georgettekleid, an dessen Nähten Nissen klebten, auf dem Kopf eine gelbe Stoffkappe mit braunen Streifen, die von einem Skianzug stammen mochte, und über der Schulter die unvermeidliche Sammlung von Taschen und Handtaschen, die prall gefüllt waren mit ihren übrigen Habseligkeiten und sie hinabzogen (Ring I, 654, S. 3).

Beim Portrait des 9-jährigen Hersz Leib hat wiederum gerade das Gesicht eine wesentliche Bedeutung. Sein Gesicht ist nicht - wie es die Physiognomiker gerne hätten - ein Spiegel seiner Seele. Es ist im Gegenteil völlig undurchdringlich, stellt ein schreckliches Geheimnis, eine Herausforderung für den Betrachter dar; dieses Gesicht ist gleichsam ein Zeichen, dass der Betrachter eine unüberschreitbare Grenze überschritten hat. Etwas Ungreifbares ist darin eingeschrieben, ein Ausdruck des Unausdrückbaren. Hersz Leib ist Kind und alter Mann zugleich.

Schon damals hatte er dieses spitz zulaufende, blutleere Gesicht mit weißer pergamentener Haut und einer flachen Nase mit eigentümlich geblähten Flügeln, diesen sackleinenen Anzug, eine Hand in der Hosentasche, nackte Füße und eine zu große Schirmmütze auf dem Kopf. Diese tieftraurigen Augen und die Bewegungen eines Menschen, der schwer an der Last des Lebens zu tragen hat. Das Gesicht eines alten Juden, das Gesicht eines Menschen, der bereits auf alle menschenmöglichen Erfahrungen und Enttäuschungen zurückblickt (Ring I, 654, S. 62).

\section{Der Tod}

Innerhalb der Ordnung meiner Betrachtungen über das Ghetto ist nun die Zeit gekommen, den Blick von den Lebenden den Toten zuzuwenden. Geht man von den Portraits Lebender zu den Bildern der Toten über, muss der Blick bei einem Zwischenglied innehalten - bei den Todesszenen. Welche Gestalt geben die Autoren solchen Szenen? Wie ist das Verhältnis zwischen der Übermittlung der Realien und den Umständen der konkreten Begebenheit einerseits und der Bewertung, Interpretation, den Reflexionen des Autors andererseits? Ich möchte hier bei den Bildern des natürlichen Todes ansetzen. Dazu habe ich drei verschiedene Beispiele ausgewählt, die eine bestimmte Ähnlichkeit aufweisen - die mehr oder weniger deutlich exponierte Gewissheit, dass ein gewöhnlicher Tod zu jener Zeit etwas Ungewöhnliches war.

Ludwik Hirszfelds Tochter Marysia erkrankt an Tuberkulose und stirbt, trotz der verzweifelten Bemühungen ihrer Eltern und Ärzte, nach dem Verlassen des 
Ghettos in einem Versteck auf dem Land. Hirszfeld verzeichnet wenige dürre Informationen über den Krankheitsverlauf, der von einem anderen Thema überlagert wird - den Versuchen, aus dem Ghetto zu entkommen, einen sicheren Unterschlupf zu finden, alles in dem Bemühen, das Kind zu retten. Der Autor sieht einen Zusammenhang zwischen dem sich verschlechternden Gesundheitszustand seiner Tochter und der Verschärfung der Judenverfolgung ab 1943. Die Bedrohung der nahenden Vernichtung seines Volkes wird zum Hintergrund für sein persönliches Drama. Die Todesszene selbst baut auf einem Kontrast auf: In das Zimmer der Sterbenden schallen die betrunkenen Stimmen einer Gruppe Deutscher herauf.

Das Kind liegt im Fieber. Unten halten Deutsche ein Festmahl. Sie sind zur Jagd gekommen, haben sich ein Essen bestellt. [...] Rufe tönen herauf: Hoch!, und das Stimmengewirr satter, ausgelassener Menschen. [...] Und neben mir mein sterbendes Kind [...]. Da fühlte ich, wie Hass und Ekel in mir aufstiegen und mich in der Kehle würgten. Hass auf jene dröhnenden, zufriedenen Stimmen (S. 319).

Hiszfeld erlebt den Tod seiner Tochter in einem privaten und intimen Raum, wie es zu jenen Zeiten eher selten vorkam. Doch auch diese Ruhe erfährt eine Störung, was eine zornige Tirade auf die Deutschen auslöst. Der Rahmen dieses Todes jedoch ist traditionell, ruhig, majestätisch. Die Mutter schließt dem Kind die Augen, die Totenmesse wird von Marysias verehrtem alten Priester gehalten, das Begräbnis verläuft in geradezu idyllischem Rahmen.

Die letzte Ruhestätte fand meine Tochter auf dem Dorffriedhof, wo sie hatte begraben werden wollen. Die Glocken der kleinen Kirche läuteten sie in den ewigen Schlaf. Polnische Dorfleute kamen zusammen und sangen. Die Wintersonne schien (S. 320).

5. August 1942. Avrom Levin notiert: „Sie haben Balaban gefasst“. Für Stefan Ernest, der offenbar Zeuge des Ereignisses war, wird es zum Aufhänger für die Konstruktion einer großen Holocaustmetapher:

An der Spitze des Menschenzuges ein gebeugter alter Mann mit wunderschönem weißen Bart - Prof. Dr. Majer Balaban, Rabbiner. Er führt den Zug des Volkes an, dessen Geschichte, dessen Ruhm und Niederlagen über die Jahrhunderte er so gut kannte und zu schildern wusste, einer der führenden Geister der Judenheit - nun geht er vorneweg beim letzten Gang seines Volkes, zur Hinrichtung. Mit nicht-existenter Feder auf nichtexistentem Papier prägt er gemessenen Schrittes, auf dem Weg zum Umschlag[platz], Buchstabe für Buchstabe die Worte des Letzten Kapitels der Geschichte der Juden von Warschau ... („Pamiętniki“, Sign. 195, S. 182).

Jene pathetische Szene, die Ernest beobachtete, erwies sich allerdings nicht als die Todesszene. Prof. Majer Balaban überlebte die große Liquidierungsaktion, obwohl er bereits auf dem Umschlagplatz angekommen war - durch glückliche 
Umstände konnte er noch rechtzeitig fortgebracht werden. Er starb Ende 1942 eines natürlichen Todes und wurde auf dem jüdischen Friedhof in Warschau beigesetzt. Avrom Levin nahm an dem Begräbnis teil, beschrieb es anschließend in seinem Tagebuch unter dem Datum des 28. Dezember 1942. Er notiert genau den Todeszeitpunkt und die Todesursache, was seine besondere Aussage hat, bedenkt man die Erfahrung der Massenvernichtungen vom Juli, August und September desselben Jahres. Balaban stirbt in seinem Bett eines ruhigen, sanften, idealen Todes. Der Verfasser des Tagebuchs legt sein Augenmerk jedoch nicht auf die Tatsache des Todes selbst, sondern auf den Eindruck, den die Begräbniszeremonie in ihm hinterlässt. Unter den Gegebenheiten des Ghettos zur Jahreswende 1942/1943 ist ein normales Begräbnis eines normal gestorbenen Menschen etwas erschreckend Unnormales.

Vorgestern um halb drei Uhr nachts verstarb ganz unerwartet, infolge einer Herzattacke, der Gelehrte und Historiker Dr. Majer Balaban. [...] Die letzten jüdischen Intellektuellen kamen, um ihm die letzte Ehre zu erweisen. Gott! Welch traurigen und niederschmetternden Eindruck machten die Menschen auf mich, die zum Begräbnis kamen. Erstens - es kamen nur sehr wenige. Wir konnten ohne jeden Zweifel feststellen, dass nur noch eine Handvoll von uns geblieben ist, ein paar Menschen nur. Und zweitens - wie sehen sie aus! Welche Bedrücktheit, welche Entfremdung spiegelte sich in den Gesichtern dieser Menschen! (BŻIH 25, S. 122).

In Levins Aufzeichnung wird wenig Konkretes über die Situation an sich gesagt; es überwiegen seine eigenen Reflexionen und Urteile. Im Grunde erfährt man gar nicht, wie das Begräbnis vonstatten ging. Leon Najberg hingegen sättigt seine Schilderung eines anderen Begräbnisses mit Realien, scheut nicht einmal vor makabren Details zurück. Die nun folgende Begebenheit ereignete sich während des Ghettoaufstands.

Im Versteck starb Ing. Tajst an Auszehrung und einer Vergiftung durch Kohlenmonoxid. Einen ganzen Tag lang lag sein Leichnam bei den Lebenden in der engen Isolationszelle, in der Nacht dann stellte sich heraus, dass er sich nicht durch die Zellenöffnung hinaustragen ließ. [...] Als auch mehrfache Versuche, den Leichnam durch die Öffnung nach draußen zu befördern, erfolglos blieben, verkündeten die Ärzte, man müsse die unteren Extremitäten vom Rumpf abtrennen. Doch auch dies erwies sich unter den gegebenen Umständen als technisch nicht durchführbar. [...] Der Leichnam blieb noch einen weiteren Tag bei uns. Die Folgen davon waren äußerst fatal (S. 67).

Stirbt jemand im Versteck, zieht das eine Reihe von unerwarteten Problemen mit der Bestattung nach sich, was für die anderen Menschen im Unterschlupf zur Plage wird. Ein entscheidender Punkt ist hier, dass der Autor diese Verwicklungen nicht verschweigt, die schließlich nur schlecht zur heroischen oder auch märtyrerhaften Konvention der sonstigen Schilderungen des Ghettoaufstands 
passen wollen. Der Leichnam wurde schlussendlich durch ein eigens zu diesem Zweck in die Mauer geschlagenes Loch hinausgeschafft und in der Nacht nach allen Regeln der Begräbniszeremonie bestattet, was unter den damaligen Umständen an ein Wunder grenzte. Tajst bekam das, was vielen anderen versagt blieb: einen „normalen“ Tod und ein „normales“ Begräbnis.

Der Trauerzug bestand aus vier Personen und dem Rabbiner an der Spitze. Bei flackerndem Kerzenschein trugen sie den Leichnam in den Keller eines anderen Seitenflügels in demselben Haus hinüber und bestatteten ihn dort. Am Grab sprach der Rabbiner das Kaddisch (Totengebet), danach sagte er: „Diesem Juden war der Himmel gnädig, dass er eines natürlichen Todes sterben durfte und sein Begräbnis im jüdischen Geiste abgehalten wurde" (S. 67).

\section{2}

Die Nachricht vom Freitod des Gemeindevorsitzenden verbreitete sich blitzschnell im geschlossenen Bezirk. Allen war bewusst, dass Ing. Adam Czerniakóws Tod eine Zäsur in der Geschichte des Warschauer Ghettos bedeutete. Indem er sich am Abend des 23. Juli 1942, am zweiten Tag der großen Liquidierungsaktion, in seinem Arbeitszimmer das Leben nahm, vollführte Czerniaków einen öffentlichen Akt. Dieser Selbstmord nämlich ließ sich nicht in den Bereich des rein Privaten einordnen, so zutiefst persönlich die Beweggründe auch gewesen sein mochten. Hingegen nahm die Tat eine politische und zugleich moralische Bedeutung an, wurde zu einer Begebenheit von historischem Gewicht. Sie wurde von der Allgemeinheit als schlechtes Zeichen angesehen, als Vorbote einer nahenden Katastrophe, als das definitive Ende jeglicher Hoffnung. Sein Freitod war wie das letzte Wort des Vorsitzenden an seine Ghettogemeinde.

Geschildert wird das Ereignis in zahlreichen persönlichen Dokumenten. Die Autoren von aktuell im Ghetto oder heimlich im Versteck auf arischer Seite geführten Tagebüchern verzeichneten die Tatsache und gingen daraufhin in der Regel zu eigenen Bewertungen, Interpretationen, Kommentaren über. Die Nachricht von Czerniakóws Tod war der Aufhänger für allgemeinere Reflexionen über den Sinn seiner Mission im Ghetto, über die moralische Grundlage seiner Haltung, über Konsequenzen und Aussage seines Handelns. Das Spektrum der Urteile reichte dabei - je nach politischer Orientierung des Schreibenden und seinem Platz in der gesellschaftlichen Hierarchie - von schärfster Verurteilung bis hin zur Heroisierung. Diese Bandbreite fasste wohl Henryk Bryskier am treffendsten in Worte:

Manche hielten diesen Freitod für eine Heldentat, andere hingegen für eine große Feigheit, doch es gab auch Menschen, die den Akt seines Selbstmords für den idiotischen 
Versuch ansahen, Gerechtigkeit walten zu lassen für den Verrat an seinem Volk (Pamiętniki z getta, S. 103).

Ich möchte hier weder die Beweggründe des Vorsitzenden erörtern noch die Urteile und Kommentare seiner Zeitgenossen analysieren, sondern das Verhältnis zwischen einer allgemeinen Reflexion über den Selbstmord und seiner Schilderung herausarbeiten, zwischen der Äußerung eines Urteils und der Darstellung des Sachverhalts. Es interessiert mich, wie der Freitod als Ereignis registriert wurde. Ob die Autoren es für wesentlich befanden, die Art und Weise des Geschehens festzuhalten oder sich wenigstens einen möglichen Ablauf vorzustellen zu versuchen.

Die analysierten Aufzeichnungen geben in überwältigender Mehrheit entweder nur eine kurze Information oder konzentrieren sich darauf, Czerniakóws Handeln zu interpretieren und zu beurteilen. Der Verlauf des Geschehens bleibt unbeleuchtet. Zwar kommen Bemerkungen über bestimmte konkrete Sachverhalte vor (z.B. über die Art des Giftes), doch sie beschränken sich auf bereits konventionalisierte Formulierungen vom Typus: „Adam Czerniaków beging Selbstmord mit Zyankali“ (Makower, S. 56); „[D]er Vorsitzende des Judenrates schluckte eine tödliche Dosis Gift“ (Adler, S. 270); „Das erste Opfer des Deportationsdekrets war der Präsident, Adam Czerniaków, der sich mit Gift im Judenratsgebäude das Leben nahm“ (Kaplan, Buch der Agonie, S. 385-386); „[E]r ging von uns, nachdem er Zyankali eingenommen hatte" (Ernest, Pamiętniki z getta, S. 51).

Bei der Suche nach konkreten Berichten, in denen die Szenerie, das Verhalten der Beteiligten und der Verlauf des Gesamtereignisses beschrieben werden, stellen sich zwei unterschiedliche Fragen. Die erste lässt sich so auf den Punkt bringen: Wer könnte Zeuge von Czerniakóws Selbstmords gewesen sein, den er hinter geschlossener Tür in seinem Büro beging? Die zweite Frage bezieht sich auf die Konvention der Schilderung und lässt sich wie folgt formulieren: Wer von den Autoren beschloss, Czerniakóws Freitod als „beobachtetes“ Ereignis (obwohl er ihn in Wirklichkeit nicht mit eigenen Augen mit angesehen hatte) und nicht als Aufhänger für wertende Kommentare und Urteile darzustellen?

Mir sind vier Berichte bekannt (oder müsste ich sagen: ganze vier?), die Umstände und Details nennen, die wir nirgendwo sonst finden. Ihre Autoren Jan Przedborski, Samuel Puterman, Barbara und Adolf Berman sowie Gustawa Jarecka - verraten ein Wissen in dieser Materie, das über den normalen Bewusstseinsstand der Ghettobewohner hinausging. Das muss jedoch nicht im wortwörtlichen Sinne eine Augenzeugenschaft jener Autoren bedeuten. 
Eigentlich kann nur Jan Przedborski als Augenzeuge betrachtet werden; er befand sich in größter Nähe zu den Ereignissen und gibt in seinem Bericht nur das wieder, was er mit eigenen Augen gesehen hat. Die Narration erfolgt in der ersten Person Singular, der Erzähler nimmt direkt an den geschilderten Ereignissen teil. Przedborski - Kinderarzt, Leiter des Kinderheims Dom Dziecka [Haus des Kindes] an der Wolność-Straße 14 - war ein Freund Czerniakóws. Am kritischen Tag hielt er sich in der Wohnung des Vorsitzenden auf; er schreibt: „Ich war Zeuge“ („Pamiętniki“, Sign. 172, S. 11). Samuel Putermans Text hingegen besitzt die Form einer literarischen Konstruktion, die den vermuteten Verlauf der Ereignisse zeigt. Der Autor - ein Funktionär des Ordnungsdienstes, der sich bestens auskannte in den Funktionsmechanismen des Ghettos - hinterließ einen dramatisierten Bericht reich an detaillierten Beobachtungen und ausgefeilten Figurenportraits, der die Form einer narrativen Prosa annahm. Die Verzeichnung der rekonstruierten Fakten wird hier jedoch von kreativen Elementen überlagert - worin auch die Ursache für einen entscheidenden sachlichen Fehler liegt, der sich bei der Darstellung der beiden Besuche der Deutschen in Czerniakóws Dienstbüro einschleicht: am 22. Juli, als auf einer Sondersitzung der Gemeinde offiziell der Beginn der Deportationen angekündigt und die Unterzeichnung jener Verordnung gefordert wird, und am 23. Juli abends, als Czerniaków eigens zum Sitz der Gemeinde gerufen und ihm detaillierte Forderungen gestellt werden. Wie die Szene bei Puterman geschildert ist, suggeriert sie, dass der Vorsitzende sich gleich nach dem Befehl zur Unterzeichnung des Deportationsdekrets, also bereits am ersten Tag der großen Aktion, vergiftet hätte.

Gustawa Jarecka sowie Adolf und Barbara Berman gehörten ohne Zweifel zu den sehr gut Informierten. Als die Deportationen begannen, war Jarecka, die vor dem Krieg mehrere Romane publiziert hatte, Beamtin bei der Gemeinde und arbeitete zusammen mit Ringelblum im Untergrundarchiv. Berman war Direktor des Zentralverbands für die Waisenfürsorge [Centralne Towarzystwo Opieki nad Sierotami, Centos]. In ihren Berichten geben sie demnach wieder, was sie (wahrscheinlich vom Hörensagen und nicht von der Autopsie) über die Sache wissen, und bemühen sich, den Ablauf der Ereignisse in eine Ordnung zu bringen. Dabei legen sie besonderes Gewicht auf die dem Selbstmord unmittelbar vorausgegangenen Umstände. Ihre Aufzeichnungen fassen sie in ähnliche narrative Rahmen: „Seinem Tod gingen folgende Umstände voraus“, beginnt Jarecka ihren Text (BŻIH 62, S. 141), während bei den Bermans zu lesen ist: „Es geschah unter folgenden Umständen" (S. 140).

Auf der Grundlage jener vier Berichte lässt sich der Ereignisverlauf rekonstruieren. „Am Nachmittag des 23. Juli verließ Czerniaków gegen fünf seine Diensträume in der Grzybowska-Straße und begab sich nach Hause in die 
Chłodna-Straße“, beginnt Jarecka. Später klingelt in seiner Wohnung das Telefon; der Vorsitzende bekommt die Nachricht, dass in der Gemeinde die Gestapo auf ihn warte. Das geschieht laut Przedborski „in den Vorabendstunden“ (S. 11), den Bermans zufolge "gegen 8 Uhr abends“. „Der Vorsitzende begab sich sogleich zur Gemeinde“, fahren die Bermans fort. Der Augenzeuge Przedborski setzt hinzu, Czerniaków sei „in höchster Aufregung aufgebrochen“ (S. 11). Jarecka führt ein Detail an, das bei den anderen nicht vorkommt: „[M]an schickte einen Funktionär des Ordnungsdienstes mit der Rikscha zur Chłodna-Straße“, denn am Vortag ist Czerniaków sein Dienstwagen abgezogen worden, dessen Verlust er „empfindlich spürte“ (S. 142). Czerniaków erreicht das Gebäude der Gemeinde, wo „die Gestapo-Männer ihm eine Reihe Verordnungen bezüglich der Deportationen mitteilten "176 (Berman, S. 140). Nachdem die Deutschen gegangen sind, „bat er den diensthabenden Polizisten um ein Glas Wasser“. Dieses Detail erscheint einzig in den Aufzeichnungen der Bermans. Dagegen ist nur von Przedborski zu erfahren, was damals in Czerniakóws Wohnung vor sich geht. Dort herrscht nämlich nervöse Anspannung. Felicja Czerniaków ruft, als sie eine halbe Stunde lang keine Nachricht von ihrem Mann erhalten hat, in der Gemeinde an. „Sie ließ sich telefonisch mit dem Sekretariat verbinden, wo ihr mitgeteilt wurde, er sei mit den Deutschen in seinem Büro.“ Eine weitere Viertelstunde später ruft sie wieder an, „und diesmal hörte sie ein unverständliches Gebrabbel, das unvermittelt abriss“. Der diensthabende Gemeindesekretär fordert die Frau des Vorsitzenden auf, möglichst rasch herzukommen, „denn »der Herr Vorsitzende fühlt sich nicht gut “" (S. 11). Frau Czerniakowa eilt aus dem Haus, und Przedborski bleibt noch eine Weile in der Wohnung der Czerniakóws, um Ärzte zu rufen; anschließend läuft auch er zur Gemeinde. Erteilen wir ihm nun länger das Wort:

Als ich beim Rat eintraf, war Ing. Czerniaków schon nicht mehr am Leben. Er lebte offenbar seit dem Moment nicht mehr, in dem seine Frau seine letzten gestammelten Worte am Telefon hörte, das auf dem Schreibtisch stand, an dem er seinem Leben ein Ende setzte. Die Todesursache war klar, auf dem Tisch stand ein großes Glas mit einem lege artis geschliffenen Deckel, und darin eine größere Menge an Zyankali. Offensichtlich hatte er nach der „Konferenz“ mit den Deutschen etwas von dem Inhalt zu sich genommen. Was der Inhalt der Konferenz gewesen war, konnte man anhand der Papiere

176 Aus dem November-Bericht der vereinigten Untergrundorganisationen des Ghettos „Die Liquidierung des jüdischen Warschau“ ist zu erfahren, dass Czerniaków damals die Instruktion erhalten hatte, „weitere Kontingente für die »Deportation« in einer Menge von 7000 bis zum Freitag, 24. Juli, und 10000 bis zum Samstag, 25. Juli, bereitzustellen" (Archiwum Ringelbluma, op. cit., S. 281). 
erahnen, die auf dem Tisch lagen - eines erhielt die verschiedenen Punkte des Befehls der Deutschen, das zweite eigene Hinweise an den Judenrat, das dritte einen Abschiedsbrief an seine Frau, die er für seine Tat um Verzeihung bat, aber er könne sein Gewissen nicht damit belasten, die Vernichtung des Ghettos geleitet zu haben (S. 12). ${ }^{177}$

Die hier besprochenen Textsequenzen, die ihren ursprünglichen Kontexten entnommen und gewissermaßen parallel gelesen worden sind, fügen sich zu einer Art Einheit zusammen. Sie behandeln dasselbe Thema, vor allem jedoch versuchen sie, dieses Thema auf ähnliche Weise darzustellen, indem sie das Hauptgewicht auf seine Konkretisierung legen, auf die Verdeutlichung der äußerlichen Ebene, auf die Wiedergabe der Ereignisdynamik, und schließlich mit Details über das Verhalten der Figuren oder über die Szenerie der Ereignisse operieren. Das ruft beim Leser eine bestimmte Haltung bei der Lektüre hervor. Zweck dieser Haltung wäre es, aus der Schilderung der vorgestellten Welt etwas zutage zu fördern, was man die „harte Realität“ nennen könnte, errichtet aus Worten. Die unartikulierten Laute aus dem Telefonhörer, Czerniakóws Bitte um ein Glas Wasser oder die Gestalt des hinter dem Schreibtisch stehenden Giftbehälters das alles sind winzige Fragmente der Ghettorealien, die die Schreibenden aufnehmen und den Lesern zugänglich machen. Auf jene Realität - die vom Autor so und nicht anders wahrgenommen und im Text festgehalten wurde - richtet sich die Aufmerksamkeit des Adressaten.

Eine Etappe auf dem Weg zur direkten Vernichtung stellten der Hunger und die Krankheiten dar, die die Zahl der Ghettobewohner dezimierten. Tötungen in einem solchen Ausmaß waren nicht nur für die Opfer selbst unvorstellbar; der eiskalte, methodische, im Rahmen von bürokratischen Prozeduren organisierte

177 Ich möchte an den Inhalt jenes Briefes an die Ehefrau erinnern: „Sie verlangen von mir, mit eigenen Händen die Kinder meines Volkes umzubringen. Es bleibt mir nichts anderes übrig, als zu sterben“ (Das Tagebuch des Adam Czerniaków, op. cit., S. 285). Die Notiz, die Przedborski „Hinweise an die Gemeinde“ nennt, lautete wie folgt: „Worthoff und seine Kollegen [vom Umsiedlungsstab] waren bei mir und verlangten, daß für morgen ein Kindertransport vorbereitet wird. Damit ist mein bitterer Kelch bis zum Rand gefüllt, denn ich kann doch nicht wehrlose Kinder dem Tod ausliefern. Ich habe beschlossen abzutreten. Betrachtet dies nicht als einen Akt der Feigheit oder eine Flucht. Ich bin machtlos, mir bricht das Herz vor Trauer und Mitleid, länger kann ich das nicht ertragen. Meine Tat wird alle die Wahrheit erkennen lassen und vielleicht auf den rechten Weg des Handelns bringen. Ich bin mir bewußt, daß ich Euch ein schweres Erbe hinterlasse“ (ebd.). 
Massenmord entzog sich auch jeder individualisierten Beschreibung. Das Bild einer kollektiven Ermordung ist gewissermaßen verschwommen, es weist keine deutliche Kontur, keine Schärfe, keine charakteristischen Details auf. Es stellt eher Typisches als Außergewöhnliches, eher Wiederholbarkeit als Einzigartigkeit zur Schau. Die Opfer, denen die Henker ihre Identität genommen hatten, blieben meist auch in den Berichten von Zeugen und Überlebenden namenlos. Ein Extrembeispiel hierfür ist eine spezielle Figur der Entpersonalisierung, bei der in animalischen Kategorien von Menschen gesprochen wird. „Eine halbe Million dieses menschlichen Wilds wurde ausgerottet durch Typhus und Hunger, gejagt und gequält, seit das Ghetto eingerichtet war", schrieb beispielsweise Henryk Rudnicki (S. 13). Zweck dieser Figur war es in der Regel, das Phänomen der Massenvernichtung treffend wiederzugeben. In zahlreichen persönlichen Dokumenten aus jener Zeit wiederholt sich in vielen Varianten, gleich einem Refrain, die metaphorische Phrase vom Vieh auf dem Weg zur Schlachtbank. Nur selten wurde die namenlose Masse zum Hintergrund für die Darstellung einer Person mit eigenem Gesicht und eigenem Namen.

Aus der Anonymität jenes kollektiven Todes gelingt es in überwiegendem Maße, die Gesichter bekannter Menschen zu retten. An ihnen bleibt der Blick hängen, ihre Silhouette hebt sich von der Menge ab, die Nachricht von ihrem Schicksal dringt über den engsten Familien- und Bekanntenkreis hinaus, gelangt auf die Seiten von Tagebüchern und Chroniken. Janusz Korczaks Marsch an der Spitze seiner Kinder aus dem Haus der Waisen von der Sienna-Straße zum Umschlagplatz, also tatsächlich quer durch das gesamte Ghetto, wurde sogleich mehrfach schriftlich festgehalten, um Jahre später zum Thema zahlreicher Erinnerungen zu werden. Andere Angestellte in Waisenhäusern, die das Gleiche taten wie Korczak, blieben im Schatten ${ }^{178}$. Dank Samuel Putermans Bericht ist

178 Ringelblum erwähnt das heldenhafte Handeln eines Aron Koniński und einer Frau Janowska unbekannten Vornamens, die freiwillig mit den Kindern aus dem Waisenhaus, das sie leiteten, in die Waggons stiegen (Bd. 1, S. 417). Adolf Berman nennt noch weitere Beispiele: „Das vorbildliche Jungeninternat an der Twarda-Straße 7 wurde deportiert, mitsamt seinem wertvollen und aufopfernden Leiter Dąbrowski an der Spitze, sowie auch das Mädchenheim an der Śliska-Straße 28, mitsamt seiner verdienten Leiterin Broniatowska an der Spitze. [...] Das »Dom Dziecka « [Kinderheim] von der Wolność-Straße 14 wurde aufgelöst [...].Mit den Kindern ging Leiter [...] Szymański, ein Mann mit einem Herzen, so rein wie Kristall. [...] Damals wurde auch die »Pogotowie Opiekuńcze« [Notfürsorge] für Kinder an der Wolność-Straße 16 deportiert [...] mitsamt ihrem Leiter Goldkorn [...]. Die vorbildliche Kleinkinderanstalt an der Dzielna-Straße 67 [...] ging zusammen mit ihrer aufopferungsvollen 
bekannt, dass der berühmte Maler und Graphiker Roman Kramsztyk, der während einer Blockade im August 1942 im Hinterhof seines Hauses angeschossen wurde, lange auf einem notdürftigen Lager im Keller dahinsiechte. Allerdings konnte er sich noch vom Verfasser des Berichts verabschieden, wobei er ihm seine Rötelkreiden und seine goldene Uhr mit der Gravur „Liberté, Egalité, Fraternité" überreichte (Pamiętniki z getta, S. 250-252). Emanuel Ringelblum (Bd. 1, S. 522) und Stanisław Adler (S. 297-299) schildern detailliert, wie Icchak Giterman zu Tode kam, ein herausragender gesellschaftlicher Aktivist und Direktor der polnischen Abteilung des Joint, der am 18. Januar 1943 am ersten Tag der sog. Januaraktion vor seiner Wohnungstür erschossen wurde. Giterman war am Morgen ins Treppenhaus hinausgegangen, um mit seinen Nachbarn über die Notwendigkeit zu sprechen, sich in ein Versteck zurückzuziehen. In dem Moment schoss ein Gendarm von der Straße aus durch ein offenes Fenster auf ihn.

Der Tod von Marysia Ajzensztad - einer blutjungen Sängerin, Tochter des Chordirigenten von der Warschauer Synagoge, der „Nachtigall des Ghettos“ mit einer wundervollen Stimme - wurde ebenfalls bemerkt und gesondert festgehalten, was die Sängerin aus dem Hintergrund hervortreten ließ. Avrom Levin notiert unter dem Datum des 10. August 1942 knapp: „[W]ährend des gestrigen Blutbads wurde die bekannte Warschauer Sängerin Marysia Ajzenstadt getötet" (BŻIH 21, S. 136), und setzt hinzu, dass die Verstorbene Schülerin am „Yehudyah"-Gymnasium gewesen sei, an dem er selbst vor dem Krieg unterrichtet hatte. Für ihn war Marysia vor allem eine ehemalige Schülerin, für Ringelblum hingegen eine wichtige Figur im kulturellen Leben des Ghettos. Daher zeichnet er ihr Bild auch in seinen Sylwetki und beschreibt die Umstände ihres Todes. Sie war eine von Tausenden, die an jenem Tag nach Treblinka geschickt wurden. Allerdings fuhr sie nicht mit dem Waggon ab, sondern blieb auf der Rampe am Umschlagplatz. In Ringelblums Schilderung wird ihr Gesicht skizziert, ein Handgemenge, Schüsse - das Momentbild eines individuellen Schicksals, eines einzelnen Todes.

Die junge, schöne, schwarzhaarige Marysia war die populärste Person in Warschau. [...] Im August [1942] wurde sie von den Deutschen auf den Umschlagplatz geschickt, wo Remba (der viele Menschen rettete) sie aus dem Todeswaggon holte, in den man sie zusammen mit ihren Eltern verfrachtet hatte. Das bemerkte ein SS-Mann und scheuchte die Ajzenstadts mit einer Peitsche zurück in den Waggon. Kurz darauf schickte Remba

Leiterin Sara Grober Janowska und dem gesamten Personal, das die Kinder nicht verließ, in die Vernichtung" (Wojna $z$ dziećmi [Krieg mit Kindern], S. 9). 
wieder seine Leute, um Marysia und ihre Eltern zu holen. Marysia war jedoch zu aufgewühlt, um Rettung suchen zu können. Sie wurde auf dem Umschlagplatz erschossen, da sie Widerstand gegen die SS-Männer leistete (Bd. 1, S. 599).

Wesentlich seltener kommt es vor, dass ein Opfer - immer noch anonym - sein eigenes Portrait wiedererlangt, das es von der namenlosen Masse abhebt. Als Beispiel sollen hier einige Einträge in Avrom Levins Tagebuch gelten. Der Verfasser berichtet von der Ermordung eines Bettlers. Er kommt zwei Mal darauf zurück, ergänzt neue Einzelheiten, präzisiert die vorangegangenen Feststellungen, konkretisiert das Bild. Ein Eintrag - vom 21. Mai 1942 - beginnt mit der Bemerkung, dass die geschilderte Begebenheit ,in ihrem raffinierten Zynismus und ihrer Menschenverachtung" (BŻIH 19-20, S. 183) selbst für die Bedingungen des Ghettos ungewöhnlich sei. Das ist auch der Grund, aus dem Levin sich länger bei dieser Begebenheit aufhält. Später gibt er die genaue Zeit und den Ort des Geschehens an: „Gestern [...] um 10 Uhr nachts [...] an der Dzielna-Straße

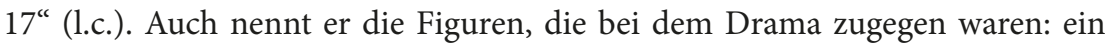
alter armer Jude, genannt „der Bettler“, zwei deutsche Gendarmen auf Patrouille, die Juden, die vor einem Hauseingang ihren Dienst für die Flugabwehr taten, ein Bäcker und einige Prostituierte, die jedoch erst im zweiten Eintrag erwähnt werden. Am Freitag, dem 22. Mai, liefert er, um einige Informationen reicher, eine vollständigere Version der Ereignisse und stellt ihr eine bezeichnende Erläuterung seiner Intention voran:

Um der Wahrheit willen möchte ich die Einzelheiten im Mordfall von Mittwochnacht in der Dzielna-Straße 17 genau festhalten. Der Ermordete war ein Bettler von 30 Jahren. Die deutsche Patrouille hatte ihn um halb zehn auf der Straße angetroffen. Einer der Gendarmen wollte ihn erschießen, der andere hielt ihn zurück. Sie brachten den Bettler zu dem erwähnten Hauseingang und ordneten an, dass man ihm Essen und ein Nachtlager geben solle. Das Essen bekam er sogleich. Mit dem Nachtlager jedoch war es schwieriger. Es gab dort ein kleines Bordell. In einer Kammer wohnen vier „Pensionatsschülerinnen“. Die Gendarmen betraten das Haus und ordneten an, dass der Bettler dort schlafen solle. Dann gingen sie. Die Mädchen und ihr Patron begannen mit dem Bettler zu streiten; sie wollten nicht, dass er bei ihnen schlief, weil er ganz verdreckt sei. Sie baten ihm Geld an. Der Bettler beharrte darauf, bei ihnen zu schlafen, denn so hätten es die Deutschen befohlen. Als sie ihn aus der Kammer zu schieben versuchten, begann er, „Polizei“ zu rufen, worauf eine andere Patrouille kam. Die Mädchen sagten, sie ekelten sich, mit dem verdreckten Bettler in einem Raum zu schlafen. Darauf befahlen die Deutschen dem Juden, mitzukommen, brachten ihn zu der Kirche gegenüber dem Pawiak-Gefängnis und erschossen ihn (BŻIH 19-20, S. 185).

Eine sehr detaillierte Schilderung zu geben und den Verlauf des Geschehens getreu wiederzugeben, ist das direkt deklarierte Bestreben des Autors. Levin 
enthüllt ein ganzes Geflecht von ungewöhnlichen Umständen, in deren Lichte die Prostituierten und ihr Zuhälter zu Mitschuldigen am Tod des Bettlers werden. Die Geschichte verliert ihre eindeutige Aussage, entzieht sich dem martyrologischen Schema und wird dadurch noch erschreckender. Enthüllt wird eine Wahrheit über den geschlossenen Bezirk, die auf andere Weise schwer zugänglich oder sogar unerreichbar bleibt. Ereignisse in ihrer Einzigartigkeit und Konkretheit zu erfassen, das Aussehen von Menschen und die Gestalt von Gegenständen präzise nachzuzeichnen, erweist sich als geeignete Methode zur Beschreibung des Ghettos - lässt es sich doch mit dieser Vorgehensweise bis in die Tiefe vordringen.

\section{Die Leichen}

1

Die zeitgenössische westliche Kultur ist charakterisiert durch eine starke Tabuisierung des Todes. Eine dementsprechende Entwicklungsrichtung zeigt die bereits klassische historische Essayistik von Philippe Ariès - von einer allgemeinen Schicksalsergebenheit und einem Gefühl der Normalität des Todes, der als natürliches Ende angesehen wird, hin zu seiner Individualisierung und Wahrnehmung als brutale Unterbrechung einer Kontinuität. Von der Haltung „Wir alle müssen sterben" über ein tieferes Erleben eigener und fremder Todeserfahrung bis hin zu einer Verschleierung, Vertuschung, Eliminierung des Todes ${ }^{179}$.

Mit einem noch strengeren Tabu belegt ist die Leiche. Louis-Vincent Thomas siedelt sie außerhalb des Diskurses an ${ }^{180}$. Das äußere sich in zahlreichen Euphemismen, Umschreibungen, Pseudonymen, die je nach Situation eingesetzt würden und die Vermeidung einer direkten Benennung ermöglichten. Über Leichen zu sprechen sei nämlich eine Herausforderung, die letzten Endes zu einer Dekomposition der Sprache, zu einem Abgleiten in die Sphäre des Unartikulierten führen könne - zum Schweigen oder zum Schrei. Die Leiche als solche wird auch nicht zum Gegenstand literarischer Schilderung, sie verweist immer auf etwas anderes als sich selbst. Sie ist den Lebenden und deren Problemen

179 In deutscher Übersetzung sind von Philippe Ariès erschienen: Studien zur Geschichte des Todes im Abendland, München/Wien 1976; Geschichte des Todes, München/Wien 1980; Bilder zur Geschichte des Todes, München/Wien 1984.

180 L.-V. Thomas: Trup. Od biologii do antropologii [franz. Originaltitel: Le cadavre: de la biologie a l'anthropologie], poln. Übers. von K. Kocjan, Łódź 1991, S. 52-61. 
zugewandt. Ein Diskurs rund um die Leiche ist somit immer nur der Aufhänger für etwas anderes.

Die Leiche ist das große Thema des Holocaust. Die Leichname der vernichteten Menschen können nicht in Frieden ruhen, man muss sie erst als Rohstoff nutzen und danach endgültig vernichten, gewissermaßen einen zweiten Holocaust an ihnen verüben. Deswegen geht die fortschreitende Technologie für die Tötung der Lebenden mit der Weiterentwicklung einer Technologie für die Leichenvernichtung einher, was innerhalb der Maschinerie des Holocaust ein industrielles Problem darstellt. Die Leichen der Opfer, anfangs in Massengräbern verscharrt, werden später wieder ausgegraben und verbrannt, um jede Spur von ihnen zu tilgen. Dieser ganze Prozess erfährt in späterer Zeit eine Vereinfachung: Die Leichen schafft man nun direkt von den Gaskammern in die Krematoriumsöfen. In später bei den Krematorien gefundenen Aufzeichnungen von Mitgliedern des Sonderkommandos in Birkenau oder erhaltenen Berichten von Geflüchteten aus Treblinka lassen sich Angaben über die massenhafte Verbrennung von Leichen finden.

Die Leiche ist das große Thema des Ghettos. Manchmal nannten die Bewohner den abgeriegelten Bezirk einen einzigen großen Friedhof. Avrom Levin verwendet unter dem Datum des 16. Oktober 1942 die Formulierung „tote Stadt" und ergänzt gleich: „im wahrsten Sinne des Wortes“. Leichen vor Häuserwänden und auf Gehsteigen und ringsumher hektischer Fußgängerverkehr, mit leblosen Körpern beladene Wagen der Bestattungsfirma Pinkert, kalkbestreute Massengräber auf dem jüdischen Friedhof an der Okopowa-Straße - solche und ähnliche, von Augenzeugen eilends notierte Szenen wurden schon damals zu symbolischen Bildern für das Ghetto. Sie bündeln jene Art Erfahrung, deren Verzeichnung der Hauptgegenstand dieser meiner Reflexionen ist.

„Nekrolog" bedeutet - etymologisch gesehen -, über eine Leiche zu sprechen (vom griechischen nekros - „Leiche“ - und logos - „Wort"). Auch die Beschreibung von Leichen, in der unterschiedliche Haltungen zu dem Thema und unterschiedliche Formen seiner Darstellung offenbar werden, könnte man in diesem Kontext als eine bestimmte Art von Nekrolog bezeichnen. Solche Texte versuchen, einen Grenzbereich zwischen Ausdrückbarkeit und Unausdrückbarkeit in Worte zu fassen, der durch die gegensätzlichen Reaktionen von Abstoßung und Anziehung, krankhafter Faszination und physiologischem Ekel entsteht. Eines der ältesten Beispiele für eine solche Ambivalenz ist Platons Geschichte aus Buch IV der Politeia [Der Staat] über Leontios, der beim Haus des Scharfrichters Leichen liegen sieht. Dabei geraten in ihm zwei gegensätzliche Wünsche in Widerstreit - einerseits möchte er die Leichen ansehen, andererseits ekelt er sich vor ihnen, „schließlich wurde er aber von der Begierde übermannt, lief mit 
weit aufgerissenen Augen zu den Leichen hin und rief: »Schaut sie euch an, ihr Unseligen, und sättigt euch an dem herrlichen Anblick."“181

Die Darstellung der Leiche ist somit der Versuch, die Barriere einander gegenläufiger Bestrebungen zu überwinden und in gewissem Sinne auch die Grenzen eines Tabus zu überschreiten. Ausgangspunkt meiner Analyse ist somit die Beobachtung, auf welche verschiedenen Weisen und in welche Richtungen jene Grenzen überschritten, jene Barrieren überwunden werden.

\section{2}

Der Tod ist für die Ghettobewohner eine alltägliche, ja fast schon banal gewordene Erscheinung. Epidemien, Hunger und Terror, später dann die Massenvernichtung ließen den Tod ins Alltagsleben einziehen, ließen ihn Gedanken und Gespräche ausfüllen. Er ist allgegenwärtig in den Wohnungen und auf den Straßen, allumfassend bis zu dem Grade, dass er zu einer Domäne des Gewohnten, der Gleichgültigkeit wird. Der Vorgang des Sterbens, dem jegliche Intimität und Würde genommen wird, hat nichts Ungewöhnliches und Majestätisches mehr an sich, ist nicht mehr von einer Aura erhabenen Leidens umgeben, ruft nicht mehr die gebotene Achtung und Ehrfurcht hervor. Die natürliche Distanz zwischen Leben und Tod wurde zunichtegemacht. Das Unvermeidliche des Todes, das normalerweise aus dem Bewusstsein verdrängt wird, tritt nun an die Oberfläche und nimmt reale Formen an. Es drückt allem seinen Stempel, seine Färbung auf, wie ein unwiderrufliches, an Ort und Stelle vollzogenes Urteil. Ein kulturelles und anthropologisches Modell des Ghettos könnte die Stadt in den Zeiten einer Seuche sein, wenn das entfesselte Element des Todes die ungeteilte Herrschaft über die Menschen übernimmt ${ }^{182}$.

181 Platon: Der Staat - Politeia, dt. Übers. von R. Rufener, Düsseldorf, Zürich 2000, S. 355.

182 Die Figur der Seuche setzte Gustaw Herling-Grudziński in seiner Skizze über Ludwik Landaus Kronika lat wojny i okupacji ein und nennt als eines der Gattungsvorbilder Daniel Defoes fiktiven Bericht Die Pest in London [Originaltitel: A journal of the plague year]. Reminiszenen dazu - ob nun bewusst oder unbewusst eingesetzt - entdeckt er auch in Ringelblums Kronika getta warszawskiego („Kronikarz piekła“ [Chronist der Hölle], in: „Kultura“ 1962, Nr. 11, S. 6). Am ausführlichsten über die Analogien zwischen Ghetto und seuchenbefallener Stadt schrieb bislang Barbara Engelking: Czas dla mnie przestał istnieć, op. cit., S. 160-177. Mit dem anthropolgischen und mythologischen Sinn einer Seuchensituation beschäftigt sich Monika Sznajderman: Zaraza. Mitologia dżumy, cholery i AIDS [Die Seuche. Eine Mythologie von Pest, Cholera und AIDS], Warschau 1994. 
Rings um die Lebenden wachsen Leichenberge in die Höhe. Der Friedhof kann sie nicht mehr alle fassen, deswegen türmen sie sich auf Straßen, Gehsteigen, Hauseingängen. Sie sind überall, werden zum natürlichen Element der Ghettorealität - sichtbar nahezu auf Schritt und Tritt, jeglicher Würde und ihrer Kleidung beraubt, ein banaler Anblick in der Alltagslandschaft. „Auf den Straßen überall Leichen“, schreibt Jan Mawult, „besonders in der Gegend um das Städtische Gericht. Es sterben Alteingesessene und Flüchtlinge, Kinder und Alte, Männer und Frauen" (BŻIH 62, S. 107). In Stefan Ernests Erinnerungen kommt eine drastische Schilderung vor, wie Bettler, noch lebend, bei den Häuserwänden sitzen und warten, bis „morgen, spätestens übermorgen [...] Pinkert [ihre] Leichen zum Massengrab der Ärmsten karrt“ („Pamiętniki“, Sign. 195, S. 55). Sein Panorama der Ghettostraße lässt der Autor mit dem in vielen Schilderungen dominierenden Motiv der Abstumpfung und täglichen Routine enden:

Die Fälle, dass Menschen auf offener Straße an Hunger und Erschöpfung sterben, erreichen mit der Zeit eine solche Häufigkeit, dass sie bei den Passanten keinerlei Angst, kein Gefühl der Bedrohung, Mitleid oder auch nur irgendein Interesse mehr wecken. Eine Alltagserscheinung eben (ebd.).

So stellt sich das allgemeine Bild dar. Andere Autoren kommen den Leichen nahe. So gibt es häufig Situationen, in denen ein Leichnam auf einer überfüllten Straße ein simples Hindernis darstellt, das einen eher mit Ärger denn mit Entsetzen erfüllt. Mary Berg notiert:

An einer Stelle stolperte ich über einen menschlichen Körper, in der Dunkelheit hatte ich gar nicht bemerkt, dass ich über einen Leichnam ging. Es war ein halbnackter Leib, bedeckt nur von ein paar Zeitungsfetzen, die im Wind flatterten [...]. Die langen, milchigweißen Beine waren kalt und steif (S. 117).

Lejb Goldin beschreibt dieselbe Erfahrung, allerdings auf eine etwas andere Weise:

Du stößt gegen etwas vor dir auf dem Boden. Fast kommst du zu Fall. [...] Auf dem Boden, quer über den ganzen Bürgersteig, liegen ein Haufen Lumpen und ein grüner, stoppeliger Klumpen Dreck, der einmal ein menschliches Gesicht mit Bart gewesen ist (S. 90).

Hier macht sich ein charakteristischer Stilwechsel bemerkbar. Für Mary Berg ist das Erlebnis bereits etwas Gewöhnliches, dennoch bemüht sie sich, in ihrer Schilderung keine umgangssprachlichen oder herabwürdigenden Ausdrücke zu verwenden. Sie schreibt von einem „menschlichen Körper“ und einem „Leichnam“, schildert den Verstorbenen auf dem Straßenpflaster zurückhaltend, mit einem gewissen Respekt. Eine andere Aufzeichnung von ihr, in der es um dieselbe 
Situation geht, lässt die bezeichnende Mischung von Grauen und Gewöhnung erkennen: „Es ist ein schrecklicher Anblick, der einem die Haare zu Berge stehen lässt, aber die Vorübergehenden sind daran gewöhnt" (S. 140). Lejb Goldin verwendet eine expressionistisch gefärbte Periphrase, die das Objekt der Beschreibung klar vergegenständlicht. Władysław Szpilman hingegen betont, wenn er von seiner allabendlichen Heimkehr berichtet, dass er damals „mit Toten noch nicht so vertraut" gewesen sei wie später. Er stellt eine ironische Distanz zur Realität her, um auf diese Weise seine Angst und seinen Ekel zu überwinden. Die Leiche lässt sich jedoch nicht gänzlich milde stimmen durch die scherzhafte Umschreibung, sie verliert nicht völlig ihren Schrecken:

Man deponierte die Toten, denen man die für die Lebenden allzu wertvollen Kleidungsstücke entwendet hatte, in Papier gewickelt vor dem Haus, auf dem Gehsteig [...]. Ich leuchtete mir mit der Taschenlampe und hielt dabei nach Leichen Ausschau, um nicht über sie zu stolpern. Der kalte Januarwind [...] ließ das Papier rascheln, in das die Toten eingewickelt waren, hob es an und enthüllte nackte ausgemergelte Schienbeine, tief eingesunkene Bäuche, Gesichter mit bleckenden Zähnen und ins Leere starrende Augen (S. 69).

Jenes Motiv, dass der Fußgänger auf der Straße über Leichen stolpert, ist der Darstellung des Ghettos und der Darstellung seuchenbefallener Städte gemein$\operatorname{sam}^{183}$. In beiden Fällen werden kollektive Verhaltensweisen mittels charakteristischer Bilder textuell festgehalten. Die Bilder dokumentieren einen bestimmten Zustand und sind zugleich Teil eines symbolischen Codes, der zur Aufzeichnung jener Erfahrung dient.

Die konventionellen Methoden des Umgangs mit Verstorbenen - kulturell sanktionierte Bräuche und die Ordnung ritueller Handlungen - verlieren im Ghetto ihre Berechtigung. Die Vielzahl an Leichen sorgt für zahlreiche Probleme formell-rechtlicher und organisatorischer (Transport, Bestattung, finanzielle Abrechnung) sowie auch sittlicher und religiöser Natur.

Stanisław Adler, der beim Ordnungsdienst in der Abteilung Verwaltung und Organisation arbeitete, befasste sich als Jurist mit solchen Angelegenheiten. Die geltenden Regeln des Strafgesetzbuches aus der Vorkriegszeit sahen für den Fall eines Leichenfundes auf der Straße ein kompliziertes Prozedere vor, z.B. war

183 Zum Beispiel ist in einer italienischen Pest-Chronik von 1630 zu lesen: „[D]ie einzeln da und dort oder in Häusern liegenden Leichname, die die Einwohner immer vor den Augen, immer vor den Füßen hatten, [machten] aus der Stadt gleichsam ein einziges großes Leichenfeld." Zitat von Manzoni, nach: J. Delumeau: Angst im Abendland. Bd. 1., dt. Übers. von M. Hübner, G. Konder, M. Roters-Burck, Reinbek 1985, S. 161. 
eine staatsanwaltliche Bewilligung für die Beseitigung der Leiche unumgänglich. Im Ghetto war das selbstredend nicht durchführbar. Daher schlägt Adler dem Ordnungsdienst eine Vereinfachung der Vorschriften und deren Anwendung auf die herrschende Situation vor. Er arbeitet einen entsprechenden Plan aus, in dem zwei - allerdings nie umgesetzte - Ideen besonders bemerkenswert sind. Die erste lautet, dass ein spezielles „Album unidentifizierter Leichname“ mit den Photographien anonymer Toter angelegt werden solle. Die zweite will die jüdischen Polizeidienststellen dazu verpflichten, nach Einbruch der Dunkelheit Wachleute und Warnlichter bei Leichnamen auf den Straßen aufzustellen. Adler beklagt sich, die Leuchten seien fortwährend gestohlen worden, was letztendlich zur Aufgabe des gesamten Plans geführt habe, da für den Kauf neuer Leuchten das Geld fehlte (S. 122-123).

Es gibt ein ganzes Heer armer Menschen, die kein Geld für Bestattungsgebühren haben und die daher ihre Verstorbenen einfach auf der Straße ablegen. Die Ghettoverwaltung hat verschiedene Methoden, damit umzugehen. Manche Mitarbeiter erpressen die Nichtzahler, indem sie sie in ihre Häuser sperren, andere, „die sich nicht wegen einer Leiche mit Formalitäten herumschlagen wollen, schaffen die Leichname einfach von einem Gehsteig auf den anderen. [...] Die Bestattungsunternehmer, besonders die Gebrüder Pinkert, machen glänzende Geschäfte" (Ringelblum, Bd. 1, S. 309). Nach Ansicht von Ghettokommissar Auerswald sorgen die Leichen auf den Straßen für einen schlechten Eindruck. Czerniaków muss eine Rüge über sich ergehen lassen. In seinem Tagebuch vermerkt er, eine Empfehlung erhalten zu haben, dass die Leichen möglichst rasch zu beseitigen seien. Die Leiche wird zum Objekt, mit dem Beamten sich befassen müssen, sie wird zum wichtigen Punkt in der täglichen Berichterstattung. Sie unterliegt - sozusagen - einer Bürokratisierung. Jenen bürokratischen Mechanismus gibt Mawult gut wieder:

Bestattungswagen fahren die Leichen zum Friedhof, zum Sammelmagazin (so heißt die allgemeine Leichenaufbewahrung), von wo es nicht weit zu den Massengräbern ist. Vom Friedhof geht ein täglicher Bericht über die Leichenfunde auf den Straßen an die Friedhofsabteilung des Judenrates, an den Ordnungsdienst, an die Statistische Abteilung. Die Bezirksfunktionäre des Ordnungsdienstes schicken Rapporte an ihre Regionen, die Regionen an die Leitung des Ordnungsdienstes. Die Zahlen werden in Tabellen, in statistische Aufstellungen, in Diagramme eingetragen (BŻIH 62, S. 107).

Mit dem Leichentransport befassen sich Bestattungsunternehmen, spezialisierte Desinfektionskolonnen, aber auch gewöhnliche Menschen, freiwillig oder gezwungenermaßen. Mary Berg erinnert sich, wie „Heniek für eine winzige Ordnungswidrigkeit der Befehl erteilt wurde, zusammen mit einem Kollegen eine 
Leiche aus einer bestimmten Wohnung zu tragen“"(S. 163). Emanuel Ringelblum notiert, „nachts werden Juden geholt, um aus den Spitälern nackte Leichname fortzuschaffen, die anschließend mit Wagen zum Friedhof gebracht werden" (Bd. 1, S. 263) - was im Grunde eine Art Krankenhaussteuer darstellt. Adam Czerniaków platziert in seinem Tagebuch Ausschnitte von detaillierten Berichten über die Tätigkeit der Sanitärkolonnen im Sommer 1941. In jenem Sommer mussten aus verschiedenen Wohnungen die bereits halb verwesten Leichen von Typhusopfern geholt werden, die dort zurückgelassen oder von ihren Familien versteckt worden waren. Sie wurden an die Bestattungswagen von Pinkert, von der Gesellschaft „Wieczność“ [Ewigkeit] oder von anderen Unternehmen übergeben, die auf den Straßen unterwegs waren.

Im Ringelblum-Archiv ist ein Bericht erhalten, „Obrazek z getta przy zbieraniu trupów“ [Bildausschnitt aus dem Ghetto bei der Leichensammlung]; er stammt aus der Feder des Fahrers eines solchen Bestattungswagens. Der Bericht enthält sowohl eine genaue Topographie der Strecke und ein Verzeichnis der Tätigkeiten als auch einen diszipliniert, ja asketisch zum Ausdruck gebrachten Zustand innerer Erregung. Der Autor verzeichnet das Phänomen der Gleichgültigkeit und Apathie; keinerlei Bewegung ruft der Tod mehr hervor, zu banal ist er geworden. Dennoch lassen sich in der emotionslosen, fast grausam naturgetreuen Schilderung verborgene Gefühlsregungen erahnen.

Auf einer schmutzigen Lagerstatt liegt eine noch lebende Mutter neben ihrem gut zwanzigjährigen Sohn, der vor drei Tagen gestorben ist. Die Totengräber heben den Leichnam hoch, er ist leicht wie ein vertrockneter Holzspan, und tragen ihn zu ihrem Wagen. Die Mutter zeigt keine Regung. Sie wendet nicht einmal den Kopf. [...] Die Totengräber erreichen ihren Wagen, holen Schwung und werfen die Leiche, die einmal ein Mensch gewesen ist, so weit nach hinten wie möglich, damit sie nicht zu viel Platz wegnimmt. Von einem Sarg ist nicht die Rede. Der Tote bleibt mit dem Kopf auf dem Wagenboden liegen, den Rücken an der Hinterwand, in einer seltsam akrobatischen Pose (Ring I, 243).

Man könnte den Eindruck gewinnen, diese beharrliche Konzentration auf geradezu technische Details sei für den Schreibenden eine Form des Selbstschutzes, mit der er sich gegen das Grauen wappnet. Er will dieses Grauen nicht direkt benennen und verharrt daher bei einer kühlen, dokumentarischen Verzeichnung der Fakten. In einem bestimmten Moment jedoch bekennt er sich zu seiner Hilflosigkeit, stößt an die Grenzen des Beschreibbaren: beim Anblick einer von Ratten benagten Kinderleiche. Das ist die einzige Stelle im gesamten Bericht, an der der Autor einräumt, das sei „nicht beschreibbar“. Trotzdem gibt er nicht auf und schreibt nach einem kurzen Zögern - so, als habe er nach einem Innehalten seine Stimme wiedergefunden - weiter und vollendet jenes Bild, gegen das seine 
Feder sich sträubt, mit der trockenen Auskunft: „Auch diese Leiche wird weit nach hinten in den Wagen befördert."

Der Friedhof an der Gęsia-Straße wurde Ende 1941 aus dem Ghetto ausgegliedert, was eine ernsthafte Behinderung bei der Organisation von Bestattungen darstellte, für Schmuggler jedoch enorme Möglichkeiten eröffnete. Auf beide Aspekte weist Henryk Bryskier hin:

Lebende, die ihre Verstorbenen auf deren letztem Weg geleiteten, benötigten kostenpflichtige Passierscheine, die nur in begrenzter Anzahl ausgegeben wurden. Jeder Verstorbene wiederum, der von einem Leichenzug aus dem Ghetto hinausbegleitet wurde, gab dem Fahrer des Leichenwagens die Gelegenheit, mit einer Schmuggelladung zurückzukehren. Anstelle des Leichnams wurden dann Produkte geladen, und der Leichenwagen kehrte im Triumphzug ins Ghetto zurück, brachte denjenigen eine Überlebensspritze, die selbst die nächsten Kandidaten für einen Transport waren ... in entgegengesetzter Richtung (BŻIH 67, S. 113).

Der recht unbekümmerte Tonfall des Verfassers dieser Erinnerungen, vor allem aber die Tatsache, dass der Leichenwagen doppelt genutzt wurde - für den Leichentransport in die eine Richtung und den Transport von Lebensmitteln in die andere - zeugen von der Verschiebung, die die natürlichen Grenzen und Regeln im Umgang der Lebenden mit den Toten erfahren hatten.

Am schwerwiegendsten in dieser Hinsicht sind die - der Ausnahmesituation geschuldete - Verletzung der durch Religion und Brauchtum geprägten Prinzipien des Umgangs mit Verstorbenen sowie die Entwertung der Begräbniszeremonie. Das für das Judentum wesentlich Versprechen der Auferstehung bildet das Fundament zahlreicher Bräuche zur Behandlung des Körpers nach dem Tod. So bringt man den Verstorbenen Achtung entgegen, da sie Gottes Bild in sich getragen haben. Im ersten Kapitel des Buches Genesis spricht der Schöpfer: „Lasst uns Menschen machen als unser Abbild“ (1. Mose 1,26). Deshalb müssen die Verstorbenen bestimmten Ritualen unterzogen und dürfen nicht verbrannt werden. Die jüdische Tradition ehrt die Verstorbenen und wehrt sich gegen eine Erniedrigung des Menschen durch die Behandlung seines Leichnams wie ein wertloses Abfallprodukt ${ }^{184}$. Indessen notiert Czerniaków am 20. November 1941: „Ständige Klagen, es gebe nichts, worin man die Leichen beisetzen könne. Selbst Papier, das eventuell das Leinen ersetzen könnte, gibt es nicht" (S. 205). Ringelblum wiederum schreibt, bei den Massenbestattungen würden die Toten „wie Hunde in die Gräber geworfen [...], in der Nacht schaufeln

184 Siehe B. L. Sherwin: Sparks Amidst the Ashes: The Spiritual Legacy of Polish Jewry, op. cit. 
Plünderer die Gräber wieder auf, reißen den Verstorbenen die Goldzähne heraus und ziehen ihnen die Totengewänder vom Leib“ (Bd. 1, S. 322). In Lejb Goldins Schilderung verstößt die Bestattung gegen wirklich jedes göttliche oder menschliche Gesetz. Dem Tod wird jede Würde genommen, der Leichnam endgültig erniedrigt, wie durch einen zerrissenen Vorhang schimmert die erschreckende Nacktheit der Leiche - die keinerlei Wert mehr besitzt und jeglicher kultureller und religiöser Inhalte entbehrt.

Wie Müll ergießen sich die Leichen in die Tiefe. Der Kasten wird umgedreht, Sache erledigt. Auf den Gesichtern der Anwesenden malt sich dabei ein erschütternder Ausdruck des Ekels, so als nähme der Tod Rache, weil er seines geheimnisvollen Nimbus beraubt worden ist, jener verschiedenen überflüssigen Zusätze, die ihm zugeschrieben wurden. Nun hat er sich wie zum Trotz entblößt, das Leichengewand abgeworfen und reckt sich allen - „Hier! Seht nur her!“ - in seiner Nacktheit entgegen (S. 86).

Im Frühjahr 1942 gründete eine Gruppe gesellschaftlicher und religiöser Aktivisten einen Verein mit Namen „Halawajat Hamet“ - „Fürsorge für die Leichen der Armen“. Sie fertigten eine Denkschrift für den Vorsitzenden Czerniaków an, in der sie wegen der Profanierung der Leichen, die erschreckende Formen annehme, Alarm schlugen. In kürzester Zeit seien „die grundlegenden Prinzipien von Ethik und Tradition im Umgang mit dem verstorbenen Juden“ abhanden gekommen. „Die breiten jüdischen Massen [....] sehen der schamlosen Verunglimpfung ihrer Leichname mit blutendem Herzen zu“, schreiben die Verfasser und schlagen umgehendes Handeln vor. Vor allem wollen sie armen Menschen bei den Bestattungsformalitäten helfen und dafür sorgen, dass Tote unverzüglich von öffentlichen Plätzen geborgen und zum Friedhof gebracht werden, „der Anblick von Leichen, die auf der Straße liegen, lässt das Gefühl der Menschlichkeit, das Einfühlungsvermögen und die gegenseitige Hilfsbereitschaft abstumpfen" (Ring I, 119). Es war dies keine Einzelinitiative. Jechiel Górny schildert in seinem Tagebuch den Fall eines Totengräbers und einer Altwarenhändlerin, die die Waschung und Herrichtung von Leichen übernahmen, da sie dies als einen aus ihren religiösen Pflichten sich ergebenden Akt der Frömmigkeit begriffen ${ }^{185}$.

Nichts war jedoch imstande, den Todesreigen aufzuhalten, der Massen von Leichen hinterließ, der die bisherige Ordnung auf den Kopf stellte und das bis dahin gültige Modell der Verhältnisses zwischen Lebenden und Toten zunichtemachte. Das Massensterben, die Fuhrwerke, die die Leichen von den Straßen aufsammelten, die Gruben, in die die Toten wahllos hineingeworfen wurden - das

185 Übersetzte Textstelle aus J. Górnys Tagebuch, siehe R. Sakowska: Ludzie z dzielnicy zamkniętej, op. cit., S. 136-137. 
sind Szenen, die aus der Feder des Chronisten einer Epidemie stammen könnten. Bei der Lektüre mancher Ghettoberichte könnte man den Eindruck gewinnen, dass ihre Verfasser sich - bewusst oder unbewusst - auf eine kulturimmanente Seuchenmythologie beziehen, auf eine symbolische Sprache der Pest. Ein Emblem einer seuchenbefallenen Welt ist das häufig auftauchende Motiv des randvoll beladenen Leichenwagens. Ein solches, sehr überzeugendes Bild vermittelt Daniel Defoe in seiner Schilderung der Epidemie, die London in den Jahren 1665-1666 heimsuchte. ${ }^{186}$ Bezeichnend ist, dass das Thema des triumphierenden Todes - ebenso populär wie die Artes Moriendi und der Danse Macabre ebenfalls mithilfe der Vorstellung eines Wagens dargestellt wurde. Der Tod setzt sich in einen von Ochsen gezogenen Wagen; die Zugtiere stampfen beharrlich voran und trampeln alle nieder, die im Weg stehen. Die berühmteste Darstellung dieser Art ist auf einem Gemälde Pieter Bruegels des Älteren zu sehen: Der Triumph des Todes. Der von Skeletten gelenkte und mit Totenschädeln beladene Wagen wird hier von einem abgemagerten Klepper gezogen. Auf den Totenschädeln ruht die Schaufel des Totengräbers. Die riesigen Räder zermalmen die unter ihnen liegenden Menschen, daneben zappelt eine Gruppe noch Lebender in einem von Skeletten aufgespannten Netz. Zu diesem Bruegel-Bild bemerkt Jean Delumeau: „Wer wissen will, woher Breughel [die Schreibweise des Namens variiert; Anm. d. Übers.] das Motiv für sein Gemälde [...] genommen hat, auf dem u.a. ein mit Skeletten beladener Karren dargestellt ist, braucht nicht lange zu suchen. “187

Ähnliche Wagen begegnen dem Leser auf den Seiten der persönlichen Ghettodokumente. Bei Ringelblum ist ihre Darstellung kühl und sachlich:

Die Wagen mit den vorgespannten Pferden sind nicht nur innen mit Leichen beladen, es ragen auch zwei, drei Kisten mit Toten über den Rand hinaus (Bd. 1, S. 309-310).

186, „[...] und dann rumpelte auch schon der Leichenkarren heran. [...] Auf dem Karren lagen 16 oder 17 Leichen, einige in Leintücher eingeschlagen, andere in Fetzen, noch andere fast gänzlich nackt oder nur so leicht zugedeckt, daß die Hülle sich losmachte, als sie nun in die Grube geworfen wurden. Da lagen sie nun völlig nackt unten, aber für sie war es gleich, denn sie waren alle tot, und sonst konnte wohl auch niemand daran Anstoß nehmen, da sie nun alle im gemeinsamen Grab der Menschheit ruhten. Denn hier gab es keinen Unterschied, arm und reich lagen beieinander. Eine andere Art von Begräbnissen war unmöglich, denn woher hätte man die Särge für die ungeheure Anzahl der der Seuche Erlegenen nehmen sollen?"; D. Defoe: Die Pest $z u$ London (Originaltitel: A journal of the plague year; London 1722).

187 J. Delumeau: Angst im Abendland, Bd. 1, op. cit., S. 163. 
Adolf und Barbara Berman zeichnen ein vergleichbares Bild, mit dem Unterschied, dass bei ihnen zusätzlich Blut vom Wagen tropft (S. 153). Marian Berland nimmt die Situation eher in symbolischen Kategorien wahr, als Triumph des Todes eben. Seine Schilderung erinnert am stärksten an die Bilder von seuchenbefallenen Städten in Chroniken und in der Literatur:

Mehrmals täglich sehe ich die vom Todeshauch umwehten Leichenwagen der Pinkerts durch die Muranowska-Straße sausen. Das sind die Aassammler. Auf dem Dach eines Wagens sehe ich zwei Kisten mit verunstalteten und von Schüssen zerfetzten Leichen. Auf dem Bock sitzen zwei schwarz gekleidete, blutbesudelte Juden. Sie tragen runde schwarze Hüte auf ihren Köpfen. Der Wagen ist schwer beladen, die Federn biegen sich. Das Pferd kann ihn kaum ziehen (S. 24).

An einer anderen Stelle führt der Autor die Geschichte eines 13-jährigen Jungen an, der sich sein täglich Brot in Pinkerts Bestattungsinstitut verdient. Man könnte fast meinen, dass Bruegels Triumph des Todes die Illustration zu den furchtbaren Erlebnissen jenes Jungen sei.

Er war Gehilfe auf dem Wagen, der die Leichen der Juden von Straßen und aus Wohnungen aufsammelte und zu den Massengräbern auf dem jüdischen Friedhof an der Gęsia-Straße brachte [...]. Diese grauenvolle Arbeit hat ihre Spuren bei dem Jungen hinterlassen. [...] Er erzählt haarsträubende Geschichten. Immer nur Leichen, Leichen, ganze Berge von Leichen (S. 348).

3

Die Todeswagen wurden für die Ghettobewohner - ähnlich wie für die Menschen in epidemiebefallenen Städten - zum alltäglichen Anblick, der sie dennoch stets aufs Neue mit Entsetzen erfüllte. Dieses Bild enthüllt unweigerlich das Spannungsverhältnis zwischen einer zunehmenden Banalisierung des Sterbens und dem Entsetzen beim bloßen Gedanken daran. Auf diese Weise wird die grundlegende Ambivalenz der Erfahrung eines Massensterbens deutlich; diese Ambivalenz verleiht dem Sterben eine dramatische Dimension, indem ein Mysterium tremendum durchlebt wird, indem sich eine außerhalb des Bereichs von Ethik und Werten angesiedelte Macht offenbart ${ }^{188}$.

188 In diesen Kategorien nimmt M. Sznajderman (Zaraza, op. cit.) die Seuche wahr; sie bezieht sich auf den Begriffsapparat von Mircea Eliade, Gerard van der Leeuw, Rudolf Otto. In seinen Arbeiten zur mittelalterlichen, in den Begriff des Danse macabre gefassten Sicht des Todes nennt J. Huizinga den Pariser Friedhof Cimetière des Innocents einen „sonderbaren und makabern Treffpunkt [...]“; „, dort kostete der Geist den Schauder des Makabern bis auf den Grund aus“, zugleich „war das 
Die Bearbeitung der Todesthematik in der westlichen Kunst und Kultur äußert sich vor allem in Form von Totentänzen, Todesreigen (Danse macabre) und geht ganz eindeutig über den Rahmen des Mittelalters hinaus. Während Johan Huizinga dieses Bild gegen Ende der Epoche zeichnet, schreibt Jean Delumeau über eine Vorliebe für das Makabre und Schwarzseherische im Zeitalter der Renaissance ${ }^{189}$. Es bildete sich zu jener Zeit nicht nur eine plastische und dramaturgische Vorstellung von Tod und Sterben, sondern auch eine starke philosophisch-moralische und theologische Konzeption heraus. Jener überaus reiche kulturelle Kontext wird in seiner Gesamtheit zwangsläufig zum Hintergrund für die Beobachtung, in welcher Form die Todesthematik in Berichten aus dem Ghetto auftritt.

Etymologie und Bedeutung des Wortes macabre sind unklar, höchstwahrscheinlich aber steht der Begriff in Verbindung mit einer Bezeichnung für menschliche Leichname. Ariès zufolge bedeutet er dasselbe wie der Ausdruck macchabée (volkstümliche Bezeichnung für eine Leiche) im heutigen Französisch. Um das 14. Jh. - meint Ariès - gab man einem „toten Körper“ den Namen der heiligen Makkabäer, da das Wort cadavre (Leiche) damals noch nicht in Gebrauch gewesen sei. Die Makkabäer wurden seit jeher als die Beschützer der Toten verehrt. ${ }^{190}$ Diese etymologische Hypothese bekräftigt Delumeau, indem er schreibt, das Adjektiv macabre hänge wahrscheinlich mit Judas Makkabäus zusammen, der die Juden anwies, für die Seelen der Toten zu beten. Da die Kirche den Gläubigen die Lehre vom Fegefeuer einschärfen wollte, nahm sie diese Figur in die ekklesische Sprache auf. Durch die Verbreitung von Geisterlegenden gelangte sie bis in den Volksmund. Es habe nämlich - wie Jean Delumeau anführt - einen unzweifelhafte Zusammenhang zwischen dem Danse macabre und dem Volksglauben an tanzende und Jagd auf Lebende machende Verstorbene gegeben. ${ }^{191}$

Die Bilder des „Makabren“, die sich in der Literatur des persönlichen Dokuments aus dem Warschauer Ghetto wahrnehmen lassen, konzentrieren sich um zwei zentrale Motive. Eines ist der Berg von Leichen, die Masse gedrängter, überund untereinander liegender Leiber. Das andere ist die Vermischung von Lebenden und Toten, die Aufweichung der Grenze zwischen Leichnam und lebendem

Schaudererweckende wieder zur Gewohnheit geworden“" (J. Huizinga: Herbst des Mittelalters, Bd. 1, dt. Übers. von T. Wolff-Mönckeberg, München 1928, S. 204, 209-210).

189 Siehe J. Huizinga, op. cit.; J. Delumeau: Angst im Abendland, op. cit.

190 Siehe Ph. Ariès, op. cit.

191 Siehe J. Delumeau: Angst im Abendland, Bd. 1, op. cit. 
Menschen. Beide Motive sind tief in der Tradition der europäischen Kultur verwurzelt.

Bei Władysław Szpilman lässt sich eine Szene finden, die an Platons bereits erwähnte Geschichte über Leontios denken lässt. Auf dem Umschlagplatz liegen die Leichen Ermordeter. „Alle umkreisten diese Stelle, ohne länger stehenzubleiben, und blickten voller Entsetzen dorthin" (S. 96). Der Ort, an dem viele Leichen liegen, wirkt anziehend und abstoßend zugleich. Die Passanten meiden ihn und wollen zugleich näher hinsehen. Das Grauen beim Anblick der Leichen ruft bei den Augenzeugen widerstreitende Gefühle hervor, aber - wie bei Leontios - der Drang, hinzusehen, trägt die Oberhand davon. Platon beschreibt allerdings nicht das Aussehen der Leichen, während genau das bei Szpilman zu einem entscheidenden Bestandteil der erzählten Szene wird, die mit einem Bild der Verwesung endet: „Über die Toten und die Fladen geronnenen Blutes auf der Erde spazierten große schwarze Fliegen, und fast sichtbar blähten sich die Leiber und verwesten in der Hitze" (S. 97) ${ }^{192}$.

Bie Szpilman sind noch keine der Bezeichnungen zu finden, die bei anderen Autoren makabre Szenen charakterisieren. Dort ist von dem bereits genannten Motiv der Leichenstapel, Leichenberge oder gar Leichenpyramiden die Rede, und auch von einer extremen Missachtung der Würde der Verstorbenen, die als Haufen Müll dargestellt werden. Marian Berland schreibt in seinem Bericht über den Weg auf den Umschlagplatz von Leichen ermordeter Juden zu beiden Seiten der Straße:

192 Das Bild verwesender Leichen findet sich häufig in Berichten aus dem Ghetto. Avrom Levin notiert ein Erlebnis seiner Tochter, die „auf der Ogrodowa-Straße den Leib eines getöteten Juden sah, der bereits in verwestem Zustand war; um ihn herum breitete sich eine getrocknete Blutlache aus. Offensichtlich lag der Leichnam dort schon seit geraumer Zeit“ („BŻIH“ 24, S. 49). Czerniaków überträgt in sein Tagebuch einen Inspektionsbericht des Ordnungsdienstes vom 22. Juli 1941: „Vor dem Haus Krochmalna-Str. 16 hielt mich der Führer einer militärischen Sanitätskolonne an und wies auf die dort liegende Leiche eines Kindes hin, die im Zustand völliger Verwesung war" (S. 172). Rokhl Oyerbakh schildert eine Szenerie auf dem Friedhof an der Gęsia-Straße: „Draußen vor dem Schuppen sah ich in einer Grube einige halb verfaulte Leichen [...]. Das sind diejenigen, die im Versteck gestorben sind, die zu spät gefunden wurden, schon im Stadium der Verwesung" (Ring I, 654, S. 36-37). Die vom Hunger aufgeschwollenen, fast schon abgestorbenen Beine eines Bettlers wiederum beschreibt Wojdysławski (Ring I, 489, S. 28). Man braucht nicht extra zu erwähnen, dass Fäulnis und Verwesung eines der zentralen Themen der Kunst des macabre sind. „Eine halb zersetzte Leiche wird zur häufigsten Darstellung des Todes“, schreibt Ariès, „es ist ein Transi, ein nackter, von Würmern zerfressener Leichnam“ (op. cit.). 
Wie ein Leichenspalier, eine wahre Allee des Todes. [...]S] eitlich, exakt an der Straßenecke liegt, wie ein vorsorglich für die Stadtreinigung zusammengekehrter Müllhaufen, ein ganzer Berg Leichen unterschiedlichen Geschlechts und Alters. Schlaff hängen bläuliche Arme und Beine, zerschmetterte Schädel und blutüberströmte Gesichter (S. 85).

Ein ähnliches Bild zeichnet Leon Najberg:

Bei der Giebelwand des Hauses in der Świętojerska-Straße 38 lagen beim Müllplatz in einem Meer von Blut Frauen, Mädchen und Kinder. Ein weggeworfener Haufen wie alte, nutzlose Lumpen, ein Haufen alter Lappen. Eine Leiche auf der anderen. Eine Pyramide aus 42 Leichen (S. 91).

Najberg lässt seinen Blick auf dem Leichenhaufen ruhen, auf dessen ungeheurer Größe, die die Ausmaße einer „Pyramide“ erreiche. Die Szene aus Berlands Tagebuch ist bereits deutlich in metaphorischen Kategorien dargestellt und erhält auf diese Weise eine bestimmte symbolische Form. Bezeichnungen wie „Leichenspalier" und „Allee des Todes“ scheinen die Vorstellung hervorzurufen, man befinde sich auf einem von massakrierten menschlichen Körpern gesäumten Weg ins Jenseits. Gleich wird sich herausstellen, dass die Autoren eine solche Interpretationsrichtung der symbolischen Inhalte auch tatsächlich bestätigen. Zunächst jedoch möchte ich bei der allgemeinen Beobachtung bleiben, dass sowohl im ersten wie auch im zweiten Beispiel die Wirklichkeit als Gegenstand der Beschreibung den Autoren mehr abverlangt als eine reine dokumentierende Registrierung. Im Übrigen bleibt die Frage, inwieweit - bei einer solchen Wirklichkeit - überhaupt eine objektivierte Darstellung oder dokumentierende Registrierung möglich sind. Man kann sich schwer des Eindrucks erwehren, dass es eine innere Dynamik der Bilder gibt, die diese wie eine gespenstische Vision wirken lässt. Sie werden weniger vom Prinzip einer mimetischen Abbildung regiert als vielmehr von Deformation, Kreation. Die so entstehenden bildlichen Darstellungen sind nicht zufällig, sondern wurzeln tief in der symbolisch-mythischen Sprache der Kultur.

Eine besondere Kondensierung makabrer Bilder wird erkennbar bei den Schilderungen des Friedhofs an der Okopowa-Straße, vor allem der Leichenhalle, wo die noch nicht begrabenen Leichen gelagert werden. Ringelblums Zeugnis zufolge kamen „die Deutschen [...] gewöhnlich zuhauf auf diesen Friedhof und besahen sich den berühmten Schuppen, in dem täglich ganze Stapel von Skeletten abgelegt wurden“ (Bd. 1, S. 369). Sie betrachteten die Leichen, photographierten sie, kommentierten die Situation. Diese Ausflüge erreichten eine solche Häufigkeit, außerdem „wirkten sie sich äußerst ungünstig auf die Besucher aus, weswegen sie verboten wurden“. Ringelblum gibt an, über dem 
Eingang sei eine "große deutsche Aufschrift“ angebracht worden, „die es Deutschen untersagte, den Friedhof aufzusuchen“ (ebd.).

Wie sah jener berühmte Leichenschuppen aus? Ein paar Hinweise hierzu sind überliefert.

Der Anblick der Leichenhalle ist erschütternd [...] - schreibt Ringelblum. - Der Anblick der übereinandergeworfenen, halbnackten, nur von Lumpen bedeckten Toten - makaber. [...] Besonderes Interesse ruft der Schuppen hervor, in dem im Laufe des Tages zig Verstorbene abgelegt werden. Ich war heute in diesem Schuppen. Das reinste Grauen. Unter einer Abdeckung aus schwarzem Papier liegen unzählige Leichen, bedeckt nur von Fetzen ihrer Kleidung, fast wie nach einem Massaker. Die Leichen sind Skelette, man sieht nur mit dünner Haut überzogene Knochen (Bd. 1, S. 268, 288).

Der Autor qualifiziert oben genannte Szenen als „makaber“. Es wiederholt sich hier das Motiv der vielen, wahllos übereinander geworfenen Körper - des Leichenberges. In Stefan Ernests Beschreibung liegen die Leichname ebenfalls in ganzen Stapeln aufeinander. Der erschütternde Effekt wird hier nicht nur durch die Anhäufung von Leichen hervorgerufen, sondern auch durch eine Darstellung, die die Grenze zwischen leidendem, sterbendem Menschen und Leiche bewusst verwischt.

Gespenstisch ragen erschreckend magere Beine unter achtlos, eilig übergeworfenen Leichentüchern in der Leichenhalle des Friedhofs hervor. Ganze Stapel von Beinen, die noch vor kurzem mit solcher Mühe ihre vertrockneten oder aber von Hungerödemen aufgeschwollenen und noch recht wohlgeformten, wenn auch von den roten Flecken einer Krankheit entstellten Körper getragen haben. Nun liegen sie aufgestapelt da, in Erwartung der letzten Ehre („Pamiętniki“, Sign. 195, S. 76).

Zum Vergleich möchte ich noch die Schilderung eines neutralen Augenzeugen anführen, eines Außenstehenden, der eindeutig nicht zur Gemeinschaft von Juden oder Deutschen gehörte. Franz Blättler (Mawick), Fahrer bei der schweizerischen Rote-Kreuz-Mission, der 1942 in Warschau seinen Dienst tat, war u.a. im Ghetto und auf dem jüdischen Friedhof an der Okopowa-Straße. In seinen jeweils aktuell notierten Aufzeichnungen beschreibt er den berühmten, von Ringelblum so häufig erwähnten Schuppen genau.

Links ist ein niedriger Schuppen, dessen Tore geöffnet sind. Davor liegen, zu einem grossen Haufen aufgestapelt, Leichen eintägiger bis etwa dreijähriger Kinder, es sieht wie ein grosser Haufen zerbrochener Puppen aus. Wie ein böser Traum haftet dieses Bild in mir. [...] Die Halle besitzt keine Fenster und ich muss mich zuerst an das mich umgebende Halbdunkel gewöhnen. Der Geruch der Toten ist unausstehlich. [...] Und so geht diese grauenvolle Musterung weiter. Die Ernte eines einzigen Morgens ist hier aufgestapelt, Verhungerte, Gehängte, Erschossene. 
Es gibt in Blättlers Aufzeichnungen jedoch etwas, das ich in anderen Berichten nicht gefunden habe. Die pedantisch beschriebene Technik zur Befüllung der Massengräber wird zum Ausgangspunkt für eine schockierende Beobachtung. Die Totengräber packen die Leichen an Händen und Füßen und werfen sie in die Gräber.

Unten, wenn die Leiche aufschlägt, gibt es einen unangenehmen Ton, hervorgerufen durch den hohlen Bauch, der wie ein Resonanzboden tönt, im wahrsten Sinne eine schaurige Melodie des Todes. ${ }^{193}$

Die toten Kinder, die an einen Haufen kaputter Puppen erinnern, das Bild der nackten, ausgemergelten Körper, die in die Grube geworfen werden und dabei wie ein unheimliches Instrument eine sich über dem Friedhof erhebende Todesmelodie spielen - die ganze Szenerie wirkt wie eine Vision der Welt von einem Hieronymus-Bosch-Gemälde.

Die Straßen des Ghettos, der Friedhof mit seinen Massengräbern, schlussendlich die Gaskammern und Todesgruben von Treblinka - das sind die aufeinanderfolgenden Akte eines sich zuspitzenden Schreckensszenarios. Wiederkehrend erscheint das Motiv ineinander verknäuelter toter Leiber. Ein aus Treblinka Geflohener berichtet: „Über- und untereinander lagen Massen von Leichen mit furchterregenden Gesichtern. [...] [D]ie Körper waren ineinander verknäuelt und schlaff“ (BŻIH 40, S. 80). In einem Rapport der vereinigten Untergrundorganisationen heißt es über die Gaskammern: „[A]us all den Leichen wurde gewissermaßen eine einheitliche Masse, [...] auf grauenvolle Weise verflochten Beine, Arme, Rümpfe sich zu einem riesigen Knäuel“ (Raport, S. 302). Eine „Masse schrecklich zusammengepresster, miteinander verklebter und verknäuelter Leiber" erwähnt Henryk Rudnicki in seiner Darstellung über die Abläufe der Vernichtungsmaschinerie in Treblinka (S. 44). In den aus der Asche von Birkenau ausgegrabenen Schriften des Sonderkommandos ist u.a. zu lesen: „Sterbend fielen - wegen des großen Gedränges - die einen auf die anderen, bis ein Haufen von fünf und sechs übereinanderliegender Schichten entstand [...] Ein Teil der Menschen bildete eine formlose Masse. “194

Ein anderer Typus des Grauens ist die Vermischung Lebender und Toter; sie kommt in drei Varianten vor. Die erste ließe sich so paraphrasieren: „Lebende wie Tote - Tote wie Lebende“. Die zweite Variante ist das Bild einer grauenerregenden

193 F. Blättler: Warschau 1942, op. cit., S. 28-29, 31.

194 Schriftdokument von Lejb (Langfus), Zitat nach: Inmitten des grauenvollen Verbrechens, op. cit., S. 125-126. 
Symbiose von Lebenden und Toten. Die dritte ist die Situation, wenn unter einem Stapel Leichen noch lebendige Personen hervorkriechen.

Der Ausdruck "lebende Leiche" ist ein Oxymoron und wird in den hier untersuchten Texten meistens als Trope verwendet. Diese Verwendungsarten exponieren unterschiedlich stark ihre Literarizität, sind deutlich konventionalisiert und beziehen sich auf eine bestimmte Konzepttradition. Ihr Vorkommen im Diskurs hebt zweifelsohne die Temperatur der Expression, ist aber zugleich ein Zeichen für die Rhetorizität eines Textes. In eine solche Konzeption einordnen lassen sich beispielsweise Samuel Putermans Darstellung:

Durch das offene Tor strömte eine lange Reihe lebender Leichen auf den Umschlagplatz, die die roten Säcke ihrer Federbetten hinter sich herschleppten (Pamiętniki z getta, S. 162),

oder auch die Beschreibung von Eugenia Szajn-Lewin:

Als sie an der Biegung in die Nalewki-Straße vorbeikommen, sehen sie mit lebenden Leichen beladene Wagen. Das ist das Spital, das ebenfalls liquidiert wird (S. 23).

An anderer Stelle jedoch zerschlägt dieselbe Autorin die Regelmäßigkeit der Trope, als sie schildert, wie die große Liquidierungsaktion begann, und ein anrührendes Bild in der Tradition des Danse macabre kreiert:

Da kam es zu einem Aufruhr auf der Straße. [...] Aus dem Schatten der Mauern erhoben sich liegende Gestalten. Die Leichen wurden lebendig. Sie standen auf, große, schwere, eiternde Leiber - und gingen. Das ganze Elend kam in Bewegung. Sie streckten nicht mehr die Hände aus, jammerten nicht mehr nach Brot. [...] Sie warteten nicht mehr auf den Tod - sie gingen (S. 9).

Auch Rokhl Oyerbakh modifiziert das verwendete Oxymoron, indem sie das makabre Antithetische daran in Worte kleidet und damit die mittelalterlichen Bilder des Transi heraufbeschwört:

Eine Woche zuvor hatte sich sein Anblick auf grauenvolle Weise verändert, eine echte lebende Leiche, die aussah, als habe sie bereits begraben gelegen und sich mit den Spuren der Verwandlung im Gesicht wieder hervorgewühlt (Ring I, 654, S. 44).

Die lebende Leiche, im wahrsten Sinne des Wortes, ohne Anführungsstriche, ist eine Realität des abgeriegelten Bezirks. Deshalb sind auch bestimmte Auszüge aus Dawid Sierakowiaks Tagebuch aus dem Ghetto Litzmannstadt wie eine Schreckensvision zu lesen und nicht nur wie ein Beispiel für eine tropische Sprachverwendung.

Die wandelnden Leichen in unseren Straßen geben dem ganzen Ghetto bereits ein fahles, fauliges, schwindsüchtiges Gesicht. [...] 
Die Zahl der wirklich lebendigen Menschen im Ghetto ist minimal. Alles nur noch Tote, wandelnde Schatten. ${ }^{195}$

Grauenvolle Bestätigung dafür ist der Eintrag vom 14. Oktober 1941 in Rokhl Oyerbakhs Pamiętnik $z$ getta [Tagebuch aus dem Ghetto]:

Sie schreien und wehren sich bis zum Letzten, bis zur letzten Stunde und zur letzten Minute, aber diese Stunde und diese Minute kommen. [...] Irgendwo in einem Hauseingang [unleserliches Wort - J.L.] ruft ein Junge [jiddischer Text - J.L.]: „Ich spüre meinen Körper nicht mehr, ich bin schon eine Leiche“ (Ring I, 654, S. 47-48).

Wir bewegen uns somit bereits nicht mehr in der Sphäre der literarischen Konzepte, sondern des tatsächlich eingetretenen, realen Grauens. Ein besonders drastisches Beispiel dafür sind die Szenen, die einen ganz eigentümlichen Umgang der Lebenden mit den Toten zeigen, eine entsetzliche Symbiose. All diese Szenen handeln im Grunde nur von zwei Situationen: Ein Kind saugt noch an der Brust seiner verstorbenen Mutter oder eine Mutter legt ihr totes Kind an die Brust. Solche Sequenzen - sie wiederholen sich in bezeichnender Weise in mehreren Texten - haben den Charakter von Genrebildern, die sozusagen mit dem kühlen Auge einer Kamera aufgenommen wurden. In dokumentarischer Konvention sind die Aufzeichnungen in Mary Bergs (S. 125-126) oder Stanisław Sznapmans Tagebüchern (Pamiętniki z getta, S. 204) gehalten. Marek Edelman hingegen verleiht der von ihm beschriebenen Situation ein zurückhaltendes, doch merkliches Pathos:

Niemandem fällt auf, [...] dass die Mutter, die ihren Säugling stillt, schon seit drei Tagen kalt und starr ist, und das Kind schreit vergeblich in diesen Leichenarmen und saugt vergeblich an der toten Leichenbrust (S. 59). ${ }^{196}$

Der Haufen Leiber, auf dem sich Lebende und Tote gleichermaßen stapeln, scheint nur das Produkt einer raffinierten oder gar perversen Phantasie zu sein. Doch tatsächlich handelt es sich dabei um ein vollkommen reales und für eine bestimmte Etappe auf dem Weg zur „Endlösung“ sogar typisches Bild. Szenen, in denen lebende Menschen in Todesgruben geworfen werden, in denen Menschen lebendig begraben in Massengräbern liegen, in denen schließlich Überlebende

195 Das Ghettotagebuch des Dawid Sierakowiak: Aufzeichnungen eines Siebzehnjährigen. 1941/42, dt. Übers. von R. Matwin-Buschmann, Leipzig 1993, S. 81, 134

196 Einen ähnlichen Charakter hat folgende Szene aus J. Katzenelsons Poem, die sich in einem Waggon auf dem Weg nach Treblinka abspielt: „Ein Kind fleht seine tote Mutter an: Gib mir was ab/Ein Schlückchen Wasser nur! [...] “ [im jiddischen Original: $a$ jidisch kind bet bei sein tojter mamen: wasser! gib wasser mir a trop! [...]"] (Großer Gesang vom ausgerotteten jüdischen Volk, op. cit., Vierter Gesang, S. 68-69). 
einer Hinrichtung unter einem Haufen Leichen hervorkriechen, finden in den überlieferten Texten recht zahlreich Bestätigung ${ }^{197}$. All das lässt den Eindruck entstehen, in der Welt, in der sich die Verfasser jener Texte bewegen und die geschilderten Ereignisse abspielen, sei die unübertretbare Grenze zwischen Leben und Tod aufgehoben worden. Die der Alltagserfahrung zugängliche Wirklichkeit nimmt damit eschatologischen Charakter an: Die Welt, die da ist, wird zugleich zu einer Welt, die kommen soll. Die große Vision von der Endzeit, wenn sich die Gräber öffnen, die Toten lebendig werden und sich gemeinsam mit den Lebenden aufstellen, wird hier und jetzt Realität.

Leon Najberg führt den Bericht eines Mädchens an, das den eigenen Tod überlebt. Im aufständischen Warschauer Ghetto haben die Deutschen einen Bunker an der Świętojerska-Straße 38 entdeckt, die dort versteckten Menschen herausgezerrt und alle erschossen; im Hinterhof des brennenden Hauses blieb nur ein Stapel blutbesudelter Leichen liegen. Jenes Bild findet der Autor vor:

Zwischen den Leichen rührt sich etwas ... Jemand versucht, aufzustehen ... Wir laufen hin ... Ein kleines, etwa zehnjähriges Mädchen mit verbundenen Augen spricht uns auf Jiddisch an [...]: „Ich habe hinter mir Schüsse gehört und bin hingefallen, jemand drückte mich mit seinem Gewicht nieder, Blut lief mir übers Gesicht. Ich wusste nicht, ob ich verwundet war oder schon starb. [...] Die Deutschen sind gekommen und haben uns getreten - wer schrie oder sich bewegte, auf den haben sie mit kleinen Revolvern geschossen. Ich habe den Atem angehalten und bin ganz stillgelegen. Nach einiger Zeit habe ich gehört, wie sie singend fortgingen ... Ich bin noch ein bisschen liegengeblieben, dann habe ich die Leiche von mir heruntergeschoben, und da habe ich gesehen, dass diese Leiche, die auf mir lag“, schließt Irka weinend, „meine Mama war. Ihr Blut war auf mich geflossen. Mama war nicht mehr am Leben. Ich habe sie noch einmal geküsst und bin zwischen den Leichen auf die Suche gegangen. Ich dachte, meine Schwester hätte auch überlebt, so wie ich. Aber es waren alle tot" (S. 91-92).

Henryk Bryskier beschreibt die Szene seiner eigenen Auferstehung von den Toten. Sein Bericht enthüllt die Erfahrung des Übergangs, der Aufhebung der Grenze zwischen Lebenden und Toten, der Angleichung von Leben und Tod. Am 24. April 1943 betritt ein Trupp SS-Männer mit General Stroop an der Spitze das Gelände des Shops von Brauer an der Nalewki-Straße 28-32. Die Leiter der einzelnen Shop-Abteilungen werden an die Mauer gestellt und erschossen.

197 Bekannt sind auch ähnliche Berichte aus dem Warschauer Aufstand sowie, aus späterer Zeit, im Fernsehen gezeigte Berichte der Augenzeugen von Massenhinrichtungen in Bosnien, die es geschafft haben, zu überleben und sich aus einem Berg von Leichen hervorzugraben. 
Eine Salve ging los, und in derselben Sekunde erlitt ich einen [Herz]krampf und fiel benommen hin. Das Gehirn meines Nachbarn spritzte mir an Gesicht und Kopf. Ich weiß nicht, ob jemand bemerkte, dass mich keine Kugel getroffen hatte oder dass das Blut an meinem Kopf nicht meines war, vielleicht hatte ich mich auch bewegt, jedenfalls kam jemand vom Erschießungskommando herüber und schlug mir mit seinem Gewehrkolben gegen die Stirn, über dem Auge. Nun lief mir mein eigenes Blut die Nase entlang in den Mund und bis zum Hals. Ich meinte aber, eine Patrone hätte mich getroffen und das Blut sei die Folge des Schusses. Langsam nahm meine Benommenheit ab. Ich konnte nicht davon ausgehen, dass ich lebte; obwohl ich lebte, glaubte ich, gestorben zu sein. Es schien mir, als folgten Leben und Tod nicht aufeinander, sondern als existierten sie stets nebeneinander. Ich versank in einem dunklen Abgrund, und dann war es, als schwebte mein Astralkörper im Raum, mal hatte er die Wolken unter sich, mal über sich. [...] Ich wollte mich bewegen, aufrichten, aber ich fürchtete, die kleinste Bewegung könnte verraten, dass ich noch lebte, und dann würden sie mich endgültig töten. Also blieb ich liegen und spielte nun ganz bewusst den Toten, während ich abwartete, was weiter geschehen würde („Nowiny Kurier“ [Neuigkeiten Kurier], 4. Mai 1990, S. 6).

Diese beiden brandaktuell notierten Geschichten aus dem Warschauer Ghetto müssen noch um eine dritte ergänzt werden, die Yaffa Eliach Jahre später niederschrieb und zusammen mit fast hundert anderen Erzählungen in einem einzigartigen Buch namens Hasidic Tales of the Holocaust veröffentlichte. Die Herausgeberin forschte sechs Jahre lang in chassidischen Gemeinschaften nach Holocaustüberlebenden und deren Kindern. Die größte Gruppe von Chassiden lebt, wie sich herausstellte, in Brooklyn in der Vereinigten Staaten, und so führte Yaffa Eliach dort ihre Gespräche, die zur Quelle der von ihr niedergeschriebenen Geschichten wurden. Eine davon handelt von den Juden in einem litauischen Städtchen und spielt an Rosch ha-Schana (dem jüdischen Neujahr) 1941. Damals wurde die ganze Gesellschaft der kleinen Stadt auf einen alten jüdischen Friedhof getrieben. Dort befahl man den Menschen, sich auszuziehen, teilte sie in Gruppen von je 250 Personen ein, ließ sie sich am Rand eigens ausgehobener Gruben aufstellen und erschoss sie. Der Sohn des örtlichen Melamed (Lehrers), der 16-jährige Zwi Michalowski, stürzte den Bruchteil einer Sekunde früher ins Massengrab, noch bevor ihn die Kugel erreichte. Sogleich lag er unter einem Haufen Leichen begraben. Er spürte, wie das Blut an ihm herablief und wie die sterbenden Menschen über und unter ihm in Todeszuckungen bebten. Es wurde kalt und dunkel. Als alles ruhig geworden war, begann Zwi sich aus der Masse von Leibern herauszuarbeiten. Dann stand er nackt und blutverschmiert auf dem leeren Friedhof. Es war eine kühle Septembernacht. Er näherte sich vorsichtig ein paar Gebäuden in der Umgebung, klopfte an und bat um Hilfe. Doch man jagte ihn fort, schrie: „Zurück ins Grab, Jude, wo du hingehörst!“ Eine alte Witwe kam mit einem brennenden Holzscheit auf ihn zu, als wollte sie einen unreinen 
Geist einem Exorzismus unterziehen. Da sagte Zwi zu ihr: „Ich bin dein Herr Jesus Christus, der vom Kreuz herabgestiegen ist. Sieh mich an - hier sind das Blut, der Schmerz und das Leid eines Unschuldigen. Lass mich ein." Die Witwe rief aus: „O mein Gott, o mein Gott!“, führte ihn in die Stube, wusch ihn, gab ihm zu essen und kleidete ihn an. Zwi versprach ihr den ewigen Segen - unter der Bedingung, dass sie drei Tage lang absolutes Stillschweigen über ihre Begegnung wahren würde, so verlange es die besondere Mission, die er auf Erden zu erfüllen habe. Ausgestattet mit Kleidung und Lebensmitteln ging er in den Wald. Auf diese Weise, endet Yaffa Eliach, entstand in jener Gegend eine jüdische Partisanenabteilung ${ }^{198}$.

Die Hauptfiguren jener drei Geschichten sollen erschossen werden, können sich aber - von den Körpern der anderen Ermordeten bedeckt wie von einem Schutzschild - verstecken und so ihr Leben retten. Jedem von ihnen wir die Erfahrung zuteil, die Grenze zwischen Leben und Tod zu überschreiten. Damit legen sie gewissermaßen die mythologische Reise zweimal zurück: von der Erde in das Land der Toten und zurück aus dem Jenseits auf die Erde.

In manchen Ghettoberichten wird gerade der Umschlagplatz zum Ort, an dem die Geschichte endet und der von den Propheten angekündigte Tag Jahwes beginnt. In der biblischen Apokalyptik wird die Vision vom Ende der Welt in Bildern einer kosmischen Katastrophe und einer Rückkehr zum wilden und chaotischen Urzustand dargestellt. Die Figur für jenes Chaos und für die Ankündigung des Weltendes ist die Vermischung von Lebenden und Toten. Marian Berland sieht den Umschlagplatz als apokalyptisches „lebendes Grab“:

Wir alle hier sind eine Schar von Halbtoten [...]. Sterbende und Verstorbene zusammen mit Lebenden. Kot, Dreck und anderer Unrat, dazwischen die Menschen. Mit einem Wort, ein schreckliches, grauenvolles, lebendes, wimmelndes Grab (S. 89, 95).

198 Y. Eliach: Hasidic Tales of the Holocaust, New York 1988, S. 53-55. Die Hauptfigur in der geschilderten Situation, Zwi Michalowski, war einer der Gesprächspartner der Verfasserin. Auch in einer Geschichte von Schalom [Scholem] Asch, „Chrystus w getcie" [Christus im Ghetto] kommt das Motiv des vom Kreuz in die Welt des Holocaust hinabgestiegenen Jesus Christus vor. Darin weigert sich ein Rabbi, das Kreuz in der Allerheiligenkirche am Warschauer Grzybowski-Platz zu entweihen; er wird ermordet und seine Leiche am Fuß der Kirche liegen gelassen. Da steigt von einem Kruzifix an der Wand der gemartete Jesus herab, kleidet sich in die Gewänder des ermordeten Rabbis, zieht dessen blutbefleckten Tallit [Gebetsmantel] über, spricht über dem Ermordeten einen Segen und geht dann von der Kirche in die Straßen des Ghettos, um dort die erstbeste Wohnung zu betreten und die Bewohner mit dem Wort „Schalom“ zu begrüßen. 
Leon Najberg erinnert sich, dass auf dem Umschlagplatz ein „Vorgeschmack auf die Hölle“ zu spüren gewesen sei, es sei eine „Hölle zu Lebzeiten“ gewesen, wo "Verwundete und Leichen zusammen mit Lebenden" eingepfercht gewesen seien, „bis zu dem Moment, in dem alle in die Waggons getrieben wurden“ (S. 27-28). Henryk Makower empfindet Ähnliches beim Anblick der langen Schlange von Kranken, die auf die Bahnrampe getrieben werden: „Dieser schrecklich anzusehende Menschenzug lässt den Gedanken aufkommen, wir alle befänden uns in der Hand des Satans, er herrsche nun über die Welt" (S. 135). Stanisław Sznapman nimmt die Szenerie auf dem Umschlagplatz bei der Stawki-Straße mit einem allumfassenden Blick wahr und schreibt: „Dantische Szenen ereigneten sich auf dem Umschlagplatz" (Pamiętniki z getta, S. 155).

Innerhalb der schrecklich überfüllten Waggons, die von hier aus nach Treblinka aufbrechen, finden ebenso Dantische Szenen statt. Diese bereits recht abgedroschene Umschreibung gewinnt in dem vorliegenden Fall ihr Gewicht und ihre wortwörtliche Bedeutung wieder: Gleich dem Boot des Charon bringen die Züge ihre Insassen ins Totenreich. „Wir betreten den Umschlagplatz. Es ist dies ein Platz, von dem Züge ins Jenseits gehen, der erste und einzige derartige Platz auf der ganzen Welt", schreibt Noemi Szac-Wajnkranc (S. 28). Es war daher eine Reise in die ,jenseitige Welt“ - und wer aus ihr zurückkam, kehrte „aus dem Jenseits“ zurück. Ebendiesen Titel - Powrót z tamtego świata [Rückkehr aus dem Jenseits] - gibt eine unbekannte Autorin ihrem Bericht, in dem sie die Geschichte einer Frau erzählt, die am 19. Januar 1943 in den Waggon verfrachtet wird.

Waren Sie denn auch in einem Todeswaggon? [K]ennen Sie die Rückkehr aus „dem Jenseits"? Nein, das habe ich nicht vollständig durchlebt. Ich weiß, so wie auch die wenigen Tausend am Leben Gebliebenen, was „im Angesicht des Todes“ heißt, was es heißt, den Tod häufig zu suchen und sich häufig vor ihm zu verbergen, aber ich bin noch nie jemandem begegnet, der mit „dem Jenseits“ zu tun hatte.

Eine junge Frau hält sich krampfhaft, mit letzter Kraft am Fenstergitter fest. Es ist erstickend heiß, die Luft von draußen spürt sie nicht; die Hitze verbrennt sie, sengende Hitze. [...] „Das Jenseits“ - das ist der letzte Bewusstseinsblitz - dann - stürzt sie hin. Wie viele Stunden vergehen, weiß sie nicht. [...] Sie will sich bewegen, es geht nicht, auf ihr liegen schlaffe, schwere Leichen. Sie ist vom Willen besessen, in die Welt der Lebenden zurückzukehren. [...] Sie setzt sich auf die Pyramide der Toten, legt die Leiber gleichmäßiger übereinander, um bequemer sitzen zu können. Zart, empfindsam, menschlich, menschlich fühlen kann sie nicht mehr, sie ist allem gegenüber abgestumpft. Der Zug fährt. Fünf Lebewesen von über zweihundert atmen noch. Starkes Herz und starke Lunge. Sie stellen sich auf die Leichen ihrer Brüder und schneiden die Drähte mit einer Schere durch, beißen sie mit ihren Zähnen durch. [...] Fünf lebende Gestalten, hinter ihnen Leichen (S. 324-327). 
Es war wahrscheinlich derselbe Tag, an dem der Kantor der Warschauer Synagoge, Alter, vom Umschlagplatz nach Treblinka fuhr. Von seinen Erlebnissen im verplombten Waggon, seiner Flucht und Rückkehr nach Warschau berichtet Stanisław Adler. Die eng zusammengepferchten Menschen sind am Ersticken. In jener eiskalten Januarnacht herrscht im Waggon eine schier unerträgliche Hitze.

Die meisten Juden in dem Viehwaggon waren bereits gestorben. Alter hielt sich, auf einem Leichenstapel stehend, verzweifelt am Fenster. Sein Bruder Mieczysław hatte keine Kraft mehr. Alter, der ihn ans Fenster bringen wollte, damit er frische Luft bekäme, musste die grauenvolle Pyramide noch erhöhen. Deshalb begann er, die Körper mit den Füßen zurechtzuschieben, und da hörte er ein Ächzen, er beugte sich hinunter und erkannte die Schriftstellerin Jarecka. Kurz darauf tat sie ihren letzten Atemzug. Später dann starb auch sein Bruder Mieczysław unter schrecklichen Qualen (S. 327).

Der Waggon mit der zusammengepferchten Masse Lebender und Toter nimmt sich aus wie ein Vorhof der Hölle. Auf seinem Weg über den geradewegs zu den Gaskammern führenden Schienenstrang bewegt er sich zugleich in einem Dantischen Raum. Die Wirklichkeit des Hier und Jetzt lässt sich einzig in einer Sprache der Höllensymbolik beschreiben, verkörpert sie doch die klassischen Vorstellungen von der Hölle, ist die Realisierung des mythischen Modells eine höllischen Wirklichkeit ${ }^{199}$. In ebenjenen Kategorien nimmt Marian Berland den

199 Eine Hölle ist natürlich das ganze Ghetto, nicht nur die Strecke Umschlagplatz-Treblinka. N. Szac-Wajnkranc gesteht, dass die Welt des geschlossenen Bezirks ihre wahrgewordenen Vorstellungen von der Hölle seien: „In meiner Phantasie stellte ich mir manchmal ein Bild der Hölle vor. Ich sah gequälte Menschen, kauende Teufel [...]. Die Hölle des Ghettos. Die Menschen eingesperrt, jeder Möglichkeit zur Arbeit, zum Handeln beraubt; gebrandmarkte Menschen, zur qualvollen Ausrottung verurteilt“ (S. 18). Im Dantischen Kreis befindet sich die Sammelstelle für Geflüchtete an der DzikaStraße 1-3-5: „Dort zeigte sich uns ein Bild, das selbst die lebhafteste Phantasie eines Künstlers nicht hätte ersinnen, das selbst im Traum nicht hätte erscheinen können. Kot überschwemmte Flure und Treppen, Haufen von Abfällen, Müll, Exkrementen auf dem Hinterhof reichten bis zur Höhe des ersten Stocks, in den Zimmern schliefen die Lebenden - wenn man sie überhaupt noch Lebende nennen konnte - auf dem Boden nebeneinander, neben den Leichen, Typhuskranke zusammen mit Gesunden, Männer, Frauen, Kinder - geisterhafte Gestalten. Alles zusammen - wie Dantes Hölle“ (N.N. „Pamiętniki“, Sign. 129, S. 55-56). Wichtig zu bemerken ist, dass bereits die Szenerie des belagerten und bombardierten Warschau im September 1939 Assoziationen mit Dante aufkommen ließ. In Wojdysławskis Aufzeichnungen ist zu lesen: „Dante ist tot und wird nicht mehr auferstehen, aber selbst wenn er hier wäre, würde er doch diese Tausenden Leichen von Menschen, Pferden, Häusern nicht zu malen schaffen, die sämtlich in stummer Klage reglos dalagen, nackt, entblößt, grauenerregend“ (S. 11). 
Weg nach Treblinka wahr, der im April 1943 vom Umschlagplatz abfährt. Er wird sich bewusst, dass vor seinen Augen Dantes literarische Vision wahr wird:

Die Dampflok schnauft, aus dem Schornstein schlägt ein roter Federbusch, die Waggons rattern mit hohlem Klang, hier, in seinem Innern, unentwegtes Ächzen und Stöhnen, und wenn wir noch die fortdauernde Kanonade von Schüssen hinzunehmen, erhalten wir ein in seinem Grauen fürwahr eindringliches Bild, das einem das Blut in den Adern gefrieren lässt. Der König der Satane selbst könnte keinen würdigeren Streitwagen fahren. Ich habe einmal Dantes Hölle gelesen, diese Nacht, wir hier, in den Waggons, diese Szenen wirken wie direkt Dantes Werk entnommen (S. 172).

Das Motiv der zusammengepferchten Leiber, der Stapel von Leichen, der überwältigenden Menschenmassen, die in dieses Drama des Weltendes hineingezogen werden - ein Motiv, das, wie bereits mehrfach erwähnt, in den persönlichen Dokumenten aus dem Ghetto aufscheint - kommt in der mittelalterlichen Ikonographie, der visionären Literatur und bei Dante vor ${ }^{200}$. Und so leiden zum Beispiel im ersten Kreis der Dantischen Hölle „[... S Scharen, groß und zahlreich, [...]/Von Kindern und von Weibern und von Männern“. Im vierten Kreis sieht der Wanderer eine wahnsinnige, dicht gedrängte, einander niedertrampelnde Menschenmenge ${ }^{201}$.

Die Konzeption, derzufolge die Höllenqualen sowohl durch Feuer als auch durch schneidende Kälte verursacht werden, hat ihren Ursprung in den apokryphen Schriften des Alten Testaments (Zweiter Henoch) und ist in der mittelalterlichen Tradition fest verwurzelt, unter anderem in Dantes Hölle, wo Charon sagt: „Zum Ufer jenseits, komm’ ich, euch zu führen/In ew'ge Finsternis, in Frost und Gluten “202, und auch in Werken aus späteren Epochen, bei Shakespeare

200 A. Gurjewitsch beschreibt u.a. Bilder des Dramas vom Ende der Welt, die sich über die Fassaden gotischer Kathedralen erstrecken. Eines jener Bilder war das Hinabstoßen in die Hölle. Dort sehe man, wie „eine Schar der Verdammten von den Teufeln in die Höllenglut geleitet" wird; „, die schrecklich verzerrten und gekrümmten Leiber der von Gott Verworfenen“ („„ «Die göttliche Komödie» vor Dante“, in: Mittelalterliche Volkskultur, dt. Übers. von M. Springer, Dresden 1986, S. 171-172.

201 Dante Alighieri: Die Göttliche Komödie, dt. Übers. von Philalethes (König Johann von Sachsen, 1801-1873), Berlin um 1925. Erster Kreis - Die Hölle, Vierter Gesang, Vers 29-30. Vierter Kreis: „Sah schlammbedecktes Volk in dieser Lache/Nackt insgesamt und mit erzürntem Antlitz/Die schlugen nicht allein sich mit den Händen/ Auch mit dem Haupt, der Brust und mit den Füßen/Stückweise mit den Zähnen sich zerfleischend“ - Die Hölle, Siebenter Gesang, Vers 110-114.

202 Ebd., Die Hölle, Dritter Gesang, Vers 86-87. 
(Maß für Maß) oder Milton (Das verlorene Paradies) ${ }^{203}$. Bei der Analyse dieser Schilderungen kann man sich kaum des Eindrucks erwehren, dass eines der Merkmale des Holocaust die jenen traditionellen Vorbildern nachempfundenen Höllenqualen waren. Es ist eine eisige Januarnacht im Jahr 1943; die im Waggon zusammengepferchten Menschen quälen Durst, Hitze, Luftmangel. Hinter der stacheldrahtvergitterten Fensterluke -

so nah erstrecken sich große, weite Schneefelder. [...] Von den Waggonwänden rinnt es. Die Temperatur steigt stark, die Hitze nimmt zu. Alles beginnt zu glühen. Wieder zerreißt ein Schrei die Luft, ein letzter vielstimmiger Schrei entringt sich der Brust. Wer näher am Fenster steht, befeuchtet ein Taschentuch an der Fensterbank, reicht es an andere weiter, doch es trocknet sofort wieder. Eine Sisyphosarbeit; zu wenig Feuchtigkeit und Kälte im Januar (N.N.: Powrót z tamtego świata, S. 326).

In Salmen Lewenthals Handschrift, der Mitglied des Sonderkommandos von Birkenau war, nimmt der Weg zu den Gaskammern Züge einer wahrhaft apokalyptischen Vision an. Ein Lastwagen fuhr vor und „man begann die menschliche Masse so herabzuwerfen, wie man Kies auf der Chaussee auslehrt“. Nackte Frauen, bereits völlig entkräftet, „begannen sich aus diesem Körperhaufen herauszuarbeiten, richteten sich auf [...] und versuchten zu gehen“. Es ist Anfang 1944, empfindliche Kälte und eisiger Wind. Die Opfer frieren entsetzlich. Die quälende Kälte geht den Qualen in der Gaskammer und dem Krematoriumsfeuer voraus ${ }^{204}$.

Ein Attribut des Höllenschlundes sind Chaos, Unordnung, Durcheinander. Von einer derartigen infernalen Verwirrung betroffen ist auch die Welt des Ghettos, der jede elementare Ordnung fehlt, die sich in einem geradezu satanischen Wirbel befindet. Auf ebendiese Weise enthüllt das Ghetto Litzmannstadt sein höllisches Antlitz vor Dawid Sierakowiak. Bei einer Selektion wird Dawids Mutter zur Deportation bestimmt, aus ihrer Wohnung abgeholt und zusammen mit anderen Opfern eingesperrt. Dawids Vater schafft es, an den Aufenthaltsort der Gefangenen zu gelangen. „Vater sagt“, notiert Sierakowiak in seinem Tagebuch,

203 Siehe Zweiter Gesang von J. Miltons Verlorenem Paradies in dt. Übersetzung von H.H. Meier, Stuttgart 1968, 2008, S. 67-68, wo es heißt: „Es brennt die Luft, vor Frost erklirrend, und/Die Kälte nimmt des Feuers Wirkung ein./Dorthin verschleppen zu gewissen Zeiten/Harpyienfüßige Rachegeister alle/Verdammten [...]/Vom Bett der Feuergluten auf das Eis,/Das ihre sanfte Himmelswärme tötet,/Gerissen, um darauf so lang zu schmachten,/Erstarrt und unbeweglich eingefroren,/Bis man zurück sie in das Feuermeer [...]/Hin- und herüber schifft [...]."

204 S. Lewental: Inmitten des grauenvollen Verbrechens, op. cit., S. 216. 
„drinnen sei die reinste Hölle. Alles geht drunter und drüber, alles ist in einem fürchterlichen Zustand." ${ }^{\text {205 }}$

\section{4}

Das Makabre, Grauenerregende nimmt in der Darstellung des Ghettos - genauer gesagt, im Bereich des hier erörterten Bildes von Tod und Leiche - eine dominierende Stelle ein. Grauen und Entsetzen erlangen bisweilen eine Intensität, die alles zu überlagern und die dargestellte Welt ganz zu beherrschen scheint. Dennoch gibt es in dieser überwältigenden Dominanz wichtige Brüche. Bereits das Motiv der Alltäglichkeit des Todes und der Entwicklung einer ganz eigenen Routine im Umgang mit dem Massensterben beweisen eine bestimmte Aneignung des Grauens. Derartige Aneignungen finden häufiger statt. In den persönlichen Ghettodokumentationen lässt sich beobachten, dass die Menschen das rein Makabre zu durchbrechen und sich dem alles beherrschenden Grauen zu entziehen versuchen. Solcherart Bestrebungen sind nicht repräsentativ für das gesamte Material und stellen kein vorrangiges Motiv dar, einige Beispiele sind sogar eher nebensächlich - trotzdem ist das Motiv in den untersuchten Texten unzweifelhaft anzutreffen und erscheint daher eine wesentliche Bedeutung zu besitzen, gestattet es doch die Vermutung, dass das Repertoire der Formen zur Aufzeichnung von Holocausterfahrung breiter und reicher ist als allgemein angenommen.

Sehen wir uns nun zwei Methoden an, mittels derer das Grauen bei der Darstellung von Leichnamen durchbrochen werden kann. Eine davon strebt durch Ästhetisierung der Leiche die Überwindung der vernichtenden Kraft des Todes an, die Heilung der durch ihn verursachten Wunden, die Verknüpfung gerissener Bande und Wiederherstellung einer zerstörten Harmonie. Betrachtet man einen Leichnam von ästhetisierender Warte, so verliert er alles Abstoßende; er ruft kein Entsetzen mehr hervor, sondern bekommt eine eigentümliche Schönheit, die sich stärker als der Tod erweist, die Schmerz und Angst abmildert, Trost spendet. Die andere Methode zur Entwaffnung des lähmenden Grauens, das der Tod hervorruft, besteht darin, ihm ein groteskes Antlitz zu verleihen. Bei einer solchen Auffassung ist die Leiche erschreckend und komisch zugleich, sie ruft Grauen, aber auch Lachen hervor. Es ist dies jedoch - anders als bei Bachtin - kein karnevaleskes Lachen, das in dichotomischem Verhältnis zur elitären 
Kultur des Ernstes steht. Dieses Lachen hier ist ambivalent, eigentümlich, finster, besitzt zwei Gesichter. Es ist ein „lästerliches, satanisches Lachen“206.

Die Flucht vor dem Makabren führt demnach in zwei Richtungen - zur Hervorhebung von Schönheit, Harmonie, Ruhe, Empfindsamkeit oder aber zu hybriden, deformierten Bildern des Grotesken. Die Quelle der ersteren könnte ganz allgemein betrachtet - in der antiken Kultur gesehen werden, die zweite Richtung steht organisch mit der Kunst des Makabren und der sich im Mittelalter herausbildenden Sicht des Todes in Verbindung.

Im ersten Teil des Ringelblum-Archivs befinden sich unter der Signatur 489 die Aufzeichnungen eines Mannes namens Wojdysławski aus den Jahren 1939-1942. Jener kurze, gerade einmal 30 handbeschriebene Seiten umfassende Text in polnischer Sprache stellt ohne Zweifel eines der interessantesten persönlichen Dokumente aus dem Ghetto dar. Umso unverständlicher ist es, warum er über 50 Jahre lang in keiner Form veröffentlicht wurde. Großen Eindruck macht die außergewöhnliche sprachliche Gewandtheit, ja geradezu Virtuosität des Autors, seine Fähigkeit, mit verschiedenen Stilen, verschiedenen Färbungen von Wörtern zu operieren. Wojdysławski zielt bewusst auf bestimmte künstlerische Effekte $a b$, indem er Wörter und Bedeutungen miteinander kontrastiert, Bilder und Kommentare aufeinander abstimmt, Metapher und wörtliche

206 „Lästerliches, satanisches Lachen“ ist eine Bezeichnung von J. Lotman und B. Uspenskij [siehe dies.,,NNachtrag“, in: D.S. Lichačev, A.M. Pančenko: Die Lachwelt des alten Russland, München 1991, S. 187; Anm. d. Übers.], die von M. Sznajderman zitiert wird. Sie schreibt, das Lachen werde in Zeiten der Seuche zum gleichberechtigten Partner des Todes. „Das Lachen steht in Zeiten einer Epidemie [...] weder für Leben noch für Fröhlichkeit - es erinnert er an ein sardonisches Lachen, das klassische Lachen im Angesicht des Todes [...]. Daher ist es im Land des Schattens angesiedelt" (Zaraza, op. cit., S. 58). Über die Ambivalenz des Lachens im Kontext der mittelalterlichen Groteske schreibt A. Gurjewitsch, wobei er mit der Bachtinschen Konzeption der Lachkultur polemisiert. „Bachtin hat die mittelalterliche Groteske entdeckt, sie anscheinend jedoch ganz einseitig aufgefaßt, nur als die komische Groteske, und ihr [...] die Ambivalenz abgesprochen [...] " („«Höhen» und «Tiefen»: Die mittelalterliche Groteske", in: Mittelalterliche Volkskultur, op. cit., S. 267). Auf die Schwächen in Bachtins Konzeption des Lachens weist ausdrücklich B. Geremek hin: „Das Polyseme der mittelalterlichen Kultur [...] drückt sich [...] auch in der besonderen Verbindung von Lachen und Ernst, von Körperlichkeit und Geistigkeit, "niederem« Realismus und Erhabenheit aus. Eine dichotome, trennende Interpretation im Sinne Bachtins ließe es weder zu, die Dichtung François Villons, noch, die mittelalterliche Weltsicht zu verstehen“ („Śmiech w cieniu szubienicy: o Villonie“ [Lachen im Schatten des Galgen: über Villon], in: „Znak“ 1983, Nr. 8, S. 1292). 
Bedeutung einander begleitend einsetzt, Symbol und Konkretes gegenüberstellt. Übergänge von rein lyrischen Passagen zum Makabren, von futuristischer und expressionistischer Poetik (Rhythmus von Einwortsätzen und Onomatopöien, Typus der Darstellung) zur realistischen Schilderung, von Groteske zu Pathos, von Genrebildern zu leidenschaftlichen Hasstiraden - all das zeugt von der außergewöhnlichen Dynamik des Diskurses in Wojdysławskis Aufzeichnungen. In seiner Handschrift notierte er zum Beispiel eine Szene, die, wie ich denke, in all ihrer Stille und Intimität doch eines der erschütterndsten Ghettobilder bleibt. $\mathrm{Da}$ ist die Mauer. Vor der Mauer ein Abflusskanal, durch den eben ein kleiner Schmuggler schlüpft. Schon streckt er den Kopf auf der arischen Seite hinaus, da sieht er ein paar Deutsche. In panischer Angst will er sich rückwärts ins Ghetto zurückziehen, doch seine Mutter, die drinnen an der Mauer steht, schiebt ihn mit aller Kraft an den Beinen hinüber auf die andere Seite.

Wojdysławski führte seine Aufzeichnungen bereits während der Belagerung Warschaus. Im Laufe von drei Tagen Massenbombardierungen und Artilleriebeschuss rund um die Uhr (24., 25. und 26. September) ändert sich die Situation der kämpfenden Hauptstadt. Kulminationspunkt der Bombardements war der 25. September - der tragische schwarze Montag, der den Einwohnern lange in Erinnerung blieb. Am Tag darauf betritt der Autor die Straße, notiert unter dem Datum des 26. September seine Eindrücke und Beobachtungen. Vor ihm erstreckt sich der Blick auf eine ermordete Stadt: Häuserleichen, Menschenleichen. Eine Szenerie, beschrieben in der Poetik der Bilder von Bronisław Wojciech Linke. Das Schlachtfeld nach den mörderischen Bombardements empfindet Wojdysławski als eine Landschaft der Vernichtung. Inmitten all der Zerstörung, der Brände, Trümmer und verwesenden Leichen - liegt plötzlich der schöne, nackte Leichnam eines Mädchens.

Ich ging hinaus auf die seltsam, unnatürlich stille Straße. Seltsam! Kein Sausen fallender oder Dröhnen explodierender Bomben, kein Sirren von Schrapnellen. Dafür überall Leichen, Leichen, Leichen ... Menschen- und Pferdeleichen, seit drei Wochen nicht begraben, faulend, stinkend. Selbst von den Krähen verschmäht. [...] Auf den Straßen Trümmer, Ziegel, Kugeln, alles bedeckt nur von Leichen. [...] Häuser waren nicht zu sehen. Häuser gab es keine. Überall nur Leichen. Häuserleichen. Rote, rissige Ränder, die Reste der alten Wände und Mauern, durchlöchert mit Ziegelstaub, aufgerissen, aufgeschlitzt, tot. [...] Das Skelett eines Hauses, wie sattgegessen an Leibern, ohne Dach, starrt mit den leeren, ausgebrannten, schwarzen Augenhöhlen seiner Fenster. [...] Die Leiche eines Mädchens, nackt, stellte ihren jungen wohlgeformten Körper zur Schau. Diese Reglosigkeit, deutlich sich abzeichnende Brüste, bleich, aber ohne jede Wunde, ohne einen Makel. Nur an der Hüfte war ein kleiner Fleck zu sehen. Dort war der Schrapnellsplitter eingedrungen. Und diese Augen! Die Augen! Offene Augen, wie aufgerissen 
in Todesschmerz und -angst, Augen von bodenloser Tiefe, in denen der ganze Schmerz stand, die ganze Todesfurcht, Augen, die leben werden, solange es Kriege gibt (S. 8-10).

Ein paar Seiten weiter stößt der Leser auf das Bild eines anderen Mädchens. Kraft der inneren Logik des Textes legt es sich über das Bild des in Warschau durch ein Schrapnell getöteten Mädchens. Die Schilderung des ersten Herbstes der Besatzungszeit, einer Zeit des Regens, der grauen Verhangenheit und der Trauer, bildet den kompositionellen Rahmen für eine Erinnerung an die Sommerferien 1939, die sich zu einer eigenen kleinen Novelle von zart gezeichneter nostalgisch-erotischer Atmosphäre ausweitet. Eine Augustnacht, ein Kiefernwald, ein See. Vor diesem Hintergrund erscheint die zarte und zierliche Silhouette „meiner Sommerkönigin - Rachela“. Ein nächtliches Bad, die nassen Körper berühren sich: „sie schmiegte sich fest an mich. Ich fühlte an meiner Brust zwei Hügel, spürte ihren warmen, biegsamen Körper, der sich an meinen drückte“ [15]. Diesem Ferienbild schickt der Autor die Information voraus, dass Rachela im September 1939 beim Bombenangriff auf Łomża umkam.

Das von Wojdysławski gezeichnete Portrait der Mädchenleiche mit den bleichen Brüsten, „ohne jede Wunde, ohne einen Makel“ lässt an die berühmte Darstellung des Leichnams der jungen Armenierin aus Stefan Żeromskis Vorfrühling denken. Außer einer ästhetischen, stellenweise fast erotischen Faszination für den Körper der Verstorbenen manifestieren beide Darstellungen eine - in Wojdysławskis Aufzeichnungen nur angedeutete, bei Żeromski voll zutage tretende - Auflehnung gegen den Tod. Der Tod setzt zwar dem gerade erst erblühenden Leben ein jähes Ende, kann jedoch die Schönheit des Körpers nicht zerstören. Cezary Baryka, der in Baku die von den Türken niedergemetzelten Armenier begraben muss, geht neben einem zweirädrigen Ochsenfuhrwerk. Vom Leichenstapel „wand sich [...] der Leichnam einer jungen Frau“. Baryka „[kam] die außerordentliche Schönheit ihres Gesichts zu Bewusstsein und [gab] ihm einen Stich [...]“. Dann folgt eine detaillierte Beschreibung aller physiognomischen Eigenschaften. In den Gesichtszügen, in der Lage des Leichnams nimmt Żeromski einen Schrei des Protests gegen die brutale Beendung jenes jungen Lebens wahr, doch auch eine nicht durch den Tod angetastete körperliche Schönheit. Bei Wojdysławski drücken diesen Protest vor allem die Augen aus, „die leben werden, solange es Kriege gibt“. Bei Żeromski schreit der ganze Körper der getöteten Armenierin:

Die nackte Kehle und die kleinen, jungfräulichen, entblößten Brüste bargen denselben verhexten Schrei [...] Cezary Baryka versenkte seinen Blick in die Augen der Verstorbenen und hörte ihr Rufen. Wenn er auf ihren überirdisch schönen Leib, auf die herrlich gespannten Bögen ihrer Brauen, auf ihre drohenden Lippen sah, hörte er 
ein Bekenntnis, das deutlicher war, als wenn es in menschlichen Worten ausgedrückt worden wäre: „[...] Weshalb habt ihr mich ermordet, ihr nichtswürdigen Männer? [...] Vergiss das mir angetane Unrecht nicht, junger Fuhrmann! Sieh dir das Verbrechen der Menschen gut an! Hüte dich! Denk daran!“207

Die zitierte Textstelle aus Wojdysławskis Aufzeichnungen handelt von Warschau Ende September 1939. Es gab noch keine Mauer um den geschlossenen Bezirk, der Besatzer sollte erst in einigen Tagen in die Hauptstadt einmarschieren. Ein kürzlich wiedergefundener Text mit dem Titel „Dwie trumny (na Smoczej i na Śliskiej)“ [Zwei Särge (auf der Smocza- und auf der Śliska-Straße)] von Janusz Korczak entstand an der Jahreswende 1941/1942 - also mitten in der Zeit, in der das Ghetto langsam starb. Er war wahrscheinlich für die Zeitung des Waisenhauses Dom Sierot gedacht. Der Text umfasst drei maschinenbeschriebene Seiten. Sein Inhalt geht durch Mark und Bein; es gibt wohl unter den erhaltenen Texten aus dem Ghetto keinen von vergleichbarer Kraft und Tiefe, der sich zugleich durch eine so weitgehende Askese der Ausdrucksmittel auszeichnet. Korczaks Text scheint auf vollkommene Weise jenen „lautlosen Schrei“ zu verkörpern, eine Reaktion auf großes Leiden, die Rabbi Mendel von Worki meinte ${ }^{208}$. Piotr Matywiecki schreibt daher zu Recht, dass Korczaks Werk „uns zu schweigen gebietet angesichts der Offenbarung solch einer menschlich-unmenschlichen Durchsichtigkeit, hinter der nur der Tod zu sehen ist“" ${ }^{\text {“209. }}$

Die zwei Särge aus dem Titel bezeichnen zwei Portraits von Verstorbenen der eine ist ein 15-jähriger Junge, der im Schnee auf dem Straßenpflaster der Smocza-Straße gefunden wird, der andere ein dreijähriges Kind, das in graues Papier eingewickelt und bei der Śliska-Straße im Schnee abgelegt worden ist. In beiden Bildern transportiert das Weiß des Schnees reiche symbolische Inhalte. Die Farbe Weiß wird seit ältesten Zeiten mit allem Heiligen und Göttlichen verbunden, sie bedeutet moralische Reinheit und Vollkommenheit. Auch hier ist sie ein Zeichen für Linderung und Trost, spielt somit die Rolle einer indirekt gesprochenen Consolatio - eines unerlässlichen Bestandteils der Begräbnisliteratur.

207 S. Żeromski: Vorfrühling, dt. Übers. von K. Harrer, E. Thiele, Leipzig 1975, S. 57-58.

208 Rabbi Mendel von Worki spricht von einem lautlosen Schrei und einem innerlichen Weinen, das ein „jüdisches Gewein“ sei. Man fragte den Rabbi, was den wahren Juden ausmache: „Uns geziemen drei Dinge“, entgegnete er, „ein aufrechtes Knien, ein lautloser Schrei, ein unbewegter Tanz. “ M. Buber: Die Erzählungen der Chassidim, Zürich 1996, S. 819.

209 A. Nasiłowska, P. Matywiecki: „Dwugłos o Korczaku“ [Zwiegespräch über Korczak], in: „Teksty Drugie“ 1992, Nr. 5, S. 141. 
Ihr kennt doch die Smocza-Straße. Sie war so wie immer. So viele Menschen - sie drängeln - sie hasten - sie zanken und feilschen - sie schreien heraus, wer was zu verkaufen hat: einer Kartoffeln, ein anderer Zigaretten, noch ein anderer Kleider, wieder ein anderer Bonbons.

Und da lag dieser hübsche Junge, still, ganz still, am allerstillsten - so lag er im Schnee, im weißen Schnee, im sauberen weißen Schnee.

Neben ihm stand seine Mutter und sagte immer wieder:

So helft doch, ihr Menschen.

Sie war mit Sicherheit seine Mutter. - Nur diese paar Worte - sie schrie sie nicht heraus - sie flüsterte sie nur immer wieder, nur diese Worte, sonst nichts:

So helft doch, ihr Menschen, so helft doch.

Doch die Menschen gingen einfach weiter - sie taten nichts Schlimmes, denn Hilfe brauchte er keine mehr.

Er liegt da so ruhig und so heiter, so hell im weißen Schnee.

Seine Lippen sind geöffnet wie zu einem Lächeln - ich habe nicht darauf geachtet, welche Farbe seine Lippen hatten, aber ich meine, sie waren rosig. Und die Zähne weiß. Und die Augen hat er gesenkt, und in einem Auge, genau in der Pupille - leuchtet ein kleiner Funke, ein allerkleinster Stern.

So helft doch, ihr Menschen, so helft doch

(Bd. 2, S. 203-204)

In einer ähnlichen Funktion erscheint der Schnee bei Wojdysławski in einem Bild von Warschau in Ruinen am Allerseelentag 1939:

Und dann geschah eine seltsame Sache, eine fast wundersame, paradoxe Sache! Es fiel Schnee. Und dieser Schnee war weiß! Nach diesen Leichen, nach all diesen Strömen von rotem, heißem Blut - fiel weißer Schnee. Denn das ist das Werk von Mutter Natur. So muss es sein. So ist das Gesetz (S. 11).

Orientierte man sich für diese Erörterungen an der Dantischen Metapher von der Wanderung durch aufeinanderfolgende Höllenkreise, so übernähme die Führung zum Kreis der Ghettogroteske mit Sicherheit Rokhl Oyerbakh. In ihren Texten nämlich (die sie auf Polnisch schrieb und die auch auf Englisch erhältlich sind) findet die - von der Autorin bewusst und konsequent verwendete Formel einer grotesken Sicht auf die Ghettorealität Ausdruck. An dieser Stelle beschränke ich mich nur darauf, das Bild der Leiche zu zeigen, und lasse die interessante Frage nach dem Platz der Groteske im Repertoire der möglichen Ausdrucksweisen von Holocausterfahrung für eine gesonderte Bearbeitung beiseite.

Nahezu alle in diesem Kapitel besprochenen Themen und Motive finden in Rokhl Oyerbakhs Aufzeichnungen ihre groteske Gestalt. Einer grotesken Deformation unterlegen sind manche Personenportraits, wie beispielsweise die bereits zitierte Darstellung der Frau namens „Damówna“, die an einen grotesken Clown erinnert. Grotesken Charakter nehmen auch die mit ein paar 
Federstrichen skizzierten Straßenbeobachtungen an. So qualifiziert sie im Übrigen die Autorin selbst, die den Begriff „Groteske“ offenbar als Bezeichnung für einen bestimmten Typus von Gattungsszene oder Naturbild behandelt. „Zwei Grotesken. Eine davon überaus stark, makaber“ (Ring I, 641, S. 7) - so beginnt sie ihren Bericht über zwei beobachtete Straßenszenen. Im ersten Fall geht es um eine Leiche, die an der Ecke Smocza- und Gęsia-Straße liegt, im zweiten um die Verwechslung eines „łapacz“ [in etwa: „Grabscher“, „Schnapper“; Anm. d. Übers.] - eines Straßenbettlers, der Passanten Lebensmittel aus den Händen reißt -, der einen Mann mit verbundener Hand in einer Armschlinge angreift, weil er glaubt, der Überfallene trage ein Lebensmittelpäckchen. Die Autorin arbeitet den komischen Effekt heraus, indem sie die Überraschung beider Beteiligten schildert: das Erstaunen des „łapacz“, als er die Armbinde in Händen hält, und den Schrecken des vor Schmerzen aufheulenden Verwundeten. Die Groteske liegt hier somit in der Realität, sie ist kein Produkt der Phantasie oder künstlerischen Schöpfung.

Kommen wir zur makabren Groteske. In Rokhl Oyerbakhs Schriften haben wir es hin und wieder mit einem ganz speziellen Karneval des Todes zu tun. Das Ghetto in ihrer Auffassung ist eine „Revue der Leichen“" (Ring I, 654, S. 32) oder auch ein "Jahrmarkt der Leichen“ (Ring I, 654, S. 39). Die Todeswagen auf den Straßen ... stürzen um: „Einmal stürzte eine Pinkert-Rikscha vor unserem Haus um und acht Leichen fielen auf die Fahrbahn ..." (Ring I, 654, S. 38). Das Ghetto ist weiterhin eine grauenerregende Stadt des Todes, doch nimmt es hier karnevalesk aufgeputzte, dekorierte Züge an, als feiere man auf seinen Straßen ein einziges langes Fest des Sterbens.

Gelangt man in die Nähe der Gęsia-Straße, meint man, die ganze Stadt liege im Sterben. An jeder Straßenecke neu eröffnete Bestattungsinstitute, eines neben dem anderen. Manche mit verzierten Schildern, auf denen Lorbeerkränze den vorgeschriebenen Davidsstern mit silbernen Schnörkeln auf goldenem Grund umgeben. Und diese Namen [...]: „Letzte Ehre“, „Letzter Weg“, „Wahre Welt", „Ewige Welt". Ein Jahrmarkt der Leichen. Über alle Straßen und Sträßchen kommen munter schwarze Wagen und Karren zur Gęsia hin gefahren. Man begegnet ihnen auf Schritt und Tritt. Sie sind wie Bäche, wie Nebenflüsse zu einem großen Fluss, der alles verschlingt ... (Ring I, 654, S. 39).

An einem solchen Ort kann nichts der grotesken Verformung entgehen. Die auf der Straße liegenden Leichen - ein alltägliches Element der Ghettolandschaft, eine gewöhnliche und nicht weiter aufsehenerregende Sache - werden unter Rokhl Oyerbakhs Feder gewissermaßen in den Bereich der grotesken Situationen verlegt. Zwei Beispiele. Das erste: An der Ecke Gęsia- und Smocza-Straße liegt eine Leiche, während ringsum ein reger Altwarenhandel blüht. 
Sie lag allein da wie ein [hier wurde ein Teil des Satzes von der Verfasserin gestrichen J.L.] in den Frühlingsschlamm getretener Lumpen. Vor allem sprangen ihre Beine ins Auge - schlammbesudelte Beine mit mehr schlecht als recht beschuhten Füßen, die breit gespreizt vom Rest des Leibes abstanden. Unter einem Bogen des „Kurier Warszawski“ mit roter Schlagzeile, der den Kopf der Leiche verdeckte, schaute seitlich, aus dem Ärmel eines einstmals schwarzen Wintermantels, ein teigiger, gelblicher, lebloser Arm hervor. Von der Hand bis zum Ellbogen. Das Groteske jedoch bestand in etwas anderem. Über diesem waagerecht daliegenden menschlichen Kadaver ragte eine andere, ebenso grauenhaft zerlumpte, sich aber noch senkrecht haltende Gestalt auf und rief, als Verkäufer irgendwelcher Behältnisse von einem Wagen, ein ums andere Mal in geschäftigem Tonfall: [Text auf Jiddisch - J.L.] - und es regnete Münzen. Ein hübsches Häuflein - Zehner, Fünfer - lag schon auf der Zeitung, die das Gesicht verdeckte ... (Ring I, 641, S. 8-9).

Auch das zweite Beispiel handelt von ebenjenem im Ghetto so weit verbreiteten Anblick: der mit Zeitungen bedeckten Leiche.

Und so sah ich einmal mit eigenen Augen nahe des Eingangstores zu dem Haus, in dem sich die Küche und zugleich auch die Bezirksstelle der jüdischen Polizei befanden, beim Eingang zur Konditorei eine Kinderleiche, die überdeckt war mit einem Plakat vom „Monat des Kindes“, auf dem zu lesen stand: Retten wir die Kinder! Unsere Kinder müssen leben! (Ring I, 642, S. 1).

Dasselbe Bild notiert Ringelblum, allerdings versieht er es - bezeichnenderweise - mit einem die beobachtete Situation rationalisierenden Kommentar: „Sie [die Menschen] wollen auf diese Weise ihren Protest gegen Centos [die Waisenfürsorge; Anm. d. Übers.] ausdrücken, die nichts unternimmt, um diese Kinder hier herauszuholen und vor dem Tod zu retten“ (Bd. 1, S. 334). Rokhl Oyerbakh hingegen denkt dabei an die "Seltsamkeit“ der Form, in der die Ghettorealität erscheint: „überaus seltsame grelle, symbolische Kürzel, wie melodramatische Einfälle in einem platten Film“.

Einen noch grelleren Kontrast bietet ein Vergleich der Darstellungen jenes berühmten Friedhofsschuppens. Ringelblum und andere Autoren verstärken den Effekt des Makabren noch, während das Makabre bei Rokhl Oyerbakh zum Grotesken wird.

Hier drei aus den vorangegangenen Analysen bereits wohlbekannte Motive. Groteske Ausmaße nimmt die Arbeit bei den Leichnamen an.

Jemand erklärte mir, wie Kinderkadaver auf dem Friedhof abgeladen werden. Diese kleinen Leichen wiegen weniger als andere, und die Handwerker, Fuhrmänner, all die schwer schuftenden Leute, die hier während dieser Hochsaison den Tod feiern, werfen die zarten Körperchen einander zu wie Warenpäckchen und fangen sie geschickt in der Luft auf. Die ganz Kleinen lassen sich am besten an einem Bein packen. In einer Geburtsklinik habe ich einmal gesehen, wie eine tüchtige Krankenschwester ebenfalls ein fiependes Würmchen an seinem feisten Beinchen packte, ihm ein paar Klapse auf 
sein kleines Hinterteil gab und es in ein duftendes [gestrichenes Wort, unleserlich - J.L.] legte (Ring I, 654, S. 8).

Ich habe darüber nachgedacht, was an dieser Arbeit bei den Leichen Besonderes ist. [...] [D]ie einen werden auf Tragen herumgeschleppt oder -geschoben, andere in Gräben [geworfen], wieder andere werden einfach von zwei Leuten an Armen und Beinen gepackt, mit einer Geste, die die Maler so häufig bei „Bildern vom Kreuz“ studieren. Für die Jüngeren braucht es keine zwei Leute. So ist es. Dieses Mal habe ich es mit eigenen Augen gesehen. Ich habe gesehen, wie der Friedhofsgeselle so einen kleinen Nackedei bei der Haut packte, an der Stelle, wo man ihn wie einen Sack greifen kann, zwischen Nacken und Schulterblättern, und den Kleinen, der nun mit abgespreizten Armen und Beinen baumelte, zum Schuppen hinübertrug - wie eine Katzenmutter ihr Junges am Nackenfell -, um ihn dort auf einen Leichenhaufen zu werfen (Ring I, 654, S. 36).

Im Friedhofsschuppen beschreibt die Autorin einen Stapel von Leichen wie Marionetten und eine groteske Handlung, die sich zwischen diesen entspinnt.

In der Hochsaison des Todes lagen sie so eine neben der anderen vor uns [unleserliches Wort - J.L.], tote Menschen, kreuz und quer, [unleserliches Wort] Platz ist im Schuppen - der angeblich vor dem Krieg als [unleserliches Wort] für Pferde diente für gerade einmal siebzehn bis zwanzig. In der Mitte wurden lange Liegen mit etwas erhöhtem Kopfteil platziert, auf denen die besseren Herren ausgestreckt und ordentlich mit schwarzem Papier bedeckt ruhen [...]. Sicherlich haben sie auch zu Lebzeiten in Einzelbetten geschlafen [unleserliches Wort] und behindern somit einander auch jetzt nicht, haben es sich jeder auf seinem eigenen Platz bequem gemacht. Eng, ja, das ist es, aber ein Minimum an Platz ist gegeben. So liegen sie da und tun, als sähen sie nichts, bemühen sich, nicht diejenigen anzustarren, die längs der Wände liegen, einer über den anderen geworfen. Einer längs, einer quer, einer mit dem Gesicht nach oben, einer nach unten, und einer in ganz absurder Stellung, akrobatisch - alle wie auf einem Haufen. In Haufen. Eine Segregation auch hier noch. Männer für sich, Frauen für sich. Und die Kinder auch für sich. Hier und da ist eine Kinderleiche vom Stapel gekullert. Ein 2-3jähriges kleines Ding habe ich gesehen, genießerisch lag es da, die Arme angewinkelt, mit Fäustchen, die, wie es schien, jeden Moment die kleinen Äuglein reiben wollten, während das Kind sich schläfrig räkelte ... Hier und da hört man ein Rascheln wie von Papier. Dann sucht eine Leiche nach einer bequemeren Lage, will vielleicht heimlich ihre Glieder ein wenig strecken. Dieses Rascheln weckte nicht die geringste Furcht in mir, und das tut es auch jetzt nicht, obgleich ich um zwei in der Nacht schreibe, allein im Zimmer, im Arbeitszimmer nebenan ist auch niemand, schlafen doch meine beiden Nachbarn außer Haus. Und so werden Leichen sicherlich niemals mehr meine Furcht wecken. Der Schuppen hat mich von meinen letzten Befindlichkeiten kuriert (Ring I, 654, S. 33-34).

Und schließlich das Motiv der ineinander verknäuelten Leichen, das in Rokhl Oyerbakhs Darstellung irgendwo zwischen Grauen und makabrer Komik angesiedelt ist. 
Der Gestank aus dieser Grube war fürchterlich, doch meine Neugier zwang mich, auch in sie hineinzusehen. Am Anfang erschien es mir in meiner Kurzsichtigkeit, als liege dort nur ein einziger Mensch, doch L. wies mich an, näher hinzuschauen. Zwischen den gespreizten Schenkeln eines auf dem Bauch liegenden Toten lugte der ergraute Kopf einer alten Frau hervor. Es musste noch jemand in dieser Grube liegen, und zwar ausgestreckt auf dem Rücken, denn seitlich ragte unter dem Papier eine schlanke, bleiche Hand mit galant gebogenem Handgelenk hervor und schien das Gras, das an jener Stelle wuchs, mit unendlich eleganter Bewegung zu durchkämmen ... (Ring I, 654, S. 37).

Sämtliche hier angeführten Beispiele verbindet die Hybridität ihrer Form, das Zusammentreffen lähmenden Entsetzens mit satanischem Gelächter. Ich denke, die Welt des Ghettos in Rokhl Oyerbakhs Aufzeichnung ist fremd in dem Sinne, in dem Wolfgang Kayser über die Fremdheit der grotesken Welt schreibt ${ }^{210}$. Jene Fremdheit erfüllt uns mit Grauen, erweist sich doch die uns bis dahin bekannte Welt und wiedererkennbare Welt als verändert, deformiert. Wir finden uns nicht in ihr zurecht, können ihr aber auch nicht entfliehen. Wir können nicht in ihr leben wie früher, wir können nicht in ihr sterben wie früher. Alles ist eigentümlich, unheimlich, monströs, schrecklich und lustig zugleich. Vermischt und verknäuelt wie die Leichenhaufen im Friedhofsschuppen.

Es scheint mir, als sei die Formel der Groteske ein Versuch, Zeugnis von einer Erfahrung zu geben, die sich für die klassischen, harmonischen, rationalisierenden Formen als außerhalb des Diskurses angesiedelt erweist. Außerhalb der möglichen Ausdrucksweisen.

\section{Zusammenfassung}

Indem wir uns Schritt für Schritt auf die Spuren der Verfasser der zitierten Texte begaben, konnten wir selbst gewissermaßen einen „Blick durchs Fenster“ auf das Ghetto werfen. Das sollte uns zur Gegenständlichkeit, zur äußerlichen Schicht, zum Konkreten führen. Wir haben die Gesichter von Menschen betrachtet, Sterbeszenen, die Darstellung von Leichen. Auf diese Weise konnten wir - sozusagen - die „Hülle“ des Ghettos untersuchen.

210 Über das groteske Gelächter schreibt Kayser u.a.: „Das Lachen [...] [s]elber schon mit Bitterkeit gemischt, nimmt [...] beim Übergang ins Groteske Züge des höhnischen, zynischen, schließlich des satanischen Gelächters an [...], in: W. Kayser: Das Groteske. Seine Gestaltung in Malerei und Dichtung. Nachdruck der Ausgabe von 1957, Tübingen 2004, S. 201. In seinem Buch Das Groteske in Malerei und Dichtung schreibt Kayser mit Bezug auf Friedrich Schlegel und Jean Paul von einem „infernalischen Lachen“ ["rire infernal"], München 1960, S. 5. 
Eine solche Art der Lektüre ist - wie bereits zuvor gesagt - ein bestimmter Vorschlag zur Annäherung an jene Texte und die darin verzeichnete Erfahrung. Die Botschaft ist nämlich beileibe nicht nur im begrifflichen Diskurs angesiedelt, in explizit formulierten Urteilen, Meinungen, Appellen, ja nicht einmal auf der faktographischen Ebene, die schließlich eine niederschmetternde Aussage enthält. Ebenso eindringlich sprechen die menschlichen Gesichter, Ereignisse, Gegenstände zu uns. Sie nehmen bestimmte Gestalten an und werden gewissermaßen zum Gesprächspartner in einem hermeneutischen Dialog. Durch sie bekommt die Bedeutungswelt des zitierten Textes ein Fundament der Realität, eine Körperlichkeit, Substanz.

Der Leser hat nun die Chance, Bekanntschaft mit jener Realität zu machen, seine Lektüre ist eine aktive. Jene Aktivität kann in unterschiedliche Richtungen gehen, ohne Zweifel jedoch trägt sie zu einem umfassenderen Einblick in die Aufzeichnungen bei und erweitert die Möglichkeiten zu deren Interpretation. Schließlich rückt sie für den Leser die rekonstruierte Welt in geradezu fühlbare Reichweite, sie gibt ihm die Chance, persönlich mit jener Welt in Berührung zu kommen und den Gegenstand dessen, was es zu verstehen gilt, selbst zu erleben.

Allerdings hat sich gezeigt, dass die Beschreibung des Konkreten, der Oberfläche, der äußerlichen Struktur jener Welt und ihrer Ereignisse unweigerlich in die Tiefe führt, dass der dokumentarische Bericht die Fundamente einer mythischen Narration enthüllt. Es ist nämlich die Reflexion über den Tod - denn genau diese wird hier zum übergeordneten Thema -, welche den Quellen der Kultur zugrunde liegt.

Die literarische Tradition, von den Verstorbenen, vom Tod und vom Sterben $\mathrm{zu}$ sprechen, ist eine lange und reiche Tradition. Man denke nur an die klassischen Gattungen der Begräbnis- und Trauerliteratur wie Epicedium, Epitaphium oder Threnus und auch Nekrolog. Gemeinsam ist ihnen, dass sie das Gedenken an eine bestimmte Person aufrechterhalten sowie Trauer ausdrücken sollen, allerdings mit dem Ziel, Trost zu spenden. Fest steht, dass die konventionalisierten Formen, über einen Verstorbenen zu sprechen, diesen vor der Vergessenheit bewahren und den Hinterbliebenen ein wenig Linderung bringen sollen. Der Nachruf oder Nekrolog stellt den Verstorbenen vor, den Lauf seines Lebens und seine Errungenschaften. Kurze Todesanzeigen halten sich meist an eingeschliffene Formeln, längere Artikel hingegen bieten Platz für eine umfangreichere, ausgewogene Präsentation oder auch persönliche Erinnerungen. Beim klassischen Epitaphium gaben es die Gattungsregeln vor, dass zunächst Name und Alter des Verstorbenen genannt wurden und anschließend dann seine guten Seiten, worauf Trost spendende Worte folgten. Trostworte waren nämlich ein festes und unerlässliches Element der Begräbnisliteratur. Epicedien bestanden 
in der Regel aus drei Teilen: lamentio bzw. comploratio (Klage), laudatio (Lob) und consolatio (Trost). So wird der Tod in eine kulturell festgelegte Ausdrucksform gebracht und dadurch fassbar, erträglich. Der Zerstörung, die er verursacht, werden unzerstörbare Werte entgegengestellt. Die consolatio soll Schmerz und Trauer lindern, beruhigen und Hoffnung spenden; die ins Wanken geratene Harmonie des Seins soll ins Gleichgewicht gebracht werden.

Die analysierten Darstellungen, die als spezielle Art von Nekrolog angesehen werden können, zeigen das Bemühen, die Todeserfahrung in mehr oder weniger traditionelle Formeln zu bringen. Daraus speist sich auch das in manchen Schilderungen sichtbare Bestreben, den Moment des Todes zu individualisieren, eigene Charakterzüge des Verstorbenen zu erfassen und zu verewigen, wenigsten die Spur eines Begräbnisrituals zu verzeichnen, eine eschatologische Perspektive zu zeichnen. Die Besonderheit der Ghettonekrologe besteht jedoch im starken Spannungsverhältnis zwischen dem Bild des individuellen und dem Bild des massenhaften Todes. Der Verfasser eines solchen Nekrologs sieht sich fassungslos einer anonymen Menge von Toten gegenüber. Diese Art von Tod steht außerhalb jeglicher bisheriger Erfahrung, außerhalb der Grenzen jeglichen Begreifens, außerhalb der Sphäre erprobter Ausdrucksmittel. Er lässt keinen Raum für Trost, birgt keinen Sinn, eröffnet keine Hoffnung.

Aber lässt er sich nicht doch auf irgendeine Art aneignen, erfassen, in universale Vorstellungswelten und in die Sprache der kulturellen Symbole eingliedern?

Die Realität des Ghettos erweist sich als Verkörperung der Vorstellungen, die die Kunst des Makabren mittels einer bildhaften und symbolischen Sprache ausdrückt. Was aus Ikonographie und Literatur bekannt ist, sprengt den Rahmen von Bild, Skulptur, symbolischer Darstellung und ereignet sich nun tatsächlich. Die makabre Vision materialisiert sich, wird wahr - so als hätten sich die Grenzen zwischen Alptraum und Wachzustand, zwischen außerhalb der Geschichte verharrendem, jetzt ewigem Mythos und aktuell durchlebter Wirklichkeit verwischt. Als habe sich in der Ghettorealität ein Spalt aufgetan und - wie bei den Kettfäden eines Wandteppichs - das geheime Knüpfmuster jener Welt, des Gegenstands der Erfahrung, freigegeben.

$\mathrm{Zu}$ den Dantischen Motiven, die kulturell verankerte Vorstellungen von Hölle und Jenseits in Gang setzen, geleiten uns nicht nur die direkten Hinweise mancher Autoren, die ihre Darstellungen in jene Tradition stellen und sie in infernalen Kategorien interpretieren. Davon spricht in ausreichender Weise auch der Inhalt jener Bilder, die das dokumentarische Element der Berichterstattung darstellen, eine textuelle Photographie der Realität, und die zugleich ein bestimmtes archetypisches Muster bilden. Sie nehmen die Gestalt von apokalyptischen Visionen an, von in der Kultur wurzelnden, sprachlich ausgedrückten Symbolen, 
die unter der Oberfläche wechselnder Dinge und Ereignisse die unveränderliche Realität eines Mythos zutage treten lassen. Eines Mythos, der im Sinne von Paul Ricœurs Hermeneutik verstanden wird als ein „überlieferte[r] Bericht, bezogen auf Ereignisse, die sich am Ursprung der Zeiten zugetragen haben, und dazu bestimmt, das rituelle Tun der jetzt von ihm angesprochenen Menschen zu untergründen und überhaupt alle Formen des Tuns und Denkens zu regeln, durch welche der Mensch sich selbst in seiner Welt versteht." Ein solcherart begriffener Mythos, schreibt Ricœur weiter, helfe dank seiner "Symbolfunktion“, also seines Vermögens, „die Bindung des Menschen an das ihm Heilige zu entdecken, zu entschleiern“, beim Verstehen der elementaren menschlichen Erfahrungen $^{211}$. Die Lektüre der erhaltenen Holocaustzeugnisse im vorliegenden Text ist eben ein solcher Versuch, die darin verzeichnete Erfahrung dieser Vernichtung zu verstehen.

Einschneidende Erlebnisse von Seuchen, Kriegen und Gewalt, die in großem Umfang Schrecken, Tod, Leid verbreiten und sich in der Geschichte stets wiederholen, stellen den Menschen vor eine Endsituation, die er mittels einer speziellen Sprache der Symbole beschreibt. Zweifellos müsste eine der Quellen möglicher Ausdrucksmittel der Holocausterfahrung in ebendiesem Vorstellungsbereich anzusiedeln sein. Die in fieberhafter Eile niedergeschriebenen und in persönlichen Dokumenten festgehaltenen Aufzeichnungen aus jener Zeit verwenden in gewissem Sinne eine ähnliche Symbolik. Die immer wieder in den analysierten Dokumenten vorkommenden Bilder - Massen ineinander verknäuelter Körper, Stapel von Leichen, Tote und Lebende eng zusammengepfercht, ein einziger Haufen, der ins „Jenseits“ befördert werden soll - offenbaren die mythische Vision einer verdammten Erde. Forscher meinen zum Beispiel, hinter Hieronymus Bosch' visionärer Welt, die die Erde als Hölle darstellt, verberge sich „dasselbe Verhältnis zu einem allgegenwärtigen Tod, der jedes Leben, jede Hoffnung lähmt und den Kern der Seuchenerfahrung ausmacht ${ }^{\text {“212 }}$. In einigen der hier zitierten Texte scheint es ähnlich zu sein. Die von Augenzeugen gezeichneten Blicke aufs Ghetto dokumentieren die dortige Wirklichkeit und geben zugleich einer Erfahrung Gestalt, die weit über das gegenwärtige Erlebte hinausgeht, indem sie sie in einer mythischen Dimension ansiedeln, in der Dimension archetypischen Erlebens.

211 P. Ricœur: Die Symbolik des Bösen, dt. Übers. von M. Otto, Freiburg, München 2002, S. 11.

212 M. Sznajderman: Zaraza, op. cit., S. 27. 
Ein Erleben dieser Art stellt das uralte Motiv der Reise ins Jenseits dar. In seiner hochinteressanten Studie, die ikonographische, vor allem aber literarische eschatologische Darstellungen im Mittelalter rekonstruiert, betont Aaron J. Gurjewitsch, Dantes Göttliche Komödie sei als Krönung einer langen Tradition erschienen und bediene sich eines bereits voll ausgestalteten Kanons, in dessen Mittelpunkt die Figur der Wanderung außerhalb des Grabes stehe. Um sie herum entwickle sich ein eigener Blick über das Grab hinaus ${ }^{213}$.

Die Darstellung der Hölle - in ihrer im Laufe der Jahrhunderte kulturell ausgeformten Gestalt - ist ohne Zweifel eine der Figuren des Holocaust. Ähnlich sieht die Sache wohl mit der Kategorie des Grotesken in der Ghettowelt aus. Vielleicht kann ja gerade die Formel der Groteske, bei der sich höllisches Grauen und satanisches Gelächter vermengen, die radikale Fremdheit der Holocausterfahrung vermitteln? Wenn der Holocaust ein Fenster zur anderen Seite des Seins ist, ein Fenster, das enthüllt, was anders nicht erkennbar wäre ${ }^{214}$, vielleicht ist dann gerade die Formel der Groteske in der Lage, diesem ungeheuerlichen Geheimnis eine Gestalt zu geben, die infolge einer langjährigen Tradition von Ausdrucksformen und kulturellen Zeichen bereits vertraut ist - und daher auch kommunizierbar -, eine Gestalt, die eine verständliche Botschaft vermittelt.

Zum Schluss möchte ich noch eine grundlegende Einschränkung wiederholen: Die hier geäußerten Urteile beziehen sich einzig auf die Arten, wie der Holocaust in Worte gefasst wird, und auf die Ausdrucksmittel bei diesen Versuchen - keinesfalls jedoch sind sie Feststellungen über das Wesen des damals Geschehenen. Mit Mutmaßungen über den Sinn des Holocaust möchte ich mich strikt zurückhalten. Ich interpretiere somit - das muss ich ausdrücklich betonen - nicht die dargestellten EREIGNisse selbst, sondern die DARSTELLung der Ereignisse, ihre textuelle Wiedergabe.

\section{Der religiöse Diskurs}

Bei den verschiedenartigen Stimmen in den überlieferten Ghettotexten lässt sich ein intern sehr vielfältiger Diskursbereich von religiösem Charakter ausmachen. Der Schwerpunkt bei jenen Texten ist von einer Schilderung der Welt auf deren Interpretation und Bewertung verlagert. Dem Autor liegt hier nicht so sehr daran, die Spuren der ihn umgebenden Wirklichkeit festzuhalten und deren sozusagen - äußeres Erscheinungsbild vor der Vergessenheit zu bewahren. Eher

213 A. Gurjewitsch: „ «Die göttliche Komödie» vor Dante“, op. cit.

214 Die Metapher des Holocaust als Fenster, das den Blick auf eine besondere Erfahrung freigibt, formulierte Prof. Zygmunt Bauman in einem privaten Gespräch. 
will er in die Tiefe der Ereignisse vordringen, die sich vor seinen Augen abspielen, und einen verborgenen Sinn und Zweck darin ausfindig machen. Um dort Sinn zu finden, wo der Verstand passen muss, weil die Intensität des Grauens, der Brutalität und des Sinnlos-Absurden jedes menschliche Maß übersteigt, verlegt der Autor sich auf die Sphäre des Übernatürlichen. Es geht ihm nicht so sehr um die Dokumentation von Phänomenen wie um die Aufdeckung von deren geistiger Dimension und die Übermittlung einer von ihnen ausgehenden moralischen Lehre - vor allem aber will er ein Glaubenszeugnis abgeben. Nicht der menschliche Verstand soll nämlich die Welt erklären, sondern der Glaube, der grundlegende Wahrheiten über die Beziehung Gottes zum Menschen und über die göttlichen Absichten hinsichtlich der Schöpfung offenbart. Ausgehend von der übergeordneten Erfahrung des Sacrum fördert der Autor aus dem Chaos der Katastrophe eine höhere Ordnung zutage, setzt aus Splittern und Scherben ein Ganzes zusammen, das sich mit einem Akt des Glaubens erfassen lässt. Der religiöse Diskurs verlässt also den Bereich der beobachtbaren Wirklichkeit, stellt eine transzendente Ordnung von Bedeutungen und Werten her. In ebendieser Ordnung sucht er die Quellen zum Verständnis dessen, was hier und jetzt geschieht.

Einleitung zu diesen Erörterungen soll eine Analyse von Aufzeichnungen über Glauben und Frömmigkeit im besetzten Warschau und anderen jüdischen Ballungszentren sein. Dabei gehe ich von Zeugnissen religiösen Brauchtums aus der damaligen Zeit über Reflexionen zum Gebet bis hin zur Charakterisierung dreier Diskurstypen: der Klagelieder Karol Rotgebers, des Martyrologiums von Szymon Huberband und der Predigten von Rabbi Klonimus Kelmisz Szapiro [Kelman Kalonimus Szapiro; Kalonymus Kalman Shapira].

\section{Das religiöse Leben während der Besatzung}

1

Historiker, die sich mit dem besetzten Warschau befassen, weisen auf die Vielfalt der Formen repressiver Handlungen der deutschen Besatzer gegenüber den beiden größten Glaubensgemeinschaften - Katholiken und Anhängern des jüdischen Glaubens ${ }^{215}$ - hin.

215 Siehe T. Szarota: Okupowanej Warszawy dzień powszedni [Der Werktag des besetzten Warschau], Warschau 1988, S. 468-471; K. Dunin-Wąsowicz: Warszawa w latach 1939-1945 [Warschau in den Jahren 1939-1945], Warschau 1984, S. 186-191; W. Bartoszewski: 1859 dni Warszawy [1859 Tage Warschaus], Krakau 1974; hier sind zahlreiche Beispiele für den konkreten Ausdruck von Religiosität in der Besatzungszeit 
Der Besatzer gestattete offiziell das innerhalb der römisch-katholischen Kirche organisierte religiöse Leben, vermehrte jedoch Beschränkungen und Verbote. Es wurde beispielsweise verboten, kirchliche Feiertage zu begehen, wenn sie auf Werktage fielen, nicht gestattet waren außerdem Prozessionen auf Straßen oder die Feierlichkeiten zum 3. Mai [Tag der Verfassung; Anm. d. Übers.], 15. August [Mariä Himmelfahrt], 11. November [polnischer Unabhängigkeitstag]. Die Eingriffe der deutschen Behörden waren oftmals äußerst pingelig und betrafen die Form, in der religiöse Bräuche oder sogar Gottesdienste abliefen. Es herrschte beispielsweise das Verbot, zu Ostern Feuerwerke zu entzünden; Mitte Januar 1941 wurde mittels einer speziellen Verordnung untersagt, in den Kirchen das Lied Boże, coś Polskę [Gott, der Du Polen; auch bezeichnet als eine Art „Zweite Nationalhymne“ Polens; Anm. d. Übers.] und das Marienlied Serdeczna Matko [Maria Herzensmutter] ${ }^{216}$ zu singen, und im Mai 1942 forderte der Besatzer von der Warschauer Erzdiözese die Zensur einer Litanei an die Muttergottes: die Streichung der Fürbitte „Królowo Korony Polskiej, módl się za nami“ [Königin der Polnischen Krone, bete für uns] ${ }^{217}$.

Das Vorgehen der Besatzungsmacht gegen die religiösen Institutionen und die Gemeinschaft der Anhänger mosaischen Glaubens hatten ein anderes Ausmaß und einen anderen Kontext. Repressionen und die Eskalation der Gewalt bis zur „Endlösung der Judenfrage“ stellten eine notwendige Etappe bei der Realisierung der nationalsozialistischen Weltsicht dar, in der der Antisemitismus eine Schlüsselrolle spielte. Außer dem rassistischen hatte dieser Antisemitismus einen deutlichen - wenn auch vielleicht nicht direkt ausgedrückten - antijudaistischen Charakter, scheint es doch, als habe sich der Schlag nicht nur gegen die Juden an sich, sondern auch gegen das transzendente Fundament jenes Volkes gerichtet: gegen dessen Bündnis mit Gott. Der Krieg gegen die Juden nahm in manchen seiner Ausprägungen, in der Symbolik der Verhaltens der Mörder somit die Form eines Religionskrieges oder gar eines Krieges gegen Gott und dessen auserwähltes Volk an ${ }^{218}$.

angegeben. Zu den zwei Strömungen des religiösen Lebens im Ghetto siehe R. Sakowska: Ludzie z dzielnicy zamkniętej, op. cit., S. 133-140.

216 Siehe K. Gorzkowski: Kroniki Andrzeja. Zapiski zpodziemia 1939-1941 [Die Chroniken des Andrzej. Aufzeichnungen 1939-1941], bearb. v. T. Szarota, Warschau 1989, S. 121.

217 Siehe T. Szarota: Okupowanej Warszawy dzień powszedni, op. cit., S. 468-469.

218 Ein klassischer Ausdruck dieser Konzeption ist ein Essay von G. Steiner: „Un saison en enfer", in: ders.: In Blaubarts Burg - Anmerkungen zur Neudefinition der Kultur, dt. Übers. von F. Polakovics, Berlin 1972, S. 35-64. In Polen wurde der Holocaust von R. 
Die an den Juden verübten Gewalttaten trugen schon ab den ersten Kriegstagen häufig die Merkmale religiöser Verfolgung. Eine Chronik dieser Verfolgungen und zugleich ein vielschichtiges Panoramabild des jüdischen religiösen Lebens während der Besatzung Polens durch die Nazis - lässt sich in Rabbi Szymon Huberbands Schriften finden ${ }^{219}$.

Opfer sadistischer Übergriffe wurden zumeist orthodoxe Juden, die durch ihre besondere Kleidung und ihr Aussehen auffielen. Der Tortur des Bartabschneidens gut bekannt von vielen erhaltenen Fotos - widmet Huberband eine ganze Arbeit mit dem Titel Brody [Bärte]. Er notiert darin raffinierte Methoden, mit denen die Deutschen bärtige Juden peinigten: von den Opfern selbst zu zahlende Zwangsrasuren in Friseursalons, das Abschneiden von Bärten mit der Schere, worauf die Opfer gezwungen wurden, das abgeschnittene Barthaar herunterzuschlucken, brutales Bartscheren mit dem Bajonett oder das Ausreißen des Bartes mitsamt der Haut, ja selbst das Abbrennen von Bärten. Jene Art der Verfolgung interpretiert der Autor ganz eindeutig:

Die Intention [der Deutschen] bestand darin, die religiösen Gefühle frommer Juden auszumerzen; diesem Zweck diente auch das Niederbrennen von Synagogen, das Zerschneiden der Bücher der Tora, die Verwüstung von Friedhöfen (S. 188).

Mehrmals liest man bei Huberband von der systematischen Zerstörung von Orten und Gegenständen jüdischen religiösen Brauchtums. Bilder von brennenden Synagogen und einer entweihten Tora, deren zerrissene Rollen Nahrung für die Flammen werden oder auf dem Erdboden vom Regen durchnässen, kehren häufig wieder. Zahlreich sind auch die Schilderungen von Juden, die zur Schändung ihrer Tallitot [Gebetsmäntel], Tefillin [Gebetsriemen] oder heiligen Bücher gezwungen werden. Der Autor beschreibt des Weiteren empfindliche Schikanen gegen Gläubige, z.B. das im ganzen Generalgouvernement geltende Verbot ritueller Schlachtungen ${ }^{220}$. Die körperlich misshandelten und erniedrigten Juden

Śpiewak in ähnlicher Richtung interpretiert: „Szoah, drugi upadek“ [Die Schoa, der zweite Niedergang], in: „Więźc 1986, Nr. 7-8.

219 Genaueres zu Huberband und seinen Schriften siehe Kapitel „Das Martyrologium des Rabbi Szymon Huberband“.

220 Das Verbot der Schächtung (Schechita) war einer der ersten rechtlichen Akte der deutschen Besatzer. Er wurde am 26. Oktober 1939 erlassen, also genau in dem Moment, als in den nicht dem Deutschen Reich zugeteilten polnischen Gebieten die Militärverwaltung endete und das Generalgouvernement ins Leben gerufen wurde. Es blieb also nur noch die illegale Schächtung. Die Schächter (Schochtim) führten die Schlachtung an geheim gehaltenen Orten durch (in Bródno, Pelcowizna, Otwock), von wo aus das koschere Fleisch dann ins Ghetto geschmuggelt wurde. Der Schächter erhielt für 
wurden als Bekenner des Judaismus zum Gegenstand des Hohns. Es wiederholen sich Berichte über Repressionen und Torturen, die um jüdische Feiertage herum ihren Gipfel erreichten. Die Nazis passten nämlich ihren eigenen Kalender der Repressionen und Verbrechen häufig an den jüdischen liturgischen Kalender an. Ringelblum notiert:

Tag des Gerichts, 22. September 1942. Tag der Selektion. Frauen, Kinder, Illegale werden dahingeschlachtet. Es gilt die Vorhersage, derzufolge sich am Tag des Gerichts stets etwas ereignet: im ersten Jahr (1939) - die Bombardierung des jüdischen Bezirks in Warschau; 1940 - die Eröffnung des Ghettos; 1941 - die Deportation der Sienna-Straße. Es ist bereits Tradition, dass den Juden in den Städten am Tag des Gerichts Schlimmes zugefügt wird (I, S. 405) 221 .

Was die Juden in Warschau betraf, so führten die Deutschen Anfang 1940 ein Verbot des gemeinsamen Betens in Synagogen und Privatwohnungen ein. Unter dem Datum des 5. Januar 1940 notiert Czerniaków, es sei ihm befohlen worden, „das Bethaus, die Synagogen und Mikwess zu schließen“ (S. 31). Nicht alle hielten sich an diesen Befehl, es entstanden illegale Bethäuser, wofür der Gemeindevorsitzende eine Ermahnung von den Polizeibehörden bekam. „Man rief mich zur Gestapo“, schreibt Czerniaków am 30. Oktober 1940. „Wie Mende verlautbarte, befindet sich ein illegales Bethaus in der Grzybowska-Str. 11 Whg. 79 - Rabbi Najhaus" (S. 126). Zum Frühjahr 1941 wurde dieses Verbot wieder zurückgenommen, und im Juni erfolgte die feierliche Einweihung der Großen Synagoge an der Tłomackie-Straße, im Herbst desselben Jahres eröffneten zwei weitere Synagogen - in der Twarda-Straße 6 und in der Dzielna-Straße 7. Noch 1939 war die Schließung der Bäder abgeordnet worden, wodurch das rituelle Bad unmöglich wurde. Daher tauchten die Menschen nun in die Weichsel

eine Arbeit eine feste Entlohnung (1941 waren das 50 Złoty pro geschächtetem Tier). Huberband bemerkt, dass am Mitte 1941 nicht mehr heimlich geschächtet wurde; aufgrund der immer größer werdenden Hungersnot und Verarmung nahm die Nachfrage ab. Siehe S. Huberband: „The Ritual Slaughter of Polutry“, „The Ritual Slaughter of Cattle“, „Pious Jews and the Problem of Kosher Meat", in: Kiddush Hashem. Jewish Religious and Cultural Life in Poland During the Holocaust, hg. v. J.S. Gurock, R.S. Hirt, New York 1987.

$221 \mathrm{Zu}$ ergänzen ist, dass die Hinrichtungen im Warschauer Ghetto freitagabends stattfanden, wenn der Sabbat begann. Die große Liquidierungsaktion begann am Mittwoch, 22. Juli 1942, am Vorabend des Neunten Tages des Monats Aw [Tischa beAw] - eines Gedenk- und Fastentages zur Erinnerung an die Zerstörung des 1. und des 2. Tempels und an die Vertreibung der Juden aus Spanien. Der Ghettoaufstand brach am Vortag zum Pessachfest aus. 
ein, und wenn es irgend möglich war, fuhr man an andere Orte, beispielsweise nach Rembertów, Falenica oder Pruszków. Auch zu geheimen Bädern gingen die orthodoxen Juden, wofür jedoch drakonische Strafen drohten, bis hin zur Todesstrafe. Huberband schreibt über vier versteckte rituelle Bäder: in der Grzybowska-Straße 1 und 14, in der Dzielna-Straße 38 und der Smocza-Straße 22.222 Auch erzählt er die Geschichte vom Besuch einer geheimen Mikwe, an dem er selbst im Oktober 1940 teilnahm. ${ }^{223}$

Hinter den Ghettomauern befanden sich viele Rabbiner und Zaddikim [Lehrer im Chassidismus; Anm. d. Übers.], die aus den umliegenden Orten hierher umgesiedelt worden waren. Außer Huberband, der aus Piotrków nach Warschau gekommen war, lebte im Ghetto u.a. Rabbi Klonimus Kelmisz Szapiro, ein Zaddik aus Piaseczno. Die Unterschriften von Rabbi Jakub Icchak Landau, Zaddik aus Stryków, und Rabbi Ajdelberg aus Maków stehen unter einer Denkschrift der Schirmherren der Fürsorge für die Leichname armer Juden vom 31. März 1942, in der dem Gemeindevorsitzenden ein Plan für die Organisation von würdigen religiösen Begräbnissen für mittellose Verstorbener vorgeschlagen wird. ${ }^{224} \mathrm{Im}$ August 1941 wurde beim Judenrat die Abteilung für religiöse Angelegenheiten und für das Rabbinat wieder ins Leben gerufen und damit das religiöse Leben im Ghetto in einen öffentlich sichtbaren und offiziellen institutionellen Rahmen gefasst. Jedoch existierte hinter den Mauern - wie Ruta Sakowska betont ${ }^{225}$ auch ein informelles religiöses Leben. Geheime Gemeinschaftsgebete wurden in Privatwohnungen abgehalten, außerdem gab es geheimen Religionsunterricht, versteckte Talmudschulen und Bethäuser. Die orthodoxen Juden bemühten sich trotz aller Hindernisse und Schikanen weiterhin, ihre religiösen Gebote zu befolgen.

222 Siehe S. Huberband: „»Mikvehs« and Jewish Family Purity“, in: ders.: Kiddush Hashem, op. cit.

223 „The Journey to the »Mikveh" at the Beginning of the Year 5701 (October 1940)“, in: Kiddush Hashem. Die Deutschen erteilten die Genehmigung zur Eröffnung zweier Mikwaot, u.a. derjenigen in der Dzielna-Straße 38, in der eine Gruppe deutscher Filmleute, das damals im Ghetto unterwegs war, am 12. Mai 1942 auf der Straße aufgegriffene Passanten zusammentrieb und eine sexuelle Orgie inszenierte. Darauf weist T. Szarota („Getto warszawskie u progu zagłady“, op. cit.) hin und führt einen Eintrag aus dem Tagebuch des Avrom Levin an, wo der Verfasser jene Szene genau beschreibt. Siehe A. Levin, „Biuletyn ŻIH“ 19-20, S. 174-175.

224 Siehe Dokument auf Polnisch, enthalten im zweiten Teil des Ringelblum-Archivs (Ring II, 119).

225 Ludzie z dzielnicy zamkniętej, op. cit., S. 136-137. 
Rabbi Szymon Huberband schildert die Wut, mit denen die Deutschen gegen Bekenner des Judaismus vorgingen, die trotz der drohenden Verfolgung in der frühesten Kriegszeit ihr religiöses Leben aufrechterhielten und Feiertagsrituale begingen. Die Juden sollten mit Gewalt von der Ordnung ihres Sacrum entwöhnt werden. Feiertagsrituale wurden entwürdigt und degradiert, in die Sphäre des Verbotenen und Geächteten verlegt. Gottesdienste und religiöse Rituale mussten versteckt abgehalten werden, unter Terror, häufig in verkürzter und vereinfachter Form, ohne entsprechende Gefäße, Kerzen, Nahrungsmittel. Und allzu oft auch in Einsamkeit, wenn es nicht möglich war, den zum Gebet notwendigen Minjan [das für einen Gottesdienst nötige Quorum; Anm. d. Übers.] einzuladen.

Es gab kein Öl für die Chanukkalampen. Die Menorot [siebenarmigen Leuchter; Anm. d. Übers.] waren verdeckt, man konnte keine Kerzen im Fenster anzünden, wie es das jüdische Gesetz befiehlt, da die Menschen sich fürchteten (S. 55).

Die bedrohlichen Zeiten, die hereingebrochen sind, erinnern ihn an frühere Judenverfolgungen, allerdings, unterstreicht Huberband, nehme sich die Heilige Inquisition im Vergleich mit der Grausamkeit der Deutschen noch recht harmlos aus (S. 46). Die Begleitumstände des Feiertags Simchat Tora (am 3. Oktober 1939) kommentiert Huberband wie folgt: „Wir beteten in einem dunklen fensterlosen Raum. Mir wurde bewusst, dass unsere Lage schlimmer war als die der Marranen [unter Zwang zum Christentum bekehrte Juden; Anm. d. Übers.] in Spanien“ (S. 54). Ähnliche Assoziationen verzeichnet Chaim Aron Kaplan in seinem Tagebuch:

Die Synagogen sind verschlossen, doch in jedem Haus ist ein provisorischer Gebetsraum, in dem der Kantor die Gebete mit seinem Gesang verschönert. Das erinnert bis $\mathrm{zu}$ einem gewissen Grad an die Zeiten der spanischen Inquisition und die Marranen (BŻIH 50, S. 106).

Diese Parallele ist adelnd, schreibt aber zugleich die Jetztzeit mitsamt dem Tagebuchverfasser in ein sich unweigerlich wiederholendes martyrologisches Schema der Geschichte des Volkes ein.

Sowohl Huberbands als auch Kaplans Aufzeichnungen zeigen ein heldenhaftes Bestreben, trotz aller Widrigkeiten die religiösen Vorschriften einzuhalten und die heiligen Bräuche zu erfüllen. Das Verzeichnis der Verfolgungen wird zum Zeugnis einer unverbrüchlichen Frömmigkeit. Kaplan notiert mit Bewunderung, dass die Zeichen eines religiösen Rituals der Wirklichkeit zum Trotz sichtbar sind:

24. April 1940 (der zweite Pessachtag des Jahres 5700, abends). [...] [S]elbst jetzt, in diesem Meer von Leid, feiern wir das Fest der Freiheit, und alle vollziehen das Seder- Ritual. 
[...] Was die Festausstattung angeht, so besitzt selbst der Ärmste etwas Matze. Vor den Feiertagen waren auf den Straßen viele Juden mit Matzepäckchen unter dem Arm zu sehen, dabei drohte ihnen doch eine Anzeige wegen Sabotage. [...] In jedem jüdischen Haus sieht man die Zeichen des Festes (BŻIH 50, S. 105-106).

Die Befolgung traditionellen Brauchtums hält die Identität des Volkes aufrecht, stärkt die Glaubensgemeinschaft. Im Bericht eines anonymen Funktionärs des Ordnungsdienstes verleihen Zeit und Ort jenem Brauchtum einen außergewöhnlichen Charakter. Die Intimität der bewegten Feiertagsstimmung mischt sich mit offiziellem Pomp. Was echt und wahr ist, verflicht sich mit amtlich Verordnetem und Konventionellem. So findet im jüdischen Gefängnis an der GęsiaStraße im Frühjahr 1942 ein feierlicher Sederabend statt, außerdem gibt es ein Ostermahl für Katholiken. Das von oben durch offizielle Institutionen inszenierte Festtagsritual bewegt die Teilnehmer zutiefst, verbindet sie. Die Szenerie im „Gęsiówka“ genannten Gefängnis sowie das Wissen darum, was im Ghetto im Frühjahr 1942 geschieht, bildet einen gespenstischen Kontrast zur gesamten Feierlichkeit. Daher lässt sich beim Lesen des Berichts trotz seiner Authentizität ein hartnäckiger Eindruck der Künstlichkeit nicht vertreiben:

Auf den Fluren hatte man lange Tische aufgestellt [...], und auf den Tischen standen die traditionellen Gerichte: Matze; Eier, bittere Kräuter, ein wenig Wein für jeden Festgast. [...] Bei jedem Tisch verlas ein älterer Häftling eine Haggada: die Geschichte des Auszugs der Juden aus Ägypten. [...] Auf den nächsten Tag fiel das katholische Osterfest, andere Funktionäre teilten sich mit anderen Häftlingen im Beisein eines Priesters geweihte Speisen. Bei den Gebeten, bei dem, was in den Gebetspausen gesagt wurde, schwang [...] der Traum von der Freiheit mit; hier jedoch, im Zentralarrest für den Jüdischen Bezirk, an Ostern 1942 trat jene ungewöhnliche Variante eines allgemeinen Phänomens ein, dass Gefängniswärtern, Offizieren, Damen und Herren vom Patronat dieselbe Sehnsucht aus den Augen leuchtete und in den Worten mitschwang (N.N. „Pamiętniki“, Sign. 129, S. 70).

Der Bericht über das Osterfest, das Juden und Christen im Gefängnis an der Gęsia-Straße feierten, offenbart die Existenz zweier Strömungen des religiösen Lebens im Ghetto. Aufgrund der Rassenkriterien der Nazis befanden sich nur sehr wenige Menschen römisch-katholischen, evangelischen oder christlichorthodoxen Glaubens innerhalb der Mauern des geschlossenen Bezirks. Eine kleine Gruppe Juden hatte sich erst zur Besatzungszeit taufen lassen. Bis zur Zeit der Deportationen im Juli 1942 waren innerhalb des ummauerten Gebietes die Kirche der Allerheiligsten Jungfrau Maria an der Leszno-Straße und die Allerheiligenkirche am Grzybowski-Platz in Betrieb. Die wenigen Juden aus konvertierten Familien trugen Armbinden mit Davidsstern und kultivierten zugleich ihre christliche Frömmigkeit und Lebensart. Sie stellten, wenn auch keine zahlreiche, 
so doch eine auffällige Gruppe dar. Meistens zählten sie zur intellektuellen Elite, standen unter der Fürsorge der kirchlichen Caritas, ihrer Familien und Bekannten von der arischen Seite. Auch bekleideten sie häufig exponierte Ämter in der Ghettoverwaltung und wurden von der jüdischen Gemeinde bevorzugt behandelt. 226

In weiten Kreisen des Ghettos wurden getaufte Juden eher unwillig oder sogar feindlich betrachtet. Mit ironischer Distanz und leichtem Spott stellt Emanuel Ringelblum sie vor:

In der Allerheiligenkirche am Grzybowski-Platz und in der Kirche der Allerheiligsten Jungfrau Maria an der Leszno-Straße fanden katholische Gottesdienste statt, zelebriert von Neophyten-Geistlichen und begleitet von Gesängen von Neophyten-Chören. In jenen Kirchen konnte man wahrhaft gläubige Menschen sehen. Frömmlerinnen lagen platt auf dem Boden und beteten eifrig. Die Verstorbenen karrte man im kircheneigenen Leichenwagen auf den katholischen oder evangelischen Friedhof, ihre Familie durfte nur bis zum Ghettotor mitgehen (Bd. 2, S. 149).

Vollkommen anders beschreibt Jechiel Górny in seinem Tagebuch die Atmosphäre in der Kirche an der Leszno-Straße am Sonntag, dem 14. Juni 1942 ohne jede Boshaftigkeit, mit unverhohlener Sympathie und Empathie für die Teilnehmer der Feier. Die ganze Szene atmet Ruhe und nostalgische Schönheit, ganz als befände sich der Kirchgarten nicht im Ghetto, in dem bereits in wenigen Wochen die große Liquidierungsaktion beginnen soll.

Durch das offene Fenster dringen Orgelklänge. Eben findet in der Kirche an der LesznoStraße der feierliche Gottesdienst statt (der Kirchgarten grenzt an mein Haus - Nowolipie-Straße 23). [...] Gruppen festlich gekleideter Menschen spazieren umher, die Männer in dunklen Anzügen, die Damen in eleganten Sommerkleidern, unter ihnen eine hochgewachsene Gestalt in schwarzer Soutane. Sie unterhalten sich angeregt, bis plötzlich alles verstummt, um kurz darauf, zu den Klängen der Orgel, die Stimmen in einem wundervollen Chor emporschwingen zu lassen. Leise, dann immer lauter steigen die Töne eines Kirchenliedes in die Lüfte. [...] [Die Gläubigen] haben weithin sichtbare $[\ldots]$ weiße Armbinden mit dem Zionsstern, wie weiße Flicken, an ihrem rechten Oberarm. Weil das Schicksal es so wollte, sind die, [...] die aus verschiedenen Gründen die Juden verworfen haben, von den Barbaren des 20. Jahrhunderts wieder dorthin

226 In den Erinnerungen eines unbekannten Autors, eines Juristen aus Włocławek und höheren Funktionärs des Ordnungsdienstes, ist zu lesen, dass Polentum und Katholizismus - d.h. der Grad der Assimilierung, der Glaubenswechsel und der Status eines Kriegsveteranen - favorisiert worden seien (N.N. „Pamiętniki“, Sign. 129). Ringelblum schreibt: „Es ist so weit gekommen, dass man sich, wenn man bei einigen Abteilungen der jüdischen Gemeinde Beamter werden will, als Raufbold ausweisen muss" (Bd. 2, S. 149). 
zurückversetzt worden, wo sie herkamen. Viele von ihnen, besonders die jungen, wussten nicht einmal, dass ihre Vorfahren Juden gewesen waren [...]. Das scheint heute eine größere Feierlichkeit in der Kirche an der Leszno-Straße zu sein. Wohl eine Hochzeit [...]. Es verstummen die Klänge des Kirchenliedes und leise, kaum hörbar erklingt in der Stille des Juniabends das halblaut gesungene Lied Boże, coś Polskę. ${ }^{227}$

Nur wenig mehr als drei Monate nach jener Abendmesse war die Leszno-Straße bereits wieder arisch. In das verkleinerte Ghetto drängten Geflohene aus Treblinka, um denjenigen, die bis jetzt überlebt haben, die Nachricht von der wahren Bestimmung der Züge vom Umschlagplatz zu überbringen. Doch selbst dann reißen die Gebete nicht ab. Ein Eintrag aus Avrom Levins Tagebuch:

Montag, 21. September, Tag des Gerichts (Jom Kippur) [1942], [ein Flüchtling aus Treblinka] erzählt schlimme, erschütternde Geschichten. [...] Eine so allumfassende Tragödie hat unser Volk in seiner gesamten Geschichte noch nicht erlitten. Hinten im Hof beten einige Juden, sie offenbaren ihre schmerzerfüllten Herzen vor dem Ewigen (BŻIH 22, S. 104).

Am Tag des Gerichts - dem Tag der Deportationen - fanden die Gebete selbst auf dem Umschlagplatz statt. Noemi Szac-Wajnkranc beschreibt diese Szene:

Die letzten Gruppen gingen zu den Waggons, die beladenen Waggons fuhren ab. Wir atmen erleichtert auf. Eine Nacht Leben, doch morgen früh kommen andere, leere Züge - um neue Ware abzuholen. [...] Gesang ertönt, eine eigentümliche Melodie! Ich schaue hin und traue meinen Augen nicht: Juden holen ihre Tallitot hervor (von denen sie sich niemals trennen) und beten so, in diesen weißen Gewändern, beugen die gepeinigten Rücken, strecken flehend ihre Hände aus. Heute ist der Tag des Gerichts. Könnte es etwas Makabreres geben? Dunkel, Regen, Ächzen, weiße Gestalten, vielstimmiges Beten, Gesang zum Hall von Schüssen. Jahwe, schau auf Deine Kinder, wir rufen Dich (S. 29).

Im April 1943 saß Marian Berland in einem Versteck, in dem sich verschreckte Menschen drängten. Der Ghettoaufstand war in vollem Gange, die umstehenden Häuser brannten, die Schüsse, die Zerstörung, das Töten nahmen kein Ende. So sah die Szenerie in der allerhöchsten Todesgefahr, in articulo mortis aus:

Ein paar Alte sitzen da und beten inbrünstig. Sie sprechen die Psalmen Davids. So vertieft sind sie in ihr Gebet, dass sie gar nicht bemerken, was um sie herum geschieht (S. 15).

An dieser Stelle lohnt ein Blick in das Tagebuch der Ursulinenschwester Maria Teodozja Hoffman, die in der ersten Augusthälfte 1944 über einen

227 Zitat nach: R. Sakowska: Ludzie z dzielnicy zamkniętej, op. cit., S. 139-140. 
Sonntagmorgen im Versteck an der Przejazd-Straße 5 berichtet. Dieses Haus stand an der Grenze des damals bereits nicht mehr vorhandenen Ghettos.

Die Brände mehren sich. Bombardements und Schießereien gehen die ganze Nacht hindurch. Wir beten laut und im Stillen. Die Menschen im Versteck sind bleich, voller Todesangst. [...] Dicht gedrängt, Kopf an Kopf - manche weinen, manche fluchen, andere beruhigen sie. Ungefähr um 6 Uhr morgens reicht uns ein Kaplan die Hl. Kommunion, später wird im Versteck eine Hl. Messe abgehalten, denn es ist Sonntag. ${ }^{228}$

Die Berichte von Berland aus dem Warschauer Ghetto und von Schwester Hoffman aus dem Warschauer Aufstand sind, wenn auch innerhalb unterschiedlicher Glaubenstraditionen geformt, im Grunde Zeugnisse ein- und derselben Erfahrung: des Ausdrucks der religiösen Natur des Menschen und einer die Gemeinschaft stärkenden liturgischen Handlung in einer Situation äußerster Bedrohung.

\section{2}

Aufzeichnungen über verschiedene Formen von Gläubigkeit, über Arten und Umstände des Gebets dokumentieren das geistliche Leben. Doch sogar wenn sie Gebetsformeln angeben, bleiben sie doch immer außerhalb; sie registrieren nur das äußere Erscheinungsbild dessen, was das Wesen des Gebets ausmacht: das Band zwischen Mensch und Gott, das in einem besonderen sprachlichen Akt Ausdruck findet. Selbst wenn das Gebet narrative Elemente enthält, sagt es weniger über die Gott-Mensch-Beziehung aus als es diese Beziehung realisiert. Außerdem hat es liturgischen Charakter, das heißt, es hat nicht nur einen traditionell bestimmten Platz und eine traditionell bestimmte Funktion in der Ausübung religiöser Bräuche, sondern auch ein im Laufe von Jahrhunderten gefestigtes Muster der textuellen Organisation. Ich möchte daher nun zur Gebetsanalyse kommen.

Ein auf Jiddisch verfasstes Dokument, das im zweiten Teil des RingelblumArchivs gefunden wurde, enthält einen Gebetstext, der im Dezember 1942 von einer Gruppe Rabbiner und im religiösen Bereich tätiger Menschen verfasst wurde. Unter ihnen war auch Rabbi Klonimus Kelmisz Szapiro, dessen Schriften aus dem Ghetto ich noch gesondert besprechen werde. Das Gebet entstand in der kurzen Zeitspanne zwischen der ersten und zweiten Liquidierungsaktion

228 Zitat nach: Ludność cywilna w powstaniu warszawskim. Pamiętniki. Relacje. Zeznania [Die Zivilbevölkerung im Warschauer Aufstand. Tagebücher. Berichte. Aussagen], Bd. 1, T. 1, bearb. v. M. M. Drozdowski, M. Maniakówna, T. Strzembosz, Warschau 1974, S. 248. 
und dem Ghettoaufstand. Es sollte für die Menschen gesprochen werden, die bei der Großaktion von Juli bis September deportiert wurden; seine Bestimmung wird durch folgende Inskription verdeutlicht: „Ein Gebet - eigens für die derzeitige Situation“" („Modlitwa“ [Gebet], 332).

Angesichts der Vernichtung, angesichts des allgegenwärtigen Chaos und Zerfalls der Welt bestärkt das Gebet der Rabbiner den Glauben daran, dass das Bündnis des Volkes Israel mit Gott weiterhin stabil und unverändert bestehe. Das derzeitige Unglück gliedert sich in die lange Reihe von schlimmen Geschehnissen in der Geschichte des auserwählten Volkes ein, wobei das erfahrene Leid eine Aneignung erfährt, indem es in Bezug zum gesamten Paradigma des Leidens gesetzt wird. In der derzeitigen Situation erneuere sich somit lediglich ein uraltes Muster. Die Rabbiner nehmen in ihrem Gebet das schicksalhafte Erbe ihres Volkes sowie das Erbe der von vielen Generationen erarbeiteten religiösen Formeln zum Umgang mit jenem Schicksal an.

Vor dem eigentlichen Gebet empfehlen die Verfasser die Lektüre der Psalmen 94 und 42. Diese gehören zur Gruppe der Klagepsalmen, in denen ein Einzelner oder eine Gemeinschaft von Menschen, denen Unglück widerfährt, klagen und Gott um Hilfe anrufen. Das Unheil ist so groß und unbegreiflich, Gott erscheint so fern und so stumm, dass das Gebet zur Herausforderung für den Glauben wird. Überwunden wird der Zweifel schließlich in einem Akt grenzenlosen Vertrauens und Glaubens. Die Psalmen schließen auch die gegenwärtige Situation - die drohenden Verfolgungen, den vergeblichen Ruf um Hilfe, die Verlassenheit - in die Klageformel mit ein.

Die Psalmen bilden den entsprechenden Kontext für die Worte des Gebets: Es ist die Erneuerung der Klage aus den Psalmen, stellt ein Kontinuum zwischen dem biblischen und dem Ghettotext her. Der Gegenstand des Gebets ist derselbe („die Generation Abrahams, Isaaks und Jakobs“), der Hilferuf ist derselbe, gleich geblieben sind auch das feste Vertrauen in Gott und die Überzeugung vom weiterbestehenden Bündnis.

Herrscher des Alls! Herr der Welt! Höre unser Weinen und die Seufzer unseres Herzens - sieh unser Leiden und unsere Qual - und hilf uns in dieser großen Not. Ihr Nachkommen Abrahams, Isaaks und Jakobs - wir werden verfolgt, bekämpft und zur Schlachtbank getrieben wie die Schafe. Dein Wille geschehe, Guter Gott, auf dass Du uns schützest vor allem Unheil und jegliches Böse, jegliche Grausamkeit des Feindes vernichtest („Modlitwa“, 322).

Die Phrase „wir werden verfolgt, bekämpft und zur Schlachtbank getrieben wie die Schafe" und verschiedenste Varianten davon erscheinen in vielen Ghettotexten; nach dem Krieg sollen sie zu einer weit verbreiteten Bezeichnung für 
die Massenvernichtung der Juden werden - oder eher für deren Passivität ihren Mördern gegenüber. Hier ist nicht der Ort für eine breitere Analyse dieser Problematik oder der Art und Weise, in der die Formulierung „wie Lämmer/Schafe/ Vieh zur Schlachtbank gehen“ in den überlieferten Erinnerungen und in der historischen Publizistik verwendet wird. Es lässt sich lediglich feststellen, dass diese Formulierung fast immer eine mehr oder weniger pejorative Färbung aufweist. Eingesetzt wird sie zum Ausdruck einer tragischen Selbstanklage, wenn der Schreibende sich mit den zur Schlachtbank geführten Massen identifiziert ${ }^{229}$, auch in Fragen, die gestellt werden, während der Holocaust noch andauert, taucht sie zur Herstellung eines rhetorischen Pathos auf ${ }^{230}$, um schließlich zum Zeichen für eine unwürdige Haltung zu werden, zur Formel für einen schändlichen und sinnlosen Tod. ${ }^{231}$

Im Gebet der Rabbiner bezieht sich die Formulierung von den zur Schlachtbank getriebenen Schafen auf die Realien des Warschauer Ghettos im Jahr 1942. Doch auch hier nimmt sie eine zusätzliche Dimension an. In den Kontext eines Gebets gesetzt, gestattet sie es, die Situation des massenweise hingerichteten Volkes in biblische Kategorien zu fassen, mit der Sprache des Propheten Jesaja darüber zu sprechen. Im Buch Jesaja nämlich ist von einem Knecht des Herrn zu lesen, der „bedrängt und misshandelt“ wird; jedoch „wie ein Lamm, das man zum Schlachten führt, und wie ein Schaf vor seinen Scherern verstummt, so tat auch er seinen Mund nicht auf. [...] Er wurde vom Land der Lebenden abgeschnitten und wegen der Vergehen meines Volkes zu Tode getroffen“ (Jesaja 53,7-8). Diese - wie häufig in der rabbinischen Literatur - nicht direkt

229 „Trugen wir denn irgendwelche Schuld daran? Sollten wir uns einfach so, wie die Lämmer, zur Schlachtbank führen lassen? War es noch erlaubt, an all dem teilzunehmen, beim Massenmord an unseren Brüdern mitzuhelfen?“ (J. Mawult, „Pamiętniki“, Sign. $38,90)$.

230 „Warum wehrte sich niemand, als die Deportation von 300000 Juden aus Warschau begann? Warum ließen sich alle wie Schafe zur Schlachtbank führen? [...] Wie konnte es dazu kommen, dass die Juden ihre Kinder und Frauen, Alten und Kranken auf Wagen herbeikarrten, wenn sie doch wussten, dass sie auf die Schlachtbank kommen sollten?" (E. Ringelblum, Bd. 2, S. 409, 426).

231 „Jüdisches Volk!“, ist in einem Aufruf der Jüdischen Kampforganisation ŻOB vom Januar 1943 zu lesen. „Die Stunde naht! Macht Euch bereit zum Widerstand, damit sie Euch nicht abschlachten wie die Schafe!" (Zitat nach: Archiwum Ringelbluma, op. cit., S. 336). - „Wir schämen uns für die Juden aus Chełmno“, schreibt Marek Edeman 1945, „weil sie sich ohne den geringsten Widerstand in den Tod führen ließen. [...] [Sie] [kamen] passiv und demütig [um]." (Das Ghetto kämpft, op.cit., S. 35). 
formulierte, sondern durch Anlehnung an den Bibeltext nur angedeutete Gleichstellung des Todes der Warschauer Juden mit dem Tod eines Knechts des Herrn ist der tapfere Versuch, der Ermordung des jüdischen Volkes irgendeinen Sinn zu verleihen und ihr einen Platz im göttlichen Plan zuzuweisen. ${ }^{232}$

Da die zum Umschlagplatz geführten Juden in diesem Gebet nun also als schweigend leidende Knechte des Herrn erscheinen, kann der Glaube an den gerechten und guten, den einen Gott trotz der fürchterlichen Wirklichkeit gerettet werden. Immer nämlich bot er und nur er die letzte Zuflucht, Schutz und Hoffnung. Sogar - wie es scheinen mag - entgegen jede Hoffnung. Nur Gott allein nämlich vermag sein Volk zu retten, wie er es schon manches Mal getan hat. Die Analogien zur biblischen Geschichte des auserwählten Volkes schreiben die derzeitige Situation in einen großen Zyklus von Unglück und Errettung ein, um die Hoffnung zu stärken:

Barmherziger Gott! Voll der Gnade bist Du für alle, die Dich aus tiefstem Herzen rufen: Hab Erbarmen mit uns, die wir vom Volke Israel geblieben sind, sprich - auf dass unser Leiden ein Ende finde. Nimm uns in Deine Obhut - diese spärliche Handvoll Juden, so wie Du unseren Urvater Abraham vor dem Schlag Nimrods bewahrt hast, unseren Urvater Jakob vor Esaus und Labans Hand, Moses vor dem Pharao, König David vor dem Philister Goliath, Chanania und Azaria vor Nebukadnezar. Und wie Du Daniel aus der Löwengrube errettet hast. Und Mordechaj und Ester vor dem Schlag des Übeltäters Haman. So schütze Dein Volk Israel vor allen seinen Feinden und sende uns den gerechten Befreier, der uns aus unserer schweren Unfreiheit erlöst. Auf dass es bald und zu unseren Lebzeiten geschehe! Amen („Modlitwa“, 333).

232 Eine der traditionellen Antworten des orthodoxen Judentums auf den Holocaust, die weiterentwickelt wurde von Rabbi Abraham Joshua Heschel [Avrom-Shiye Heshel], Eliezer Berkovits (Faith after Auschwitz, New York 1973) und Ignaz Maybaum (The Face of God after Auschwitz, New York 1976), beruft sich auf genau jene Theologie des leidenden Knechts des Herrn aus dem Buch Jesaja. Das Leiden der unschuldigen Holocaustopfer hat darin einen stellvertretenden Charakter. Auf diese für den Menschen unbegreifliche Art erhalte Gott das Kräftegleichgewicht im Universum der Schöpfung. Er bringe den Sündern Erlösung, bedenke dabei zugleich die unschuldigen Opfer mit besonderer Liebe und belohne sie in einem zukünftigen Leben. Er teile sogar mit den Gerechten deren Leiden. Siehe „The Jewish philosophical and theological responses to the Holocaust", in: I. Gutman (Hg.): Encyclopaedia of the Holocaust, New York, London 1990. 


\section{Die Klagelieder Karol Rotgebers}

1

Am 15. Februar 1943 überwand Karol Rotgeber, ein 55-jähriger, im Bürstenshop beschäftigter Zahntechniker, auf der Świętojerska-Straße in der Nähe des Krasiński-Parks die Ghettomauer und gelangte auf die arische Seite. Zusammen mit seiner Ehefrau, die das Ghetto ein paar Tage vor ihm hatte verlassen können, fand er einen Unterschlupf im Warschauer Stadtteil Praga. Und dort - mit Blick von der anderen Seite der Weichsel auf das brennende Ghetto - begann er, seine Erinnerungen aufzuschreiben. Eröffnet wird das Tagebuch mit einem knappen, die Biographie des Verfassers bis zum 1. September 1939 umreißenden Prolog; in halsbrecherischem Tempo erfährt der Leser eine Lebensgeschichte, die dem Helden eines Abenteuerromans würdig wäre. 1915 zieht Rotgeber von Warschau nach Petrograd [Sankt-Petersburg; Anm. d. Übers.]. Da er nicht in seine von den Deutschen besetzte Heimatstadt zurückkehren kann, geht er nach Moskau, wo er in der Produktion von Fußlappen für das Militär arbeitet. Um mehr Baumwolle herbeizuschaffen, wird er nach Fernost geschickt, durchquert Sibirien, die Mandschurei, Japan. Er knüpft Kontakte zu japanischen Firmen, organisiert Transitgebiete in Irkutsk und Chabarowsk, doch Waren kann er nicht mehr verschicken: Erst bricht die Februarrevolution aus, dann die Oktoberrevolution. Das Land versinkt im Chaos. 1919 gelingt es Rotgeber, Russland zu verlassen. Über China, Korea, Japan, Hawaii gelangt er nach San Francisco. Auf seiner weiteren Reiseroute liegen Kalifornien, Texas, Cañon City in Colorado, Mexiko, Chicago, New York. Von dort aus nimmt er ein Schiff nach England. Über Ostende und Berlin kommt er schlussendlich nach Warschau zurück. Diese schwindelerregende Lebensgeschichte stellt einen Kontrapunkt zum eigentlichen Gegenstand der Erzählung dar - vier Jahre unter deutscher Besatzung in Warschau. Zwei Arten von räumlicher Erfahrung treffen aufeinander: einerseits die weite und unbegrenzte Erdkugel, ein Gebiet freien und ungehinderten Reisens; andererseits der geschlossene und von der Welt abgeschnittene Ghettoraum, der schrittweise und unbarmherzig auf die Größe vier beengender Wände eines Verstecks schrumpft.

Rotgeber widmet das Tagebuch seinem 13-jährigen Sohn Paweł, der am 18. August 1942 während einer Selektion bei Toebbens auf den Umschlagplatz gebracht wurde. Der Text beginnt mit einer Anrufung des geliebten einzigen Sohnes, die in eine Anrufung Gottes übergeht, der helfen möge, die Feinde zu überwinden und die Gerechtigkeit wiederherzustellen. Die Figur des Sohnes wird mehrmals erwähnt; der Autor will sich nicht mit dessen Tod abfinden. 
Ich will, ich muss Dich retten [...]. Dich noch einmal in meinem Leben glücklich und wohlbehalten sehen (S. 22), schreibt er am Anfang, und schließt mit folgendem Bekenntnis: Ihr lächelt mitleidig, dass ich nach alldem, was ich beschreibe, meinen Sohn noch wiederzufinden glaube. [...] Und es ist seltsam, ich glaube trotz allem, dass er noch lebt. [...] Ich glaube, dass der barmherzige Gott ihn nicht umkommen lässt und seine Kraft und seinen Glauben erhält (S. 204).

Die Haltung des Gottvertrauens - allen Umständen und jeder Wahrscheinlichkeit zum Trotz - ist das Auffallendste an diesem Tagebuch. Rotgeber lässt - „im tiefen Glauben, dass ein helleres Morgen für uns anbrechen wird“ (S. 204) - das letzte seiner Notizhefte mit einem erhabenen Schlusssatz voller Kraft und Vertrauen enden.

Aber Du, Gott, weißt besser, was wird und getan werden muss. Dein Name sei gepriesen auf ewig! Es Lebe Israel!! Hoch wehe die Flagge Zions!!

Warschau, am 12. September 1943 (S. 215).

In der Einleitung erklärt der Autor, er sei zwar nie Schriftsteller gewesen, wolle sich aber bemühen, seine Erlebnisse und das Martyrium seines Volkes „vom Anfang dieser unerhörten weltweiten Morderei bis heute“, damit „der zukünftige Historiker [...] das wahre Tempo der Ereignisse nachvollziehen [kann] “ (S. 1). Rotgeber übernimmt zwar die Aufgabe eines Chronisten, vergisst aber nicht einen Moment auch das persönliche Leiden, bleibt stets der leidenschaftlich gläubige Jude. Sein Augenzeugenbericht über die Ghettorealität ist durchsetzt von stoßgebetartigen, an Klagepsalmen erinnernden Bittgesuchen.

\section{2}

Rotgebers Tagebuch unterscheidet sich von anderen persönlichen Dokumenten aus dem Warschauer Ghetto durch seinen stilistischen Eklektizismus, durch das Auftreten zweier (und sogar dreier) Rollen des sprechenden Subjekts sowie durch den in zwei Bahnen verlaufenden Diskurs. Während die ersten beiden Eigenschaften noch in anderen Texten beobachtet werden können, scheint die letzte spezifisch nur für Rotgeber zu sein. Alle drei zusammen bilden ein einzigartiges Ganzes. Auf der Ausdrucksebene lässt sich eine stilistische Durchmischung mit zwei dominierenden Mustern feststellen: dem biblischen Stil und dem expressiven Stil der emotionalen Exaltation. Die biblische Stilisierung stützt sich vor allem auf psalmisch-klagende sowie auch apokalyptische Muster, wobei das so erzielte Pathos einer die Alltagsrealien beschreibenden Sprache gegenübersteht. Hin und wieder macht die hierarchische Ordnung der biblischen Phrasen berichtenden Notizen über die Verpflegungssituation Platz, über Zahnbehandlungen, über Schmiergelder und Schmuggel, über die Situation an der Front. Die 
Tagebuchnarration ist in einer Sprache voller stilistischer Emphase gehalten, ja wirkt manchmal geradezu exaltiert. Erzielt werden die starke Expressivität und intensive emotionale Spannung (Zorn, Entrüstung, Entsetzen, Schmerz, ekstatische Freude oder Sorge) durch rhetorische Mittel wie Fragen, Apostrophen, Ausrufe, syntaktische Umkehrungen, durch poetische Verwünschungen und Schmähungen an die Adresse des Feindes; zugleich sind zärtliche Anrufungen nahestehender Personen in den Text eingeflochten.

In Karol Rotgebers Tagebuch wird das sprechende Subjekt äußerst deutlich gezeichnet. Der Leser weiß gleich, wer er ist, kennt seine Geschicke bis zum Ausbruch des Krieges. Er verfolgt, was nach Einmarsch der Deutschen in Warschau mit ihm geschah, was er im Ghetto durchlebte, wie er auf die arische Seite gelangte, wie sein Leben im Versteck aussah. Der Verfasser des Tagebuchs enthüllt seine Privatsphäre, legt persönliche Erfahrungen offen, gibt seinen individuellen Gesichtspunkt bekannt. Zudem nennt er zahlreiche Details und faktographische Beobachtungen, wie zum Beispiel, dass er selbst für einen Arbeitsplatz in Müllers Shop an der Franciszkańska-Straße 2.000 Złoty Schmiergeld und eine Flasche Spiritus hinlegen muss und für den Schlupfwinkel auf der arischen Seite in Praga einmalig 10.000 und dann monatlich 400 Złoty. Mehrere Male tritt auch das Motiv des zahnärztlichen Behandlungsstuhls seiner Frau in Erscheinung, der von Wohnort zu Wohnort durch die Ghettostraßen geschleppt wird. Doch der Verfasser möchte nicht nur seine individuelle Leidenswelt beschreiben, sondern auch als Chronist der Nachwelt die Geschichte des Martyriums seines Volkes überliefern. Es schmerzt ihn das Los der Gemeinschaft; zugleich redete er sich seinen eigenen Schmerz von der Seele, beklagt sein privates Unglück. Der Chronist und Tagebuchschreiber tritt darüber hinaus als das Subjekt von Klagegebeten auf. Er kommuniziert mit Gott über das Schicksal der Welt.

Bei Rotgeber prallen zwei verschiedene Diskursordnungen aufeinander: die Ebene der Erinnerungsnarration und die Ebene von Klage und Gebet. Beide existieren nebeneinander. Sie durchdringen oder überlagern einander nicht, sondern verflechten sich; eine Übergangszone zwischen ihnen gibt es nicht. Die erinnernde Narration wird plötzlich durchbrochen von einem Stoßgebet, einem Bittgesuch, einer Klage, einem Ruf nach Beistand und Rache, einem Glaubensbekenntnis, einem Akt der Hoffnung. Danach kehrt der Text - ebenso plötzlich und unerwartet - zum vorherigen Narrationsstrang zurück, zum Ghettoalltag, zur Verzeichnung von Torturen und Verfolgungen, zum Konkreten und zur Topographie, zum privaten Schicksal des Autors.

Die narrative Ebene des Tagebuchs besitzt sämtliche Attribute der persönlichen, unter dem Druck der Ereignisse entstandenen Dokumentationsliteratur. So wie viele andere beginnt Rotgeber erst zu schreiben, als er die arische Seite 
und ein verhältnismäßig sicheres Asyl außerhalb des Ghettos erreicht hat. Diese Situation rief in den Menschen häufig den Wunsch hervor, das eben erst überstandene Grauen zu schildern. Doch es kommt auch eine zutiefst persönliche Motivation hinzu: der Verlust des einzigen Sohnes. Rotgeber erzählt, ähnlich wie manch andere Autoren, vor allem seine eigene Geschichte, wobei jedoch die Aufzeichnung der Ereignisse aus dem Privatleben Züge eines Zeugnisses über das kollektive Schicksal annimmt. In alldem ist Rotgebers Narration typisch.

Allerdings genügt es ihm nicht, über das Ghetto zu berichten, es genügt ihm nicht die Rolle eines Chronisten, der „beim Lärm der Geschosse mit zittriger Hand" seine Aufzeichnungen macht. Er findet keinen ausreichenden Platz im Rahmen einer gewöhnlichen Erinnerungsnarration, bietet sie doch nur ein Verzeichnis des Laufs der Ereignisse, die sich jeglichem Urteil und Verständnis entziehen. Rotgeber registriert das Geschehen, doch verweilt er nicht dabei. Die Ereignisse, deren Zeuge er wird, lassen sich weder im Rahmen einer individuellen Erfahrung noch innerhalb einer geschichtlichen Ordnung begreifen. Rotgeber schreibt die Welt des Ghettos in eine transzendente Wirklichkeit ein und macht diese letztendlich zum Thema seines Tagebuchs. Er teilt seine Feder zwischen der Geschichte (die Vernichtung der Juden aus dem Warschauer Ghetto) und der Ewigkeit (das kosmische Ringen des Guten mit dem Bösen, die göttlichen Pläne mit dem Volk Israel).

Der Diskurs spaltet sich, die Chronologie der Narration zersplittert. Drei zeitliche Ebenen vermischen sich miteinander: die Zeit der Narration, die Zeit der berichteten Ereignisse und die heilige, die ewige Zeit - die atemporale Dimension des Gebets.

Der Autor bemüht sich um Einhaltung einer chronologischen Ordnung, versucht, „,on Anfang an“ zu berichten, d.h. von September 1939 an über sämtliche Phasen in der Geschichte der Warschauer Juden während der Besatzung. Die chronologische Kette wird jedoch durch autothematische Einschübe, reflexive Rückgriffe und gebetsähnliche Klagen unterbrochen. Der aktuelle Zeitpunkt des Schreibens drängt sich durch zahlreiche Bemerkungen über die Umstände des Schreibenden in den Text, z.B. „[N]un, während ich schreibe, höre ich ganz deutlich ein Geschoss explodieren" (S. 56). Auch unterbricht Rotgeber den Narrationsfluss, um eine während des Schreibens eintreffende aktuelle Nachricht zu vermerken, z.B. die Nachricht vom Fund der Gräber in Katyń und der antisemitischen Propaganda des Besatzers, der die „roten jüdischen Henker“ des Mordes an den polnischen Offizieren bezichtigt (S. 26). Retrospektiven weiten sich zu eigenen Skizzen aus. Der Bericht über den ersten Besatzungswinter geht in einen langen Rückblick in die Zweite polnische Republik über, in dem der Autor über die Wurzeln des Antisemitismus, die Politik der rechtsgerichteten 
Nationaldemokratie [Narodowa Demokracja (ND); Anm. d. Übers.], antisemitische Übergriffe in der Vorkriegszeit sinniert und sich bitteren Gedanken über die derzeitige Haltung der Polen gegenüber den Juden hingibt (S, 23-24). An anderer Stelle unterbricht Rotgeber die Schilderung der Ankunft deutscher Juden im Warschauer Ghetto im Frühjahr 1942 durch einen breit angelegten historischen Rückblick über die Kriegsvorbereitungen der Deutschen und über das Verhältnis der deutschen Juden zu den Deutschen (S. 90). Und endlich löst sich der aktuelle Zeitpunkt in einer apokalyptischen Vision auf - der Erzengel Gabriel steigt mit einer himmlischen Schar vom Himmel herab. Ewigkeit und Gegenwart verschwimmen, dann kehrt die Narration urplötzlich zur Kriegsrealität zurück: „Der Krieg dauert fort. Ein Luftangriff der Alliierten ist im Gange. Es ist der 10. Juni 1943“ (S. 208).

Rotgeber kann nicht mit der konventionellen Narration brechen und sich nur in der Dimension der Ewigkeit bewegen, lässt er doch seine Klagen von einem konkreten Ort zu einer konkreten Zeit laut werden. Das Ghetto ist der Nährboden des Schmerzes, aus dem seine an Gott gerichtete Klage erwächst. Indem der Verfasser seinen Ton dem Klang der Klagelieder Jeremias angleicht, überwindet er die Endlichkeit und Beschränkung seiner eigenen Erfahrung. Jeremia beweint die Zerstörung Jerusalems im Jahr 587 v. Chr., aber seine Stimme hallt im ewigen Jetzt des Klagegebets nach. Mit seinen Worten beklagten die nachfolgenden Generationen von Juden ihren Kummer. Rotgeber beschreibt das Grauen des Ghettos, jedoch in der Tonlage von Jeremias Lamentationes. Dadurch wird die vor seinen Augen stattfindende Vernichtung der Warschauer Juden zum Kettenglied in einer heiligen Geschichte, zur Etappe bei der Erfüllung eines göttlichen Plans, der - wie er glaubt - über die Katastrophe zur Reinigung, Heiligung und zum endgültigen Triumph Israels führen wird.

3

Karol Rotgeber beruft sich sowohl auf die Poetik als auch auf die Theologie biblischer Klagen. Daher möchte ich nun an die Themen und Motive erinnern, auf die er zurückgreift, sowie auch auf die Botschaft, welche die ihn inspirierende biblische Tradition in sich trägt. ${ }^{233}$

233 Bei der Besprechung von Klagepsalmen und Jeremias Lamentationes stütze ich mich v.a. auf den Artikel „Lamentations, Book of“, in: Encyclopaedia Judaica, Jerusalem 1972, und auf Józef Sadziks Einleitung zum Buch der Psalmen in der Übersetzung von Czesław Miłosz, Paris 1979. 
Die Thrēnī des Propheten Jeremia sowie die Klage- und Bittpsalmen beschreiben das Drama eines vom Unglück befallenen Volkes und das Drama eines von Leid überwältigten Menschen. Sie sind die Präfiguration einer Erfahrung der Niederlage und Demütigung, aber auch des Sieges und der Wiederaufrichtung; sie bringen ein Muster des Ausdrucks von Schmerz, Verzweiflung und Zweifel ein, vor allem aber eine Botschaft des absoluten Gottvertrauens und der Hoffnung auf den Sieg.

Die Hauptfigur in den Psalmen ist eingebunden in eine zwischen Gut und Böse gespaltene Welt. Somit muss sie sich entscheiden: Spricht sie sich für die Seite des Guten aus, oder stellt sie sich auf die Seite des Bösen? Die Entscheidung für das Gute ist heldenhaft und entspringt dem grenzenlosen Vertrauen in Gott. Nichts als der Glaube liegt einer solchen Entscheidung zugrunde, wird dem Menschen doch die niederdrückende Erfahrung des Bösen, des Unrechts und der Verlassenheit zuteil. Auf die gotteslästerlichen Verhöhnungen eines in Hülle und Fülle lebenden Frevlers: „Gott ahndet nicht. Es gibt keinen Gott. [...] Gott hat vergessen, hat sein Angesicht verborgen (Ps 10,4; 11), antwortet die Stimme des von Unglück heimgesuchten Gerechten, sein flehendes Rufen richtet sich gen Himmel, der jedoch schweigt: „Herr, steh auf, Gott, erheb deine Hand, vergiss die Elenden nicht!“ (Ps 10,12). Die Psalmen berühren hier ein unergründliches Geheimnis. Warum muss der Gerechte Verfolgung erleiden, und der Frevler triumphiert? Dazu schreibt B. L. Sherwin, die talmudischen Rabbiner hätten vor Hunderten von Jahren gelehrt, dass es weder in unserer Macht stehe, die Leiden der Gerechten, noch, das Wohlergehen der Frevler zu erklären. ${ }^{234}$

Psalm 88, einer der pessimistischsten Psalmen, zeichnet die Situation eines Menschen, über dem sich Gottes Zorn zusammenbraut. Von Leid gebeutelt, verlassen in seinem Unglück, verzweifelt und hilflos richtet er seine Klage zum schweigenden Himmel. In jenem Psalm gibt es einige bildhafte Motive, die in das klassische Ausdrucksrepertoire für Verzweiflung, Leiden, Erniedrigung eingegangen sind, zum Beispiel das Motiv der Abgeschiedenheit, Gefangenschaft, Isolation. Als wäre jemand lebendig begraben worden. Der Raum des Lebens verwandelt sich in einen Raum des Todes, in eine Grube, ein Grab (V. 5-6). Es kommt das Motiv vor, in Finsternisse, in Tiefen hinabgestoßen zu werden (V. 7), oder das Motiv der Flut, die von allen Seiten auf den Leidenden eindringt (V. 17-18). Diese Sprache des Leidens erweist sich als besonders geeignet für die Darstellung des Ghettos als geschlossenen, von allen Seiten näherrückenden,

234 Siehe B. L. Sherwin: Sparks Amidst the Ashes, op. cit. 
erdrückenden Raum und wird nicht nur von Rotgeber verwendet, sondern stellt vielmehr ein gemeinsames Erbe der jüdisch-christlichen Kultur dar.

Gegen die niederschmetternde Macht von Gottes Zorn kann nichts bestehen, „unter deinem Zorn schwinden wir hin, durch deine Zornesglut werden wir starr vor Schrecken“, ruft der Verfasser der Psalmen (Ps 90,7). In den Lamentationes hingegen ist die Klage noch ausgeschmückt durch realistische Bilder einer kollektiven Tragödie, Szenen von Verheerung, Mord, Zerstörung. „Am Boden liegen in den Gassen Kind und Greis. Meine Mädchen und jungen Männer fielen unter dem Schwert. Du hast sie erschlagen am Tag deines Zorns, schonungslos geschlachtet. [...] Am Zorntag des Herrn gab es keinen, der entkam und entrann" (Jer 2, 21-22). Aus der Tiefe des Leidens dringt ein Schrei der Verzweiflung - jenes klagende de profundis clamavi. Gott wird zum Handeln aufgefordert. Die flehenden Anrufe schwellen an zu einer fiebrigen, ungeduldigen, zur Eile antreibenden Litanei: „Wach auf! Warum schläfst du, Herr? Erwache ... Eile, Herr, gib mir Antwort ... Wie lange noch, Herr? ... “ (siehe z.B. Ps 44,24-25; Ps 143,7; Ps 31,2-3; Ps 79,5; Ps 89,47).

Die Rufe verhallen nicht ohne Echo, Bedingung für eine Antwort ist jedoch ein absolutes Vertrauen in Gott. Nur das gibt Kraft und bringt Rettung. „Die aufschrien, hat der Herr erhört, er hat sie all ihren Nöten entrissen. [...] Viel Böses erleidet der Gerechte, doch allem wird der Herr ihn entreißen“ (Ps 34,18-20). Im Psalm über Gott, die sichere Zuflucht, vertraut der Psalmist sich ganz dem Herrn an und kann daher froh verkünden: „[...] du hast mein lautes Flehen gehört, als ich zu dir um Hilfe rief" (Ps 31,23), und auch andere in ihrem Glauben bestärken: „Euer Herz sei stark und unverzagt, ihr alle, die ihr den Herrn erwartet“ (Ps 31,25).

Die Autorschaft an den Klageliedern - den Lamentationes -, in denen das zerstörte Jerusalem und die babylonische Gefangenschaft beweint werden, schreibt die Tradition Jeremia zu - einem Propheten, der jene unheilvollen Ereignisse vorausgesehen hatte und zum Zeugen der Erfüllung seiner Prophezeiungen wurde. Der Zyklus setzt sich aus fünf kunstvoll konstruierten Liedern zusammen. Die ersten vier haben die Bauweise eines Akrostichons, ihre Strophen beginnen mit den aufeinanderfolgenden Buchstaben des Alphabets. Das letzte Lied weist diese Bauart nicht auf, aber es zählt 22 Verse - so viele wie die Buchstaben im hebräischen Alphabet. Dieser alphabetische Code bedeutet, dass die Klage im Text der Lamentationes ihren vollsten und ausgefeiltesten Ausdruck findet; sie erreicht eine Vollkommenheit - von "A“ bis „Z“. Das Vorkommen verschiedener aus den Psalmen und anderen biblischen Büchern bekannter Klageformeln ist ein Erkennungszeichen für die Gattungsqualifikation eines Textes, setzt ihn in Bezug zu althergebrachten Mustern. 
Die Einfassung des Textes in strenge formale und Gattungsregeln zeigt, dass der Ausdruck hier einer besonderen Disziplin unterworfen worden ist. Die Lamentationes sind jedoch nicht nur ein Muster für den sprachlichen Ausdruck von Leiden - sie formulieren auch eine für die biblische Tradition klassische Antwort auf die Frage nach dessen Sinn.

Kulminationspunkt des Zyklus ist das dritte Lied. Die hier ausgedrückte Theorie vom Leidens als einer für den Menschen wertvollen, nützlichen und notwendigen Erfahrung wurzelt in der biblischen Weisheitstradition. Viele von deren Eigenschaften lassen sich im Buch der Psalmen oder im Buch der Sprichwörter wiederfinden; ihr Echo klingt in der Rede eines Freundes und Trösters von Hiob wider: „Ja, selig der Mensch, den Gott zurechtweist. Die Zucht des Allmächtigen verschmähe nicht!“ (Hi 5,17). Dass Gott, der niemals jemanden endgültig verstößt, das Leiden zulässt, bedeutet, dass dessen tiefster Grund nur eine Sünde sein kann. Der Glaube, demzufolge das Leiden die verdiente Strafe für eine Sünde ist, wird zur Grundlage für eine Hoffnung, die die Verzweiflung besiegt. Nimmt der Mensch sein Leiden demütig und reuevoll an, vertraut er auf Gott und ruft ihn, so wird sein Rufen erhört.

\section{4}

Die Gebetspartien in Rotgebers Tagebuch sind aus psalmischen Motiven und Anklängen an Jeremias Klagelieder zusammengesetzt. Während er von der anderen Weichselseite das brennende Ghetto im Blick behält, scheint Rotgeber zugleich - wie Jeremia - auf den Trümmern des verlassenen Jerusalem zu sitzen. Die Klage über das Unglück fasst er in biblische Klageformeln, wodurch die Subjektivität des Klagenden eine Universalisierung erfährt. Somit kann der Text von Rotgebers Lamentationen, der ja auf der Grundlage des Bibeltextes entstanden ist, nicht anhand seiner Originalität bemessen werden. Der Verfasser wird hier vielmehr zum Medium, das ein Muster erneuert, eine liturgische Wiederholung vollzieht.

Der Text gliedert sich in Klagen über die Vernichtung des Warschauer Ghettos und in Phasen, in denen das Drama eines gläubigen Menschen zutage tritt, der sich der Erfahrung einer Vernichtung gegenübersieht. Das Gebet zum erzürnten Gott geht in einen Akt der Sühne über, in die Forderung an Gott, zu intervenieren und sich auf die Seite des Klagenden zu stellen. Die Klage verwandelt sich in einen Akt des Vertrauens und ein Glaubensbekenntnis. Das Zwiegespräch zwischen Gerechtem und Frevler wird zu einer inbrünstigen Apologie Gottes. Schließlich erfolgt eine apokalyptische Vision des eintreffenden Messias. Die einzelnen Glieder sind nicht in der Reihenfolge ihres Erscheinens im Text 
zusammengesetzt, sondern so, dass sie ein bestimmtes theologisches Ganzes bilden - man könnte sagen: nicht in syntaktischer, sondern in paradigmatischer Ordnung.

Eines der düstersten Tagebuchelemente beginnt mit einem Schuldbekenntnis angesichts von Gottes rasendem Zorn, dessen Folgen die Vernichtung des Volkes und die Profanierung alles Heiligen sind. Gott bleibt taub gegen alles Bitten und Flehen. Er schweigt zur Vernichtung.

Wir haben also große Schuld auf uns geladen. Nichts nützt unser Flehen und Bitten. Jahwe hat seinen Blick von uns abgewandt. Es zürnt uns der Gott Israels. Womit können wir ihn milde stimmen? Wann ist das Ende unseres Leidens erreicht? Verlässt Du uns, Gott [...]? Brauchst Du uns nicht mehr? Zerstört sind Deine Bethäuser. Geschändet ist das Gotteshaus, heilige Pentateuchrollen verkleiden die Holzwände von Warschauer Marktbuden. Es gibt keine Niedertracht, mit der man uns verschont hat. Und Du, Gott Israels, siehst all das und schweigst? (S. 124).

Diese Stelle enthüllt die für Rotgebers Klage charakteristische Dialektik von Individualität und Allgemeinheit, von Geschichtlichkeit und Ewigkeit. Vor dem Hintergrund der biblischen sprachlichen Basis erscheint ein originaler Strang, ein umstandsbezogenes Detail, das das ewige Jetzt der Gebete in einen aktuellen Bezug setzt. Jeremias Klage über das vernichtete Jerusalem, den zerstörten und entweihten Tempel (vgl. Jer 2,7) erweitert Rotgeber um einen Bezug zum besetzten Warschau - die heiligen Pentateuchrollen an den Wänden der Marktstände. In Kombination mit den vielen Berichten über die Entweihung von Torarollen eröffnet die oben zitierte Phrase ihre doppelte Verwurzelung: eine biblische und eine in den Realien des Ghettos. Oder anders: Sie spielt sich auf zwei Ebenen zugleich ab. In das uralte Muster der Klagelieder Jeremias eingeflochten wird ein Bruchstück der Erfahrungen der Juden aus dem Warschauer Ghetto. Der gegenwärtige Alltag sickert in die Ewigkeit ein und verfestigt sich dort zu einem Exempel.

Gemäß des logischen Ablaufs der Klagelieder, demzufolge auf die Klage eine Tröstung folgt, erhört der zornige und beharrlich schweigende Gott schlussendlich doch die Hilferufe und tritt als mächtiger Rachegott, als siegreicher Jahwe auf. Zunächst aber ist es dem Leidenden gegeben, Gefühle von Zweifel und Verlassenheit zu durchleben. „Wo ist das Gewissen der Welt geblieben?“, fragt Rotgeber. „Man hört nur Kriegstumult, Säbelrasseln, das Stöhnen von Verwundeten und das Röcheln von Sterbenden" (S. 42). An anderer Stelle wendet er sich an Gott: „Vergeblich ist unser Flehen und Bitten. [...] Und Du, Gott Israels, siehst das und schweigst?" (S. 124). 
Vom Balkon seiner Wohnung im Ghetto beobachtet der Autor die Blockade einer Sammelstelle für Flüchtlinge in der Franciszkańska-Straße 20 während der großen Liquidierungsaktion. Der dramatische Tatsachenbericht weicht rasch einem Klagegebet - unter einem sonnigen Himmel geht das von Gott vergessene Volk zugrunde, während der Feind ungestraft davonkommt. Es ist dies ein klassisches Beispiel für den Zwei-Bahnen-Diskurs in Rotgebers Erinnerungen.

Ein Schauer des Entsetzens überlief mich, doch ich blieb stehen. Ich schaute, schaute hin bis zuletzt. Ein schrecklicher Schmerz erfasste mich, das leiderfüllte Herz krampfte sich zusammen, während ich meine Augen zum Himmel hob und nach Engeln ausschaute, auf dass sie meine unglücklichen Brüder in ihre Obhut nähmen. Der Himmel war heiter, kein Grollen eines nahenden Gewitters zu hören, das von Gottes Zorn künden würde. Der Gott Israels hatte seinen Blick von uns abgewandt. Er hatte seine armen Kinder vergessen. Der Feind erhebt sich über uns, und es gibt keine Strafe für ihn (S. 99).

Ein dramatischer Moment des Schweigens von Gottes Seite tritt ein, in dem es scheint, als gebe es keine Hoffnung mehr und alles sei verloren. Rotgeber flicht an dieser Stelle Bilder ein, die er im Geiste apokalyptischer Visionen zeichnet, Bilder vom Ende der Welt, einem letzten Gefecht von Dunkel und Licht:

Es fließen blutgefüllte Flüsse. Schreckliche Seufzer gehen ihnen voran. Ein Lichtschein erhellt alles. Die Schreie hallen bis zum Himmelszelt. - Wo ist Dein Königreich, oh Gott? Wo ist Deine Herrschaft über die Welt? [...] „Die Rufe verhallen.“ Niemand hört - niemand sieht (S. 125).

Nach dem Vorbild des Psalmisten treibt Rotgeber Gott zum Handeln an:

Allmächtiger Gott [...], nun hat Israel genug gelitten. Jahwe, unser Gott [...], denk an unsere Ahnen [...], rette uns verirrte Schäfchen [...], erlasse uns unsere Sünden [...], lass dich erweichen (S. 147-148).

An einer anderen Stelle wiederum verlässt er die Tradition der Klagelieder und findet, anstatt Gott anzurufen, eine Fürsprecherin in der Figur der biblischen Rachel. An sie wendet er seine Bitte um Beistand und Hilfe.

Steh auf, unsere geliebte Mutter Rachel! Sieh Dir Deine Kinder jetzt an! Eile zu Gott, solange noch die Zeit ist! Du hast in Deinem Leben gelitten. Dich wird der Gott Israels anhören. Beeile Dich, eile, teuerste Mutter, es ist höchste Zeit. Sonst kehrt Totenstille ein. Aufstehen soll das Volk Israel! (S. 124-125).

Die Anrufung der Figur Rachels beweist, dass der Verfasser sowohl in der biblischen als auch in der postbiblischen jüdischen Tradition zu Hause ist. Rachel (hebr. „Mutterschaft"), Jakobs Ehefrau, gilt in der Bibel, gemeinsam mit ihrer Schwester Lea, als Mutter der Generationen Israels ( $\mathrm{Ru} 4,11)$. Rachel soll es gewesen sein, die die Zerstörung des Tempels und die Vertreibung aus Jerusalem 
am bitterlichsten beweinte, und sie tröstete Gott als Erste mit der Aussicht auf eine Rückkehr. Darum beriefen sich auch in der Entstehungszeit des Talmuds die Rabbiner, die über die Zerstörung Jerusalems und die Zerstreuung des Volkes in alle Richtungen klagten, meistens auf Jeremia, Moses und eben die Figur Rachels als Urbilder einer klagenden Haltung. ${ }^{235}$

Rotgeber war nicht der Einzige, der sich in jener Zeit an Rachel als Mittlerin für die Bitte um Rettung wandte. Ein Dichter der Ghettos Litzmannstadt, Symcha Bunim Szajewicz, der 1944 nach Auschwitz deportiert wurde, malt in einem Gedicht mit dem Titel Wiosna 5702 [1942] [Frühling 5702] eine makabre Landschaft der Aussiedlung, Leere und Düsternis, wo weder Platz für Rache noch für Hoffnung bleibt, ist Gott doch schon getötet worden. Der Dichter hat somit nur noch eine Möglichkeit - die Mutter Rachel und den Rabbiner Levi Jizchak von Berditschew [Lewi Izaak/Lewi-Yitskhok z Berdyczowa] anzurufen, dass diese sich für Israel einsetzen sollen, auch wenn es dafür ohnehin schon zu spät ist. ${ }^{236}$

Die Quälerei geht auf ihren Zenit zu. Rotgeber richtet einen vorwurfsvollen Ruf an Gott: „Wofür, Allmächtiger Gott, bringst Du dem Moloch das Blut der Unschuldigsten dar“ (S. 42). Ähnlich formuliert es der Psalmist: „Du gibst uns preis wie Schlachtvieh und unter die Völker hast du uns zerstreut“ (Ps 44,12). Und doch erklingt diese herzzerreißende Klage nicht unter leerem Himmel; Gott antwortet demjenigen, der ihm grenzenlos vertraut. Im Drama um Zweifel und Hoffnung, Verzweiflung und Wiederaufrichtung kommt die Zeit, dass der Mensch seinen Glauben einer letzten Probe unterziehen muss. Die Zeit, sich Gott restlos hinzugeben. Und Rotgeber legt, nach dem Vorbild des Psalmisten, ein heroisches Glaubenszeugnis ab. Doch als er schreibt: „Ich fürchte mich nicht, der Glaube stärkt mich“ (S. 33), ist diese Deklaration nicht nur die Erneuerung der Gebetsformel eines Psalms. ${ }^{237}$ Im Gesamtkontext - also umgeben von der Schicht der Erinnerungsnarration über die Gräuel des Ghettos und die Leiden des Verfassers - wird jenes heroische Bekenntnis zu einer authentischen und zutiefst persönlichen Antwort auf die Erfahrung des Holocaust. In Zeiten von Chaos und Vernichtung ist der Glaube für Rotgeber das einzige Reale, was bleibt, die einzige Wahrheit, die sich in Schutt und Asche noch finden lässt. Auf ihn stützt sich die Hoffnung auf Befreiung aus der Bedrängnis, auf Rache für das

235 Siehe „Rachel“, in: Encyklopeadia Judaica.

236 Siehe D.G. Roskies: Against the Apocalypse, op. cit., S. 213.

237 Wie zum Beispiel „[...] ich fürchte kein Unheil, denn du bist bei mir“ (Ps 23,4) oder „auf Gott setzte ich mein Vertrauen, ich fürchte mich nicht“ (Ps 56,12). 
Unrecht und Bestrafung der Verbrecher, auf ein neues, besseres Leben, auf ein Israel, das wieder neu entsteht und mächtiger ist als je zuvor.

Entwürdigt, verfolgt, zum Leben im Versteck gezwungen, aus dessen Fenstern er den Rauch über dem sterbenden Ghetto aufsteigen sieht, setzt Rotgeber nur noch auf Gott:

Noch stärker ist der Geist geworden, noch stärker der Glaube an den Gott Israels. Ich glaube fest daran - Israel wird nicht untergehen. Einzig mein Körper kann, leider, nicht mehr Schritt halten mit meinem Geist (S. 55).

Die Vernichtung des aufständischen Ghettos wird in Rotgebers Augen zum Moment der Überwindung des Bösen. Er blickt aus messianischer und nicht aus historischer Perspektive auf die schwelenden Überreste. Die Vollendung des Verbrechens ist ein Vorbote der unweigerlichen Niederlage der Täter. An die Deutschen gerichtet, prophezeit Rotgeber: „Dunkelheit überlagert eure Gestalt. [...] [A]ll das wird in Trümmern liegen bei einem Hauch der ewigen Kraft, die Verbrechen straft" (S. 33). Erst in diesem Kontext erfolgt das Glaubensbekenntnis. Gott allein hat nämlich die Macht, das Böse zu besiegen, den Gerechten aus der tiefsten Erniedrigung zu erheben und den Frevler zu bestrafen. Deshalb kann man auch nur mit Gott (und es müsste hinzugefügt werden: sogar mit Gott) über die Errettung reden.

Ich fürchte mich nicht, der Glaube stärkt mich. [...] Vor einer Woche habe ich mit Gott geredet (Lacht ruhig! Nur mit ihm kann ich noch reden!). Mir kam der Gedanke, dass unser Leiden bald schon vorüber sein und die Strafe die unmenschlichen Unterdrücker ereilen wird (S. 33).

Die Bemerkung in Klammern erscheint dort als automatische Digression, die die narrative Fiktion unterbricht, indem sie sich direkt an den Leser wendet. Sie soll die Glaubhaftigkeit des eben Gesagten bestätigen. Doch die Gesprächssituation mit Gott braucht auf der Ebene der Klage nicht extra glaubhaft gemacht zu werden, ist sie doch das Fundament der betenden Haltung. Notwendig ist dies allerdings auf der Ebene der Erinnerungsnarration.

In diesem Einschub in Klammern laufen die beiden Diskursordnungen zusammen; die Geschichte überschneidet sich mit der Ewigkeit, die Erfahrung des Holocaust wird zugleich zur Erfahrung des Sacrum. Rotgeber offenbart sich hier als Autor, der seine eigenen narrativen Vorgehensweisen preisgibt, vor allem jedoch als Mensch von ungetrübtem Glauben. Wer im Frühjahr 1943 auf den Trümmern des Ghettos Gott begegnet, für den ist Gott ein realer Gesprächspartner. 
Der Glaube gibt ihm Mut und Kraft, um im imaginierten Gespräch mit dem Frevler - eine für die Klagepsalmen charakteristische Formel ${ }^{238}$ - der grausamen Realität die Stirn zu bieten. Der Frevler sagt:

Ich habe Israel geschmäht, zertreten - dachtest du in deinem Hochmut. [...] Nie wieder werden sie sich erheben! Ich werde der Herr des Weltalls sein und alle zu Sklaven machen! Gott fürchte ich nicht! Meine Macht reicht bis zum Himmel, ich werde auch Gott zur Unterwürfigkeit zwingen! (S. 14).

Darauf erwidert Rotgeber - der Gerechte:

Sieh dich vor! [...] Der Tag der Rache wird kommen - der Rachegott wird aufstehen und dich mit dem unschuldig vergossenen Blut übergießen. Du erreichst dein Ziel nicht (l.c.).

Die Replik des Gerechten verwandelt sich in eine Verteidigung Gottes gegen den die höhnischen Vorwürfe des Frevlers. Diese Verteidigung stützt sich auf die Doktrin der göttlichen Vergeltung und messianischen Hoffnung auf Erlösung.

$\mathrm{Du}$ fragst, wo mein Gott ist? Warum mein Gott zugelassen hat, dass Israel vernichtet wurde? Du weißt, du niederträchtiger Mörder, dass Gott dir beizeiten eine Strafe schicken wird, aber er träumt nicht, er schläft nicht, der Beschützer Israels. Die Vernichtung erwartet dich, und auf deinen Ruinen entsteht ein stärkeres, noch mächtigeres Israel (S. 57)

Die Doktrin der göttlichen Vergeltung besagt, alles Unglück, das Menschen ereile, sei eine Strafe für Sünden. Diese traditionelle, aus der hebräischen Bibel stammende Antwort auf die Frage nach dem Grund für das Böse auf der Welt wurde nach dem Krieg in jüdischen theologischen Diskussionen wieder aufgenommen. In diesem Licht erschiene der Holocaust als Strafe für begangene Sünden. Den Orthodoxen zufolge sollten die Juden zum wiederholten Mal das Bündnis gebrochen und Gott zum wiederholten Mal mit einer furchtbaren Strafe darauf reagiert haben. Eine solche Haltung drückt sich im orthodoxen Judentum auf dreierlei verschiedene Art aus. Die erste Art formuliert den allgemeinen Vorwurf an das Volk, Sünden begangen und nicht geglaubt zu haben; die zweite bringt den Holocaust mit einer Welle von aufklärerischen Reformen (Haskala) und unorthodoxen Formen des Judaismus in Verbindung; die dritte sieht die Schuld im Zionismus als einem gottlosen Plan zur Erneuerung des Staates, das die Erwartung eines messianischen Akts der Erlösung verwirft. ${ }^{239}$

238 Rotgeber wiederholt nicht nur das Motiv des Kampfes zwischen Gerechtem und Frevler, sondern auch bestimmte Phrasen. Vgl. z.B. Ps 10,4, - 5,11; Ps 53,2.

239 Siehe „Jewish Philosophical and Theological Responses to the Holocaust", op. cit. 
In Karol Rotgebers Tagebuch findet jene religiöse Haltung den vollsten Ausdruck, sowohl auf der Ebene der Klage:

Nichts nützt unser Flehen und Bitten. Jahwe hat seinen Blick von uns abgewandt. Es zürnt uns der Gott Israels (S. 124),

$[$ U]nser Gott $[\ldots]$, rette uns verirrte Schäfchen [...], erlass uns unsere Sünden [...], lass dich erweichen (S. 148),

als auch in der Erinnerungsnarration. Während der großen Liquidierungsaktion tröstet der Autor so seinen Bruder:

Sei frohen Mutes, auch wenn Israel bitter büßen muss, so gibt es doch keine Macht der Welt, außer der göttlichen, die uns vernichten könnte [...]. Für unsere Sünden tragen wir die Strafe davon, doch Gott in seiner Gnade wird den vollständigen Untergang abwenden (S. 106).

Jene messianische Hoffnung auf Erlösung teilte Rotgeber sicherlich mit so manchem gläubigen Juden im Ghetto. Ihre Quellen sind in der für den Judaismus fundamentalen Idee der Erwartung des Messias zu suchen, doch kann sie ihre Inspiration auch aus gar nicht lange zurückliegenden theologischen Diskussionen geschöpft haben. Kurz vor Kriegsausbruch zeichnete Rabbi Elchonon Wasserman, einer der größten Rabbiner der Vorkriegszeit, seine apokalyptische Vision vom Ende der Welt. Er formulierte die orthodoxe Leidenstheologie neu. 1938 besuchte er die Vereinigten Staaten und sah dort, angesichts der Tatsache, dass zahlreiche dortige Juden das Studium der Tora und der Traditionen aufgaben, die Apokalypse nahen. Er schrieb eine Broschüre namens Ikvasa di-Meshicha [Auf den Spuren des Messias], in der er den Juden wegen ihrer Abkehr vom Glauben eine schreckliche Vernichtung vorhersagte. Bis heute wird in orthodoxen Milieus allgemein geglaubt, dies sei eine Prophezeiung gewesen, die sich im Holocaust erfüllt habe. ${ }^{240}$ Wasserman kam 1941 durch die Hand der Nazis um.

Die apokalyptische Vision von der Ankunft des Messias, der Katastrophen, Unheil, Ausbrüche des Bösen und Zerstörungen vorhergehen sollten, war in der jüdischen Tradition tief verwurzelt. Die Ungeheuerlichkeiten des Holocaust konnten somit angeeignet und als „Geburtswehen“ vor dem Eintreffen des Messias interpretiert werden. Dahingehend deutet Aron Chaim Kaplan in seinem Tagebuch den Bewusstseinszustand zumindest eines Teils der gläubigen Juden von Warschau:

240 Siehe N. Solomon: „Czy Szoah wymaga radykalnie nowej teologii?“, op. cit., S. 138-139. 
28. Juni 1940

Als die unseligen Ereignisse zunahmen und der Feind uns sehr zusetzte, begannen immer mehr Menschen Zählungen anzustellen, wann der Tag des Jüngsten Gerichts eintreten und der Messias eintreffen werde [...]. [Man glaubte, dass] die Leiden eine Vorankündigung der Erlösung seien, sollten sie doch - wie Geburtswehen - die Ankunft des Messias einleiten (BŻIH 50, S. 118).

Auch Ringelblum erwähnt mehrmals apokalyptische Stimmungen und messianische Vorhersagen. ${ }^{241}$ Rabbi Huberband widmet diesem Phänomen eine eigene kleine Abhandlung mit dem Titel „Signs of the Messiah“, in der er zwölf Beispiele für im Ghetto umgehende kabbalistische Interpretationen der heiligen Bücher nennt. Sie sagten die Ankunft des Messias für das Jahr 5700 oder 5701 voraus $(1939-1941) .^{242}$

Karol Rotgeber zeichnet eine apokalyptische Landschaft und eine Vision der bereits nahenden Erlösung:

Leer ist es [...], Gespenster, Skelette [...]. Entsetzliches Klagen im Himmel. Der Berg Sinai beginnt zu rauchen. Blitz- und Donnerschlag. Eine mächtige Stimme ist zu hören, die durch die ganze Welt erklingt: „Ich bin der Herr, dein Gott, der dich aus dem Land Ägypten geführt hat, aus dem Sklavenhaus. “ [...] Mein Israel. Verzweifle nicht. Auch du wirst auferstehen, heiliger Glaube. Die Zeit ist da! Deine Schuld ist getilgt. Die helle Sonne senkt dir ihr Rund entgegen. Bald erstrahlt ein helles Morgen. Der Tag des Wunders wird kommen (S. 179).

Die unerschütterliche Überzeugung vom nahenden Sieg des Messias erfüllt Rotgeber mit überschäumender Energie und einem Gefühl außerordentlichen Triumphes, erneuert sich doch das Gesicht der Erde:

Der Sieger wird Gott allein sein. Er allein wird herrschen. Alle Brände und alles Morden, alle satanischen Einfälle waren vergebens. Die modrigen Dünste Europas verfliegen, nicht ein Hauch bleibt von ihnen. Die hochmütigen, unverschämten Mörder verschwinden. Frieden kehrt auf der Welt ein, zur Ehre Gottes. [...] Jahwe, hörst und siehst Du das? Ich werde zum Titanen, zum Riesen, die erlöschenden Pupillen hat neues Feuer entzündet, in die Hände kehrte Kraft zurück, und ich erhebe [sie] wie einst unser heiliger Moses, um die Siegesschale Jahwe zuzuneigen (S. 197-198).

241 Beispielsweise notiert er im März 1940: „Auf der Pańska-Straße, heißt es, sei ein Kind geboren worden, das sofort zu sprechen begann. Es habe weisgesagt, dass an Rosch ha-Schana die Erlösung der Juden eintreten solle, und sei dann gleich gestorben" (Bd. 1, S. 117). An anderer Stelle führt er kabbalistische Zählungen an, aus denen hervorgeht, der Krieg ende im Jahr 5700, also 1940. „Damit trösten sich die Juden derzeit“", kommentiert er (Bd. 1, S. 153).

242 Siehe S. Huberband: „Signs of the Messiah“, in: ders.: Kiddush Hashem. 
Das Feuer, von dem Rotgeber so häufig schreibt, wird so letztendlich zur Vorankündigung des Sieges, der Erlösung und des Triumphs. Hinter den Flammen, die das Ghetto - Menschen und Häuser - umlodern, wird das Antlitz des Messias sichtbar. Und nach dessen Ankunft „tritt Gerechtigkeit ein auf der Welt. Israel wird leben, stärker, mächtiger" (S. 43). Im Feuer - das die Körper der Menschen in den Krematoriumsöfen verzehrt - vollzieht sich ein Opfer und eine Wiedergutmachung. Von einem reinigenden Feuer sprach ebenfalls der bereits erwähnte Rabbi Wasserman kurz vor seinem Märtyrertod. Seine letzte Rede führt ein Augenzeuge an:

Es scheint, als werden wir im Himmel für Zaddikim (Gerechte) gehalten, wird doch von uns gefordert, mit unseren Körpern die Sünden Israels wiedergutzumachen. [...] Bald erfüllen wir die größte Mitzwa von allen - „mit Feuer hast du zerstört und mit Feuer wirst du wiedererrichten “ - das Feuer, das unsere Körper vernichtet, ist dasselbe Feuer, das das jüdische Volk wiedererrichtet. ${ }^{243}$

\section{5}

Karol Rotgebers Tagebuch ist ein erhabenes Glaubenszeugnis, erstellt im Abgrund der Ghettos. Am gegenüberliegenden Pol wäre Calel Perechodniks Tagebuch anzusiedeln - ganz anders in der Form, doch mit seiner klaren antireligiösen Aussage ein Spiegelbild jenes ersteren. Der Autor sucht auf kompromisslose Weise nach der Wahrheit über den Holocaust und über seine eigene Rolle in ihm. Er gelangt zu einer Ablehnung Gottes. Zwischen diesen beiden Extremen - dem Stoßgebet unerschütterlichen Glaubens vonseiten Rotgebers und den Schmähungen in Perechodniks Text - spielt sich der religiöse Diskurs im Ghetto ab. Für den Zweck der kontrastiven Darstellung möchte ich hier in Kürze jenen schmähenden Pol umreißen.

Hillel Zeitlin, der in seinen Gebetsmantel gehüllt auf den Umschlagplatz ging und der eine unvollendete Übersetzung der Psalmen ins Jiddische hinterließ, hat den Prozess beschrieben, in dessen Laufe das religiöse Leben im Warschauer Ghetto zurückging. Die auflehnende Haltung gegenüber Gott verbreite sich unter den religiösen Juden, sie glaubten nicht mehr an die Gerechtigkeit der

243 Diese Szene führt Rabbi Ephraim Oshry an, der den Holocaust in Kowno [heute Kaunas; Anm. d. Übers.] überlebte. Dort verfasste er seine sog. rabbinischen Responsen, die nach dem Krieg ins Englische übersetzt und publiziert wurden: E. Oshry: Responsa from the Holocaust, op. cit. Zitat nach: N. Solomon: „Czy Szoah wymaga radykalnie nowej teologii?"“, op. cit., S. 142. 
göttlichen Urteile, schreibt Zeitlin 1941. ${ }^{244}$ Gottes Schweigen wird für die Opfer zum Beweis gegen seine Existenz. Perechodnik fragt:

Gibt es einen Gott? Existiert irgendeine höhere Gerechtigkeit, die diese Welt regiert? Warum schweigt sie? Warum fallen keine Blitze vom Himmel? Warum tut sich die Erde nicht auf, um die Henker und Mörder der Kinder, Frauen und Greise zu verschlingen? (S. 114)

Da er keine Antwort findet, lehnt er sich gegen Religion und Tradition auf, verwirft die Doktrin des göttlichen Urteils als Verrücktheit. Er erhebt sich gegen seinen eigenen Vater, der „meint, dass die Ermordung des jüdischen Volkes die Folge von Sünden sei, die die Juden gegen Gott begangen hätten, dass diese ganze Katastrophe nach Gottes Willen geschehe“ (S. 150).

Perechodniks theologische Reflexion ist gekennzeichnet durch radikalen Widerspruch, Negation, Ablehnung. Mehrmals formuliert der Autor offen gotteslästerliche Äußerungen: „[I]ch glaube nicht an Gott und ich werde nie wieder an ihn glauben“ (S. 283). „Das heißeste Thema bot die Frage nach Gottes Gerechtigkeit. Ich lästerte ganz offen“ (S. 204). Nicht nur mit der Religion rechnet er grausam ab, sondern auch mit dem gesamten Judentum. Den Juden gibt er die Schuld am Hass der Deutschen auf sie, und im Judaismus sieht er eine Doktrin, die ihre Bekenner vom Leben abschneide und ins Verderben führe. Hier eine Stelle aus Perechodniks gotteslästerlicher Tirade. Ihr pathetischer Stil - Reihen von rhetorischen Fragen und Apostrophen, eine expressive Wortwahl und bildliche Darstellung - scheint in der Tradition der großen Anklagereden zu stehen:

Vielleicht hat uns Gott auserwählt, aber wofür? Dafür, daß wir der Sündenbock aller Völker sind, daß wir verantwortlich sein sollen für alle Sünden der Welt? [...] Ja, die jüdische Religion trennte uns durch eine chinesische Mauer von anderen Völkern ab, sie prägte uns eine Sonderpsyche ein und gebot uns, die Knaben zu beschneiden. Wir stempelten uns freiwillig nicht etwa mit dem Zeichen der Einheit mit Gott, sondern mit dem Todesstempel, der uns nach Treblinka brachte. [...] Heutzutage bekommen wir eine Kostprobe davon, wie gut es ist, in der mächtigen Obhut Gottes zu sein. [...] Vielleicht gibt es einen Gott auf dieser Welt, umso schlimmer für ihn - offensichtlich ist es ein Gott der Starken und Mächtigen und nicht der Schwachen und Benachteiligten. Und wenn es gar keinen Gott gibt, dann gibt es keinen Grund zu streiten (S. 248-250).

244 Siehe N. Polen: The Holy Fire. The Teachings of Rabbi Kolonymus Shapira, the Rebbe of Warsaw Ghetto, Northvale, New Jersey 1994, S. 81-82 (dort wird eine Stelle aus den überlieferten Schriften Zeitlins zitiert). 
Die Welt des Holocaust ist eine Welt ohne Gott, ähnlich wie bei Tadeusz Borowski Birkenau ein „Königreich des Bösen“ ist, „wo es keinen Gott gibt“245. Im Gedicht eines unbekannten Autors, das sich im zweiten Teil des RingelblumArchivs befindet, wiederholt sich die Titelfrage: „Wo ist Gott?“:

Dort wo der Himmel war

Gehen Juden im Sträflingszug in den Tod.

Zerbrochen die Tafeln - zertreten die Gesetze,

Ringsum herrscht Dunkel und Grau.

Ein Volk kommt um - die Mörder kümmert kein Gebot -

Wo ist Gott? ${ }^{246}$

Mit dieser Frage korrespondiert das auf arischer Seite verfasste Gedicht eines anonymen polnischen Arbeiters, „Płonące getto“ [Das brennende Ghetto]. Der Autor beobachtet von der anderen Seite der Mauer die Vernichtung des Warschauer Ghettos und fragt: „[G]ibt es denn keinen Gott?“247. Der Tod Gottes bewahrt - paradoxerweise - einen alptraumhaften Sinn dieser Vernichtung. Wenn es nämlich Gott tatsächlich gibt, dann muss es auch einen Grund für das ganze Böse geben - und ein solcher Grund ist schließlich unmöglich zu finden und zu begreifen. Da es Gott aber nicht gibt, „gibt es keinen Grund zu streiten“, wie Perechodnik schreibt. Die radikalste Konsequenz aus einem derartigen Gedankengang zieht wohl Jitzhak Katzenelson. In seinem Großen Gesang vom ausgerotteten jüdischen Volk, in dem er den grauenerweckenden „Kessel“ auf der Miła-Straße schildert, schreibt der Dichter:

\author{
[...] Hört! Hört alle her: 's ist gut \\ Dass Gott sich hier nicht sehen läßt, in der Mila gibt's ihn nicht \\ [...] \\ Und noch viel ärger wäre alles, gäb es doch 'nen Gott \\ Hier Gott und hier die Mila - na, das gäb ein hübsches Paar \\ $\mathrm{O}$ reißt sie aus den Koffern wieder raus, aus dem Versteck \\ Und schleudert sie, zerschmettert eure Kinder an der Wand \\ Und zündet Scheiterhaufen an, ringt eure Hände, springt
}

245 T. Borowski: „**(Drutami okolony skrawek świata ...)“ [Von Stacheldraht umgebenes Stückchen Welt], in: Poezje [Gedichte], Warschau 1972, S. 73.

246 Zitat nach: Archiwum Ringelbluma, op. cit., S. 221. Die polnische Übersetzung erfolgte auf Grundlage einer philologischen Übersetzung aus dem Jiddischen von H. Piasecki, A. Rozenfeld [meine deutsche Fassung ist somit die Übersetzung einer Übersetzung, Anm. d. Übers.]

247 Das Gedicht befand sich in einer 1943 im Warschauer Untergrund herausgegebenen Broschüre von M. Kann: Na oczach świata [Vor den Augen der Welt]. 
Ins Feuer und zerreißt die Kleider, reißt euch aus das Haar Denn gäb's hier einen Gott, das wär 'ne Ungerechtigkeit Für diese Menschen, Hohn! und was für eine Affenschand! ${ }^{248}$

Die Zeichen für Werte wurden hier verdreht und in ihr Gegenteil verkehrt. Die Abwesenheit Gottes wird normal und verständlich, sie bekommt einen Sinn. Nicht hinnehmbar ist der Gedanke, Gott könnte bei all den entsetzlichen Erfahrungen jener Welt dennoch existieren. Gott und die Miła-Straße schließen einander vollkommen aus.

\section{Das Martyrologium des Rabbi Szymon Huberband}

Karol Rotgebers Religiosität erwuchs sicherlich aus seiner Familientradition, über die wir nichts wissen, und bildete sich unter dem Einfluss seiner Lebenserfahrungen weiter aus. Seine religiöse Bildung kann nicht über das Durchschnittsniveau hinausgegangen sein, das einem gläubigen Juden normalerweise zuteilwurde. Rotgeber, Absolvent einer siebenklassigen Handelsschule in Warschau sowie einiger zahntechnischer berufsbildender Kurse, steht neben Rabbi Szymon Huberband als zufälliger Passant neben einem Schriftgelehrten.

Der 1909 in Chęciny bei Kielce geborene Huberband stammte aus einer Familie mit einer reichen religiösen Tradition und wuchs in einer Atmosphäre auf, wie sie für das chassidische Milieu charakteristisch war. ${ }^{249}$ Seine Mutter war eine

248 J. Katzenelson: Großer Gesang vom ausgerotteten jüdischen Volk, op. cit. Zwölfter Gesang, S. 128-131 [im jiddischen Original: „noch gut wos s' is kejn Gott nito ... s' is take/schlecht ohn ihm, o sejer sejer, schlecht!/nor tomer wolt er sein wolt erger noch/ gewen! i Gott un i die Mila gass ... as a a por!/o nemt arojs die kinder eiere bahaltn in/ walises, schleidert sej, zeschmetert sej on want!/zindt feiern grojss on uns springt ahin arein/mi hent varbrochn, reisst sich bei die hor:/ s' is do a Gott! umgerechtikejt asa!/a spot asa! un grojss asa a schand!"]

$249 \mathrm{Zu}$ Szymon Huberband siehe G. Hausners Vorwort zur englischen Ausgabe seiner Schriften Kiddush Hashem, op. cit. (Huberband schrieb auf Jiddisch und wurde bis jetzt ins Hebräische und Englische übersetzt); T. Kuberczyk: „Życie religyjne w getcie warszawskim w relacji rabina Szymona Huberbanda“ [Das religiöse Leben im Warschauer Ghetto im Bericht von Rabbi Szymon Huberband], in: D. Grynberg, P. Szapiro (Hg.): Holocaust z perspektywy półwiecza. Pięćdziesiąta rocznica powstania w getcie warszawskim. Materiały z konferencji zorganizowanej przez Żydowski Instytut Historyczny $w$ dniach 29-30 marca 1993 [Ein halbes Jahrhundert nach dem Holocaust. Der fünfzigste Jahrestag des Warschauer Ghettoaufstands. Materialien von einer Konferenz des Jüdischen Historischen Instituts am 29.-30. März 1993], Warschau 
Tochter des Zaddik von Chęciny, Samuel Lewy Hurwicz, er selbst heiratete eine Tochter des Rabbiners Jakub Arie Glazer, eines religiösen Richters in Piotrków, und seine zweite Ehefrau war eine Tochter des Bezirksrabbiners von Praga, Jakub Zylbersztajn. Sein älterer Bruder leitete in Warschau eine Jeschiwa, deren Gründer und Schirmherr Rabbi Klonimus Kelmisz Szapiro war, der Zaddik aus Piaseczno. Huberbands geistige Formung und religiöse Erziehung ergänzte sich gut mit seinen vielfältigen wissenschaftlichen und seinem journalistischen Interesse. Er schrieb Artikel zum Thema jüdische Ethik und jüdisches Recht, befasste sich mit Numismatik und Medizingeschichte, studierte alte jüdische Schriften und Dokumente aus den Archiven des Kahal [der jüdischen Gemeinde]. Seine Arbeiten erregten die Aufmerksamkeit des bekannten Historikers Majer Balaban. Dank seiner Zusammenarbeit mit der Zeitschrift „Socjaler Medicine“ lernte er auch Emanuel Ringelblum kennen.

Der Krieg erreicht Huberband in Piotrków, wo er ab 1928 mit seiner Familie lebt. Bereits im September 1939 kommen seine erste Ehefrau, sein 10-jähriger Sohn und sein Schwiegervater durch deutsche Bomben um. Im Frühjahr 1940 geht Huberband nach Warschau, nimmt dort die Stellung als Leiter der Religionsabteilung bei der Jüdischen Sozialen Selbsthilfe an, tritt der konspirativen Organisation Oneg Schabbat bei, die das Untergrundarchiv des Ghettos erstellt. Es ist sehr wahrscheinlich, dass der einfache Jude Karol Rotgeber und der gebildete Rabbiner Szymon Huberband einander begegneten, gelangten doch beide in den Shop der Heeresunterkunftsverwaltung [im Orig. deutsch; Anm. d. Übers.], der sog. „Bürstenmacher“. Für beide war dies die letzte Adresse im Ghetto. Rotgeber überlebte die große Liquidierungsaktion, schlug sich auf die arische Seite durch und versteckte sich dort. Huberband wurde am 18. August 1942 bei der Selektion in der „Bürstenfabrik“ zum Umschlagplatz mitgenommen (am selben Tag, an dem Rotgebers Sohn aus Toebbens' Shop geholt wurde). Ringelblum, der eine Liste der Verluste bei der Warschauer jüdischen Intelligenz führt, notiert im Dezember 1942:

Die Verbrecher achteten bei dieser Selektion nicht auf Dokumente, nur auf Gesichter. Das bleiche, eingefallene, vom Hunger gezeichnete Gesicht Rabbi Huberbands fand keine Gnade bei den Mördern der SS. Zusammen mit den anderen wurde er direkt in den Waggon getrieben, anschließend dann nach Treblinka ins Todeslager deportiert (Bd. 1, S. 452).

[ohne Jahresangabe]; R. Sakowska, Anmerkungen der Herausgeberin zu Archiwum Ringelbluma, S. 255-157. 
Rabbi Huberband trug mit seinen Schriften aus dem Ghetto zur Entstehung des Untergrundarchivs bei. Er vermehrte die Archivsammlungen um eine beträchtliche Zahl an Texten (rund vierzig Arbeiten, Abhandlungen, Thesen). Mit der Aufzeichnung seiner persönlichen Dokumentation jedoch begann er erst an der Schwelle des Krieges. Sein erster chronologischer Text umfasst die Zeitspanne von März bis September 1939 und trägt den Titel Doświadczenia wojenne obywateli żydowskich [Kriegserfahrungen jüdischer Bürger]. Seinen Bericht über die ersten Kriegsmonate, der zu einer eigenen Chronik der religiösen Verfolgung wird - Die jüdischen Feiertage im Jahr 5739 (September 1939 - Juni 1940) [Originaltitel auf Jiddisch; Anm. d. Übers.] - beginnt er in Piotrków, von wo er im März 1940 nach Warschau umzog. Im Ghetto wurde er zu einem der engsten Mitarbeiter Ringelblums, der sich stets mit Hochachtung und Sympathie über ihn äußerte und seine intellektuellen Fähigkeiten, seine Offenheit und Umgänglichkeit. ${ }^{250}$ Die Begegnung mit Ringelblum gab also Huberbands bereits vorher bestehender Tätigkeit nur einen neuen Impuls. Sie verstärkte und festigte sein Bedürfnis zu schreiben, gestattete ihm, sich in ein großes historisch-dokumentatives Vorhaben einzubringen.

Die Herausgeber der englischen Übersetzung von Huberbands Schriften unterteilen sie in vier Themengruppen: (1) autobiographische Materialien, (2) Alltagsleben und Tod im Warschauer Ghetto, (3) jüdisches religiöses Leben

250 „Gleich in den ersten Monaten, nachdem ich die Arbeit bei »Oneg Schabbat« angenommen hatte“, schrieb Ringelblum, „holte ich mir ein paar Leute zur Mitarbeit, doch das war mir kaum von Nutzen. Erst in der Person eines jungen Historikers, Rabbi Szymon Huberband, fand "Oneg Schabbat" einen der besten Mitarbeiter" (Bd. 1, S. 472). An anderer Stelle ist eine solche Bewertung zu lesen: „Rabbi Szymon Huberband, ein Mensch von edlem Charakter - was in den heutigen Zeiten überaus selten anzutreffen ist" (Bd. 1, S. 451). Als er über die Atmosphäre der Toleranz unter den Oneg-Schabbat-Mitarbeitern berichtet, notiert Ringelblum: „Viele Monate lang saßen sie an zusammen einem Tisch: der gottesfürchtige Rabbi Huberband und der linke Poale-Zion-Anhänger Hersz Wasser" (Bd. 1, S. 494). Hier muss daran erinnert werden, dass Ringelblum selbst ein linker Intellektueller war. Verwunderlich ist, dass es bis heute keine einzige polnische Übersetzung der Texte Huberbands gibt (er schrieb auf Jiddisch) - außer einer Arbeit, die hebräische Berichte über die slawischen Länder aus dem frühen Mittelalter analysiert und keinerlei Bezug zum Warschauer Ghetto aufweist. Huberbands Schriften sind, soweit ich weiß, die reichste Quelle zur Problematik des religiösen jüdischen Lebens zur Besatzungszeit, dennoch werden sie in der polnischen Historiographie so gut wie nicht genutzt (über die Erkundung Huberbands durch Historiker schreibt T. Kuberczyk, op. cit.). 
im nazibesetzten Europa, (4) die Vernichtung der osteuropäischen Juden. Zu einer anderen Einordnung führt die Anwendung des Kriteriums der Diskursart. Aus einer solchen Perspektive wird Huberbands Erbe vom Typ des religiösen Diskurses dominiert, der in jeder der aufgeführten Themengruppen aufscheint. Seine Anwesenheit ist nämlich themenunabhängig, sie ist einfach eine Art der Konstruktion von Aussagen über die Wirklichkeit, eine Art des Sprechens über die Welt.

In den Texten, die von den Herausgebern zur Gruppe „jüdisches religiöses Leben“ gezählt werden, tritt der religiöse Diskurs noch am wenigsten deutlich zutage. Huberband spricht dort vor allem als Historiker, der die unterschiedlichen Erscheinungen religiösen Lebens und verschiedenen Tätigkeitsformen im Zusammenhang mit der jüdischen Religion vor und nach der Einrichtung des Ghettos dokumentiert. Er zeichnet demnach die Geschichte des höheren religiösen Schulwesens im besetzten Warschau und der chassidischen Warschauer Jugend, beschreibt Schabbatfeiern, die Abläufe in den Mikwaot, die Durchführung von rituellen Schlachtungen während der Repressionen und Verbote, schreibt über die Tätigkeiten der Rabbiner im Ghetto, Rechtsfragen, den Gegenstand religiöser Bräuche und Bücher, die Kleidung. Ein Text handelt auch vom moralischen Leid und moralischen Verfall jüdischer Frauen. Deutlichen Dokumentcharakter haben des Weiteren einige Texte über das Alltagsleben im Ghetto, z.B. „Kriegsfolklore“, „Wie Juden einander Geld aus der Tasche ziehen“ oder „Das Bildvorführgerät im Ghetto“ - der erhaltene Teil einer ganzen Serie namens Vergnügungsorte im Ghetto [Originaltitel auf Jiddisch; Anm. d. Übers.]. Hier tritt der Verfasser in der Rolle eines Chronisten des Alltags auf, der ein Mosaik verschiedenster - lustiger und rührender, erschreckender und abstoßender, allesamt jedoch für den geschlossenen Bezirk charakteristischer Phänomene festhält. Ein andermal verlässt er die Position des unpersönlichen Chronisten oder Historikers und nimmt eine subjektive, individuelle Sichtweise ein. In der Gruppe der autobiographischen Materialien befindet sich unter anderem eine Schilderung der Erlebnisse Huberbands im Sommer 1940 auf dem Areal der SS-Automobilwerkstätten in Dynasy - einer berüchtigten Folteranstalt für Juden, die von den Deutschen in der Anfangszeit des Krieges direkt von den Straßen aufgegriffen und hierher verschleppt wurden. Es gibt auch einen Bericht über das Lager in Kampinos, wo der Verfasser von April bis Mai 1941 bei der Melioration der umliegenden Wiesen mitarbeiten musste. Jene Texte drücken den Typus der Erinnerungsnarration aus, der bei den persönlichen Dokumenten aus dem Ghetto am häufigsten vertreten ist.

Der religiöse Diskurs stützt sich bei Huberband - ganz allgemein gesagt auf eine semantische Struktur mit zwei Ebenen. Die Schilderung konkreter 
Ereignisse, Menschen, Situationen wird zum Exempel für religiöse Wahrheiten; die geschichtliche Ordnung gibt eine ewige Ordnung frei, der weltlichen Zeit entströmt eine sakrale Zeit. Ein solcherart verstandener Diskurs verläuft gewissermaßen quer durch die gesamte thematische Unterteilung.

Bei den Texten autobiographischen Charakters dominiert der religiöse Diskurs vor allem in der umfassenden Arbeit Die jüdischen Feiertage im Jahr 5739. Der Rhythmus der Narration wird hier bestimmt durch die aufeinanderfolgenden Feiertage eines vollen liturgischen Jahres; der Rahmen und die einzelnen Erzählphasen sind Maßstäben von außerhalb der Geschichte, außerhalb des Vergänglichen untergeordnet. In diesem Kontext ändert die Formel der Narration in der ersten Person ihre Funktion - sie durchläuft eine Entindividualisierung. Das private Erleben repräsentiert hier das Drama des von Gott auserwählten Volkes. Von den antijüdischen Repressionen in Piotrków und später im besetzten Warschau wird aus der Perspektive des kollektiven Schicksals berichtet, deren jetzige Geschichte auf dem Urbild der biblischen Geschichte Israels gründet.

Ein Kapitel dieser Arbeit, „Purim 5700 in Warschau (24. März 1940)“, widmet sich zur Gänze den antijüdischen Ausschreitungen jenes Frühjahrs. Hier ist eine kleiner geschichtlicher Rückgriff vonnöten, geht doch das allgemeine Wissen über diese Ereignisse gegen Null, und die diesbezügliche Geschichtsschreibung äußerst dürftig und unvollständig. ${ }^{251}$ In der Anfangsphase der Besatzung, vor der Einrichtung des Ghettos, wurden Juden häufig von Gruppen polnischer Halbwüchsiger auf der Straße angefallen. Davon künden zahlreiche Aufzeichnungen, besonders vom Januar, Februar, März 1940, in den Tagebüchern Kaplans, Czerniakóws, in Landaus Kronika und bei Ringelblum. Letzterer wurde am 30. Januar 1940 Opfer eines solchen Angriffs: „Im Sächsischen Garten“, schreibt

251 Am umfassendsten wird diese Sache von T. Szarota dargestellt, der sie vor dem Hintergrund ähnlicher Vorkommnisse in Paris, Prag, Amsterdam, Den Haag, Antwerpen, Oslo, Kopenhagen und auch in Litauen, Lettland, Weißrussland und der Ukraine abbildet. „All diese Vorfälle hatten zwei gemeinsame Eigenschaften - einerseits die Beteiligung von lokalen Faschisten und Antisemiten, andererseits die Inspiration, Unterstützung oder jedenfalls billigende neutrale Haltung vonseiten der deutschen Obrigkeit“ („Zajścia antyżydowskie i pogromy w okupowanej Europie“ [Antijüdische Vorfälle und Pogrome im besetzten Europa], in: D. Grynberg, P. Szapiro (Hg.): Holocaust z perspektywy półwiecza, op. cit., S. 154). Über den Warschauer Pogrom sei in der polnischen Historiographie „entweder gar nicht geschrieben worden oder nicht viel, und das fehlerhaft“ (S. 167). Von den beiden historischen Monographien des Warschauer Ghettos - R. Sakowska: Ludzie z dzielnicy zamkniętej, op. cit., sowie I. Gutman: Żydzi warszawscy 1939-1943, op. cit., - erwähnt nur Letztere die Exzesse jenes Frühjahrs (S. 52-55). 
Ringelblum, „erspähte eine Bande polnischer Raufbolde im Alter von 14, 15 Jahren mich mit meiner Armbinde. Ich kam nur knapp mit dem Leben davon" (S. 85). Den Höhepunkt erreichten diese Ausschreitungen, die fast zu einem regelrechten Pogrom wurden, um Ostern 1940 herum. Sie waren auf eine für diese Art Ereignisse klassische Weise provoziert worden: Ein polnischer Junge hatte von einem Stand in der Markthalle am Mirowski-Platz einen Apfel geklaut und war von den jüdischen Händlern festgehalten und verletzt worden. Darauf kam ein Gerücht über die Ermordung eines christlichen Kindes in Umlauf und eine aufgepeitschte Menschenmenge schritt zur Tat. Die Vorfälle dauerten vom 22.-29. März: Scheiben von Ladenlokalen wurden eingeschlagen und die Läden geplündert, Wohnungen ausgeraubt, Passanten mit Armbinden malträtiert, antisemitische Parolen gebrüllt. Es besteht kein Zweifel, dass die Exzesse von den Deutschen angeregt worden waren und den von ihnen angestrebten propagandistischen Nutzen bringen sollten: die Polen zu kompromittieren und die Deutschen als heldenhafte Verteidiger der vom polnischen Pöbel geprügelten Juden darzustellen (die Vorfälle wurden photographiert) sowie einen Grund für die Einrichtung des Ghettos zu liefern, das die Juden vor den antisemitischen Polen schützen sollte. Jedoch hätten „die Deutschen selbst solche Banden nicht organisieren können, also musste jemand von den Polen ihnen geholfen haben, nur wer?", fragt Tomasz Szarota ${ }^{252}$.

In den seinem Text übergeordneten religiösen Diskurs flicht Rabbi Szymon Huberband eine genaue Schilderung der Begebenheiten ein (und sein Bericht ist stellenweise geradezu ,journalistisch“, dramatisch und spannend - besonders

252 „Zajścia antyżydowskie i pogromy w okupowanej Europie“, op. cit., S. 169. Der Autor zitiert Landaus Kronika (27. März 1940): Landau nimmt an, dass hinter dem Pogrom "die auf antisemitische Aktionen spezialisierte »Atak«-Gruppe“ gestanden habe (in der Marszałkowska-Straße 114/5 befand sich Anfang 1940 ein Verlag, der eine in Kooperation mit den Deutschen gegründete, am »Stürmer orientierte Zeitschrift namens »Atak« herausgab). Die polnische Untergrundzeitschrift „Biuletyn Informacyjny“ [Informationsbulletin] vom 29. März 1940 nennt als wahrscheinliche Organisatoren Andrzej Świetlicki (beteiligt im Herbst 1939 am Gründungsversuch einer polnischen Entsprechung der NSDAP, erschossen im Juni 1940 in der Gestapo- und SS-Hinrichtungsstätte Palmiry), den Geistlichen Stanisław Trzeciak (einer der führenden Antisemiten beim polnischen Klerus der Zwischenkriegszeit, ermordet von den Deutschen bei Beginn des Warschauer Aufstands) sowie Prof. Zygmunt Cybichowski (der möglicherweise, wie Szarota bemerkt, mit seinem Sohn Jerzy verwechselt wurde. Jerzy Cybichowski stand vor dem Krieg mit der illegalen national-radikalen Bewegung Falanga und wahrscheinlich auch mit Andrzej Świetlicki in Verbindung, er kam im Mai 1943 als Untergrundsoldat um). 
die Szenen des jüdischen Widerstands und der Selbstverteidigung in der Nalewki-Straße). Der Alptraum der ersten Kriegsmonate, die allgegenwärtigen Verfolgungen und Repressionen und schließlich der Pogrom werden zum Hintergrund für seine Erzählung über die jüdischen Feiertage. Gegenstand von Huberbands Narration sind weniger die antijüdischen Repressionen als die Enthüllung eines dramatischen Ringens zwischen der Gewalt des Bösen, das in die Ordnung des Sacrum eindringt, und der unverbrüchlichen Gläubigkeit der Juden, die heroische Glaubenszeugnisse ablegen. Im Kontext eines so entwickelten Diskurses wird der Bericht über den Pogrom in den bereits vorher ausgearbeiteten Interpretationsrahmen eingefügt. Der Pogrom wird zum weiteren Glied in der Kette der Ereignisse, deren Sinn weit über ihren faktographischen Wert hinausgeht. Die Erzählung offenbart die universale Dimension der jüdischen Erfahrung den Versuch, angesichts eines Angriffs auf das Sacrum weiterhin am Glauben festzuhalten. Die antijüdischen Ausschreitungen in Warschau im Frühling 1940 waren nicht mit Akten der Profanierung verbunden, die Verfolgungen vom Inhalt her nicht im engeren Sinne religiös motiviert. Sie wichen in nichts von traditionellen antijüdischen Zusammenrottungen ab. Eingegliedert in das Umfeld eines religiösen Diskurses jedoch nehmen sie Bedeutungen an, welche andere Berichte nicht aufweisen. Huberband, der stets den Fakten treu bleibt, erzählt einfach auf andere Weise als Ringelblum, Aron Chaim Kaplan oder Ludwik Landau. ${ }^{253}$

253 Eine genauere Analyse der „Pogromberichte“ ist an dieser Stelle nicht möglich, daher beschränke ich mich auf ihre Lokalisierung. Kaplans Tagebuch: Einträge vom 26., 27., 28. und 30. März 1940; Das Tagebuch des Adam Czerniaków: Einträge vom 24. und 28. März 1940; E. Ringelblums Kronika getta warszawskiego: ausführliche Einträge unter den Daten: 27., 28., 29., 30. März 1940; L. Landaus Kronika lat wojny $i$ okupacji: ausführliche tägliche Einträge vom 24.-30. März 1940. Szarota nennt noch die „Zapiski Stanisława Srokowskiego wrzesień 1939-sierpień 1940“ [Notizen des Stanisław Srokowski September 1939-August 1940], Archiv der Polnischen Akademie der Wissenschaften PAN, Sign., III-22 („Zajścia antyżydowskie i pogromy w okupowanej Europie“, op. cit., S. 167), und I. Gutman die Aussage eines Augenzeugen des Pogroms, der kurz darauf Polen verlassen konnte, nach Palästina ging und dort dem Vereinigten jüdischen Hilfskomitee für die polnischen Juden Bericht erstattete (op. cit., S. 54). Eine Bestätigung dafür, dass Huberbands Schriften von den Historikern nicht genutzt werden, ist die Tatsache, dass keine der Abhandlungen - selbst Tomasz Szarotas für dieses Thema fundamentaler Artikel - die umfängliche und faktenreiche Berichterstattung des Rabbiners über den Pogrom anführt. 
Um die Tradition aufzuzeigen, in der Huberbands religiöser Diskurs wurzelt, und um das Gattungsmuster seines Martyrologiums - einer Geschichte über heilige Märtyrer des Glaubens - zu rekonstruieren, gilt es, zum Anfang unseres Zeitalters zurückzukehren. Von da an wird nämlich das umfassende und äußerst verschiedenartige jüdische Schrifttum (rechtliche, theologische, ethische, philosophische oder poetische Texte, die auf die Bibel als Urquelle zurückgehen und eine mündliche Erzähltradition repräsentieren) einer systematischen Ordnung unterzogen. Das so entstehende mächtige Textkorpus besteht aus der Halacha und der Haggada.

Der Begriff halacha bedeutet „Art und Weise“ oder „Weg“. Mit diesem Namen wird der Teil der jüdischen Lehre bezeichnet, der die rechtliche Seite des Judaismus betrifft, bei der es um Rituale und Verhaltensnormen im Alltagsleben geht. $\mathrm{Zu}$ den halachischen Schriften gehören die Mischna und der Talmud. Die Haggada wiederum (abgeleitet vom Wort hagged - „Hinweise geben“) repräsentiert den Teil der mündlichen Tradition nicht-rechtlichen Charakters. Sie setzt sich aus zwei grundlegenden Textgruppen zusammen: Materialien von legendär-historischem Charakter sowie ethisch-theologischer Literatur. Zu den Schriften der Haggada gehören die Midraschim ${ }^{254}$.

Bis Ende des zweiten Jahrhunderts n. Chr. dauerte die redaktionelle Bearbeitung der Mischna. Die Schriftgelehrten der damaligen Zeit - die Tannaiten erarbeiteten und wandten in ihren Tora-Studien grundlegende exegetische Regeln an. Nach diesen interpretativen Regeln gelesen, enthält die Bibel ein universales Geschichtsmodell und einen zu ihrem Verständnis unentbehrlichen Schlüssel. Damit können die nacheinander eintretenden geschichtlichen Ereignisse als Erfüllung eines biblischen Musters verstanden werden. Alles, was geschah, geschieht oder geschehen wird, lässt sich im Lichte des Dialogs zwischen Gott und Mensch interpretieren, der auf den Seiten der Bibel dargestellt ist. Um Vergangenheit, Gegenwart und Zukunft zu verstehen, muss man sie in die liturgische Formel der Geschichte einschreiben. ${ }^{255}$

Mit anderen Worten: Die Geschichte der Juden nach der Zerstörung des Tempels durch die Römer wird nach einem bestimmten Narrationsschema erzählt. Über Ereignisse wird nicht nur um ihrer selbst willen gesprochen, es geht nicht allein um Dokumentation oder Verzeichnung von Fakten. Die dargestellten

254 Siehe „Literature, Jewish“ (Abschnitt „Early beginnings to the medieval period“), in: Encyclopaedia Judaica, op. cit.

255 Vgl. D.G. Roskies: Against the Apocalypse, op. cit., S. 25. 
Ereignisse sind gewissermaßen nicht eigenständig, sie stellen den Teil eines größeren Ganzen dar. Sie weisen auf das Wesentlichste hin - auf das biblische Paradigma. Erst im Bezug auf jenes Muster nehmen sie einen Sinn an. Und um jenen Sinn zu enthüllen, wird über die Ereignisse berichtet.

Die Zeit der Tannaiten, die nach der Zerstörung Jerusalems im Jahr $70 \mathrm{n}$. Chr. und der Zerstreuung der Juden in alle Himmelsrichtungen eintrat und die gekennzeichnet war durch die blutige Niederschlagung des Bar-Kochba-Aufstands (132-135 n. Chr.), war eine Phase der ständigen Katastrophen. In jener Epoche der Niederlagen suchte die in ihrer Existenz bedrohte Gemeinschaft der Juden eine Antwort auf die Frage nach dem Grund für all das Unheil. Die religiösen Verfolgungen unter Kaiser Hadrian (132-138) machten eine Erklärung dieser Kette von leidvollen Erfahrungen notwendig. Die Haltung, die sich damals herauszukristallisieren begann, sollte zum Fundament für die gesamte spätere Tradition werden. Es handelt sich dabei um die klassische jüdische Antwort auf eine Katastrophe; man könnte sie die Kanonisierung der Erinnerung nennen. Die frührabbinische Hermeneutik der Leiden des jüdischen Volkes schreibt diese Leiden in ein biblisches Paradigma ein und macht sie damit zu einem Bestandteil der Liturgie, heiligt sie gewissermaßen. Die Verfolgungen werden zu Gliedern derselben Kette - vom Auszug aus Ägypten bis zur Jetztzeit. Somit hat die Zeit der Tannaiten etwas viel Bedeutenderes hinterlassen als nur eine Chronik der Verfolgung - wurde damals doch ein ganzes System zur Codierung von Ereignissen eingeführt, eine Methode zur Verzeichnung der historischen Wirklichkeit, zu deren Modellierung gemäß einer liturgischen Ordnung. Dem Kalender wurden neue Daten und dem Kanon neue Gebete hinzugefügt; die Gegenwart entdeckte ihre Verwurzelung in der Ordnung der Archetypen ${ }^{256}$.

Im rabbinischen Schrifttum aus tannaitischer Zeit bildete sich die Gattung der martyrologischen Erzählung heraus. Sie wird repräsentiert durch das Traktat Semahot („Trauergesang“, „Klage“), das aus acht Kapiteln besteht, die sich vorwiegend rechtlichen Vorschriften zum Thema Tod und Trauer widmen. Am wesentlichsten für dieses Gattungsmuster ist die Art der Narration. Das Traktat handelt von den Rabbinern des ersten und zweiten Jahrhunderts - was sie in ihrem Leben vollbrachten, wie sie starben. Ihre Biographien wurden gemäß dem Muster der Geschichten über biblische Patriarchen verstanden; wichtig war nicht so sehr der Lebenslauf eines Schriftgelehrten wie der Sinn, der sich aus

256 Zum Begriff „Kanonisierung der Erinnerung “ und zum Prozess, in dessen Verlauf sich eine jüdische Antwort auf die Katastrophe herausbildete, siehe D. G. Roskies, op. cit., Kap. „The Liturgy of Destruction“. 
dessen Leben ablesen ließ. Konkrete Taten verwandelten sich im Erzählprozess in Exempel. Ihre Rolle bestand darin, das Beispiel eines Heldentods für den Glauben zu geben; sie schufen ein Vorbild für ein gutes Sterben. Statt der Form einer biographischen erhielt die Erzählung die Form einer hagiographischen Narration.

Das Traktat Semahot spielt eine wichtige Rolle bei der Herausbildung der Idee des Märtyrertums und des Märtyrerbegriffs in der jüdischen Tradition. Die erste Phase dieses Prozesses stützt sich auf biblische Texte und führt zur Festlegung eines Modells märtyrerhaften Verhaltens. Die drei jungen Männer aus dem Buch Daniel (1,1-7; 3,13-30), die Nebukadnezar zum Kniefall vor einem goldenen Standbild zwingen will, geben dem Druck nicht nach und werden in einen glühenden Feuerofen geworfen. Doch die Flammen lassen sie unberührt. Gott vollbringt ein Wunder und rettet seine Anhänger, die bereit gewesen sind, für ihren Glauben zu sterben. Doch die lange Reihe von Leiden und Verfolgungen hinterlässt eine reiche Ernte des Todes, der nach einer Begründung verlangt. Gott schützt seine Bekenner bereits nicht mehr vor dem Feuer - im Gegenteil, es entzünden sich immer neue Flammen, die ihre Körper verzehren. Daher wird in der nächsten Evolutionsphase der Idee des Märtyrertums, die sich auf Quellen aus der postbiblischen Epoche bezieht, vor allem die Unschuld des Märtyrers und dessen freiwilliges Opfer betont. Die Konzeption, derzufolge der Tod der Gerechten das erste Symptom des herannahenden Bösen ist, übermittelt das erwähnte Traktat Semahot. Es ist ein Martyrologium zum Gedenken an die Schriftgelehrten, die während Kaiser Hadrians Herrschaft den Märtyrertod starben. ${ }^{257}$

Der circa drei Jahrhunderte später vollständig redigierte Babylonische Talmud beschreibt die letzten Momente des Rabbi Akiba wie folgt:

„In der Stunde, als sie herausführten den R. Akiba zum Tode, war es Zeit zu lesen das Schema [Schma; Anm. d. Übers.]; und sie zerrissen sein Fleisch mit eisernen Hecheln, er aber nahm auf sich das Joch des Himmelreiches [Erläuterung 27: dass er das Schema las]. Es sagten zu ihm seine Schüler: Unser Lehrer! bis hierher [Erl. 28: er sollte aufhören zu beten]. Er sagte zu ihnen: Lebenslang habe ich mich betrübt wegen dieses Verses: „Mit deiner ganzen Seele,“ (nämlich) sogar wenn man dir nimmt die Seele. Ich dachte, wann wird dies sich mir ereignen, dass ich es erfülle, und jetzt, da es sich mir ereignet hat, soll ich es nicht erfüllen? Er hielt an bei Echad [Erl. 29: Welches bedeutet,

257 Zum Traktat Semahot und der Herausbildung der Idee des Märtyrertums in der tannaitischen Zeit siehe D.G. Roskies, op. cit., S. 27-32; D.G. Roskies (Hg.): The Literature of Destruction. Jewish Responses to Catastrophe, Philadelphia 1988 (Kap. „Kiddush Hashem/Martyrdom"). 
dass der Ewige ein einziges ewiges Wesen sei], bis ausging seine Seele bei Echad. Da ertönte ein Bath Kol und sagte: Wohl dir, R. Akiba! dass ausging deine Seele bei Echad. [...] Wohl dir, R. Akiba! denn du bist bestimmt zum Leben in der künftigen Welt.

Die Erzählung über den Tod des Rabbi Akiba enthält ein Musterbeispiel dessen, was die postbiblische Tradition Kiddusch HaSchem (Heiligung des Namens [Gottes]) nennt - ein Begriff, der einen Akt religiösen Märtyrertums bezeichnet. Die endgültige Kodifizierung der Idee des Kiddusch HaSchem, die sich im Laufe von Jahrhunderten herausbildete, vollzog Maimonides (1135-1204). Er erließ die Todesstrafe für die Übertretung verschiedener Tora-Gebote, „denn es steht geschrieben: »Wer sie einhält, wird durch sie leben« (3. Mose, 18,5) LEBEN, und nicht durch sie STERBEN“. In keinem Fall jedoch war es erlaubt, die Verbote des Götzendienstes, des Ehebruchs bzw. Inzests und des Blutvergießens zu übertreten. In solchen Fällen sollte ein Jude unbeugsam bleiben und eher sterben, eher sein Leben für den Glauben und die göttlichen Gebote geben, als es bewahren zu wollen. Durch sein Märtyrertum wurde er zum Kadosch zum Heiligen. Er gab sein Leben bewusst und freiwillig hin, wählte den Tod, stellte sich gegen die Schmähung Gottes. Eine solche Entscheidung fällt Rabbi Akiba und stirbt unter Qualen, preist Gott in einem letzten Gebet und Glaubensbekenntnis - dem Schma Jisrae ${ }^{259}$. Diese Umstände - der Tod mit dem Aufschrei: „Höre, Israel! Der Herr, unser Gott, der Herr ist einzig“ - gehen in den

258 Talmud Babli, Traktat Berachoth. Segensprüche, dt. Übersetzung und Erläuterung von E.M. Pinner, Berlin 1842, Berachoth 61, S. 2.

259 Das Schma Jisrael [Höre, Israel] ist der Anfang eines Gebets aus dem 5. Buch Mose (6,4-9); es drückt die Alleinigkeit Gottes aus, das Gebot der Liebe zu ihm sowie des Gehorsams gegenüber seinen Weisungen. Dem täglichen Morgen- und Abendgebet geht das Schma Jisrael voran. Es nimmt eine zentrale Stellung im Judaismus ein und erfüllt, da es kein offizielles Credo gibt, die Funktion eines feierlichen Glaubensbekenntnisses. Teile des Schma Jisrael befinden sich in der Mesusa [Schriftkapsel; Anm. d. Übers.] am Türrahmen jedes jüdischen Hauses und sind auch (zusammen mit anderen Bibelversen) in den Gebetskapseln an den Gebetsriemen enthalten, die ein Jude für das Morgen- und Abendgebet an seinem Kopf und seiner linken Hand befestigt. Der erste Vers des Schma Jisrael: „Höre, Israel! Der Herr, unser Gott, der Herr ist einzig", gehört auch zur letzten Beichte auf dem Totenbett. Siehe N. Solomon, op. cit., S. 140; A. Unterman: Żydzi. Wiara i życie [Die Juden. Glaube und Leben], Łódź 1989, S. 204. Zum Begriff Kiddusch HaSchem siehe die Einträge in: G. Wigoder (Hg): The Encyclopaedia of Judaism, New York 1989; Encyclopaedia of the Holocaust; N. Solomon, op. cit., S. 133-134 und 139-140; The Literature of Destruction (Kap. „Kiddush Hashem/Martyrdom"). 
martyrologischen Kanon ein. Mit diesen Worten auf den Lippen werden Generationen von Märtyrern sterben.

\section{4}

Rabbi Szymon Huberband formulierte das traditionelle Verständnis des Kiddusch HaSchem in entscheidender Weise um. In seiner Wohnung in der Zamenhof-Straße 19 im Warschauer Ghetto verfasste er ein Traktat mit ebendiesem Titel, das einerseits mit seiner Konstruktion an das Gattungsmuster der martyrologischen Erzählung anknüpft und andererseits die klassische Definition des Kiddusch HaSchem grundlegend erweitert.

In der langen Geschichte der Verfolgungen war das Märtyrertum stets ein freiwilliger Akt der bewussten Entscheidung. Der Holocaust änderte dies radikal; dem Opfer blieb keine Wahl, es wurde endgültig und unwiderruflich verurteilt. Seine Schuld war die Existenz an sich. Man konnte nicht mehr sein Leben retten, indem man den Glauben wechselte, sich freikaufte oder floh. Das Urteil traf alle und jeden Einzelnen. Sämtliche Formen der Verteidigung erwiesen sich auf lange Sicht als wirkungslos. Angesichts der Erfahrung der Massenvernichtung revidiert Huberband die bisher gültigen Konzepte religiösen Märtyrertums. Indem er sich auf die Autoritäten Maimonides und Rabbi Moses Sofer [Mosche Schreiber] beruft, entwickelt er deren Lehren weiter und passt sie an die neuen Umstände an. Nun lässt sich das Kiddusch HaSchem auf drei Arten erfüllen: (1) wenn ein Jude zur Aufgabe seines Glaubens gezwungen wird und zu dessen Verteidigung sein Leben opfert, (2) wenn ein Jude für die Rettung eines anderen Juden oder einer bestimmten Gemeinschaft von Juden sein Leben als Opfer darbringt, (3) wenn ein Jude beim Kampf zur Verteidigung anderer Juden umkommt. Der Autor weist darauf hin, dass er in seinem Traktat lediglich die zweite aufgeführte Art erörtern wird. Seine martyrologischen Erzählungen sollen somit nur Fälle des sog. aktiven Kiddusch HaSchem aufzeigen. Ein passives Kiddusch HaSchem dagegen wird den Tausenden auf verschiedenste Weise zu Tode gequälten und ermordeten Juden zugeschrieben. „Sie alle sind Märtyrer“, stellt Huberband fest, „auch dann, wenn sie nicht gezwungen wurden, ihren jüdischen Glauben zu leugnen“" (S. 247).

Die Literatur des persönlichen Dokuments aus dem Warschauer Ghetto enthält Schilderungen von Situationen, die - wie man sich denken kann - innerhalb der Poetik martyrologischer Erzählungen ihren Platz finden. Es taucht in ihnen beispielsweise ein Motiv auf, das für diese Gattung charakteristisch ist: das Motiv des Glaubensaktes im Moment eines gewaltsamen Todes, der letzte Ausruf: Schma Jisrael! 
Und so notiert Calel Perechodnik die Umstände, unter denen ein Flüchtling aus dem Arbeitslager in Piekełko bei Warschau ermordet wird:

[Gestapomann Lipszer] nahm einen Gummiknüppel und fing an, auf Kramarz einzuschlagen. Er schlug ihn, wo immer er konnte. Schließlich warf er den fast Bewusstlosen in die Grube und erschoß ihn. Vor seinem Tod konnte der Unglückliche noch auf hebräisch ausrufen: „Höre, Israel, der Herr, unser Gott, der Herr ist einzig" (S. 188).

Im Kontext des Kiddusch HaSchem sieht auch Karol Rotgeber den Tod ermordeter Juden:

Eine Salve aus einem Maschinengewehr, Ächzen und Stöhnen. Israel betet inbrünstig, man hört gedämpftes Beten, Schma Jisrael. Totenstille kehrt ein. Ruhet sanft, Brüder und Schwestern. Über unserer großen, weiten Grabstätte sprechen die Erzengel Totengebete (S. 71).

Ein unerschütterliches, unter grauenvollen Umständen abgelegtes Glaubenszeugnis verzeichnet Marian Berland. In seinem Tagebuch führt er die letzten Worte einer sterbenden alten Frau an. Der Vorfall ereignet sich auf dem Umschlagplatz. Eine Mutter will ihre von einem Ukrainer vergewaltigte Tochter beschützen, und der schlägt der alten Frau mit seinem Gewehrkolben den Schädel ein. Auch wenn in den letzten Worten der Frau das Schma Jisrael nicht wörtlich formuliert wird, stellt ihre Rede doch ein heroisches Glaubensbekenntnis angesichts des nahenden Todes dar. Sie ist eine unfassbare Apologie Gottes, gesprochen am Grund der Hölle, auf dem Umschlagplatz:

Mein Kind, das Ende ist gekommen. Ich fühle es. [...] Offensichtlich ist das des Herrgotts Wille. [...] Ich habe im Leben Gutes und Schlechtes erfahren. Ich habe immer daran geglaubt, dass man auf Gott vertrauen kann. Ich sterbe in diesem Glauben. Es gibt nichts, was ich bereue. [...] Du wirst von nun an eine Waise sein. Aber wisse, dass es einen Gott im Himmel gibt. Nicht wir selbst bestimmen, Gott bestimmt über uns. So ist Sein Wille. Er ist der beste Vater, der sicherste Beschützer. Er wird dich nie enttäuschen. Du kannst Ihm immer und überall vertrauen. Wenn alle dich verlassen, verlässt Er, der Alleinige, dich nicht. [...] Lebe in Gott, hab Ihn immer im Herzen. [...] Merke dir, liebe die Welt und liebe die Menschen, denn Gott hat sie geschaffen. Er weiß, was Er tut (S. 127).

Wenn sich die eben zitierten Beispiele auch im Rahmen der Poetik martyrologischer Erzählungen bewegen - deren Gattungsregeln erfüllen sie dennoch nicht. Ich habe die Beispiele hier einzig zur Illustration der geschilderten Realität in den Verlauf der Erörterungen zur Erinnerungsnarration eingebracht. Sie festigen das Bild der Ereignisse und Menschen, befinden sich zur Gänze innerhalb des Rahmens der Erzählung, deren übergeordnetes Ziel hier die geschichtliche Dokumentation, der Faktenbericht ist. Sie sollen bezeugen, wie etwas gewesen 
ist, und damit endet ihre Funktion. Der Unterschied zwischen ihnen und Rabbi Huberbands Erzählungen besteht im unterschiedlichen Diskurstypus, schließlich ist das Thema ja hier wie dort dasselbe - der Märtyrertod.

Huberbands Traktat Kiddush Hashem besteht aus aus einer theoretischen Einleitung und 14 kurzen Kapiteln, die als Titel die Namen der Handlungsorte der Erzählungen tragen - Piotrków, Krakau, Będzin, Międzyrzec etc. Auf diese Weise entsteht eine in der Geographie des besetzten Polen verortete Sammlung von Märtyrerportraits. Die einzelnen Geschichten sind, wenn auch knapp und ohne emotionales Pathos, so doch in einer erhabenen Sprache gehalten. Sie handeln von konkreten Situationen und konkreten Personen, datieren die Ereignisse genau, ordnen sie präzise in den Raum ein. Dennoch bildet die Faktennarration in diesem Fall lediglich die oberste Schicht der Erzählung - eine Schicht, die eine tiefere Bedeutung enthüllt und im Ganzen ein Zeichen darstellt, das auf höhere Sinnebenen verweist.

In dem Martyrologium fügen sich die Fakten - der Gegenstand der Erzählung - zu einer auf eigene Weise organisierten Komposition zusammen. Sie werden hauptsächlich erwähnt, um eine religiöse Botschaft $\mathrm{zu}$ formulieren, um die Lobpreisung des Märtyrers zu verewigen und vor allem, um in seinem Handeln die Größe und Macht Gottes wahrzunehmen und zu vermitteln. Daher werden die Taten einzelner Menschen festgehalten und verschiedene Darstellungen zusammengestellt, bis das gesamte Mosaik sein universales Muster zeigt. So können einzelne Ereignisse in eine der Geschichte gegenüber transzendente Dimension, in eine Ordnung sakraler Werte, in die Ewigkeit erhoben werden. In diesen Kategorien sollen sie gelesen und verstanden werden.

Die einzelnen Kapitel in Huberbands Martyrologium sind jeweils aus zwei Teilen zusammengesetzt. Der erste Teil sind die eigentlichen Erzählungen, die sich auf räumliche und zeitliche Umstände beziehen und in den Realien des besetzten Polen angesiedelt sind. Doch bedient sich der Narrator hier zweier Arten der Zeitmessung zugleich: des allgemein verwendeten weltlichen gregorianischen Kalenders und des jüdischen liturgischen Kalenders. Alles, wovon erzählt wird, ereignet sich vor, nach oder während eines Feiertages; jedes Geschehnis wird in den liturgischen Jahreszyklus eingeordnet. Dadurch verflechten sich die historische und die sakrale Zeit, ergänzen einander und bilden ein eigenes Kontinuum. Der zweite Teil besteht jeweils aus der kurzen Phrase, mit der alle Erzählungen enden. Diese Phrase besitzt die schematisierte Gestalt einer liturgischen Formel und wiederholt sich mit nur kleinen Veränderungen: „Ihr Gedenken sei geheiligt und der Herr räche ihr Blut", „Ihr Gedenken sei geehrt. Möge der Herr ihr Blut rächen“, „Sie starben wie Märtyrer. Möge ihr Gedenken gesegnet sein und möge der Herr ihr Blut rächen“. 
Solcherart konstruierte martyrologische Erzählungen lassen sich bei Huberband nicht nur im Traktat Kiddush Hashem finden, sondern auch in einigen anderen Texten wie „Galgen“ oder „Die Zerstörung von Synagogen, Bethäusern und Friedhöfen" [Originaltitel jiddisch; Anm. d. Übers.]. Alle überschreiten mit ihrem faktographischen Material die Mauern des Warschauer Ghettos. In der Arbeit „Das Ghetto und die Hinrichtungen“ wurde die Formel des Martyrologiums auf das Schema eines Fragebogens übertragen, dessen sich die Mitglieder der Gruppe Oneg Schabbat bei der Sammlung und Bearbeitung des dokumentarischen Materials bedienten. Es ist ein geradezu winziger Bericht über zwei Hinrichtungen im Gefängnishof an der Gęsia-Straße 24. Die erste wurde am 17. November 1941 durchgeführt (8 Opfer) ${ }^{260}$, die zweite am 15. Dezember 1941 (15 Opfer in zwei Durchgängen). Die Opfer waren für die Übertretung der Ghettogrenzen zum Tode verurteilt worden. Huberband geht vor wie ein versierter Historiker, nennt Fakten, die er zusammentragen konnte, führt Zeugenberichte an, zitiert aus Dokumenten. Er schildert die Tätigkeiten der Ghettobehörden, die dem Urteil vorausgingen, beschreibt die Vorgänge bei der Exekution mit photographischer Genauigkeit. Daten, Zahlen, Namen - all das verleiht der Erzählung einen Dokumentcharakter, macht sie fast zu einem Verlaufsprotokoll. Dennoch bewahrt der Text das Schema einer martyrologischen Erzählung. So wird zum Beispiel der Moment der zweiten Hinrichtung zunächst in der sakralen und dann erst in der weltlichen Zeit genannt: „Am Montag, dem ersten Tag des Chanukkafestes 5702 (15. Dezember 1941) [...]“ (S. 166). Die Verurteilten bezeichnet der Autor mehrmals als Märtyrer im religiösen Sinn. Er betont, dass im Augenblick der Erschießung „Schma Jisrael!“ gerufen worden sei - laut dem Bericht eines Augenzeugen, der die Hinrichtung vom Balkon seiner Wohnung in

260 Ringelblum betont den ungewöhnlichen Charakter jener Hinrichtung: „Das Todesurteil, das an acht Juden, davon sechs Frauen, vollstreckt wurde, erfüllte ganz Warschau mit Betroffenheit. [...] Zuerst wurde gefordert, dass die Exekution von jüdischen Polizisten durchgeführt werden und dass Mitglieder des Judenrates anwesend sein sollten. Einige Menschen sagen, Szeryński [der Kommandant des Ordnungsdienstes] habe dem Kommandanten der polnischen Polizei, Przeworski, eröffnet, er könne das Urteil vollstrecken, werde aber eine Viertelstunde danach Selbstmord begehen. Andere behaupten, Szeryński habe verkündet, dass er das Urteil natürlich nicht vollstrecken werde, selbst wenn ihm dafür Erschießung drohen sollte. Fest steht, dass das Urteil dann von polnischen Polizisten vollstreckt wurde. Manche sagen, die Kandidaten hätten sich freiwillig gemeldet" (Bd. 1, S. 336-337). Huberband erwähnt in seinem Bericht den Namen eines Freiwilligen: Wiktor Zelek, Wachtmeister vom 20. Polizeiregiment, Dienstnr. 3497, wohnhaft in der Czerniakowska-Straße 101 (S. 153). Zelek wurde in der polnischen Untergrundpresse gebrandmarkt. 
der Gęsia-Straße aus beobachtete: „Kurz darauf hallten zwei Salven aus Maschinengewehren. Die gefesselten Kriegsgefangenen stürzten zu Boden. Wir riefen laut: Schma Jisrael!“" (S. 159).

In Huberbands Kiddush Hashem begegnet man Szenen und Bildern, die den Wert eines martyrologischen Topos besitzen. So ist es zweifellos beim Motiv des Todes, das den brennenden Torarollen innewohnt. Im tannaistischen Traktat Semahot aus dem 2. Jh. n. Chr. erzählt ein Kapitel vom Tod des Rabbis Chanina [Chananja] ben Teradjon, der bei seiner Hinrichtung in Torarollen eingewickelt und verbrannt wurde. Seiner verzweifelten Tochter hatte er zuvor gesagt: „Die Tora ist Feuer, und Feuer kann nicht von Feuer verzehrt werden. Sieh: Die Buchstaben erheben sich in die Lüfte, und es brennt nur das Pergament“"261. Huberband führt drei solche Situationen an. Im September 1939 wurde in Będzin ein Jude namens Szlezinger erschossen, der die Tora aus einer brennenden Synagoge heraustrug; er schlug auf der Schwelle hin und verbrannte (S. 252). Zu derselben Zeit übergießen die Deutschen in Włodawa den Rabbiner Avron Mordka Maroko mit Benzin und zünden ihn an, und als er in Flammen steht wie eine Fackel, werfen sie Torarollen auf ihn. „Rabbi und Tora brennen gemeinsam“, betont der Autor (S. 254). Ebenfalls im September 1939 wird in Sierpc der junge Mojsze durch eine Kugel niedergestreckt, als er versucht, Pentateuchrollen vor dem Feuer zu retten. „Sein Leib verbrennt zusammen mit der Synagoge und der Tora. Möge der Herr sein Blut rächen“ (S. 259).

Die von Huberband nacherzählten Geschichten sind mehr als nur Berichte über die Verfolgungen vonseiten der Nazis - ähnlich wie Nathan Hannovers bereits erwähnter Bericht Jawen Mezula mehr ist als eine bloße geschichtliche Chronik des Blutbads und der Pogrome unter Bohdan Chmelnyzkyj. Beide Texte sind in der Gattungskonvention martyrologischer Erzählungen verfasst, dank der die geschilderten Ereignisse eine Universalisierung erfahren. Unter Bewahrung ihrer ganzen entsetzlichen Konkretheit werden sie eingegliedert in eine auf die Bibel rekurrierende und um die Erfahrungen der Folgegenerationen erweiterte national-religiöse Liturgie der Zerstörung und der Rhetorik des Leidens. Über die Jahrhunderte hatte sich nämlich ein gewisser Kanon des sprachlichen Ausdrucks von Leid und Unglück herausgebildet, sei es zu Chmelnyzkyjs Zeiten, sei es zur Nazizeit. Obwohl ein Jahrhundert dazwischenliegt, sind die Ausdrucksweisen ähnlich. Bei Huberband ist beispielsweise von Rabbi Yehezkiel Levin zu lesen, der nach der Einnahme Lwóws durch die Deutschen die Juden vor dem ukrainischen Pogrom schützen will und sich mit der Bitte um Hilfe zum

261 D.G. Roskies: op. cit., S. 31. 
Metropoliten der Ukrainischen Griechisch-Katholischen Kirche, Andrej Scheptyzkyj, begibt. Auf dem Rückweg wird er auf der Straße von Ukrainern angegriffen und zu Tode geprügelt (S. 254). Bei Hannover wiederum flüchtet Rabbi Yechiel Michal von Niemirów, der am Vortrag der Eroberung der Stadt durch die Kosaken die Juden ermuntert, ihrem Glauben treu zu bleiben, gemeinsam mit seiner Mutter vor dem Pogrom auf den Friedhof. Dort werden sie entdeckt und mit Stöcken erschlagen. Die Erzählung endet auch hier mit der liturgischen Schlussformel: „Möge der Herr ihren Tod rächen!“262

Majer Balaban, der Herausgeber der polnischen Übersetzung von Hannovers Chronik, nimmt dem Autor die Verwendung eines biblischen Stils übel („der Prophet Jeremia ergießt seine Klagen durch den Mund unseres Chronisten“) und beschwert sich, dass sein Werk den Eindruck einer "ahistorischen Beschreibung" mache ${ }^{263}$. Was Balaban nicht gefällt, ist aber einfach ein Zeichen für die hier realisierte Formel des Martyrologiums.

\section{Die Predigten des Rabbi Klonimus Kelmisz Szapiro}

1

Der religiöse Diskurs fand im Warschauer Ghetto noch eine weitere Ausdrucksform. Kennenlernen kann man sie anhand der glücklich geretteten Schriften eines anderen hinter den Ghettomauern wirkenden Rabbis: Klonimus Kelmisz Szapiro, der berühmte Zaddik aus Piaseczno. Szapiro hielt regelmäßig Predigten vor einer Gruppe von Schülern und Anhängern. Die erste trägt das Datum „Rosch ha-Schana 5700 (14. September 1939)“, die letzte - „Schabbat Hason 5702 (18. Juli 1942)“. Gesammelt und unter dem Titel Esch Kodesch (Heiliges Feuer) verzeichnet, wurden sie versteckt und überdauerten bis heute. Sie sind die einzige Sammlung von rabbinischen Homilien aus Warschau während der Kriegszeit, ja, im Grunde sogar das einzige Beispiel für diese Art Literatur im gesamten nazibesetzten Europa, wie der Verfasser einer Monographie über Szapiros Predigten bemerkt ${ }^{264}$. Den hier bereits besprochenen Formen wie Gebet,

262 N. Hannover: Jawen Mezula, op. cit., S. 30.

263 Siehe die Einleitung zur polnischen Ausgabe von N. Hannovers Werk, op. cit., S. 7.

264 N. Polen: The Holy Fire, op. cit., S. 23. Dieses hervorragende Buch ist meine grundlegende Wissensquelle über Esch Kodesch und seinen Verfasser. N. Polen zitiert häufig und umfassend aus den Predigten Szapiros, führt manche sogar zur Gänze an. Ein kurzer Auszug aus der Sammlung Esch Kodesch [Esh Kodesh] findet sich auch in D.G. Roskies Anthologie The Literature of Destruction. Jedoch habe ich keinen Zugang zu der in hebräischer Sprache geschriebenen Gesamtheit der Predigten, was mir eine 
Klage, martyrologische Erzählung muss somit noch eine weitere hinzugefügt werden: die Derascha (Predigt).

Die Predigten Rabbi Szapiros bilden einen kontrastiven Hintergrund zu Huberbands Martyrologium. Der Verfasser von Kiddush Hashem sättigt seinen Text mit Realien, die erste Narrationsschicht dokumentiert Fakten, Phänomene und Figuren aus dem Ghetto sowie dem ganzen besetzten Polen. In Szapiros Sammlung Esch Kodesch hingegen fehlt der Bezug zu Ort und Zeit, zu den politisch-historischen Umständen. Beispielsweise kommen nie die Wörter „Deutsche“ oder "Nazis“ vor, es fällt nicht ein Name einer privaten oder öffentlichen Person. Auch von den Tätigkeiten der jüdischen Gemeinde oder der gesellschaftlichen Organisationen des Ghettos ist nicht die Rede. Es werden keinerlei Geschehnisse aus dem Leben des abgeriegelten Bezirks erwähnt - weder das Eintreffen geflüchteter Menschen noch Hunger und Epidemien noch konkrete Verfolgungen. Jede Predigt ist allerdings datiert und in den jüdischen liturgischen Kalender eingeordnet. Das gestattet es dem Leser, die Evolution der Predigten in Esch Kodesch nachzuverfolgen und in Bezug zu den einzelnen Etappen in der Geschichte des Ghettos zu setzen. Die Sammlung dieser 85 Predigten mit jeweils genauem Tagesdatum könnte demnach als ein ganz spezielles „PredigtTagebuch" gelten. Doch sind die Tagesdaten nahezu die einzigen Spuren der geschichtlichen Wirklichkeit in diesem „Tagebuch“, das auch so gut wie keine persönlichen Erlebnisse verzeichnet. Die Lektüre des Textes erlaubt keine Einordnung, wo, wann und unter welchen Umständen sein Autor ihn schrieb. Die grauenvollen Lebens- und Todeserfahrungen aus dem Warschauer Ghetto, die zum Gegenstand der Darstellung bei Huberband, Rotgeber und einer ganzen Reihe anderer Autoren der damaligen Zeit werden, fehlen in Esch Kodesch. Die Predigtsammlung des Zaddik von Piaseczno ist ein religiöser Diskurs in Reinform.

„Esch Kodesch ist kein Tagebuch, kein Verzeichnis von Erinnerungen und keine Chronik von Ereignissen“, schreibt Nehemia Polen. „Es ist eher ein Testament des Glaubens an Tora und Tradition angesichts der Bemühungen des Feindes, dies alles zu vernichten. Die Gattungsformel hält sich eng an die Muster

tiefere Analyse des Diskurses unmöglich macht. Ich stütze mich daher auf N. Polens Erkenntnisse (was ich nicht jedes Mal mit Fußnoten kennzeichnen kann, weswegen ich diesen Bezug hier allgemein kennzeichne) sowie auf die Lektüre von Textstellen, die auf Englisch erhältlich sind. Soweit mir bekannt, schrieben in Polen bislang einzig B. Engelking-Boni („Czas przestał dla mnie istnieć“, op. cit.) und P. Śpiewak („Kaznodzieja getta warszawskiego“ [Der Prediger des Warschauer Ghettos], in: „Znak“ 1996, Nr. 3), über den Rabbiner Szapiro. 
aus talmudischer und midraschischer Literatur. Es lassen sich zahlreiche Stellen finden, die leidvolle Erfahrungen und Verfolgungen des Volkes erörtern. Jedoch fügen sie sich nicht zu einer streng historischen Chronik zusammen, liegt doch ihre grundlegende Aufgabe eher darin, jene Ereignisse in einen für den Adressaten verständlichen theologisch-ethnischen Rahmen einzugliedern sowie ein Modell für geistigen Widerstand zu bieten. “265

2

Um die Form jenes Diskurses wenigstens ganz allgemein beschreiben zu können, muss ich zunächst die Tradition der jüdischen homiletischen Literatur und der Gattung der Derascha kurz umreißen. ${ }^{266}$

Die in Synagogen und Bethäusern, vor allem am Schabbat, aber auch an anderen Feier- und Festtagen gehaltenen Predigten sind eine der ältesten Formen religiöser Ausübung im Judentum. Lange gehörten sie einzig zur mündlichen Tradition, später wurden sie auch niedergeschrieben, was den Textaufbau deutlich beeinflusste. Die jüdische Homiletik gehört zur Gattung der ethischen Literatur, deren Ziel die moralische und religiöse Bildung der Volksgemeinschaft sowohl im alltäglichen Leben als auch in Krisen- und Unglückszeiten ist. Ausgangspunkt einer Predigt ist immer eine Bibelstelle oder ein Auszug aus Midrasch oder Talmud, die bei den Juden seit dem Mittelalter ebenfalls als heilig gelten. Indem er also von einem heiligen Text ausgeht, vollführt der Prediger dessen Exegese, um in ihm eine Antwort auf aktuelle Fragen und Herausforderungen zu finden. Auf diese Weise macht er die Kraft und das Gewicht der Tradition sowie ihre Schlüsselrolle im Verständnis des heutigen Tages sichtbar.

Der klassische Predigttypus, der sich damals herausbildete - die Derascha -, ist zweiteilig aufgebaut. Dieser Typus besteht aus einer "großen“ und einer „kleinen" Predigt, wobei jeder Teil von eigenen Regeln bestimmt wird, sich in eigenen charakteristischen Formeln ausdrückt und auch einen eigenen künstlerischen Wert besitzt. Die „große“ Predigt umfasst die Gesamtheit der Struktur der Homilie, die sich auf die jeweils geltenden rhetorischen Regeln stützt. Ihre Achse ist ein zum gegebenen Feiertag passender Auszug aus der Tora oder einem berühmten Tora-Kommentar. Sie erfüllt vor allem eine didaktische, moralische oder ideologische Funktion, je nach Absicht des Predigers. Der zweite Teil - die „kleine“ Predigt (hebr. Derusch) - stellt das Fundament der ganzen Predigtstruktur dar.

265 N. Polen: The Holy Fire, op. cit., S. 19

266 Ich bediene mich dazu dreier Einträge aus der Encyclopaedia Judaica: „Homiletic Literature, Preaching, Derash“. 
Sie weist einen streng exegetischen Charakter auf, der sich aus der altertümlichen Tradition des Midrasch speist, und hat weder in der christlichen noch in der muslimischen Predigttradition eine Entsprechung. Das Wesen der hier angewandten exegetischen Methode besteht nicht darin, die Bedeutung von Bibelversen ganz simpel zu erläutern, sondern darin, ihre vielfältigen Interpretationsmöglichkeiten zu eröffnen. Vor dem Zuhörer oder Leser enthüllt sich somit eine unermessliche und unvorstellbare Tiefe verborgener Sinndeutungen in dem besprochenen Text.

Eine Predigt sollte die außergewöhnliche Interpretationsgabe des Predigers und die unerschöpfliche Macht des heiligen Textes eröffnen, der universale Maßstäbe für die Vergangenheit, Gegenwart und Zukunft in sich barg. Schließlich musste sie die Geschichte erklären können, die eine Generation nach der anderen vor immer neue Dilemmata stellte. Besonders Zeiten von Unglück und Verfolgung verlangten allzu oft eine Revision der bisherigen Lehre, eine Erneuerung der früheren Verständnisweise, der alten Texte und Glaubenswahrheiten. ${ }^{267}$ Somit war eine Predigt so konstruiert, dass durch die meisterhafte Anwendung alter Traditionen auf neue Umstände immer wieder andere und überraschende Deutungsmöglichkeiten in wohlbekannten Texten entdeckt werden konnten. Um sich der brennenden gegenwärtigen Probleme annehmen zu können, interpretierte sie die Bibel auf schöpferische Weise neu und formulierte kühne Antworten auf aktuelle Fragestellungen. Dem untergeordnet war der Predigtdiskurs, der Formen wie Erzählung, Parabel, Märchen, Scherz, Epigramm verwendete. Der neuen Auslegung diente vor allem die Interpretationsmethode, die der Predigt nicht nur einen exegetischen, sondern auch einen künstlerischen Wert verlieh. Mithilfe von Effekten wie überraschenden Wendungen, Wortspielen,

267 Klassisches Beispiel für eine solche Predigt als Reaktion auf eine sich aktuell ereignende Tragödie des Volkes ist die Predigt von Isaac Aboab, die er zur Jahreswende 1492-1493 vor Vertriebenen aus Spanien hielt. Für meine Analyse des religiösen Diskurses aus dem Warschauer Ghetto ist dieser Text doppelt interessant. Er ist ein Musterbeispiel für die traditionelle jüdische Antwort auf unglückselige Ereignisse. Darüber hinaus liefert er das Konzept für die Interpretation der historischen Dimension der Katastrophe als Anzeichen für die nahende Ankunft des Messias, über das ich bei der Analyse von Rotgebers Klagen geschrieben habe. Aboab führt u.a. eine Parabel über einen Vater und seinen Sohn auf einer gemeinsamen Wanderung in die Stadt an. „Der Sohn, der müde und immer schwächer wird, fragt seinen Vater, ob es noch weit ist bis zur Stadt ... Der Vater erklärt ihm, woran sich das erkennen lässt: Wenn du den Friedhof siehst, sind wir schon ganz nahe bei der Stadt ... Kommt Unheil auf uns zu, dann ist das ein Zeichen, dass der Messias nahe ist. “Zitat nach: Encyclopaedia Judaica, Jerusalem 1978, Bd. XIII, Spalte 1000. 
der Kombination von scheinbar weit auseinanderliegenden Begriffen wurden unvermutet innere Verbindungen enthüllt. Ein guter Prediger erzielte den erwünschten und in der klassischen hebräischen Homiletik stets hoch geschätzten Überraschungseffekt, indem er unerwartete Verknüpfungen zwischen dem interpretierten heiligen Text und dem Thema der Predigt herstellte.

3

Anfang des 20. Jh. lasen sich die Anforderungen an einen jüdischen Prediger wie folgt:

Seine Brüder - alte und junge - Gottes Wort lehren; ihnen helfen, die erhabensten Religionswahrheiten zu erfassen; ihre in Grobheit, Dreck und Selbstgefälligkeit versunkenen Seelen erheben; den Trauernden Trost, den Zweifelnden Hoffnung, den Verlorenen Rat geben; Kampfesmut spenden im Streben nach dem Guten. ${ }^{268}$

Rabbi Szapiros Predigten im Warschauer Ghetto erfüllen musterhaft jene Postulate. Jedoch sind sie zugleich, wie ich meine, auch einzigartig und einmalig.

Die Sammlung Esch Kodesch - also Heiliges Feuer - entstand im Feuer des Holocaust. Unter dem Blickwinkel dieser Predigten betrachtet, nimmt das Ghetto - das, wie zu beachten ist, in diesen Texten als geschichtliche Realität praktisch nicht vorkommt und lediglich in den Datumsangaben in Erscheinung tritt - die Gestalt eines kosmischen Wirbels an. Geschichte und Ewigkeit prallen aufeinander, Gott und Satan, Gut und Böse, Fluch und Segen. Wahrscheinlich stand der Hörerschaft von Rabbi Szapiros Predigten innerhalb der Mauern des geschlossenen Bezirks genau so ein grauenerregendes Spektakel vor Augen. In der ersten, an Rosch ha-Schana 5700 (14-15. September 1939) gehaltenen Predigt der Sammlung werden die Belagerung Warschaus, der Bombenterror und die Atmosphäre des allgegenwärtigen Entsetzens mit keinem Wort erwähnt. Thema ist stattdessen die überwältigende Angst, die der Prediger sublimiert, indem er das lähmende Gefühl der Todesfurcht in eine mit Gottes Anwesenheit einhergehende Ehrfurcht umdeutet.

Die Leiden, die der September 1939 mit sich brachte, waren nur ein Vorgeschmack dessen, was den Juden innerhalb der Ghettomauern noch widerfahren sollte. Draußen vor den Fenstern der Wohnung des Zaddik aus Piaseczno Dzielna-Straße 4 - herrschte ein wahrhaft heiliges Grauen, ein tremendum. Rabbi Szapiro befindet sich im Zentrum dieser Erfahrung und bemüht sich, sie

268 S. Singer: „Lectures and Addresses“ (1908). Zitat nach: Encyclopaedia Judaica, op. cit., Bd. 13, Spalte 1004. 
zu erfassen, zu schildern, eine Ausdrucksform für sie zu finden. Seine Predigten müssen einander durchkreuzenden Herausforderungen gerecht werden: einerseits Antwort geben auf das Grauen des Ghettos und die Tatsache der Vernichtung seines Volkes, die immer offensichtlicher wird, und andererseits die Heiligkeit der Tora bewahren, das Weiterbestehen des Bündnisses mit Gott und die Wahrheit der göttlichen Versprechen. Wie kann Szapiro Worte finden für die Stimme der Klage, für den Ruf nach Hilfe, den Schrei der Verzweiflung? Wie kann er das Leiden ausdrücken, das den Körper des Menschen zerreißt, seine Seele zerstört, ihn in den Abgrund der Auflehnung gegen Gott stößt? Der Prediger des Warschauer Ghettos steht vor einem Dilemma. Können die jüdische Liturgie der Zerstörung und Rhetorik des Leidens, die jahrhundertealte Tradition, dem Unglück die Stirn zu bieten, der derzeitigen Erfahrung gerecht werden?

Jene Zerrissenheit - präzedenzlos in der Gattungstradition der Derascha wird spürbar in einer der ergreifendsten Textstellen der Esch Kodesch. In der Regel fließen keine autobiographischen Themenstränge oder situativen Bezüge direkt in die Predigten ein. Hier ist es anders. Dies ist vielleicht das einzige Beispiel innerhalb der gesamten Sammlung - so Nehemia Polens Kommentar -, dass der Autor sich so weit entblößt und schmerzlich in die Tiefe seiner inneren Unsicherheit, seiner inneren Zweifel hineinbegibt. Diese Stimmungslage hat zwei Gründe: der erste ist das Bewusstsein über die Hilflosigkeit der Sprache angesichts der Unmenge an Leid, der zweite ist die Gefahr, in einen zerstörerischen Seelenzustand zu verfallen, der das Gebet unmöglich machen würde.

In seiner Homilie am 28. Februar 1942 spricht Rabbi Szapiro:

Wir durchleben zur Zeit sehr bittere und schlimme Erfahrungen [...], die bereits so lange andauern. Selbst wer vorher sich selbst und anderen Juden Mut zugesprochen hat, ist jetzt zu erschöpft, um noch die innere Kraft dafür zu finden; er ist es müde, Trost zu suchen. Und wenn er auch vorher seine Fassung bewahren, einige tröstende Bemerkungen äußern und anderen hat beistehen können, so fehlen ihm nun die Worte, hat er doch im Laufe der endlosen Krisentage schon viele Male alles gesagt, was er nur sagen konnte. Nun sind die Worte bereits abgenutzt, sie rufen keine Wirkung bei ihm und seinen Zuhörern mehr hervor. ${ }^{269}$

Die Worte versagen, es ist bereits alle ausgesprochen. Ist es unter diesen Umständen überhaupt möglich, eine Predigt zu verfassen und zu halten? Das unaussprechliche Leid tötet die Seele. Erschöpft von einem Leiden, das über seine Kräfte geht, ist der Mensch nicht einmal mehr in der Lage zu einer Klage aus 
tiefster Seele. Der Prophet Jeremia - der Prediger erinnert hier an die Lehren der Weisen des Talmud ${ }^{270}$ - schrieb seine Lamentationes noch vor der Zerstörung Jerusalems, in einer prophetischen Vision, nicht erst angesichts der Katastrophe. Als Prophet der Zerstörung, nicht als deren Zeuge! Ist somit im Jahr 1942 im Warschauer Ghetto überhaupt ein Gebet möglich, das schließlich einem Geist der Freude und feierlichen Hochstimmung entspringen sollte? Ist das Tora-Studium in solchen Zeiten nicht gefühllos, fragt Rabbi Szapiro in seiner Predigt vom 14. März 1942:

Es gibt eine Zeit, in der der Mensch sich über sich selbst wundert. [Er denkt:] „Treibt mich all das nicht zur Verzweiflung? Brennen mir nicht unentwegt die Tränen hinter den Augenlidern - und weine ich nicht manches Mal tatsächlich? Wie soll ich in so einem Seelenzustand die Tora studieren? Wie soll ich die Kraft finden, schöpferisch über die Tora und den Chassidismus nachzudenken?" - Es gibt eine Zeit, in der den Menschen Gedanken quälen: „Werde ich je in meinem Herzen wieder etwas spüren außer Stumpfheit, sodass ich mich sammeln und studieren kann, trotz all meiner Sorgen und der Sorgen, die in solcher Vielzahl über Israel gekommen sind?" - Und dann sagt der Mensch sich wieder: „Treibt mich all das nicht zur Verzweiflung? Ich habe so viele Gründe zu weinen, mein Leben ist düster und grau. ${ }^{{ }^{\prime 2} 21}$

Rabbi Szapiro sah in den Verfolgungen durch die Nazis zunächst einfach ein weiteres Glied in der Unglückskette seines Volkes. In der Predigt zu Chanukka 5702 (15. Dezember 1941) ist zu lesen:

Warum ist es so, dass den Menschen die heutigen Leiden stärker berühren als all die Leiden, die in der Vergangenheit über Israel gekommen sind? Warum ist es so, dass unser Glaube, wenn wir in der Schrift, im Talmud oder den Midraschim von den Leiden Israels von frühester Zeit bis zum heutigen Tage lasen, nicht geschwächt wurde, heute aber schwächer wird? Denn wer sagt, Israel habe nie solches Leid erfahren wie heute, der irrt. Seit der Zeit, in der der Tempel zerstört wurde und die Festung Betar fiel usw., gab es immer wieder ebensolches Leid wie jetzt. ${ }^{272}$

Durch die Erfahrung der großen Liquidierungsaktion, bei der über 300.000 Warschauer Juden nach Treblinka deportiert wurden, gelangte Rabbi Szapiro, der überlebte, schließlich doch zur Überzeugung, dass es sich beim Holocaust um ein Ereignis mit einem absoluten Ausnahmecharakter handle. Dieser gravierende Wandel in seiner Einstellung wird an einer von zwei Ergänzungen deutlich, die er im Herbst 1942 der bereits fertiggestellten Sammlung Esch Kodesch

270 Siehe die Predigt vom 11. Juli 1942. Ebd., S. 32.

271 Zitat nach: Ebd., S. 31.

272 Zitat nach: Ebd., S. 83. 
hinzufügt. Die letzte Predigt in der Reihe stammt vom 18. Juli 1942. Vier Tage danach beginnt die große Liquidierungsaktion. Der Prediger verstummt. Nach vier Monaten bricht er sein Schweigen und versieht die oben zitierte Predigt mit folgendem Zusatz:

Nur bis zum Ende des Jahres 5702 [Sommer 1942] war die Lage so, dass unsere Leiden dem bis dahin erfahrenen Leid ähnelten. Was jedoch die Höllenqualen und den scheußlichen, unmenschlichen Tod betrifft, die uns unsere erbitterten und verabscheuenswürdigen Feinde bereiteten, so hat das Haus Israel - nach meinem rabbinischen Wissen und meiner Kenntnis der gesamten Geschichte Israels - noch nie etwas Ähnliches erlebt wie seit dem Ende des Jahres 5702. Möge Gott sich unserer erbarmen und uns rasch aus ihrer Hand befreien.

Freitag, der Tag vor dem Schabbat, 18. Kislev 5703 [27. November 1942].

Der Verfasser ${ }^{273}$

Der Ausnahmecharakter des Holocaust zwingt zu einer außergewöhnlichen Antwort. Das Außergewöhnliche an der Sammlung Esch Kodesch besteht darin, dass diese Antwort zugleich zutiefst traditionell und radikal neu ist. Die vollkommen klassische, durch eine jahrhundertelange Tradition geheiligte DeraschaFormel füllt der Autor mit einem Material, das sie zu sprengen scheint. Rabbi Szapiro unterwirft eine präzedenzlose und unfassbare Erfahrung einer formal und theologisch disziplinierten Reflexion. Er bemüht sich, das ganze Übermaß der Unglücks zu ergründen, um ihm nicht zu erliegen, nimmt die gesamte Last des Leidens auf sich, ohne sich ihm zu ergeben. Dazu positioniert er sich gewissermaßen „außerhalb“ seines eigenen Bewusstseins und macht dieses, gleichermaßen wie die heiligen Texte, zum Gegenstand der Exegese.

Hier nur ein - allerdings hinreichend aussagekräftiges - Beispiel für die exegetische Methode, die in Esch Kodesch zur Anwendung kommt. Der Prediger tut hier den klassischen Regeln des homiletischen Diskurses genüge, indem er einen Überraschungseffekt einarbeitet, der vonnöten ist, um die alten und gut bekannten Texte aus neuer, unerwarteter Perspektive zu zeigen. In der Predigt vom 17. Januar 1942 zitiert er, um das Motiv des Leidens als Opfer zu erörtern, eine bestimmte Stelle aus dem Talmud, in der ein außergewöhnliches, im Tempel von Jerusalem verwendetes Musikinstrument beschrieben wird. Das hebräische Wort magrefah, das im Talmud als Name jenes Instrumentes genannt wird, bedeutet wörtlich „Schaufel“. Raschi [Rabbi Schlomo ben Jizchak], einer der größten talmudischen Exegeten, verbindet beide Bedeutungen und erläutert, dass die Schüssel, die zur Beseitigung der Asche vom Altar diente, auch

273 Zitat nach: Ebd., S. 84. 
als Musikinstrument genutzt worden sei. Raschis Interpretation bildet das Fundament für Szapiros Exegese, die im Kontext der bekannten Realien des Holocaust eine schockierende Wortwörtlichkeit annimmt. Der im Folgenden zitierte längere Auszug aus jener Predigt verdeutlicht nicht nur die Methode, sondern verrät auch einiges über auch die Sprachwahl des Predigers. Auffallend ist nämlich die stilistische Strenge angesichts des erörterten Themas: Beherrschtheit, Lakonie, sogar eine gewisse emotionale Kühle sind das Ergebnis einer bewussten Entscheidung. Erschütterung und emotionale Bewegtheit werden in eine Form eingespannt, die sie nicht verunstaltet, sondern sublimiert.

Alle Opfer, die wir [im Tempel] dargebracht haben, sollen als Substitute im Geiste der biblischen Geschichte von der Opferung Isaaks verstanden werden. [...] Ein Sünder muss sich, wie jeder Mensch, der ein freiwilliges Brandopfer bringt, Gott faktisch selbst opfern. Doch die Tora hat uns eine Methode gegeben, wie wir unserer Pflicht nachkommen können, ohne uns selbst zu opfern: indem wir ein Tieropfer darbringen. Wenn das Opfer gebracht und [auf dem Altar] verbrannt worden ist, wenn es sich in Asche verwandelt hat, können wir an der Aschenmenge seine Größe erkennen ...

Jetzt, wo ein Teil der Juden nicht mehr ist, weil Gottes ewiger Wille lautete, dass sie sich als Opfer zu Ihm, Er sei gesegnet, erhoben, verspüren wir nur noch die Schwere ihrer Abwesenheit. Das Ausmaß unseres Verlustes ist ungeheuer, sowohl was die Vielzahl als auch die Güte betrifft. Als sie noch unter uns weilten, waren sie uns so lieb und teuer [...] wie unser eigener Atem und unsere eigene Seele, so viel Freude brachten sie uns und so viel Vergnügen erfuhren wir durch sie, wenn wir uns auch dessen, was wir besaßen, nicht vollkommen bewusst waren. Wir waren ahnungslos, welches große Gut es für uns bedeutete, dass sie mit uns waren. Jetzt, wo sie von uns gegangen sind, spüren wir erst die Bitterkeit unseres Verlustes. Das Herz ist voll schmerzlicher Sehnsucht. Es gibt keinen Trost außer den Worten, die Gott an Moses richtete: „Auf diese Weise erwecke ich meine Gedanken [an euch]."

Und so gab ausgerechnet das Instrument, das zur Beseitigung der Asche des Opfers verwendet wurde, die laut tönendste Musik von sich. Alle Musik im Tempel war ein Gedenken an das Opfer, das Gott dargebracht wurde ... und sogar die megrefah hatte ihren Anteil daran, dass im Himmel großes Mitgefühl geweckt wurde und Israels Erlösung sogleich erfolgte. ${ }^{274}$

Die Schaufel zur Beseitigung der Asche auf dem Opferaltar wird zum Musikinstrument der tausend Klänge. Angeblich wird das Leiden im Feuer gereinigt und verwandelt sich in ein Lied der Freude. „Rabbi Szapiro deutet in seiner Predigt an“, kommentiert Nehemia Polen, „dass die Melancholie, die sich aus der Erfahrung von Tod und Verlassenheit speist, durch das Feuer des Opferaltars in eine

274 Zitat nach: Ebd., S. 66-67. 
Asche des Verlangens und der Sehnsucht und schließlich in ein Lied der Freude verwandelt werden könne. “275

\section{4}

Rabbi Szapiros unter jenen extremen Bedingungen verfasste Predigten sind in exegetischer wie auch in künstlerischer Hinsicht außerordentlich. Die Homiletik des Zaddik von Piaseczno war ein geistiger Widerstand, der mittels der klassischen Formen des hebräischen religiösen Diskurses seinen vollendeten Ausdruck fand. Ähnlich wie seine Vorgänger in früheren Jahrhunderten suchte der Prediger des Warschauer Ghettos nach einer religiösen Sprache, die sich zur Schilderung der damaligen Realität eignete, sowie nach einem Begriffsrahmen zur Erfassung der sich abspielenden Katastrophe. Dabei vermittelte er, wie es dem Grundprinzip der rabbinischen Homiletik entspricht, in seinen Predigten Trost und Beistand.

Auf mystische - und damit innerhalb der rationalen Ordnung nicht fassbare Weise gelang es ihm, die dem Chassidismus eigene Lehre der Schechina, der ständigen Anwesenheit Gottes in der realen Welt, mit der größten Herausforderung für den Glauben zu verknüpfen: der Erfahrung der tatsächlichen Abwesenheit Gottes im Ghetto. In der letzten Phase seiner homiletischen Aktivität, zwischen Februar und Juli 1942, formulierte er das Konzept des weinenden und leidenden Gottes. Dies ist - wie Nehemia Polen feststellt - eine der ungewöhnlichsten und überraschendsten Ideen in der Sammlung Esch Kodesch. Gott zeigt nicht deswegen keine Reaktion auf die Leiden der Juden, weil er sie verlassen hat - sondern Gott leidet selbst, und seine Qual ist so groß, dass er im Verborgenen weinen möchte, im inneren Himmelsgemach. Dieser Rückzug Gottes ist ein Zeichen für die nahende Apokalypse, doch Gott flieht nicht aus der Welt, die sich an der Schwelle einer Katastrophe befindet. Dank der Tora, die er dem Menschen hinterlassen hat, kann dieser sich gewissermaßen in jenes Himmelsgemach begeben und sich Gott in dessen Schmerz anschließen.

Gott, Er sei Gesegnet, lässt sich in Seinem Tränengemach antreffen, und wer dank des Tora-Studiums bis dorthin und in Seine nächste Nähe vordringt, wird gemeinsam mit Gott weinen und die Tora studieren. Darin genau liegt der Unterschied: Tränen und Schmerz, die der Mensch in Einsamkeit erträgt, können ihn zur Verzweiflung treiben und niederstrecken, sodass er nichts mehr ausrichten kann. Vergießt der Mensch aber seine Tränen gemeinsam mit Gott selbst - dann stärkt ihn das Weinen. Er weint - und

275 Ebd., S. 67. 
das verleiht ihm Kraft; er ist gebrochen - findet aber dennoch den Mut, zu studieren und zu lehren. ${ }^{276}$

Rabbi Szapiro wurde während des Aufstands aus dem Ghetto deportiert, an der Wende vom März zum April 1943. Zusammen mit einigen wenigen Menschen aus der jüdischen Gemeinschaft, die ebenfalls überlebt hatten - wie Emanuel Ringelblum oder einige Aktivisten von der Jüdischen Kampforganisation ŻOB -, kam er in das Lager Trawniki im Lubliner Land. Dort waren insgesamt 15 Rabbiner, die sich feierlich verpflichteten, sich nie mehr voneinander zu trennen; außerdem würde niemand von ihnen je versuchen, nur sich allein zu retten. Im August 1943 gelang es dem geheimen Jüdischen Nationalkomitee [Żydowski Komitet Narodowy; ŻKN], Ringelblum aus dem Lager zu befreien. Rabbi Szapiro weigerte sich, zu fliehen. Wichtiger, als den Tod noch eine Weile aufzuschieben, war ihm ein Akt der Solidarität mit den ebenso leidenden Brüdern und Schwestern. Indem er die Flucht aus dem Lager verweigerte, tat der Autor von Esch Kodesch das, was sich aus seiner Lehre ergab und worauf sie abzielte. Mit seiner Entscheidung vollführte er einen Akt des höchsten Glaubensbekenntnisses. Einen Akt der Heiligung des Namens Gottes - Kiddusch HaSchem.

\section{Zusammenfassung}

Die Zusammenfassung meiner Überlegungen zu den Formen des religiösen Diskurses in den Texten, die die Ghettoerfahrung während der Zeit ihres Geschehens verzeichneten, setzt sich aus zwei thematischen Strängen zusammen - der erste ist ein kurzer Kommentar zu den religiösen Antworten auf den Holocaust, die ich in diesem Kapitel beschrieben habe; der zweite stellt die Synthese der hier angeführten Analysen dar.

1

Die Problematik der sog. Theologie nach Auschwitz ist sehr umfassend, und ich möchte sie hier nicht zur Gänze erörtern. ${ }^{277}$ Nachdem ich das vorliegende Buch

276 Zitat nach: Ebd., S. 119.

277 Der Eintrag "Jewish philosophical and theological responses of the Holocaust", in: Encyclopaedia of the Holocaust, enthält eine ausführliche Bibliographie, jedoch sind die angegebenen Bücher in Polen schwer erhältlich. Gute Orientierung in der Problematik und Literatur zum Thema bietet der hier erwähnte Artikel von Rabbi N. Solomon (siehe auch den Artikel von C. Thoma: „Auschwitz - wielki »znak« dla Żydów i chrześcijan“ [Auschwitz - das große „Zeichen“ für Juden und Christen], in: W. Chrostowski (Hg.): Żydzi i chrześcijanie $w$ dialogu [Juden und Christen im 
bereits fertiggestellt hatte, erschien eine Arbeit von S. Krajewski: $\dot{y} y d z i$, judaizm, Polska [Juden, Judaismus, Polen], Warschau 1997, in der zwei für die hier besprochene Problematik wichtige Texte zu finden sind: „Auschwitz jako wyznanie“ [Auschwitz als Bekenntnis] und „Żydówskie teologie Zagłady“ [Jüdische Theologien des Holocaust]. Es scheint jedoch, als verlangten bestimmte theologische Fragestellungen, von denen weiter oben die Rede war, nach einem Kommentar. Die Doktrin der göttlichen Vergeltung, auf die sich Karol Rotgebers Theologie stützt, wird im jüdischen Schrifttum der letzten 30 Jahre entschieden abgelehnt. Argumentiert wird, dass „die Erklärung des Holocaust als göttliche Strafe für die Sünden der Juden [...] das Gedenken an sechs Millionen Märtyrer [beleidigt], müssen doch unter den Umgekommenen viele gewesen sein - von kleinen Kindern ganz zu schweigen -, die nicht in einem Maße gesündigt hatten, das ein solches Grauen und die Demütigung jener furchtbaren Vernichtung gerechtfertigt hätte ${ }^{\text {“278 }}$. Auch Rabbi Sherwin lehnt die Doktrin ab, jedoch schränkt er ein: „[A]uch wenn die Doktrin der göttlichen Vergeltung ganz offensichtlich nicht auf den Holocaust angewandt werden kann, muss man bedenken, dass dieses Argument sehr lange zur Erklärung für die Leiden diente und daher nicht übereilt beiseite geschoben werden darf. Die jüdischen Theologen haben bisher keine andere zufriedenstellende Erklärung gefunden. Vielleicht ist es noch zu früh, um eine solche herauszuarbeiten. “279

Vor dem Hintergrund der Überlegungen, die nach dem Krieg angestellt wurden, nehmen die Predigten Rabbi Klonimus Kelmisz Szapiros einen erstaunlich modernen Charakter an. Rabbi Szapiro vollzieht eine Neubewertung der traditionellen Konzeption des Leidens als Strafe für Sünden. Das ist die Folge der Evolution seiner theologischen Ansichten. In den letzten Monaten seiner

Dialog]), Warschau 1992. Diesen Fragestellungen widmet sich die Zeitschrift „Znak“, Nummer 5/1991, mit dem Titel „Judaizm, Szoah, Chrześcijaństwo“ [Judaismus, Schoa, Christentum] (siehe besonders: C. Thoma: „Próba teologicznej interpretacji Szoah“ [Versuch einer theologischen Interpretation der Schoa]; W. Chrostowski: „Znaczenie Szoah dla chrześcijańskiego zrozumienia Biblii“" [Die Bedeutung der Schoa für das christliche Verständnis der Bibel]; E. Wiesel: Gesang der Toten: Erinnerungen und Zeugnis, dt. Übers. von Ch. Sturm, R. Walter, Freiburg/Breisgau, Basel, Wien 1989. Die Zeitschrift „Collectanea Theologica“ 2/1992 beinhaltet eine umfassende Skizze von M. Horoszewicz: „Symbolika Auschwitz dla Żydów i chrześcijan“ [Die Symbolik von Auschwitz für Juden und Christen] sowie einen Artikel von S. Schreiner: „Auschwitz - zakwestionowanie chrześcijańskiej tradycji teologicznej“ [Auschwitz - die Infragestellung der christlichen theologischen Tradition].

278 N. Solomon, op. cit., S. 137.

279 B.L. Sherwin: op. cit., S. 246. 
Tätigkeit als Prediger formulierte er die Idee eines leidenden und im Verborgenen weinenden Gottes. Im vorderen Teil seiner Sammlung Esch Kodesch deutet er noch an, die Verfolgungen durch die Nazis könnten eine Strafe für begangene Sünden sein. „Daher ist es umso überraschender“, schreibt Nehemia Polen, „dass dieses Thema später nicht mehr zur Sprache kommt. Wenn noch hier und da Bezüge zum Leiden als Buße für Sünden aufscheinen, dann sind sie äußerst allgemein gehalten, konventionell und schablonenhaft. Kurz vor der großen Liquidierungsaktion verwirft Rabbi Szapiro ganz offen das Konzept, demzufolge die gegenwärtigen Ereignisse sich mit einer Bestrafung für begangene Sünden erklären lassen. Zwar bestätigt er grundsätzlich die traditionelle Theodizee, jedoch erlaubt ihm die starke Hervorhebung seiner Idee des göttlichen Leidens, die Standardkategorien dieser Theodizee als nicht auf die derzeitigen Ereignisse anwendbar zu verwerfen. “" 280

Einen aktuellen Kommentar verlangt auch der Gott schmähende Themenstrang, den ich am Beispiel von Calel Perechodnik erläutert habe. Die Entscheidung zur Ablehnung Gottes war eine der Formen der religiösen Verarbeitung des Holocaust. Der orthodoxe Rabbi Irving Greenberg schreibt viele Jahre nach dem Krieg: „Der Holocaust ist das radikalste Gegenzeugnis sowohl für das Judentum als auch für das Christentum [...]. Die Grausamkeit und das Morden lassen die Frage aufkommen, ob selbst die, die nach einem solchen Ereignis noch glauben können, von einem sorgenden und liebenden Gott auf eine Weise zu sprechen wagen, die keine Verhöhnung derjenigen darstellt, die gelitten haben. “281 Die radikalste in der Sprache der Theologie formulierte Antwort auf die Herausforderung des Holocaust ist die Konzeption von Richard Rubinstein (After Auschwitz: Radical Theory and Contemporary Judaism, 1966). Rubinstein zufolge bedeutete der Holocaust die Bankrotterklärung der traditionellen jüdischen Theologie. Die Welt erwies sich als absurd, ohne Sinn und Zweck. Somit müssten die Juden die Vision eines transzendenten Gottes - eines „Herrn der Geschichte", der die Welt erlöst - verwerfen und stattdessen nontheistische Religionsformen annehmen. Das wäre ein neues, immanentes und naturalistisches Wertesystem, das eine Quelle der Freude und der Glücks auf dieser Welt sein könnte. ${ }^{282}$

280 N. Polen, op. cit., S. 121.

281 L. Greenberg: „Cloud of Smoke, Pillar of Fire“, in: Auschwitz. Beginning of a New Era?, New York 1977. Zitat nach: N. Solomon, op. cit., S. 145.

$282 \mathrm{Zu}$ Rubinsteins Konzeptionen siehe „Jewish philosophical and theological responses to the Holocaust", op. cit., S. 145. 
Die letzte Sache, die nach einem Kommentar verlangt, ist die Frage einer zwischen Religion und Politik anzusiedelnden messianischen Sichtweise des Staates Israel, die den 1948 gegründeten Staatsorganismus als eine Frucht des Holocaust betrachtet. Eine solche, noch als Prophezeiung formulierte Denkweise findet sich in Karol Rotgebers Tagebuch. In Israel entwickelte sich eine eigene Zivilreligion, die Rabbi Byron L. Sherwin ${ }^{283}$ mit der amerikanischen Zivilreligion vergleicht. Dieser Religion zufolge ist der Holocaust zum Grundstein geworden für einen Staat Israel. Der klassische Zionismus vertrat die Position, die Juden in einer Diaspora seien zwangsläufig doppelt bedroht: von außen her durch den Antisemitismus, von innen her durch Assimilierung. Die einzige reelle Zukunft für die Juden liege in einem souveränen Staat. Der Holocaust ist demnach die endgültige Bestätigung und zugleich die zwar entsetzliche, aber in politisch-historischer Dimension realistische Möglichkeit zur Umsetzung dieser Konzeption. Daher nimmt der Holocaust innerhalb der Zivilreligion des Staates Israel eine fundamentale Stelle ein. Er kreiert einen Neuanfang. Die wichtigste jüdische Antwort auf den Holocaust lautet: „Niemals wieder!“ Die Konsequenz einer solchen Haltung ist eine neue, „zivile“ und nicht „religiöse“ Lesart der jüdischen Tradition. Das wiederum führt zu einer Säkularisierung der Liturgie. So legt beispielsweise die israelische Zivilreligion beim Chanukkafest die Betonung nicht auf den Triumph des Judaismus über den Hellenismus, sondern auf das militärische Heldentum der Makkabäer. Auch wenn die meisten jüdischen Feiertage eine Verbindung mit der Geschichte des jüdischen Volkes aufweisen, so gedenkt doch keiner von ihnen militärischer Erfolge. Erst in jüngster Zeit werden der Unabhängigkeitstag und der Jerusalemtag (zur Feier der Wiedererlangung Jerusalems im Zuge des Sechstagekrieges 1967) als Tage mit religiöser Bedeutung wahrgenommen. Auschwitz ist für die Juden ein Symbol für den Holocaust, der sich nie wiederholen darf. All das führt - wie Rabbi Sherwin ausdrücklich betont - unweigerlich zur Säkularisierung. Der Imperativ des Überlebens wird zum Substitut für den Judaismus. Der Fortbestand des jüdischen Volkes wird zum Ziel an sich, was aus theologischer Sicht Götzendienerei wäre - wird hier doch etwas, das nicht das Absolute ist, wie das Absolute behandelt. Dabei handelt es sich auch um ein moralisches Problem. Wenn nämlich der Fortbestand absoluten Wert besitzt, dann ist alles, was ihn befördert, erlaubt und gerechtfertigt.

Rabbi Sherwins theologische Überlegungen zum Holocaust ergeben Schlussfolgerungen, die für die hier behandelte Diskursproblematik von besonderer

283 Diese Frage referiere ich nach: B.L. Sherwin: Sparks Amidts the Ashes, op. cit. 
Bedeutung sind. Sherwin stellt nämlich eine Frage, die für mich einen Schlüsselcharakter hat: Wie kann die Geschichte des Holocaust erzählt werden? Die Haggada ist die Geschichte vom Auszug der Juden aus Ägypten, die eingegliedert wurde in die Liturgie des Pessachabends. Wie ist dann also eine Haggada des Holocaust möglich?

„Aufgrund [...] der Mentalität der amerikanischen und der israelischen Juden“, meint Rabbi Sherwin, „wird die Erzählung über den Holocaust problematisch. Sie sind nicht imstande, sich in das hineinzuversetzen, was anderen Juden widerfahren ist. [Sie] glauben, eine Akzeptanz des Geschehenen bedeute, dass sie die Verantwortung dafür übernehmen, dass es mit Gewissheit niemals wieder geschieht. [...] Die Ansicht der Israelis, dass die Existenz des jüdischen Volkes am besten durch die völlige Eigenverantwortlichkeit gesichert werden könne, führte notwendigerweise zur Umdichtung der Erzählung über den Holocaust in eine Erzählung über Situationen des Verrats an Juden durch Nichtjuden. Der Beweis wurde notwendig, dass die Geschichte des Antisemitismus in Europa den Holocaust zu etwas Unvermeidlichem gemacht und dass der Verrat von Juden durch ihre nichtjüdischen Nachbarn in deren Ländern den Nazis die Erreichung ihrer geplanten Ziele ermöglicht habe. “284 Die Honlocaustnarration ist verknüpft mit der Narration über das Land Polen. Sherwin schreibt von zwei entgegengesetzt ausgerichteten Modellen. Eines betrachte ,jeden Polen als Nazi-Kollaborateur bei der Ermordung der Juden und die katholische Kirche als krankhaft antisemitisch in theologischer Hinsicht“. Die Anhänger des anderen Modells erzählten von „Polen als einem Paradies für Juden, besonders im 16. und 17. Jahrhundert, als die Juden hier eine sichere Zuflucht vor dem deutschen Antisemitismus fanden. Sie erzählen von den polnischen Chassidim, vom Beitrag der Juden zur polnischen Kultur, Industrie, Wirtschaft und Geistlichkeit. Und so hängt die Art der geschichtlichen Darstellung von den Annahmen und Ansichten desjenigen ab, der die Geschichte erzählt. “285

\section{2}

Entschieden sich die Juden für den religiösen Diskurs, um die Geschichte ihrer Katastrophe zu erzählen, so trugen sie zu einer Verwurzelung des Holocaust in der Tradition bei und verwendeten dafür eine Sprache, deren Wurzeln ebenfalls in der Tradition lagen. Den aktuellen Augenblick siedelten sie innerhalb der göttlichen Pläne an, gliederten die Gegenwart in die sakralen Zeitläufte ein,

284 B.L. Sherwin, op. cit., S. 234-235.

285 Ebd., S. 247-248. 
schmiedeten die eben stattfindende Geschichte in einen Archetypus um. Die jüdische Liturgie der Zerstörung und Rhetorik des Leidens - über die der häufig von mir zitierte David G. Roskies schreibt - entspringen einer fundamentalen Wahrheit über das Bündnis zwischen Gott und seinem Volk, geben einen in der Bibel und der postbiblischen Literatur verewigten, sich wiederholenden Rhythmus wieder: Vernichtung - Fortbestand - Rettung.

\section{Rotgeber}

Karol Rotgebers Klagelieder charakterisiert ein in zwei Bahnen verlaufender Diskurs, ein Aufeinanderprallen zweier unterschiedlicher Ordnungen: der Ebene der Erinnerungsnarration und der Ebene von Klage und Gebet. Der Diskurs erfährt dadurch eine Spaltung, es vermischen sich zwei zeitliche Schichten. Die Risse in der Narrationsebene werden in der Gebetsebene angeeignet und ausgeglichen.

Die Struktur der Gebetsebene ist organisiert durch eine „figurale Aus-

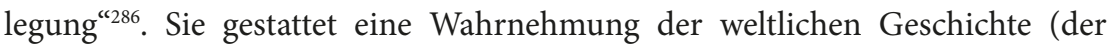
Geschichte des Volkes) als Theatrum der Menschen und Ereignisse, in dem sich die sakrale Geschichte manifestiert. Die reale Ordnung enthüllt eine transzendente Ordnung. Die historische Wirklichkeit offenbart dank des figuralen Denkens ihre Fundamente, ihren Sinn. Dieses Denken sieht in dem, was im jetzigen Moment geschieht, die Erfüllung dessen, was früher geschah. Beide Ereignisse aus der geschichtlichen Ordnung sind Figuren, sie sagen also voraus (weisen darauf hin), wie die zukünftige volLENDETE Erfüllung in der transzendenten (eschatologischen) Ordnung aussehen wird.

In Rotgebers Tagebuch lässt sich die folgende figurale Kette rekonstruieren: (1) die Ebene von Gebet und Klage - mittels einer biblischen Stilisierung wird der Archetypus des Unheils aufgerufen, also die Zerstörung des (irdischen) Jerusalem; diese Figur wird zur Figur für die Vernichtung der Juden von Warschau, (2) die Ebene der Erinnerungsnarration - eine realistische Beschreibung der Vernichtung des Ghettos. (1) und (2) sind Figuren, die die Erfüllung des

286 Zur figuralen Auslegung siehe Z. Stefanowski: Historia i profecja. Studium o „Ksiegach narodu i pielgrzymstwa polskiego" Adama Mickiewicza [Geschichte und Prophetie. Eine Studie zu Adam Mickiewiczs „Büchern des polnischen Volkes und der polnischen Pilgerschaft“], Warschau 1962, Kap. 2: „Figuralny wykład historii w »Księgach narodu «" [Die figurale Auslegung der Geschichte in den „Büchern des polnischen Volkes"]. 
göttlichen messianischen Versprechens, den endgültigen Triumph Israels voraussagen.

Von individuellem Leiden wird erzählt, indem dieses Leiden in die national-religiöse Tradition von kollektivem Unglück eingeschrieben wird und dadurch den Charakter religiösen Trosts und Zuspruchs annimmt. Was im Hier und Jetzt durchlebt wird und durch und durch absurden Anschein hat, erlangt in transzendenter Dimension einen Sinn. Es ist Anzeichen für einen vernichtenden Zorn, aber auch die Ankündigung eines zukünftigen Sieges.

\section{Huberband}

Bei Rotgeber ließen sich zwei parallele und voneinander unabhängige, dabei aber einander erhellende Diskursströmungen beobachten. In Rabbi Huberbands Schriften hingegen gibt es keine zwei voneinander getrennten Bereiche mehr. Der Diskurs erreicht hier eine Doppelstruktur, er spielt in zwei Dimensionen zugleich: Auf der Erzählebene der weltlichen Geschichte zeichnet sich schemenhaft eine sakrale Geschichte ab. Die Erzählung über das Ghetto wird zur ewigen Erzählung über ein archetypisches Muster der Geschicke des Volkes. Hier generiert die allgemeine Regel der figuralen Auslegung einen anderen Diskurstypus als bei Rotgeber - das in der postbiblischen Tradition verwurzelte Muster des Martyrologiums.

Die jüdischen martyrologischen Erzählungen fügen sich ein in das Modell einer parabolischen Narration. Die narrative Einheit - ein Kettenglied des traditionellen Martyrologiums - hat eine doppelschichtige semantische Struktur: einen wörtlichen und einen typischen Sinn. Die von Huberband mit faktographischer Akribie geschilderten Juden, die die Tora aus brennenden Synagogen retten oder im Schusshagel von Exekutionskommandos umkommen, werden zum Exempel universaler Haltungen und Werte. Ähnlich zeigt die Parabel einerseits die erzählte Begebenheit als einzeln stehenden, konkreten Fall, befreit sie aber andererseits von konkreten Bezügen, ist doch der universale Sinn das Wichtigste. Die so zutage tretende spezielle Dialektik des Konkreten und Schematischen ist eine der grundlegenden Eigenschaften der Parabel ${ }^{287}$.

Die judaistische martyrologische Tradition entwickelte sich nicht vollständig. Sie wurde überschattet von der christlichen Tradition, die die jüdischen martyrologischen Quellen übernahm und in entscheidendem Maß erweiterte ${ }^{288}$.

287 Siehe Z. Stefanowski, op. cit., S. 148, 166-179; M. Głowiński: „Norwida wiersze-przypowieści“ [Norwids Gedichtparabeln], in: M. Żmigrodzka (Hg.): Cyprian Norwid w 150-lecie urodzin [Cyprian Norwid zum 150. Geburtstag], Warschau 1973, S. 75-77.

288 D.G. Roskies: The Literature of Destruction, op. cit., S. 40. 
Als Gattungskontext für Huberbands Martyrologium könnten daher die sog. Acta Martyrum herangezogen werden - Berichte über den Prozessverlauf und die Hinrichtung von Anhängern des christlichen Glaubens in den ersten Jahrhunderten $\mathrm{n}$. Chr. Sie wiesen eine festgelegte Ordnung auf, nach der die Informationen mitgeteilt wurden, und kursierten als Briefe zwischen christlichen Gemeinden oder in Form von Gerichtsprotokollen mit Schilderungen des Martyriums. Literarische Bearbeitungen des enthaltenen Materials wurden Passiones genannt. Die Acta Martyrum schufen Muster für heldenhafte Charaktere und moralische Haltungen, an die spätere Epochen anknüpften. ${ }^{289}$

\section{Szapiro}

Die Predigten von Rabbi Klonimus Kelmisz Szapiro sind gewissermaßen die endgültige Sublimierung der hier analysierten Formen des religiösen Diskurses. Es gibt keine zwei Ebenen mehr, keine doppelschichtige Struktur, keine figurale Auslegung der Geschichte - es gibt nur, sozusagen, den typischen Sinn, die Essenz. Rabbi Szapiros Derascha repräsentiert den religiösen Diskurs in Reinform.

Nehemia Polen bezeichnet das persuasive Modell der Homiletik Rabbi Szapiros als „Lehre durch Widerstand“, und diesem Charakter sollte die Form der kontextlosen Predigt dienlich gewesen sein. Obgleich die Predigten mitten im abgeriegelten Bezirk entstehen, kommen sie bewusst ohne jegliche makabre Realien des Ghettos aus. Sie scheinen das Geschehen ringsum vollkommen zu ignorieren. Stattdessen befassen sie sich eingehend mit der exegetischen Erörterung von Textstellen aus Tora oder Talmud, geben keine direkte Antwort auf den Holocaust, der hier und jetzt im Gange ist. Dennoch verschloss der Prediger des Warschauer Ghettos nicht seine Augen vor der Realität. Er nahm ihre Herausforderung an, um ihr geistigen Widerstand zu leisten, um sich nicht überwältigen und zerstören zu lassen. Als einzige Rettung erwiesen sich die Tora und ihr Studium. „Die indirekte Botschaft jener Predigten“, schreibt Nehemia Polen, „könnte so lauten, dass die Worte der Tora und der Diskurs über die heiligen Dinge und die Würde des Menschen letztendlich über die Sprache des Hasses und der Vernichtung triumphieren. ${ }^{\text {" } 90}$

289 Siehe den Eintrag „Acta martyrum“, in: J. Sławiński (Hg.): Słownik terminów literackich [Wörterbuch der literarischen Termini], Wrocław 1988.

290 N. Polen, op. cit., S. 21. 


\section{Schluss}

Das Bewusstsein, dass es Erlebnisse gibt, die sich nicht ausdrücken, nicht beschreiben, nicht erzählen oder anderen vermitteln lassen, ist universal. Nicht ausdrückbar scheint alles zu sein, was radikal die Grenze des bisher Erlebten überschreitet und den Menschen vor eine unbekannte, fremde Wirklichkeit stellt, die sich nicht aneignen lässt. Unübertretbare Barrieren setzt der menschlichen Ausdrucksmöglichkeit das heilige Grauen, das sich außerhalb der Kategorien von Gut und Böse ansiedelt (und das Rudolf Otto als das Numinose und Gerardus van der Leeuw als „Mächte“ bezeichnet). Ein solches unbezähmbares, überwältigendes Grauen tritt bei der Erfahrung massenhaften Todes, einer allgemeinen Katastrophe, eines kollektiven, ganze Völker vernichtenden Unheils ein, bei einem Leid, das jedes menschliche Maß und jede Vorstellung übersteigt. Doch genau diese Erfahrungen verlangen mit besonderer Macht nach einem Ausdruck, nach einem Zeugnis. Unheil und Katastrophen, Schmerz und Qual bringen ein Bedürfnis hervor, das Unglück auszudrücken, zu verewigen und den Nachkommen zu vermitteln. Die Urquelle solcher Zeugnisse ist die Bibel; weitere Glieder in der Kette sind martyrologische Traktate, Seuchenchroniken, Chroniken von Belagerungen und Pogromen. In dieser Tradition finden auch die persönlichen Dokumente aus der Zeit des Holocaust Platz.

Die Autoren jener Zeugnisse sind von einem nicht unterdrückbaren Imperativ des Schreibens geleitet. Dessen Sinn erfüllt sich nicht nur in der Dokumentation des widerfahrenen Unheils, der Formulierung einer Warnung für die Nachkommen oder einem Appell an das Mitgefühl der Adressaten - vielmehr wird der Akt des Schreibens zu einem heroischen Akt der Herausforderung des Holocaust. Und obgleich die erhaltenen Texte sich viele Male auf den alten Topos der Unausdrückbarkeit berufen, manifestieren sie doch durch ihre bloße Existenz gerade das Gegenteil. Das in verschiedenste Tonarten gefasste Bekenntnis „Das lässt sich nicht mit Worten ausdrücken“ beweist, wie hartnäckig die Autoren mit der widerspenstigen Sprachmaterie rangen, es beweist jedoch nicht die Aufgabe der Worte an sich. Könnten jene auf Papierfetzen verewigten Worte nach Überzeugung ihrer Verfasser tatsächlich nichts ausdrücken, festhalten oder bewahren, dann hätten sie sie nicht so sorgsam bewacht, nicht versteckt, nicht ihr Leben für sie gegeben.

Eine besonders aussagekräftige Bestätigung jener Haltung bietet die Gegenüberstellung zweier Texte. Im Januar 1943 vermerkt Emanuel Ringelblum:

Icchak Giterman. Umgekommen bei der zweiten Deportation aus Warschau. Während eines Besuchs bei mir sah er das Verzeichnis der Getöteten durch und setzte verschiedene Namen hinzu. Nun scheint in demselben, von ihm eigenhändig vervollständigten 
Verzeichnis der Name Icchak Giterman auf. Meine Hand zittert, als ich diese Worte schreibe, denn wer weiß, ob in der Zukunft nicht ein Historiker bei der Durchsicht dieser Liste auch meinen Namen hinzusetzt: „E. Ringelblum“ (Bd. 1, S. 470).

Ein Franziskanermönch aus der Abtei von Kilkenny in Irland, der Mitte des 14. Jh. infolge des Schwarzen Todes vollkommen allein unter Toten zurückgeblieben war, führte trotz allem seine Seuchenchronik weiter, damit

[...] nicht wichtige Dinge mit der Zeit verschwinden und der Vorstellung unserer Nachkommen fremd bleiben. [...] Ich hinterlasse Pergament, um die Arbeit fortzusetzen, und wenn nur ein einziger Nachkomme Adams diese Pest überlebt, soll er die Arbeit weiterführen, die ich begann. ${ }^{291}$

Auf dem Pergamentbogen ist die bereits von anderer Hand verzeichnete Angabe zu finden, dass Bruder John ebenfalls an der Pest gestorben sei.

Im kurzen Kapitel „Statt eines Vorwortes“ zu ihrem Poem Requiem ${ }^{292}$ dreht Anna Achmatowa den Topos der Unausdrückbarkeit um und erklärt es für möglich, unbeschreibbar scheinende Dinge zu beschreiben. Achmatowas Bekenntnis ist vor allem ein Zeichen, dass sie die moralische Pflicht zu bezeugen auf sich nehmen will, und es ist ein Ausdruck ihres Willens, jenes Zeugnis anderen zu übermitteln.

In den schrecklichen Jahren unter Jeshov habe ich siebzehn Monate schlangestehend vor den Gefängnissen von Leningrad verbracht. Einmal erkannte mich jemand irgendwie. Da erwachte die hinter mir stehende Frau mit blauen Lippen, die natürlich niemals meinen Namen gehört hatte, aus der uns allen eigenen Erstarrung und fragte mich leise (dort sprachen alle im Flüsterton):

„Und das können Sie beschreiben?“

Und ich sagte:

"Ja."

Da glitt etwas wie ein Lächeln über das, was einmal ihr Gesicht gewesen war.

Die Erfahrung des Holocaust war verbunden mit der Erfahrung von Einsamkeit und Verlassenheit, mit dem Gefühl des Ausgestoßenseins, der Verdammung zur Nicht-Existenz, zum spurlosen Verschwinden. Wichtiger als der Überlebenskampf war daher der Kampf um die Erinnerung. In diesem ewigen Kampf sahen sich die Holocaustzeugen, verlassen und einsam in einer gleichgültigen Welt,

291 Zitat nach B. Tuchmann: Der ferne Spiegel: Das dramatische 14. Jahrhundert, dt. Übers. von U. Leschak, M. Friedrich, Hildesheim 1997, S. 100.

292 Anna Achmatowa: Requiem, dt. Übers. von R. Düring, Berlin 1987, S. 9. 
einer Herausforderung gegenüber, vor der bereits Generationen ihrer Großväter und Urgroßväter gestanden hatten. Damit traten sie in eine große Tradition ein, in den Bereich einer archetypischen Sprache und universaler Diskursfiguren zum Ausdruck kollektiven Unglücks und individuellen Leidens. Ihre Biografien fügten sich zu einem bestimmten Existenzmuster zusammen, ihre individuellen Lebensläufe enthüllten einen der Kulminationsmomente menschlichen Schicksals. Die persönlichen Dokumente aus jener Zeit bezeugen demnach nicht nur, dass Erfahrungen wie der Holocaust niedergeschrieben werden SOLLTEN, sondern auch, dass sie niedergeschrieben werden KöNNEN.

Das Ghetto lässt sich mittels eines universalen symbolischen Codes beschreiben, lässt sich einschreiben in kulturelle Matrizen - eine Sprache des Makabren, eine Sprache der Seuche, eine Sprache der Hölle. Auch lässt es sich eingliedern in die universelle Sprache eines religiösen Diskurses - in eine Rhetorik des Märtyrertums und eine Liturgie der Zerstörung, die als Formen der Kanonisierung von Erinnerung den Riss zwischen Ewigkeit und Gegenwart, zwischen Glaubensordnung und Ordnung der Verzweiflung, zwischen Geschichte und Transzendenz offenbaren.

Die Lektüre dieser Texte führt zu der Schlussfolgerung, dass es eine besondere Form der Aufzeichnung gibt, die das Unberührbare zu berühren, das Unausdrückbare auszudrücken, zum Kern der Holocausterfahrung vorzudringen scheint. Es handelt sich um die in Rokhl Oyerbakhs vorgefundene und auch in anderen Schriften zu entdeckende Formel der Groteske. Eine solcherart gestaltete Aufzeichnung enthüllt eine unüberwindbare Fremdheit und ein überwältigendes Grauen, die sich Urteil und Verstand entziehen.

Bestätigung findet diese Wahrheit durch die Tatsache, dass die Sprache der Groteske in der Holocaustdarstellung einem speziellen Tabu unterliegt, dass derartige Zeugnisse nur widerwillig der Öffentlichkeit zugänglich gemacht, in den Hintergrund gedrängt oder gar scharf verurteilt werden. Eine solche Formel scheint nicht annehmbar zu sein, sie kann die Barrieren der Akzeptabilität nicht überwinden. Davon zeugt beispielsweise, dass Rokhl Oyerbakhs Schriften im polnischen Sprachraum lange Zeit nicht existent waren. ${ }^{293}$

293 Mittlerweile liegt eine polnische Übersetzung von Oyerbakhs Schriften vor: Karolina Szymaniak: Rachela Auerbach. Pisma z getta warszawskiego [Rachel Auerbach. Schriften aus dem Warschauer Ghetto], ŻIH 2016. Des Weiteren wird an einer polnischen und englischen Übersetzung sämtlicher Dokumente aus dem Ringelblum-Archiv gearbeitet; die Texte sollen online auf der Webseite onegszabat.org zugänglich gemacht werden; Anm. d. Übers. 
Ist dies nicht eine Art Selbstschutz, um der Tatsache des Holocaust nicht ins Auge sehen, sich ihr nicht öffnen zu müssen? Ist es nicht ein Ausdruck der Angst, die ausgetretenen und ritualisierten sprachlichen Pfade zu verlassen, die uns durch erfolgreich von der Unerträglichkeit des Holocaust fernhalten, von einer Wahrheit, die wir nicht an uns heranlassen können oder wollen?

Der Holocaust gehört ohne Zweifel zu der Art Erfahrung, die zur Kenntnis zu nehmen das Bewusstsein sich weigert, wie Jolanta Brach-Czaina schreibt. Der Mensch schütze sich vor dem Gedanken an die Existenz eines natürlichen, durch nichts gerechtfertigten Bösen mit ambivalentem, zweideutigem Charakter. Er könne nicht akzeptieren, dass Böses zu tun und Böses zu erfahren zwei Seiten derselben Wirklichkeit seien, derselben Existenz - so wie Gutes zu tun und Gutes zu empfangen. Eine negative Tragik sei für ihn inakzeptabel. Deswegen sei eine Antwort auf das Böse etwas anderes als eine Verurteilung des Bösen. „Es gilt“, schreibt Brach-Czaina, „die eigentümliche Vorstellung abzulegen, das Böse läge auf einer irgendwie verfluchten, schlechteren Seite der Welt - liegt es doch auf derselben Seite wie das Gute. Wir können Übeltäter vernichten oder gernhaben, doch wir müssen uns immer bewusst sein, dass sie natürlicherweise zur menschlichen Gemeinschaft und zu uns gehören und dass wir uns alle auf derselben Seite befinden. “294

An dieser Stelle kehrt das Problem der Einsamkeit der Schreibenden zurück. In dem archetypischen Akt, in dem sie das Unheil verzeichneten und die Katastrophe bezeugten, waren sie nicht allein; sie tauchten ein in eine Tradition, betraten das Große Jetzt der Kultur. Bei der Niederschrift richteten sie ihre Worte an einen Adressaten, der sie irgendwann lesen würde. Letztendlich richteten sie ihre Worte an mich, an uns alle. Aber ist ihre Stimme hörbar, und wird sie auch gehört?

Henryk Grynberg bezweifelt die Ansicht, dass sich aus dem Holocaust eine Botschaft von grundlegendem Gewicht für die Menschheit ergebe, ein Wissen, dass sie vor einer Wiederholung dieser Katastrophe schützen könne. So gesehen könnte man drastisch formulieren, dass die Zeugnisse des Holocaust uns gar nichts lehren, oder genauer: nichts Neues, Bahnbrechendes. „Das große Übel, dessen Ausdruck der Holocaust gewesen ist, lehrt uns, dass es Werte gibt, ohne die die menschliche Welt nicht existieren kann, und dass es Verbote gibt, die

294 J. Brach-Czaina: Szczeliny istnienia [Die Spalten in der Existenz], Warschau 1992, S. 123. Jene Fragestellung entwickelt die Autorin v.a. in den Essays "Święte zło“ [Das heilige Böse] und „Nietykalnośćc [Die Unberührbarkeit]. 
man nicht übertreten darf, wenn man Mensch sein will. Doch das ist bereits seit mehreren Tausend Jahren bekannt. ${ }^{\text {“295 }}$

Eine der wichtigsten Entdeckungen bei der Lektüre der persönlichen Dokumente aus dem Ghetto ist für mich das Bewusstsein für den Unterschied - wie Jolanta Brach-Czaina es so treffend formuliert - zwischen der Verurteilung des Bösen und einer Antwort auf das Böse. Ich denke, eine Antwort auf das Böse ist die Tatsache, dass Zeugen und Opfer des Holocaust das Risiko auf sich genommen haben, diese Erfahrung zu verzeichnen, sprachlich zu erfassen und textuell zu verewigen. Das Risiko, dieser Erfahrung eine für andere Menschen zugängliche, interpretierbare, verständliche Form zu verleihen. Uns, den Adressaten dieser Zeugnisse, sollte die bloße Verurteilung des Bösen nicht ausreichen. Wir sollten außerdem eine Antwort auf das Böse geben - und das heißt, zu verstehen versuchen.

295 H. Grynberg: „Nowoczesne wielkie zło“ [Das moderne große Übel], in: „Res Publika Nowa“ 1994, Nr. 5, S. 10. 



\section{Bibliografie}

Aaron F. W., Bearing the Unbearable. Yiddish and Polish Poetry in Ghettos and Concentrations Camps, New York 1990.

Achmatowa A., Requiem, Dt. v. R. Düring, Berlin 1987.

Adorno T.W., „Nach Auschwitz“, in: Negative Dialektik, Frankfurt/Main 1966.

Albert A. [W. Roszkowski], Najnowsza historia Polski [Die jüngste Geschichte Polens], Bd. 1, London 1994.

Arendt H., Eichmann in Jerusalem. Ein Bericht von der Banalität des Bösen,

Dt. v. B. Granzow, München 1964.

Ariès P., Bilder zur Geschichte des Todes, Dt. v. H.-H. Henschen, München/ Wien 1984.

Ariès P., Geschichte des Todes, Dt. v. H.-H. Henschen und U. Pfau, München/ Wien 1980.

Ariès P., Studien zur Geschichte des Todes im Abendland, Dt. v. H.-H. Henschen, München/Wien 1976.

Bachórz J., „Karta z dziejów zdrowego rozsądku, czyli o fizjonomice w literaturze" [Geschichtliche Karte des gesunden Menschenverstands oder Über die Physiognomik in der Literatur], in: „Teksty“ Nr. 2/1976.

Bałaban M., Historia i literatura żydowska, ze szczególnym uwzględnieniem historii Żydów w Polsce [Die jüdische Geschichte und Literatur, unter besonderer Berücksichtigung der Geschichte der Juden in Polen] Bd. 2, Lwów, Warschau, Krakau 1925.

Bartoszewski W., 1859 dni Warszawy [1859 Tage Warschaus], Krakau 1974.

Bartoszewski W., Warszawski pierścień śmierci 1939-1944 [Warschauer Todesring 1939-1944], [ohne Ortsangabe] 1967.

Bartoszyński K., „Aspekty i relacje tekstów“ [Textuelle Aspekte und Beziehungen], in: Z. Stefanowska und J. Sławiński (Hgg.), Dzieło literackie jako źródło historyczne [Das literarische Werk als geschichtliche Quelle], Warschau 1978.

Bauman Z., Dialektik der Ordnung. Die Moderne und der Holocaust, Dt. v. U. Ahrens, Hamburg 1992.

Berenstein T., Rutkowski A., Obóz koncentracyjny dla Żydów w Warszawie (1943-1944) [Das Konzentrationslager für Juden in Warschau (1943-1944), in: „Biuletyn ŻIH“ 62(1967). 
Bergman S., Szymon Dubnow 1 IX 1860-30 XI 1941 [Simon Dubnow, 1.10.1860-30.11.1941], „Kalendarz Żydowski - Almanach 1991-1992“ [Jüdischer Kalender - Almanach 1991-1992].

Berman A., „O losie dzieci żydowskich w Zakładów Opiekuńczych w Getcie Warszawskim“ [Über das Schicksal der jüdischen Kinder in den Fürsorgeanstalten im Warschauer Ghetto], in: „Biuletyn ŻIH“ Nr. 28 (1958). Blady-Szwajger A., I więcej nic nie pamiętam [Und weiter erinnere ich mich an nichts], Warschau 1994.

Blättler F., Warschau 1942: Tatsachenbericht eines Motorfahrers der zweiten schweizerischen Aerztemission 1942 in Polen, Zürich 1945.

Błoński J., „Die armen Polen blicken aufs Ghetto“, Dt. v. K. Wolff, in: M. Klecel, Polen zwischen Ost und West. Polnische Essays des 20. Jahrhunderts. Eine Anthologie, Berlin 1995.

Booth W.C., „Rodzaje narracji“ [Arten der Narration], Poln. v. I. Sieradzki, in: „Pamiętnik Literacki“ 1971, Heft 1.

Borowski T., Poezje [Gedichte], hrsg. v. T. Drewnowski, Warschau 1972.

Borwicz M.M., Écrits des condamnés à mort sous l’occupation allemande (19391945). Étude sociologique, [Schriften der Todgeweihten unter deutscher Besatzung (1939-1945). Eine soziologische Studie], Paris 1954.

Borwicz M.M., [Einleitung], in: Pieśń ujdzie cało ... Antologia wierszyo Żydach pod okupacja niemiecka [Das Lied entkommt heil und ganz ... Eine Anthologie von Gedichten über die Juden unter deutscher Besatzung], Warschau 1947.

Borwicz M.M., Literatura w obozie [Literatur im Lager], Krakau 1946.

Brach-Czaina J., Szczeliny istnienia [Die Spalten in der Existenz], Warschau 1992.

Buber M., Die Erzählungen der Chassidim, Zürich 1996.

Celan P., Gesammelte Werke, hrsg. v. B. Allemann und S. Reichert, Frankfurt/ Main 1986, Bd. 3.

Celan P., „Nächtlich geschürzt“, in: Von Schwelle zu Schwelle. Gedichte, Stuttgart 1955.

Celan P., „Todesfuge“, 1944/1945, Erstabdruck in: Der Sand aus den Urnen, Wien 1948.

Chatman S., „Towards a Theory of Narrative“, in: „New Literary History“ Bd. 6, Nr. 2, 1975.

Cieński A., Pamiętniki i autobiografie światowe [Weltberühmte Tagebücher und Autobiographien], Wrocław 1992. 
Collection of Testimonies, Memoirs and Diaries. (Record Group 033), zusammengestellt v. J. Klibanski, Bd. 1, Jerusalem 1990 [Katalogs des YadVashem-Archivs].

Dante A., Die Göttliche Komödie, Dt. v. Philalethes (König Johann von Sachsen, 1801-1873), Berlin um 1925.

Das Ghettotagebuch des Dawid Sierakowiak, Dt. v. R. Matwin-Buschmann, Leipzig 1993.

Defoe D., Die Pest zu London, Dt.v. R. Schaller, Berlin 1956.

Delumeau J., Angst im Abendland. Bd. 1., Dt. v. M. Hübner, G. Konder, M. Roters-Burck, Reinbek 1985.

Domański J., Tekst jako uobecnienie. Szkic $z$ dziejów myśli o piśmie i książce [Text als Vergegenwärtigung. Skizze aus der Geistesgeschichte über Schrift und Buch], Warschau 1992.

Dresden S., Vervolging, vernietiging, literatuur [Verfolgung, Vernichtung, Literatur], Amsterdam 1991.

Drewnowski T., Ucieczka z kamiennego świata. O Tadeuszu Borowskim [Flucht aus der steinernen Welt. Über Tadeusz Borowski], Warschau 1972.

Dunin-Wąsowicz K., Warszawa w latach 1939-1945 [Warschau in den Jahren 1939-1945], Warschau 1984.

Dziennik Dawida Sierakowiaka, Warszawa 1960.

Eisenbach A., Einleitung zu: E. Ringelblum, Kronika getta warszawskiego: wrzesień 1939-styczeń 1943 [Chronik des Warschauer Ghettos: September 1939-Januar 1943], hrsg. von A. Eisenbach, aus dem Jiddischen ins Polnische übers. von A. Rutkowski, Warschau 1983.

Eksterminacja Żydów na ziemiach polskich w okresie okupacji hitlerowskiej. Zbiór dokumentów [Die Ausrottung der Juden in polnischen Gebieten während der Besatzung durch die Nazis. Eine Sammlung von Dokumenten], bearb. von T. Berenstein, A. Eisenbach, A. Rutkowski, Warschau 1957.

Eliach Y., Hasidic Taies of the Holocaust, New York 1988.

Encyclopaedia Judaica, Jerusalem 1972.

The Encyclopedia of Judaism, hg. v. G. Wigoder, New York 1989.

Encyclopedy of the Holocaust, hg. v. I. Gutman, New York-London 1990.

Engelking B., „Czas przestat dla mnie istnieć...": analiza doświadczenia czasu w sytuacji ostatecznej [„Die Zeit hörte für mich auf zu existieren ...“: Eine Analyse der Zeitwahrnehmung im Angesicht des Todes], Warschau 1996.

Engelking B., Zagłada i pamięć. Doświadczenie Holocaustu i jego konsekwencje opisane na podstawie relacji autobiograficznych [Vernichtung und Gedächtnis. Die Erfahrung des Holocaust und seine Konsequenzen, 
dargestellt auf der Grundlage von biographischen Berichten], Warschau 1994.

Fothergill R.A., Private Chronicles. A Study of English Diaries, London 1974.

Fuks M., Einleitung zur polnischen Ausgabe von: Das Tagebuch des Adam

Czerniaków (Adama Czerniakowa dziennik getta warszawskiego: 6 IX 193923 VII 1942), bearb. v. M. Fuks, Warschau 1983.

Fuks M., „Życie w gettach GG na tle ,Gazety Żydowskiej” (1940-1942)“ [Das Leben in den Ghettos des Generalgouvernements in der Darstellung der "Gazeta Żydowska“], in: „Biuletyn ŻIH“ 3(1971).

Geremek B., „Śmiech w cieniu szubienicy: o Villonie“ [Lachen im Schatten des Galgen: über Villon], in: „Znak“ 1983, Nr. 8 (345).

Gilbert M., The Holocaust. The Jewish Tragedy, Fontana/Collins, 1990.

Głowiński M., „Poetyka tekstów nieliterackich“ [Die Poetik nicht-literarischer Texte], in: Poetyka i okolice [Die Poetik und ihr Umfeld], Warschau 1993.

Głowiński M., „Powieść i prawda“ [Roman und Wahrheit], in: Gry powieściowe. Szkice $z$ teorii $i$ historii form narracyjnych [Romanspiele. Skizzen aus Theorie und Geschichte narrativer Formen], Warschau 1979.

Głowiński M., „Norwida wiersze-przypowieści“ [Norwids Gedichtparabeln], in: M. Żmigrodzka (Hg.): Cyprian Norwid w 150-lecie urodzin [Cyprian Norwid zum 150. Geburtstag], Warschau 1973.

Głowiński M., „Powieść a dziennik intymny“ [Roman und privates Tagebuch], in: M. Głowiński, Gry powieściowe [Romanspiele], Warschau 1973.

Głowiński M., Wprowadzenie [Einleitung (zu Übersetzungen französischer thematischer Kritik)], in: „Pamiętnik Literacki“ 1971, Heft 2.

Głowiński M., „Powieść i autorytety“ [Roman und Autoritäten], in: Porzadek, chaos, znaczenie. Szkice o powieści współczesnej [Ordnung, Chaos, Bedeutung. Skizzen zum zeitgenössischen Roman], Warschau 1968.

Głowiński M., „Stanisława Pigonia relacja z Sachsenhausen“ [Stanisław Pigońs Bericht aus Sachsenhausen], in: Gry powieściowe.

Gorzkowski K., Kroniki Andrzeja. Zapiski z podziemia 1939-1941 [Die Chroniken des Andrzej. Aufzeichnungen 1939-1941], bearb. v. T. Szarota, Warschau 1989.

Gronczewski A., „Wstęp do opisu choroby“ [Einleitung zur Beschreibung einer Krankheit], in: Wojna bez końca. Eseje [Krieg ohne Ende. Essays], Warschau 1992.

Gross N., Poeci i Szoa. Obraz Zagłady Żydów w poezji polskiej [Dichter und die Schoa. Das Bild der Judenvernichtung in der polnischen Lyrik], Sosnowiec 1993. 
Grynberg H., „Der Holocaust in der polnischen Literatur“, in: Unkünstlerische Wahrheit, Dt. v. L. Quinkenstein, Berlin 2014.

Grynberg H., „Nowoczesne wielkie zło“ [Das moderne große Übel], in: „Res Publika Nowa“ 1994, Nr. 5.

Grynberg H, „Polsko, czego ty ode mnie chcesz. Z Henrykiem Grynbergiem rozmawia Jacek Leociak" [Polen, was willst du bloß von mir. Jacek Leociak im Gespräch mit Henryk Grynberg], in: „Nowe Książki“1994, Nr. 3.

Grynberg M., „Wstęp“ [Einleitung], in: Pamiętniki z getta warszawskiego. Fragmenty i regesty [Tagebücher aus dem Warschauer Ghetto. Auszüge und Regesten], 2., überarbeitete Auflage, bearb. von M. Grynberg, Warschau 1993.

Gurjewitsch A., „«Die göttliche Komödie» vor Dante“, in: Mittelalterliche Volkskultur, Dt. v. M. Springer, Dresden 1986.

Gurock J. S., On Rabbi Shimon Huberband. From the Hebrew-Language Edition, in: S. Huberband, Kiddush Hashem. Jewish Religious and Cultural Life in Poland during the Holocaust, New York 1987.

Gutman I., Żydzi warszawscy 1939-1943. Getto - podziemie - walka [Die Warschauer Juden 1939-1943. Ghetto - Untergrund - Kampf], Poln. v. Z. Pelermuter, Warschau 1993.

Hamon P., „Czym jest opis“ [Was ist eine Beschreibung], Poln. v. A. Kuryś, K. Rytel, in: „Pamiętnik Literacki“ 1983, Heft 1.

Hannover N., Jawen Mezula. Schilderung des polnisch-kosakischen Krieges und der Leiden der Juden in Polen während der Jahre 1648-1653. Bericht eines Zeitgenossen, nach einer von J. Lelewel durchgesehenen französischen Uebersetzung, Hannover 1863.

Hausner G., Einleitung zu: S. Huberband, Kiddush Hashem. Jewish Religious and Cultural Life in Poland during the Holocaust, New York 1987.

Herling-Grudziński G., „Kronikarz piekła“ [Chronist der Hölle], in: „Kultura“ 1962, Nr. 11.

Horoszewicz M., „Symbolika Auschwitz dla Żydów i chrześcijan“ [Die Symbolik von Auschwitz für Juden und Christen], in: „Collectanea Theologica" 1992, Nr. 2.

Huizinga J., Herbst des Mittelalters, Bd. 1, Dt. v. T. Wolff-Mönckeberg, München 1928.

Im Warschauer Getto. Das Tagebuch des Adam Czerniaków 1939-1942, München 1986.

Jedlicki J., „Dzieje doświadczone i dzieje zaświadczone“ [Erlebte Geschichte und bezeugte Geschichte], in: Z. Stefanowska und J. Sławiński (Hgg.), Dzieło 
literackie jako źródło historyczne [Das literarische Werk als historische Quelle], Warschau 1978.

Kaganowski E., Vorwort zu: N. Szac-Wajnkranc, Przeminęło z ogniem.

Pamiętnik [Vom Feuer verschlungen. Erinnerungen], Warschau 1947.

Katsh A. L, Vorwort zu: Ch. A. Kaplan: Buch der Agonie: das Warschauer

Tagebuch des Chaim A. Kaplan, hg. von Abraham I. Katsh, Frankfurt/

Main 1967.

Kayser W., Das Groteske. Seine Gestaltung in Malerei und Dichtung. Nachdruck der Ausgabe von 1957, Tübingen 2004.

Kayser W., Das Groteske in Malerei und Dichtung, München 1960.

Kazimierska K., „O metodzie dokumentów biograficznych“ [Über die Methode des biographischen Dokuments], „Kultura i Społeczeństwo“ 1990, Nr. 1.

Korczak J., Tagebuch aus dem Warschauer Ghetto 1942, Dt. v. A. Dross, Göttingen 1996.

Korczak J., Pisma wybrane [Ausgewählte Schriften], Bd. 4, hg. von A. Lewin, Warschau 1986.

Kuberczyk T., „Życie religyjne w getcie warszawskim w relacji rabina Szymona Huberbanda" [Das religiöse Leben im Warschauer Ghetto im Bericht von Rabbi Szymon Huberband], in: D. Grynberg, P. Szapiro (Hgg.): Holocaust z perspektywy pótwiecza. Pięćdziesiąta rocznica powstania $w$ getcie warszawskim. Materiały $z$ konferencji zorganizowanej przez Żydowski Instytut Historyczny w dniach 29-30 marca 1993 [Ein halbes Jahrhundert nach dem Holocaust. Der fünfzigste Jahrestag des Warschauer Ghettoaufstands. Materialien von einer Konferenz des Jüdischen Historischen Instituts am 29.-30. März 1993], Warschau [ohne Jahresangabe].

Kula W., Dziennik czasu okupacji [Tagebuch der Besatzungszeit], hg. von N. Assorodobraj-Kula und M. Kula, Warschau 1994.

Kula W., Vorwort zu: L. Landau, Kronika lat wojny i okupacji [Chronik der Kriegs- und Besatzungsjahre], Bd. 1. Warschau 1962.

Langer L.L., The Holocaust and the Literary Imagination, New HavenLondon 1975.

Lewin A., „Ostatnie świadectwa“ [Die letzten Zeugnisse], in: Janusz Korczak $w$ getcie. Nowe źródła [Janusz Korczak im Ghetto. Neue Quellen], Warschau 1992.

Lewin A., A Cup of Tears. A Diary of the Warsaw Ghetto, hg. von A. Polonsky, London 1990.

Liptzin S., A History of Yiddish Literature, New York 1985. 
The Literature of Destruction. Jewish Responses to Catastrophe, hg. v. D. G. Roskies, Philadelphia 1988.

Löw R., „Ostatki polskie. Rzecz o izraelskiej prasie w języku polskim [T.1], in: „Zeszyty literackie“ 1994, Nr. 48.

Löw R., Pod znakiem starych foliantów [Im Zeichen alter Folianten], Krakau 1993.

Löw R., „Czytając Borwicza“ [Beim Lesen von Borwicz], in: „Zeszyty Historyczne“, [Paris] 1991, Nr. 98.

Lowenthal D., „Pamięć i zapomnienie“ [Erinnern und Vergessen], Poln. v. I. Grudzińska-Gross, M. Tański, „Res Publica“ 1991, Nr 3.

Lubas-Bartoszyńska R., Między autobiografia a literaturą [Zwischen Autobiographie und Literatur], Warschau 1993.

Lubas-Bartoszyńska R., Style wypowiedzi pamiętnikarskiej [Äußerungsstile in Tagebuch und Erinnerungen], Krakau 1983.

Ludność cywilna w powstaniu warszawskim. Pamiętniki. Relacje. Zeznania [Die Zivilbevölkerung im Warschauer Aufstand. Tagebücher. Berichte. Aussagen], Bd. 1, T. 1, bearb. v. M. M. Drozdowski, M. Maniakówna, T. Strzembosz, Warschau 1974.

Łopatyńska L., „Dziennik osobisty, jego odmiany i przemiany“ [Das persönliche Tagebuch, seine Spielarten und sein Wandel], in: „Prace Polonistyczne“ S. VIII, Łódź 1950.

Maciejewska I., Einleitung zur polnischen Ausgabe von: W. Szlengel, Was ich den Toten las: Texte und Gedichte aus dem Warschauer Ghetto [Co czytałem umarlym. Wiersze getta warszawskiego], Warschau 1977.

Maciejewska I., „Getto Warszawskie w literaturze polskiej“ [Das Warschauer Ghetto in der polnischen Literatur], in: M. Głowiński, J. Sławiński (Hgg.), Literatura wobec wojny i okupacji [Die Literatur angesichts von Krieg und Besatzung], Wrocław 1976.

Maciejewska L., „Getta doświadczenie w literaturze“ [Die Ghettoerfahrung in der Literatur], in: A. Brodzka et al. (Hgg.), Słownik literatury polskiej XX wieku [Wörterbuch der polnischen Literatur des 20. Jahrhunderts], Wrocław 1993.

Maciejewska L., [Einleitung zur Anthologie] Męczeństwo i Zagłada Żydów w zapisach literatury polskiej. Antologia [Märtyrertum und Vernichtung der Juden in Aufzeichnungen der polnischen Literatur. Anthologie], Warschau 1988.

Mark B., Einleitung zu: The Report of Jürgen Stroop Concerning the Uprising in the Ghetto of Warsaw and the Liquidation of the Jewish Residential Area, Warschau 1958. 
Markiewicz H., „Narratologia strukturalna i generatywno-transformacyjna“ [Die strukturelle und die generativ-transformative Narratologie], in: Teorie powieści za granicą. Od początków do schyłku XX wieku [Die Romantheorien im Ausland. Vom Anfang bis zum Ende des 20. Jahrhunderts], Warschau 1995.

Merżan I., „Ostatnia droga Janusza Korczaka“ [Der letzte Weg des Janusz Korczak], in: „Folks-Sztyme“ 1986, Nr. 6.

Milton J., Das verlorene Paradies, Dt. v. H.H. Meier, Stuttgart 1968, 2008.

Miłosz Cz., Das Zeugnis der Poesie, Dt. v. P. Lachmann, München 1984.

Nałkowska Z., Dzienniki czasu wojny [Tagebücher aus der Kriegszeit], bearb. v. H. Kirchner, Warschau 1996.

Nasiłowska A., Matywiecki P., Dwugłos o Korczaku [Zwiegespräch über Korczak], in: „Teksty Drugie“ 1992, Nr. 5.

New Catholic Encyclopedia, Washington 1967.

Oshry E., Responsa from the Holocaust, New York 1983.

Ostoja A., Vorwort zu: A. Kajzer: Za drutami śmierć [Hinter Stacheldraht der Tod], Łódź 1962.

Pamiętniki znalezione w Katyniu [Tagebücher aus Katyń], Vorwort von J. Zawodny, 2., erweiterte Auflage, Paris, Warschau 1990.

Platon, Der Staat - Politeia, Dt. v. R. Rufener, Düsseldorf, Zürich 2000.

Polen N., The Holy Fire. The Teachings of Rabbi Kolonymus Shapira, the Rebbe of Warsaw Ghetto, Northvale, New Jersey, 1994.

Polonsky A., Einleitung zu: A. Lewin, A Cup of Tears. A Diary of the Warsaw Ghetto, London 1990.

Prokop-Janiec E., Międzywojenna literatura polsko-żydowska jako zjawisko kulturowe i artystyczne [Die polnisch-jüdische Literatur der Zwischenkriegszeit als kulturelles und künstlerisches Phänomen], Krakau 1992.

Przybylski R., Wdzięczny gość Boga. Esej o poezji Osipa Mandelsztama [Gottes dankbarer Gast. Ein Essay über Mandelstams Dichtung], Paris 1980.

Ricœur P., Die Symbolik des Bösen, Dt. v. M. Otto, Freiburg, München 2002.

Rosenfeld A.H., A Double Dying. Reflections on Holocaust Literature, Bloomington-Indianapolis 1988.

Roskies D. G., Against the Apocalypse. Responses to Catastrophe in Modern Jewish Culture, Cambridge, Mass. 1984.

Rudnicki M., „Ostatnia droga Janusza Korczaka“ [Der letzte Weg des Janusz Korczak], notiert von R. Scharf, in: „Tygodnik Powszechny“ 1988, Nr. 45. 
Rufeisen-Schüpper H., Pożegnanie Miłej 18. Wspomnienia łączniczki Żydowskiej Organizacji Bojowej [Abschied von der Miła-Straße 18. Erinnerungen einer Meldegängerin der Jüdischen Kampforganisation], Krakau 1996.

Russell of Liverpool Lord, The Trial of Adolf Eichmann, London 1962.

Sadzik J., Wstęp do: Księga Psalmów, przeł. Cz. Miłosz, Paryż 1979.

Sakowska R., Menschen im Ghetto: Die jüdische Bevölkerung im besetzten Warschau 1939-1943, Dt. v. R. Henning, Osnabrück 1999.

Sakowska R., Die zweite Etappe ist der Tod. NS-Ausrottungspolitik gegen die polnischen Juden, gesehen mit den Augen der Opfer. Ein historischer Essay und ausgewählte Dokumente aus dem Ringelblum-Archiv 1941-1943, Berlin 1993.

Sakowska R., Einleitung zu: Archiwum Ringelbluma. Getto warszawskie lipiec 1942 -styczeń 1943 [Das Ringelblum-Archiv. Warschauer Ghetto Juli 1942-Februar 1943], bearb. von R. Sakowska, Warschau 1980.

Sauerland S., Od Diltheya do Adorna. Studia z estetyki niemieckiej [Von Dilthey bis Adorno. Studien in deutscher Ästhetik], Warschau 1986.

Schreiner S., „Auschwitz - zakwestionowanie chrześcijańskiej tradycji teologicznej" [Auschwitz - die Infragestellung der christlichen theologischen Tradition], in: „Collectanea Theologica“ 1992, Nr. 2.

Sherwin B. L., Sparks Amidst the Ashes: The Spiritual Legacy of Polish Jewry, New York, Oxford 1997.

Słownik teologii biblijnej [Wörterbuch der biblischen Theologie], hg. v. X. LéonDufour, ins Polnische übers. und bearb. v. K. Romaniuk, Poznań 1985.

Słownik terminów literackich [Wörterbuch der literarischen Termini], hg. v. J. Sławiński, Wrocław 1988.

Solomon N., „Czy Szoah wymaga radykalnie nowej teologii“" [Verlangt die Schoa nach einer radikal neuen Theologie], in: W. Chrostowski (Hg.): Żydzi i chrześcianie w dialogu [Juden und Christen im Dialog], Warschau 1992.

Stefanowska Z., Dyskusja nad esejem o Dzienniku Adama Czerniakowa [Diskussion eines Essays über das Tagebuch des Adam Czerniaków], in: „Biuletyn ŻIH“ 90 (1974).

Stefanowska Z., Historia i profecja. Studium o „Księgach narodu i pielgrzymstwa polskiego" Adama Mickiewicza [Geschichte und Prophetie. Eine Studie zu Adam Mickiewiczs „Büchern des polnischen Volkes und der polnischen Pilgerschaft"], Warschau 1962.

Steiner G., Language and Silence. Essays 1958-1966, London-Boston 1990.

Steiner G., „Un saison en enfer“, in: In Blaubarts Burg - Anmerkungen zur Neudefinition der Kultur, Dt. v. F. Polakovics, Berlin 1972. 
Szacki J., Historia myśli socjologicznej [Geschichte des soziologischen Denkens], T. 2, Warschau 1981.

Szarota T., „Getto warszawskie u progu zagłady“ [Das Warschauer Ghetto an der Schwelle zur Vernichtung], in: „Kronika Warszawy“ 1993, Nr. 2.

Szarota T., Okupowanej Warszawy dzień powszedni [Der Werktag des besetzten Warschau], Warschau 1988.

Szarota T., „Zajścia antyżydowskie i pogromy w okupowanej Europie“ [Antijüdische Vorfälle und Pogrome im besetzten Europa], in: D. Grynberg und P. Szapiro (Hgg.): Holocaust z perspektywy pótwiecza. Pięćdziesiąta rocznica powstania $w$ getcie warszawskim. Materiały $z$ konferencji zorganizowanej przez Żydowski Instytut Historyczny w dniach 29-30 marca 1993 [Der Holocaust aus der Perspektive eines halben Jahrhunderts. Der fünfzigste Jahrestag des Aufstands im Warschauer Ghetto. Materialien von einer Konferenz des Jüdischen Historischen Instituts, 29.-30. März 1993], Warschau [ohne Erscheinungsdatum].

Szarota T., Einleitung zur polnischen Ausgabe von: F. Blättler [eigentl. F. Mawick], Warszawa 1942. Zapiski szofera szwajcarskiej misji lekarskiej [Warschau 1942: Tatsachenbericht eines Motorfahrers der zweiten schweizerischen Aerztemission 1942 in Polen], bearb. v. T. Szarota, Warschau 1982.

Sznajderman M., Mitologia dżumy, cholery i AIDS [Die Seuche. Eine Mythologie von Pest, Cholera und AIDS], Warschau 1994.

Szukajcie w popiołach. Papiery znalezione w Oświęcimiu [„Sucht in der Asche“. In Auschwitz gefundene Papiere], Łódź 1965.

Śpiewak P., „Szoah, drugi upadek“ [Die Schoa, der zweite Niedergang], in: „Więź“ 1986, Nr. 7-8.

Śpiewak P., „Kaznodzieja getta warszawskiego“ [Der Prediger des Warschauer Ghettos], in: „Znak“ 1996, Nr. 3.

Thoma C., „Auschwitz - wielki »znak« dla Żydów i chrześcijan“ [Auschwitz das große „Zeichen“ für Juden und Christen], in: W. Chrostowski (Hg.), Żydzi i chrześcijanie w dialogu [Juden und Christen im Dialog], Warschau 1992.

Thoma C, „Próba teologicznej interpretacji Szoah“ [Versuch einer theologischen Interpretation der Schoa], in: „Znak“ 1991, Nr. 5.

Thomas L.-V., Trup. Od biologii do antropologii, [franz. Originaltitel: Le cadavre: de la biologie a l'anthropologie], Poln. v. K. Kocjan, Łódź 1991.

Trunk I., Judenrat. The Jewish Councils in Eastern Europe under Nazi Occupation, New York-London 1972. 
Tuchman B. W., Der ferne Spiegel: Das dramatische 14. Jahrhundert, Dt. v. U. Leschak, M. Friedrich, Hildesheim 1997.

Unterman A., Żydzi. Wiara i życie [Die Juden. Glaube und Leben], Łódź 1989.

Werner A., Zwyczajna apokalipsa. Tadeusz Borowski i jego wizja świata obozów [Eine gewöhnliche Apokalypse. Tadeusz Borowski und seine Sicht auf die Welt des Lagers], Warschau 1971.

Wierzbicka A., English Speech Act Verbs. A Semantic Dictionary, Sydney 1987.

Wiesel E., Gesang der Toten: Erinnerungen und Zeugnis, dt. Übers. von Ch. Sturm, R. Walter, Freiburg/Breisgau, Basel, Wien 1989.

Wróbel J., Tematy żydowskie w prozie polskiej 1939-1987 [Jüdische Themen in der polnischen Prosa 1939-1987], Krakau 1991.

Inmitten des grauenvollen Verbrechens. Handschriften von Mitgliedern des Sonderkommandos, Verlag des Staatlichen Auschwitz-Birkenau Museums, Oświęcim 1996.

Young J. E., Writing and Rewriting the Holocaust. Narrative and the Consequences of Interpretation, Bloomington-Indianopolis 1988.

Zaleski K., „Fakt i sens całości. Z problemów okupacyjnej literatury faktu“ [Tatsache und Sinn des Ganzen. Von den Problemen der Tatsachenliteratur aus der Besatzungszeit], in: M. Głowiński, J. Sławiński (Hgg.), Literatura wobec wojny i okupacji [Die Literatur angesichts von Krieg und Besatzung], Wrocław 1976.

Zaworska H., „Medaliony“ Zofii Nałkowskiej [Zofia Nałkowskas „Medaillons“], Warschau 1961.

Zeldowicz L. „Lola“, „Personal Notes on Stanisław Adler“, in: In the Warsaw Ghetto 1940-1943. An Account of a Witness. The Memoirs of Stanisław Adler, Engl. v. S. (Chmielewska) Philip, Jerusalem 1982.

Zimand R., „W nocy od 12 do 5 rano nie spałem.“ "Dziennik“ Adama Czerniakowa - próba lektury [In der Nacht habe ich von 12 bis 5 Uhr früh nicht geschlafen. Das „Tagebuch“ des Adam Czerniaków - Versuch einer Lektüre], Paris 1979.

Zimand R., Diarysta Stefan Ż. [Der Tagebuchschreiber Stefan Z.], Wrocław 1990. 



\section{Index}

A

Aaron, Frieda W. 9

Aboab, Isaac 302

Achmatowa, Anna 318

Adler, Stanisław 46, 50, 53, 56, 66-68, 81, 93, 102, 191, 197, 206,

$211,217,218,235$

Ajdelberg [Rabbi] 256

Ajzensztad, Marysia 211

Albert, A. (auch: Roszkowski, W.) 163

Alighieri, Dante 235, 236, 251

Anielewicz, Mordechaj 193, 194

Apfelbaum-Kowalski, Emil 50

Appelfeld, Aaron 46

Appenszlak, Jakub 52

Asch, Schalom 43

Arendt, Hannah 49, 110, 112

Arensztajn, Marek: siehe: Marek, Andrzej

Ariès, Philippe 213, 224

Auerbach,

Rachel: siehe: Oyerbakh, Rokhl

Auerswald, Heinz 61, 63, 165,

167,218

Augustinus, hl. 124

B

Bachórz, J. 192

Bachtin, Michail 239

Bafiks, M. 48

Balaban, Majer 123, 203, 204, 284, 299

Bartoszewski, W. 51

Bartoszyński K. 88

Bauman, Zygmunt 36, 37, 50, 251

Baumritter, Gustaw: siehe: Włast, Andrzej

Ben Gurion, David 110 ben Jakob de Bonnas, Ephraim 123

Berenstein, T. 59

Bereska, Henryk 57

Berg, Mary (auch: Wattenberg, Miriam) 47, 48, 58, 65, 68, 72, 102, 179-182, 216, 218

Berkovits, Eliezer 264

Berland, Marian 20, 23, 24, 56, 80, $81,84,85,91,102,110,185,186$, 189, 190, 225, 226, 260, 261, 295

Berman, Adolf 56-57, 81, 180, 206, 207, 208, 210

Berman, Barbara 81, 207, 223

Bialik, Chaim Nachman 104

Białoszewski, Miron 67

Biermann, W. 42

Bikont, Anna 78

Blady-Szwajger, Adina 182

Blättler, Franz 61, 62, 227, 228

Błoński, Jan 8, 14

Boguszewska, Helena 55, 153

Booth, W.C. 134

Borowski, Tadeusz 8, 282, 324, 325

Borwicz, Michał [Michel] M. 7, $8,89,90,97,98,127,129,130$, 181, 182

Bosch, Hieronymus 228, 250

Brach-Czaina, Jolanta 320, 321

Brandt, Karl 155, 165-167, 196-198

Braude-Hellerowa, Anna 50

Brodzka, A. 9

Broniatowska 210

Bruegel, Pieter der Ältere 222, 223

Bruno, Giordano 133

Bryskier [Brysker], Henryk 20, 56, 66, 81, 92, 117, 205, 220, 231

Brzozowski, S. 18

Buber, Martin 242 
C

Cassin, René 127

Celan, Paul 126, 127

Chałasiński, J. 17

Chanina [Chananja] [Rabbi] 298

Chasyd, Perec: siehe: Opoczyński, Perec

Chatman, Seymor 33

Chmelnyzkyj, Bohdan 123, 298

Chmielewska, S.: siehe: Philip, S.

Chrostowski, W. 89, 309, 310

Churchill, Winston 162, 163

Cicero 124

Cieński, A. 115, 116, 324

Cwinkiel, J. 48

Cybichowski, Jerzy 288

Cybichowski, Zygmunt 288

Czajkowski, Michał 14

Czarnobroda, Leizor 52, 75, 113

Czerniaków, Adam 23, 31, 34, 39, $41,42,46,48,49,51,58,59,63$, $72,91,95,122,155,156,161-170$, 196, 197, 205-209, 218-221, 225, 287, 289, 326

Czerniaków, Felicja 95, 208

Czermińska, Małgorzata 14

Czerwiakowski, E. 12

Czerwiakowski, J. 12

D

Damówna 201, 202, 243

Danielewicz, Hersch (auch: Danilewitch, Herschele) 43

Danilewitch, Herschele: siehe: Danielewicz, Hersch

Daume, D. 133

Dąbrowski 210

Defoe, Daniel 215, 222

de Goya, Francisco 201

Delumeau, Jean 217, 222, 224

Denda, J. 48

Domański, J. 124
Dränger, Gustawa 89

Drawert, K. 45

Dresden, Sem 9

Dross, A. 20

Drozdowski, M.M. 261

Drewnowski, Tadeusz 8

Dubnow, Simon 102

Dunin-Wąsowicz, K. 252

Düring, R. 318

Dutli, R. 100

E

Eck, N. 55

Edelman, Marek 12, 57, 96, 193, 194, 230, 263

Eichmann, Adolf 49, 109, 110, 111,112

Eisenbach, A. 40, 59, 98

Eliach, Yaffa 232, 233

Eliade, Mircea 223

Engelking, Barbara 65, 85, 215, 300

Erb, M. 45

Erb, R. 45, 63

Ernest, Stefan 24, 49, 81, 84, 103, 108, 128, 190, 191, 195, 197, 203, 206

F

Fajgenblat, Szymon 50

Falska, Maria 94, 95

Fałkowski, Stanisław 14

Fibich, Josef 48

Ficowski, Jerzy 127

Fink, B. 34

Fink, Ida 34

Fliederbaum, Julian 50

Fogelman, Dawid 11, 46, 82, 84

Fothergill, R.A. 115, 116

Frank, Anne 46

Frank, Hans 60

Friedrich, K.-P. 70

Friedrich, M. 318 
Fruchtman, Adela 182

Frylingsztajn, Beniek 48

Fuks, Marian 58, 95

G

Geremek, B. 239

Gilbert Szlojme (Schlojme, Shlomo) 43

Giterman, Icchak 211, 317, 318

Gitler-Barski, Józef 57

Glazer, Arie 284

Głowiński, Michał 8, 14, 19, 26, 29, $30,150,176,315$

Glück, Irena 47

Goldin, Lejb 24, 44, 52, 216, 217, 221

Goldkorn 210

Goldman, B. 46, 52

Gogol, Sz. 48

Gombiński, Stanisław: siehe: Mawult, Jan

Górny, Jechiel 221, 259

Gorzkowski, K. 253, 326

Graber, Dawid 98, 107

Grabowska, Halina 24

Gradowski, Salmen 105

Granzow, B. 49

Greenberg, Irving 311

Gross, Natan 9, 34

Grüning, U. 45

Grynberg, D. 59, 283, 287

Grynberg, Henryk 8, 47, 320, 321

Grynberg, Michał 10, 39, 151

Grywacz, Nachum 98

Gurjewitsch, A. 236, 239, 251

Gutkowski 172

Gutman, Israel 10, 49, 94, 287, 289

Guz, Leon 46, 61, 81, 85

H

Hagen, Wilhelm 166

Hajtler, S. 48
ha-Levi, Jehuda 125

Hall, E.T. 65

Hallmann 74, 96

Hamon, Philippe 175, 177, 178

Handelsman, Marceli 42

Hannover, Nathan 123, 124, 298, 299

Hanower, Jankiel 48

Hänschen, S. 80

Harrer, K. 242

Hasenfus, Chaim 46

Hasenfus, Jakub 46

Hausner, G. 283

Henning, R. 39

Herbst-Rosocha, U. 45

Heredia, D. 49

Herling-Grudziński, Gustaw 215

Heschel, Abraham Joshua [auch: Heshel, Avrom-Shiye] 264

Hescheles, Janina 47

Heshel, Avrom-Shiye: siehe: Heschel, Abraham Joshua

Himmler, Heinrich 70

Hirszfeld, Ludwik 24, 31, 41, 42, $50,57,84,109,117,136-141,143$, 149, 197, 202, 203

Hirszfeld, Marysia [Maria] 202

Hitler, Adolf 133, 160, 163

Horoszewicz, M. 310

Horowitz, Beniamin (auch: Pawlak, Władysław) 12, 49, 151, 152,

153, 155

Huberband, Szymon 252, 254-257, 279, 283-291, 293-298, 300, 315,316

Hübner, M. 217

Huizinga, Johan 223, 224

Hurwicz, Samuel Lewy 284

I

Ihr, Daniel 44

Iwaszkiewicz, Jarosław 45 


\section{J}

Jakub 55, 82-84, 136, 137, 139, 141,143

Janowska 210

Janowska, Sara Grober 211

Jarecka, Gustawa 45, 53, 120, 206-208, 235

Jedlicki, Jerzy 30, 128

Jurandot, Jerzy 45

$\mathbf{K}$

Kac, Szymon 54

Kaganowski, E. 56

Kahan, Samuel (auch: Lewandowski, Mieczysław) 57

Kajzer, Abram [Abraham] 89

Kalisky, A. 105

Kann, M. 282

Kaplan, Chaim Aron 23, 41, 46, 53, $60,61,68,69,72,73,93,94,102$, $104,105,122,168,169,187,188$, 190, 191, 206, 257, 261, 278, 289

Karasiówna, Estera 171, 172

Karski, Jan 172

Katsh, Abraham I. 53, 94

Katzenelson, Jizchak [Yitzhak] 33, 42, 54, 93, 104, 105, 230, 282, 283

Kayser, Wolfgang 247

Kazimierska, K. 17

Kermisz, Józef 91

Kierkegaard, Søren 141

Kirman, Josef 43

Klecel, Marek 8

Klibanski, B. 11

Knoll, Rena 47

Knott, M.-L. 49

Kołoniecki, Roman 24, 72

Konder, G. 217

Koniński, Aron 210

Korczak, Janusz 20, 21, 22, 24, 25, $28,41,49,52,72,74,94,95,138$, 179-181, 184, 210, 242
Korentajner M. 43

Kornacki, Jerzy 55, 153

Kowalczyk, Andrzej Stanisław 14

Krajewski, S. 310

Krall, Hanna 194

Kramsztyk, Roman 182, 211

Kuberczyk, T. 283, 285

Kula, Witold 157, 158, 159

Kulina, Nina [z Jabłońskich] 158

Kurowska, Irena 81

Krzepicki, A. 80

L

Landau, Jakub Icchak 256

Landau, Ludwik 23, 59, 92, 137, 157-159, 168, 169, 215

Langer, Lawrence L. 9

Lazertówna, Henryka, siehe: Łazertówna, Henryka

Łazertówna, Henryka (auch: Lazertówna, Henryka) 24, 45, 72

Lec, Stanisław Jerzy 44

Lechoń, Jan 45

Lehman, Szmul 192

Leib, Hersz 202

Leivick, Halpern 52, 53

Leociak, Jacek 47

Léon-Dufour, X. 121

Lerer, Jechiel (Ichiel) 43

Lerych, Jakub 48

Leschak, U. 318

Levin, Avrom (auch: Lewin, Abraham) 23, 43, 53, 72, 74, 80, $109,117,133,136,137,139-143$, $149,179,183,203,204,211,212$, 214, 256, 260

Levin, Yehezekiel 298

Lewenthal, Salmen 105, 106, 237

Lewin, Abraham: siehe: Levin, Avrom

Lewin, Aleksander 95 
Lichačev, D.S. 239

Lichtensztajn, Izrael 98

Lipman, M. 48

Liptzin, S. 42, 93

Łopatyńska, L. 18

Lotman, Jurij 239

Löw, Ryszard 57, 87, 127

Lowenthal, David 124, 125

Lubas-Bartoszyńska, R. 17, 115

Lubelska, Wanda 24, 60, 61, 68

Lubelski, Szymon 193

M

Machiavelli, Niccolò 101

Maciejewska, Irena 8, 9, 54, 67

Mądra, Minia 48

Maimonides 293

Makower, Henryk 24, 50, 57, 64, 66, 79, 84, 108, 197, 198, 206

Mandelstam, Ossip 100

Maniakówna, M. 261

Manzoni 217

Marczak [Familie] 51

Marek, Andrzej (auch: Arensztajn, Marek) 45, 46

Marek, B. 54

Margolisowa, Anna 95

Marianowicz, Antoni 151

Mark, Bernard 92

Markiewicz, H. 33

Maroko, Avron Mordka 298

Matwin-Buschmann, R. 47, 230

Matywiecki, Piotr 32, 242

Mawult, Jan (auch: Gombiński, Stanisław) 20, 50, 64, 110, 196, 197, 216, 218, 263

Maybaum, Ignaz 264

Merżan, Ida 180

Michal, Yechiel 299

Michalowski, Zwi 232, 233

Mickiewicz, Adam 119, 314

Milejkowski, Izrael 25, 50, 53, 77
Milton, J. 237

Miłosz, Czesław 130, 133, 176, 269

$\mathbf{N}$

N.N. 129: 194, 195, 197, 198

Najberg, Leon $12,54,78,84$, $85,91,133,191,195,198,204$, 226, 231

Najman, Leon 81

Nałkowska, Zofia 8, 57, 168, 169

Newerly, Igor 52, 94

Norwid, Cyprian Kamil 144, 315

Nowodworski, D. 80

O

Oelkers, L. 20

Opoczyński, Perec (auch: Chasyd, Perec) 44

Oppeln-Bronikowski, F. von 101

Oshry, Ephraim 89, 280

Ostoja A. 89

Otto, M. 250

Otto, Rudolf 223, 317

Oyerbakh, Rokhl (auch: Auerbach, Rachel) 24, 44, 56, 57, 118, 119, $133,185,199,200,201,225,229$, 230, 243-247, 319

$\mathbf{P}$

Paderewski, Jan 162

Pančenko, A.M. 239

Passenstein, Mojżesz 50, 78

Paul, Jean 247

Pawlak, Władysław (siehe: Horowitz, Beniamin) 153

Pelermuter, Z. 49

Perechodnik, Calel 20, 24, 31, 50, $55,81,113,117,136,137,139$ $144,149,280,281,282,295,311$

Perle, Joszua 44, 53, 55

Philalethes (auch: von Sachsen,

König Johann) 236 
Philip, S. (auch: Chmielewska,

S.) 56

Piasecki, H. 282

Pigoń, Stanisław 29, 30

Pinkert [Gebrüder] 184, 214, 216, 218, 219, 223, 244

Pinner, E.M. 293

Plath, Sylvia 33

Platon 124, 214, 215, 225

Pluskałowski, Lejb 43

Podolska, A. 48

Polakovics, F. 253

Polen, Nehemia 281, 299, 300, 301, 304, 307, 308, 311, 316

Polonsky, A. 53

Pomer, Stefan 44

Prokop-Janiec, E. 44

Przedborski, Jan 50, 206, 207, 208, 209

Przybylski, Ryszard 100

Przygoda, L. 146

Puterman, Samuel 80, 151, 153, 155, 156, 206, 207, 210

Q

Quinkenstein, L. 8

$\mathbf{R}$

Rabinowicz, J. 80

Rajgrodzki, J. 80

Rajzman, S. 80

Raschi [Rabbi Schlomo ben Jizchak] 306, 307

Remba, Nachum 49, 55, 211

Remby, N. 180

Ricœur, Paul 250

Ringelblum, Emanuel 10, 23,24, $25,39-44,48,49,51-53,59,60$, 64-68, 72-75, 80-91, 94, 96-98, $107,108,110,113,117,139,144$, $145,157,159-161,164,166,168$,
$172,173,178,180,185,191-194$, 199, 200, 207, 208, 210, 211, 215, 218-220, 222, 226, 227, 239, 245, $255,256,259,261,263,279,282$, 284, 285, 287-289, 297, 309, 317-319

Rogowińska, Julia 83

Rosenfeld, Alvin H. 9

Roskies, David G. 104, 122, 275 , 290, 291, 292, 298, 299, 314, 315

Roszkowski, W.: siehe: Albert, A.

Rotem-Ratajzen, Symcha 56

Roters-Burck, M. 217

Rotgeber, Jakub 81

Rotgeber, Karol 20, 24, 46, 81, 82, $84,91,102,108,122,138,252$, $265,266-269,271-281,283,284$, 295, 300, 302, 310, 314, 315

Rozencwajg, Daniel 52

Rozenfeld, A. 282

Różycki, Stanisław 65, 68, 73

Rubinowicz, Dawid 46

Rubinstein, Richard 94, 311

Rudnicki, Henryk 12, 114, 116, 180, 210, 228

Rufeisen-Schüpper, Helena 79

Rufener, R. 215

Rutkowski, A. 40, 59

Rutowicz, J. 48

S

Sadzik, Józef 269

Sakowska, Ruta 10, 14, 39, 49, 91, 97, 98, 108, 145, 173, 221, 256, 260, 284, 287

Sandauer, Artur 44

Scharf, R. 180

Scheptyzkyj, Andrej 299

Schlegel, Fiedrich 247

Scholem, Gershom 49

Schön, Waldemar 59 
Schreiner, S. 310

Seiffert, A. 105

Sendlerowa, Irena 78

Sherwin, Byron L. 125, 220, 270, 310, 312, 313

Shtern, Israel: siehe: Sztern, Izrael

Sierakowiak, Dawid 47, 91, 229, 230, 237, 238

Sikorski, Władysław 163

Singer, S. 303

Sitem, Izrael 53

Słapakowa, Cecylia (Luba) 44

Sławiński, J. 8, 26, 30, 88, 128, 316

Sloan, J. 23

Słobodzki, Henryk 24, 50

Słonimski, Antoni 45

Solomon, N. 89, 278, 280, 293, 309-311

Śpiewak, R. 253-254, 300

Springer, M. 236

Srokowski, Stanisław 289

Staemmler, K. 34

Starzyński, Stefan 41, 162

Stefa 75,76

Stefanowska, Z. 30, 46, 88, 128

Stefanowski, Z. 314, 315

Stein, Józef 50

Steiner, G. 253

Stok, Marek 46, 57, 65, 68, 81

Storey, Robert G. 110

Stroop, J. 51, 70, 91, 92, 231

Strzembosz, T. 261

Stryjkowski, Julian 44

Sturm, Ch. 310

Sutzkever, Avrom [Abraham] 57, $99,100,101,126$

Świetlicki, Andrzej 288

Symchowicz, Roza 192

Szacki, J. 17

Szac-Wajnkranc, Noemi 55, 56, 234, 235,260
Szarota, Tomasz 14, 59, 167, 252, 253, 256, 287, 288, 289

Szajewicz, Bunim 275

Szajn-Lewin, Eugenia 45, 55, 92 , 113, 229

Szapiro, Klonimus Kelmisz [Kelman Kalonimus, Kalonymus Kalman] 252, 256, 261, 284, 299, 300, 301, 303-311, 316

Szapiro, P. 59, 287

Szczypiorski, Aleksander

u. Teofilia 84

Szejnman, Michał 50

Szeryński, Józef 48, 50, 297

Szlengl, Władysław 24, 45, 53, 54, $62,63,182$

Szlezinger 298

Sznajderman, Monika 215, 223, 239, 250

Sznapman, Stanisław 18, 19, 24, 55, 69, 151, 153-155

Szpilman, Władysław 12, 182, 217, 225

Sztejnkolk 187

Sztern, Izrael (auch: Shtern, Israel) $43,52,53,96$

Szulcman, Gitla 48

Szwalbe, Natan 52

Szymaniak, Karolina 319

Szymański 210

Szymel, Maurycy 44

$\mathrm{T}$

Tajst 204, 205

Tartakower, Arieh 10

Temkin-Bermanowa, Barbara 46

Thiele, E. 242

Thoma, C. 310

Thomas, Louis-Vincent 213

Thomas, W.I. 17

Trunk, I. 49 
Tuchman, B. 318

Turowski, Kamil 91

Turowski, Konrad 91

Tuwim, Julian 45

U

Unterman, A. 293

Uspenskij, Boris 239

V

van der Leeuw, Gerard 223, 317

Vettori, Francesco 101

Villon, François 239

von Sachsen, König Johann: siehe:

Philalethes

W

Wagman, Saul 52

Waldorf, Jerzy 12

Walter, R. 310

Warm, Ber 50, 191, 194, 197

Wasser, Hersz 172

Wasserman [Rabbi] 278, 280

Wattenberg, Miriam: siehe: Berg, Mary

Werner, Andrzej 8, 31

Wiernik, J. 80

Wierzbicka, Anna 121, 143

Wierzyński, Kazimierz 45

Wiesel, E. 310

Wigoder, G. 293

Wilczyńska, Stefania 52

Willenberg, S. 80

Winter, Szmuel [Schmuel] 97
Wittelson, T. 48

Włast, Andrzej (auch: Baumritter, Gustaw) 45

Wojcek, Władysław 94

Wojdysławski 113, 225, 235, 239, 240-243

Wolff, K. 8, 12, 224

Wollerówna, Rena 47

Wolski, Mieczysław 51

Wróbel, Józef 9, 34

Wróblewski, Michał 95

Wulf, J. 90

Y

Young, James E. 32, 34, 122

Z

Zacuto, Abraham 123

Zaleski, K. 26

Zawodny, J. 106

Zaworska, Helena 8

Zeitlin, Hillel 43, 53, 280, 281

Zeldowicz, Ludmiła 56, 93

Zelek, Wiktor 297

Żeromski, Stefan 162, 241, 242

Zimand, Roman 14, 17, 19, $23,31,34,161,162,164$, 165,175

Żmigrodzka, Maria 315

Znaniecki, Florian 17

Zola, Émile 175

Zundelewicz, Bernard 196

Zylberberg, Michael 70

Zylbersztajn, Jakub 284 


\section{Eastern European Culture, Politics and Societies}

Edited by Irena Grudzińska-Gross and Andrzej W. Tymowski

Vol. 1 Lidia Jurek: Polish Risorgimento - Visions of the Modern Polish Nation and their Italian Foundations. 2012.

Vol. 2 Irena Grudzińska-Gross: Czesław Miłosz und Joseph Brodsky - Die Freundschaft zweier Dichter. 2012.

Vol. 3 Irena Grudzińska-Gross / Andrzej Tymowski (eds.): Eastern Europe: Women in Transition. 2013.

Vol. 4 Agata Araszkiewicz: La révolution oubliée. L'émergence d'une écriture féminine polonaise dans l'entre-deux-guerres. 2013.

Vol. 5 Irena Grudzińska-Gross / Andrzej W. Tymowski (eds.): Eastern Europe: Continuity and Change (1987-1995). Editorial assistance by Elisabeta Pop. 2014.

Vol. 6 Jan Tomasz Gross: Collected Essays on War, Holocaust and the Crisis of Communism. 2014.

Vol. 7 Andrzej Walicki: The Flow of Ideas. Russian Thought from the Enlightenment to the Religious-Philosophical Renaissance. Translated by Jolanta Kozak and Hilda Andrews-Rusiecka. Editorial Work by Cain Elliott. 2015.

Vol. 8 Robert Traba: The Past in the Present. The Construction of Polish History. Translated by Alex Shannon. 2015.

Vol. 9 Milica Antić Gaber (ed.): Gender Structuring of Contemporary Slovenia. 2015.

Vol. 10 Irena Grudzińska-Gross / Iwa Nawrocki (eds.): Poland and Polin. New Interpretations in Polish-Jewish Studies. 2016.

Vol. 11 Aleksandra Sulikowska: The Icon Debate. Religious Images in Russia in the $15^{\text {th }}$ and $16^{\text {th }}$ Centuries. Translated by Krzysztof Kościuczuk. 2016.

Vol. 12 Joanna Tokarska-Bakir: Pogrom Cries - Essays on Polish-Jewish History, 1939-1946. 2017.

Vol. 13 Jacek Leociak: Text und Holocaust. Die Erfahrung des Ghettos in Zeugnissen und literarischen Entwürfen. 2018.

www.peterlang.com 
